NRELI/CP-410-6033

DE94000236

\title{
PHOTOVOLTAIC PERFORMANCE
}

\section{AND RELIABILITY WORKSHOP}

\section{September 8-10, 1993}

\section{Golden, Colorado}

$$
\begin{aligned}
& \text { RECENVEO } \\
& \text { DEC O2 } 1993 \\
& \text { OSTI }
\end{aligned}
$$

Sponsored by

National Renewable Energy Laboratory

under contract to the

U.S. Department of Energy 
iNREL/CP-410-6033

DE94000236

\title{
PHOTOVOLTAIC PERFORMANCE
}

\section{AND RELIABILITY WORKSHOP}

\author{
September 8-10, 1993
}

Golden, Colorado

Denver Marriott West/Golden, Colorado

\section{Edited by: Laxmi Mrig (NREL)}

Sponsored by

National Renewable Energy Laboratory under contract to the

U.S. Department of Energy 


\section{NOTICE}

This report was prepared as an account of work sponsored by an agency of the United States government. Neither the United States government nor any agency thereof, nor any of their employees, makes any warranty, express or implied, or assumes any legal liability or responsibility for the accuracy. completeness, or usefulness of any information, apparatus, product, or process disclosed, or represents that its use would not infringe privately owned rights. Reference herein to any specific commercial product, process, or service by trade name, trademark, manufacturer, or otherwise does not necessarily constitute or imply its endorsement, recommendation, or favoring by the United States government or any agency thereof. The views and opinions of authors expressed herein do not necessarily state or reflect those of the United States government or any agency thereot.

$$
\text { Printed on recycled paper }
$$




\section{DISCLAIMER}

Portions of this document may be illegible electronic image products. Images are produced from the best available original document. 


\section{PREFACE}

The papers and presentations compiled in this volume form the Proceedings of the "PV Performance and Reliability" workshop held in Golden, Colorado on September 8-10, 1993. This workshop was the sixth in a series of Workshops sponsored by NREL/DOE under the general subject areas of photovoltaic testing and reliability during the period 1986-1993.

PV performance and PV reliability are at least as important as PV cost, if not more. Performance and reliability are two strategic parameters that are used to assess the development of any technology. The average consumer researches regarding the performance and reliability of any product prior to purchase whether it is an automobile or some other major product and the same will hold true when a consumer purchases PV. Those PV companies that emphasize performance and reliability as part of their product information and marketing attributes are the ones that are likely to be successful in today's competitive marketplace.

Many researchers are involved in the research, development, performance monitoring and reliability testing of photovoltaics around the world. In the U.S., PV manufacturers, DOE laboratories, electric utilities and others are engaged in the photovoltaic reliability research and testing. This group of researchers and others interested in this field were brought together under NREL/DOE sponsorship to exchange the technical knowledge and field experience as related to current information in this evolving field of PV reliability. The papers presented here reflect this effort since the last workshop held in September 1992.

My sincere thanks go to excellent speakers, session chairs, and NREL conference coordinators in making this workshop a success.

Laxmi Mrig

Workshop Chairman

NREL 
. 


\section{Photovoltaic Performance and Reliability Workshop \\ September 8-10, 1993 \\ Table of Contents}

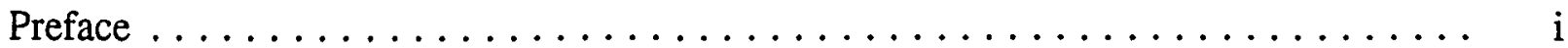

Laxmi Mrig, National Renewable Energy Laboratory

Opening Session $\ldots \ldots \ldots \ldots \ldots \ldots \ldots \ldots \ldots \ldots \ldots \ldots \ldots \ldots \ldots \ldots \ldots$

James Rannels, U.S. Department of Energy $\ldots \ldots \ldots \ldots \ldots \ldots \ldots \ldots \ldots$

Anthony Catalano, National Renewable Energy Laboratory ............. 13

Cell and Module Characterization $\ldots \ldots \ldots \ldots \ldots \ldots \ldots \ldots \ldots \ldots$

PV Efficiency Measurements Overview .................... 21

Keith Emery, National Renewable Energy Laboratory

Characteristics of Spectrolab Solar Simulator $\ldots \ldots \ldots \ldots \ldots \ldots \ldots \ldots \ldots .48$ James Lovelady, Spectrolab

Pulsed Solar Simulator Design and Applications $\ldots \ldots \ldots \ldots \ldots \ldots \ldots \ldots . \ldots 8$ Stephen Hogan, Spire

Indoor and Outdoor Efficiency Measurements of a-Si Multijunction Modules . . . . . 76 Troy Glatfelter, USSC

Radiometric Measurements for PV Characterization ................ 99 Daryl Myers, National Renewable Energy Laboratory

Module and System Testing $\ldots \ldots \ldots \ldots \ldots \ldots \ldots \ldots \ldots \ldots \ldots \ldots \ldots$

Overview of Photovoltaic Module Reliability Testing at NREL . . . . . . . . . 113 Joseph Burdick, National Renewable Energy Laboratory

Results of Module Hot Spot Testing $\ldots \ldots \ldots \ldots \ldots \ldots \ldots \ldots \ldots \ldots \ldots$

Robert Hammond, Arizona State University

Relative Humidity, Temperature and Irradiance Testing at Mobil Solar Energy Corporation . . . . . . . . . . . . . . . . . . . . . . . . . 153 Moneer Azzam, Mobil Solar Energy Corporation 
Performance and Stress Testing of CdTe Modules . . . . . . . . . . . 167

Daniel Sandwisch, Solar Cells, Inc.

Investigation of Lamination Induced Metastability in CIS-Based Modules . . . . . . 184 Dennis Willett, Siemens Solar

Testing for Module Warranties $\ldots \ldots \ldots \ldots \ldots \ldots \ldots \ldots \ldots \ldots \ldots . \ldots \ldots$ John Wohlgemuth, Solarex

Field Wet Resistance Test Procedure and Results at PVUSA . . . . . . . . . 206 Charles Whitaker, Endecon

Performance of a $1.8 \mathrm{kWac}$ Dual-Junction Amorphous Silicon System . . . . . . . . 215 Troy Strand, National Renewable Energy Laboratory

The Virginia Solar Photovoltaic Manufacturing Incentive Grant Program (SPMIGP) . . 239 Robert Somers, II, 2rw Consulting Engineers

Durability and Reliability . . . . . . . . . . . . . . . . . . . . . 249

Contact Corrosion on CdS/CdTe Solar Cells: A Photoemission Study of the Formation of the $\mathrm{CdS} / \mathrm{SnO}_{2}$ Interface . . . . . . . . . . . . . . . . . . . . . 251 David Niles, National Renewable Energy Laboratory

Thermal Bond Aging of Thick Film Silver Metallized Solar Cells . . . . . . . . . . 264 Ronald Gonsiorawski, Mobil Solar Energy Corporation

Outdoor and Indoor UV Exposure Testing $\ldots \ldots \ldots \ldots \ldots \ldots \ldots \ldots \ldots$ William Putman, DSET Laboratories, Inc.

EVA Degradation Mechanisms: A Review of What is and is Not Known ...... 311 Al Czanderna, National Renewable Energy Laboratory

Modification of EVA Formulation for Improved Stability . . . . . . . . . . 358 John Pern, National Renewable Energy Laboratory

Durability of PV Modules at The Southwest Region Experiment Station Las Cruces, New Mexico . . . . . . . . . . . . . . . . . . . . . . 375 Andrew Rosenthal, Southwest Technology Development Institute

Teamed Research and Development on PVMaT, Phase 3A-Shared Process Issues . . . 387 William Holley, Springborn Laboratories, Inc.

Stability of EVA in PV Modules . . . . . . . . . . . . . . . . . . . . . 394 John Wohlgemuth, Solarex 
System Field Experiences . . . . . . . . . . . . . . . . . . . . . . . 399

PSCO Energy Involvement to Date $\ldots \ldots \ldots \ldots \ldots \ldots \ldots \ldots \ldots \ldots \ldots \ldots$

Chris Thompson, Public Service Company of Colorado

Photovoltaic System Experience at Arizona Public Service Company . . . . . . . . . 406

Peter Eckert, Arizona Public Service Company

Performance of Maspeth a-Si PV System . . . . . . . . . . . . . . 418

Byron Stafford, National Renewable Energy Laboratory

PV System Field Experiences at SMUD . . . . . . . . . . . . . . . . 425

David Collier, Sacramento Municipal Utility District

Building Integrated PV Systems NEES's Gardner \& EPA's PV-DSM Projects . . . . . 436 Edward Kern, Ascension Technology

Seven Years of Experience with Austin's 300 Kilowatt Single-Crystal Photovoltaic

Array . . . . . . . . . . . . . . . . . . . . . . . . . . . . . . . . 439

John Hoffner, City of Austin Electric Utility Department

The Performance of PV Systems . . . . . . . . . . . . . . . 453

Margie Whipple, Sandia National Laboratories

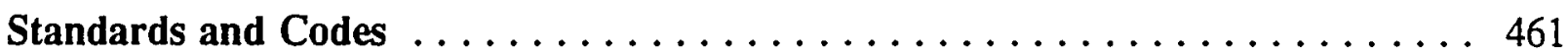

Report on 1993 PV Standards and Codes Forum .................. 463

Carl Osterwald, National Renewable Energy Laboratory

International PV Performance Standards . . . . . . . . . . . . . . . 473

Robert Klein, Solar Energy Industries Association

Photovoltaic and the National Electric Code $\ldots \ldots \ldots \ldots \ldots \ldots \ldots . \ldots . \ldots 45$

David Meakin, Solar Energy Industries Association

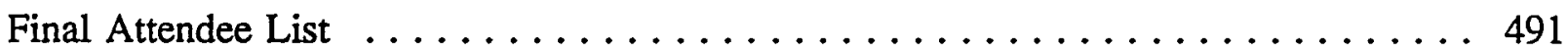




\section{OPENING SESSION}




\title{
Photovoltaic Performance and Reliability Workshop Golden, Colorado
}

\author{
James E. Rannels
}

Director, Photovoltaics Division

U.S. Department of Energy

September 8, 1993 


\section{IMPROVED EFFICIENCY}

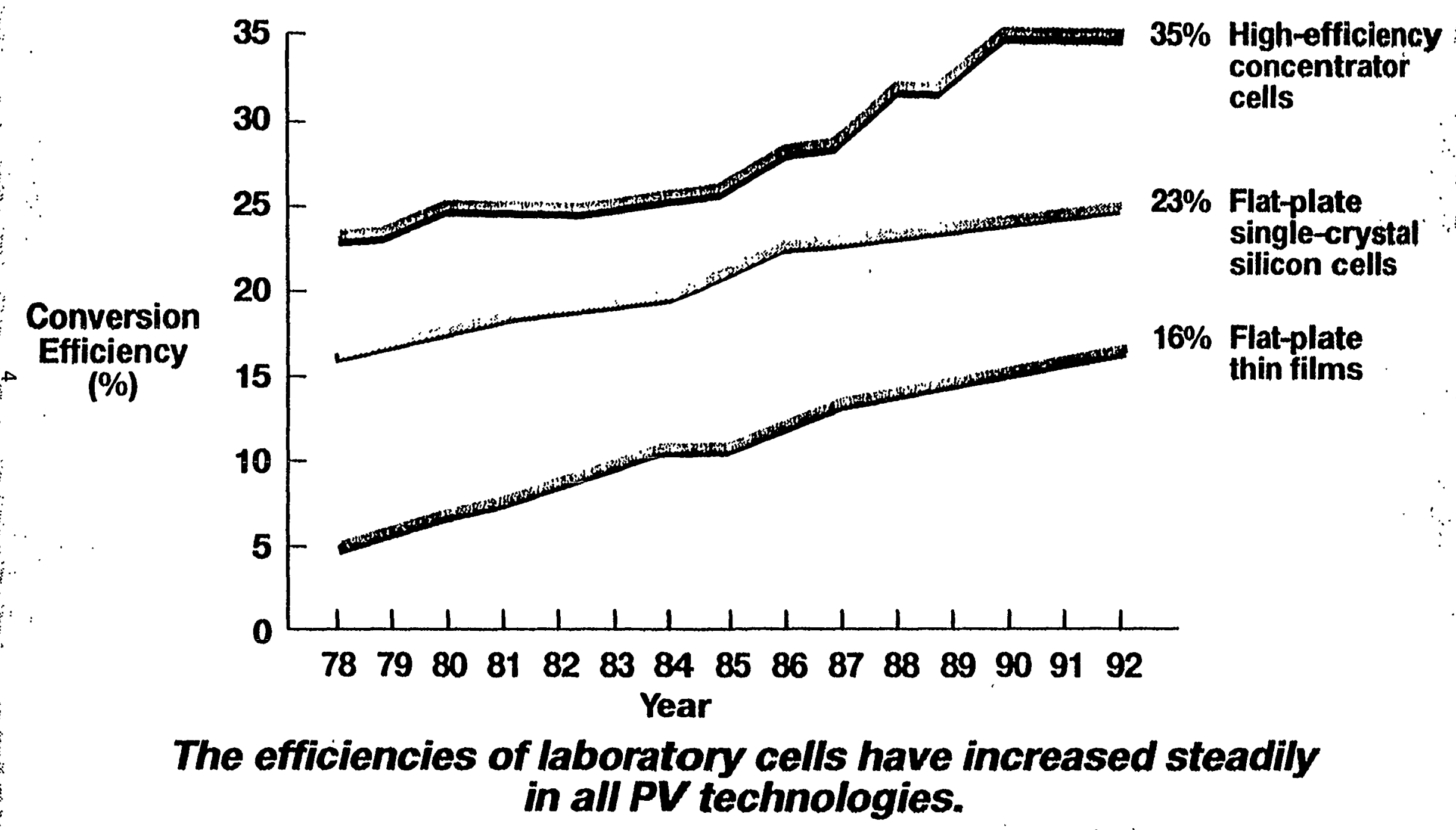




\section{PV COST REDUCTION}

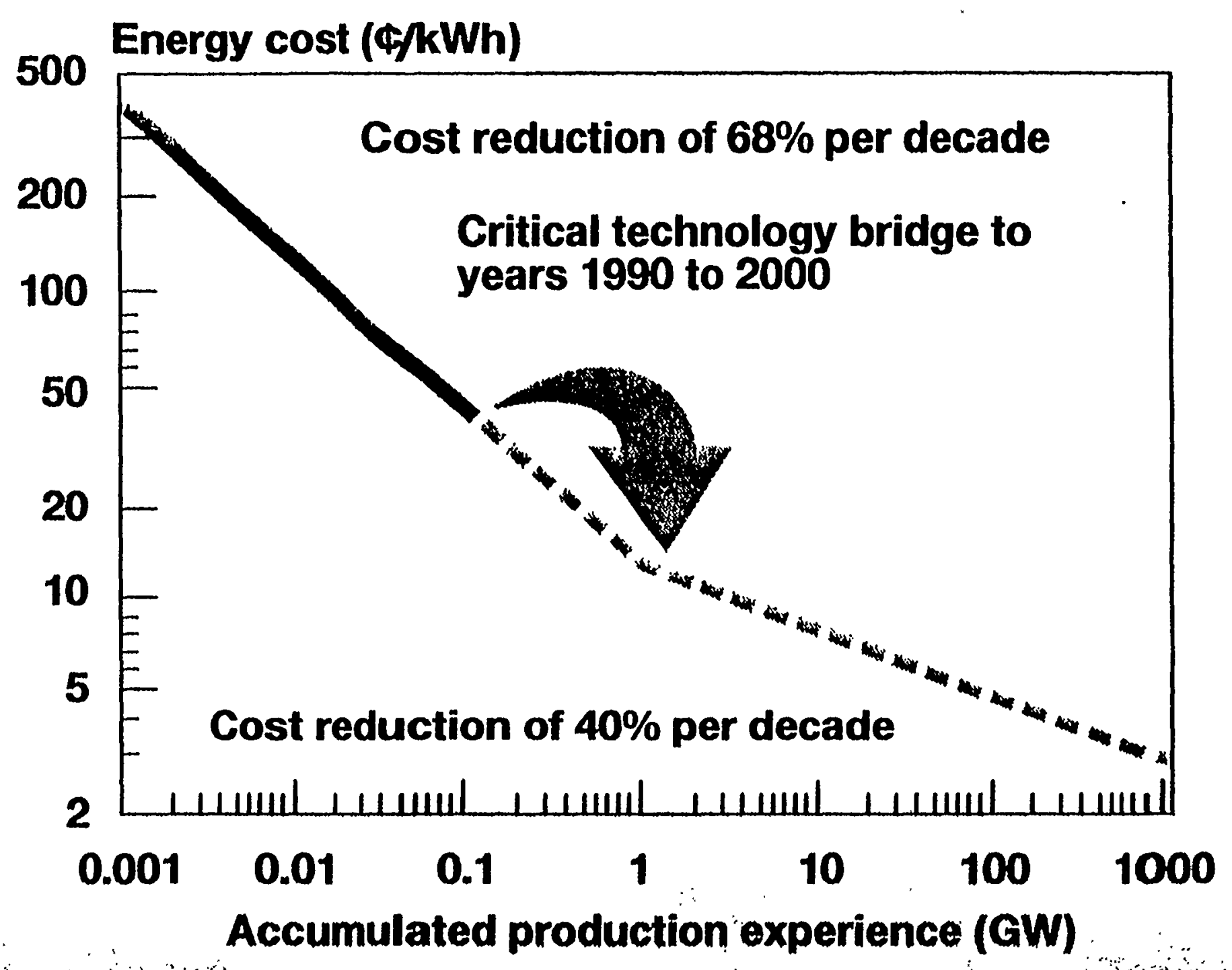




\section{PV SYSTEMS MARKET}

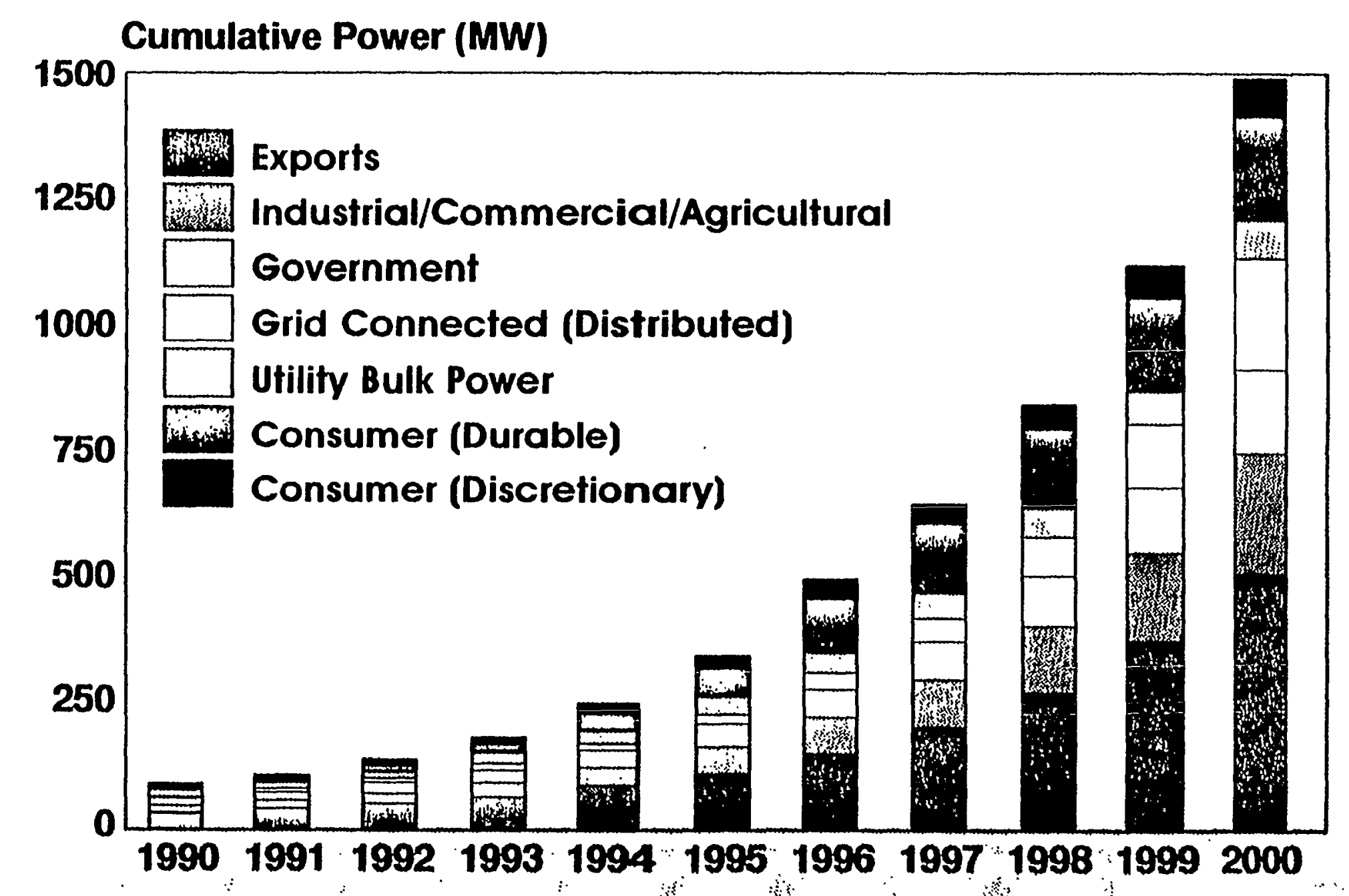




\section{SOLAR 2000 Strategy Framework Partnership of Key Players}

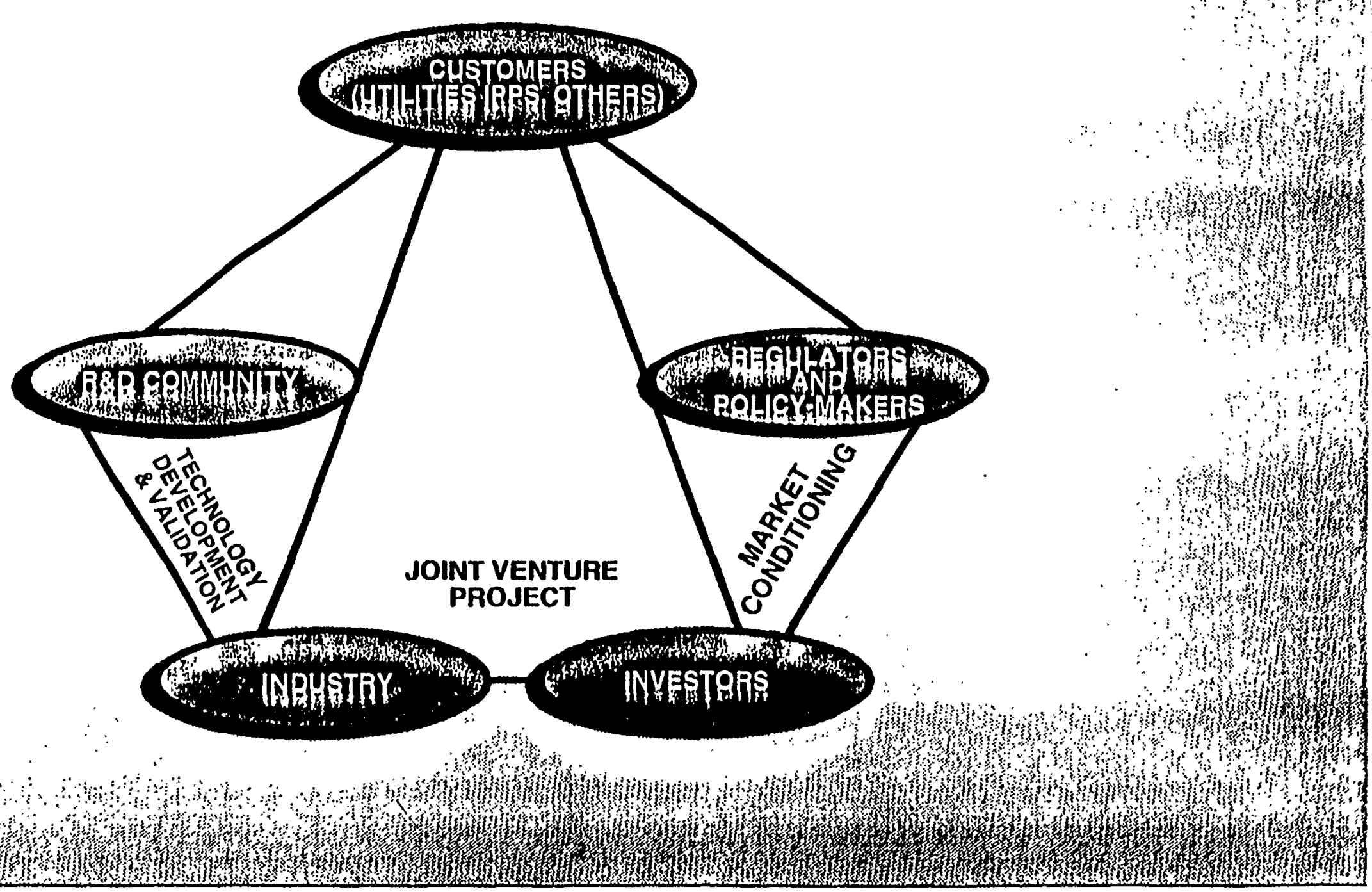




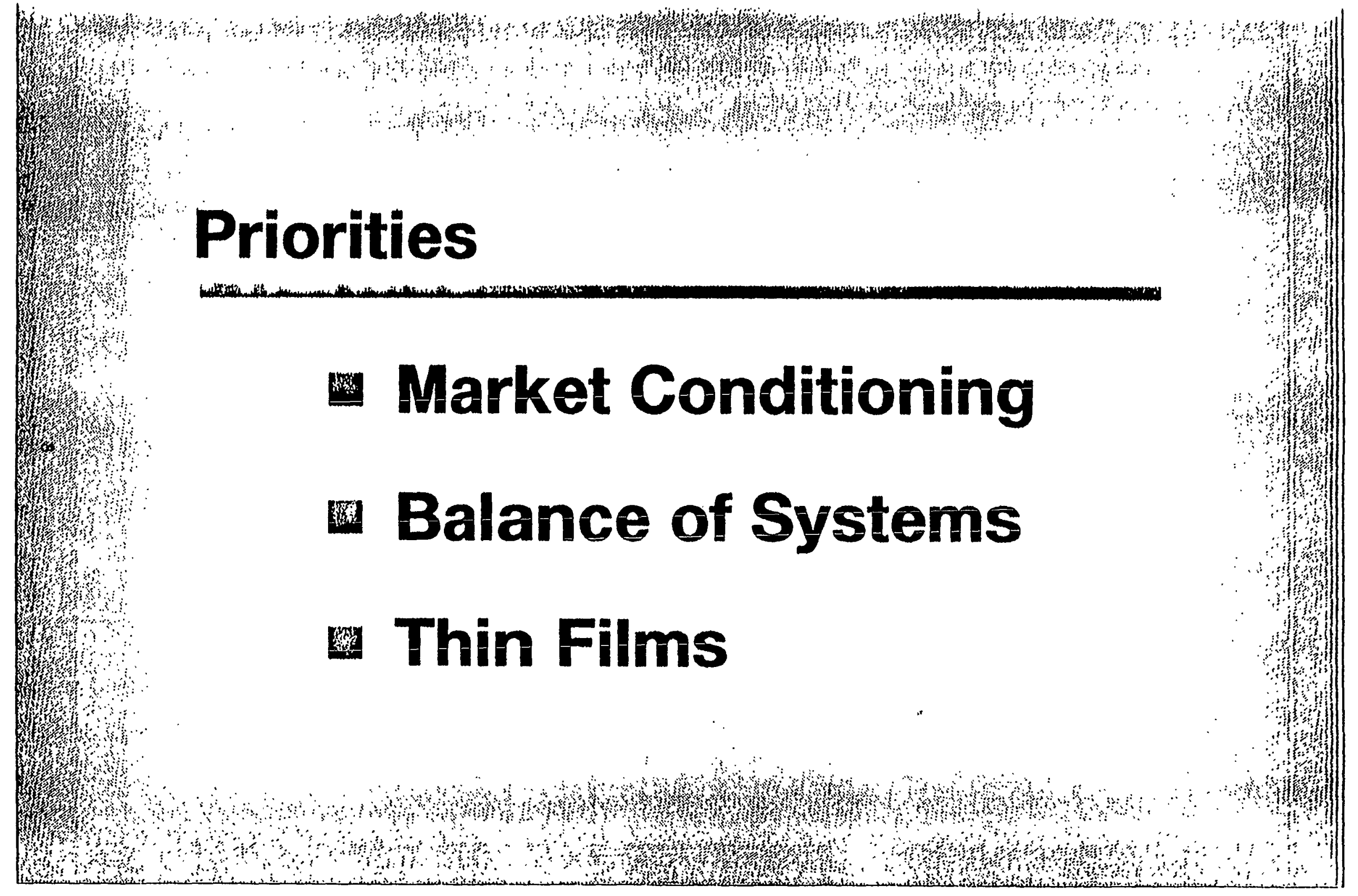




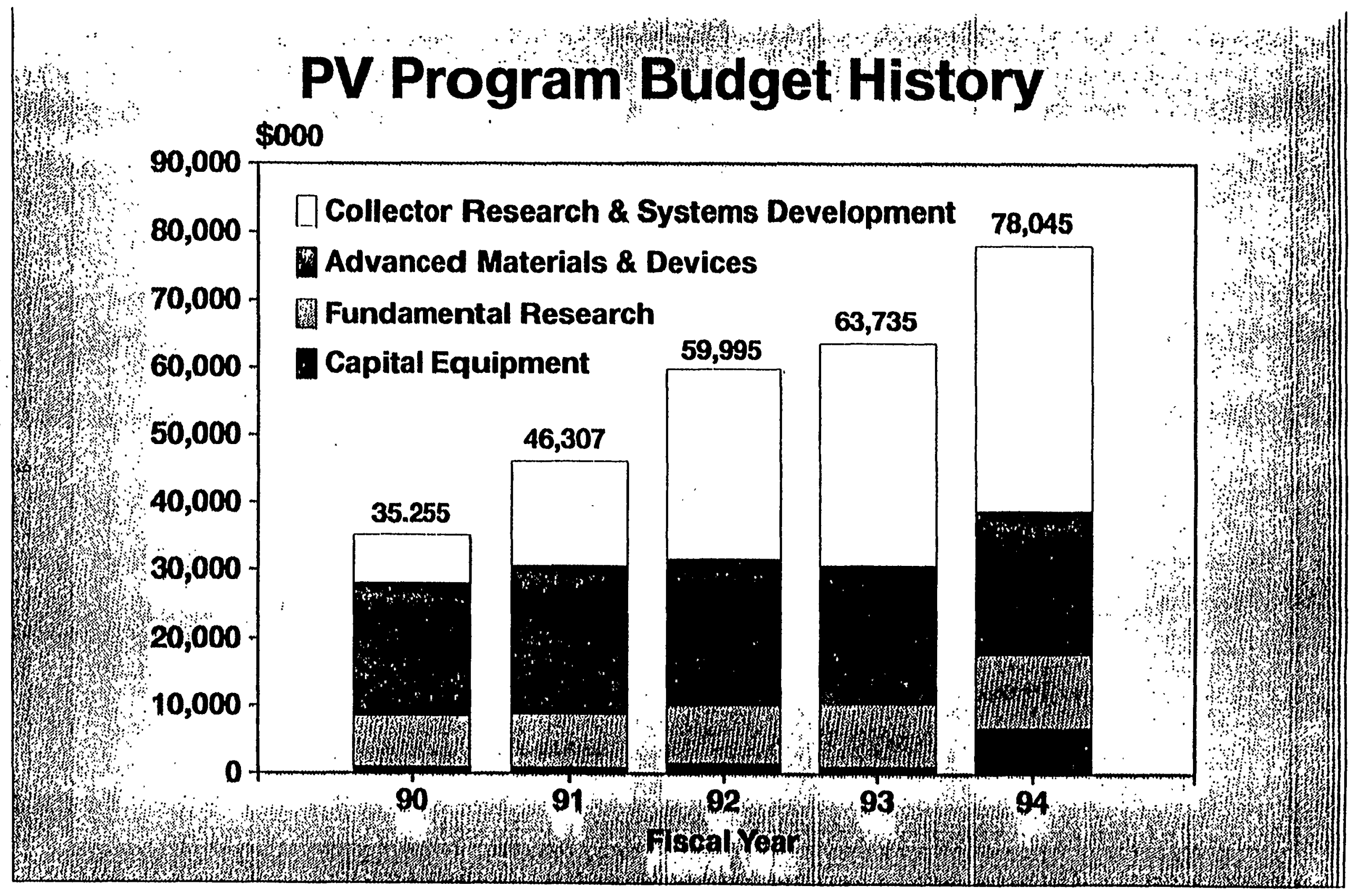




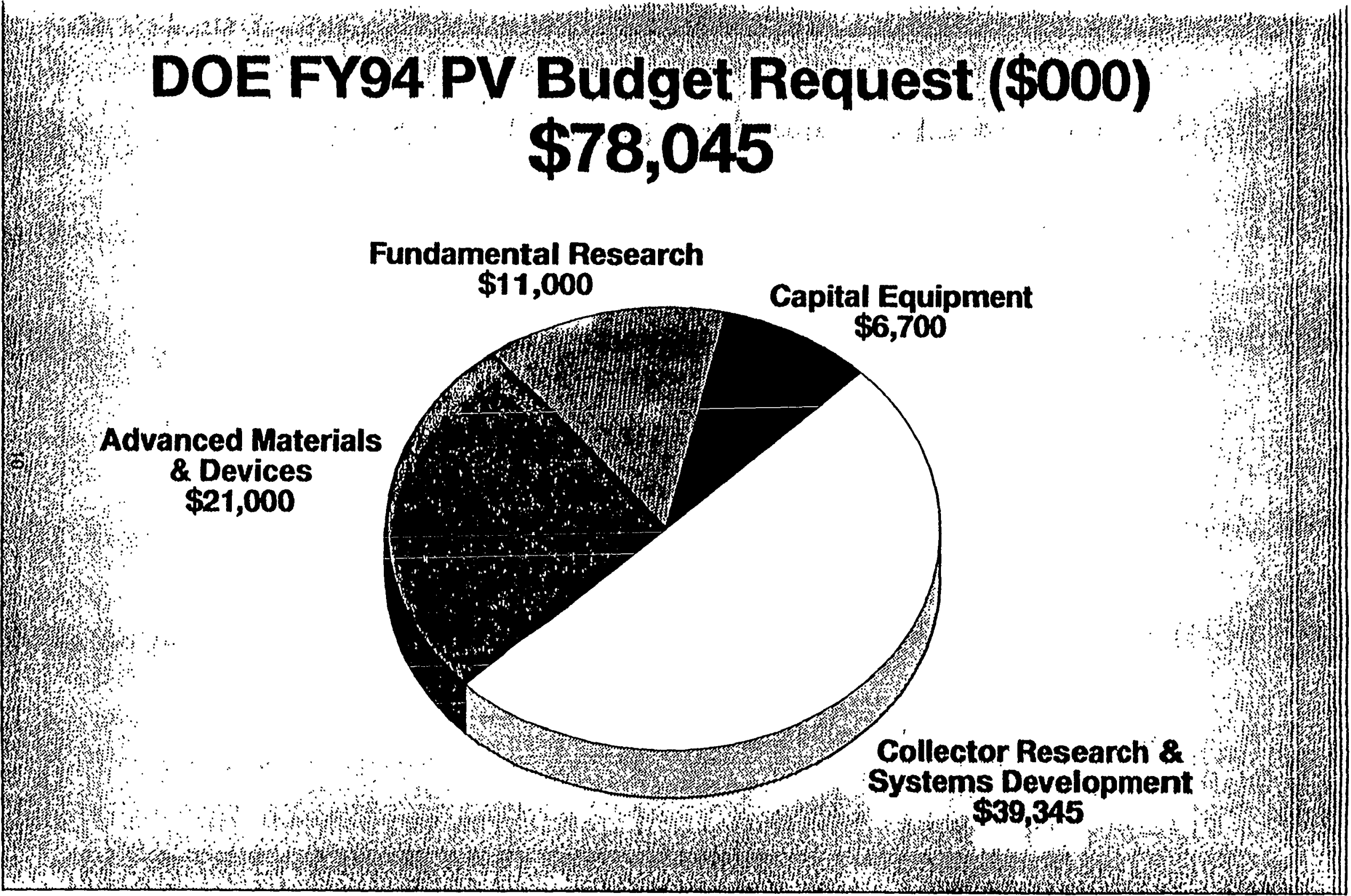




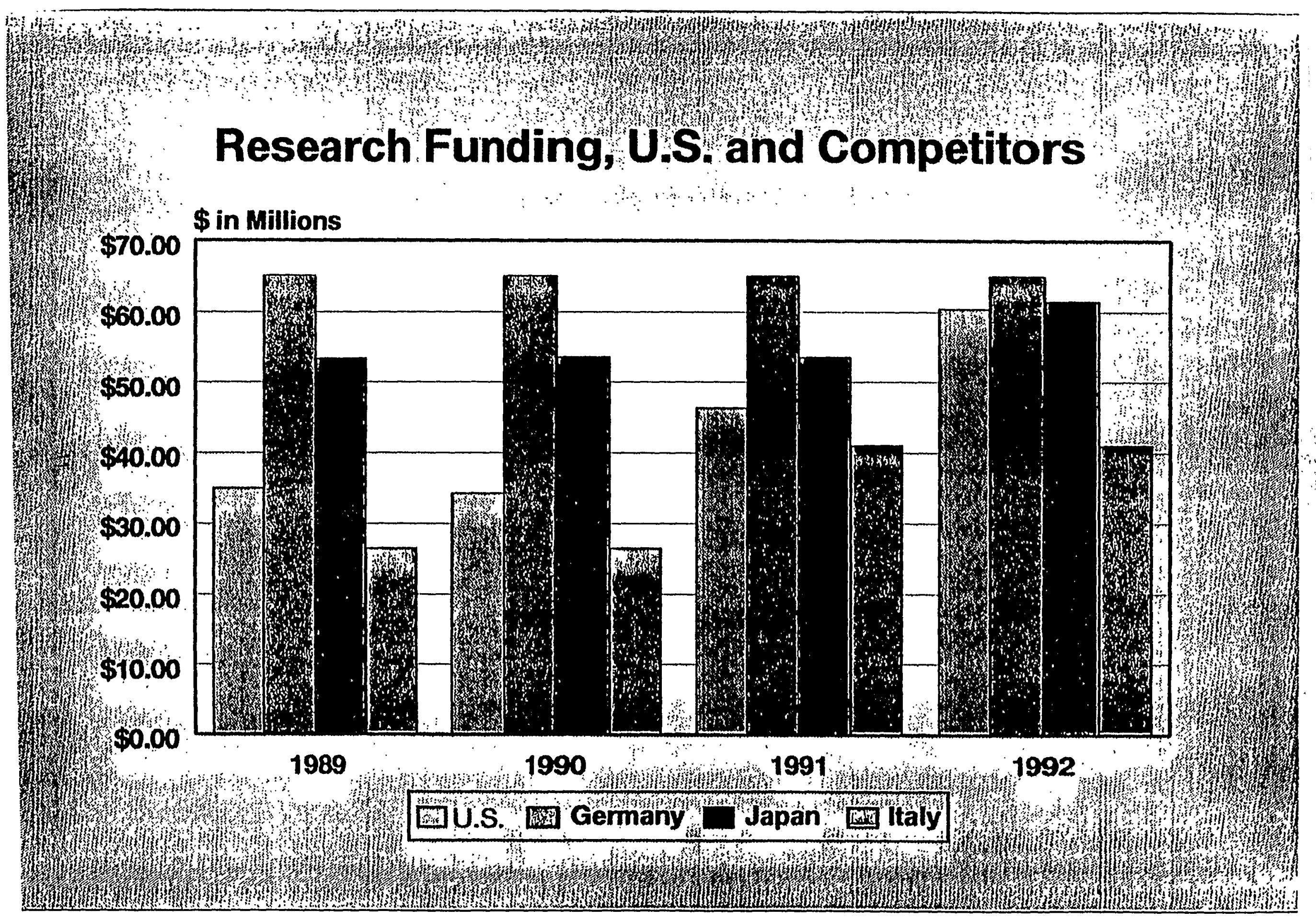




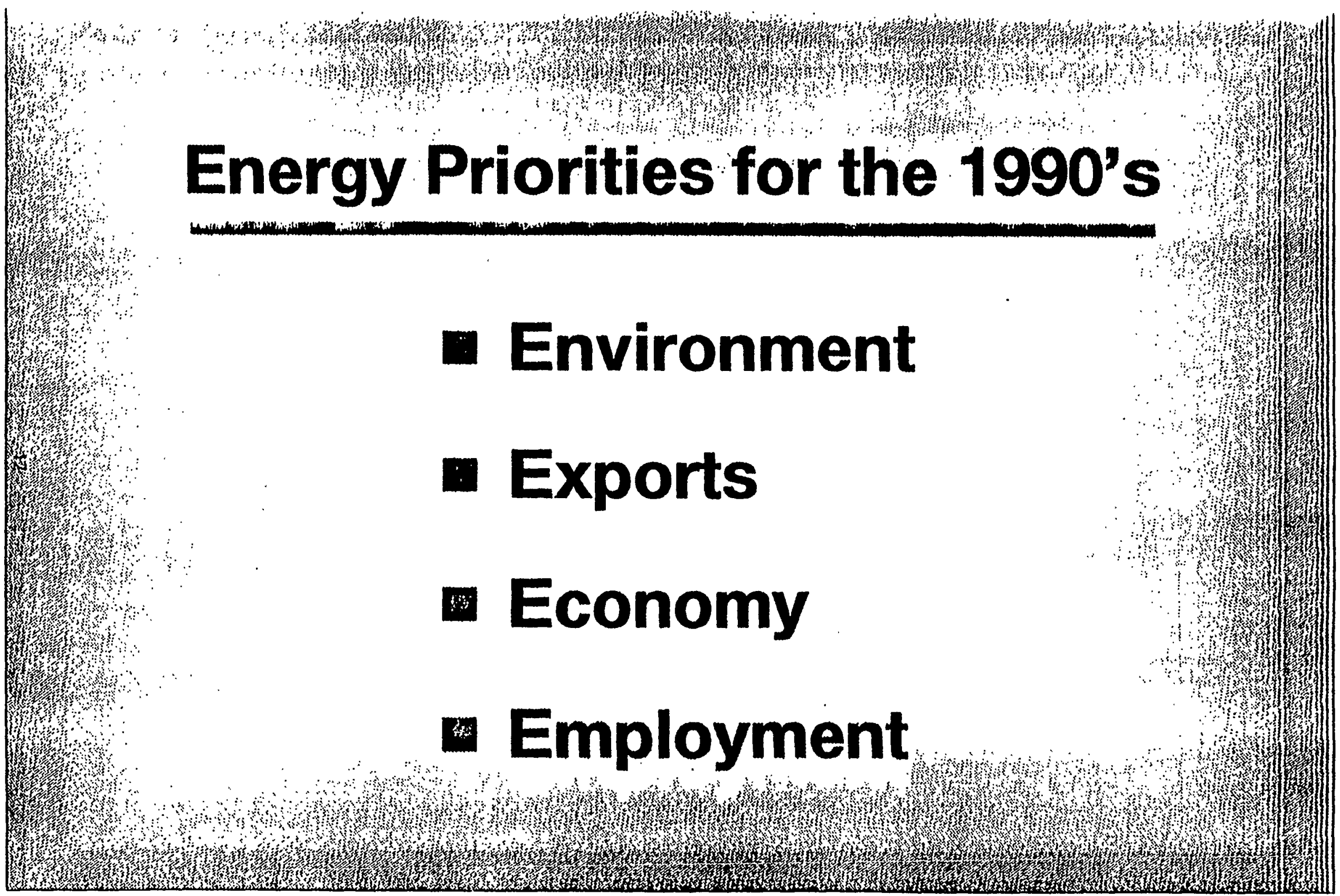




\title{
Photovoltaic Performance and Reliability Workshop
}

\author{
Anthony Catalano
}

September 8, 1993 


\section{NREL Capabilities}

- Facilities Complete for Qualification Testing

- New DC Simulator On Order

- $\quad$ - Field Area Available for New Products

-3-4 1kw System Deployments Planned

- Outdoor Test Facility

-3/94 start 12/94 Completion 


\section{High Priority Areas}

-Accelerated Testing Methods

- Standard Measurement Methods for Emerging Technologies

- Resolve Difficulties with Present Encapsulants 


\section{The Opportunity}

- Utilities and Other Large Markets Will Vastly Increase Need for PV

-BUT...

-They Will Demand...

-Proven Reliability \& Safety

-System Approach to Design

- Low Cost 


\section{The PV "Climate"}

- Healthy Market Growth at 15\%+

- Serious, Growing Interest by Utilities

- Emerging Technologies Nearing Marketplace

- Major Business Expansion Possible 
CELL AND MODULE CHARACTERIZATION 


\title{
PV Efficiency Measurements - Overview
}

\author{
Keith Emery (303-231-1032) \\ Modules \\ Steve Rummel (231-1917) \\ Yehoshua Caiyem
}

Cells

Halden Field (231-1485)

Don Dunlavy 


\section{Standard Reporting Conditions}

\section{Advantages}

Fixed set of reference conditions

Site independent

Easy to perform in the lab or on the factory floor

$25^{\circ} \mathrm{C}$ reference temperature easy to achieve

Internationally accepted

\section{Disadvantages}

$25^{\circ} \mathrm{C}$ cell temperature predicts greater performance than observed in the field

Alternative rating methods are not widely accepted

Standards do not exist for alternative rating methods 
$\eta \equiv$ Efficiency $=100 \times \frac{P_{\max }}{E_{\text {tot }}}$

$\mathrm{P}_{\text {max. }}\left\{\begin{array}{l}\text { Maximum PV power density } \\ \text { Power at a fixed load }\end{array}\right.$

$\mathrm{E}_{\text {tot }}\{$ Prevailing - pyranometer Reference irradiance - reference cell

Temperature $\left\{\begin{array}{l}\text { air } / \text { ambient } \\ \text { Junction }\end{array}\right.$

Area $\left\{\begin{array}{l}\text { TOTAL } \\ \text { active } \\ \text { aperture }\end{array}\right.$ 


\section{$\mathrm{U}_{95}$ Uncertainty Limits}

Reference cell calibration $\quad \pm 1-5 \%$

Pyranometer calibration $\quad \pm 3-8 \%$

Absolute cavity radiometer $\quad \pm 0.3 \%$

$\tilde{+}$

Single-junction cell $\eta \quad \pm 2-10 \%$

Single-junction module $\eta \quad \pm 3-10 \%$

Multi-junction cell $\eta \quad \pm 3-15 \%$

Multi-junction module $\eta \quad \pm 5-15 \%$ 


\section{Axiom for efficiency measurements and reports:}

\section{Trust but verify.}

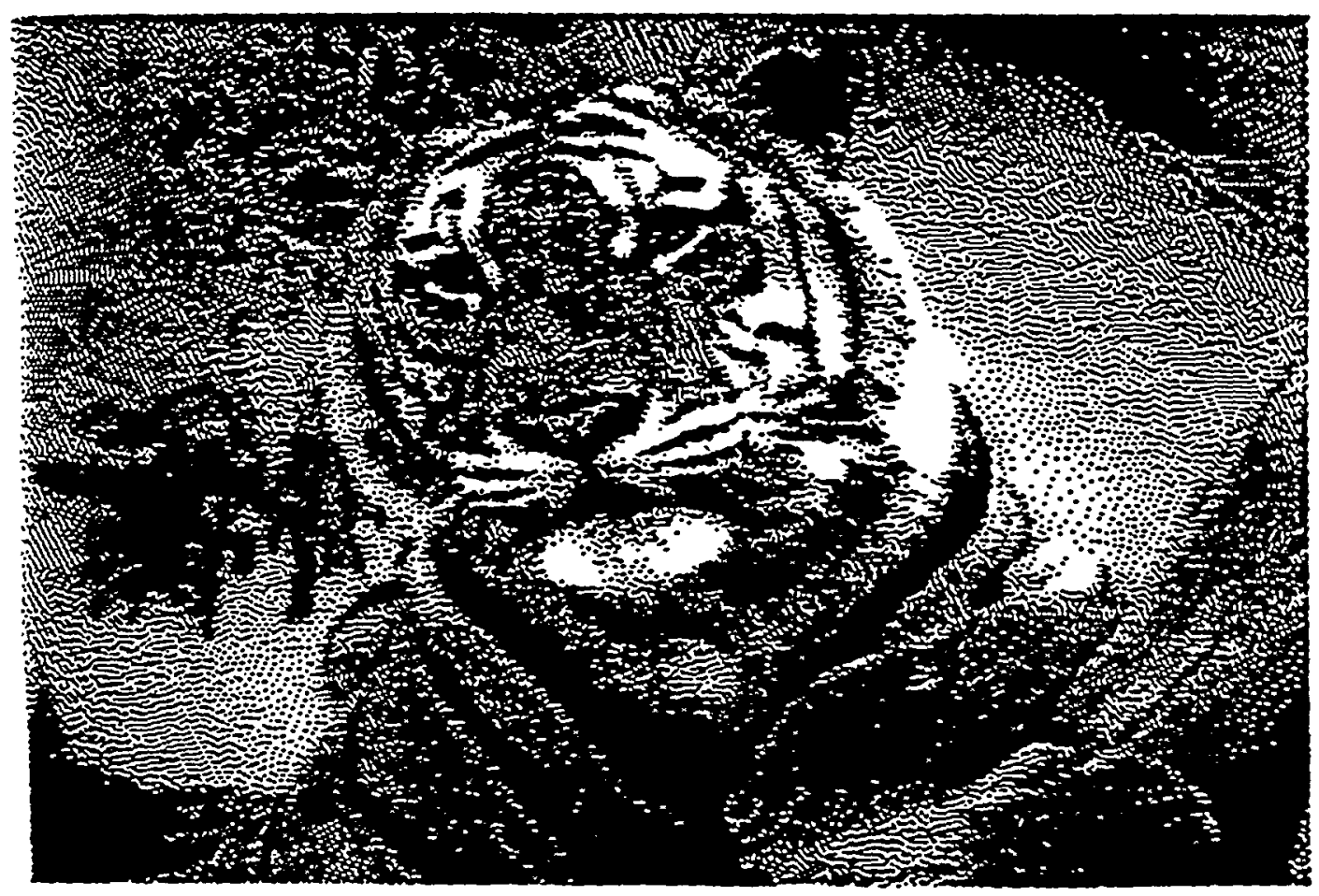




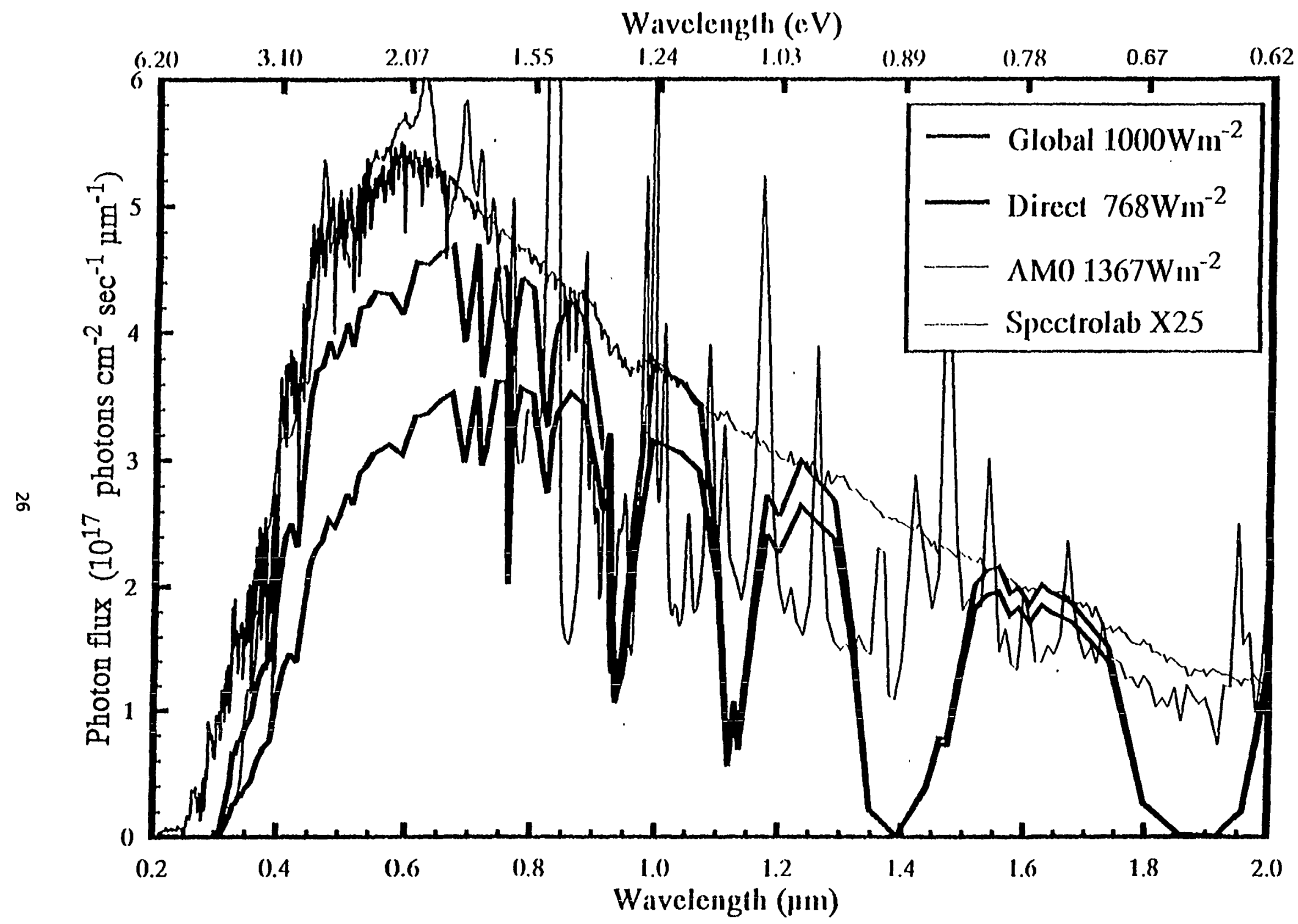




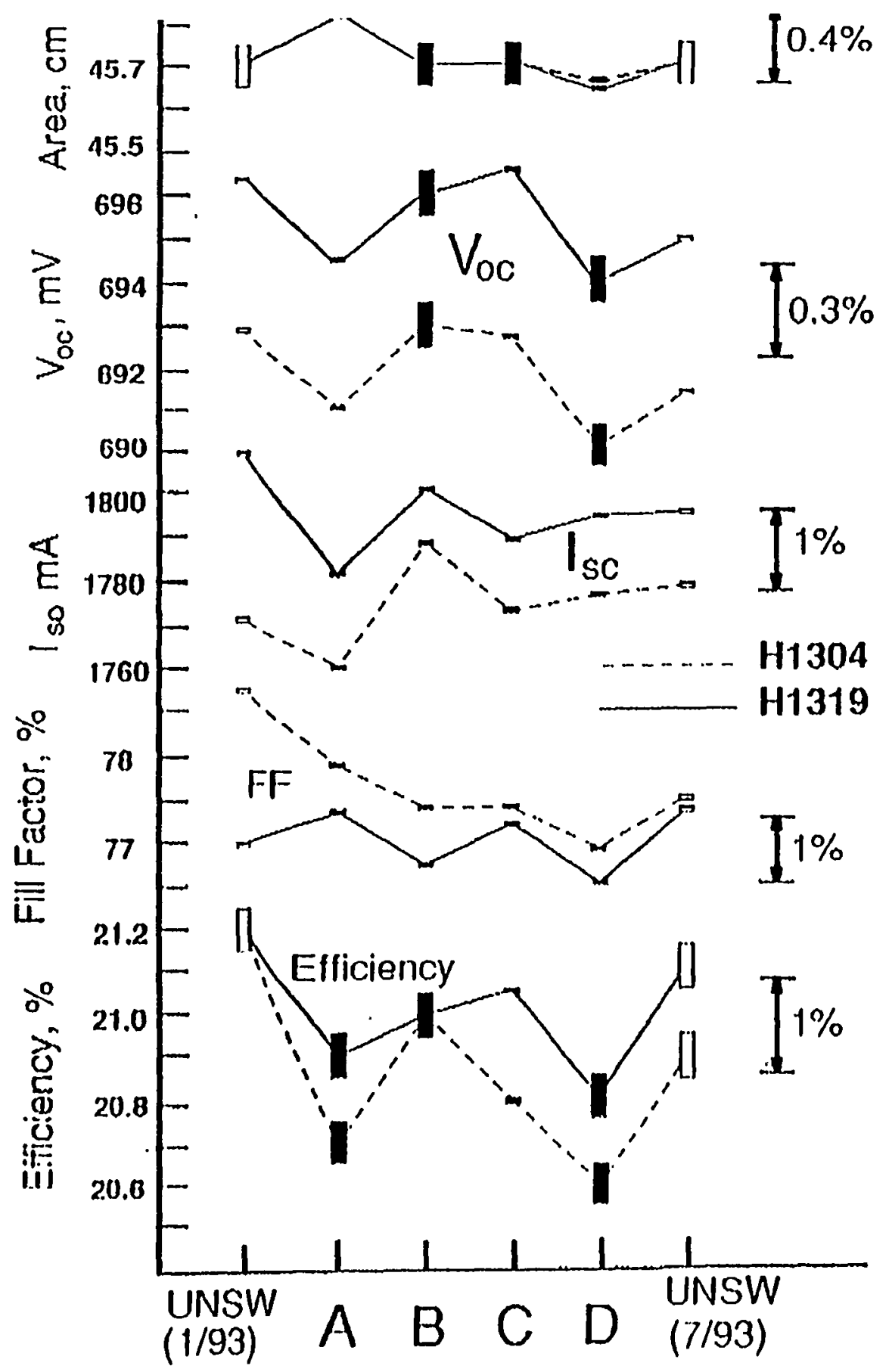




\section{ARTIFACTS / ANOMALIES}

nature.

\section{primary cause}

Excess current density

Definition

Photo-current outside of the device area

Hysterisis in $\mathrm{I}-\mathrm{V}$

Large capacitance

Pre-measurement Conditions Recombination centers

Optics

Stray reflections

Leveling

Field-ol-view 


\section{CdS/CuInSe2}

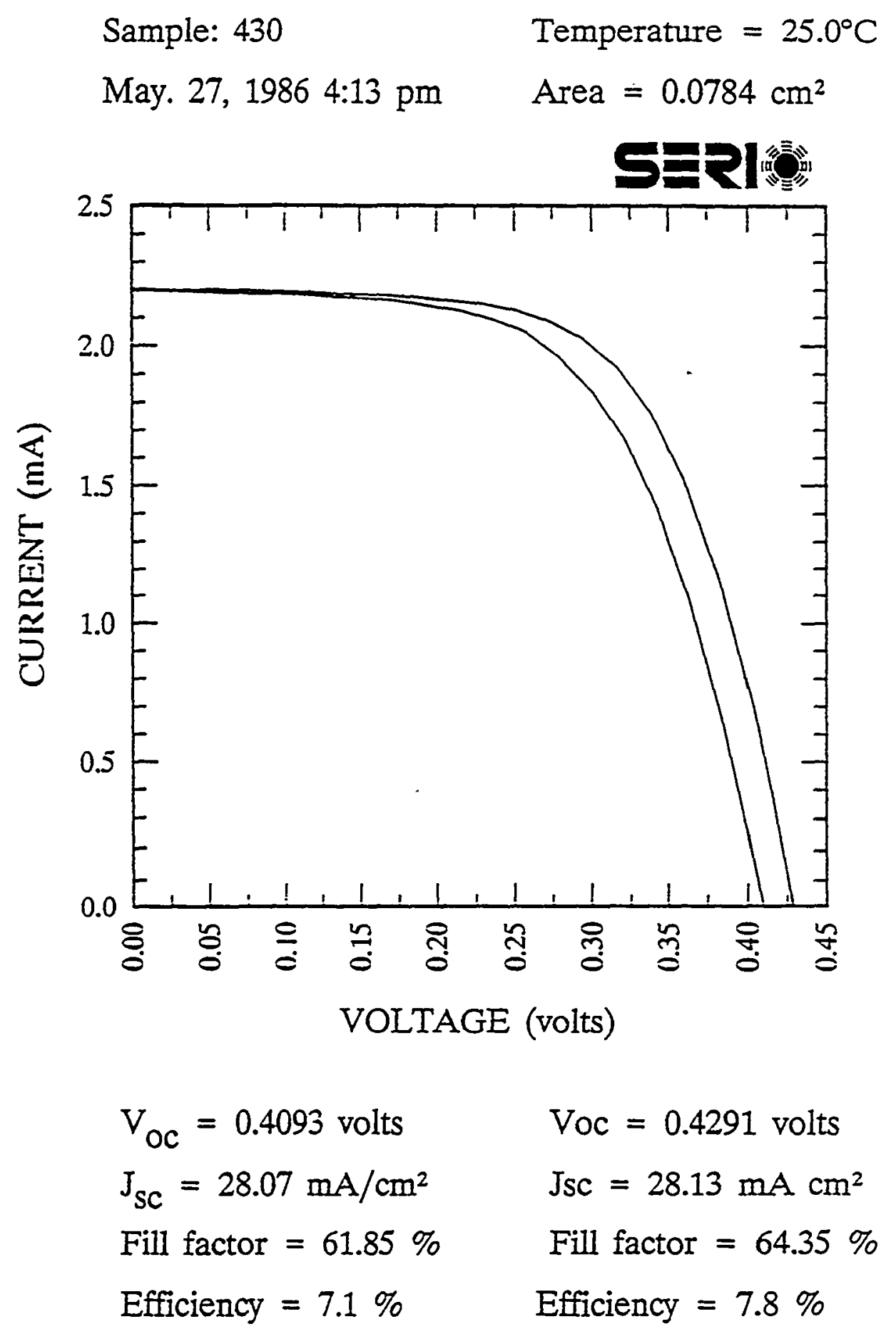




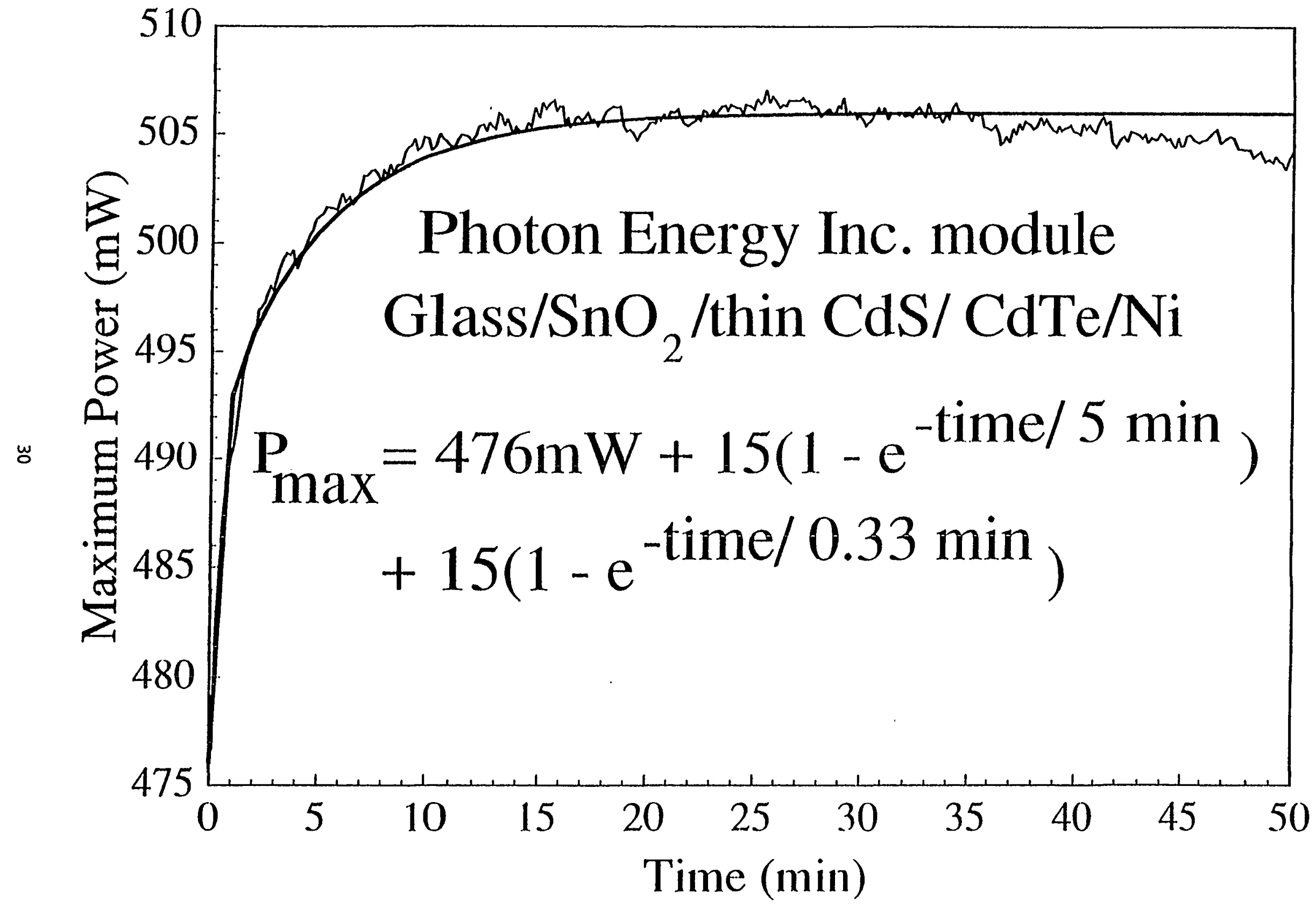


Spectrolab X-25

\section{Solar Simulator}

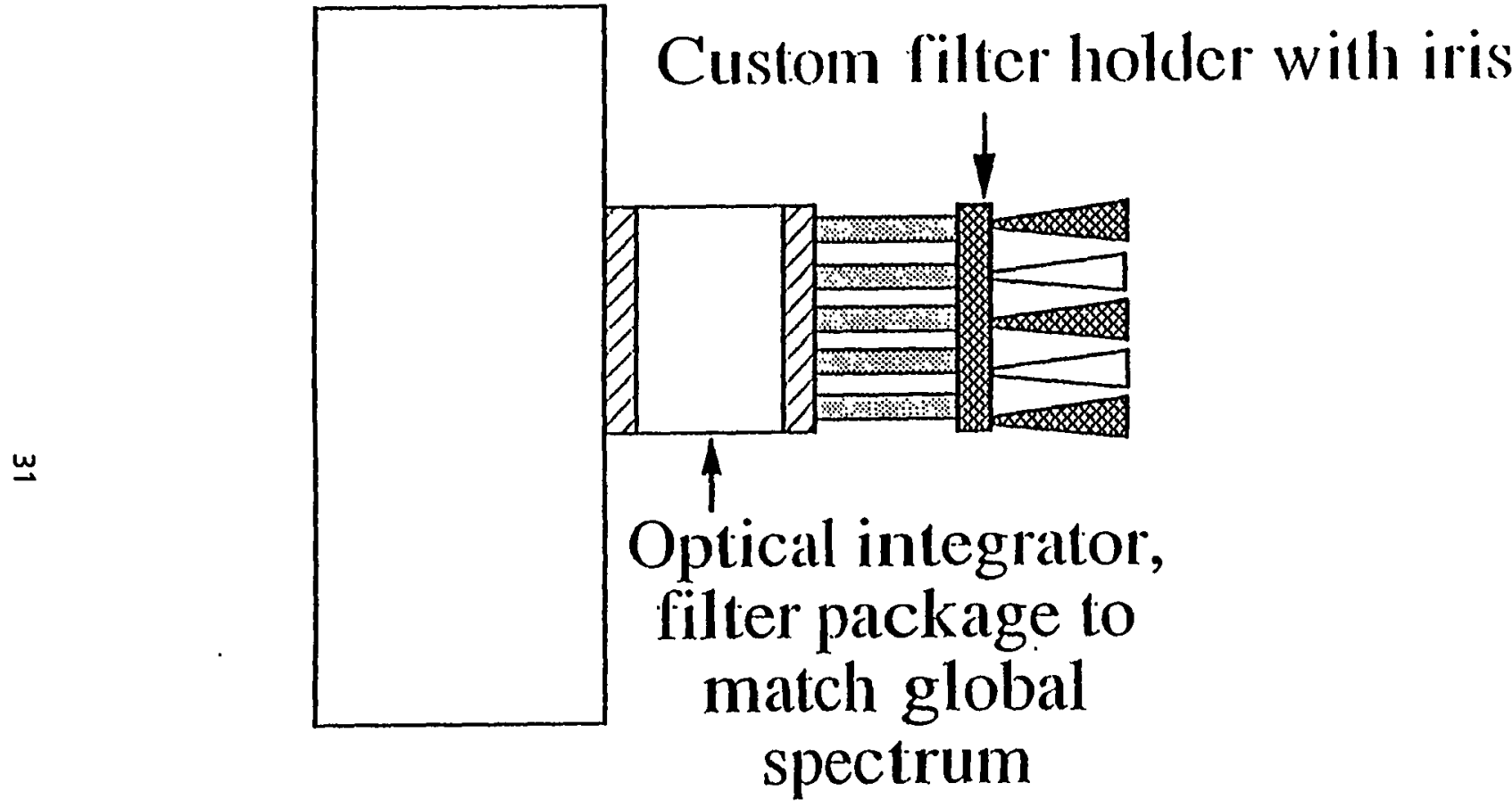

Test plane

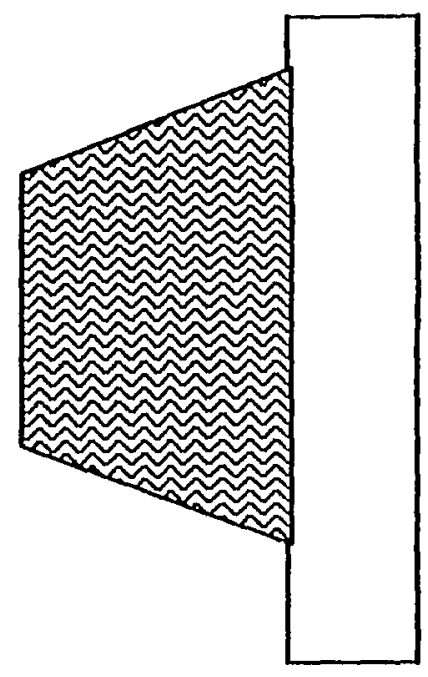

$\pm 3 \%$ Spatial and spectral uniformity over test plane 


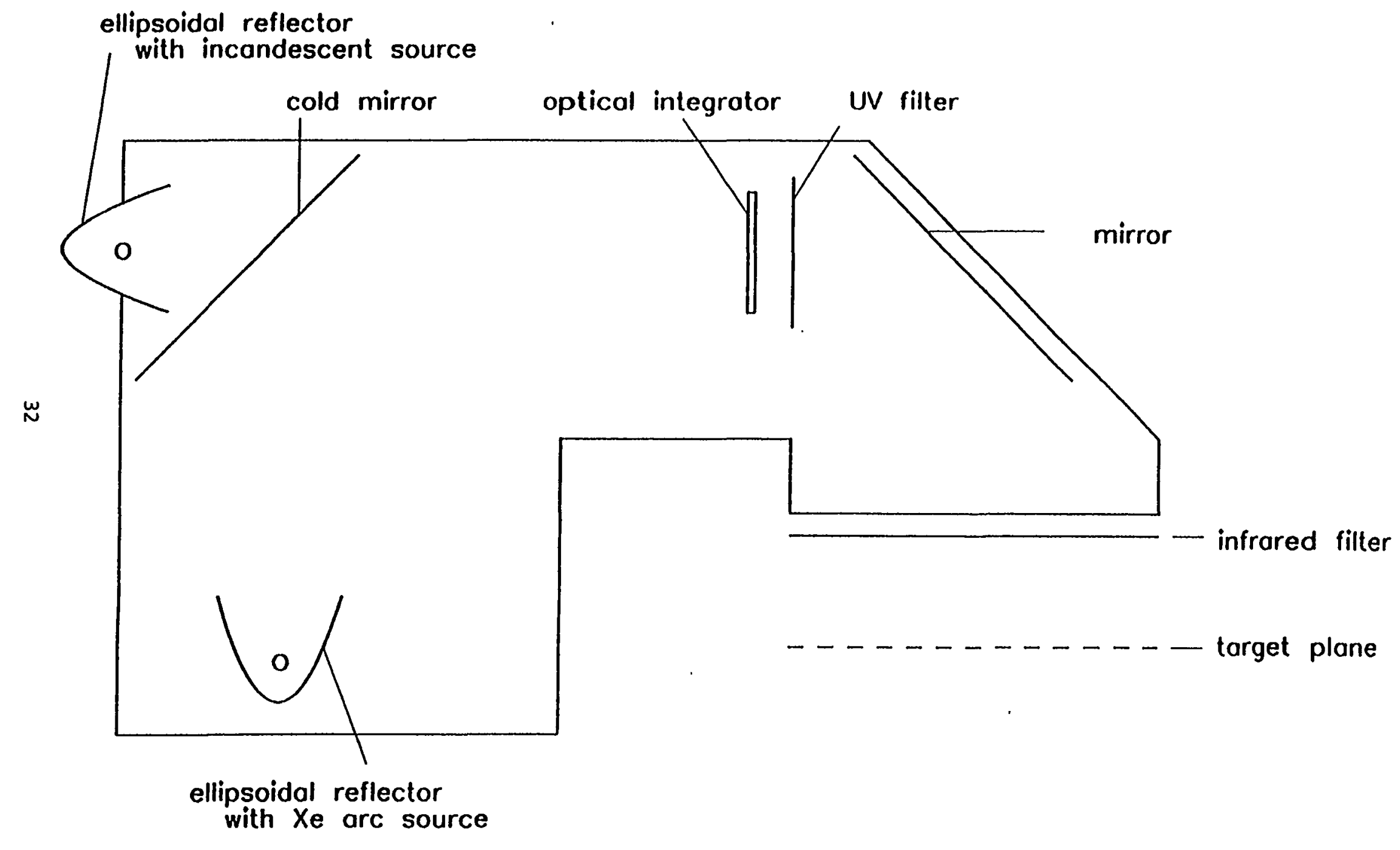




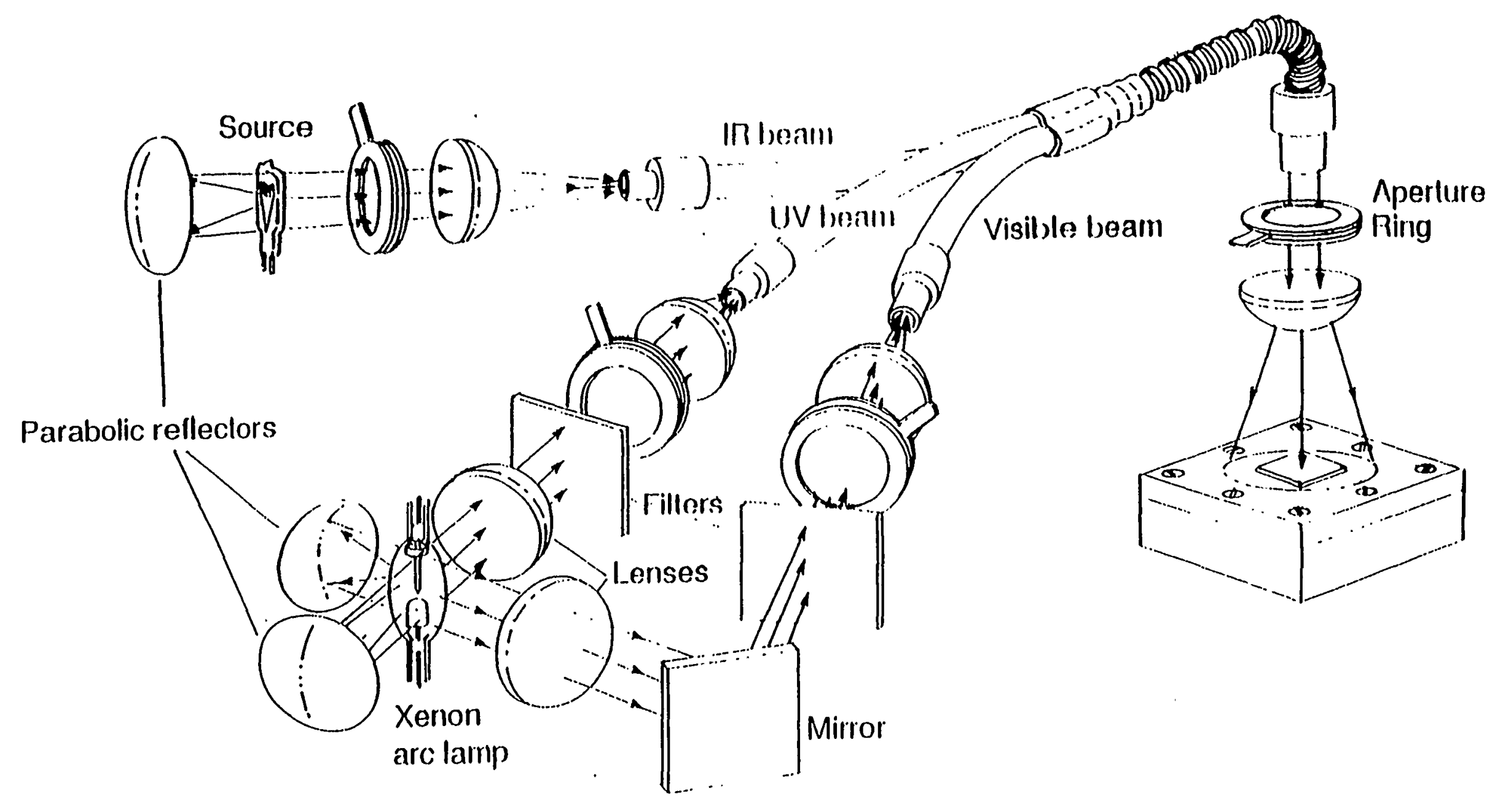

B^.G0792.101 


\section{Summary of PV Calibration Uncertainties}

Calibration Method $E_{t o t}$

Bias Random Total $\left(U_{95}\right)$

$(\%) \quad(\%)$

(\%)

Global fixed-tilt

Global fixed-tilt

pyranometer

direct + diffuse

$3.06 \quad 1.48$

4.26

$2.29 \quad 1.16$

3.24

Global-normal

Global-normal

Direct-normal

X25 simulator

pyranometer

$2.49 \quad 1.48$

3.69

direct + diffuse

0.82

1.16

2.46

cavily radiomeler

0.47

0.27

0.72

direct-normal reference cell

${ }^{\circledR}$ SPI-SUN Simulator

direct-normal reference cell

1.03

0. 21

1.09

$\begin{array}{lll}1.44 & 1.23 & 2.97\end{array}$

AM0 (JPL balloon calibration) †

AM0 (NASA airplane calibration) †

$\begin{array}{ll}0.50 & 0.24\end{array}$

0.69

1.00

1.00

† A standard uncertainty analysis has not been performed for AM0 calibration methods; these are estimates based upon published information 


\section{$U_{95}$ Global Fixed-Tilt PV Calibration Uncertainty}

Source
Bias Random Total $\left(U_{95}\right)$

$(\%)$

0.10

2.12

$(\%)$

(\%)

$I^{R, S}$

$E_{\text {tot }}$ Kipp and Zonen CM11 pyranometer

$E_{\text {tot }}$ Cavity radiometer + shaded pyranometer

$3^{\circ}$ pointing or leveling error for $20^{\circ}$ incidence $\angle$

Spectral correction

w Deviation from ideal cosine response

PV temperature correction

PV $I^{R, S}$ linearity

Thermal voltages

Time constants

Field-of-view and ground reflections
$0.59 \quad 0.24$

2.08

().20

().20

0.15

0.05

0.05

0.50

0.50
0.05

0.95

0.50

$-$

0.10

0.05

0.05

0.10

1.00
0.14

2.85

0.71

2.08

1.02

0.20

0.25

0.11

0.11

0.54

2.06

Total ( $E_{t o t}$ from pyranometer)

$3.01 \quad 1.48$

4.26

Total ( $E_{\text {tot }}$ from cavity radiometer + pyranometer) $2.29 \quad 1.16$ 


\section{$U_{95}$ Global-Normal with a Moveable False-Horizon PV Calibration Uncertainty}

Source

Bias Random

$(\%)$

$(\%)$

$\begin{array}{ll}0.10 & 0.05\end{array}$

2.120 .95

$\begin{array}{ll}0.59 & 0.24\end{array}$

0.20

$0.20 \quad 0.50$

0.02

0.15

0.05

0.05

0.20

0.50

Total (U95)

(\%)

Deviation from ideal cosine response

PV temperature correction

PV $I^{R, S}$ linearity

Thermal voltages

Time constants

Field of view and ground reflections (false horizon)

Total ( $E_{\text {lot }}$ from pyranometer)

$2.49 \quad 1.48$

0.14

$E_{t o t}$ Kipp and Zonen CM11 pyranometer, or

Total $\left(E_{t o t}\right.$ from cavity radiometer + pyranometer $)$

2.85

0.71

0.20

1.02

0.02

0.25

0.11

0.11

0.28

2.06

$\begin{array}{lll}0.82 & 1.16 & 2.46\end{array}$




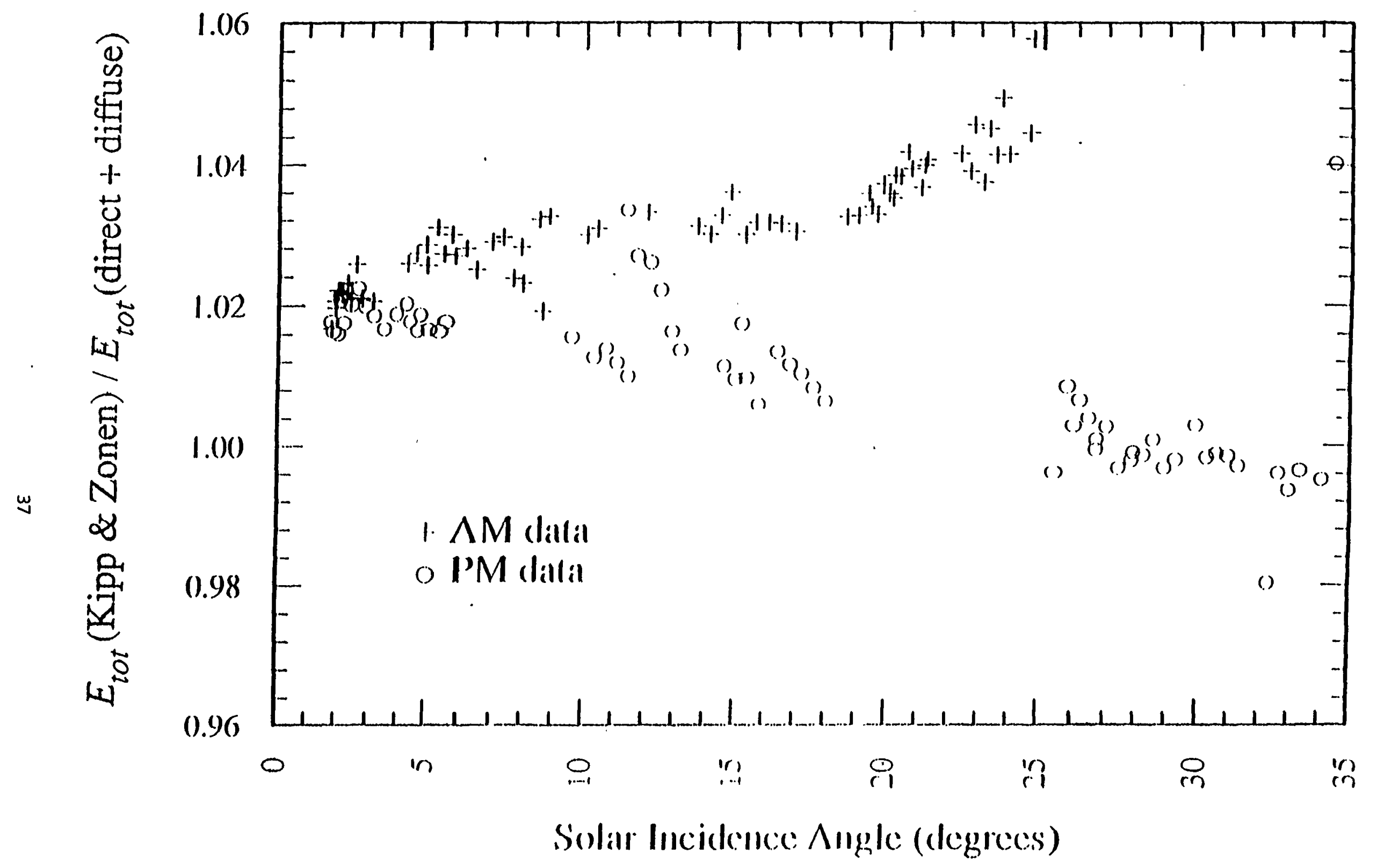




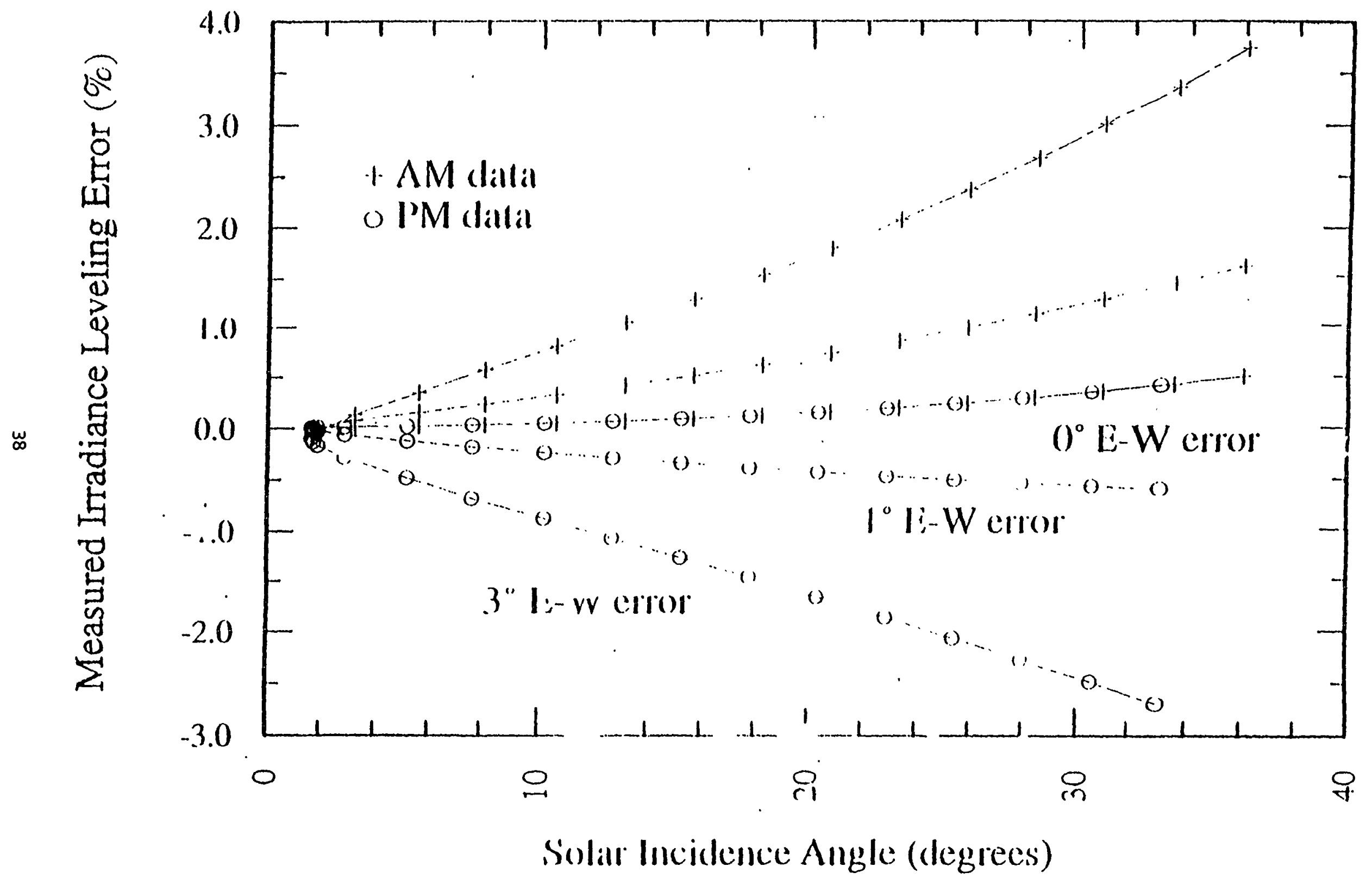




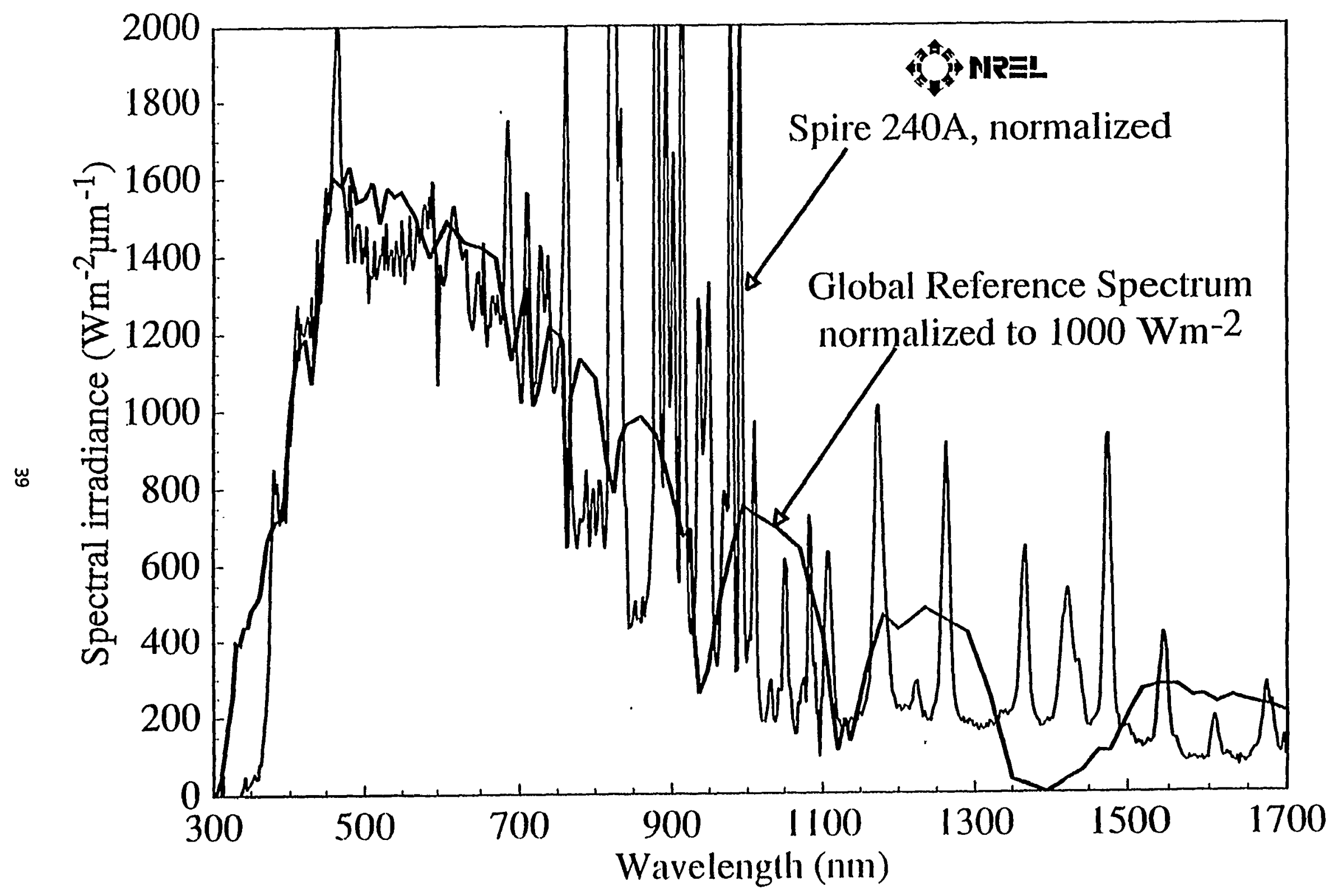




\section{USSC a-Si/a-Si UPM 880 module}

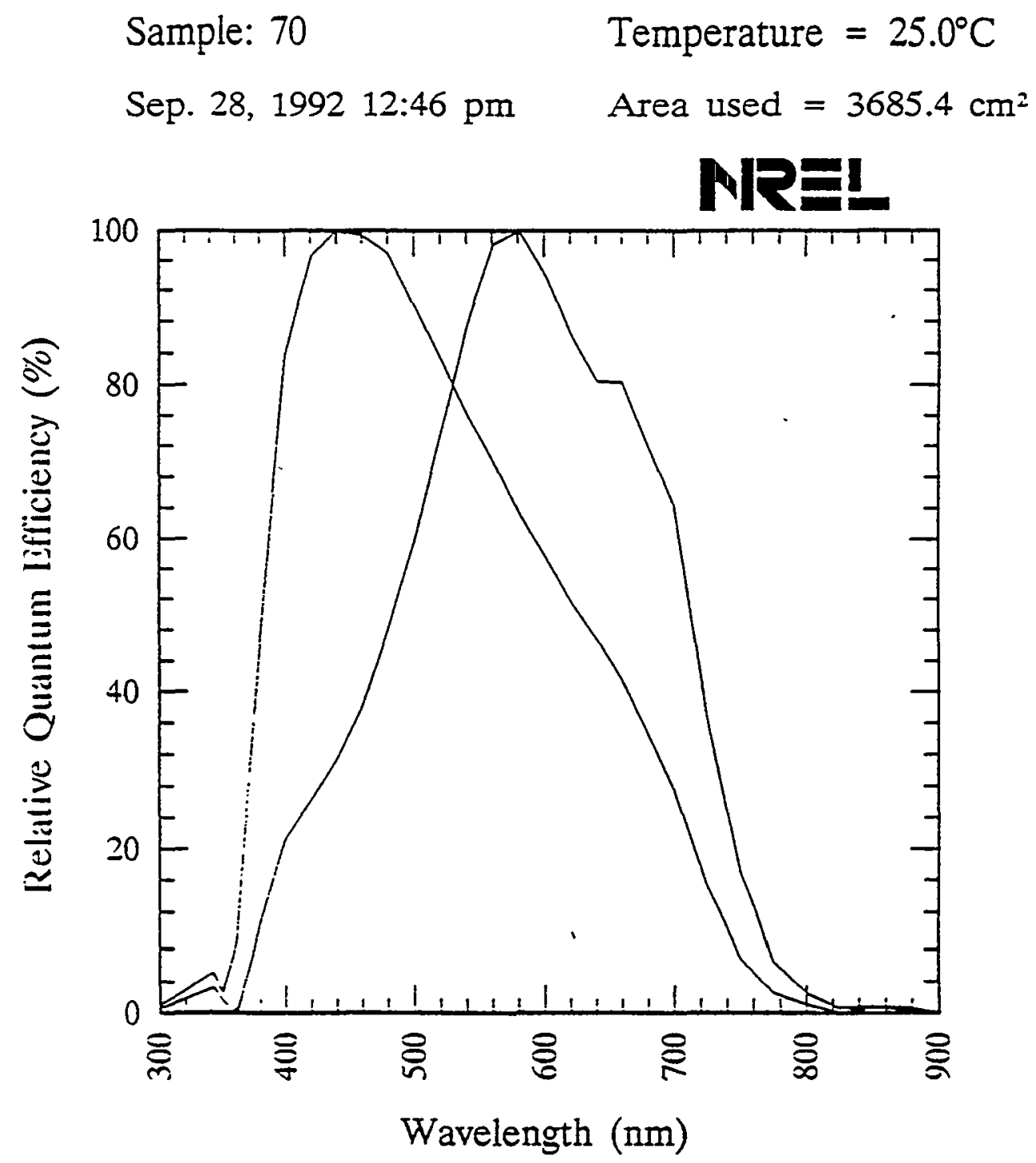


Solar Cells Inc 34W,CdS/CdTe module

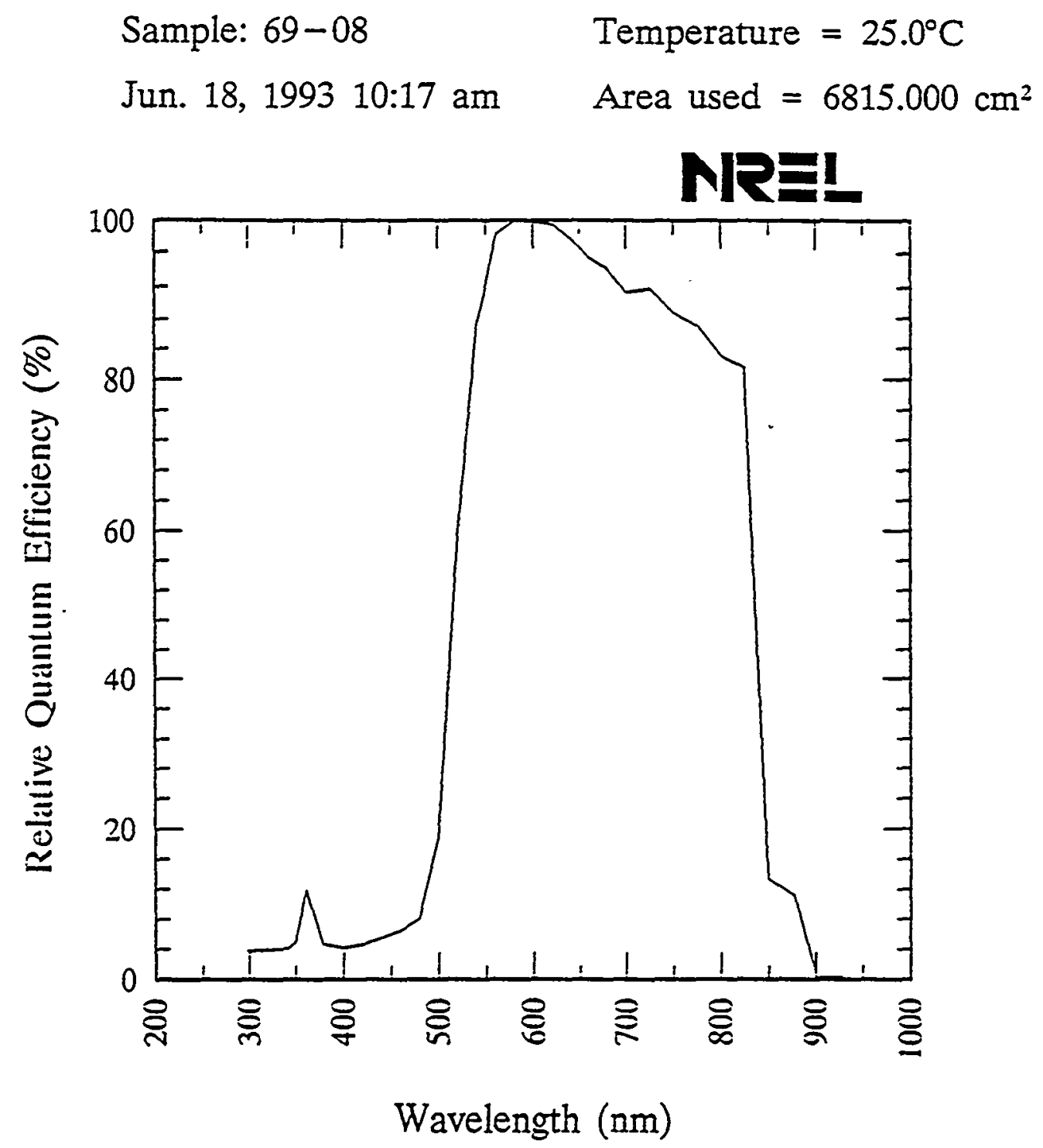

Light bias $=2.00 \mathrm{~mA}$

Zero voltage bias 


\section{ISET CIS submodule}

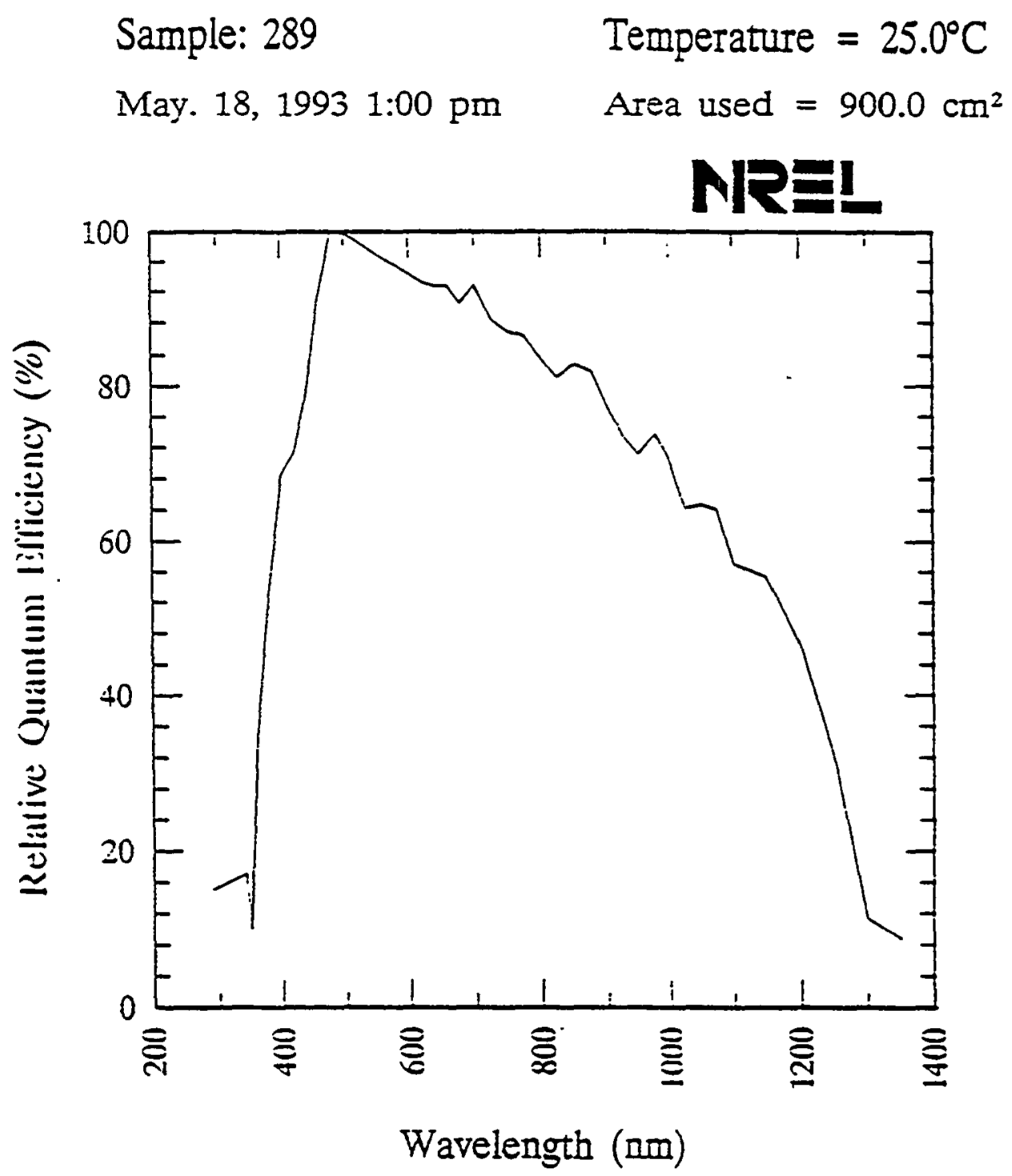

Light bias $=1.37 \mathrm{~mA}$

Zero voltage bias 


\section{SPIRE 240A Spectral Error}

Reference

Si Cell in Module

a-Si module

$$
\text { 'Test }
$$

single \& poly-Si

CdS/CIS

CdS/Cd'Te

thin film $\mathrm{Si}$

Sphere Si

a-Si module

a-Si tandem top

a-Si tandem bottom

a-Si triple top

a-Si triple middle

a-Si triple bottom
Error (\%)

$$
\begin{array}{r}
<2 \% \\
-3-4 \% \\
-3-4 \% \\
-3-4 \% \\
-3 \% \\
<1 \% \\
<1 \% \\
8-9 \% \\
<2 \% \\
<2 \% \\
9-12 \%
\end{array}
$$




\section{Amorphous Silicon Intercomparison}

$\begin{array}{llcccc}\text { Group } & \mathrm{V}_{\mathrm{Oc}} & \mathrm{I}_{\mathrm{Sc}} & \mathrm{FF} & \mathrm{P}_{\max } & \text { Comments } \\ & (\mathrm{V}) & (\mathrm{mA}) & (\%) & (\mathrm{W}) & \end{array}$

Solarex SA 5-23751 a-Si module

$\begin{array}{llllll}\text { NREL } & 24.0 & 324 & 67 & 5.2 & \text { Outdoors PSP ref., normalized }\end{array}$

$\begin{array}{lllll}24.9 & 346 & 68 & 5.8 & \text { SPI-240A, filtered Si reference cell }\end{array}$

$\begin{array}{lllll}24.7 & 331 & 68 & 5.6 & \text { SPI-240A, a-Si module reference }\end{array}$

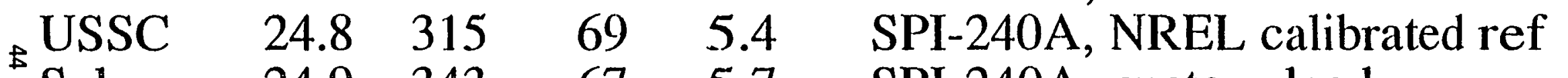

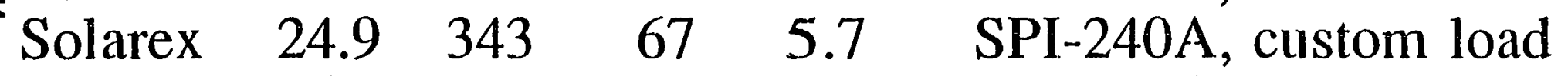

$\begin{array}{llllll}\text { Spire } & 25.3 & 340 & 68 & 5.9 & \text { SPI-240A }\end{array}$

Solarex a-Si/a-Si/a-Si:Ge module, M2037-3

$\begin{array}{llllll}\text { NREL } & 53.8 & 176 & 63 & 6.0 & \text { Outdoors PSP ref., normalized }\end{array}$

$\begin{array}{lllll}57.0 & 188 & 59 & 6.3 & \text { SPI-240A, filtered Si reference cell }\end{array}$

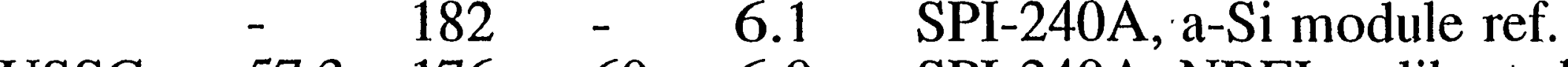

$\begin{array}{llllll}\text { USSC } & 57.3 & 176 & 60 & 6.0 & \text { SPI-240A, NREL calibrated ref }\end{array}$

$\begin{array}{llllll}\text { Solarex } & 57.5 & 189 & 59 & 6.4 & \text { SPI-240A, custom load }\end{array}$

$\begin{array}{llllll}\text { Spire } & 57.8 & 180 & 59 & 6.1 & \text { SPI-240A }\end{array}$ 


\section{Amorphous Silicon Intercomparison}

$\begin{array}{llllll}\text { Group } & \mathrm{V}_{\mathrm{Oc}} & \mathrm{I}_{\mathrm{SC}} & \mathrm{FF} & \mathrm{P}_{\max } & \text { Comments } \\ & (\mathrm{V}) & (\mathrm{mA}) & (\%) & (\mathrm{W}) & \end{array}$

USSC a-Si/a-Si:Ge light soaked module, S935

$\begin{array}{llllll}\text { NREL } & 9.15 & 1.19 & 61 & 6.7 & \text { Outdoors PSP ref., normalized }\end{array}$ $\begin{array}{lllll}9.61 & 1.27 & 60 & 7.3 & \text { SPI-240A, filtered Si reference }\end{array}$

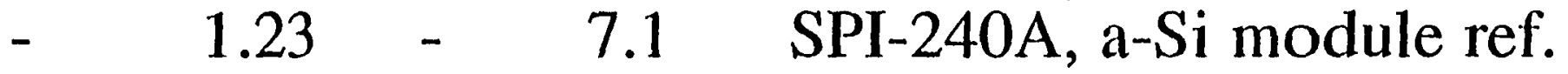

$\begin{array}{llllll}\text { USSC } & 9.65 & 1.19 & 61 & 7.0 & \text { SPI-240A, NREL calibrated ref }\end{array}$

in Solarex $9.52 \quad 1.30 \quad 58 \quad 7.3 \quad$ SPI-240A, custom load

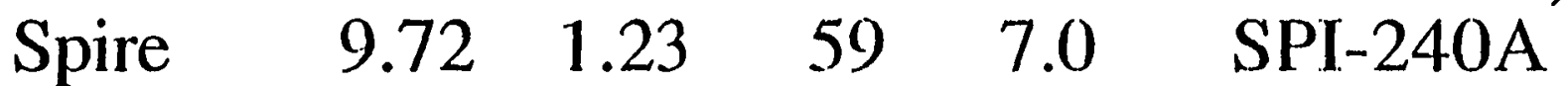

USSC a-Si/a-Si:Ge module, 2B1932

$\begin{array}{llllll}\text { NREL } & 1.62 & 8.83 & 61 & 8.8 & \text { Outdoors PSP ref., normalized }\end{array}$ $\begin{array}{lllll}1.67 & 9.50 & 60 & 9.5 & \text { SPI-240A, filtered Si reference cell }\end{array}$ $\begin{array}{lllll}1.67 & 9.33 & 60 & 9.3 & \text { SPI-240A, a-Si module reference }\end{array}$ $\begin{array}{llllll}\text { USSC } & 1.67 & 8.68 & 63 & 9.1 & \text { SPI-240A, NREL calibrated ref }\end{array}$ $\begin{array}{llllll}\text { Spire } & 1.67 & 8.97 & 60 & 9.1 & \text { SPI-240A }\end{array}$ 


\section{Amorphous Silicon Intercomparison}

Differences in $\mathrm{P}_{\max }$ from 3 to $12 \%$ were observed depending on the module with $5 \%$ being typical when the participants set their Spire 240A solar simulator following their routine procedures.

When the participants set their simulator to give the same Isc the differences in $P_{\max }$ were reduced to $2-8 \%$ with $2 \%$ being typical

For these modules the variation in $P_{\max }$ measured at NREL under the SPIRE simulator and outdoors under prevailing clear sky conditions was between 1 and $8 \%$ without corrections for temperature or spectral mismatch error. 


\section{SUMMARY}

Differences in Efficiency occur because of measurement error, definition, and artifacts.

Reversible improvements of $\sim 3 \%$ in the performance with forward bias has been observed in $\mathrm{CdS} / \mathrm{CuInSe}_{2}, \mathrm{Si}$, and $\mathrm{CdS} / \mathrm{CdTe}$ cells and Modules. $\mathrm{V}_{\text {oc }}$ changes with time after shorting then open-circuiting the sample.

Existing single-source simulators can be easily modified to be a multi-source simulator

Multi-source simulators arc essential for optimization of a twoterminal multi-junction PV device 


\section{CHARACTERISTICS OF \\ SPECTROLAB \\ SOLAR SIMULATORS \\ J. Lovelady, System Engineer \\ Spectrolab, Inc.}

\subsection{INTRODUCTION}

Spectrolab has been manufacturing solar simulators since the early 1960's. This paper gives a little of the history of the company and describes the general characteristics of the current Solar simulator products, both steady state and pulsed.

\subsection{COMPANY HISTORY}

Spectrolab was formed as a manufacturer of state of the art optical thin films, quickly branching out into other areas. In addition to other types of electro-optical instruments, the business of the company soon settled down into three main branches: photovoltaic solar panels, solar cells, and solar simulators. Searchlights (originally an outgrowth of solar simulator technology) have recently formed a fourth line of business. Some dates of interest are:

Solar panels since 1958 (Pioneer 1).

Solar Radiation Simulators since 1961.

Solar cells since 1961.

Electronic loads (for cell and panels) since 1965

Pioneers in large area simulation since 1965.

Large Area Pulse Solar Simulators since 1972

Searchlights since 1970

page 1 of 10 


\subsection{TYPES OF SOLAR SIMULATORS}

Spectrolab manufactures two distinct types of solar simulators: steady state and pulsed. The steady state simulator is the older of the two and is applicable both to the testing of photovoltaic power panels and to the thermal balance and longevity testing of space materials from samples to complete satellites. The pulse simulators are really complete photovoltaic panel test systems, including not only the pulsed light source (solar simulator), but a fast sweeping electronic load, data acquisition system, and data processing system. Each has its own characteristics and areas of application.

The steady state simulators offer good stability, both Iong and short term, excellent uniformity of illumination over the test plane, and close spectral match to sunlight. The pulse systems offer large test plane area, simple control of sample temperature, speed, and convenience at a cost considerably lower than an equivalent steady state unit.

\subsection{Steady state simulators}

spectrolab has built simulators ranging in size from 3"x6" test plane to 16 foot diameter test plane. The largest is an array of 38 modular simulators which together can illuminate an area of over 300 square feet. The most widely used simulator is the model $X-25$, a self contained laboratory instrument designed for a 2500 watt Xenon lamp, and capable of using a variety of lamps from 2500 to 4200 watts in size. The XT-10 is a smaller, less expensive unit with less stringent specifications. 
Typical specifications for the $\mathrm{X}-25$ and $\mathrm{XT}-10$ are shown in Figures 1, 2 and 3.

\subsection{Pulsed Simulators (IAPSS)}

The LAPSS system uses a specially designed Pulse Forming Network (PFN) to obtain a pulse of light with steep rise time and a flat top. (See Figure 4). The pulse is about 2 milliseconds long including rise and fall times and some overshoot at each end. There is a "flat spot" for 1 millisecond within which the light level is constant within $+/-3 \%$. All measurements are taken during this time.

During this 1 millisecond measurement period, 40 to 50 sets of data are taken, at 20 microsecond intervals. Each data set includes the test panel voltage, test panel current, and light level. The test panel voltage is varied during the pulse to sweep out the $I-V$ curve. For testing panels with rapid response to load changes, it is possible to sweep the entire $I-V$ curve in one light pulse, starting at a slight back bias and sweeping to a point beyond Voc. For slower panels, the curve is measured in several overlapping segments, each starting at preset voltage and sweeping at the maximum rate allowable for accurate measurements.

Accuracy is assured by using only that portion of the pulse where the light level is constant and by controlling the voltage sweep rate to assure that deviations from steady state measurements will be negligible. Each data point is then corrected mathematically for the small residual error due to light level variations.

page 3 of 10 
The spectral match of the LAPSS is quite good, though not as good as with the steady state simulator. An optional spectral filter is available to reduce the excess in the ultraviolet (see Figure 5). The target plane uniformity is very good, particularly for sizes up to $10 \mathrm{ft}$ square. Specifications are given in Figure 6 .

4.0

FUTURE DEVELOPMENTS

The Automatic Cell Evaluator (ACE) is nearly ready for production. This system used the same type of data acquisition system as the LAPSS for testing of cells and small modules under steady state light. It offers the same correction for minor light level fluctuations and the same convenience in data handling and storage. The first unit will be in use at spectrolab early in 1994 and will be offered for sale soon thereafter.

The need is well established for more accurate spectral simulation for testing multi-junction cells and panels. spectrolab is looking into developing a small area accurate spectrum simulator using multiple light sources. There is no firm schedule on this project.

An attachment for the $\mathrm{x}-25$ will soon be available for adjustment of the spectrum for multi-junction cells using the techniques developed at NREL.

Finally, to extend the IAASS performance for economical testing of large panels with slow response times, spectrolab is working on the development of a system with a very long pulse time (>50ms) and good stability during the pulse.

$$
\text { page } 4 \text { of } 10
$$




\section{$X-25$ SPECIFICATIONS}

\section{Target Area}

(Typical) 13 inch diameter

(Wide variety of optical systems available)

\section{Uniformity of Irradiance}

$+/-2 \%$ (Most optical systems)

Stability

$+/-1 \%$

Spectral Match

Close match in 14 discrete bands.

Meets ASTM E 927-91 Class A in all requirements.

FIGURE 1

page 5 of 10 


\section{SPECTRAI MATCH TOLERANCES FOR SPECTROSUN X-25}

WHEN EQUIPPED WITH

CLOSE SPECTRAL FILTERING ACCESSORY

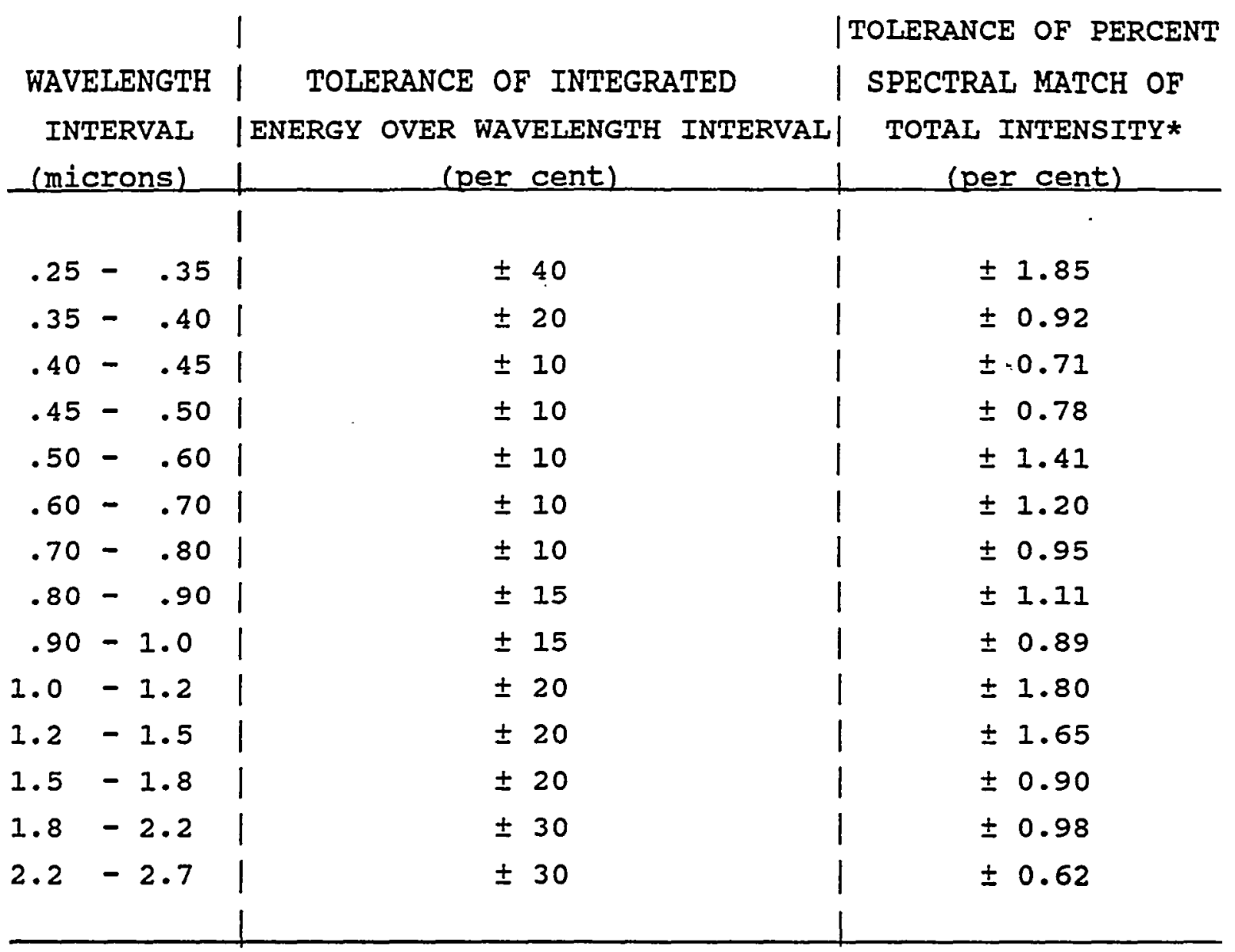

FIGURE 2

page 6 of 10 


\section{XT-10 SPECIFICATIONS}

Target Area

$8 \times 8$ inch square

Uniformity of Irradiance

$+/-3 \%$ (Most optical systems)

Stability

$+/-1 \%$ (Vertical output beam)

$+/-3 \%$ (Horizontal output beam)

Projection angle

9 deg.

Spectral Match

Less stringent match in 5 discrete bands.

\section{FIGURE 3}

page 7 of 10 


\section{STPECTIROLAB}

a subsidiery of Hughes Aircraft Co.
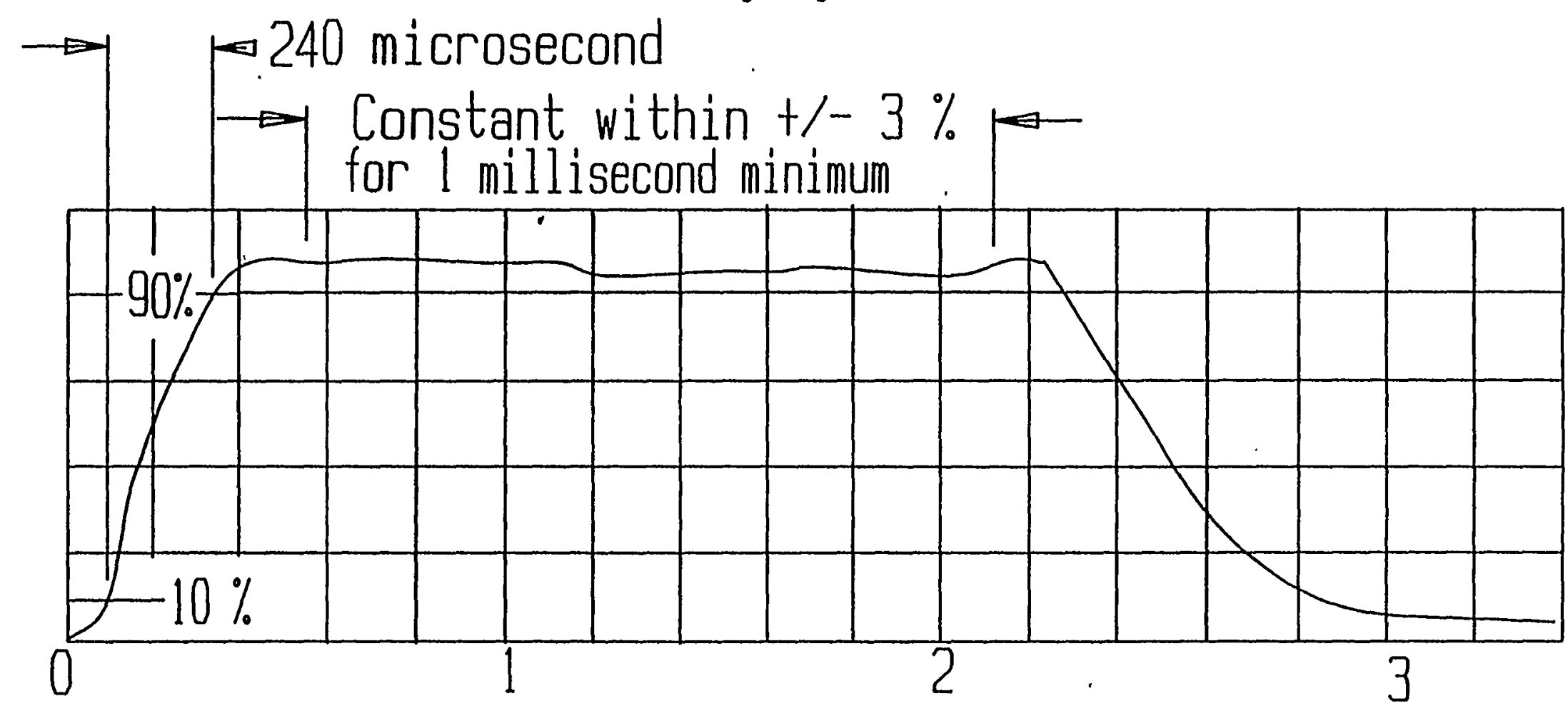

Time, milliseconds TYPICAL LIGHT PULSE-FROM SPECTROSUN LAPSS 
TYPICAL LAPSS SPECTRAL DISTRIBUTION

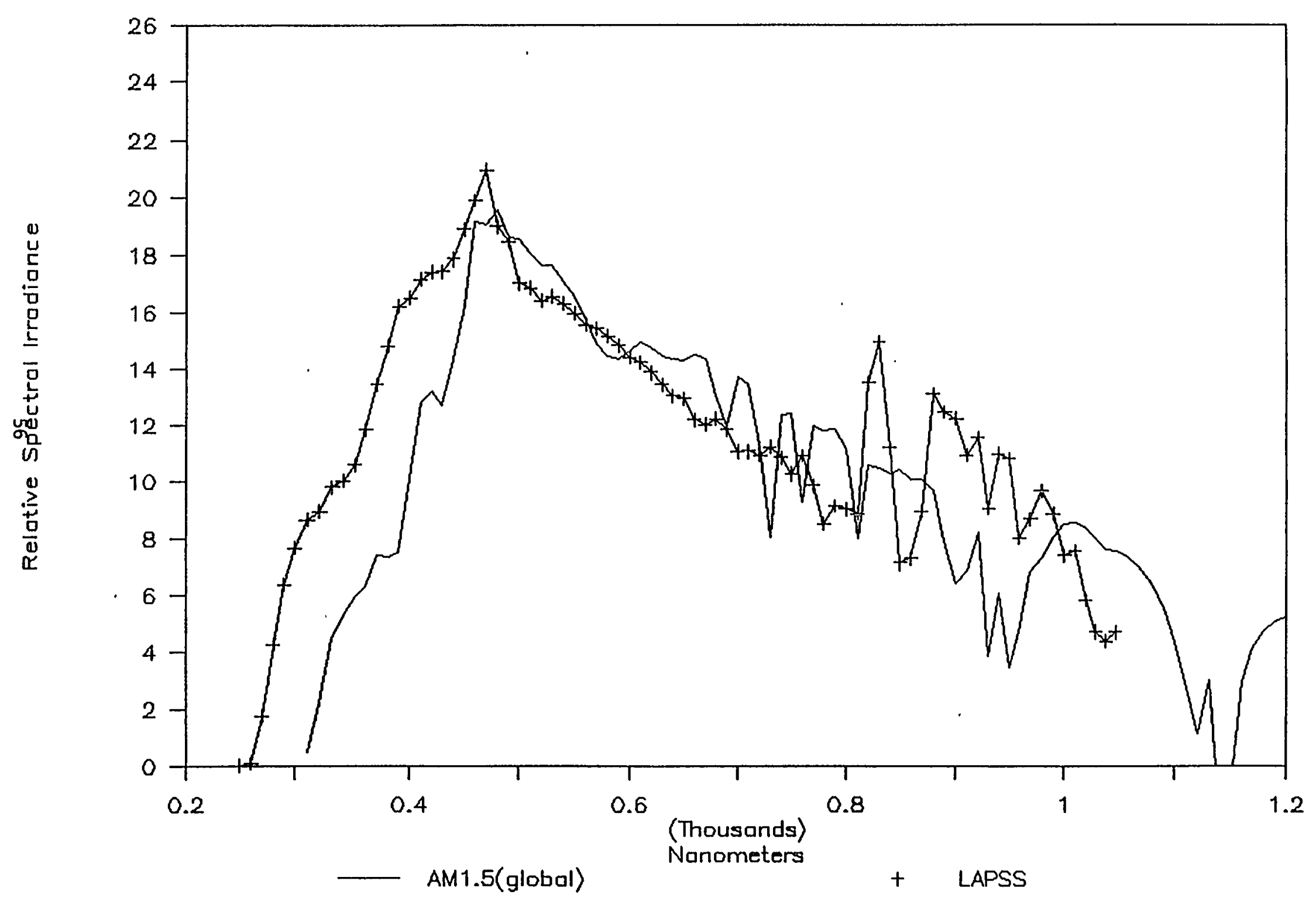




\section{IAAPSS II SPECIFICATIONS}

Complete test system, including Electronic Ioad, Data Acquisition, Data Processing, and Temperature correction

Target Area

16 foot diameter

Uniformity of Irradiance

$+/-3 \%$ over 16 foot diam.

$+/-1.5 \%$ over $2.5 \times 2.5 \mathrm{M}$. (10 $\times 10 \mathrm{ft}$ ) area Better over smaller areas.

Spectral Match

Controlled by selection of lamp current density.

Voltage range current ranges

\author{
Single cells to 100 volt panels \\ single cells to 20 amp panels \\ FIGURE 6
}




\title{
PULSED SOLARSTMULATOR DESIGN AND APPLIGATIONS
}

\author{
6x ox \\ 3

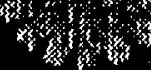 \\ spire
}

\section{Steve Hogan}

Spire Corporation

One Patriots Park/Bedford, MA 01730-2396

617-275-6000/FAX 617.275-7470

Presented at the Photovolicic Performance and Reliability Conference Seprember 8,1993 


\section{PAESENIATION OVERVIEW}

Simulator Characteristics

- Pulsed Light Characterisitics

- Spectrum.

- Uniformity

- Electronic Load

1- Applications

- Crystalline Silicon

a Thin Films 


\section{SUN SIMULATOR FLASH TIMING}

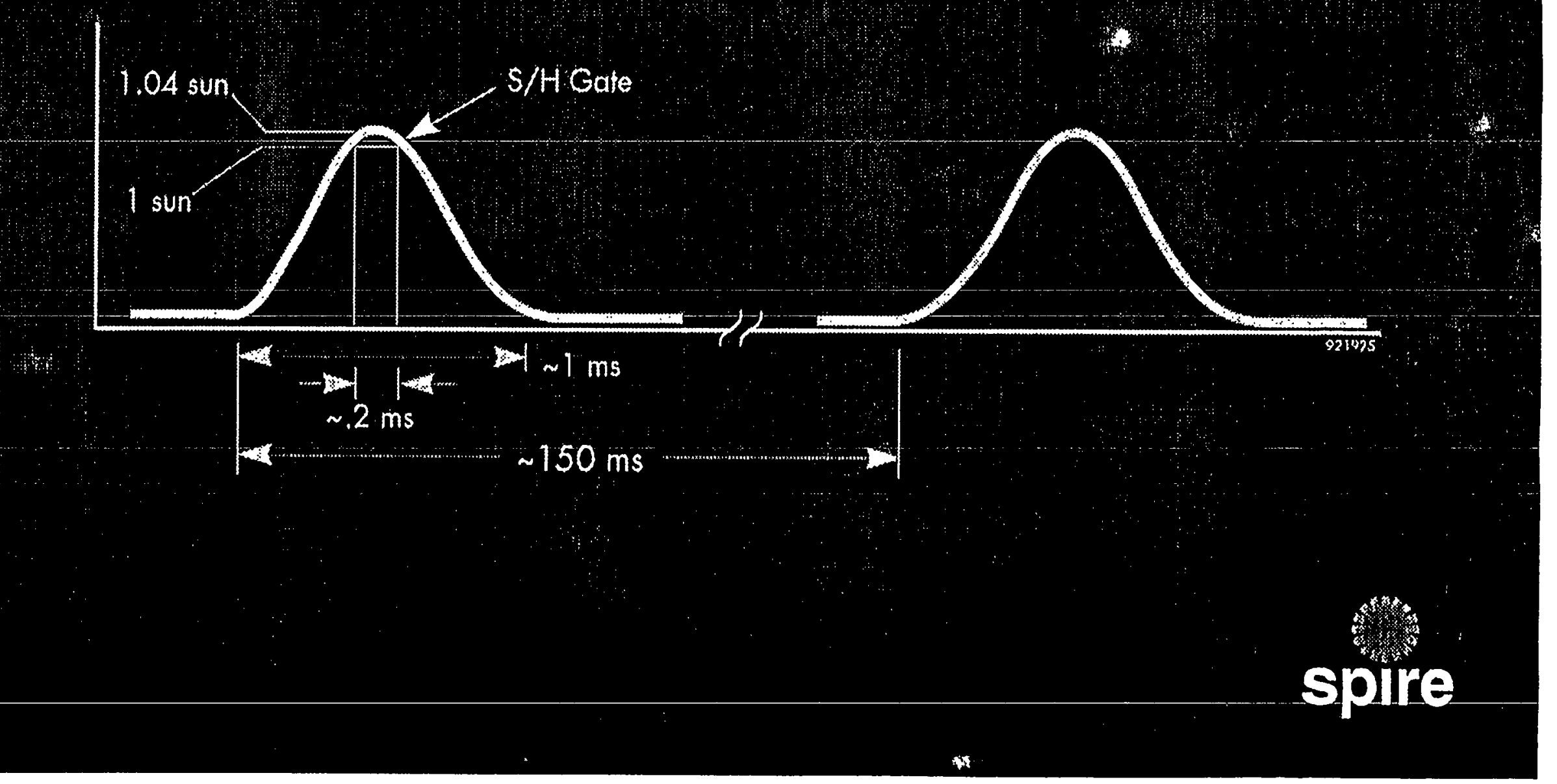




\section{PULSEVS, STEADY STATE}

Limits Panel Heating

Reduces Power Requirement

D Smaller Footprint

$d v / d t$ or $d l / d t(P)$

*.

Spectrum (?) 


\section{SPISUN SIMULATOR 2404 Spectral Composition}

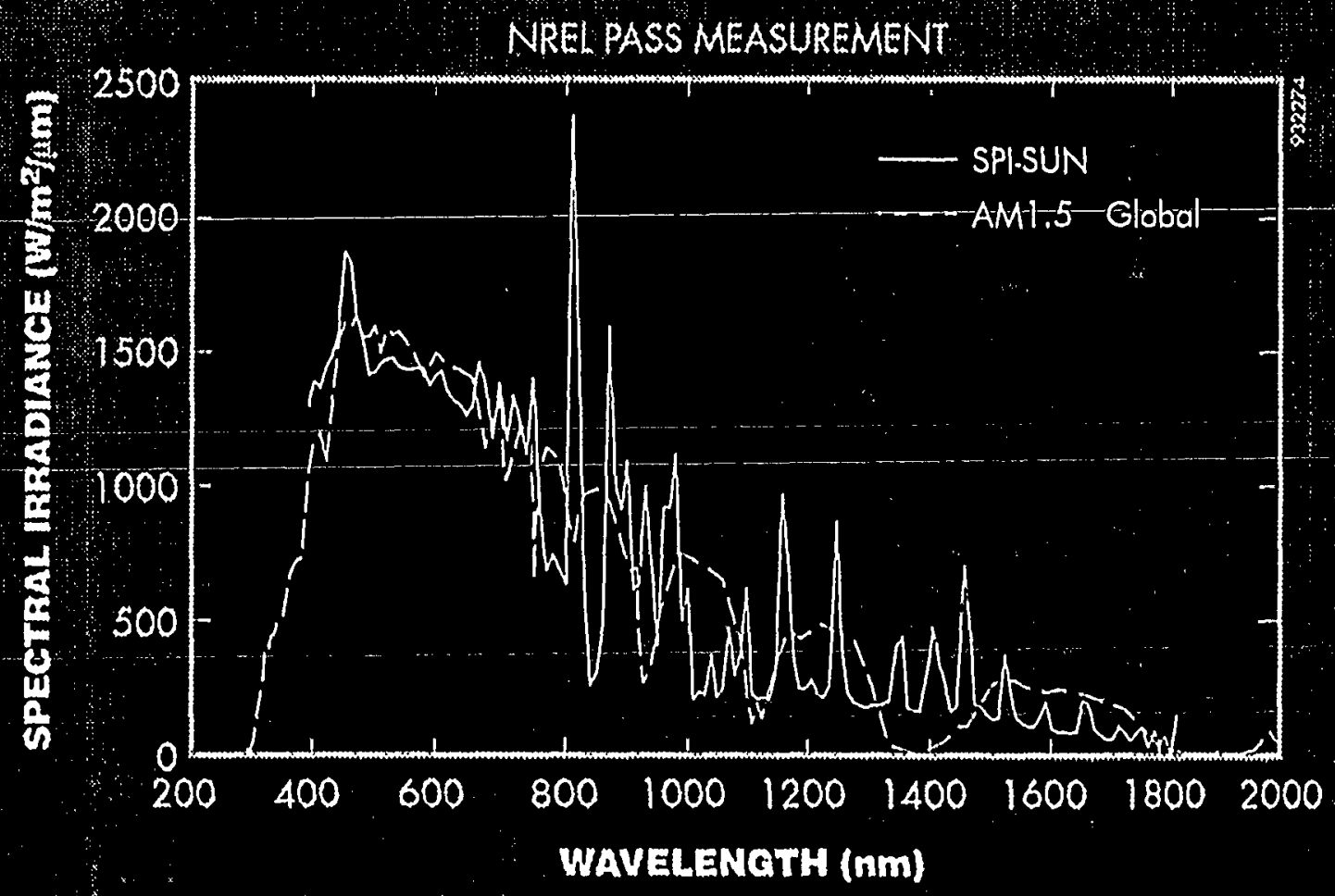




\section{SPISUN STMUL ATOR'M 240A SPECHRAL GOMPOSIIION GOMPARED TO ASTM STANDARD}

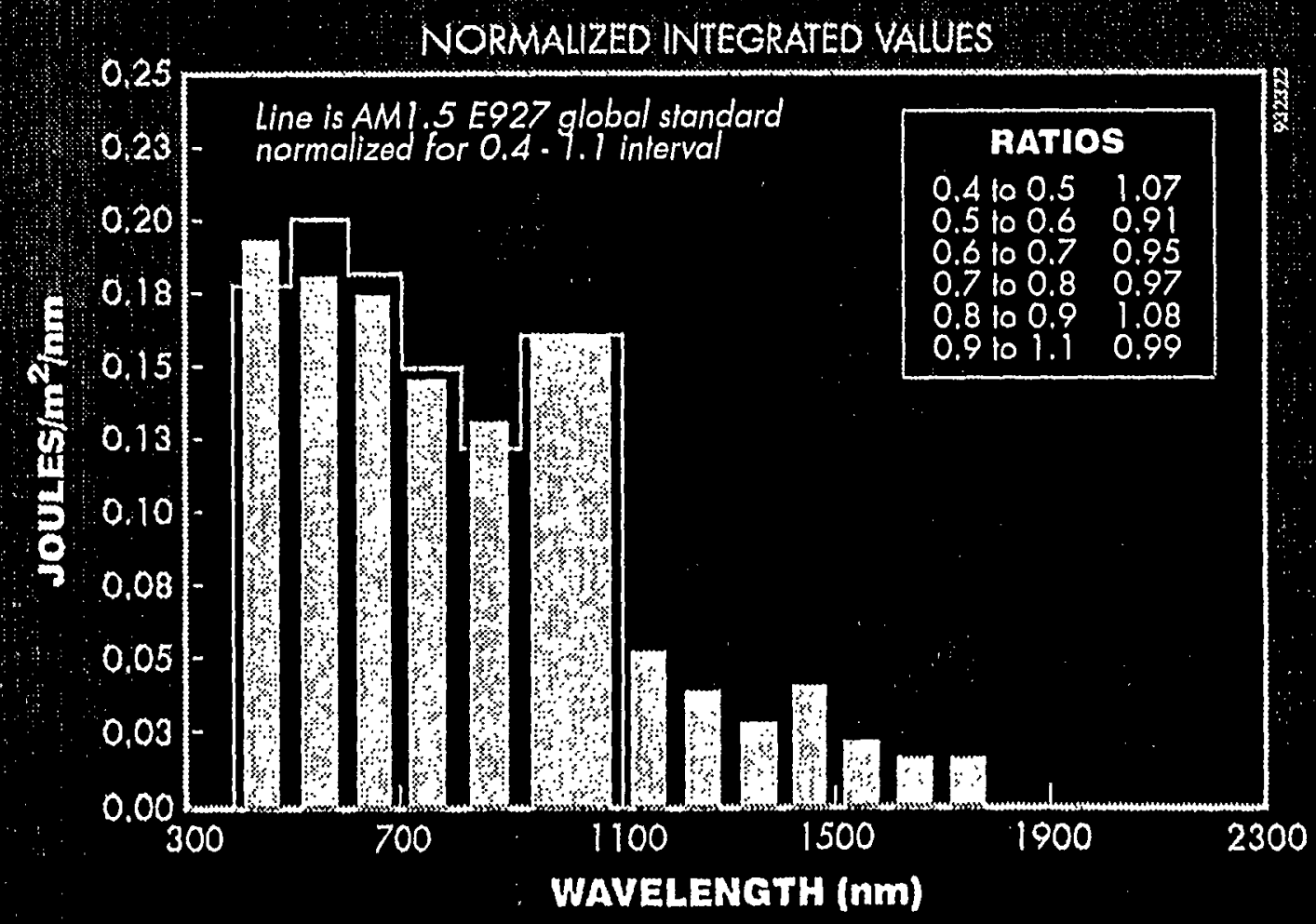

Courtesy of NREL 


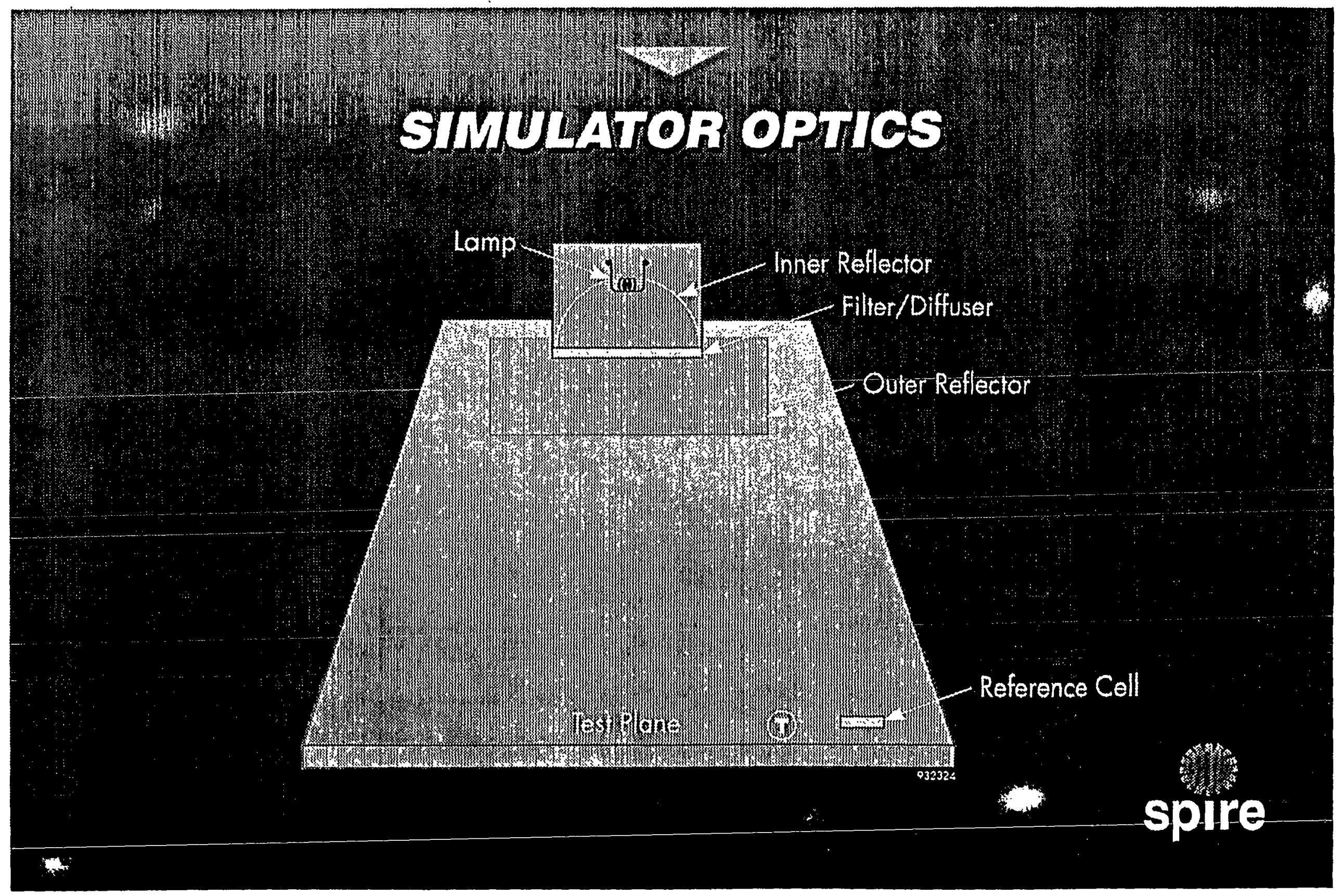




\section{SPISUN STMULATORTM 2404}

\section{Pulsed Solar Sinntator}

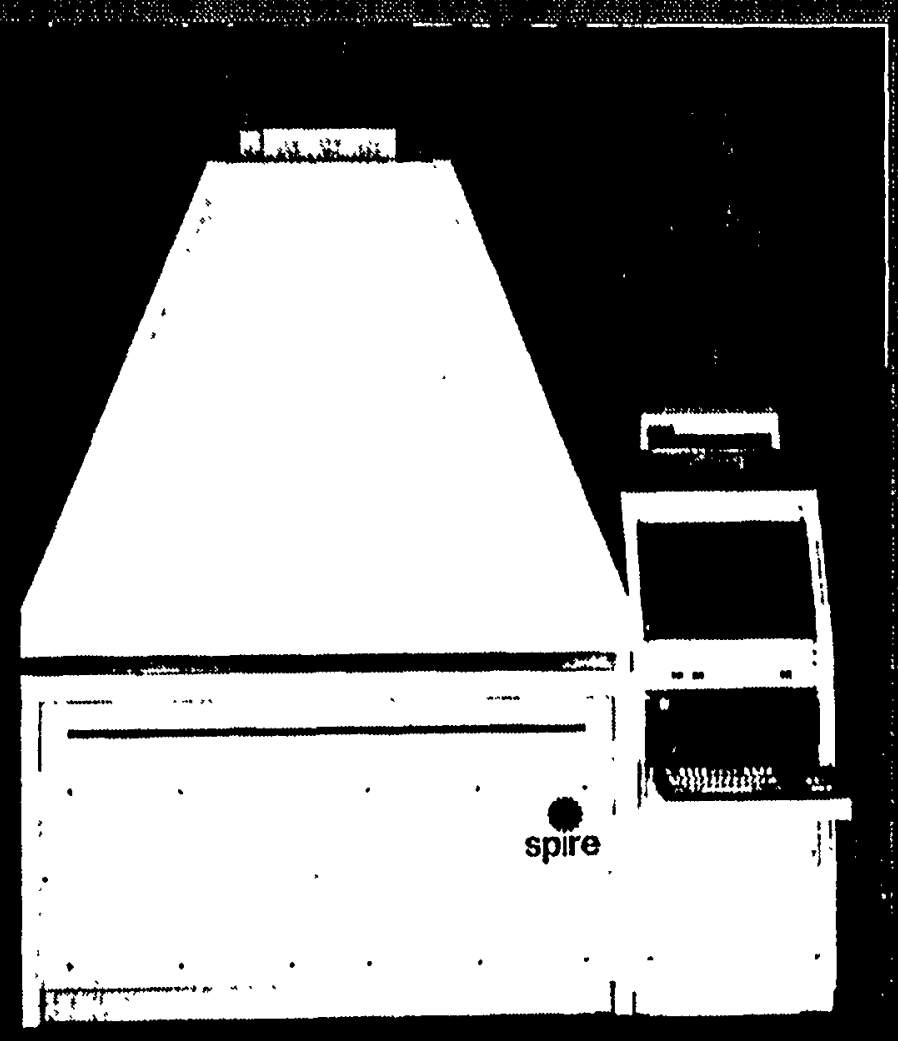




\section{IRRADIANGEUNIFORMTH DISTRIBUTION}

(Parts per Thousand)

\begin{tabular}{|c|c|c|c|c|c|c|c|c|c|c|c|c|c|c|c|c|c|c|}
\hline & 1 & $\mathbf{8}$ & 15 & 22 & 29 & 36 & 43 & 50 & 57 & 64 & 71 & 78 & 85 & 92 & 99 & 106 & 113 & 120 \\
\hline 1 & -20 & +07 & +08 & +02 & +11 & +07 & +07 & +04 & 404 & 403 & 402 & +02 & +01 & +08 & +16 & +15 & +08 & 10 \\
\hline 2 & .06 & $+\infty 0$ & +08 & +08 & .04 & +05 & .07 & .06 & .05 & .06 & .08 & .07 & 1.03 & +08 & $+\infty$ & +08 & +10 & 12 \\
\hline 3 & +07 & +10 & +13 & +03 & 01 & -13 & -14 & -12 & .14 & .12 & -15 & .08 & -13 & 10 & +10 & +13 & +07 & +16 \\
\hline 4 & +05 & $+\pi$ & +08 & 01 & -15 & -15 & -16 & -17 & .15 & 13 & 12 & 1.5 & .04 & 0.5 & \pm 0.5 & +10 & +10 & 05 \\
\hline 5 & +13 & +22 & .05 & +07 & 06 & .08 & 09 & 15 & 14 & 14 & 15 & 11. & 09 & 01 & $+\infty$ & +07 & +07 & 405 \\
\hline 6 & +09 & +08 & +16 & +03 & 05 & 205 & 08 & 03 & 11 & 05 & 07 & 104 & 05 & +01 & .00 & 03 & 07 & .15 \\
\hline & +01 & +23 & +30 & +19 & +17 & 04 & +07 & +09 & +08 & .02 & +00 & 408 & +10 & +16 & +06 & +13 & .09 & .13 \\
\hline
\end{tabular}




\section{SIMPLIFIED ELEGTRONIG LOAD SGHEMATIC}

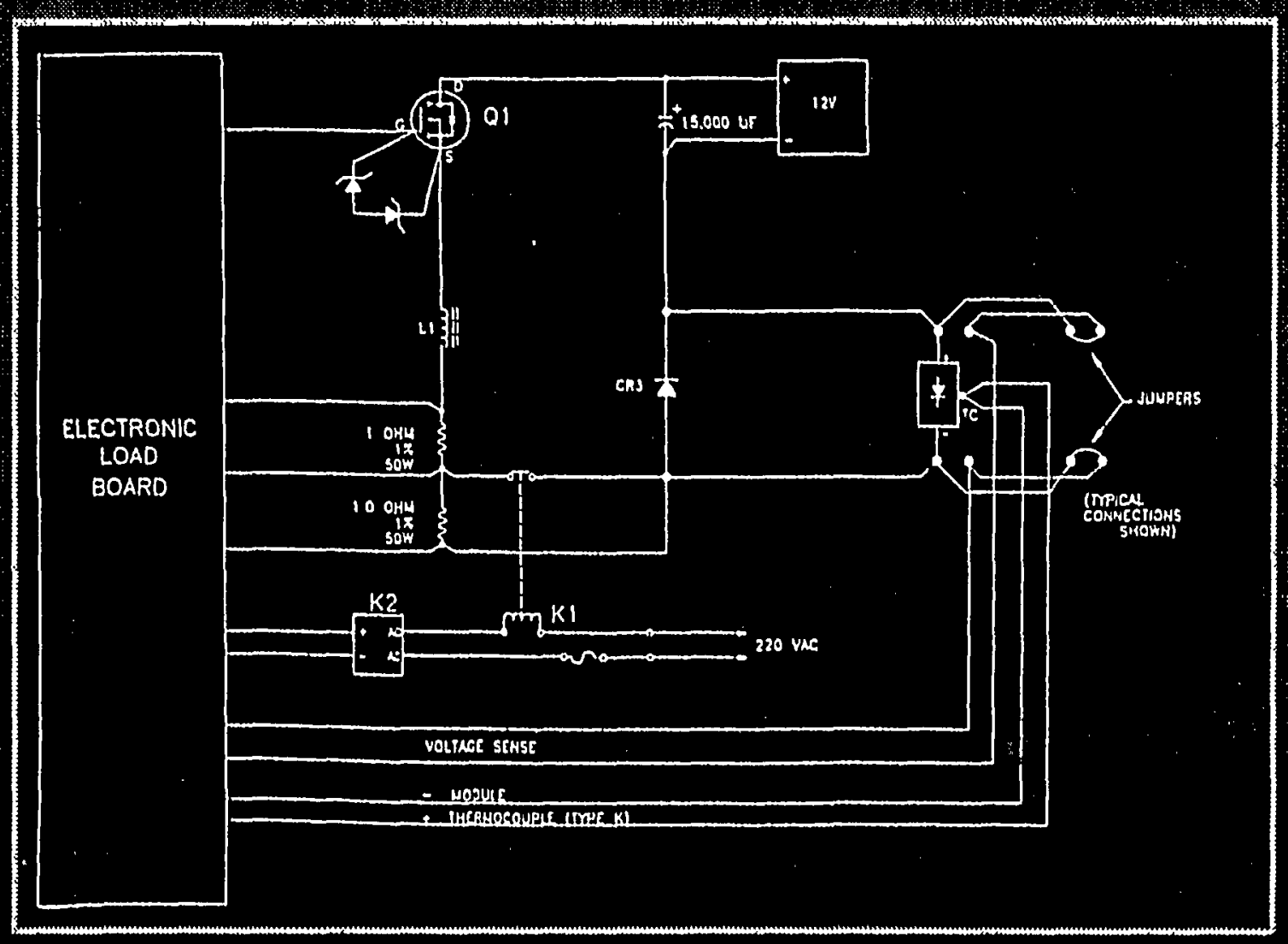

spire 


\section{GOMPUIER SOFUWARE}

trats

Operator Inputs (Irradiance, Corrections, Serial \#, etc.)

Adjust Lamp Intensity

Petermine Voc and Isc

D Adjust Ranges

Sweep Current $I_{s c}-1=0$

Input Voltage

Display I-V Curve and Computations

1. Print/Save Option 


\section{SAMPLEIVOUPUI CURVE}

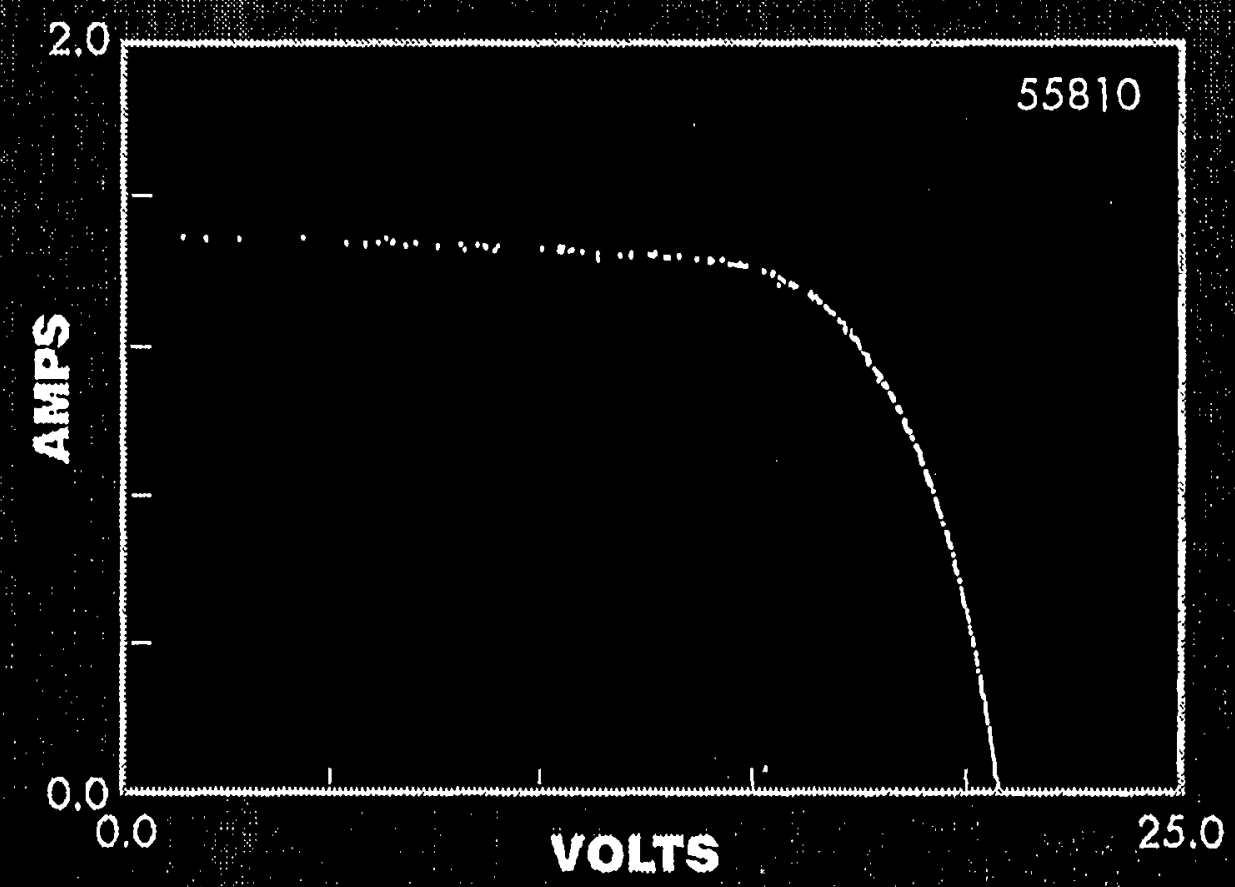

ID \#: SOLARPAC

12.05.1992, 13:16:57

Sun $\left|\mathrm{mW} / \mathrm{cm}^{2}\right|=60$

Temp (deg C) $=24,24$

Voc (Volis)

$=20,62$

Isc (Amps)

$=1.47$

$P \max$ (Walls)

$=21.51$

Vmp (Volis)

Imp (Amps)

Fill Factor:

Rs (Ohms)

Cell Eff (\%)

16.29

$=1.32$

$=.709$

$=1.51$

$=12,6$ 


\section{MEASUAEMENIS TO DATE}

\section{stilicon}

- $\mathrm{Cz}$, Multicrystal, Ribbon

Thin Films

- $\alpha-\mathrm{Si}$, Multijunction, CdTe

High Efficiency

- GaAs, Si 


\section{COARELANION EFFORTS}

\begin{tabular}{|l} 
D Customers \\
NREL \\
ISPRA \\
JMI
\end{tabular}




\section{SIMULATOR DEVELOPMENT DIRECTION}

\section{Large Area}

Butomation

Options

- Multiple Samples

Ranges

a Low Irradiance Levels 


\section{LARCE AREA SIMULATOR IARADIANGE UNIFORMITY}

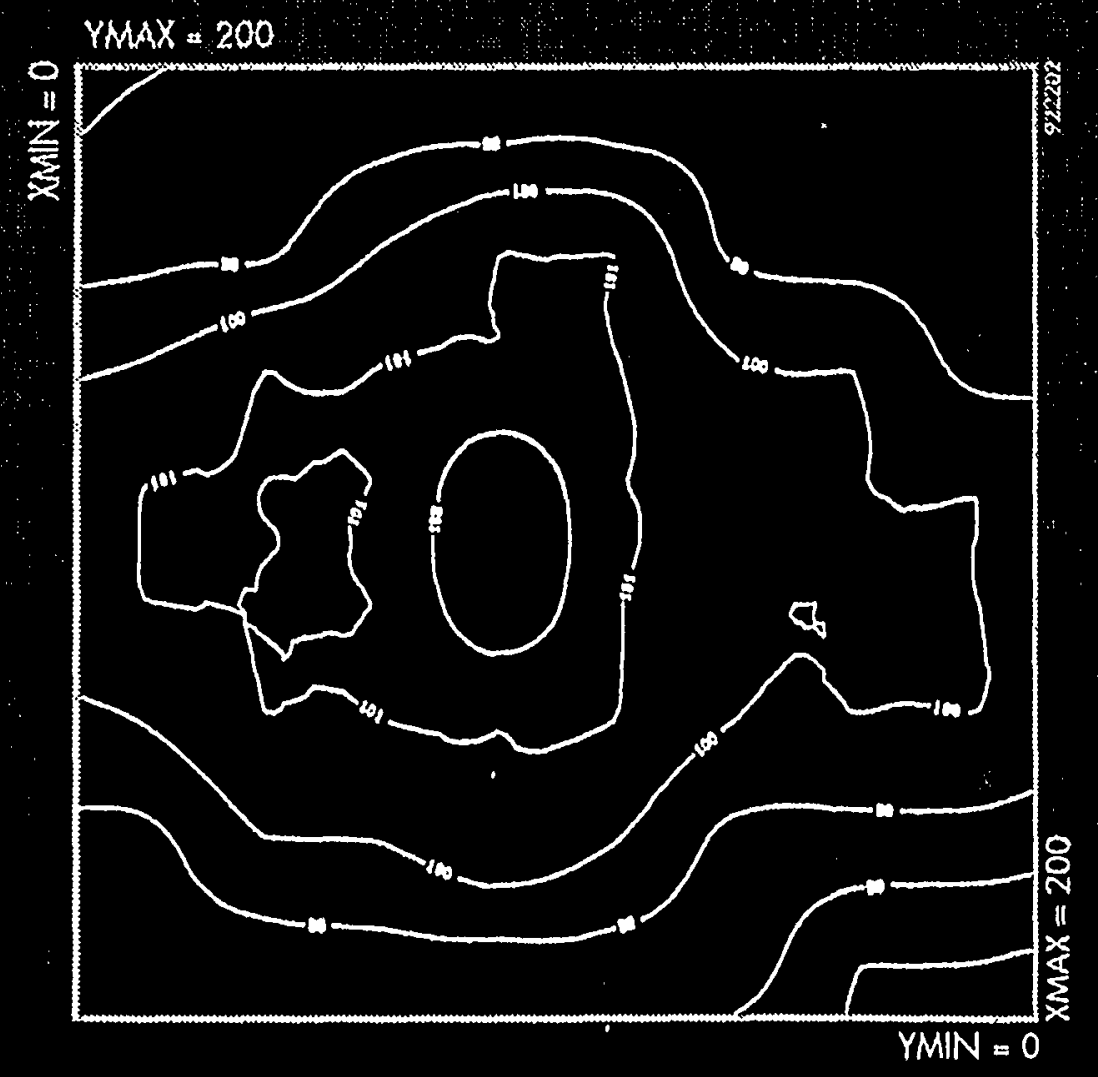




\section{SIMULATOR REPEATABILITY}

SunBurn: 50 passes $\quad 9 / 2 / 93 \quad$ 10:12:08 Sun $100 \mathrm{~mW} / \mathrm{cm}^{2}$

\begin{tabular}{|c|c|c|c|c|}
\hline & Minimum & Maximum & Average & $\begin{array}{c}\text { Sta. Dew } \\
\text { (\%) }\end{array}$ \\
\hline$V_{o c}$ (volis) & 20.89 & 21.17 & 20.99 & \pm .262 \\
\hline$I_{s c}$ (amps) & 2.30 & 2.41 & 2.33 & \pm .639 \\
\hline$P_{\max }$ (Watts) & 33,48 & 34.25 & 33.71 & \pm .394 \\
\hline$V @ P_{\text {max }}$ (volts) & 15.97 & 16.81 & 16.37 & $=1.36$ \\
\hline $1 @ P_{\max }|a m p s|$ & 2.00 & 2,12 & 2,06 & \pm 1.44 \\
\hline Fill Factor. & .669 & .703 & 689 & \pm .691 \\
\hline Temperalure $\left({ }^{\circ} \mathrm{C} \mid\right.$ & 23.19 & 24.90 & 24.17 & $\neq 1.53$ \\
\hline$R_{\text {serles }}$ (ohms) & 1.02 & 3.00 & 1.35 & $=26.24$ \\
\hline$R_{\text {stunn }}$ (ohms) & 74.76 & 224.5 & 150.5 & \pm 20.76 \\
\hline
\end{tabular}




\section{LARGEABEA (660) SIMULATOR}

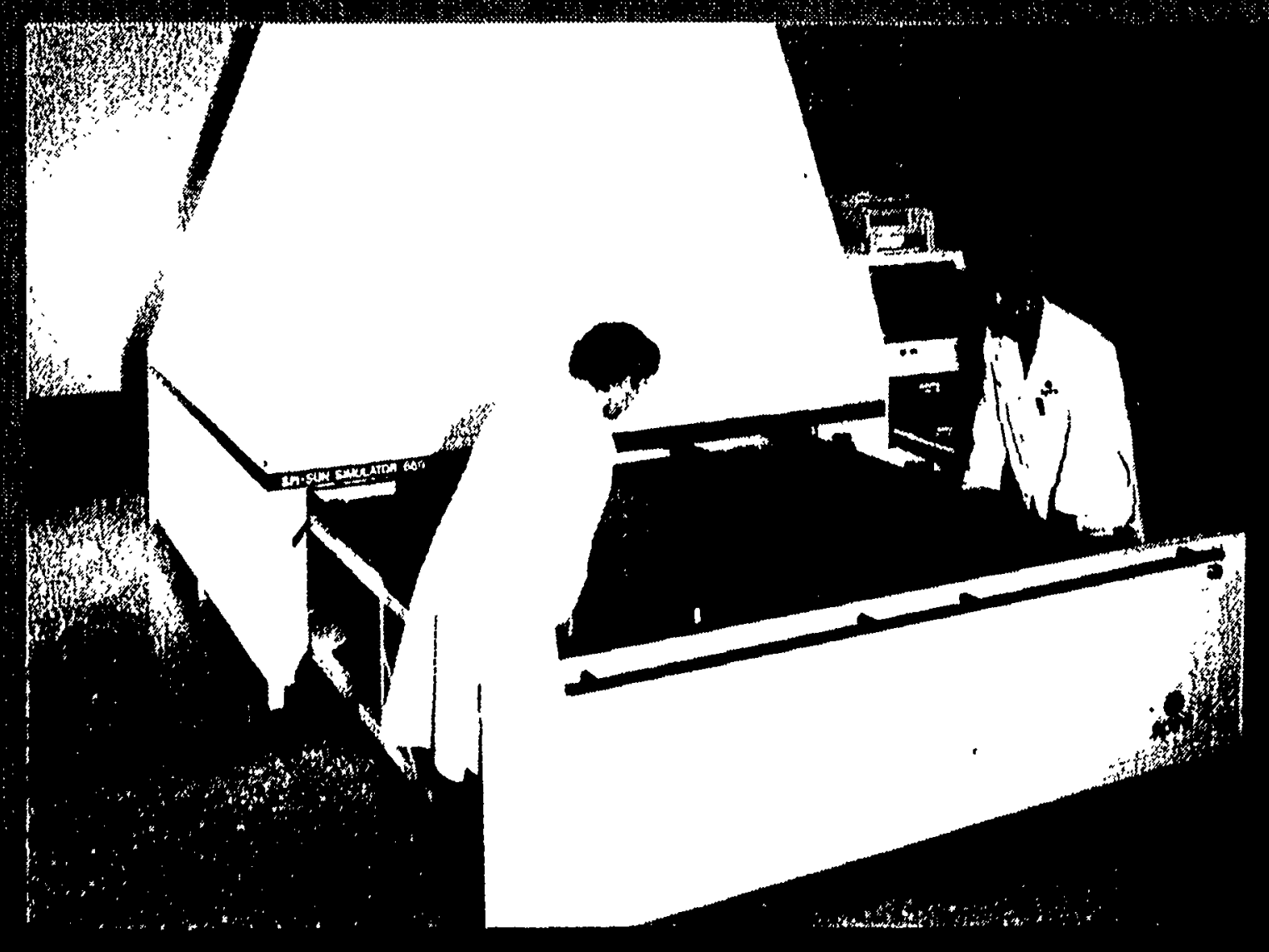

spire 


\title{
Indoor and Outdoor Efficiency Measurements of a-Si Multijunction Modules
}

\author{
by \\ Troy Glatfelter \\ United Solar Systems Corp. \\ 1100 W. Maple \\ Troy, MI 48084
}

Partially supported by NREL under Subcontract \#ZM-1-19033-2 


\section{TOPICS}

- State of Module Research at USSC

- Comparison of DC and Pulsed Simulator $\eta$ Measurements

- Comparison of Indoor and Outdoor $\eta$ Measurements 


\section{Research on Stable, High-Efficiency Amorphous Silicon Multijunction Modules}

S. Guha, Principal Investigator
A. Banerjee
J. Noch
E. Chen
T. Palmer
R. Clough
K. Parker
T. Glatfelter
I. Rosenstein
G. Hammond
D. Wolf
K. Hoffman
$\mathrm{X} . \mathrm{Xu}$
M. Hopson
J. Yang
N. Jackett
K. Younan
M. Lycette 


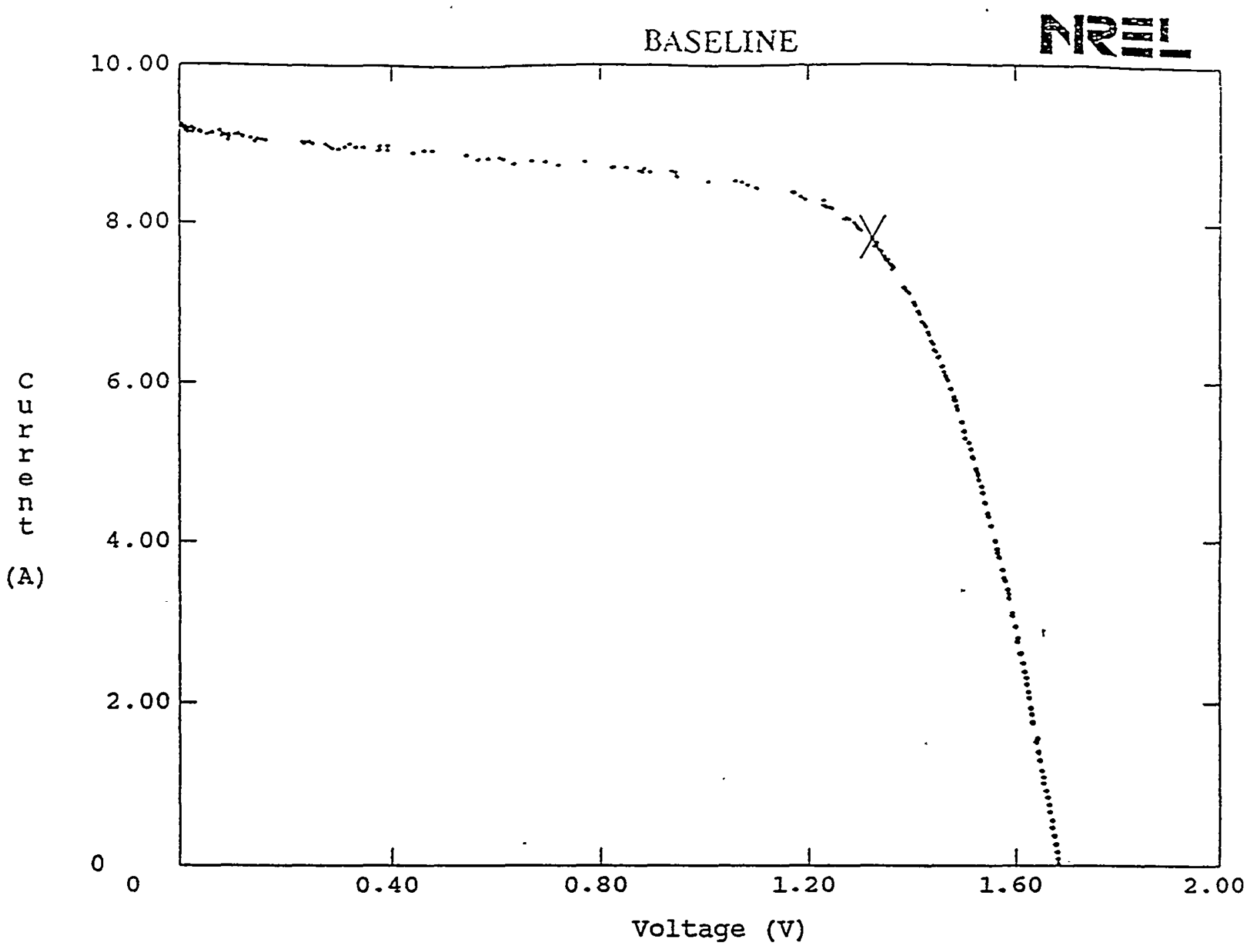

Manufacturer: USSC $\alpha-S_{i}: G e$

Sample Type : a-Si/ tandem module

Sample $\frac{\pi}{\pi}: 2 B 2185$

Test Date : July 25, 1993

Test Time: 10:13 PM

Spectrum : ASTM E892 Global

File Name : C: IIVdata\IV4383.xy

NREI Spire 240A solar simulator (peak)

Estimated total uncertainty in efficiency is $\pm 5 \%$

Total irradiance $=1000 \mathrm{~W} / \mathrm{m}^{2}$

Temperature $\quad=25^{\circ} \mathrm{C}$

Aperature Area $=902.9 \mathrm{~cm}^{2}$

Voc $\quad=1.683 \mathrm{~V}$

IsC $\quad=9.186 \mathrm{~A}$

Pmax $\quad=10.31 \mathrm{~W}$

$\mathrm{V}$ at $\mathrm{Pmax} \quad=1.321 \mathrm{~V}$

$I$ at $P \max \quad=7.800 \AA$

Fill Factor $\quad=66.6 \%$

Efficiency $\quad=11.41 \%$ 


\section{USSC Module Efficiencies}

\begin{tabular}{|c|c|c|c|}
\multicolumn{1}{c}{} & \multicolumn{1}{c}{$\begin{array}{c}\text { NREL } \\
\text { Module \# }\end{array}$} & \multicolumn{1}{c}{ NREL } & \multicolumn{1}{c}{$\begin{array}{c}\text { USSC } \\
\text { Spire }\end{array}$} \\
\hline 2B 2178 & 11.4 & 10.9 & 11.3 \\
\hline 2B 2180 & 11.3 & 10.9 & 11.2 \\
\hline 2B 2185 & $\mathbf{1 1 . 4}$ & $\mathbf{1 1 . 0}$ & $\mathbf{1 1 . 2}$ \\
\hline
\end{tabular}

1. This represents the highest thin-film module $\eta$ measured by NREL. 


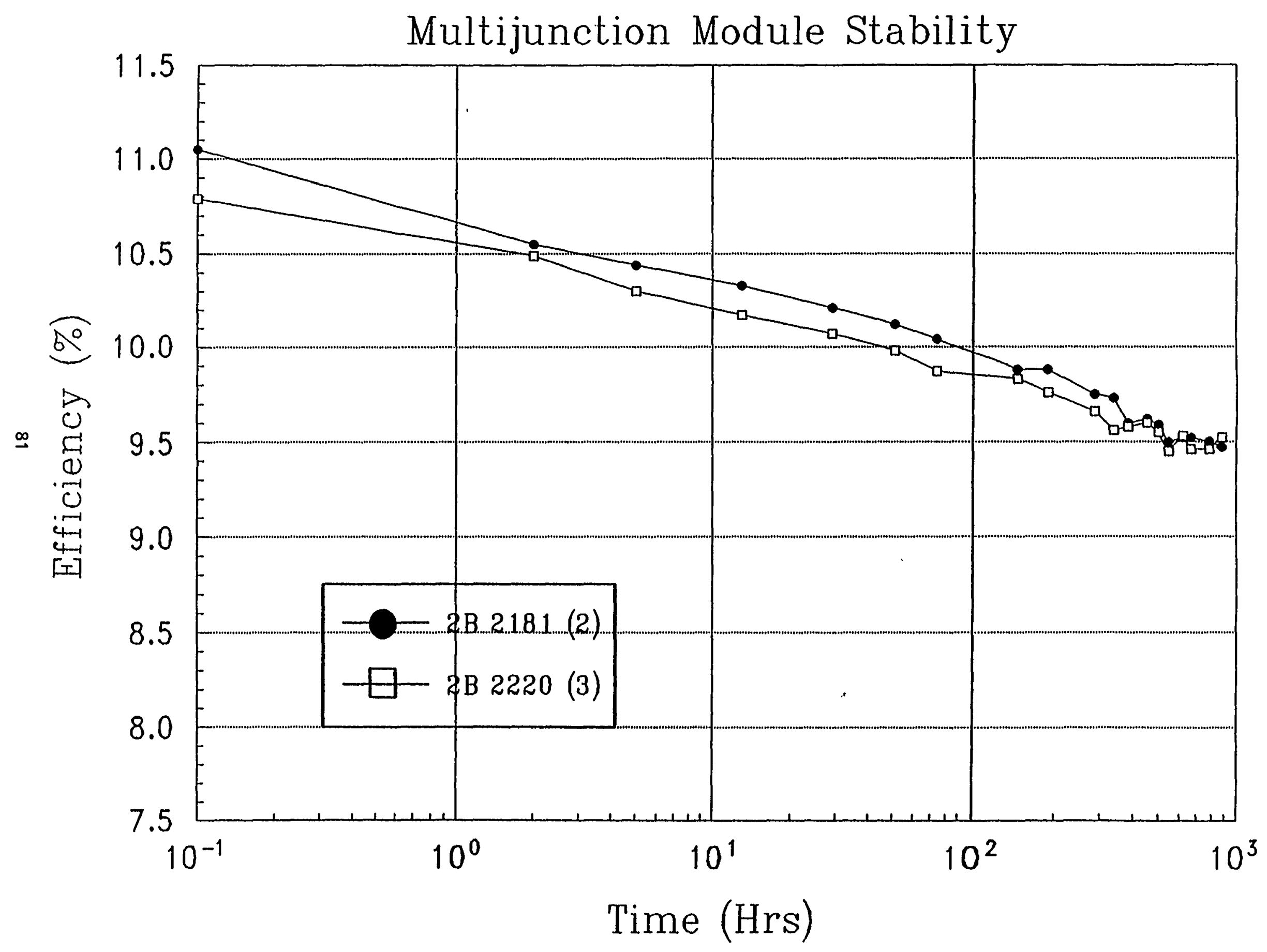




\section{USSC Stabilized Module Efficiencies}

\begin{tabular}{||c|c|c||}
\multicolumn{1}{c|}{ Module \# } & Initial $\eta$ & Stabilized $\eta$ \\
\hline \hline 2B 2181 & 11.1 & 9.5 \\
\hline 2B 2220 & 10.8 & 9.5 \\
\hline 2B 2178 & 11.4 & $?$ \\
\hline 2B 2185 & 11.4 & $?$ \\
\hline
\end{tabular}




\section{USSC Simulator Calibrations and Correlations}

- Small-area Dot Matrix

- 144 one- $\mathrm{cm}^{2}$ devices over one-ft $\mathrm{ft}^{2}$

- Establishes thin-film deposition uniformity

- Establishes module derating factors (Module $\eta$ / small cell active-area $\eta$ )

- Predicts module efficiency using DC simulator

- Coupon Modules

- Varying size "mini" modules ranging 2"x 2" to $6 " \mathrm{x} 6 "$

- Correlates DC simulator to pulsed simulator

- $1 \mathrm{ft}^{2}$ Modules

- Establishes module efficiency under pulsed simulator

- Spectral Analysis

- Establishes simulator spectral match to AM 1.5 Global in narrow bands 


\section{Module / Dot pattern Correlation}

\begin{tabular}{|c|c|c|c||}
\multicolumn{1}{c}{ Module \# } & Module $\eta$ & \multicolumn{2}{c|}{$\begin{array}{c}\text { Ave.Cell } \eta \\
\text { Module } \\
\text { Derating }\end{array}$} \\
\hline 2175 & $11.2 \%$ & $11.5 \%$ & $2.7 \%$ \\
\hline 2166 & $10.7 \%$ & $11.3 \%$ & $5.6 \%$ \\
\hline 1968 & $10.5 \%$ & $11.1 \%$ & $5.7 \%$ \\
\hline 1963 & $10.4 \%$ & $10.9 \%$ & $4.6 \%$ \\
\hline 1942 & $10.4 \%$ & $11.0 \%$ & $5.4 \%$ \\
\hline 1937 & $10.6 \%$ & $11.2 \%$ & $5.5 \%$ \\
\hline
\end{tabular}

1. Module derating factor defined as the module $\eta$ / average small cell active-area $\eta$. Theoretical derating factor for these modules is $4.5 \%$ ( $2.5 \%$ shadow loss, $2 \%$ electrical loss). 


\section{Coupon Module Measurements}

Single-cell Fill Factor

\begin{tabular}{|c|c|c|c|}
\hline Sample \# & Coupon Type & Spire $^{1}$ & Oriel $^{2}$ \\
\hline G6a & a-Si:Ge 6"x 6" & .594 & .584 \\
\hline G4a & a-Si:Ge 4"x 4" & .620 & .608 \\
\hline $\mathrm{G} 4 \mathrm{~b}$ & a-Si:Ge 4"x 4" & .579 & .579 \\
\hline S6a & a-Si 6"x 6" & .557 & .566 \\
\hline S4a & a-Si $4 " x 4^{\prime \prime}$ & .568 & .579 \\
\hline$S 4 b$ & a-Si 4"x 4" & .566 & .576 \\
\hline
\end{tabular}

1. Spire model 240A Pulsed Simulator with peak detector circuit

2. Oriel 8"x 8" DC simulator 


\section{Coupon Module Measurements}

a-Si/a-Si:Ge Multijunction

\begin{tabular}{|c|c|c|c|c|}
\hline Sample \# & Size & $\begin{array}{c}\text { Spire } \\
\text { (Pmax) }\end{array}$ & $\begin{array}{c}\text { Oriel } \\
\text { (Pmax) }\end{array}$ & $\%$ Diff \\
\hline A & $6 " x 6 "$ & 1.88 & 1.90 & -0.8 \\
\hline B & $6 " x 6^{\prime \prime}$ & 1.78 & 1.79 & -0.3 \\
\hline 7 & $4 " x 4^{\prime \prime}$ & .822 & .812 & +1.2 \\
\hline 8 & $4 " x$ 4" & .806 & .816 & -1.2 \\
\hline 9 & $2 " x 2^{\prime \prime}$ & .433 & .433 & 0.0 \\
\hline
\end{tabular}




\section{Simulator Spectral Analysis}

$$
\left(\frac{I_{s t d}}{I_{s s}}\right)_{c e I I}=\left(\frac{1}{M}\right)\left(\frac{I_{s t d}}{I_{s s}}\right)_{\text {Ief }}
$$

$$
M=\frac{\int N(\lambda)_{s t d} Q(\lambda)_{x e f} d \lambda}{\int N(\lambda)_{s t d} Q(\lambda)_{c e l l} d \lambda} \frac{\int N(\lambda)_{s s} Q(\lambda)_{c e l l} d \lambda}{\int N(\lambda)_{s s} Q(\lambda)_{x e f} d \lambda}
$$




\section{Simulator Spectrall Analysis}

\begin{tabular}{|c|c|c|}
\hline Component Ce. & $\left(\frac{I_{\text {std }}}{I_{\text {Spire }}}\right)$ & $\left(\frac{I_{\text {std }}}{I_{\text {orieI }}}\right)$ \\
\hline Top 2-jnctn & 0.997 & 0.998 \\
\hline Bottom 2-jnctn & 1.030 & 1.040 \\
\hline Top 3-jnctn & 0.996 & 0.981 \\
\hline Middle 3-jnctn & 1.002 & 1.003 \\
\hline Bottom 3-jnctn & 1.016 & 1.012 \\
\hline
\end{tabular}




\section{USSC Simulator Correlations}

- Spectral analysis showed small spectral mismatch for all spectral bands $(<1 \%$ for most bands) pertaining to a-Si multijunction devices for both the USSC Oriel DC and Spire pulsed simulators.

- Measurement of "mini" modules under both USSC Oriel DC and Spire pulsed simulators showed agreement of $1 \%$ for all samples tested.

- Based on the previous conclusions, it is evident that the Spire 240A simulator (with peak detector) is sufficiently accurate to

- determine the $\eta$ of a-Si based multijunction modules. 
Effect of Season on Multijunction

Outdoor Efficiency Measurements

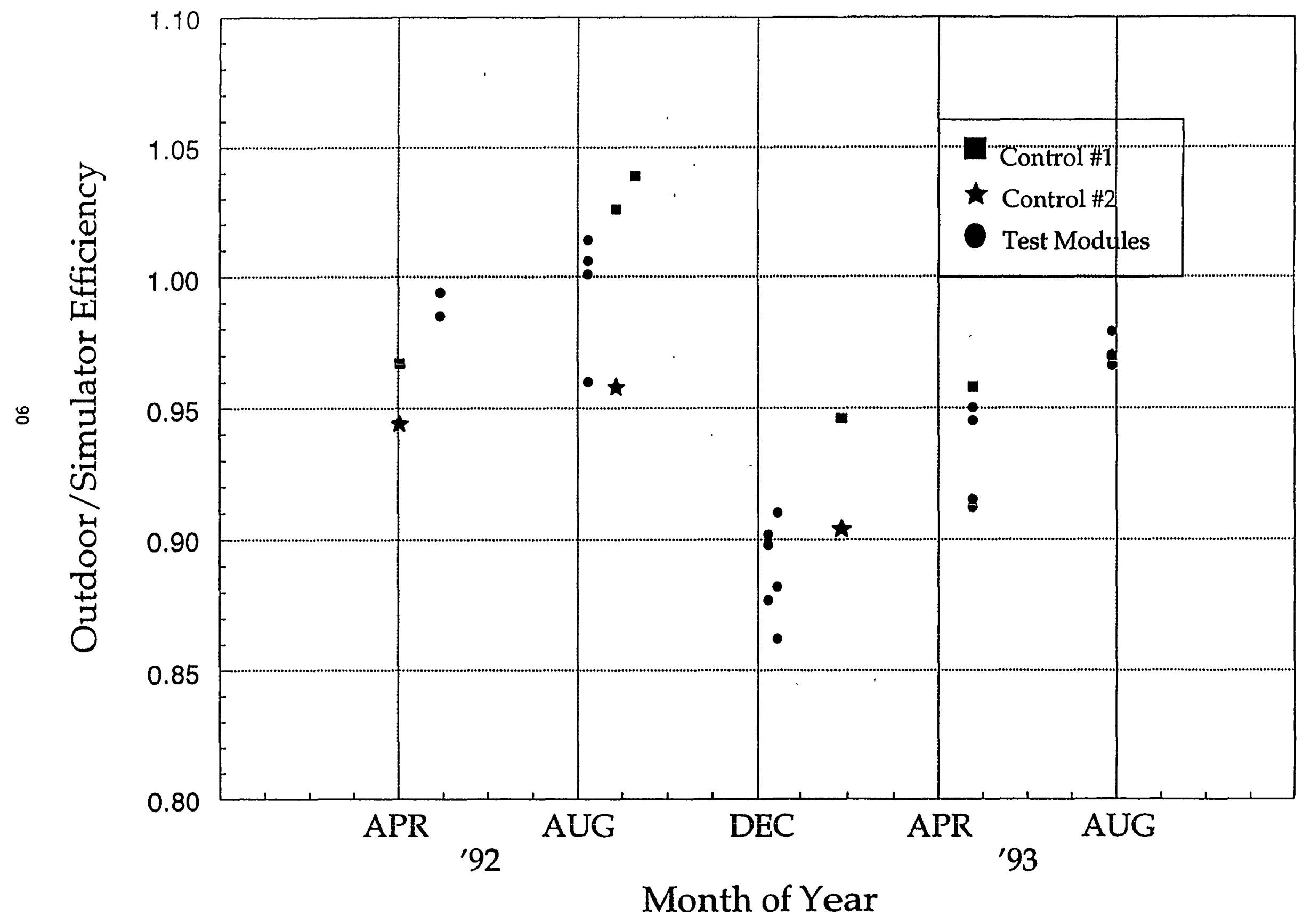


USSC Control Module under

Spire 240A Simulator

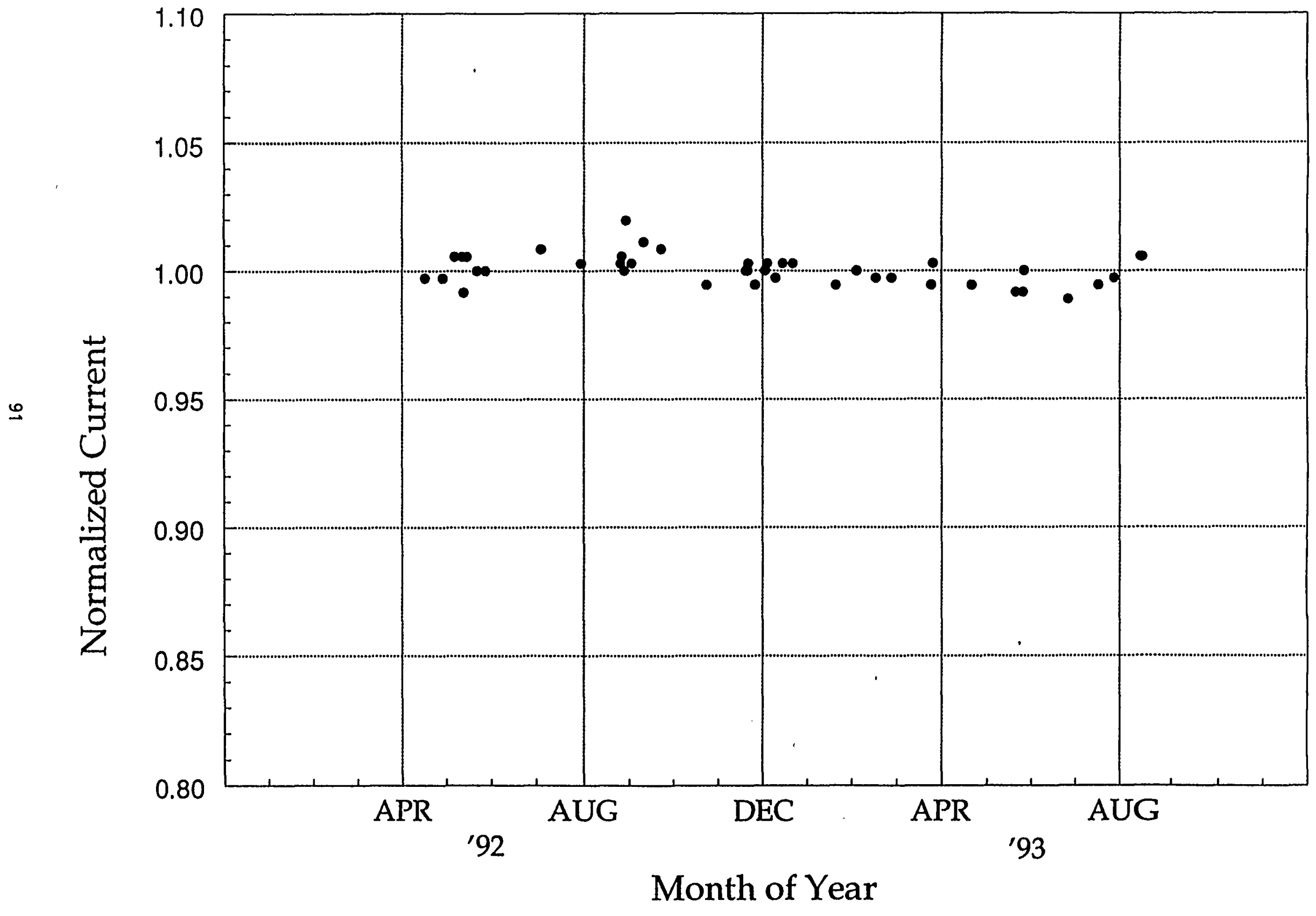




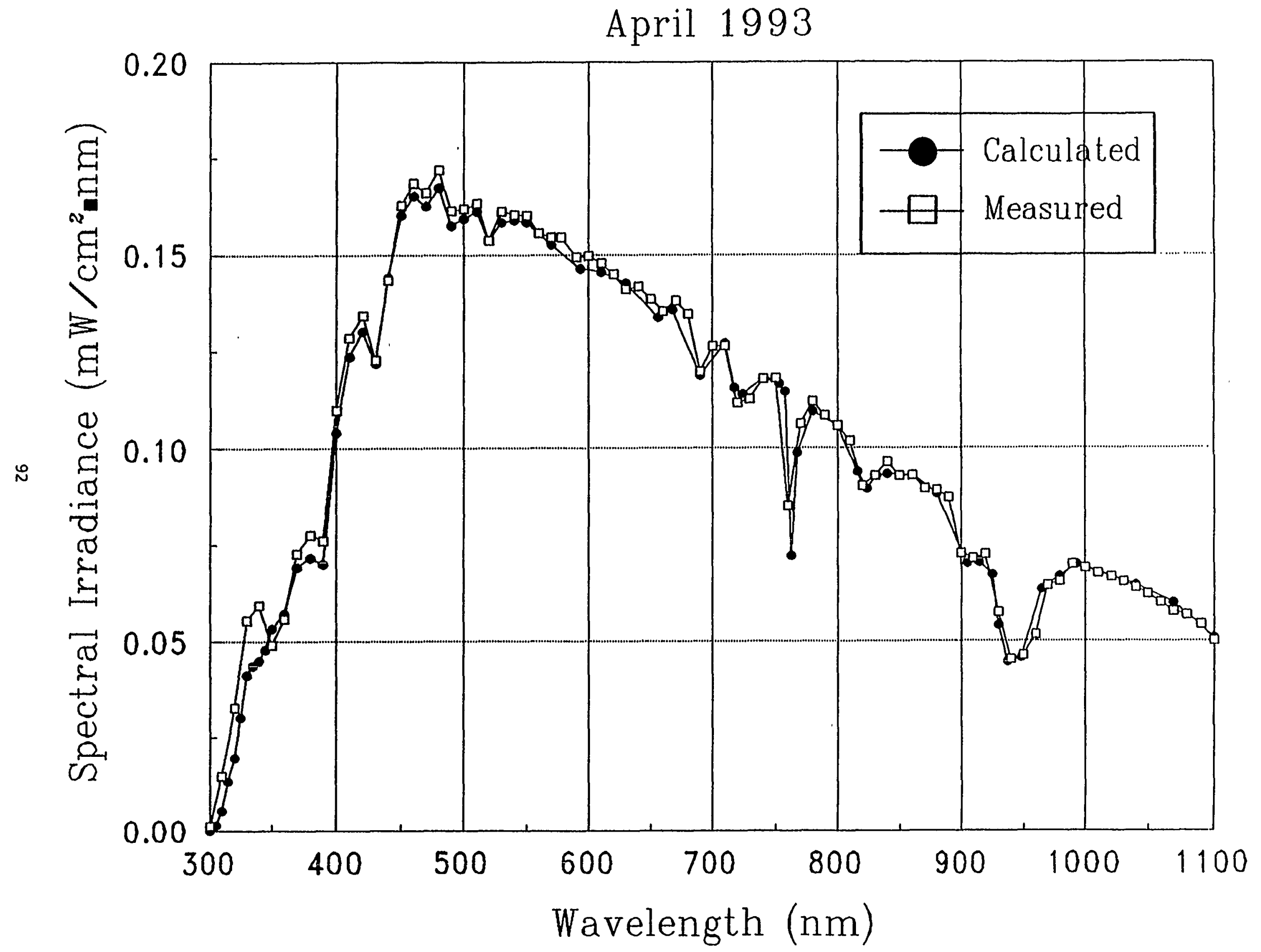


Effect of Mismatch Correction on Outdoor Measurement Variability

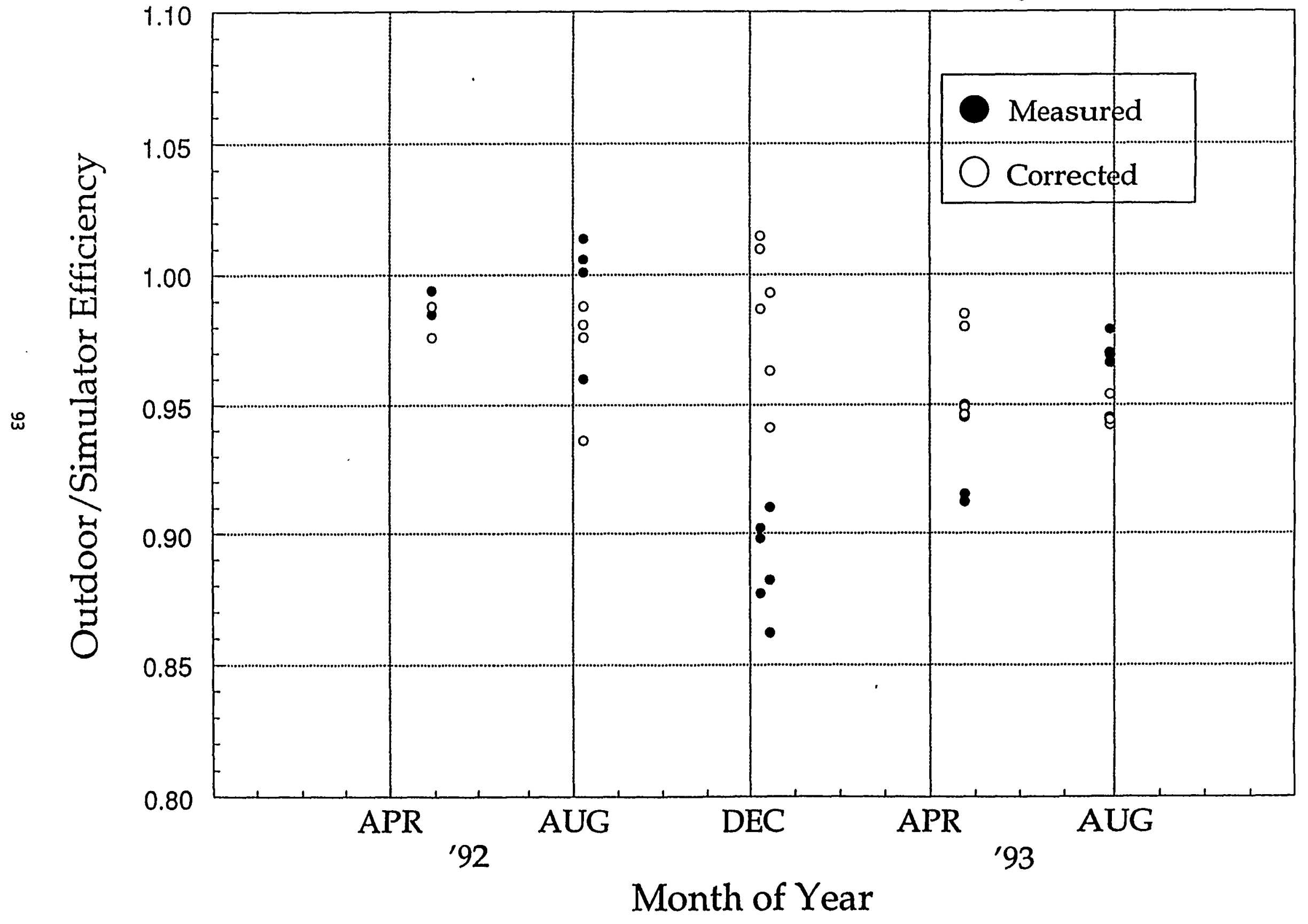




\title{
Outdoor to Indoor Correlation Factors
}

\author{
Spectral Corrections
}

\begin{tabular}{||l|c|c|}
\multicolumn{1}{c|}{ Reference Cell Type } & \multicolumn{1}{c}{ Mean } & \multicolumn{1}{c|}{ Deviation } \\
\hline \hline Pyronometer & .945 & $5.0 \%$ \\
\hline a-Si single & .970 & $3.0 \%$ \\
\hline a-Si:Ge single & $\mathbf{. 9 7 0}$ & $\mathbf{2 . 1 \%}$ \\
\hline a-Si top tandem cell & .961 & $4.3 \%$ \\
\hline
\end{tabular}


Comparison of Outdoor to AM1.5Gl

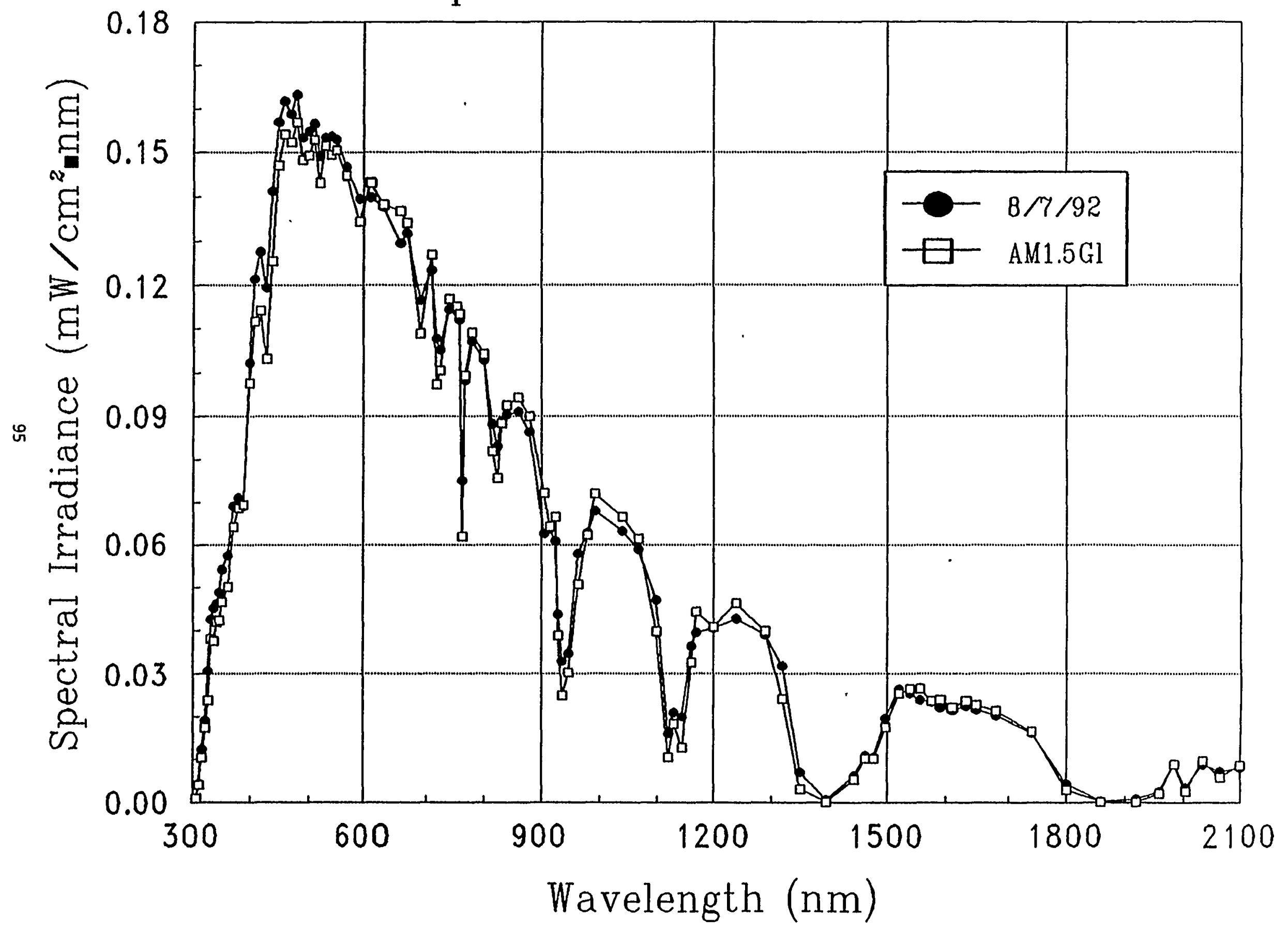




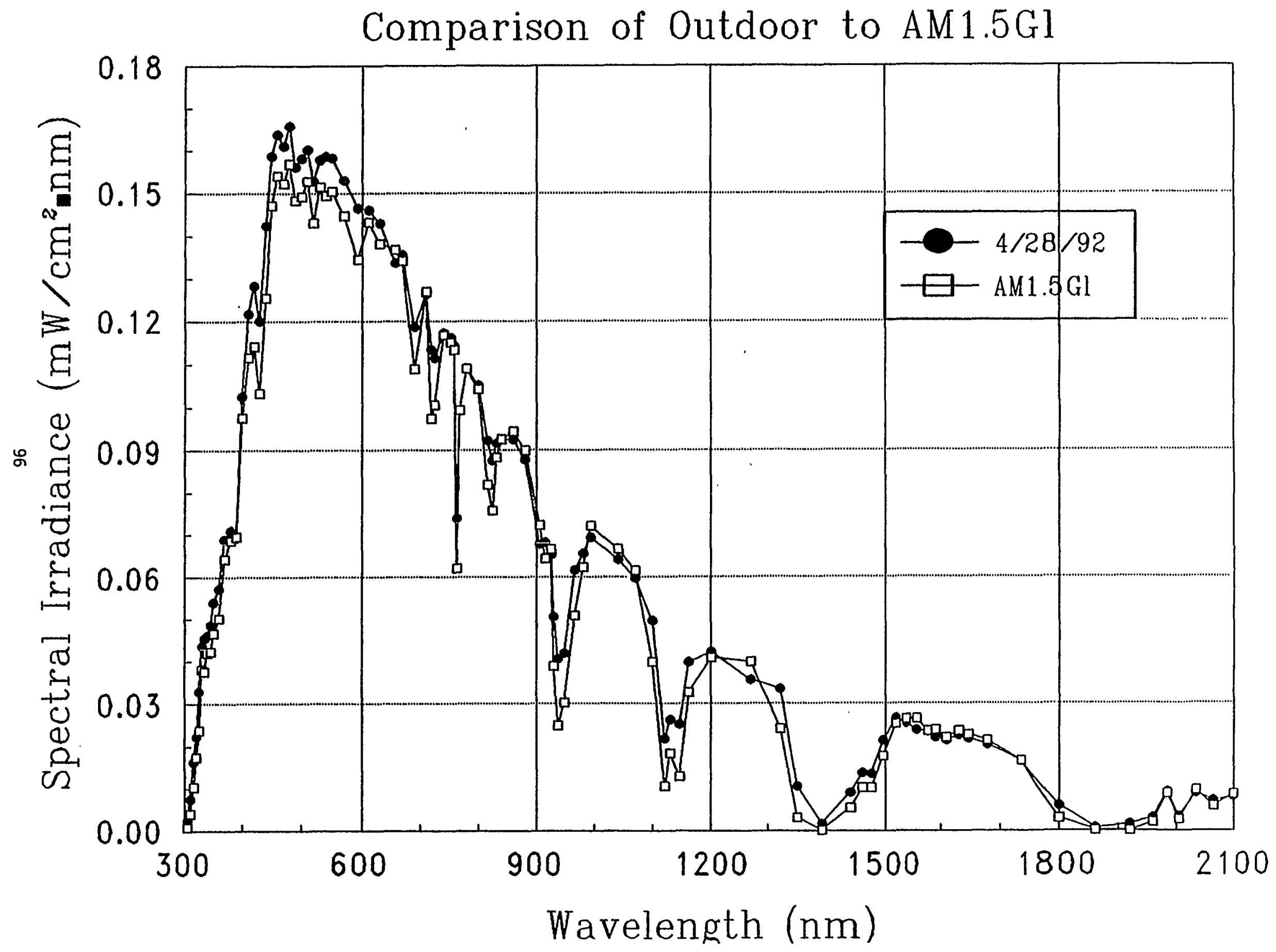


Comparison of Outdoor to AM1.5Gl

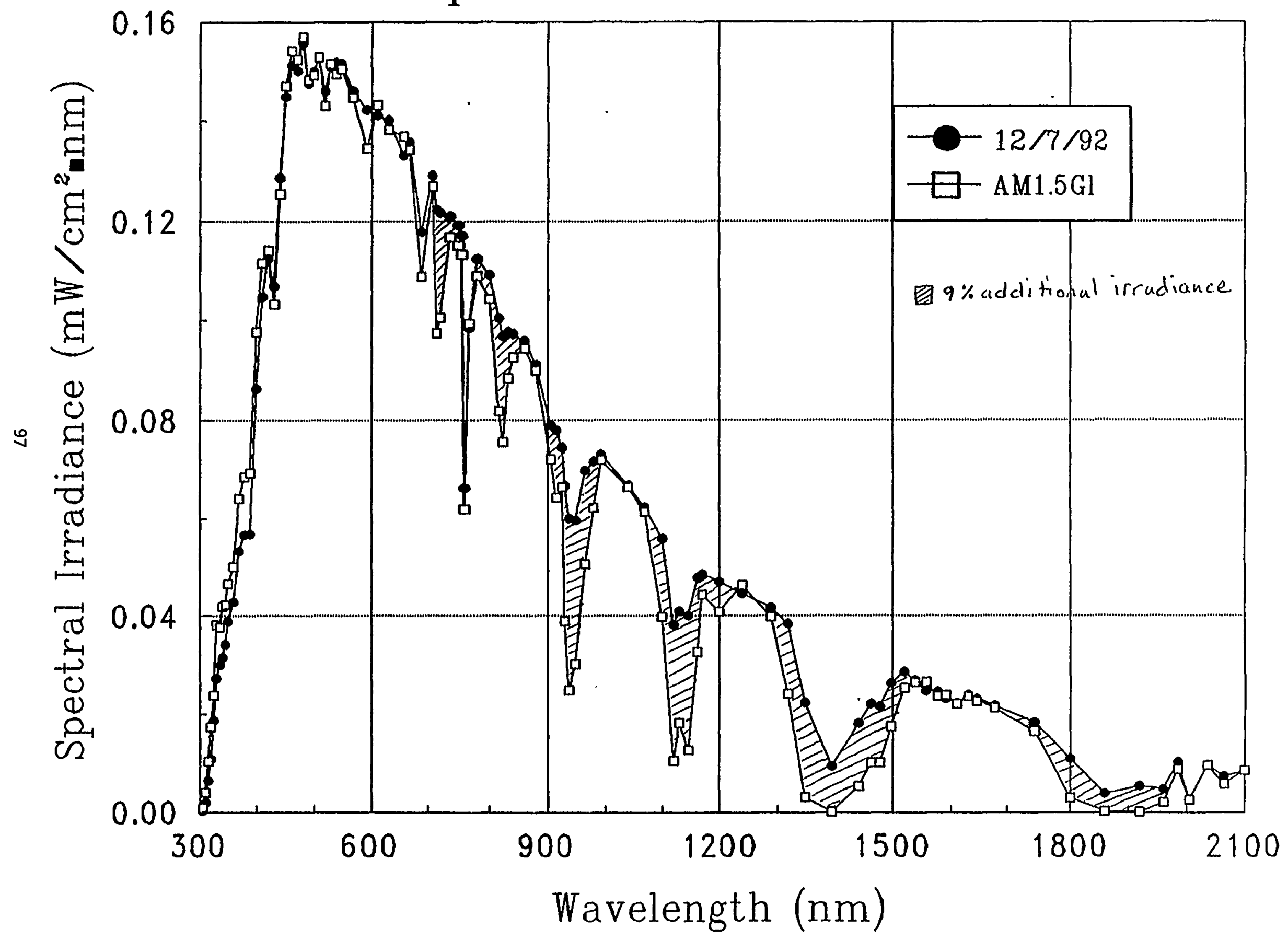




\section{Conclusions}

- Applying spectral mismatch corrections to outdoor $\eta$ measurements reduced the standard deviation in those measurements from $\pm 5 \%$ to $\pm 2 \%$ for a-Si based multijunction devices.

- The maximum range of spectral corrections applied to the outdoor module efficiencies was $-\mathbf{2 . 6 \%}$ to $+\mathbf{1 2 . 5 \%}$. 


\title{
Radiometric Measurements for PV Characterization
}

\author{
Daryl R. Myers \\ Theodore W. Cannon \\ David Trudell \\ National Renewable Energy Laboratory \\ PV Performance and Reliability Workshop \\ September 8-10, 1993 \\ Golden, $\mathrm{CO}$
}

Introduction

We describe radiometric measurements performed by the PV Solar Radiation Research (PV SRR) Task supporting the NREL PV Module and System Performance and Engineering Project. As stated in the Annual Operating Plan for the Photovoltaic Advanced Research and Development Project for fiscal year 1993 [1]. PV SRR task activities are performed

"...in direct suppor of characterization. measuring. testing. designing. and understanding the performance of PV cells. submodules. modules. and systems by providing a scientific and engineering understanding of incident solar irradiance, and through the development of instruments and/or measurement methods."

In the past, we have described radiometer calibration and characterization for broadband [2-4] and spectral instrumentation [5-8]. Here, we investigate the quality of our radiometric measurements applied to PV performance and characterization.

\section{Solar Radiation Instrumentation: A Historical Perspective}

We remind the reader some of the instrumentation in use today for PV performance testing was originally developed with completely different objectives in mind. As shown in Figure 1. radiometric instrumenation has evolved over the past 40 to 50 years 10 measure various solar radiation parameters for the meteorological. agricultural. and climate analysis communities. Only later (some 15 to 20 years ago) was that same instrumentation applied to solar energy conversion device and system performance data collection.

In concert with the climate. meteorological. and agricultural applications, various atmospheric physics and transmission models were developed, including transformation algorithms to compute solar irradiance on variously oriented surfaces [9-12]. As the needs of the solar encrgy conversion design and performance community expanded. the algorithms for providing application-specific data (tracking, tilted surface. etc.) [12] were developed, derived from and adding to the complement of conversion techniques available. Today these tools provide data for design. prediction. and evaluation of conversion system performance [13].

The point of this historical perspective is to emphasizc that. 10 a great extent. design and performance solar irradiance data are still based on instrumentation (especially) and models (less so) developed with other scientific objectives in mind. This is the reason for continuing PV SRR emphasis on application-specific calibration and characterization of instrumentation.

Recent efforts to develop improved radiometers and measurement techniques [14] and radiation transformation algorithms with performance evaluation needs as a primary objective indicate a promising future; meanwhile. PV SRR is providing current best-practice broadband and spectral measurement services. 


\section{Broadband Radiometric Measurements}

Typical solar radiation measurements. such as direct normal or beam radiation. or so-called global radiation on a plan-of-array (POA) surfaces are typical broadband radiometric measurements. These measurements generally are made with relatively simple detectors. (pyrheliometers and pyranometers. respectively) and represent the total radiation in the spectral region from $280 \mathrm{~nm}$ to $2800 \mathrm{~nm}$.

Currently. the performance testing at NREL relies upon well calibrated individual radiometers assigned to each specific test activity. To examine the performance of these radiometers and the NREL metrology laboratory calibration procedures. a pyranomerer comparison experiment was performed in November of 1992 . Five pyranometers assigned to the tield test site. were mounted on a tilt of latitude + declination (55 degrees) so as to receive near-normal incidence radiation around noon. This configuration is that used for much of the PV module performance outdoor testing on clear days.

Figure 2 presents the mean irradiance and the standard deviation of the irradiances (as percents of reading) for clear and overcast days. The figure shows that the precision of these five radiometers was better than $1 \%$ around noon on clear days: increased to more than $2 \%$ between 10 am and $2 \mathrm{pm}$. and increased to more than $10 \%$ at early moming and late afternoon hours. Note the difference in the standard deviations on the overcast day compared to the clear days. The distribution is very flat. and at about $1.5 \%$ all day long. reflecting the minimal impact of geometrical response under isotropic irradiance conditions.

These data show that the repeatability among the population of radiometers deployed at the NREL outdoor test site. calibrated at near normal incidence. is of the order of $2.8 \%$ after application of the Student 's-t correction factor of 2.8 for 4 degrees of freedom to the $1 \%$ clear sky sigma achieved in this experiment.

We have also experimented with using the direct, global and diffuse radiation data to compute. with the Perez Anisotropic Model [12], POA irradiances at 10 degree tilt intervals. Comparing the modeled and measured POA data for systems with 50 and 40 degree tilt measured data. respectively, we have been able to identify instrument tilt errors. In Figure 3. modeled values are generally within $10 \%$ of measured values over a wide regime of radiation levels.

In the near future. PV SRR will deploy an irray of precision. characterized radiation and meteorological sensors and data acquisition and distrilbution system (see Figure 4) to provide reference data to use in quality assessment of POA radiation and ancillary data collected for specific systems and module tests. We plan to compute and provide PV test engineers with incremental 10 degree tilted surface data derived from the reference measured irradiances on a near real-time basis as part of this quality assurance system.

We studied the effects of small (1.2.5 degree) errors in direct-beam incidence angles resulting from sensors being tilted in the east-west direction. say as a result of installation or mounting problems. Figures 5 and 6 illustrate the apparent (relative) shifts in data seen when errors of this magnitude exist. assuming normal incidence at solar noon. and setting the contribution to the global of the diffuse component to 0 . Note from Figure 6 that for even a 1 degree east-west tilt to the west. errors of $1 \%-3 \%$ occur in indicated irradiance within 30 degrees of the normal incidence case. We have expcrimentally conlirmed such measurement/error sensitivities at the NREL PV Outdoor Test Site by intercomparing radiometers mounted in the field. and comparing modeled and measured POA iradiance data.

\section{Spectroradiometric Measurements}

One of the most important measurement problems addressed by the PV SRR team has been the measurement of the spectral distribution for pulsed solar simulators used in testing modules indoors. We [6] and others [7.8] have addressed the problems of accuracy and uncertainty in spectral irradiance measurements in general elsewhere. The challenge of obtaining spectral data for systems with pulses only milliseconds long was faced in particular by $T$. Cannon and D. Trudell. who have developed a powerful Pulse Analysis Spectroradiometer System (PASS) for accomplishing accurate quantitative measurements of these systems. 
This system collects information on spectral distribution within a pulse. as well as from pulse to pulse and over extended periods of time. Figure 7 shows the calibration precision of the PASS system as determined experimentally, and Figure 8 is a representative spectral irradiance curve taken during operational testing of the system. Further refinement of our dnta collection technique and post-processing of the data will assist others in the task of quantifying the impact of spectral error (mismatch and calibration number) computations.

\section{Conclusion}

Because of the importance of PV module and system pertormance characterization at NREL. our attention to the accuracy and importance of radiometric measurements is a fundamental requirement. Presently, we are confident in our ability to achieve $1 \%$ to $2 \%$ precision in clear sky broadband POA irradiance data during outdoor testing. The development of a powertul. flexible. accurnte spectroradiometer system opens the door for quantifying spectral errors more definitively. and maintaining control over indoor simulator testing and calibration for a wide variety of simulators, including the pulsed sources used in large ire: (module and submodule) testing. We pian to stay on the cutting edge of soiar radiometry for PV performance me:surements and applications by continuous improvement of our instrumentation and measurement rechniques.

\section{Acknowledgements}

Without the cooperation and assistance of David Waddlington. Troy Strand. Kieth Emery. Steven Rummel, Rotert Hansen. and Joshual Caiyem al the NREL PV Outdoor Test Site. the me:surements and results presented here could not have been possible. The support of the enginecring and scientilic value of this work by Richard DeBlasio as project leader has been essential in making this work possible.

\section{References:}

1. Anon.. Annual Operating Plan. Photovoltaic Advanced Research and Deveionment Proiect. Photovoltaics Division. National Renewable Energy Laborarory. November 12. iY92.

2. Myers. Diryl R.. and T.L. Sintfel. "A Description of the Solar Radiometer Calibration (RADC.AL) Process at SER!." Proceedings of 1990 Annual Conterence of the Amenc:an Soliur Energy Society. Austun. TX. March 19-22. 1940. p. 171.

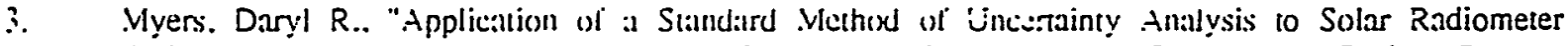
Calibrations." Proceedings of 1984 Annual Conference of The American Solar Energy Society. Denver. CO. Jun 19-22. 1989. p. +4.5.

4. Daryl R. Myers. K. Emery. and T.L. Sinliel. "Uncerainty Estimates for Global Solar Irradiance Measurements Used to Evaluatc PV Device Pcrformance." Solar Culls. 27. 1989. p. 4.56.

5. Emery. Kieth and C. Osterwald. "Mealsurcment of Phorovoltaic Device Curtent as a lunction of Voltage. Temperature. Intensity and Spectrum." Joskar Cells 21. 1987. p. 313.

6. Hulstrom. Ruland L.. C. Riordan. and T. Camnon. "Spectral Suiar Radiation Data Base. Models. and Instrumentation." Sular Cells. 27. 1989. p. 279.

7. Myers, D.R.. "Estimates of Uncertainty for Measured Spectra in the SERI Spectral Solar Radiation Data Base." Sular Energy. Vol. 43.

8. Emery, Kieth. C.V. Wells. and C.R. Osterwald. "Uncertainty Analysis of Photovoltaic Efficiency Measurements." XIX IEEE Phorovoltaic Specialists Conference. May 1990. New Orleans, LA. p. 153. 
9. Randall. Charles M. and Richard Bird. "Insolation Models and Algorithms." in Solar Resources, R. Hulstrom. Massachusetts Institute of Technology, 1989. p. 61.

10. Maxwell. Eugene L.. "A Qunsi-physical Model for Converting Hourly Global Horizontal to Direct Normal Insolation" Proceedings of 1987 Annual Conference of the American Solar Energy Society. Portland. OR. Jul 11-16. 1987. p. 35

11. Maxwell. Eugene L.. "Producing a 1961-1990 Solar Radiation Data Base for the United States." Proceedings of 1990 Annual Conterence of the American Solar Energy Society. Austin. TX.. March 19-20. 1990. p. 16.5

12. Perez. R.. P. Ineichen. R. Seals. J. Michalsky. and R. Siewart. "Modelling Daylight Availability and Irradiance Components trom Direct and Global Imadiance." Soler Energy. Vol. 44. \#5. p. 271-289. 1990.

13. Marion. W. and S. Wilcox. "Solar Radiation Data Manual for Flat-Plate and Concentrating Collectors." National Renewable Energy Laboratory" Draft Technical Report. August 1993.

14. Anon.. "Solar Resource Assessment instrumentation" in Small Business Innoration Rescarch Program Solicutation. p. 85.. January. 199?. 


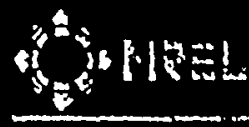

Solar Radiation Measurements

\section{Solar Radiation Data Paths}

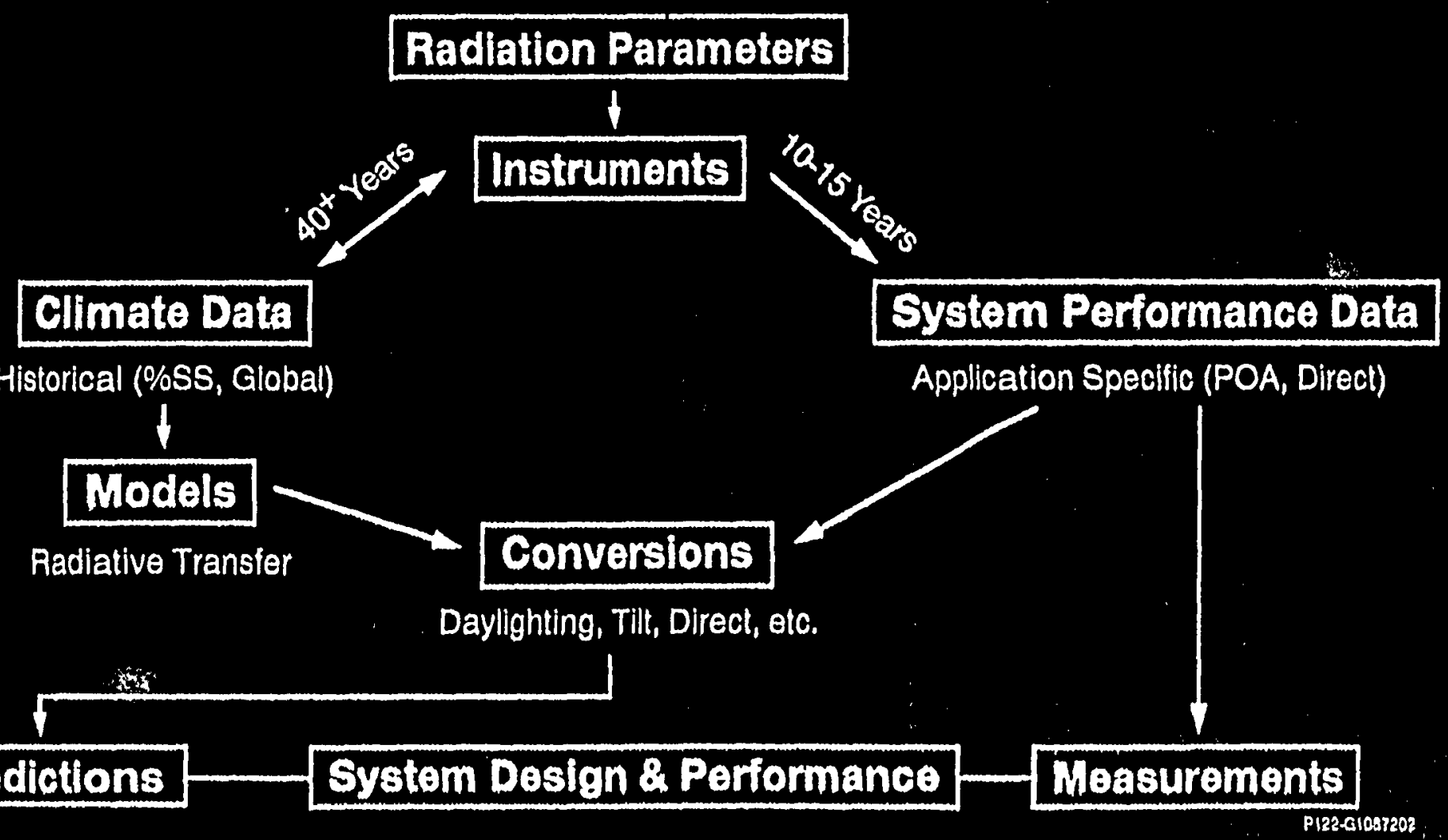


Figure 2: Statistics for 5 Pyranometers Measuring Global Plane of Array Irradiance, DEC 1992 at NREL

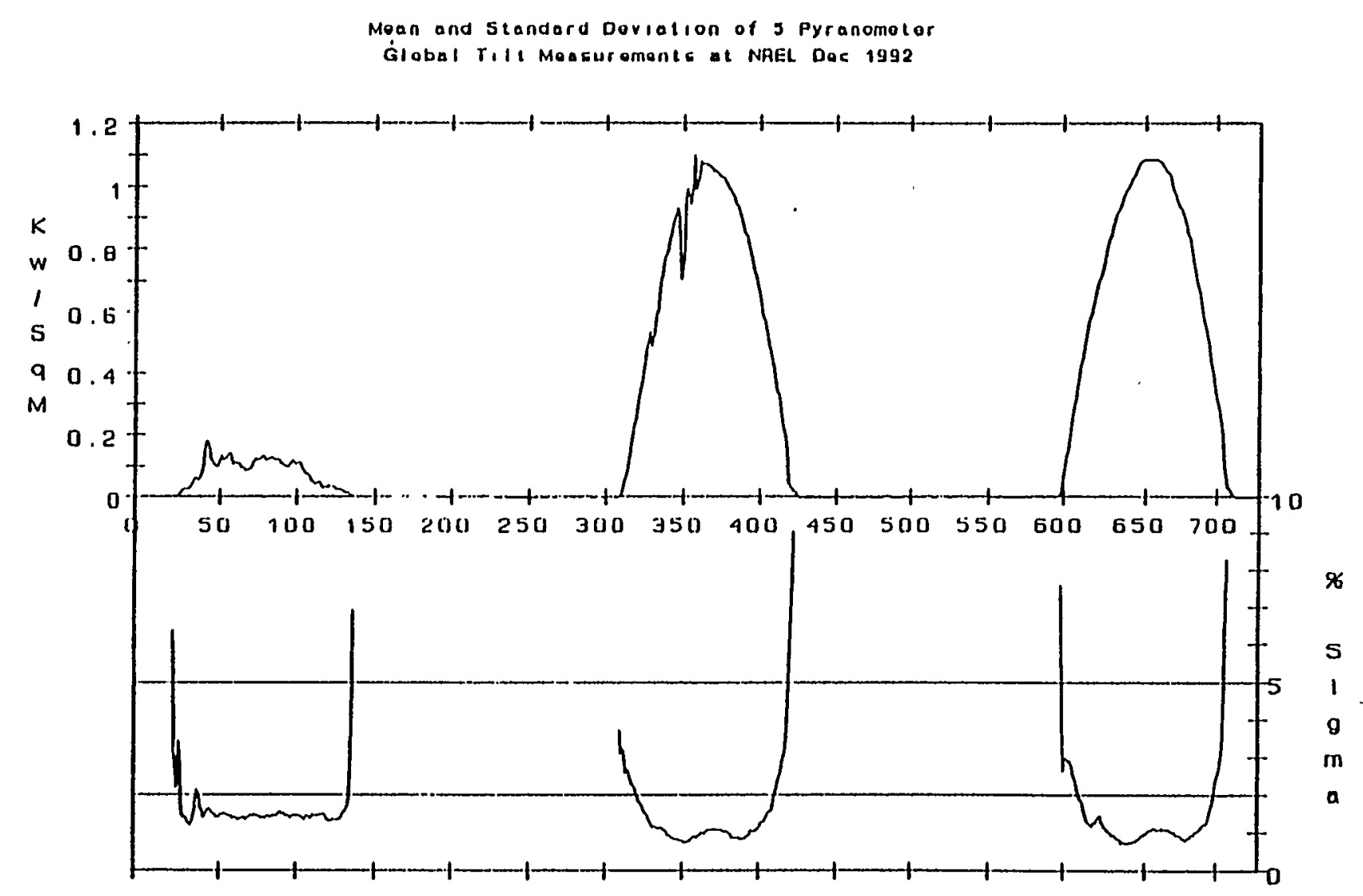

Observation No. 
Figure 3. Performance of Perez Anisotropic Diffuse Model for Computing Hourly 50 Degree POA Imadiance versus Measured POA Data

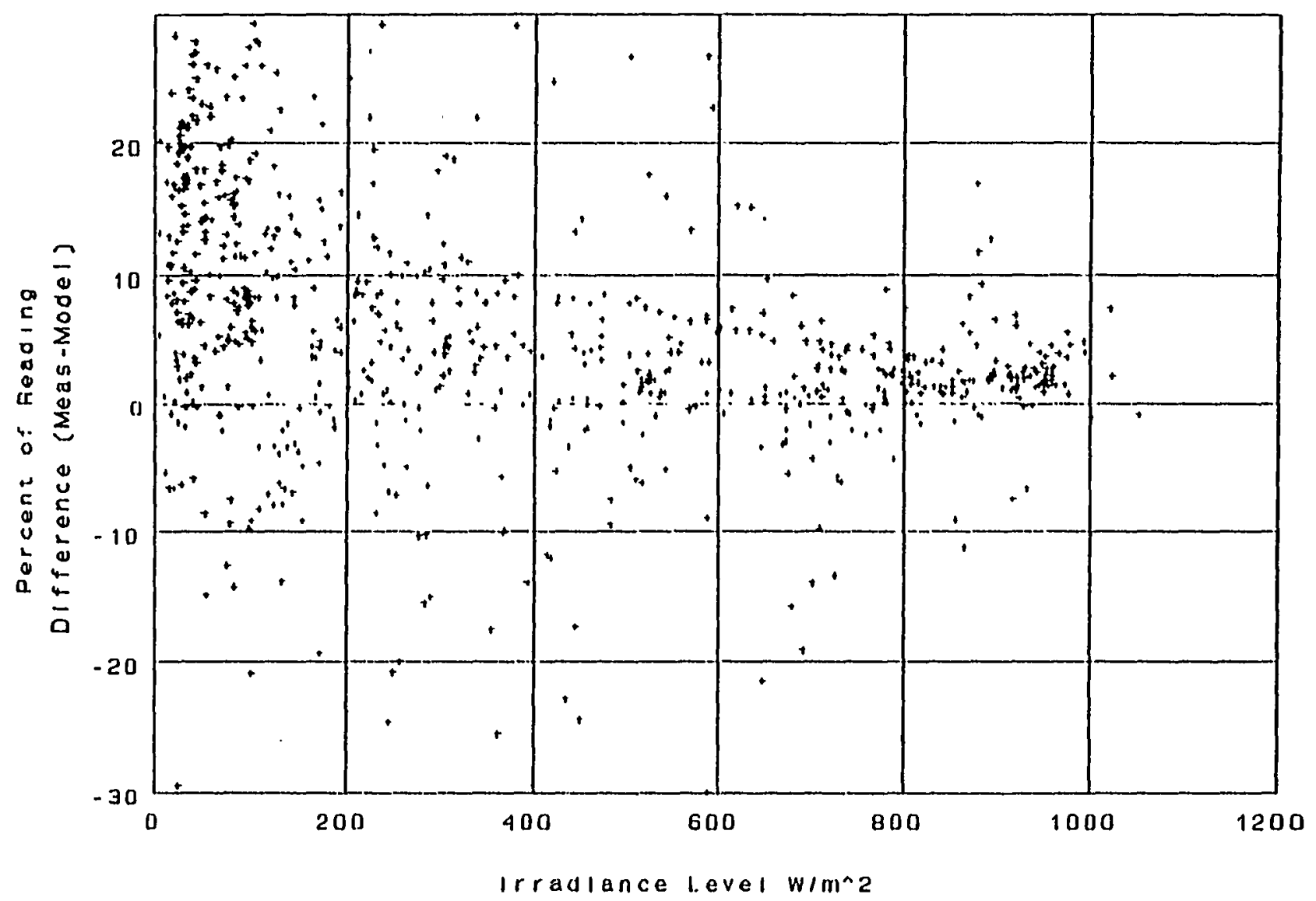

Grazllian Liohting Systom ASR Irradiance and POA Dalo O 50 Dod 
Figure 4. Reference Iratiance and Meteorological Station
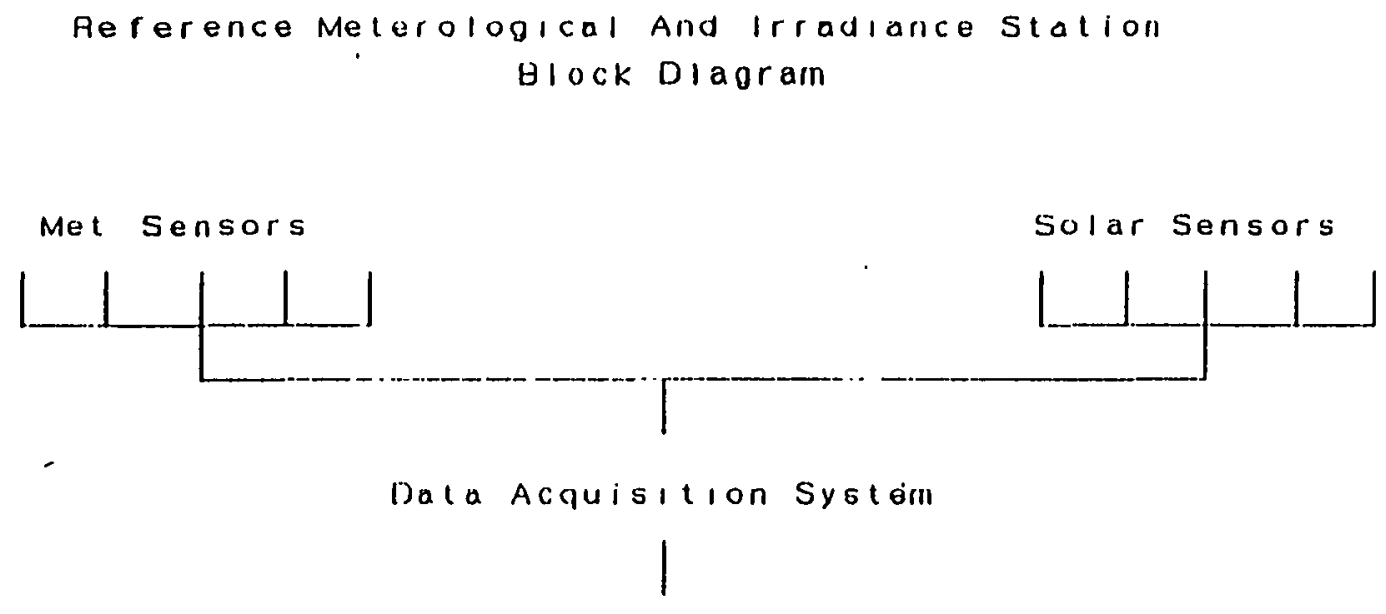

11,1 \& $131: 1,11,11011$ by

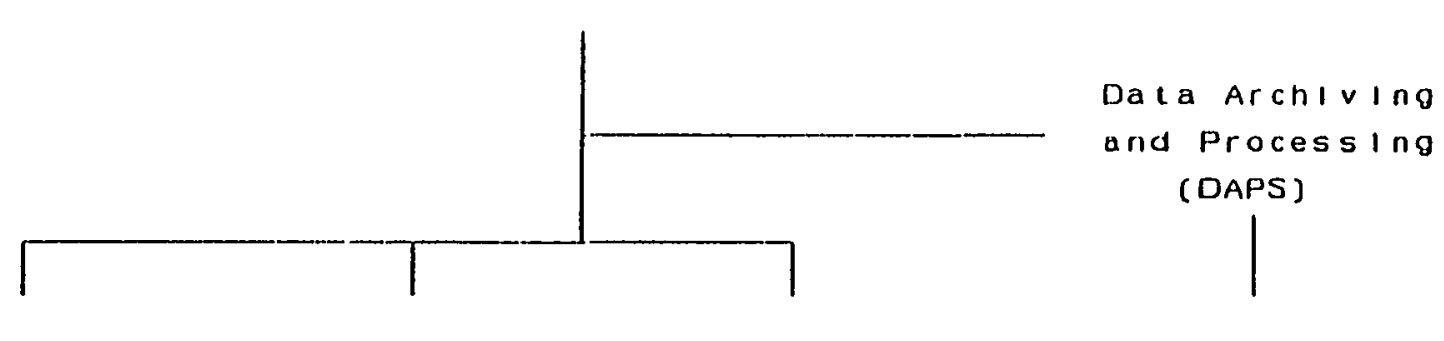

User DAS 1

User Das 2 User DAS $n$

Archlive Med I um

[ User Selectable channols] 
Figure 5. Apparent Shifts in Global Data for East-West Tilt Error of 1,2,5 Degrees

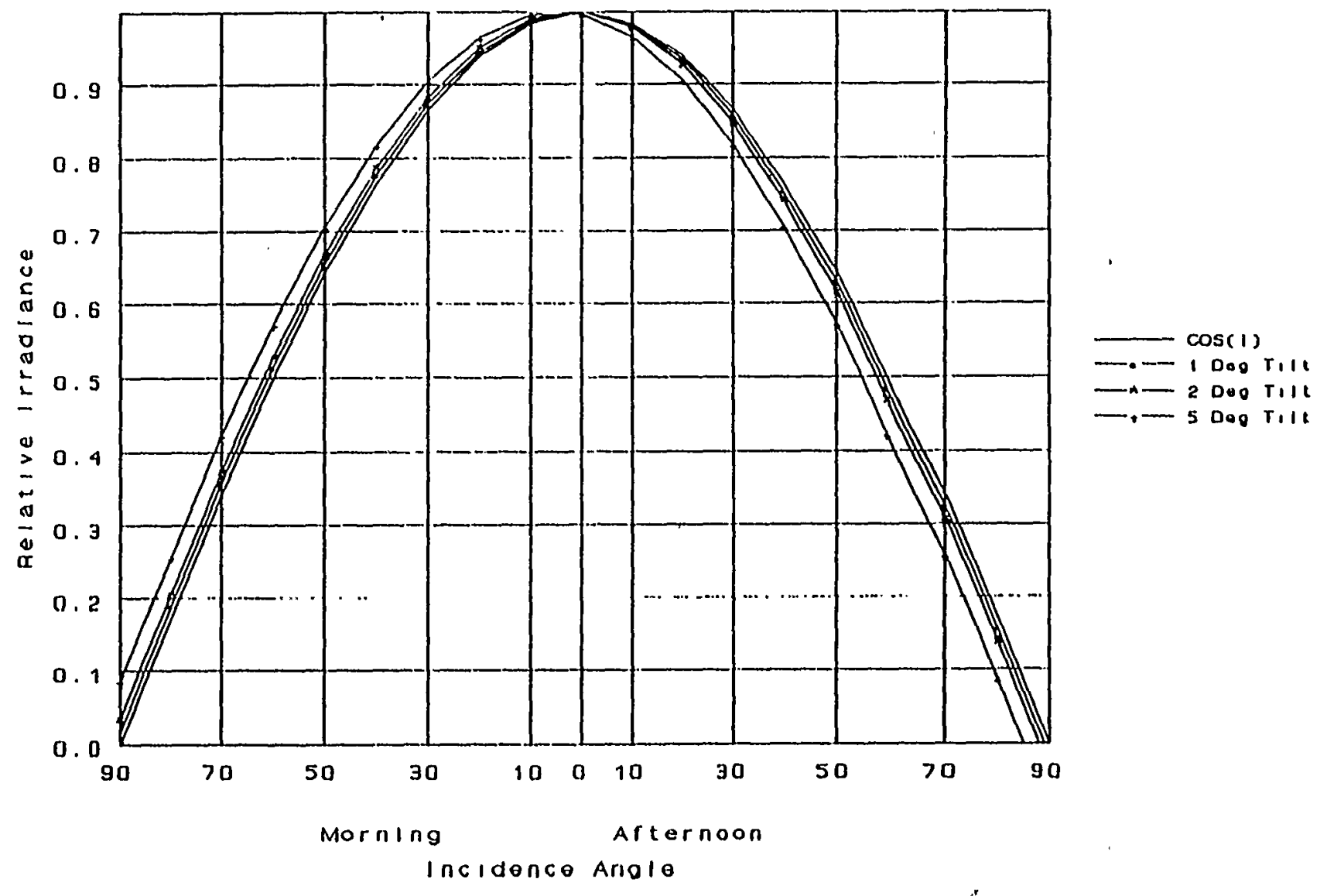

Asoumption 1. that senoor I. tllted to Ease. 
Figure 6. Relative Error in Global Data Vs Incidence Angle for Tilt Errors in East-West Direction of 1,2,5 Degrees.

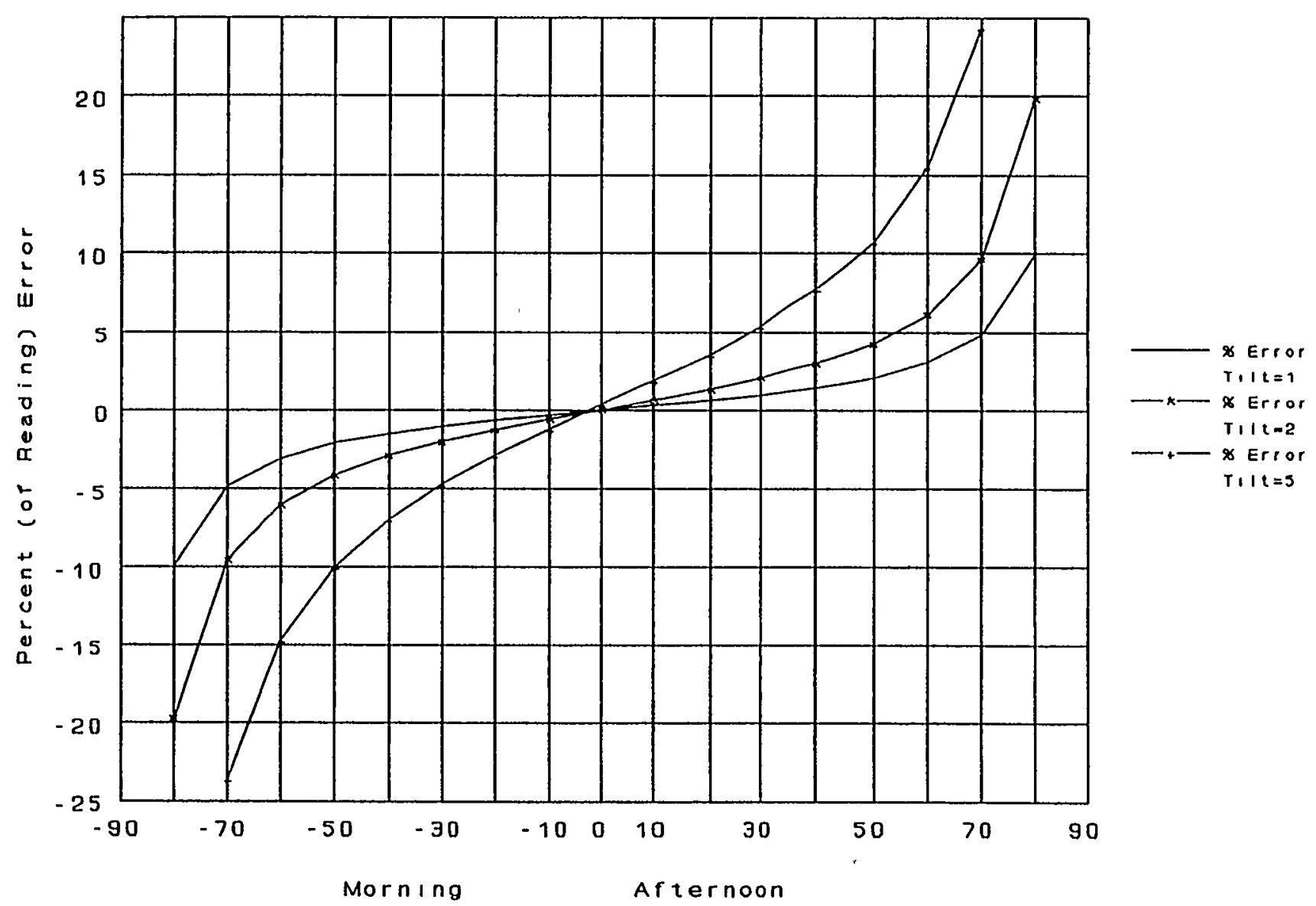

Incldence Anglo 


\section{Figure 7. Calibration Performance: PASS}

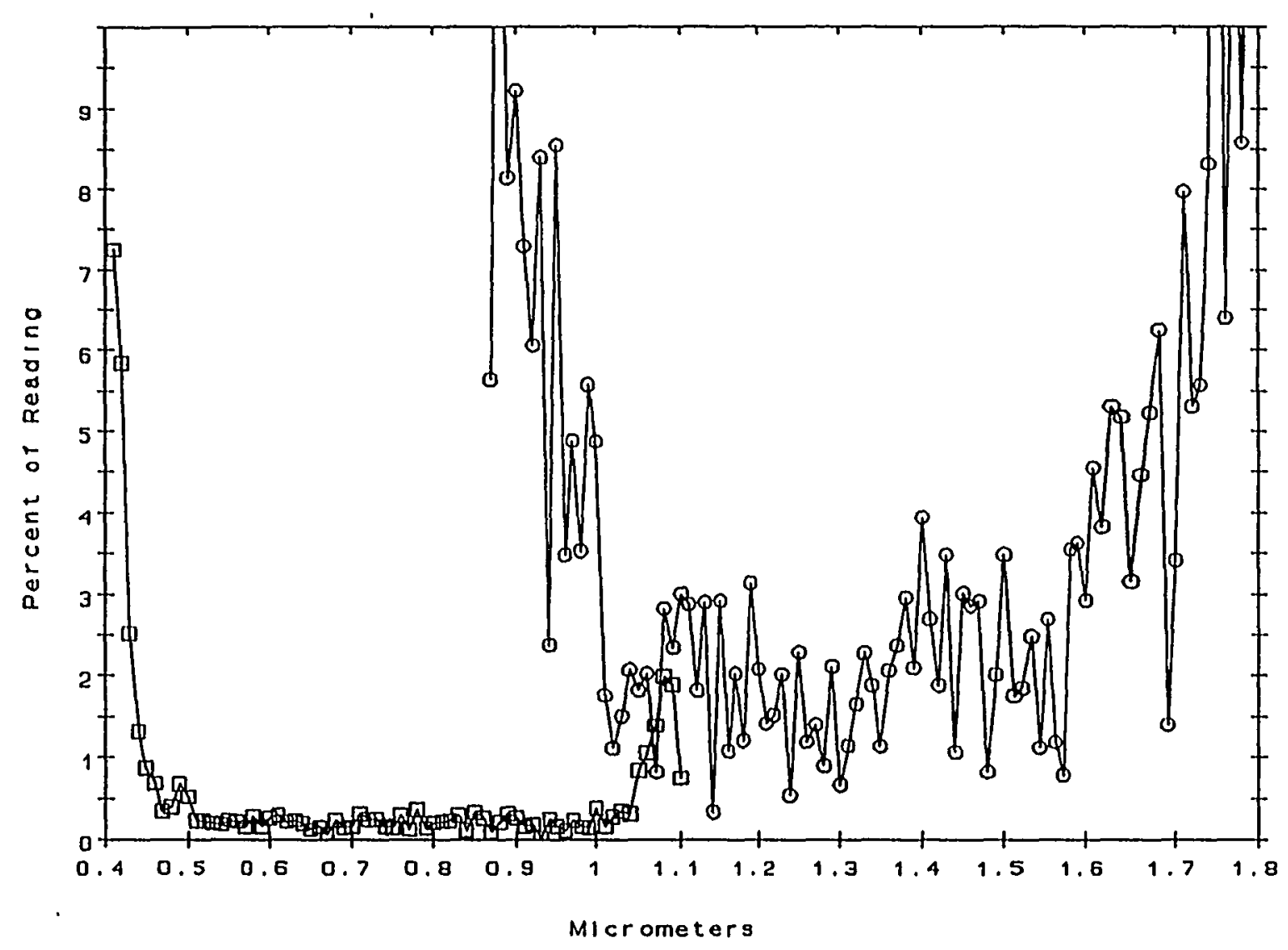

Random variation about Mean Value of PASS measurement of (chopped) NIST lamp - \% of reading 
Figure 8. PASS Pulse Xenon-Arc Solar Simulator Spectrum

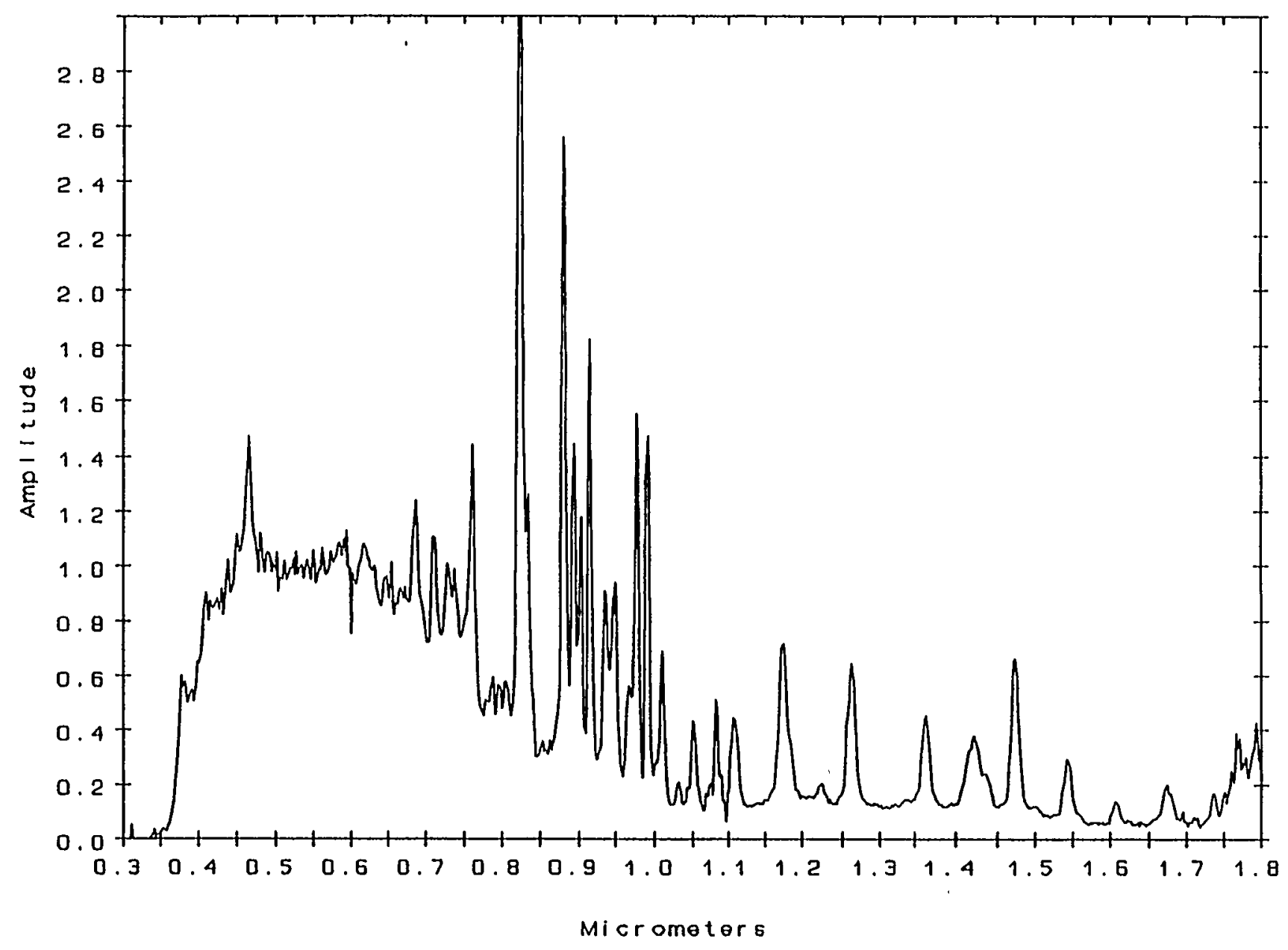




\section{MODULE AND SYSTEM TESTING}


112 


\title{
Overview of Photovoltaic Module Reliability Testing at NREL
}

\author{
by Joseph Burdick and Jim Pruett
}

Photovoltaic Performance \& Reliability Workshop

September 8, 1993 


\section{NREL Photovoltaics Program}

\section{PV MODULE \& SYSTEM PERFORMANCE and ENGINEERING PROJECT}

Team/Task:

Module Qualification Testing, Test Method Development, and Failure Analysis 
PV Performance \& Reliability Workshop Sept. 8, 1993
NREL Module Reliability Testing page 3

\section{Photovoltaics:}

- Materials

- Cells

- Modules

- Systems 


\section{Photovoltaic Modules:}

- Fabrication

占

- Testing:

- Performance

- Reliability: Qualification, Stability, etc. 


\section{PV Module Testing:}

\section{Are We Asking the Right Questions?}

"We need to obtain at least approximate answers to the right questions rather than what we believe are right answers to only approximate questions" 


\section{PV Module Reliability \& Stability:}

What are the right questions?

We believe they are:

1) Can we correlate indoor/accelerated testing and results to outdoor/real-time/natural exposure?

2) From this, can we predict the service lifetime of photovoltaic modules (is it $5,10,20,30$ years)? 


\section{To accomplish these goals (and answer these questions) we begin with an outline of our PV module reliability testing program here at NREL}




\section{NREL PV Module Reliability Testing Program}

Goals: 1. Help PV Manufacturers Make Better Modules

2. Predict PV Module Service Lifetime

$\because$ Strategy: 1. Understand and obtain correlation between indoor (accelerated) test results and outdoor (natural, real-time) exposure as related to reliability/stability/weathering issues

2. Identify module failure mechanisms

3. Work to obtain solutions to reliability problems

Method: Indoor Testing and Outdoor Testing Programs 


\section{Indoor Module Testing Program}

- Qualification Testing

- Photostability Studies

- Accelerated Weathering

\section{Outdoor Module Testing Program}

- Natural, Real-Time Exposure Testing 


\section{Outdoor Phenomena Affecting Module Reliability, Stability \& Weathering}

\section{Phenomenon}

Natural: $\quad$ Sun: UV Photons

\section{Related Effect}

Light-induced degradation of plastics, polymers, paints, textiles, metals, etc.

Sun: Visible \& IR Photons Light-induced degradation of PV materials and loss of performance

Heat \& Cold

Thermal stresses on materials, mechanical \& electrical interconnects

Mechanical stresses on materials, mechanical \& electrical interconnects snow, hail, etc.

Moisture: Humidity, Precipitation, etc.
Corrosion of materials, degradation of performance 


\section{Outdoor Phenomena Affecting Module Reliability, Stability \& Weathering}

\section{Phenomenon}

Artificial: Electrical Loads

Pollutants, etc.

\section{$\underline{\text { Related Effect }}$}

Losses due to mismatch, wiring, power conditioning equipment, improper grounding, etc.

Corrosion, performance degradation

Any one or more of these effects, or their synergistic combination, can lead to shorts, open-circuits, and other failures in the PV modules which may, in turn, lead to module and/or system losses, performance degradation, a decrease in PV efficiency and output, and even to catastropic failures in the components and/or the overall $P V$ system. 


\section{Indoor Module Testing Program}

- Qualification Testing

- Photostability Studies

- Accelerated Weathering

Outdoor Module Testing Program

- Natural, Real-Time Exposure Testing 


\section{Indoors: Module Qualification Testing (MQT) Program}

Test

Thermal Cycling

Humidity-Freeze

Cycling

\section{Outdoor Phenomenon}

Simulated

\section{Accomplishments \\ \& Present Status}

Heat \& Cold; Thermal Stresses BMA chamber used

Moisture, Precipitation, etc.

\section{Modi} open-circuits and shorts-to-ground in-situ during the cycling tests

Damp Heat BMA environmental chamber used

Dry Hi-pot Electrical Loads

Wet Hi-pot

Wet Insulation-Resistance

Ground Continuity Electrical Loads
Hi-pot tester completed

Trough tester completed New tray purchased

Test set-up completed

\section{Future Plans}

New BMA being delivered 


\section{Indoors: Module Qualification Testing (MQT) Program}

\section{Test}

\section{Outdoor Phenomenon}

Simulated

Shadowing, etc. Two thermal/IR video systems purchased

\section{Accomplishments \\ \& Present Status}

Future Plans

Hot-Spot Endurance

Bypass Diode Thermal

Mechanical Loading: Static

Mechanical Loading: Dynamic

Hail Impact
Snow loads, etc.

Wind loads, etc. Mechanical Flex Tester (MFT) operational;

Received, Installed \& Tested (April 1993)

Hail storms, etc. Hail Impact Test System (H.I.T.S.) operational; Performed tests: Golden Photon, UPG samples

Saltwater Immersion \& Corrosion Marine Effects Performed tests: Iowa Thin-Film samples test under development test under development 


\section{Indoors: Module Qualification Testing (MQT) Program}

$\begin{array}{llll}\text { Test } & \text { Outdoor Phenomenon } & \frac{\text { Accomplishments }}{\text { Simulated }} & \text { \& Present Status }\end{array}$ Future Plans

Surface-Cut Susceptibility Scratches, cuts, etc. Surface-cut instrument completed

N

Termination Robustness

Under development

Twist

Under development

Accelerated Weathering

UV/Vis/IR Radiation Accelerated-weathering chamber with Heat/Moisture proposals received \& are being evaluated

Laser Scanning

Working with micro-characterization group to identify problem/failure areas in the modules 
PV Performance \& Reliability Workshop Sept. 8, 1993
NREL Module Reliability Testing page 16

\section{MQT Project: Test Plan \& Status}

- $10 \mathrm{PV}$ manufacturers, $~ 9$ modules each: latest commercial products

- Entire NREL (IQT) / IEEE (Proposed) Test Sequence will be run: started Sept. '93

\begin{tabular}{lll} 
Manufacturer & Model & Structure/Composition \\
\hline APS & EN-25 & a-Si \\
Solarex & SA-5 & a-Si \\
UPG & PowerGlass & a-Si/a-Si \\
USSC & UPM-880 & a-Si/a-Si \\
ECD & $1^{\prime} \times 4^{\prime}$ & a-Si/a-Si/a-Si:Ge \\
Solar Cells, Inc. & $2^{\prime} \times 5^{\prime}$ & \\
Golden Photon & $2^{\prime} \times 2$ & CdTe \\
Siemens Solar & Black Frame & CdTe \\
& CIS (CuInSe2) \\
Solarex & MSX-60 & m-Si \\
Siemens & M55 \& PC-4 & x-Si
\end{tabular}




\section{Indoor Module Testing Program}

- Qualification Testing

- Photostability Studies

- Accelerated Weathering

Outdoor Module Testing Program

- Natural, Real-Time Exposure Testing 


\section{Indoor/Outdoor: Photostability Testing Program}

- Light-Soak Test \#1 completed; modules now deployed outdoors

- $\quad$ Light-Soak Test \#2 completed (April 1993)

- Light-Soak Test \#3 underway (to be completed Nov. 1993)

- Following Light-Soak Test \#3, a new photostability study will begin:

Obtain 7 commercial a-Si PV modules from each of the following manufacturers (and perhaps some others): APS, ECD, Solarex, UPG and USSC. Keeping one module from each company as a control, perform the following tests on the other 6 modules: 


\section{Indoor/Outdoor: Photostability Testing Program (cont.)}

- Indoor Continuous-Illumination Test: Our "standard" 1-sun continuous illumination test, at a module temperature of $50^{\circ} \mathrm{C}$, electrically loading each module at its maximum power point (Pmax), for a total of at least 1000 hours, with periodic I-V curves taken at 25, 50, 100, 250, 500 , and 1000 hours. Two modules from each manufacturer (a total of 10 modules) will be exposed in this test. Modifications have been made to the Tenney chamber with the Vortek argon-arc lamp to take I-V curves in-situ during exposure with a new multi-tracer apparatus, as well as the ability to monitor irradiance and temperature.

- Indoor Cycled-Illumination Test: A second group of two modules from each manufacturer (a total of 10 modules) will be exposed in this test. The illumination will be 1 -sun and $50^{\circ} \mathrm{C}$ for 5 . hours, and then the modules will be kept in the dark at $25^{\circ} \mathrm{C}$ for 19 hours. This light-dark cycling will be continued until the modules have been exposed to a total of at least 1000 cumulative hours of 1-sun illumination. The modules will also be loaded at Pmax. Periodic I-V curves will be taken after 25,50,100,250, 500, and 1000 hours of illumination. The purpose of this experiment is to approximate the actual light-dark exposure which modules see in the field. 


\section{Indoor/Outdoor: Photostability Testing Program (cont.)}

- Outdoor Natural Exposure Test: A third group of two modules from each manufacturer (a total of 10 modules) will be exposed in this test. This will involve mounting the modules at the outdoor PV test site, loading them at Pmax, and then periodically obtaining I-V curves on each module. This test will continue for at least one year of outdoor exposure; the test was begun in August, 1993. The modules are electrically loaded, and I-V curves are taken in-situ, using a new multi-plexing module I-V curve tracer apparatus (Multi-Tracer).

A comparison of the results from these three tests may provide insight into the photo-induced degradation in a-Si PV modules, from various perspectives: (1) the PV material structure and composition, (2) the effect of their exposure history on the shape and total amount of degradation, as well as the time to "stabilization", (3) the general effects of continuous versus cycled illumination and temperature, both natural and artificial, and (4) other effects not yet anticipated but possibly revealed by this study. 


\section{Indoor Module Testing Program}

- Qualification Testing

- Photostability Studies

- Accelerated Weathering

\section{Outdoor Module Testing Program}

- Natural, Real-Time Exposure Testing 


\section{Indoors: Accelerated Weathering Program}

- Proposals for an Accelerated Weathering/Environmental Test Chamber have been received and are being evaluated

- Expect delivery and program start-up in early 1994

- Concerns: Cost is high to obtain everything we really need in one large-area apparatus/chamber, i.e., UV, visible, and IR illumination, thermal cycling, and humidity, with monitoring and control features

- This is important because the effects of the light-source spectrum and intensity, as well as test chamber temperature and moisture, can dramatically alter the results of the accelerated test, thereby giving little or no correlation to outdoor natural exposure 


\section{Pitfalls in accelerated testing with a light source differing in emission properties (total and spectral irradiance) from the natural source (*):}

1. Possible reversal in stability ranking of materials under test

2. May cause an unnatural mechanism and type of degradation

3. Misleading information on the effectiveness of certain absorbers and stabilizers

4. Alters bleaching vs yellowing and other antagonistic reactions

5. Alters surface vs bulk degradation

$\Rightarrow$ These may lead to inaccurate prediction of material and/or module lifetimes

(*) Norma Searle, "Effect of Light on Materials", Atlas School for Natural and Accelerated Weathering, May, 1993. 


\section{Indoor Module Testing Program}

- Qualification Testing

- Photostability Studies

- Accelerated Weathering

Outdoor Module Testing Program

- Natural, Real-Time Exposure Testing 


\section{Outdoor Testing Program}

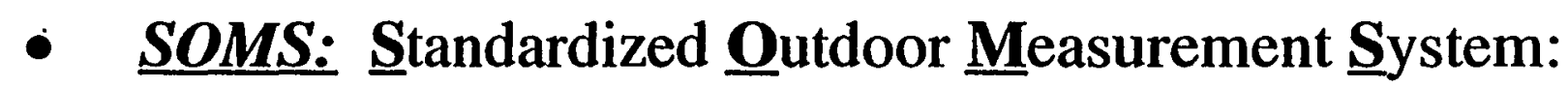

1) Reference Cells / Module Package

2) Outdoor Temperature-Controlled PV Test Enclosure

- Multi-Tracer: PV Module Multi-plexing I-V Curve Tracer:

$\Rightarrow$ In-situ monitoring and data acquisition of I-V curves, irradiance, temperature, etc.

=> Loading of modules via max. power tracking or constant voltage 


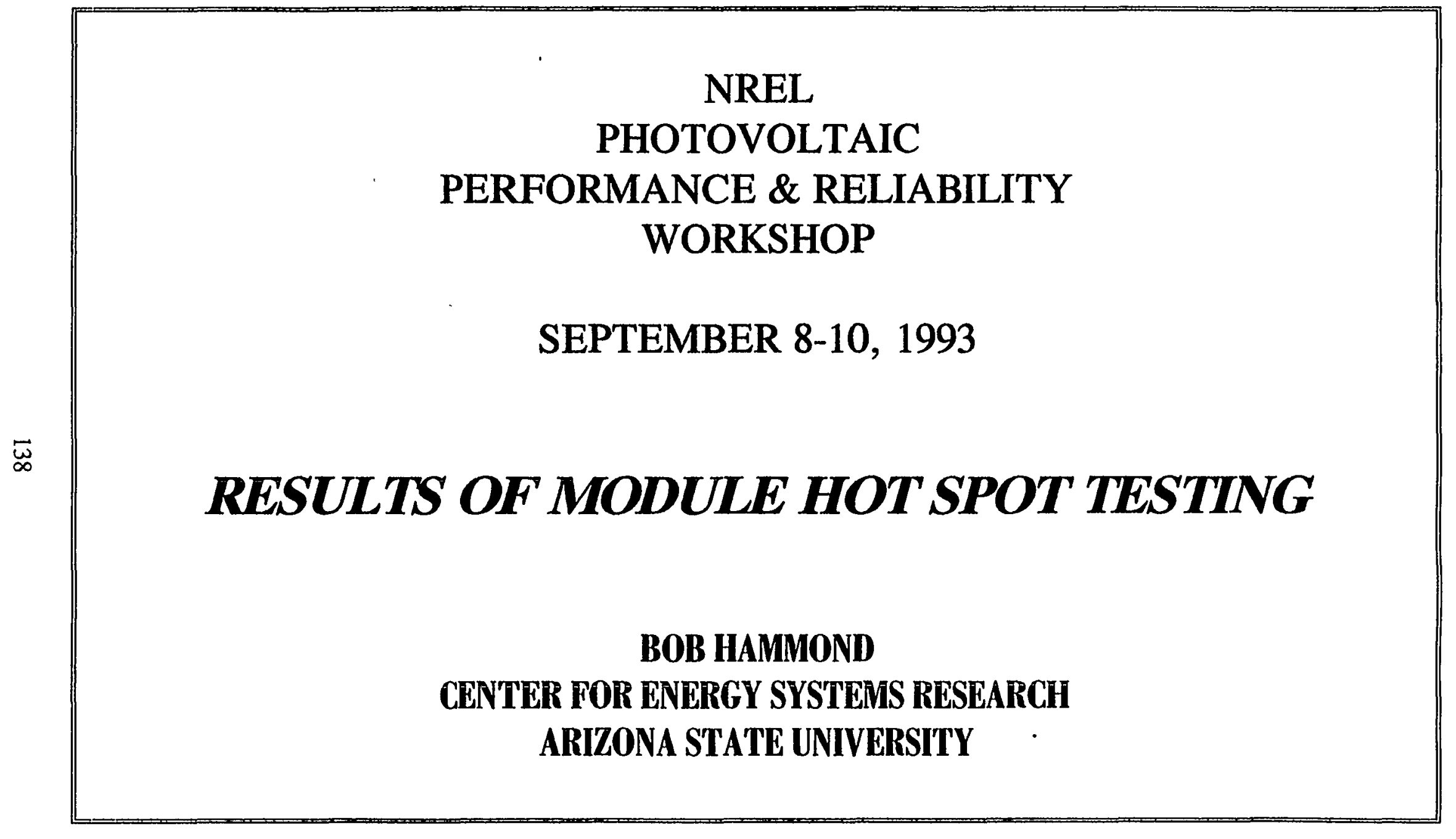




\section{SHADING CAN OCCUR DUE TO}

. BIRD DROPPINGS

. LEAVES OR OTHER DEBRIS

. SHADOWS (TREES, POLES, ETC.)

\section{CRACKED CELLS CAN PRODUCE THE SAME EFFECT AS SHADING}




\section{HOT-SPOT HEATING}

- WORST CASE CONDITION IS WITH MODULE (OR CELL STRING) SHORTED

. EIGHTY PERCENT OF STAND-ALONE SYSTEMS USE SHUNT TYPE CHARGE CONTROLLERS WHICH SHORT THE MODULE 


\section{UL 1703 \\ FLAT-PLATE PHOTOVOLTAIC MODULES \& PANELS}

36.0 HOT-SPOT ENDURANCE

"...MODULE SUBJECTED TO SIMULATED REVERSE

VOLTAGE HOT-SPOT HEATING CONDITIONS FOR 100

宝

HOURS, INTERMITTENTLY

THE TESTS SHALL NOT RESULT IN:

- THE ACCESSIBILITY OF PARTS INVOLVING A RISK OF ELECTRICAL SHOCK (HIGH POT TEST)

- MELTING OF SOLDER OR

- ANY OTHER INDICATION OF A RISK OF FIRE OR ELECTRICAL SHOCK 


\section{CONCLUSIONS}

- CELLS CAN GET VERY HOT DUE TO SHADING (OR CRACKED CELLS

- HOT-SPOT HEATING IS NOT LIMITED TO UTILITY SIZE SYSTEMS

. THE NUMBER OF CELLS BYPASS IS A MAJOR FACTOR IN SHADED CELL TEMPERATURE

- OUTDOOR TESTS ARE RELIABLE, SIMPLE, INEXPENSIVE AND REALISTIC COMPARED TO SIMULATED INDOOR TESTS (BUT TEST CONDITIONS ARE NOT AS WELL CONTROLLED). 
MODULE SUMMARY DATA

\begin{tabular}{|c|c|c|c|c|c|c|}
\hline MFG. & 1 & 2 & 3 & 4 & 5 & 6 \\
\hline SUBSTRATE & Tedlar [1] & Glass [4] & Tedlar [2] & Tedlar [5] & Tedlar [6] & Tedlar [3] \\
\hline $\begin{array}{l}\text { POWER W } \\
\text { [7] DATA SHEET } \\
\text { [8] MEASURED }\end{array}$ & 20.28 [ 9$]$ & 88.7 & $\begin{array}{c}53 \\
53.0 \\
\end{array}$ & $\begin{array}{c}64 \\
58.9 \\
\end{array}$ & $\begin{array}{c}48 \\
47.3 \\
\end{array}$ & $\begin{array}{l}62.7 \\
58.8 \\
\end{array}$ \\
\hline $\begin{array}{l}\text { Voc Vdc } \\
\text { [7] DATA SHEET } \\
\text { [8] MEASURED }\end{array}$ & $10 . \overline{4}$ [9] & $\begin{array}{c}- \\
46.1 \\
\end{array}$ & $\begin{array}{l}21.7 \\
21.8 \\
\end{array}$ & $\begin{array}{l}21.3 \\
21.2 \\
\end{array}$ & $\begin{array}{l}21.3 \\
21.7 \\
\end{array}$ & $\begin{array}{l}26.0 \\
25.9 \\
\end{array}$ \\
\hline $\begin{array}{l}\text { Isc Adc } \\
\text { [7] DATA SHEET } \\
\text { [8] MEASURED }\end{array}$ & $2.74[9]$ & 2.65 & $\begin{array}{l}3.35 \\
3.33 \\
\end{array}$ & $\begin{array}{c}4.0 \\
3.66 \\
\end{array}$ & $\begin{array}{l}3.2 \\
3.1 \\
\end{array}$ & $\begin{array}{l}3.25 \\
3.14 \\
\end{array}$ \\
\hline $\begin{array}{l}\text { FILL FACTOR } \\
\text { [7] DATA SHEET } \\
\text { [8] MEASURED }\end{array}$ & $\begin{array}{c}- \\
0 . \overline{700}\end{array}$ & $0 . \overline{726}$ & $\begin{array}{l}0.729 \\
0.728 \\
\end{array}$ & $\begin{array}{l}0.751 \\
0.757 \\
\end{array}$ & $\begin{array}{l}0.704 \\
0.703 \\
\end{array}$ & $\begin{array}{l}0.742 \\
0.724 \\
\end{array}$ \\
\hline SERIES CELLS & 18 & 80 & 36 & 36 & 36 & 44 \\
\hline CELL LAYOUT & $1 \times 18$ & $8 \times 10$ & $3 \times 12$ & $4 \times 9$ & $4 \times 9$ & $4 \times 11$ \\
\hline CELL SIZE, $\mathrm{mm}$ & $96 \times 96$ & $100 \times 100$ & $103 \times 103$ & $115 \times 115$ & $100 \times 100$ & $102 \times 102$ \\
\hline BYPASS DIODES & None & $4 ; 20$ cells & $2 ; 24$ cells & None & None & None \\
\hline "BYPASSED CELLS & 18 & 20 & 24 & 36 & 36 & 44 \\
\hline Vr, RANGE & $3.45-8.75$ & $\begin{array}{l}4.99- \\
10.13 \\
\end{array}$ & $\begin{array}{l}5.05- \\
11.76 \\
\end{array}$ & $\begin{array}{l}8.40- \\
12.12 \\
\end{array}$ & $\begin{array}{l}0.22- \\
18.18 \\
\end{array}$ & $0.65-5.50$ \\
\hline $\begin{array}{ll}\text { Note 1: } & \text { Tedlar-mylar-poly } \\
\text { Note 2: } & \text { Tedlar-mylar-Tedl } \\
\text { Note 3: } & \text { Tedlar-foil-mylar-" } \\
\text { Note 4: } & \text { Glass-acrylic } \\
\text { Note 5: } & \text { Tedlar-mylar }\end{array}$ & & $\begin{array}{l}\text { te 6: Tedlat } \\
\text { te 7: From } \\
\text { te 8: Meast } \\
\text { te 9: Single } \\
\text { ings) }\end{array}$ & $\begin{array}{l}\text { il-mylar-Te } \\
\text { nufacturer's } \\
\text { i by MSEC } \\
\text { ing (i.e., } 1\end{array}$ & $\begin{array}{l}12 \\
12\end{array}$ & & \\
\hline
\end{tabular}




\section{Bypassed}

Manufacturer Series Cell

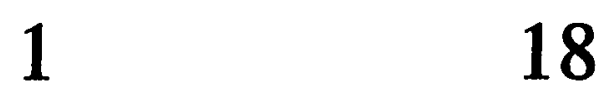

220

$3 \quad 24$

436

$5 \quad 36$

644 
TB0123S.XLS Chart 4

\section{Vr by Manufacturer}

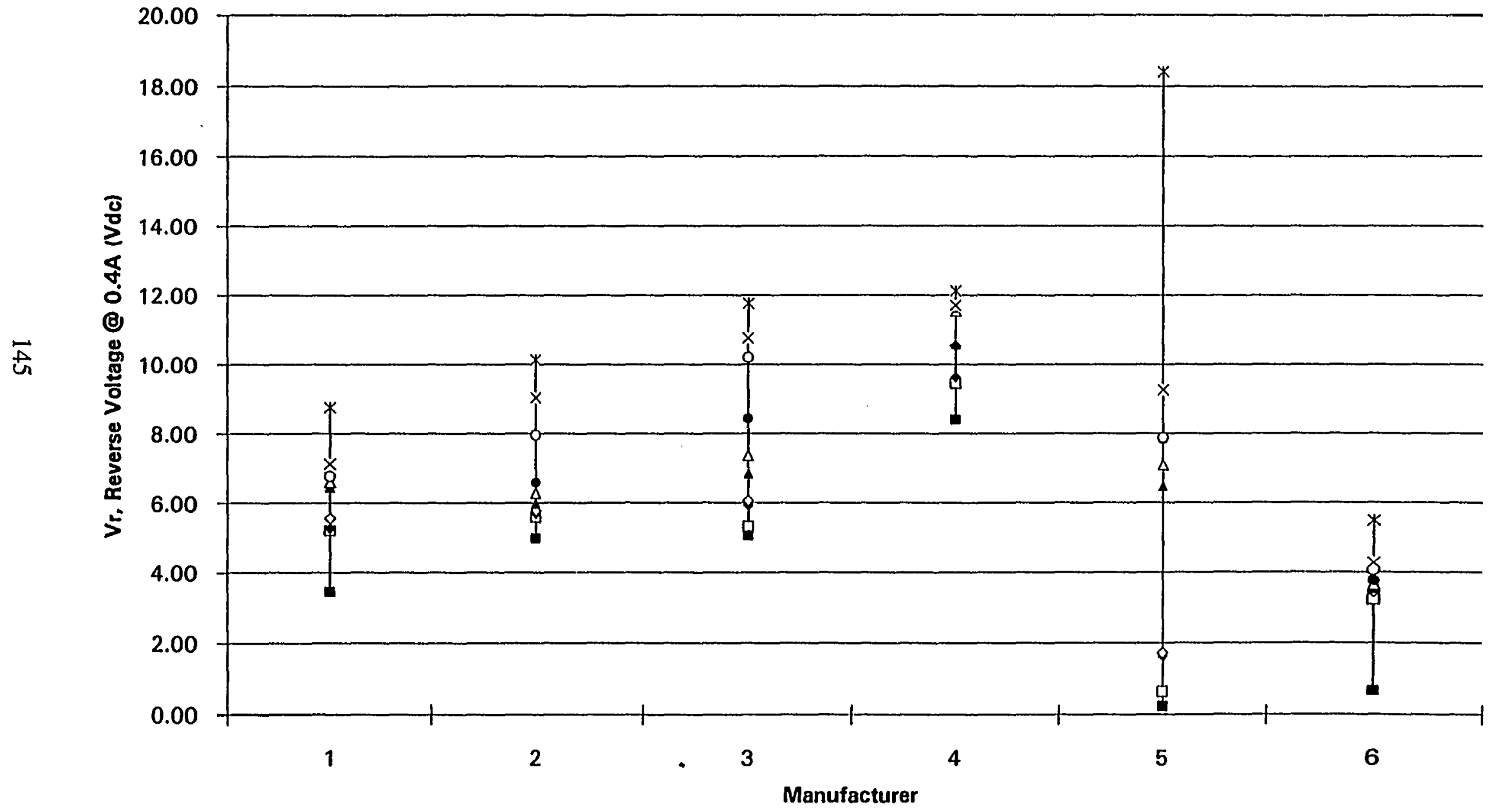

Page 1 
\#6-TC.XLC

CELL \#6, THERMAL RESPONSE

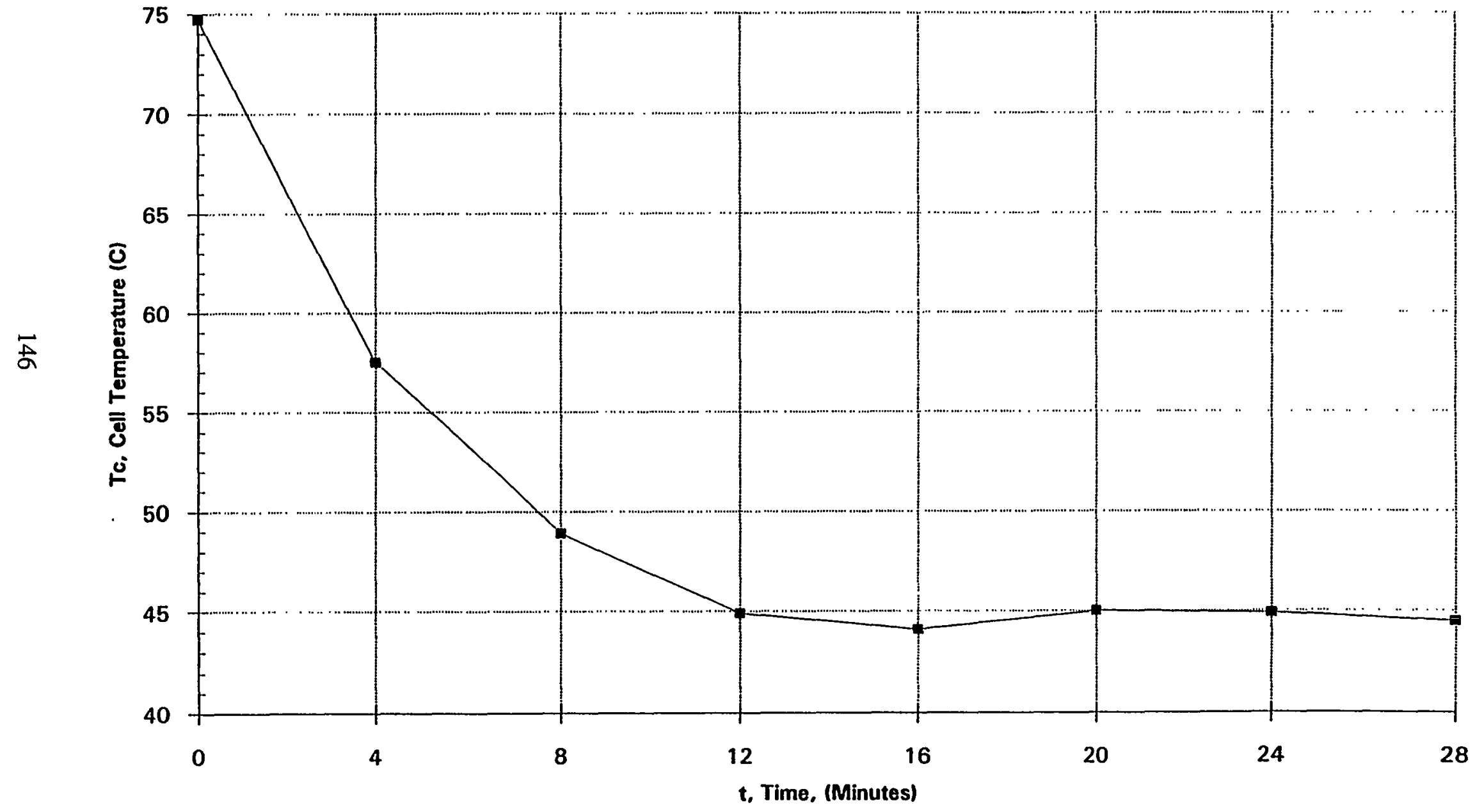

Page 1 
CELLL \#0302 (25\% Shading @ Columns 1 \& 2, and Rows 3 \& 4). Module short-circuited.

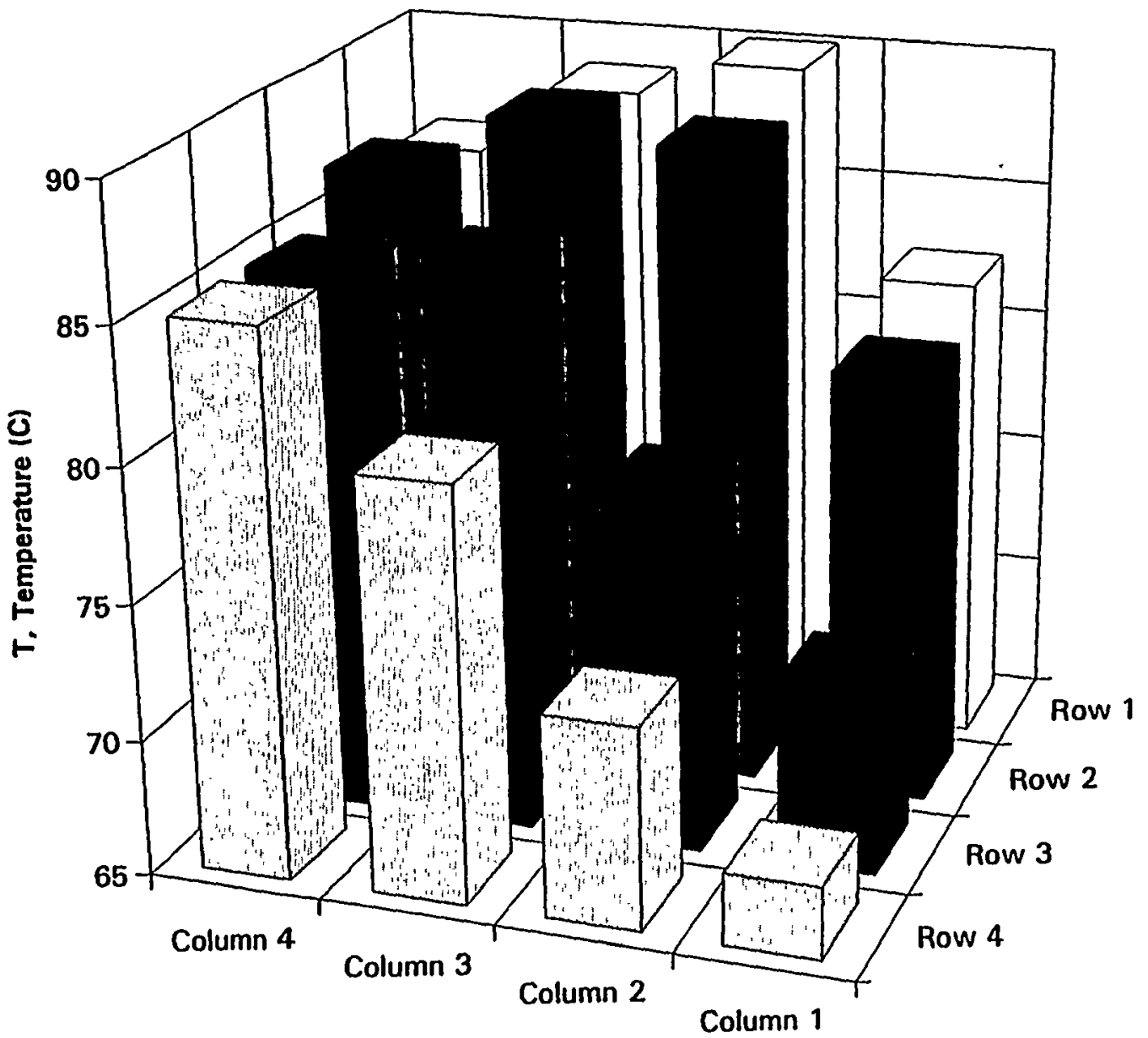




\section{6-3D-1S.XLC}

MFG \#1；CELL \#6； G=1000

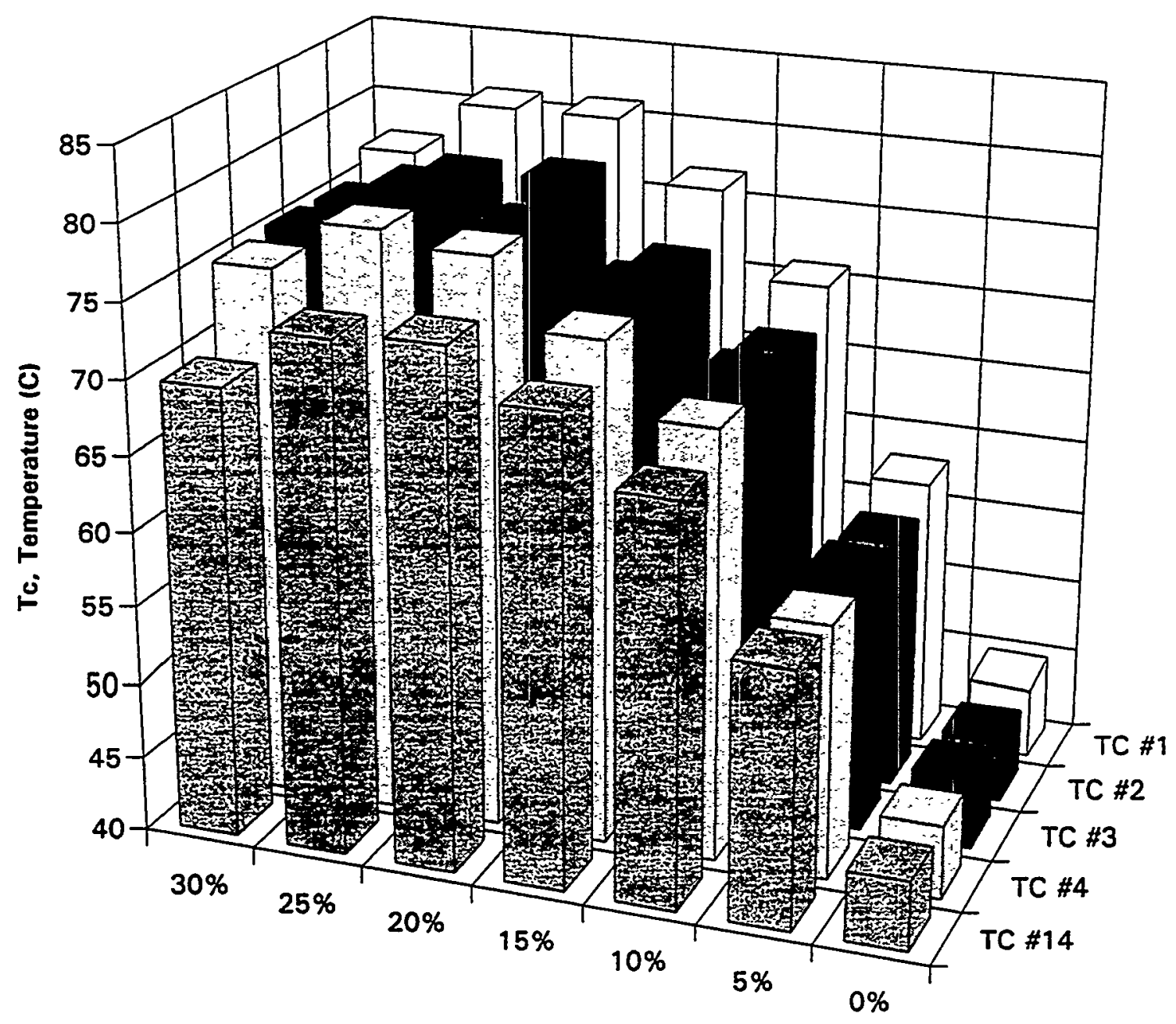




\begin{tabular}{|c|c|c|c|c|c|c|c|c|c|c|c|c|c|}
\hline \multicolumn{14}{|c|}{ NORMALIZED MAXIMUM CELL TEMPERATURE (Average of five points) } \\
\hline & & \multicolumn{2}{|c|}{1} & \multicolumn{2}{|l|}{2} & \multicolumn{2}{|l|}{3} & \multicolumn{2}{|l|}{4} & \multicolumn{2}{|l|}{5} & \multicolumn{2}{|l|}{6} \\
\hline $\mathbf{G}$ & R-shunt & T-norm & $\%$ & T-norm & $\%$ & T-norm & $\%$ & T-norm & $\%$ & T-norn & $\%$ & T-norm & $\%$ \\
\hline 1000 & HI & 75.4 & 25 & 90.9 & 20 & 101.7 & 30 & 102.7 & 30 & 112.0 & $\overline{30}$ & 105.8 & 30 \\
\hline 1000 & AVE & 77.1 & 25 & 89.9 & 25 & 102.7 & 30 & 104.1 & 30 & 78.2 & 30 & 81.8 & 30 \\
\hline 1000 & LO & 67.1 & 30 & 73.9 & 30 & 84.9 & 30 & 96.9 & 30 & 55.4 & 20 & 63.2 & 30 \\
\hline 800 & HI & 68.9 & 20 & 85.2 & 30 & 88.2 & 30 & 100.1 & 30 & 91.4 & 30 & 87.2 & 30 \\
\hline 800 & AVE & 74.3 & 30 & 82.0 & 25 & 90.2 & 30 & 98.7 & 30 & 68.1 & 30 & 72.6 & 30 \\
\hline 800 & LO & 67.5 & 30 & 67.2 & 30 & 77.2 & 30 & 91.3 & 30 & 41.5 & 20 & 52.3 & 30 \\
\hline 600 & $\overline{\mathrm{HI}}$ & 62.6 & 30 & 53.7 & 25 & 70.3 & 25 & 73.8 & 25 & 78.5 & 25 & 67.0 & 30 \\
\hline 600 & AVE & 58.9 & 30 & 52.1 & 30 & 61.7 & 25 & 81.1 & 30 & 59.4 & 30 & 57.9 & 30 \\
\hline 600 & LO & 53.9 & 30 & 51.4 & 30 & 53.3 & 30 & 76.4 & 30 & 39.9 & 0 & 47.3 & 20 \\
\hline & & & & & & & & & & & & & \\
\hline \multicolumn{14}{|c|}{ NORMALIZED MAXIMUM HOT SPOT OF SHADED CELL (One of five points) } \\
\hline & & \multicolumn{2}{|c|}{1} & \multicolumn{2}{|l|}{2} & \multicolumn{2}{|l|}{3} & \multicolumn{2}{|l|}{4} & \multicolumn{2}{|l|}{5} & \multicolumn{2}{|l|}{6} \\
\hline G & R-shunt & T-norm & $\%$ & T-norm & $\%$ & T-norm & $\%$ & T-norm & $\%$ & T-norn & $\%$ & T-norm & $\overline{\%}$ \\
\hline 1000 & मा & 78.2 & 20,25 & 92.9 & 0- & 113.1 & $\overline{30}$ & 109.2 & 30 & 121.9 & 30 & 111.6 & 30 \\
\hline 1000 & AVE & 79.1 & 25 & 93.7 & 30 & 115.2 & 30 & 111.3 & 30 & 90.6 & 30 & 85.8 & 30 \\
\hline 1000 & LO & 68.0 & 30 & 79.5 & 30 & 90.2 & 30 & 104.5 & 30 & 56.6 & 20 & 64.7 & 30 \\
\hline 800 & $\mathrm{HI}$ & 72.1 & 20 & 88.8 & 30 & 97.0 & 30 & 107.3 & 30 & 97.3 & 30 & 90.3 & 30 \\
\hline 800 & AVE & 75.9 & 30 & 84.9 & 25 & 91.7 & 30 & 104.3 & 30 & 71.1 & 30 & 75.2 & 30 \\
\hline 800 & LO & 68.8 & 30 & 70.8 & 30 & 78.8 & 30 & 97.9 & 30 & 42.4 & 20 & 52.9 & 30 \\
\hline 600 & HI & 63.9 & 30 & 72.8 & 25 & 73.8 & 25 & 77.9 & 25 & 84.7 & 25 & 69.7 & 30 \\
\hline 600 & AVE & 58.5 & 30 & 69.7 & 30 & 64.6 & 25 & 84.4 & 30 & 62.4 & 30 & 60.7 & 30 \\
\hline 600 & LO & 55.0 & 30 & 54.6 & 30 & 55.7 & 30 & 79.3 & 30 & 40.4 & 0 & 47.6 & 20 \\
\hline
\end{tabular}




\section{T-RANK2.XLS}

\begin{tabular}{|r|c|r|r|r|}
\hline RANK & MFG & G \& TYPE & $\%$ & T-NORM \\
\hline 1 & 5 & $1000-\mathrm{H}$ & 30 & 112.0 \\
\hline 2 & 6 & $1000-\mathrm{H}$ & 30 & 105.8 \\
\hline 3 & 4 & $1000-\mathrm{A}$ & 30 & 104.1 \\
\hline 4 & 4 & $1000-\mathrm{H}$ & 30 & 102.7 \\
\hline 5 & 3 & $1000-\mathrm{A}$ & 30 & 102.7 \\
\hline 6 & 3 & $1000-\mathrm{H}$ & 30 & 101.7 \\
\hline 7 & 4 & $800-\mathrm{H}$ & 30 & 100.1 \\
\hline 8 & 4 & $800-\mathrm{A}$ & 30 & 98.7 \\
\hline 9 & 4 & $1000-\mathrm{L}$ & 30 & 96.9 \\
\hline 10 & 5 & $800-\mathrm{H}$ & 30 & 91.4 \\
\hline 11 & 4 & $800-\mathrm{L}$ & 30 & 91.3 \\
\hline 12 & 2 & $1000-\mathrm{H}$ & 20 & 90.9 \\
\hline
\end{tabular}

Page 1 


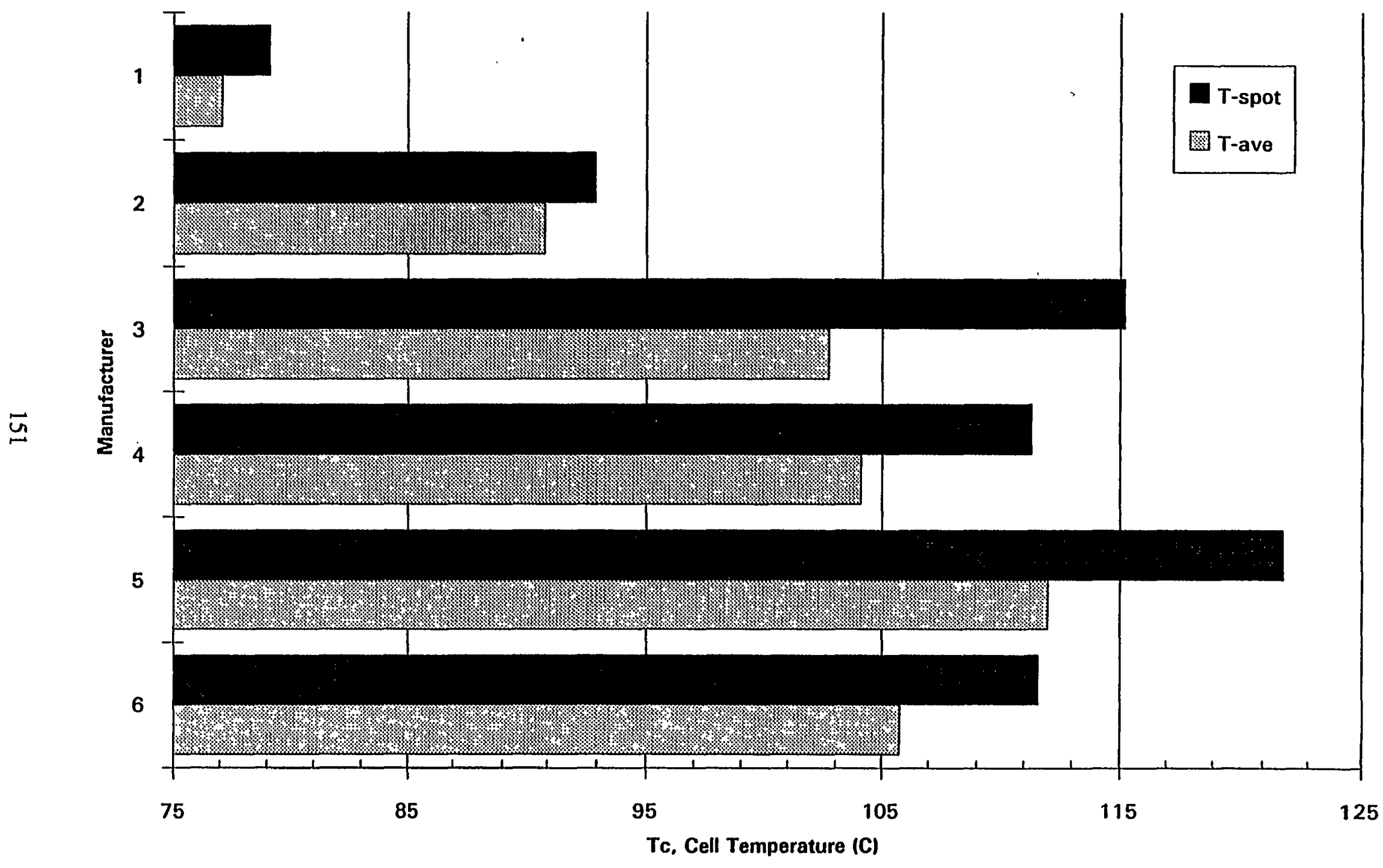

Page 1 
IV081193.XLS Chart 1

\section{DARK IV CURVES}

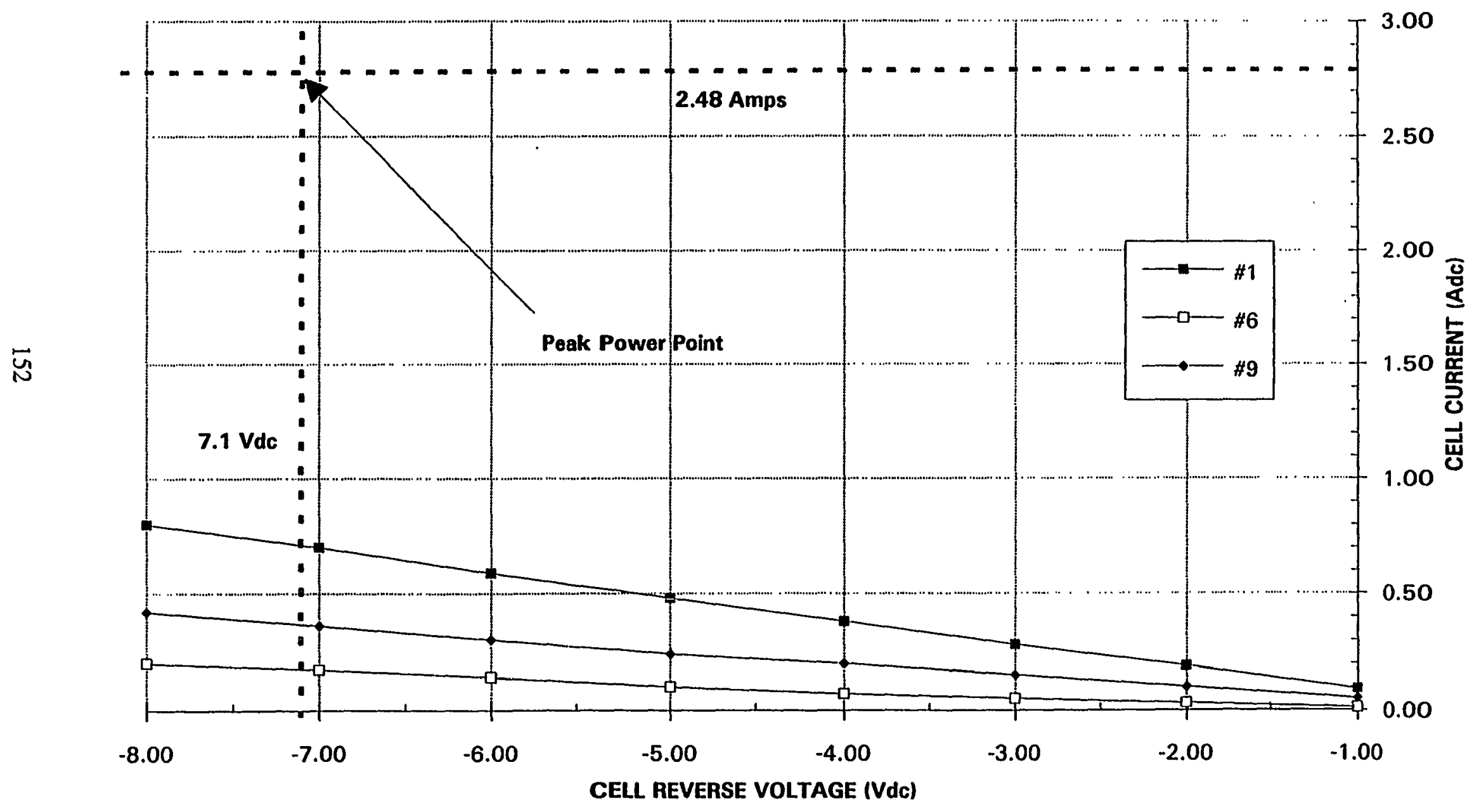

Page 1 


\title{
Relative Humidity, Temperature and Irradiance Testing at Mobil Solar Energy Corporation:
}

\author{
M. Azzam
}

\section{Summary:}

The objective of this paper is to present methods of temperature, relative humidity and irradiance testing and discuss our findings to date and plans for future tests.

Temperature, moisture and irradiance are the environmental conditions that have the most significant impact on PV module lifetime. Driven by customer satisfaction, time-to-market and a strong desire to deliver a highly reliable product to the market, these conditions are accelerated in product tests. In an effort to maintain relevance to operating conditions, while seeking to rapidly improve our product lifetime, Mobil Solar has devoted significant resources towards understanding the relationships between these conditions and the failure mechanisms that inevitably result in module performance degradation.

To date, our irradiance test results support NREL's hypotheses regarding EVA degradation. Our temperature and humidity test results do not agree with JPL's temperature/RH model. We have also learned that PV module electrical performance can vary from one manufacturer to another in these tests. Our plans are to further combine test environments and more accurately monitor product parameters.

\section{Definition of Acronyms:}

EVA- Ethyl Vinyl Acetate

EMMA - Equitorial Mount with Mirrors for Acceleration

EMMAQUA - EMMA with water spray

DSET - Desert Sunshine Environmental Test Labs

JPL Jet Propulsion Labs

NREL - National Renewable Energy Labs

PV - Photovoltaic

RH - Relative Humidity

UV - Ultraviolet

\section{Background:}

The combination of the high cost of PV, the increased competitiveness in the utility industry and the increasing costs of electric outages places a special importance on the reliability of PV modules. This importance provides PV manufacturers with significant opportunities for competitive advantage. On the other hand, the consequence of NOT providing reliable modules can be devastating to the manufacturer, if not the industry. Fortunately, in many respects, PV is up to the task. PV modules in grid connected 
systems are inherently fault tolerant. Improvements in manufacturing as well as understanding of early PV module failures have made infant mortality problems minimal. The random or "freak" failure rate of PV modules has been demonstrated to be quite low (2 per 10,000 per year) or a Mean Time Between Failure (MTBF) of 43.8 million hours versus typical electronic sub-assemblies of 100,000 hours. However, there is one aspect of module reliability Mobil Solar is not yet comfortable with: useful life. Although manufacturers appear to have resolved the long term effects of thermal cycling and mechanical loading, Mobil Solar is still quite concerned with the effects that irradiance, high temperature, and moisture have on module lifetime. That is why Mobil Solar has focused its efforts on improving our test capabilities, our analysis and most importantly, our understanding of the failure mechanisms resulting from these conditions.

\section{The Bath Tub Curve:}

Product and component (hardware, not software) reliability is best described by the bathtub curve. This curve is typically broken up into three phases: "infant mortality", "random or freak failures" and "wearout". Infant mortality failures usually occur within 90 days to a year, during which the product population exhibits a higher than normal failure rate. This higher failure rate occurs because the weakest of the population are unable to endure the typical stresses associated with normal start-up and operation. The light switch or automobile transmission that fails upon first use are examples of infant mortality failures. Workmanship warranties are designed to protect the customer from such problems. The second phase, freak failure rate phase, include the failures that occur over the useful life of the product. Most often the failure is caused by a stress that exceeds the median strength of the product, hence the term "freak" failure rate. An example might be a power surge blowing a transistor or a pot hole damaging the struts in an automobile. The "freak" failure rate is mathematically modeled by a straight line, because it is considered "random". The third phase, or the wearout phase, defines the end of the useful life of the product. In this phase, failure mechanisms such as corrosion, fatigue and polymer degradation cause the product to operate below specifications. These failure mechanisms are caused by the long term exposure to the normal stresses that the product was designed to withstand during its useful life. Most products that we use as consumerscars, dishwashers, computers - only have useful lives on the order of 5 to 10 years. PV modules are expected to have lifetimes on the order of 20 years, anywhere in the U.S.. This poses some very special challenges to those who develop and test PV products. 


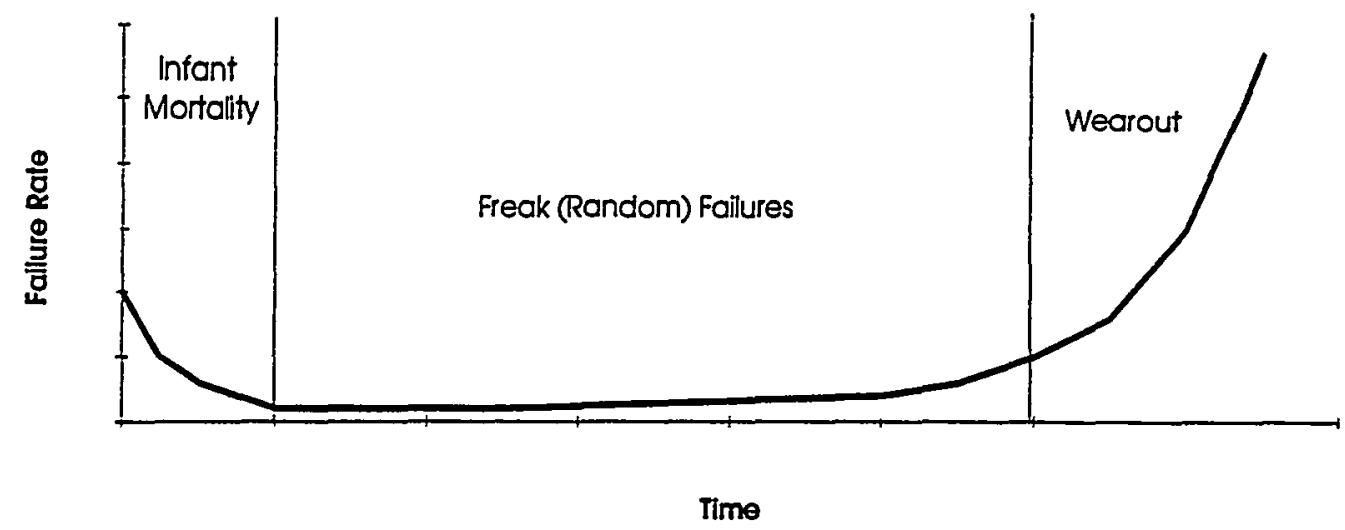

\section{Why Temperature, Relative Humidity, and Irradiance?}

The Jet Propulsion Labs (JPL) did a lot of work on the environmental conditions and failure mechanisms that are most likely to end a crystalline Si PV module's useful life. They determined that PV modules could be "worn out" by:

fatigue failures in the cell-to-cell interconnect system due to diurnal thermal cycling and/or wind/snow loading.

corrosion related failures due to moisture ingress and accelerated by higher temperatures.

electromigration failures due to the combination of moisture, voltage and temperature, further aggravated by encapsulant breakdown due to UV.

encapsulant degradation due to long term exposure to UV and high temperatures.

For the most part, failures attributed to cell-to-cell interconnect fatigue failures were addressed by the dual strap interconnection method and other JPL recommended design guidelines employed by most manufacturers. It is clear that the encapsulant degradation has not been solved. Cell and module material, processes and construction have changed rapidly enough to make it difficult for the industry to assess how much of a problem moisture/temperature induced failure mechanisms really are. Although Mobil Solar still does extensive thermal cycling and mechanical loading testing, we placed special emphasis on UV/Iradiance testing and temperature/humidity testing. 


\section{Past Testing:}

\section{Temperature and Humidity: Damp Heat $\left(8^{\circ} \mathrm{C} / 85 \mathrm{RH}\right)$}

This accelerated test environment originated in the painting industry to determine the resistance of paint coatings to moisthot environments. It was later adopted by the microelectronics industry and later by the PV industry as a form of accelerated life testing. Mobil Solar has found this testing the most aggressive of accelerated "life" tests on PV product, in terms of inducing module failures, (more effective than Thermal Cycling, Mechanical Loading, UV exposure).

$85 / 85$ tests are conducted in environmental chambers. Mobil Solar has two walk-in chambers that can accommodate our full-sized $4 \times 6$ foot modules and three standard chambers ranging from 19 cubic feet to 32 cubic feet in capacity. All chambers are capable of running $85 / 85$ tests. Typically, we expose our modules to just the $85 / 85$ environment (dark). The test is interrupted every 500 hours for electrical tests and visual inspection. We have also performed the $85 / 85$ tests on specimens, with additional conditions. Some of these added conditions are described below.

\section{5/85 with forward current}

We have conducted several experiments in which we biased several of our own minimodules under forward current and compared them to unbiased modules of the same construction. Current has ranged from the $\mathrm{mA}$ range to the 1 amp range. In all cases, the difference between the conditions was imperceptible. Since then, we do not bias the modules in the $85 / 85$ test environment.

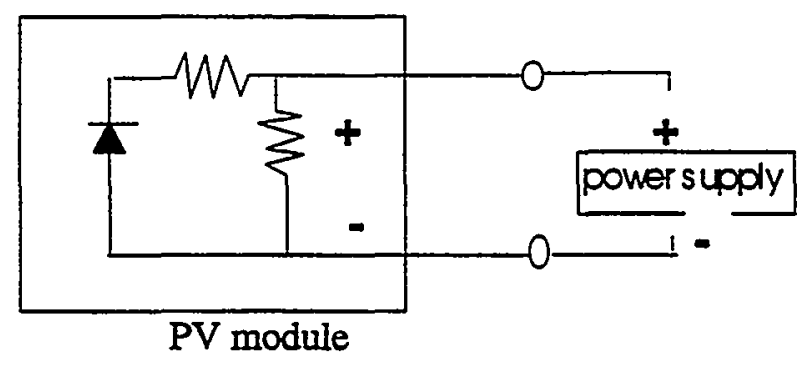

Schematic of module under forward current

\section{$85 / 85$ with voltage}

We recently conducted an $85 / 85$ test where our modules and some of our competitors' modules were also subjected to a voltage of 500 volts applied from each module's source 
circuit to its frame. Although our module and those of certain competitors were not affected, other competitors suffered immediate degradation. This will be discussed in more detail in the section entitled Temperature/Relative Humidity Observations.

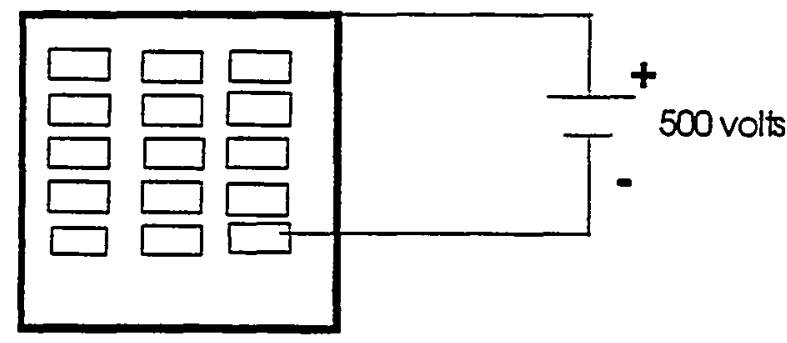

Schematic of module under 500 volts from source circuit to frame

\section{5/85 with Interim Thermal Cycling and "Humidity Freeze" Testing.}

We have combined $85 / 85$ testing with interim thermal cycling, ( 10 cycles every 500 hours of 85/85). We have also conducted humidity freeze testing of both the PVUSA cycle and JPL (soon to be adopted by the IEEE) cycle. Thus far, we have found that the interim thermal cycles and the humidity freeze test are no worse on our modules than the straight $85 / 85$ test, both in terms of power degradation and insulation resistance values. In fact, we have found that the PVUSA cycle tends to be less severe than the JPL cycle and the straight $85 / 85$ testing. We have found that the interim thermal cycling can adversely affect certain competitors.

\section{Other Temperature and Humidity Testing}

Perhaps our most significant work has been in our efforts to: a) find ways to further accelerate the test and reduce the test development times and b) gain a better understanding of the $85 / 85$ test, as it relates to the actual operating conditions. Some examples of these are:

\section{Autoclave Testing:}

We have tailored autoclave test equipment and test techniques originally developed for the microelectronics industry to further accelerate the test results of the $85 / 85$ test. After several years of work, we have found test conditions that adequately reproduce the results from $85 / 85$ testing in about $1 / 4$ the time. The advantages of this drastic reduction in test time are obvious. We are able to make changes and improvements to the processes and products in shorter time with confidence that the heat and moisture resistance of the module is not being compromised. However, these highly accelerated methods must be conducted with caution. These conditions may not be appropriate for certain materials and constructions. 


\section{Matrix Testing:}

In an effort to draw correlation with the actual operating environments, we have conducted, "Matrix" tests at various temperatures and relative humidities which included the $85 / 85$ environment. These tests are still in process. However, we have compared results attained thus far to a number of temperature/relative humidity models. Some of these models, including the one from JPL, have been dismissed based on our experimental findings to date.

\section{Irradiance Testing}

\section{Mercury vapor}

Upon our first obserations of EVA browing at the Southwest Residential Station in New Mexico, we only had one form of UV testing in house, the Sunlighter. This unit used RS -4 mercury vapor lamps, (originally used for superfast suntans.). This unit had a rotating plate to attain uniform light exposure of the samples and blower to keep the samples cool. We found that we could approximate the failure mechanism if we disabled the blower and the rotating motor, and allowed the samples to exceed $60^{\circ} \mathrm{C}$. Later, we made our own UV light boxes that could be placed in an oven or an environmental chamber so that we could attain higher temperatures and reduce test times. GE discontinued the RS-4 line, due to the reduced demand resulting from the ban on their use for suntanning purposes. We have since switched to another type of mercury vapor lamp, which has less energy in the UV and therefore requires longer exposure.

The mercury vapor lamps are effective in duplicating the particular mechanism that browns EVA, but we received several warnings from test labs and GE about using it for generic UV testing of any construction materials.

\section{Q-Panel}

Our next UV equipment purchase was a Q-Panel unit that uses UVA fluorescent bulbs. This unit does a much better job of approximating the UV spectrum of the sun. It also has a lower energy dosage rate below $300 \mathrm{~nm}$ than the mercury vapor lamps. Unfortunately, it took substantially longer than the mercury vapor lamps to achieve browning of the EVA. Furthermore, results were somewhat confusing, due, we suspect, to the nonuniform heating of the unit.

\section{DSET EMMA}

In search of other irradiance testing methods to test EVA degradation, we launched an experiment at the Desert Sunshine Environmental Test (DSET) Labs outside of Phoenix, Arizona. We placed special samples in one of their EMMA outdoor test systems. This system attains an approximately 5 to $7 \mathrm{X}$ concentration of sunlight through the use of 
mirrors. By providing samples constructed with 2 interconnected half cells, divided by a gap and covered with a clear backskin (as well as the front cover glass), we were able to make cell measurements as well as spectrophotometer measurements on the same samples. Our findings confirmed that construction and materials can delay the onset of "EVA browning" but nothing can prevent it.

\section{DSET EMMAQUA}

We have only recently launched testing that incorporates DSET's water spray with their EMMA test apparatus. So far, we have not observed any differences between the two environments.

\section{Observations:}

\section{Temp/Relative Humidity Observations:}

Almost all the modules (competitors' and our own) that we have exposed to the $85 / 85$ test have degraded substantially in power within 3000 hours. All dry megger readings dropped eventually. Some dropped much earlier than others. Stabilized megger readings ranged from $500 \mathrm{Kohms}$ to 300 megaohms. We have also observed that samples left in the dark at $85^{\circ} \mathrm{C}$ (irrespective of humidity) long enough (1500 to 3000 hours) will brown. We have not observed this browning in chambers at $45^{\circ} \mathrm{C}$. All multi-laminate backskins are subject to delamination in this test, usually within 1000 hours. We have seen cases where single layer substrates delaminate from the encapsulant, but this is not true in all cases.

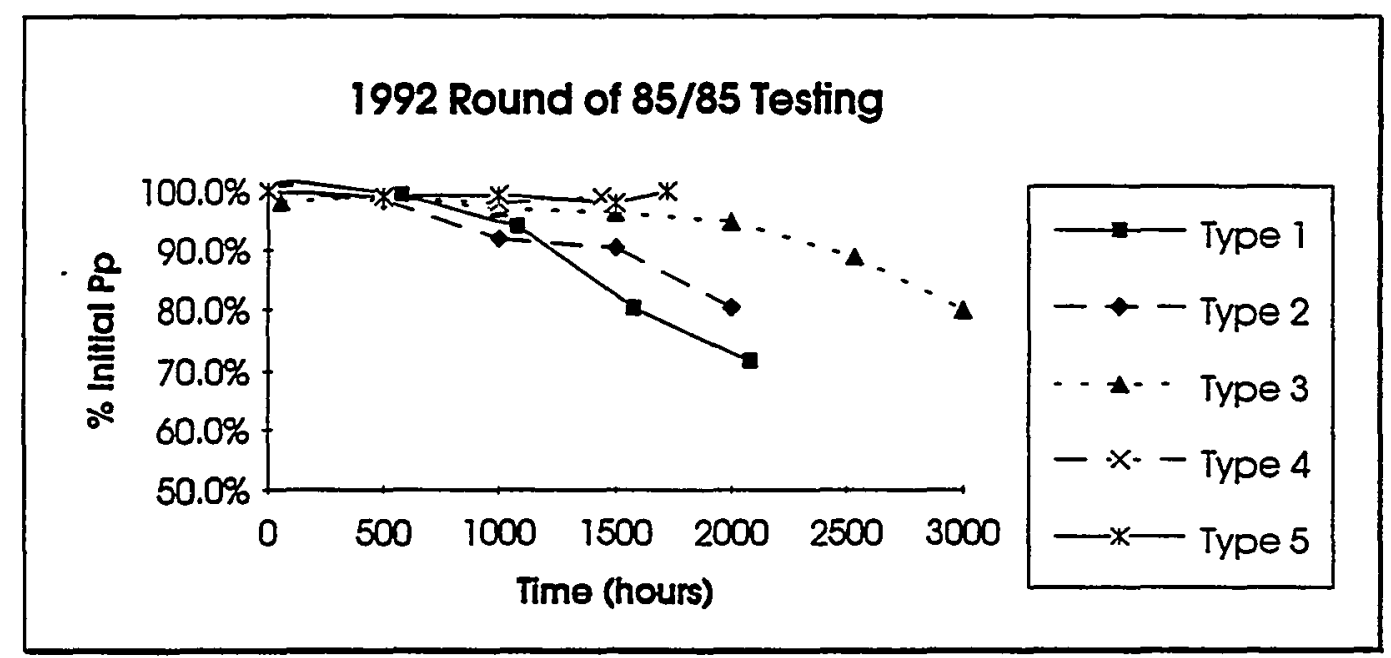




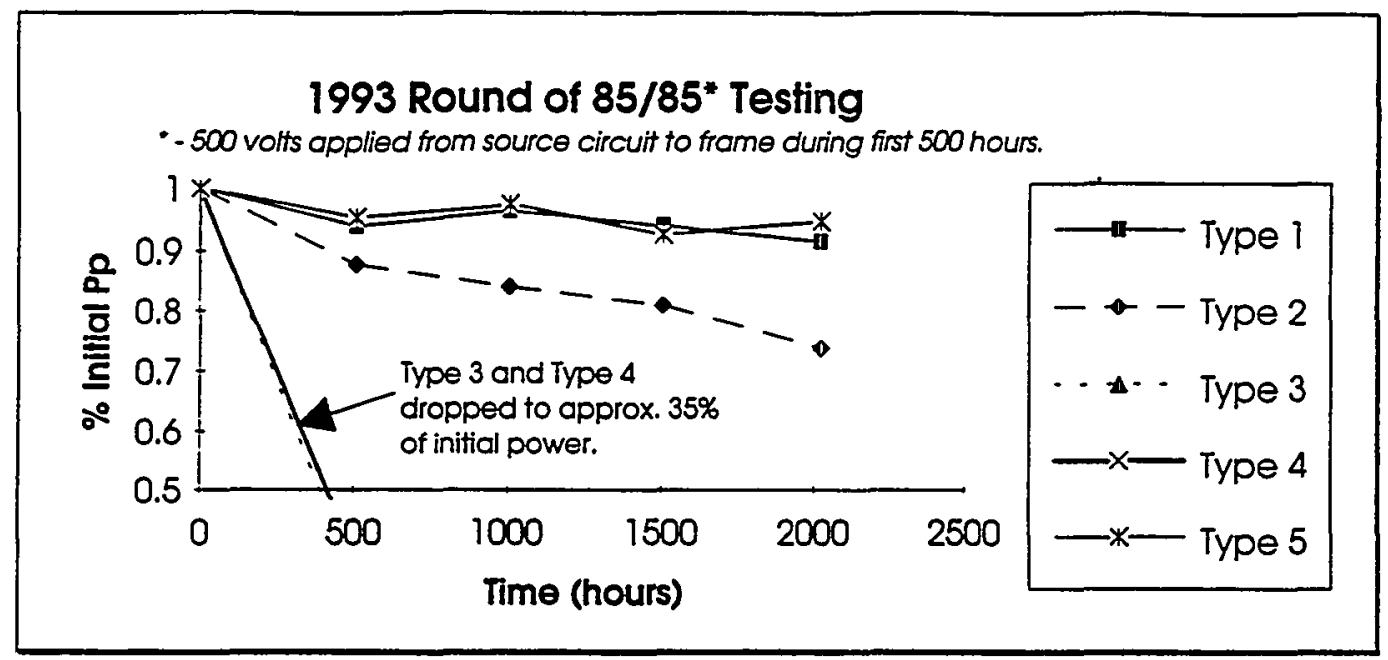

Results were further complicated when the samples were exposed to additional stresses. As stated above, neither forward current through the source circuit nor voltage applied from the source circuit to the frame nor interim thermal cycling appeared to affect our module one way or the other. We have not done much bias testing on competitors but we have found that added voltage testing and interim thermal cycling testing may have had an adverse affect on some of our competitor's product (see 1993 Round of Testing Chart above). Infrared (IR) scans of the failed competitor's modules subsequent to 85/85 with 500 volts indicate that one type may have a problem related to their interconnect system and the other type may have a problem whereby cells become shorted. It is important to note here that limited failure analysis was done on competitor's modules and these mechanisms were not confirmed.

Construction, materials and processes clearly play a large role in the performance in this test, but it is not a straightforward issue. Modules and samples that appear to achieve a "near" hermetic seal, in fact do worse than constructions that are breathable. Modules that look great are, in fact, "dead". Low insulation resistance readings show no correlation to performance. Mobil Solar has devoted significant efforts toward determining the relationships between these variables and $85 / 85$ test results. We believe we understand many of the key impacting variables, but much more work is required.

\section{Irradiance Testing Observations:}

The observations from our own studies support many of NREL's findings. EVA browning always appears to be less around the edges of cells and modules, in addition to areas where bus bars run through the module. This is because acetic acid, generated during the degradation of EVA, escapes first from these areas, and therefore is less likely to make the degradation reaction turn auto catalytic. Experiments strongly indicate that specimens made with non-breathable backskins (foil, glass) will brown somewhat faster than specimens made with breathable (tedlar only) backskins. 
The type of light and the ambient temperature of the test environment plays a significant role in the browning reaction rate. EVA browning does not seem to be dependent on particular wavelengths of the UV range as some other mechanisms are. It is very dependent on the temperature: the higher temperature, the sooner EVA browns.

Our experimentation has also found that the type of EVA and lamination process can affect the time onset of browning. Also, the type of metalization used in the cell or laminated in the EVA can affect the reaction rate. This is evidenced by the brown diffusion pattern around the copper-constantan thermocouples used in the construction of some of our samples.

\section{Approach to Lifetime Predictions:}

While we strive to make our product more resistant to accelerated tests, we also wage a battle on a second front; correlating the test results to operating conditions. We constantly endeavor to answer the question: are the tests applicable to field conditions? This question can actually broken down into two lower level questions: 1)What are the true product operating conditions and 2) How do accelerated conditions correlate to these operating conditions? We approach the answers to these questions by mathematically modeling the environmental conditions and applying those conditions to the models that relate accelerated conditions to field conditions. The process iterates between modeling and confirming the model with additional testing and studies.

\section{Operating Conditions}

We have collected a fair amount of weather data and module temperature data. We do not have actual module relative humidity data. Instead, we used JPL's approach to calculating module relative humidity. The figure below is an example of the module operating condition at the Florida Solar Energy Center in Florida.

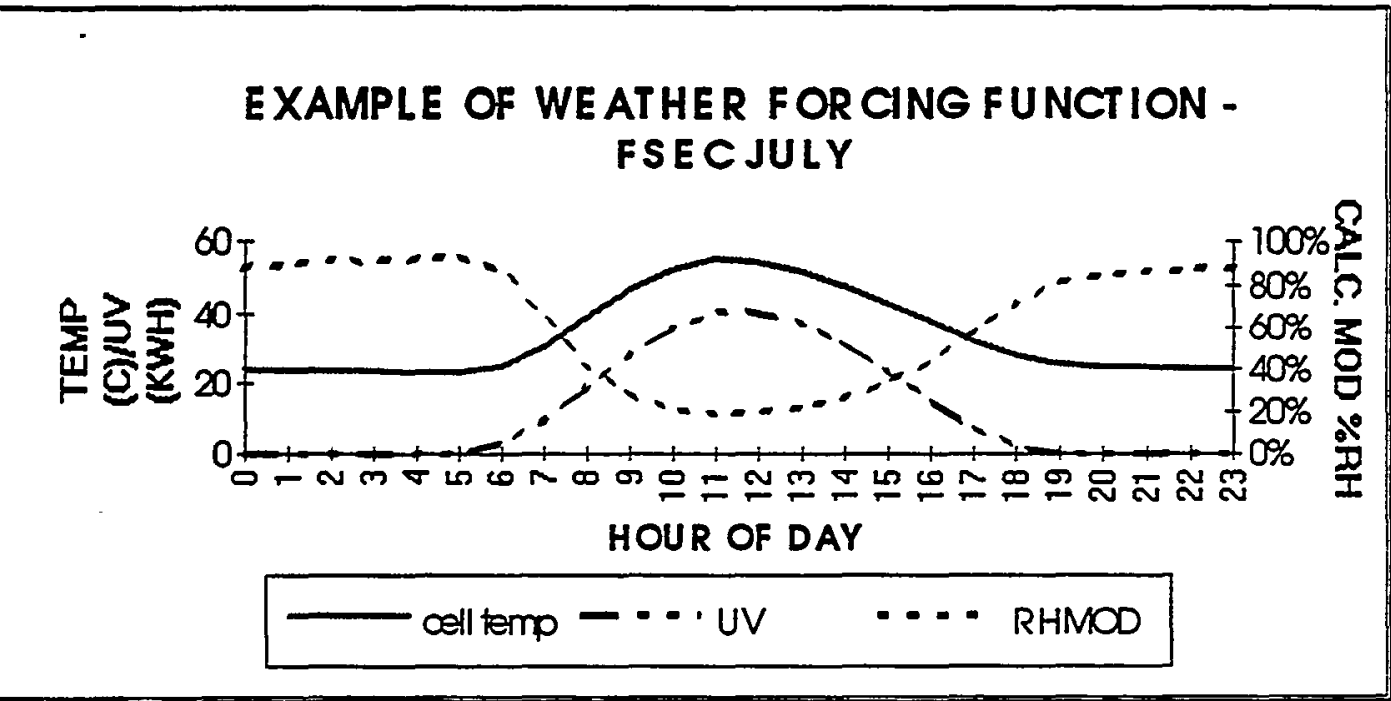


In the case of temperature and humidity, the information is averaged and aggregated in groups of $10^{\circ} \mathrm{C}$ and $10 \% \mathrm{RH}$. We can then employ the temperature/RH models based on our test findings and predict module lifetimes for various conditions throughout the country.

\section{Temp/RH models}

As previously mentioned, the $85 / 85$ test for PV is not founded on observations in the field, rather it comes from other industries. Whether or not it can really be used as a method to forecast PV lifetime is still unknown. JPL, based on its tests and analyses, estimates that in calculating temp/RH acceleration factors, a 1 degree rise in temperature will result in the same acceleration as a $1 \%$ rise in RH. Using their model and the doubling of reaction rate for every $10^{\circ} \mathrm{C}$ rule of thumb, failure mechanisms in a constant environment of $40^{\circ} \mathrm{C} / 60 \% \mathrm{RH}$ will occur 128 times slower than in an $85 / 85$ environment. In other words, 20 years of $40 / 60$ is equal to 1360 hours in $85 / 85$.

Our concerns about JPL's model led us to conduct "matrix tests". The graph below gives some indication of how module performances degraded under different environments. The precise details of this testing are currently confidential and cannot be presented in this paper. Furthermore, we are still in the midst of this testing, so the results are not complete.

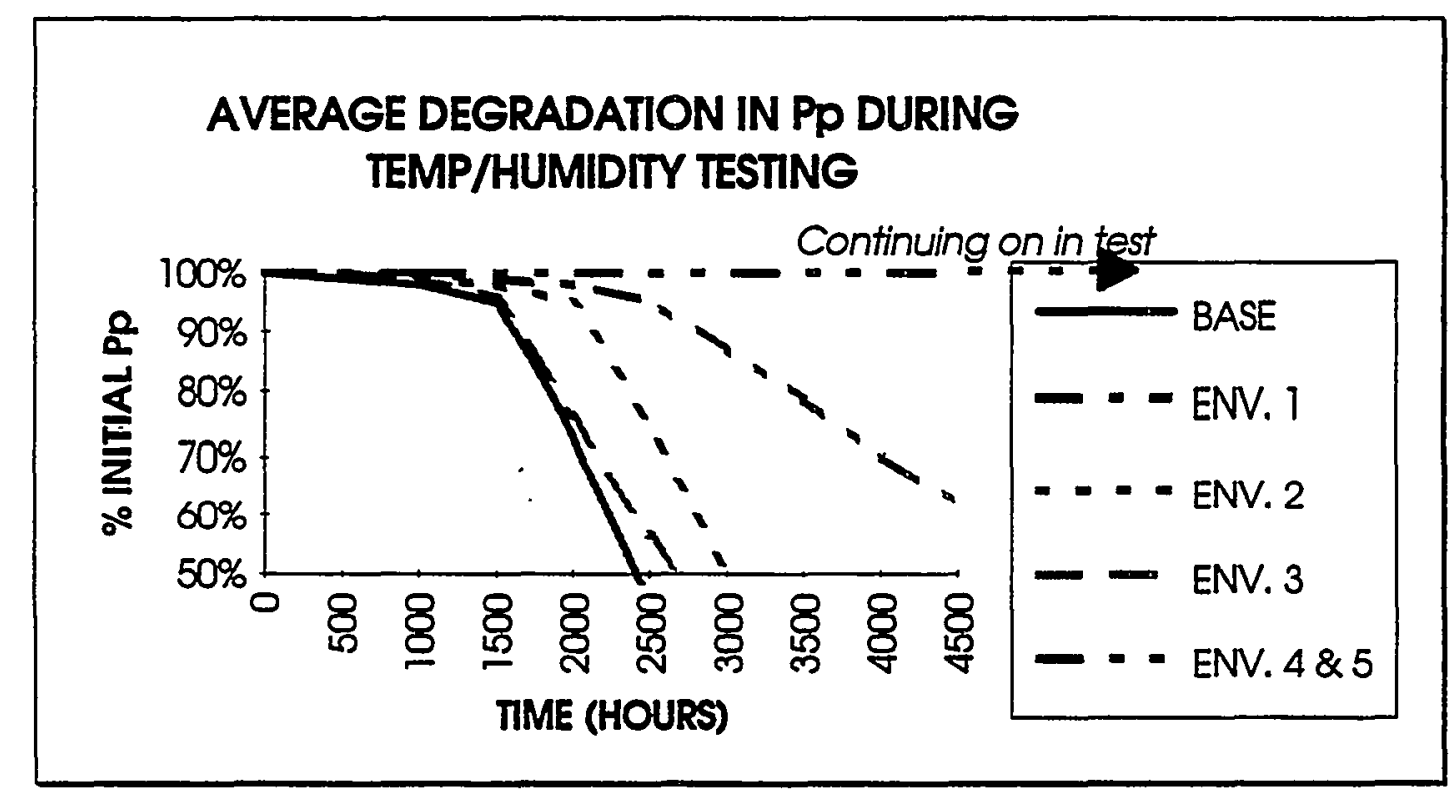

We did learn that our test results, to date, did not agree with the JPL model. It appears that JPL's model places too heavy a weight on the relative humidity factor for the product and environments that we used in our test. This discrepancy prompted us to look at other temperature/RH models. We studied six models for various electrical components and configurations and found one that seems to fit reasonably well to the data collected so far 
(see figure below). We must complete our testing to determine if this model holds true for all cases.

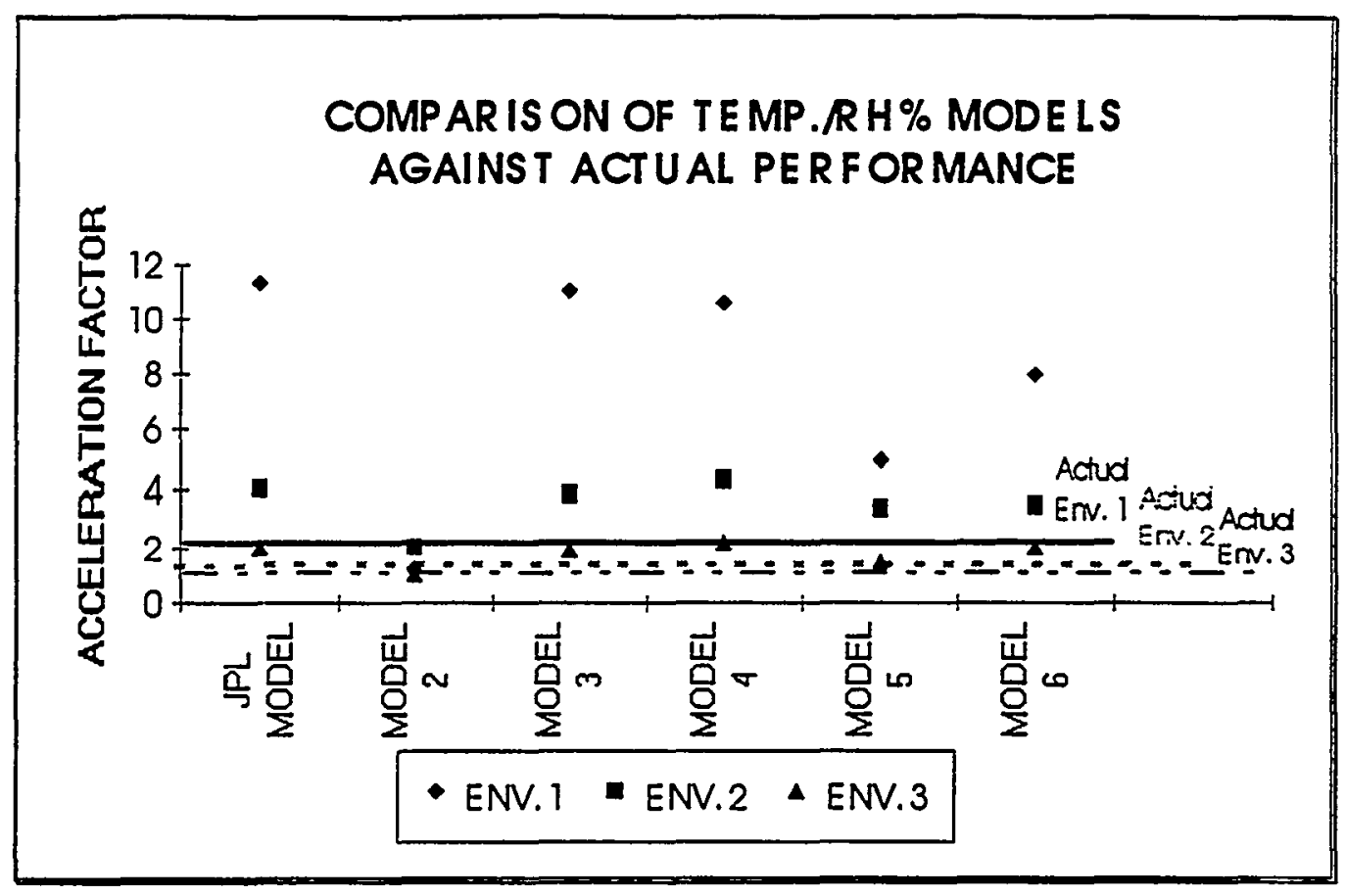

\section{Irradiance model}

Unlike the $85 / 85$ test, our accelerated irradiance and UV testing was prompted by observations in the field. EVA browning appeared to visually manifest itself within 4 to 6 years in southern United States sites. We began measuring significant power degradation (on the order of 5\%) in about 7 to 10 years. Our mercury vapor lamp testing in an oven at $90^{\circ} \mathrm{C}$ dramatically accelerated the process. Given that the spectrum of the mercury vapor lamp was so different from that of the sun, no attempt was made to correlate the results. Although the acceleration rate is much lower, testing in the DSET EMMA system appeared to correlate reasonably well with the actual product observations. As shown below, it appears that a line provides an adequate fit for the degradation, at least down to $10 \%$ power loss. 


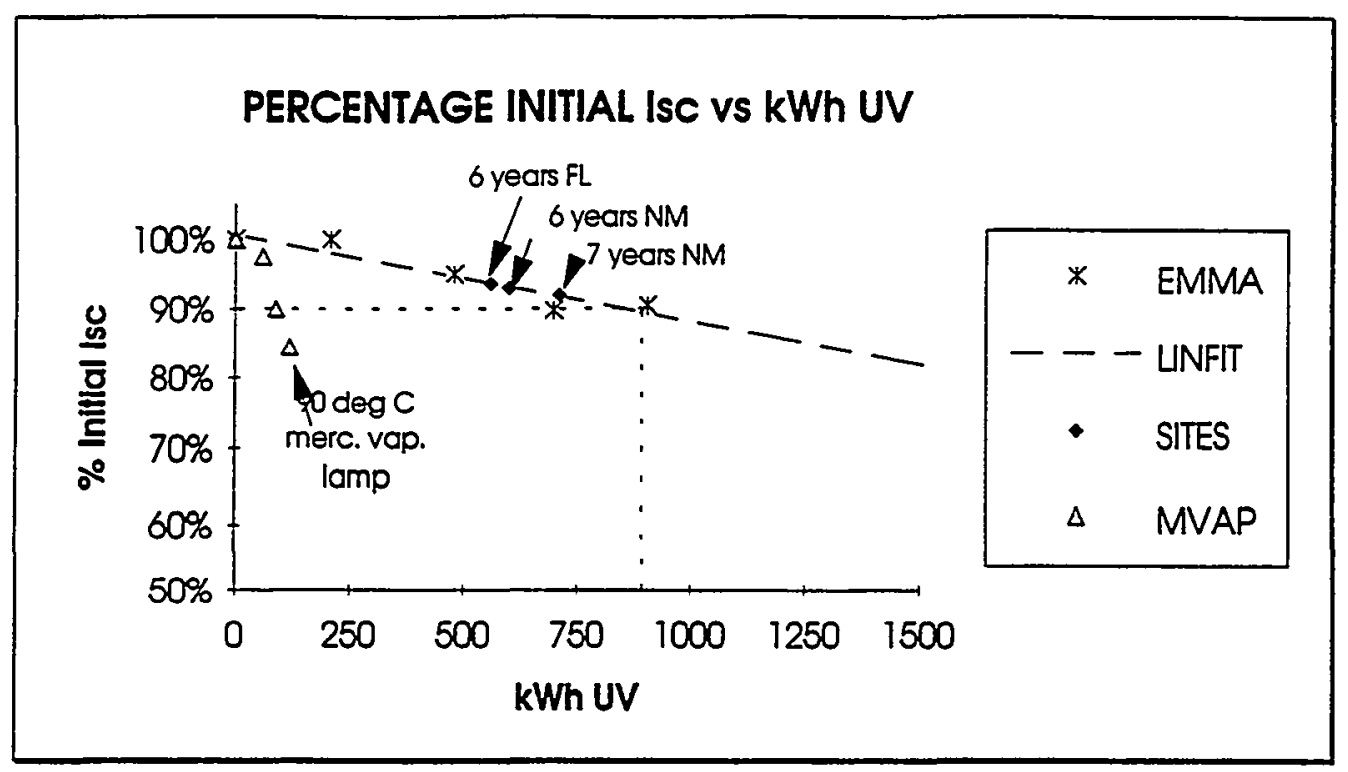

\section{Combining Models}

It is clear from our results that the southern United States is the area most likely to experience early module wearout. If the failure mechanisms associated with temperature/RH did not interact or depend on those associated with irradiance, it would be reasonable to simply add the results of the two models to obtain a lifetime forecast for this area. It is likely that there are interactions between failure mechanisms, particularly with respect to EVA. This "synergism" of environmental effects makes the simple addition of models either optimistic or pessimistic. The former is more probable.

\section{Follow-up Work:}

Aside from completing existing tests/analyses and continuing routine testing/analyses, our efforts will focus on eliminating or reducing uncertainties. Such uncertainties include: 1) the synergisms and interactions between environments and failure mechanisms, 2) the error between calculated module RH and actual module RH and 3) the dependency of the test results to various manufacturing steps.

Our basic approach to such uncertainties has always been to target the failure mechanism that causes degradation. By understanding the failure mechanisms at hand, a number of these uncertainties disappear. We continuing to employ a vast number of techniques to determine failure mechanisms, including FTIR, spectroscopy and IR imaging. In the absence of understanding the mechanisms, we strive to combine environments and improve monitoring. We are currently conducting tests in our new weatherometer that can simultaneously provide high temperature, high humidity and xenon lamp irradiance as well as thermal cycling on specimens. We are also endeavoring to better comprehend the module RH through the use of an RH monitoring device that can be laminated into the module. 
Of course all this work would be for naught, if it were not communicated to the designers and manufacturers of the product. Members from our group are intimately involved with the design and development of products, ensuring that our customers realize the benefits of these studies.

\section{Conclusions:}

The world of accelerated testing and forecasting product lifetimes is a world of assumptions, hypotheses and inaccuracy. It perhaps requires fewer assumptions and is more accurate than the world of market and financial forecasting, although that serves as little solace. Accelerated testing, if understood, does help to weed out weak designs and materials, while significantly reducing time-to-market and improving customer satisfaction and safety. Product lifetime forecasting serves to maintain the thread from test to actual operating conditions. Behind both of these activities must be an understanding of underlying failure mechanisms.

Although life testing and prediction may seem like a never ending, inconclusive activity, information that flows from it is an essential element to effective and enduring product improvements. Some of the primary conclusions that we have drawn from our program for this paper are:

EVA browns in the dark at $85^{\circ} \mathrm{C}$

There is a wide variation in $85 / 85$ performance between competitors

Irradiance test observations to date support NREL's EVA hypotheses

JPL Temp/RH model does not correlate with our temperature/RH testing

The EMMA test system provides reasonable test results to actual field operations.

\section{Acknowledgments:}

The following people should be recognized for their significant contributions to work supporting this paper: Dr. J. Amick, J. Bernier, Dr. N. Delaney, R. Gonsiorawski, J. Lally, and A. Scannell as well as many others from the Mobil Solar community.

\section{References:}

Ross, R. G., "Reliability of Photovoltaic Modules", SPIE Vol. 706 Photovoltaics for Commercial Solar Power Applications, 1986. 
Otth, D., Ross R.G., "Assessing Photovoltaic Module Degradation and Lifetime from Long Term Environmental Tests", Proceedings from 29th Annual Conference of the Institute of Environmental Sciences, 1983. 


\title{
Performance and Stress Testing of CdTe PV Modules
}

호

\author{
Solar Cells, Inc.
}

\author{
Dan W. Sandwisch \\ Manager of Manufacturing
}




\section{Performance and Stress Testing of CdTe PV Modules}

Performance

- Efficiency

- Manufacturing

- Field exposure

Stress Testing

- IQT failure analysis

- Next steps 


\section{Best Demonstrated Efficiencies}

NREL

Efficiencies

Max Power

Vmax

ธิ Imax

Voc

Isc

Aperture Area

Date
$6.9 \%$

$47.5 \mathrm{~W}$

$65.4 \mathrm{~V}$

$726 \mathrm{~mA}$

$90.7 \mathrm{~V}$

$900 \mathrm{~mA}$

$6844 \mathrm{~cm}^{2}$

$1 / 18 / 93$
$\mathrm{SCl}$

$8.2 \%$

$56.0 \mathrm{~W}$

$72.3 \mathrm{~V}$

$774 \mathrm{~mA}$

$94.5 \mathrm{~V}$

$879 \mathrm{~mA}$

$6844 \mathrm{~cm}^{2}$

8/12/93 
Total Area Efficiency vs. Number of Modules Produced averaged in groups of 20

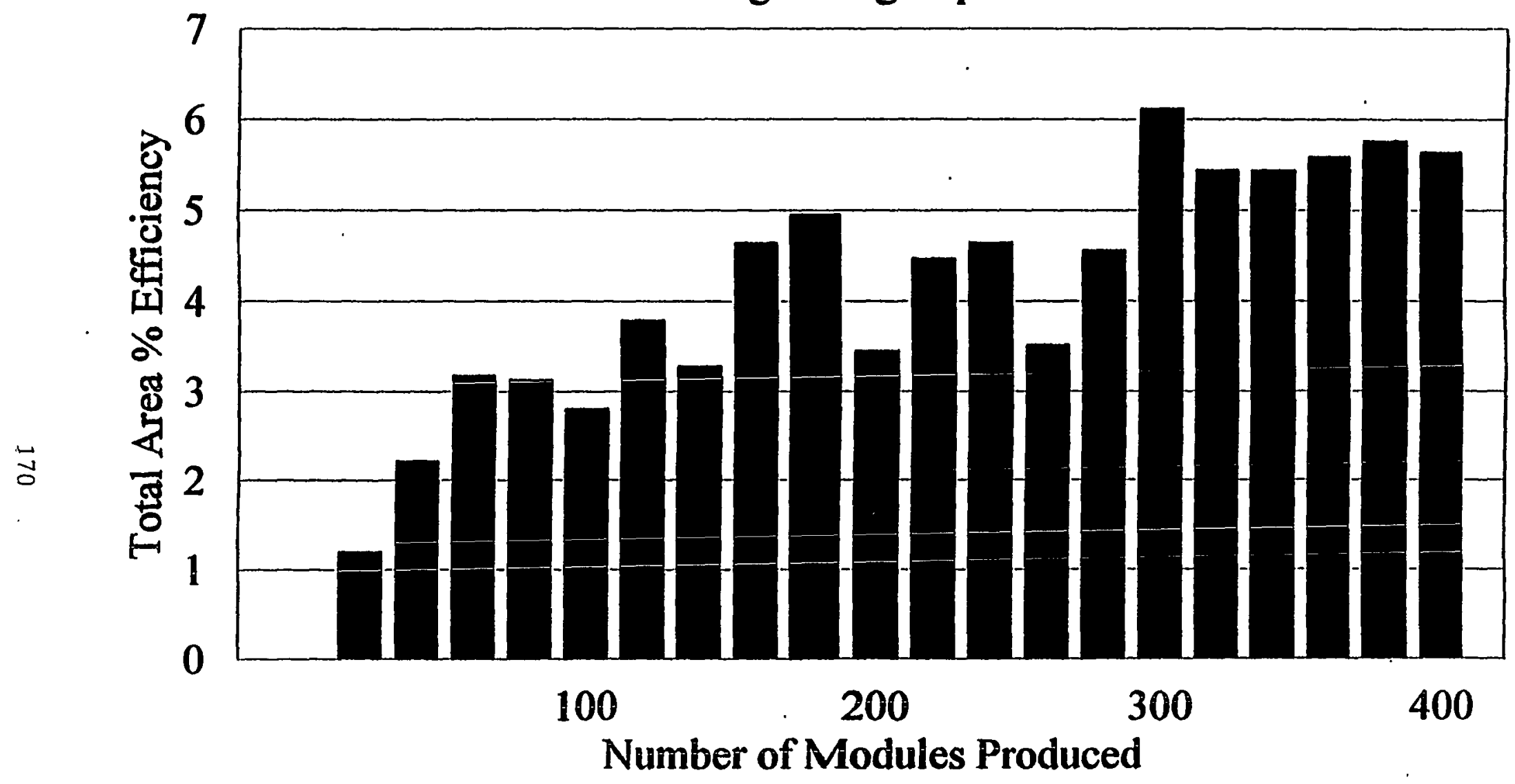




\section{Manufacturing Variability}

Power Distribution

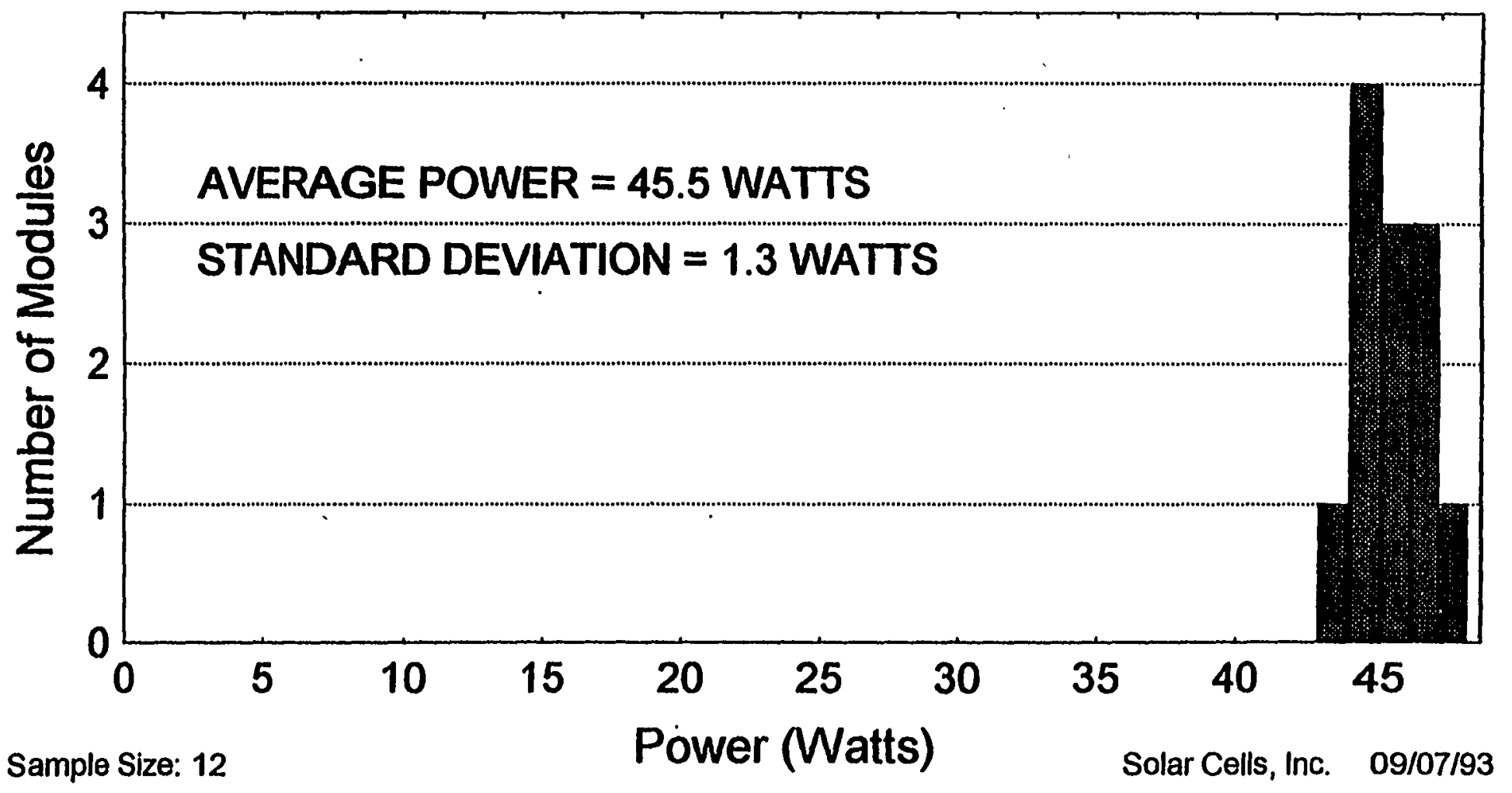




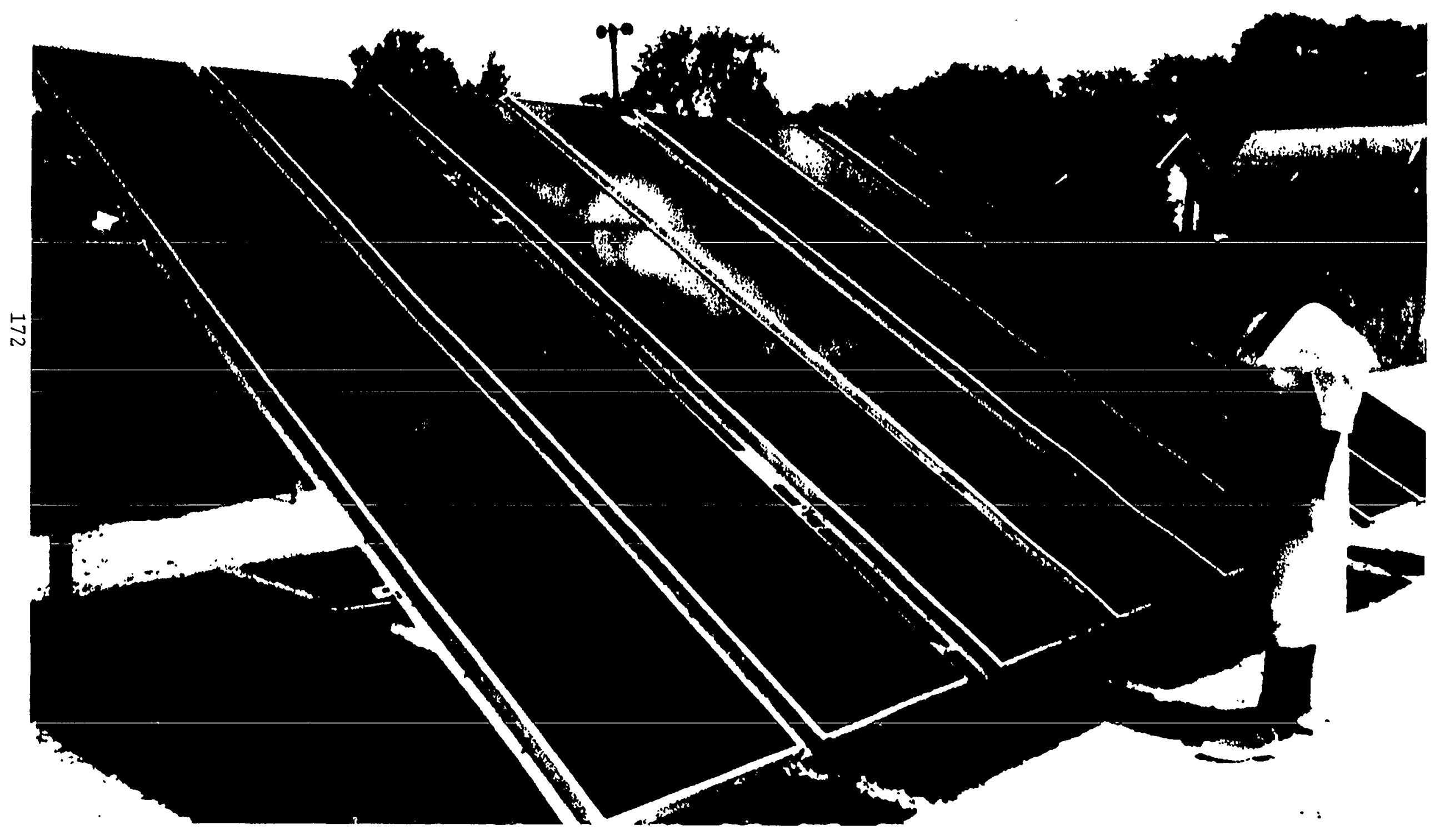




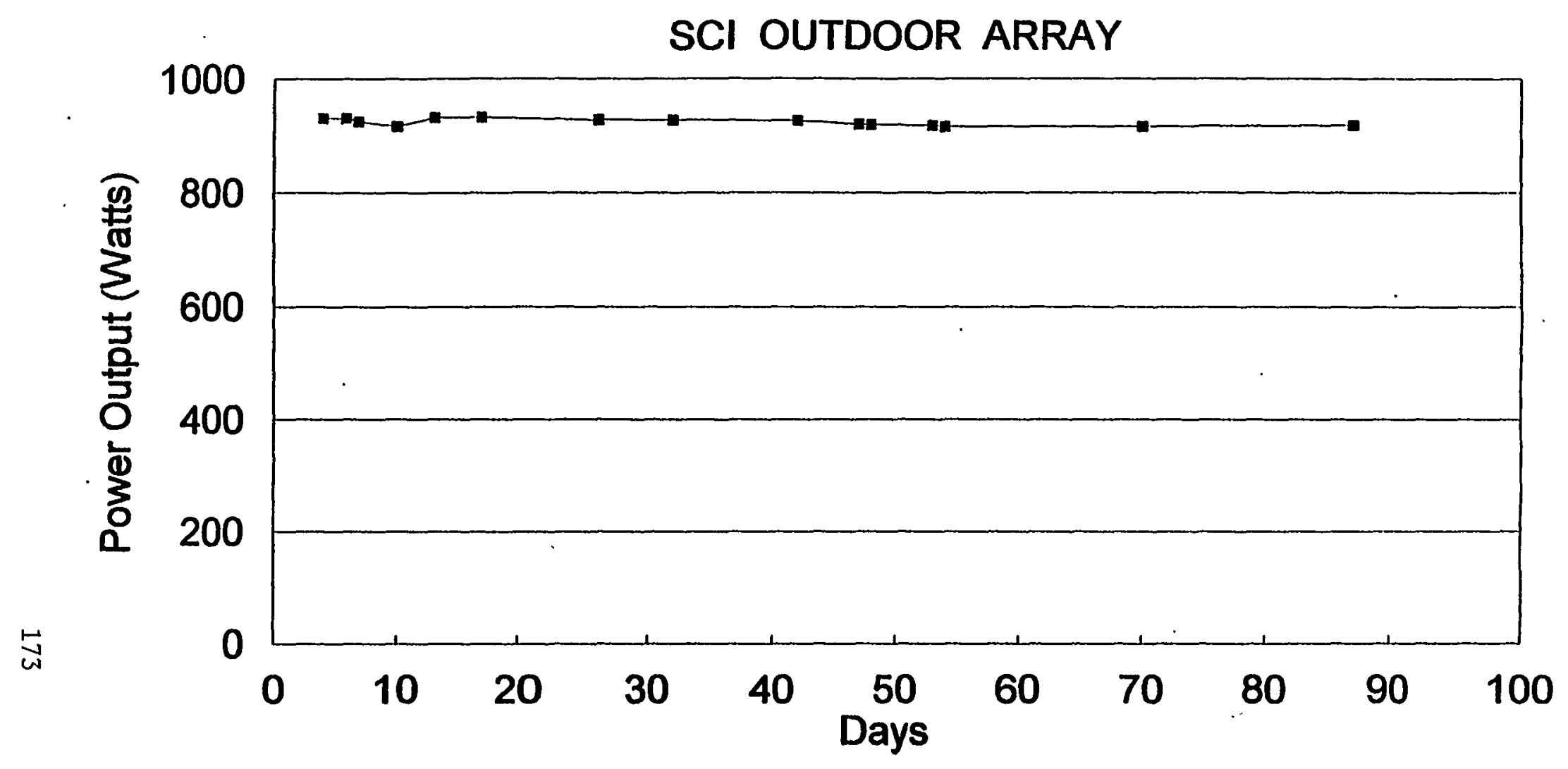

\begin{tabular}{|lc|}
\hline DAYS OF EXPOSURE: & 87 \\
INITIAL OUTPUT: & 931 WATTS \\
CURRENT OUTPUT: & 918 WATTS \\
PERCENT CHANGE: & $-1.4 \%$ \\
\hline
\end{tabular}

- No Temperature Correction

- No Spectral Correction 


\section{Stress Testing}

\section{IQT Failure Analysis \\ - Failure mode identification \\ - Manufacturing implications}

Next Steps

- Accelerated testing

- Field exposure 


\section{CdTe PV Module Testing}

Percent Change vs. Test

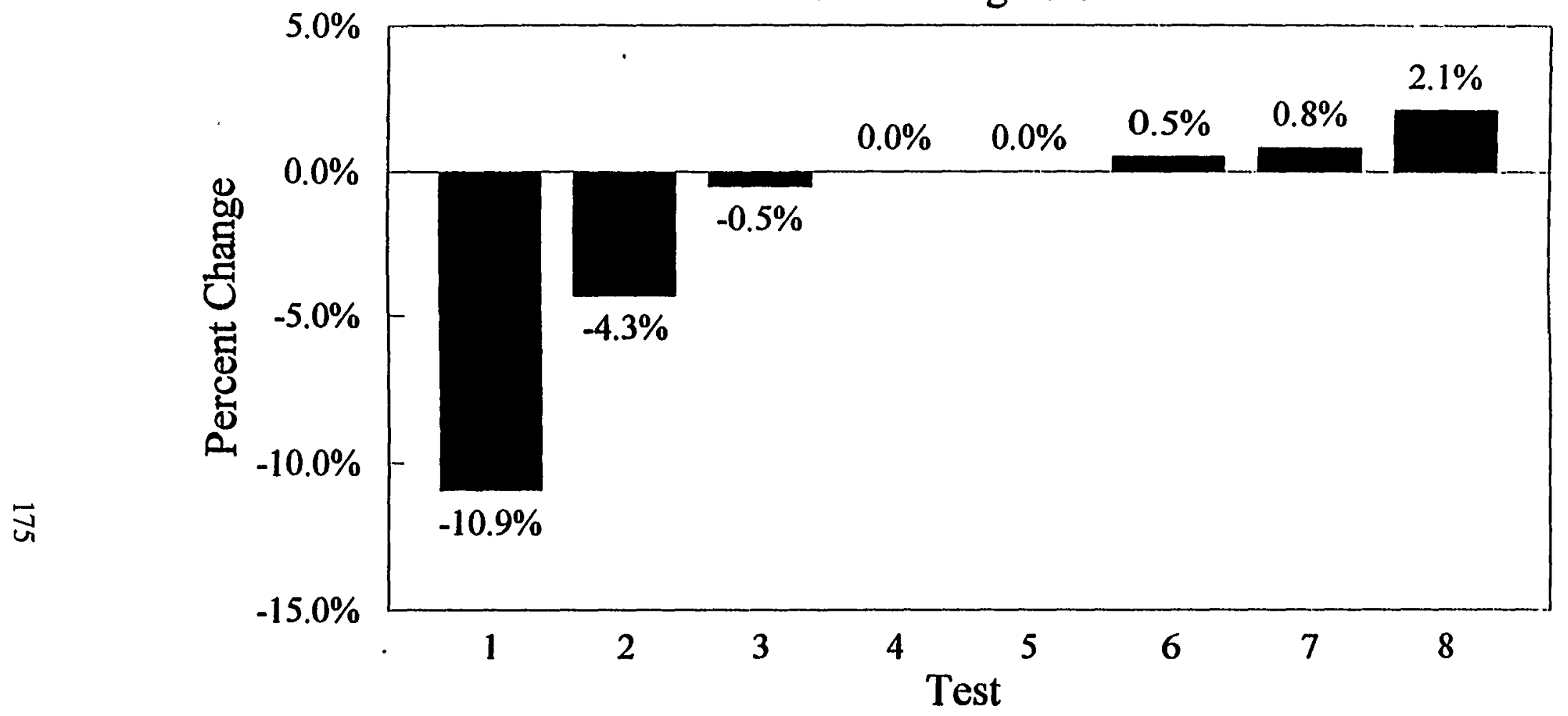

1--Humidity Freeze

2--Hail Impact

3--Wet Insulation Resistance

4--150 thermal Cycles
5--Electrical Isolation

6--50 Thermal Cycles

7--Hot-Spot Endurance

8--Mechanical Loading

Solar Cells, Inc.

09/07/93 
SCI CELL AND MODULE STRUCTURE

(FILM THICKNESS AND LASER SCRIBE DETAIL NOT TO SCALE)

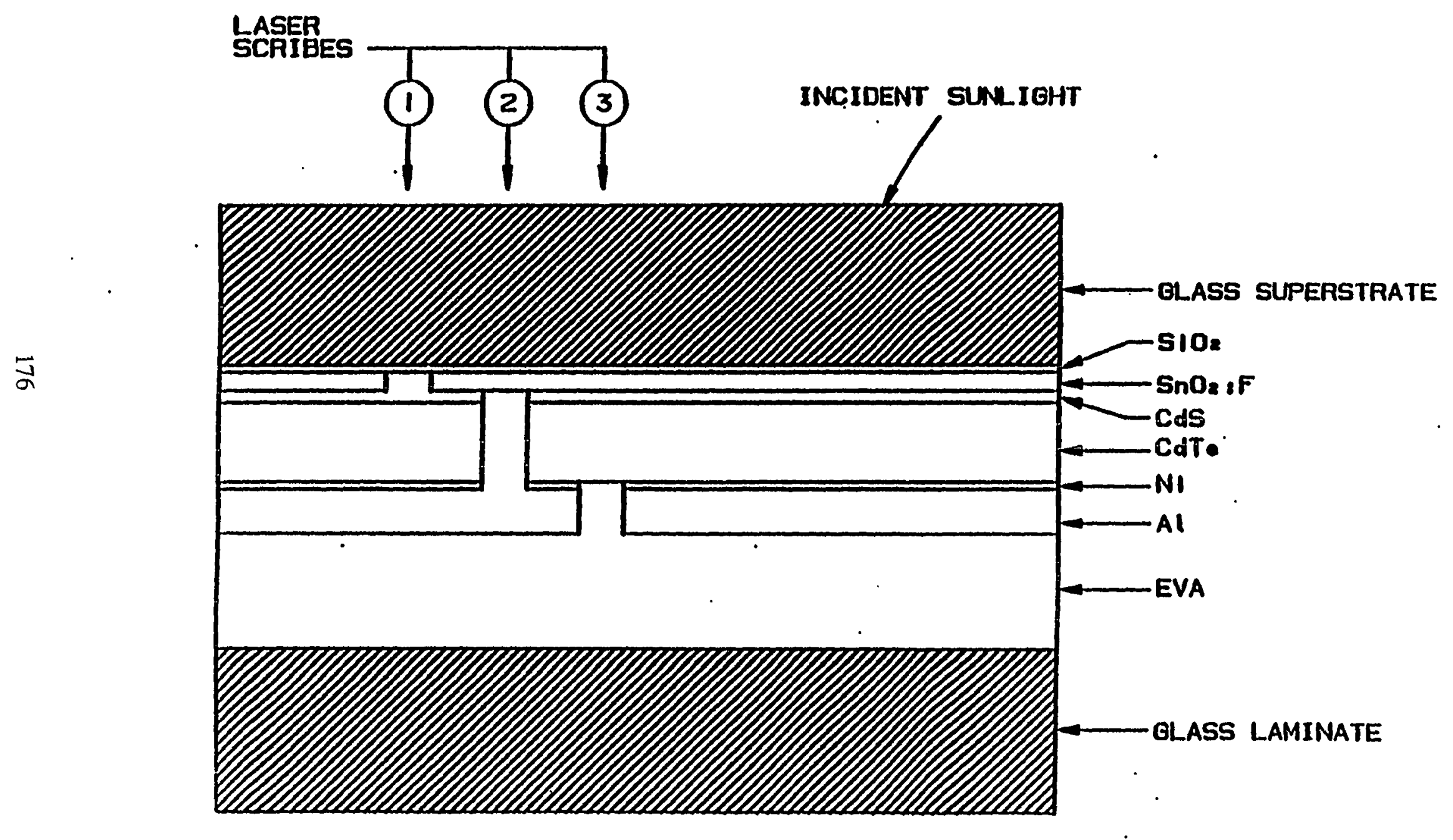




\section{Humidity-Freeze Modes of Failure}

- Internal "fingering"

- Edge delamination 
Superstrate Flatness Profile
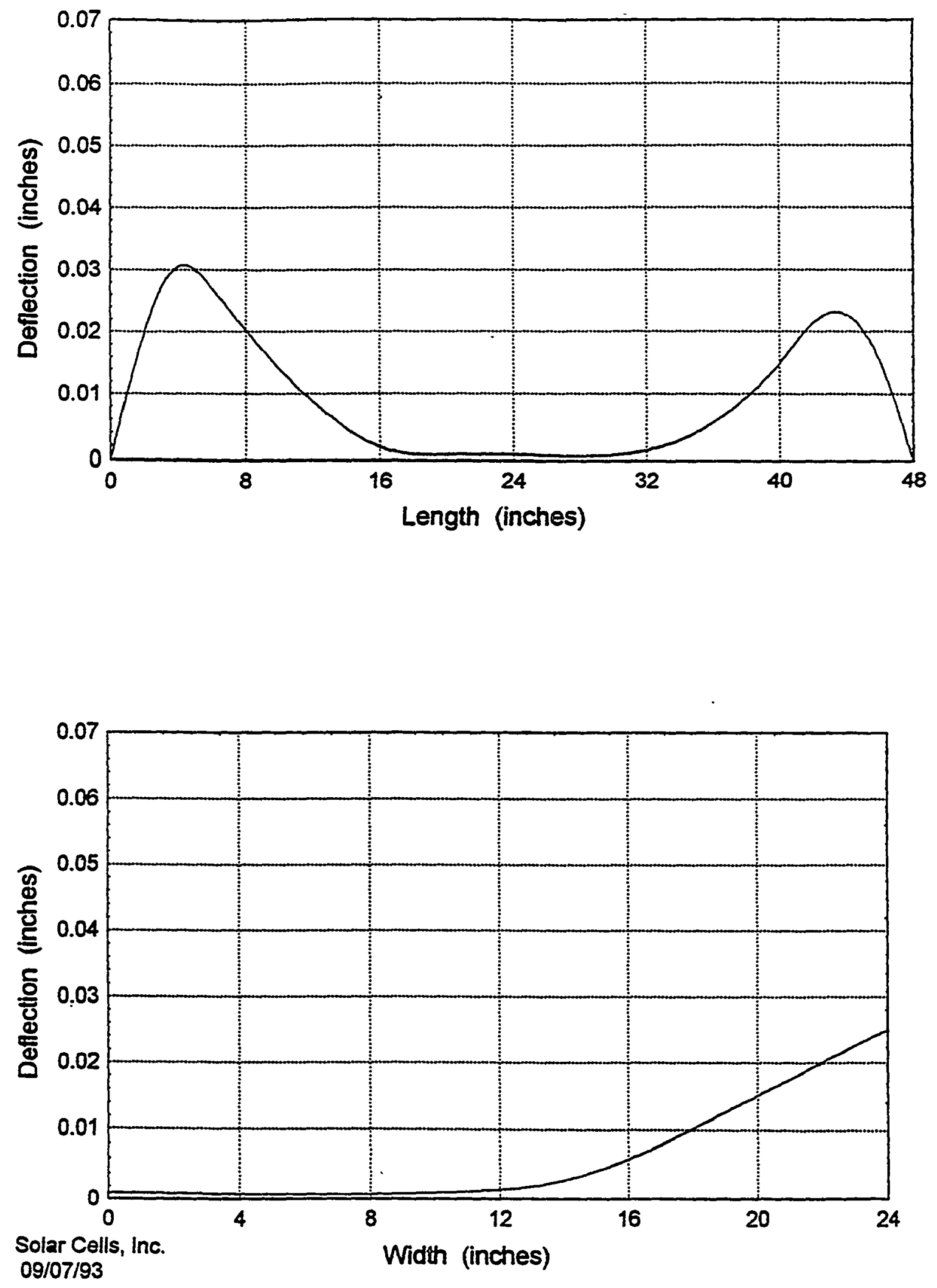


\section{Cover Flatness Profile}
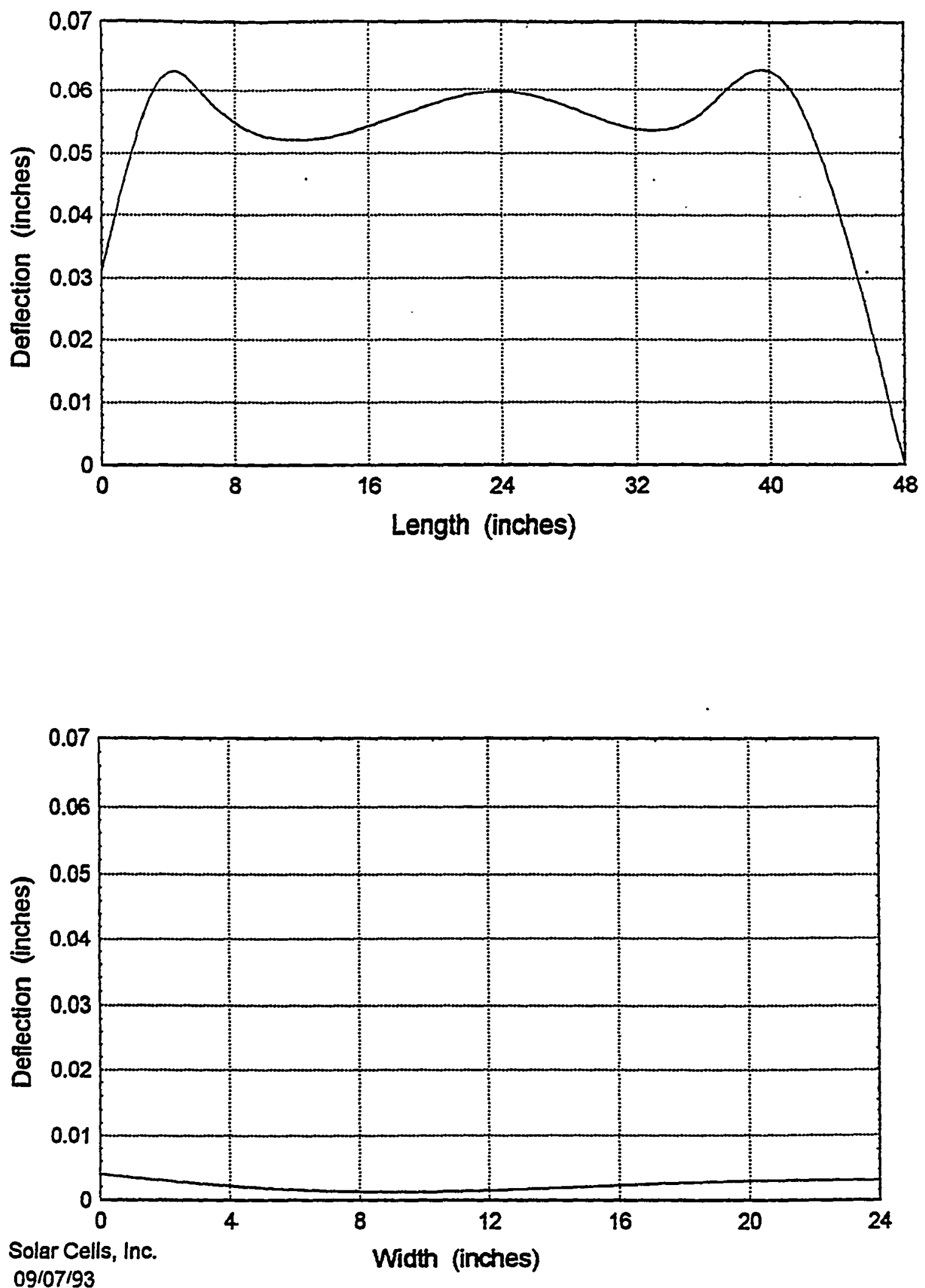


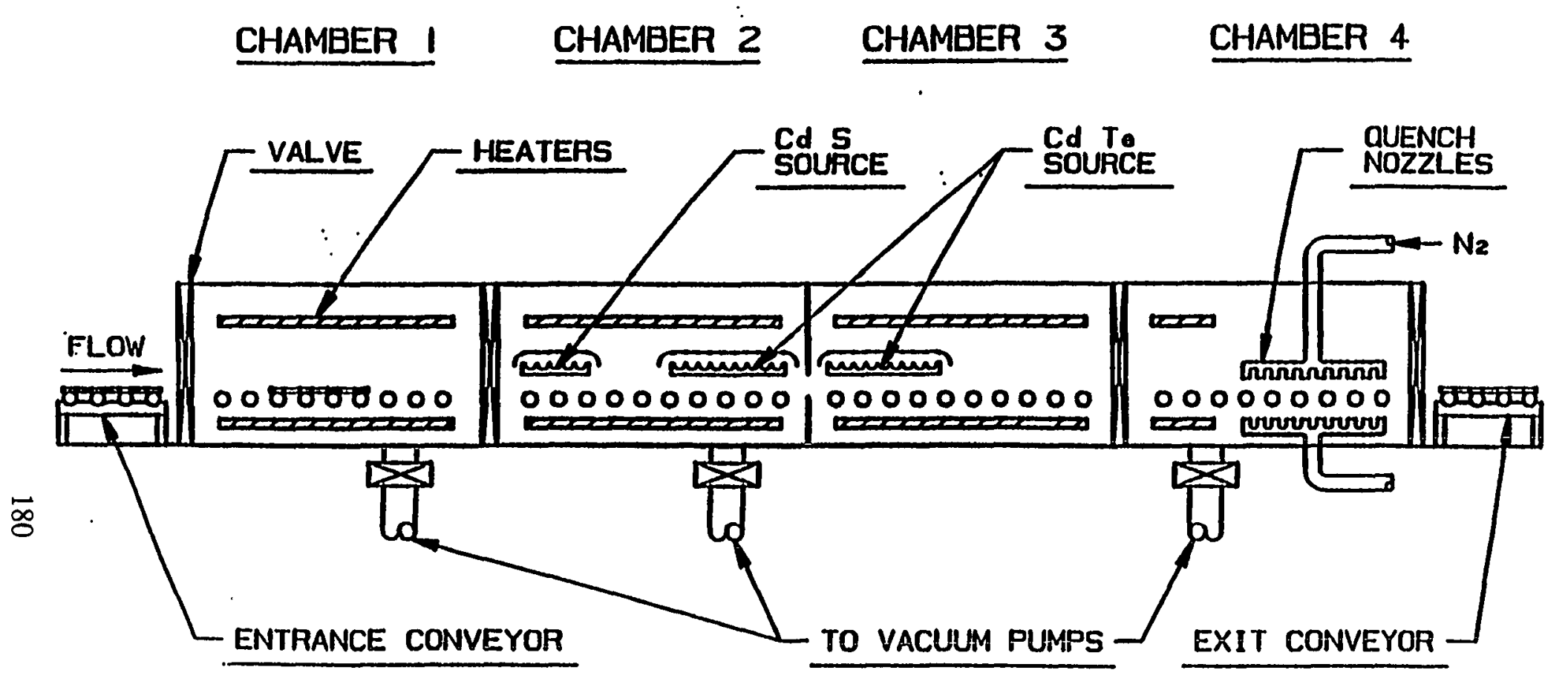




\section{Humidity-Freeze Failure Analysis}

Maximum Slope of Superstrate vs. Cycles

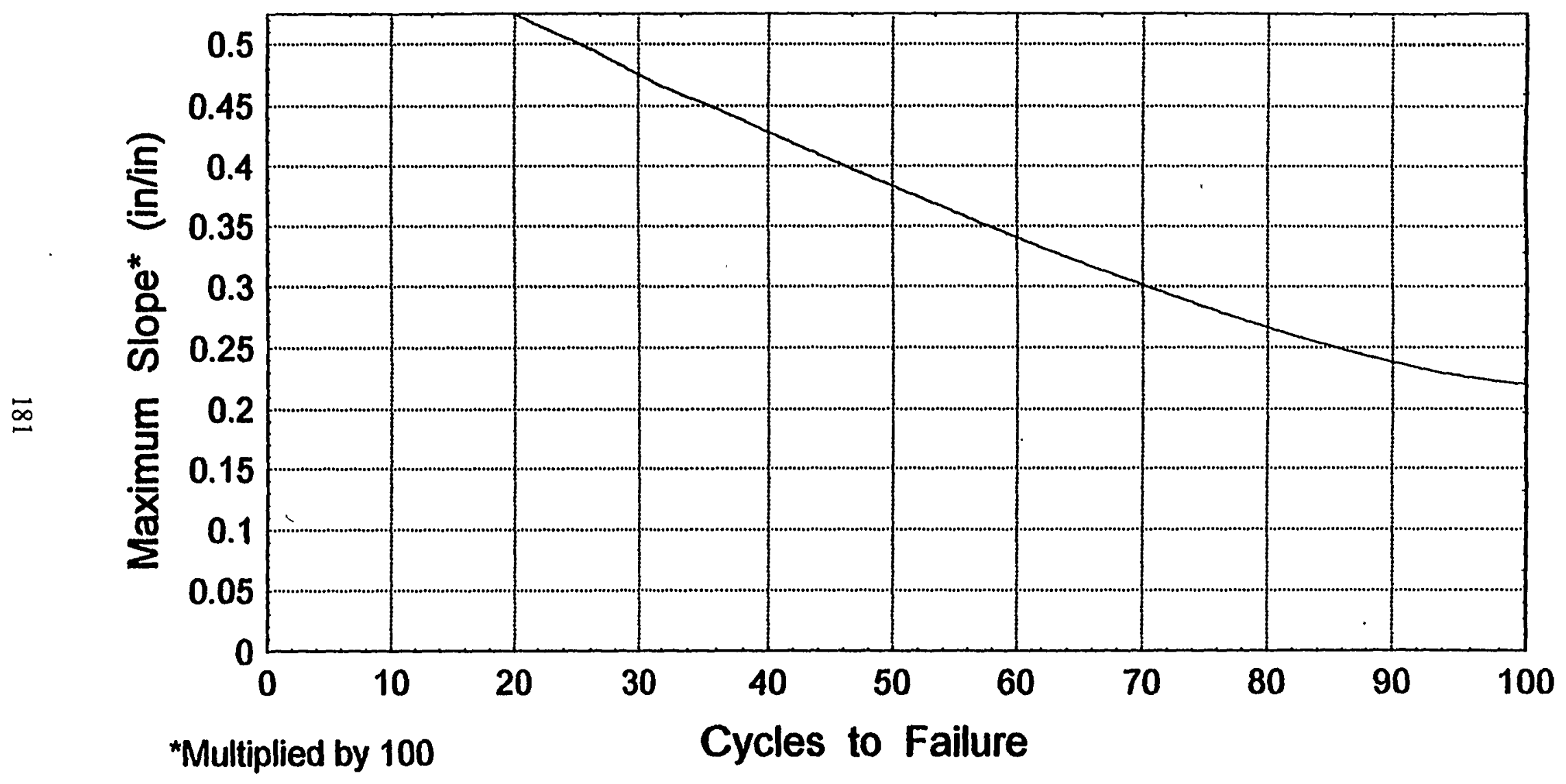




\section{Manufacturing Implications}

- Sampling on-line for flatness of superstrates and cover sheets

- Quality control indicator based on severity of glass curvature 


\section{Next Steps}

- Continue IQT Evaluations

- Accelerated Tests

- Bias conditions

- Ambient conditions

- Insolation levels

- Field Exposure

- SCl: 1-4kW

- NREL: 1kW

- Toledo Edison: 100kW 


\section{Investigation of Lamination Induced Metastability in CIS-Based Modules}

Siemens Solar Industries

Camarillo, CA 


\section{CIS-Based modules temporarily decrease power after lamination.}

The largest changes is in the FF due to an increasing slope at the open circuit voltage point.

The Voc change is typically 1 to $5 \%$.

The Jsc change is typically 0 to $2 \%$.

A typical module will lose 15 to $25 \%$ of its Pmax during lamination. The module will then recover in one to four weeks to within $5 \%$ of its initial power. 


\section{Typical lamination with "green" float glass}

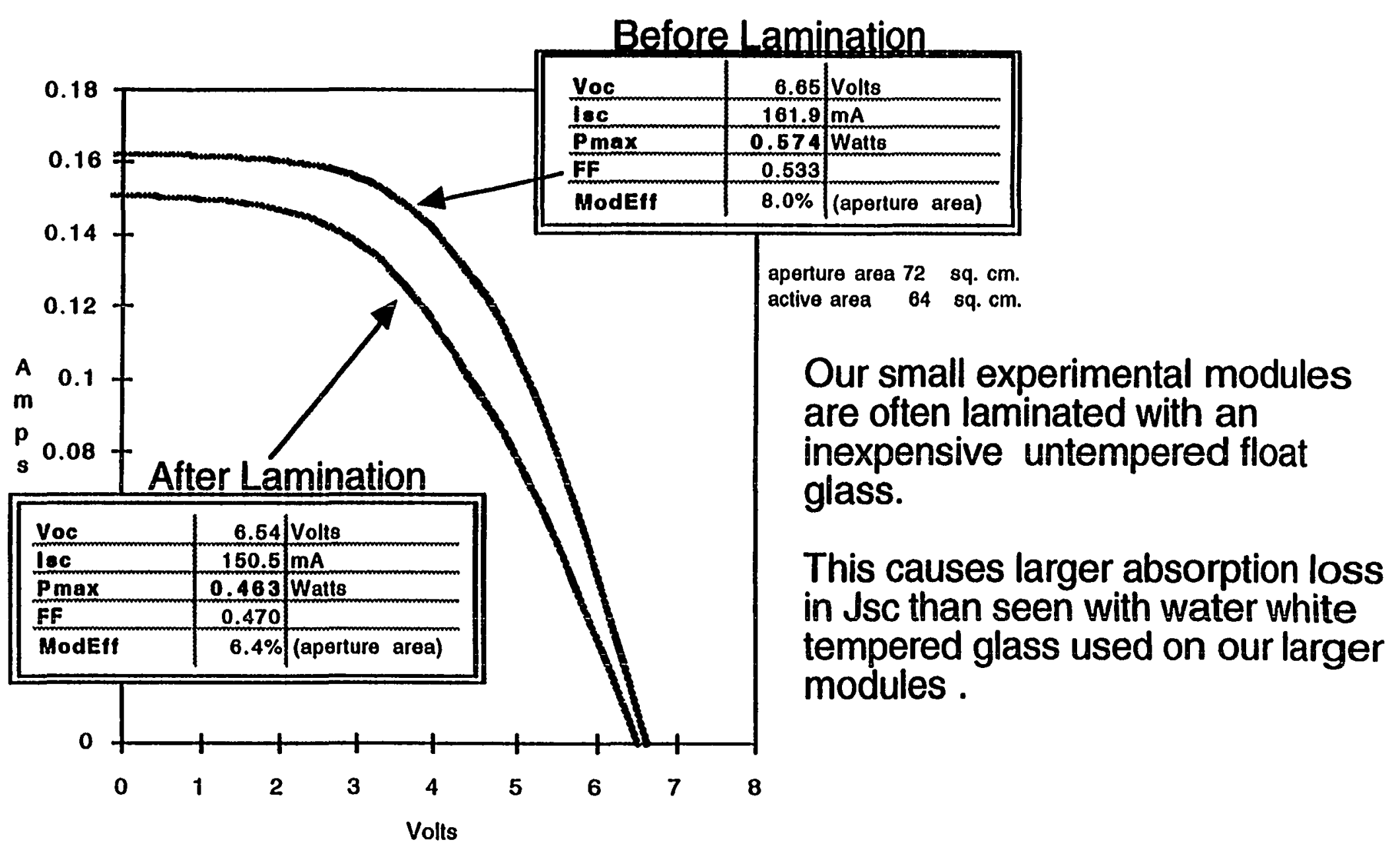



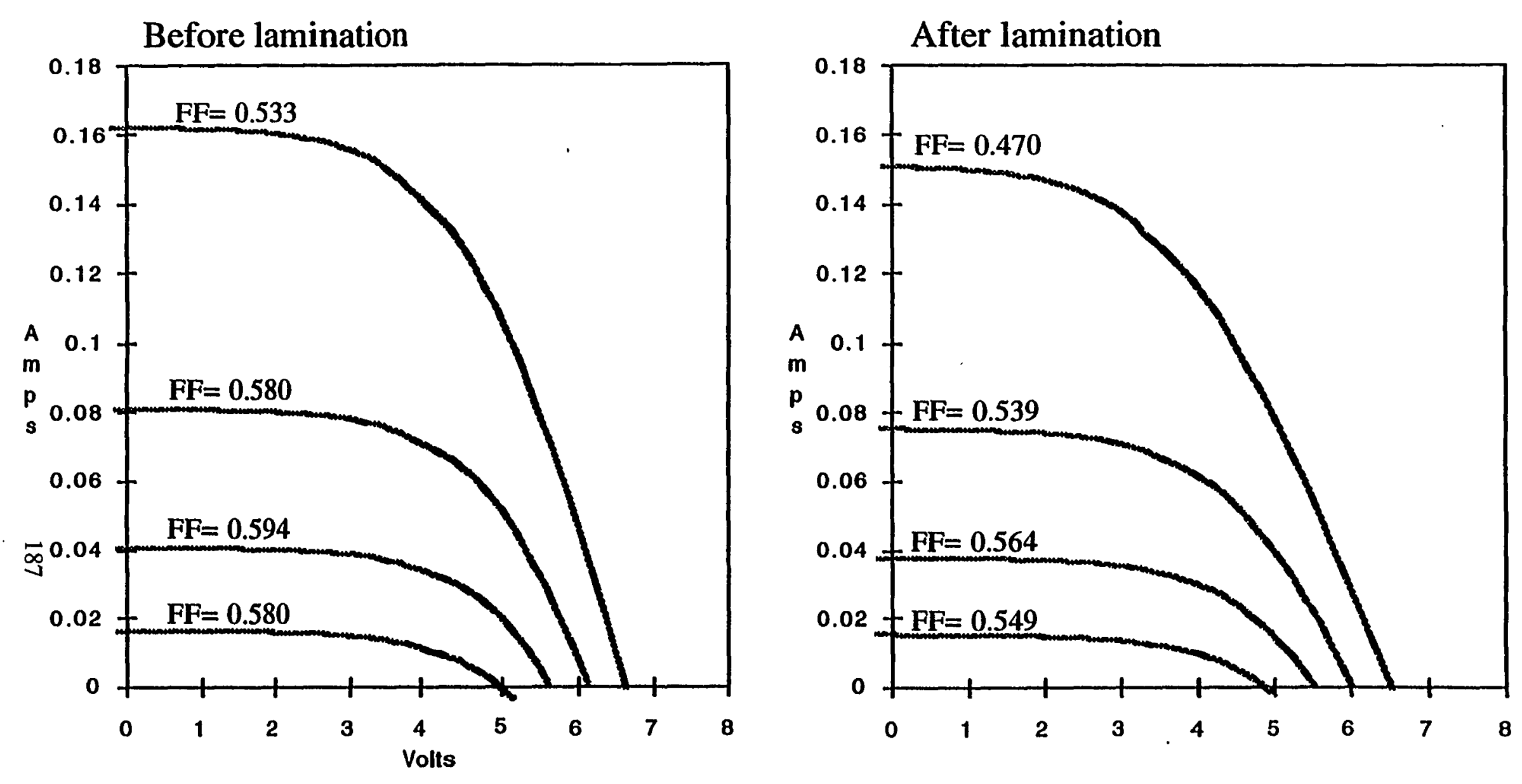

By measuring the module I-V characteristics as a function of light intensity the change in the fill factor is found to be due to an increase in the total series resistance. In this module the resistance increased $57 \%$. 


\section{Tests were made to determine what component of the module and what part of the lamination step cause the change.}

The lamination step includes:

Heat : $\quad 140^{\circ} \mathrm{C}$ for 30 to 40 minutes

Pressure : Vacuum and pressure to withdraw the air as the circuit, EVA and cover glass are pressed into a sandwich.

Chemicals : The EVA may release some agent harmful to the $\mathrm{ZnO}$ during the lamination and cure. 


\section{Test cells were put into heat and heat/pressure environments.}
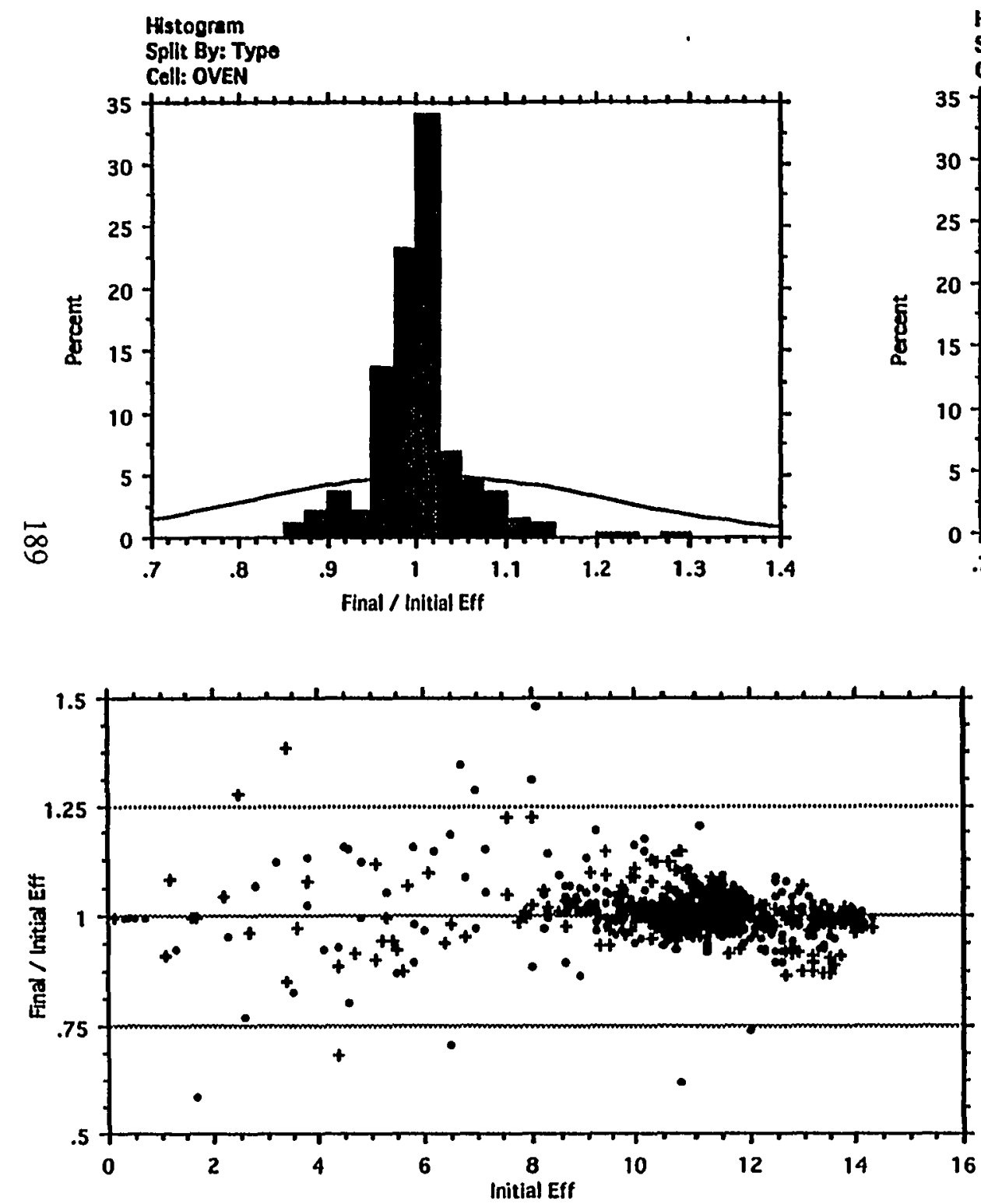

Siemens Solar Industries

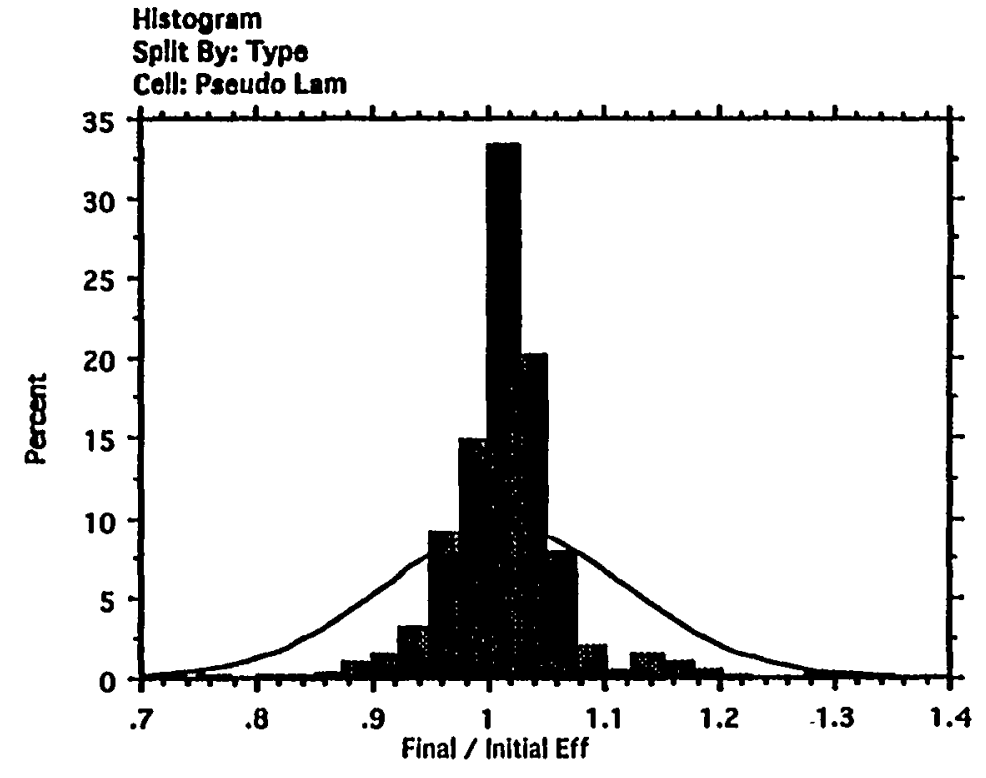

851 cells were split into two groups. The first group was oven annealed at $140^{\circ} \mathrm{C}$ for one hour; a second group received a "pseudo lamination" in which the glass/circuit

/mylar/cover-sheet was subjected to the lamination cycle.

The average efficiency of each group was unchanged by the test. 
The relative stability of this large group of cells to high temperatures is very encouraging.

However investigations of the light soaking effects seen in CIS-based cells showed that improvements due to light soaking quickly decayed at temperatures above $100^{\circ} \mathrm{C}$ in the $\bar{s}$ dark.

A newer group of cells were laminated and shows the variable impact of the lamination process and partial recovery with light soaking. 


\section{Three groups of cells were laminated with EVA/Glass.}
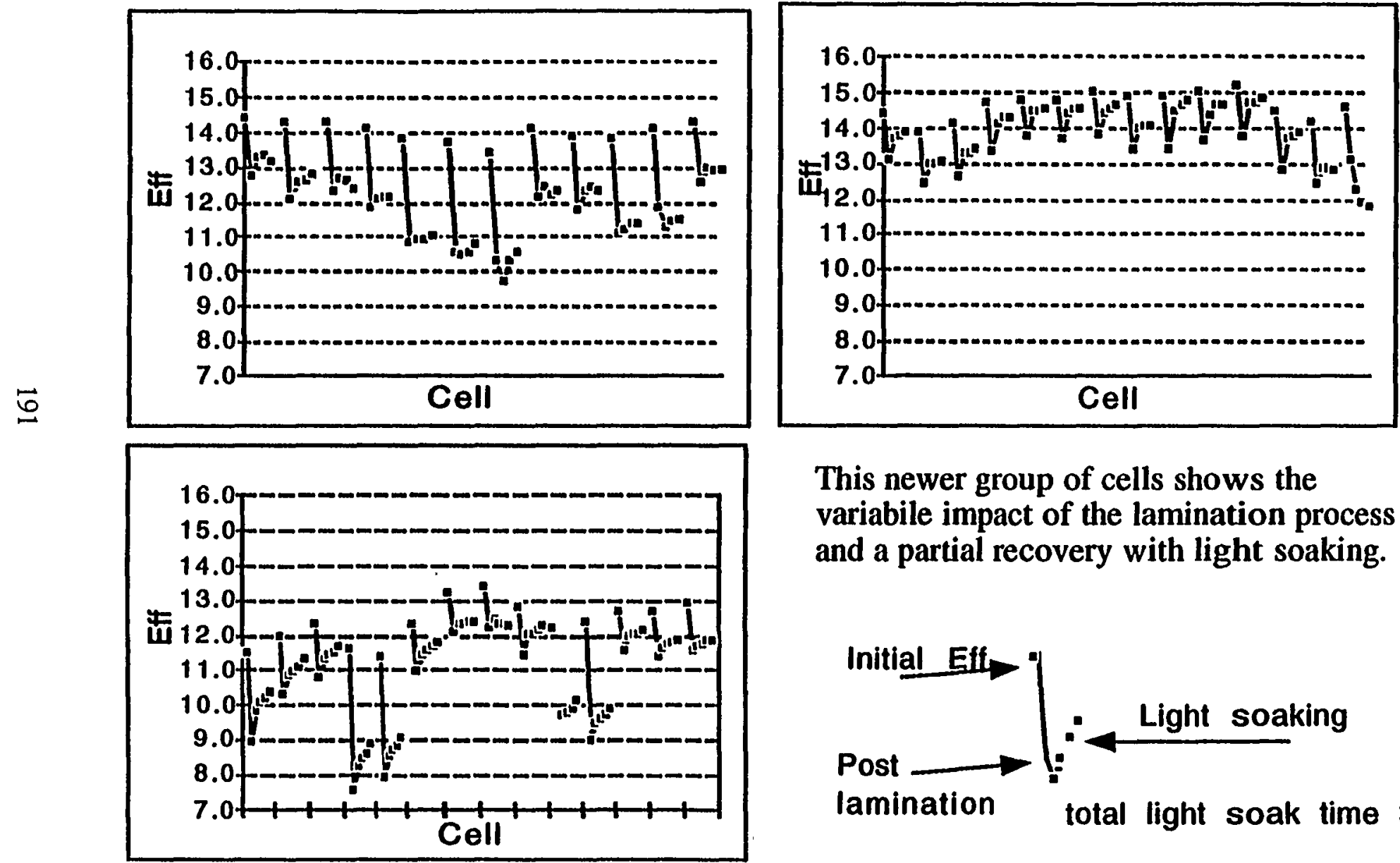

This newer group of cells shows the variabile impact of the lamination process and a partial recovery with light soaking.

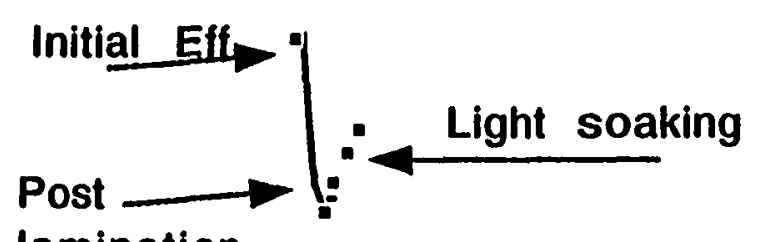

lamination total light soak time 30 minutes

Siemens Solar Industries 


\section{Pseudo laminations with mylar and oven anneals were also conducted on modules.}

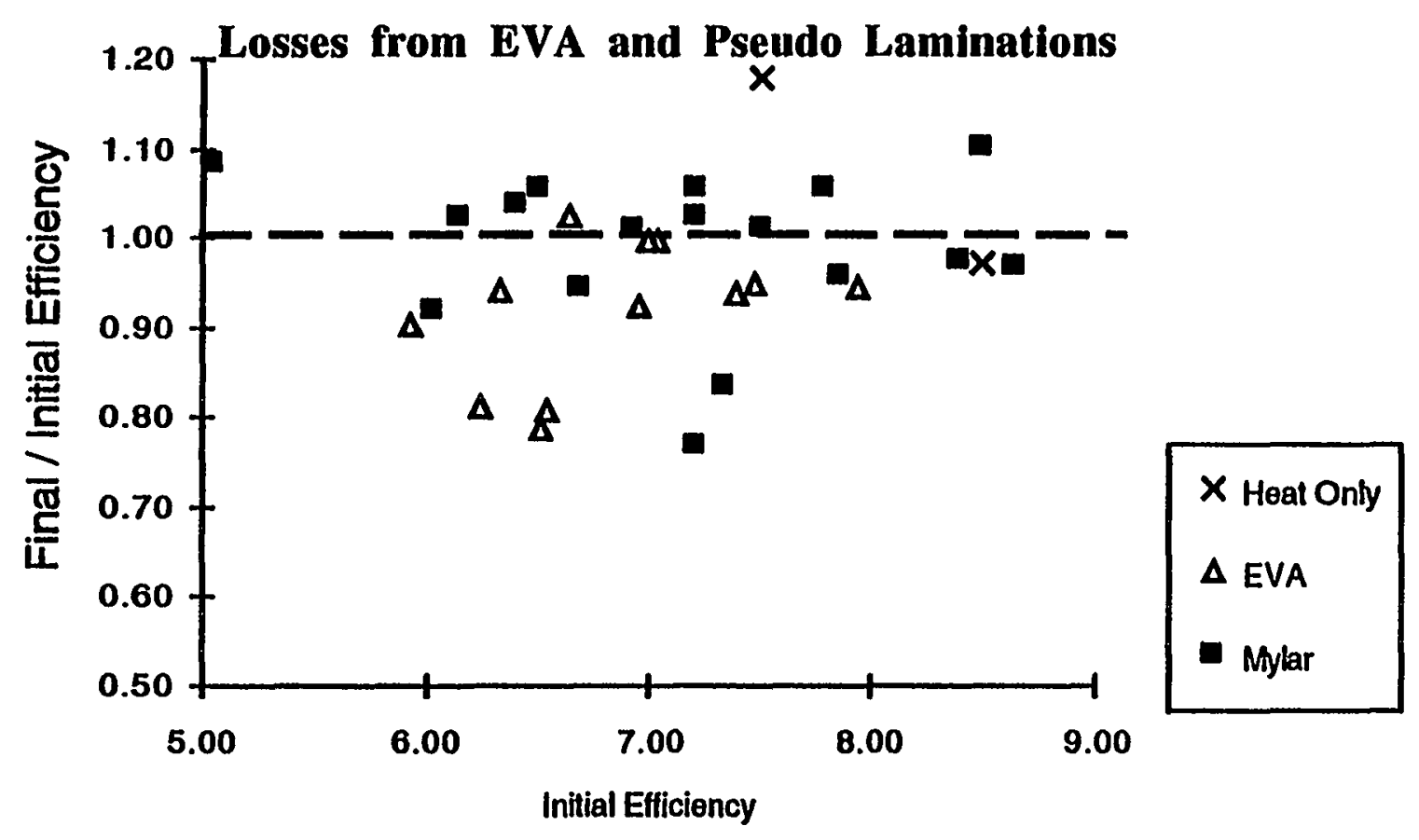


Many modules also show a rapid partial recovery if light soaked after lamination. A significant portion of the drop in performance may be due to the annealing (depopulation) of beneficial states at the lamination temperatures. These states are then regained (repopulated) with light soaking.

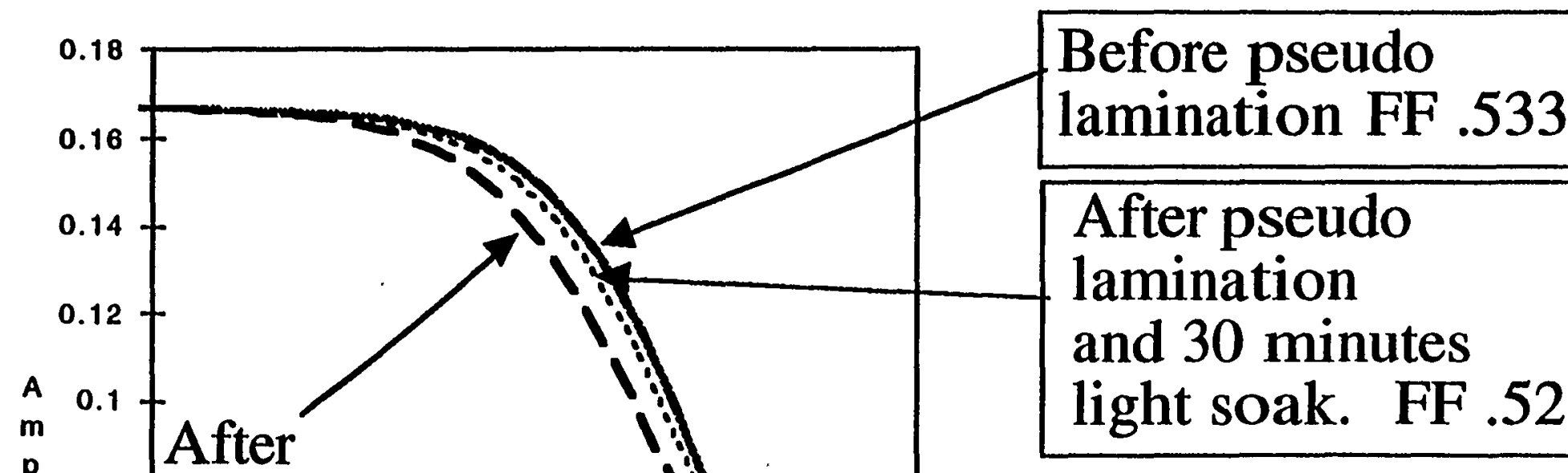


The change in the resistance of the $\mathrm{ZnO}$ was measured in laminated Glass/ZnO/EVA/Glass structures and was found to be negligible in a previous study.

However, interconnect contact resistance was found to be a significant contributor to the variability of initial module performance. 


\section{Interconnect test structures are made to evaluate the "via" quality and reliability}

Module pattern

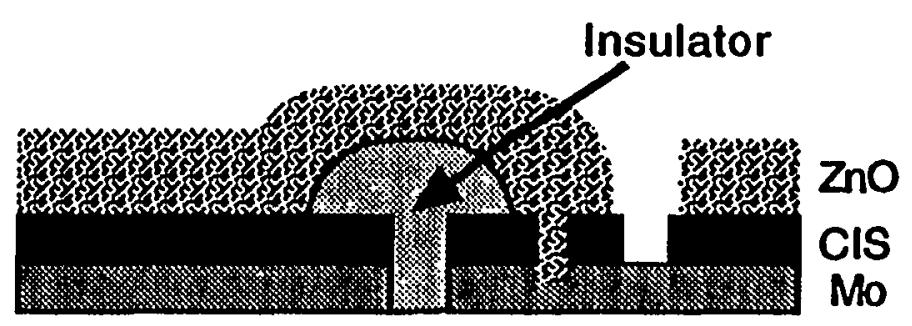

후

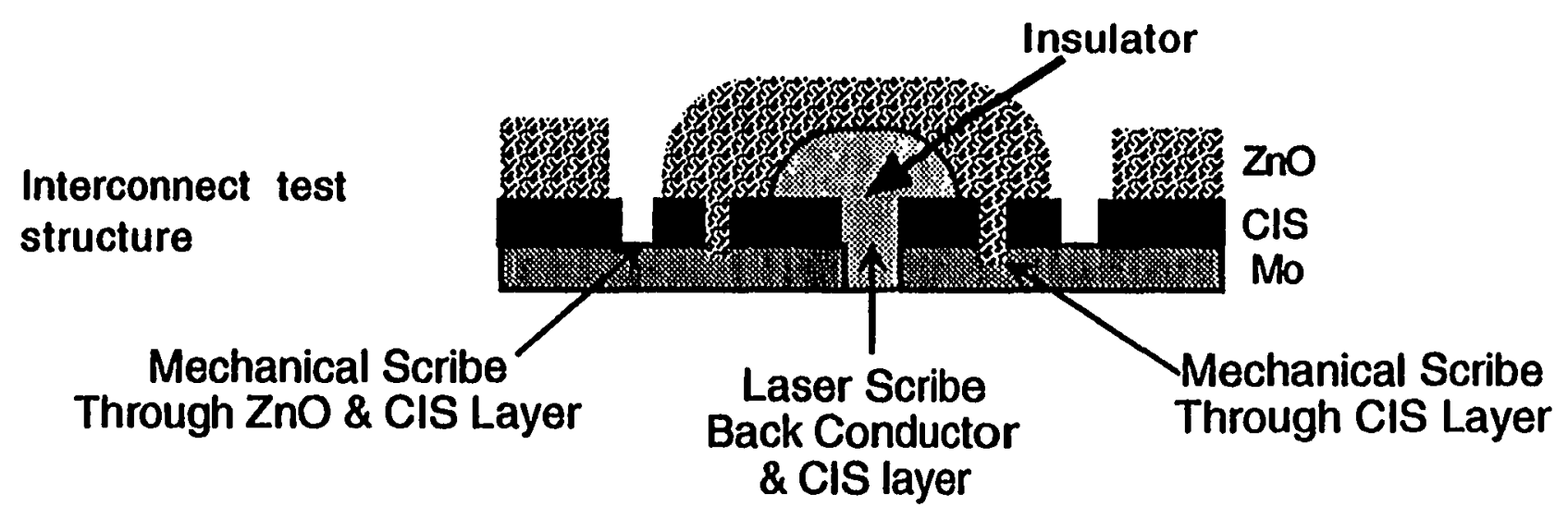


Measuring the voltage drop across

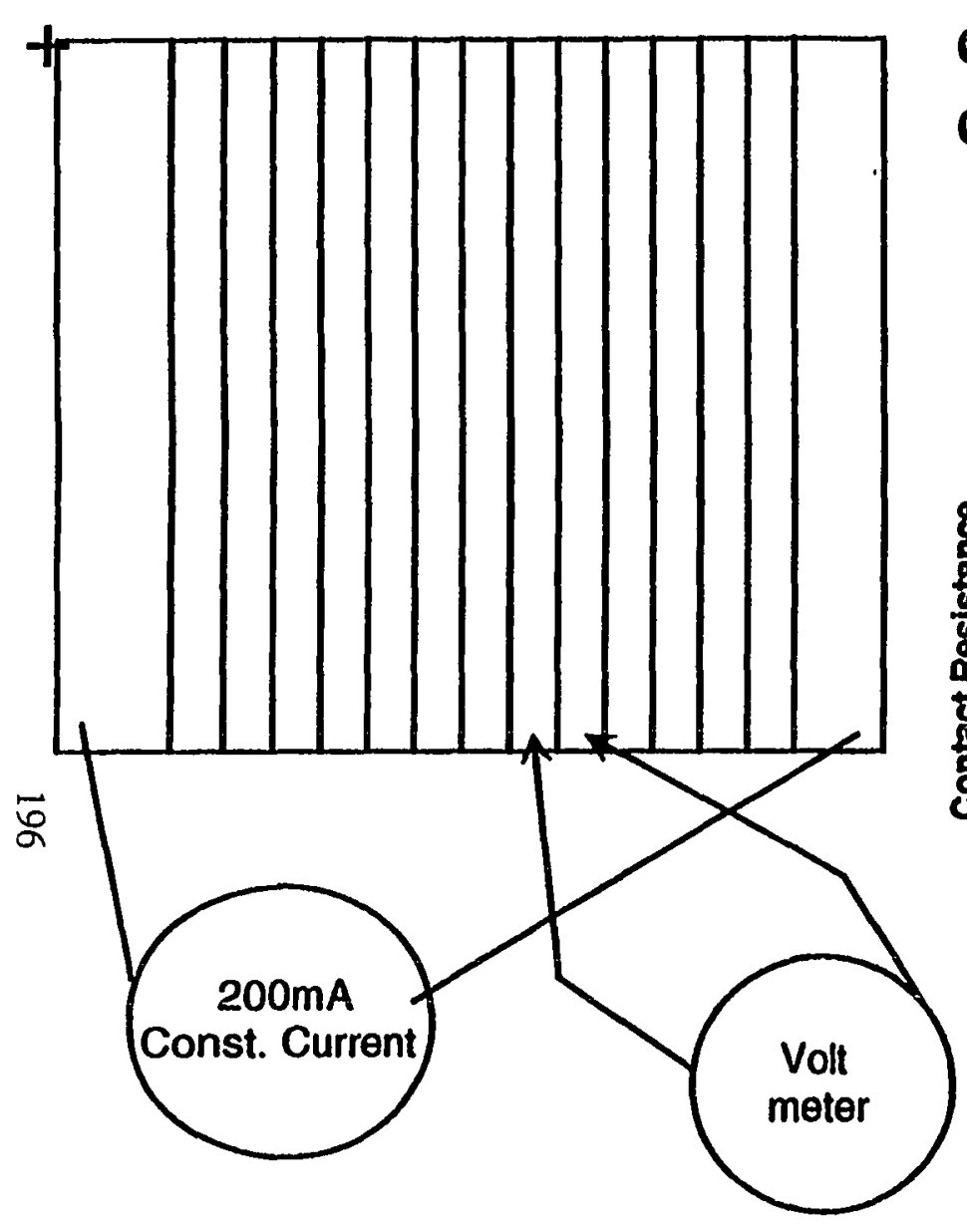
each double interconnect allows the contact resistance to be calculated.

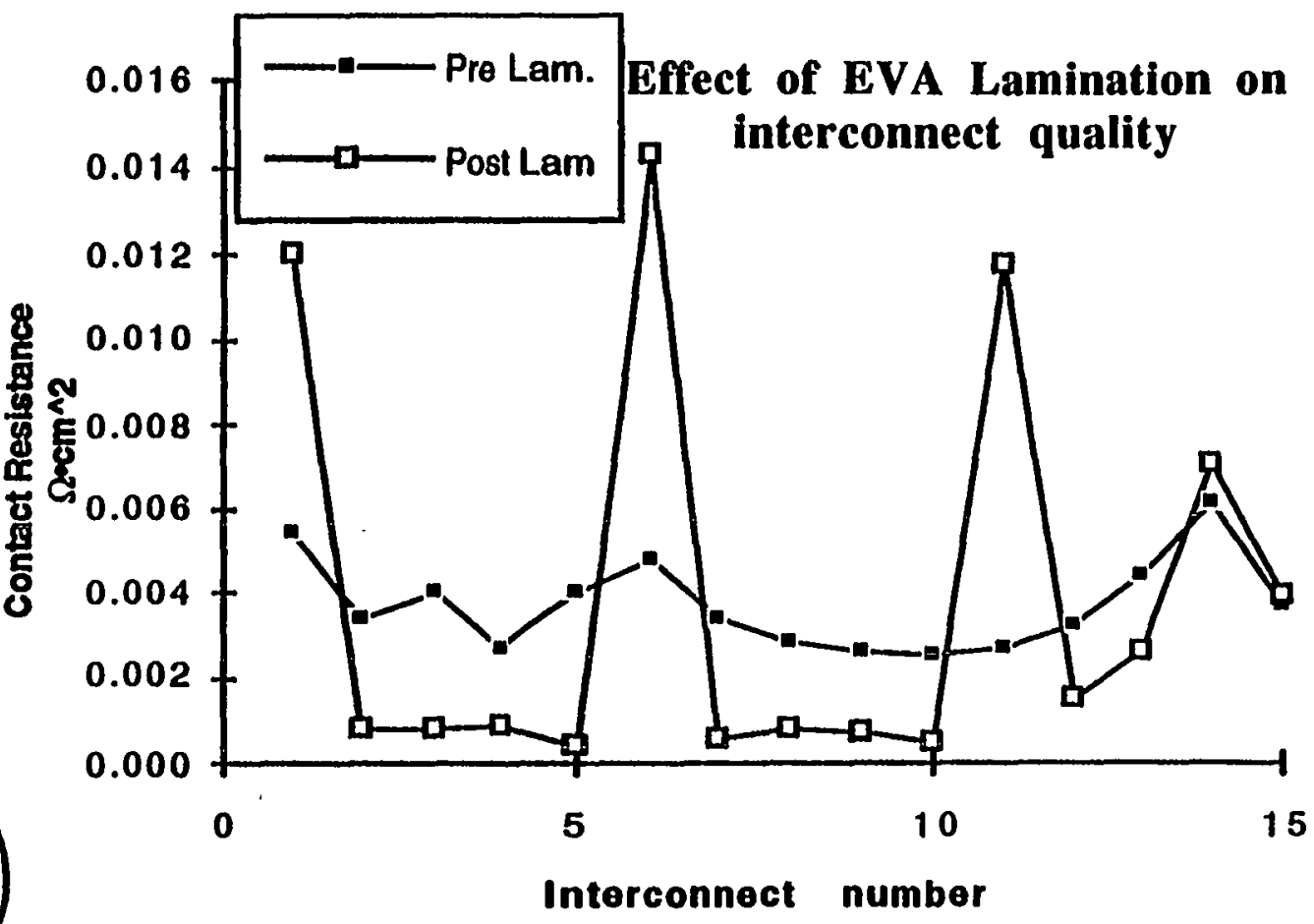

Lamination makes most interconnects better but some interconnects much worse. This method is used to evaluate new patterning techniques. 


\section{Interconnect test structures can show the sensitivity of the via to changes in glass, CIS formation process and sometimes heating and light soaking.}

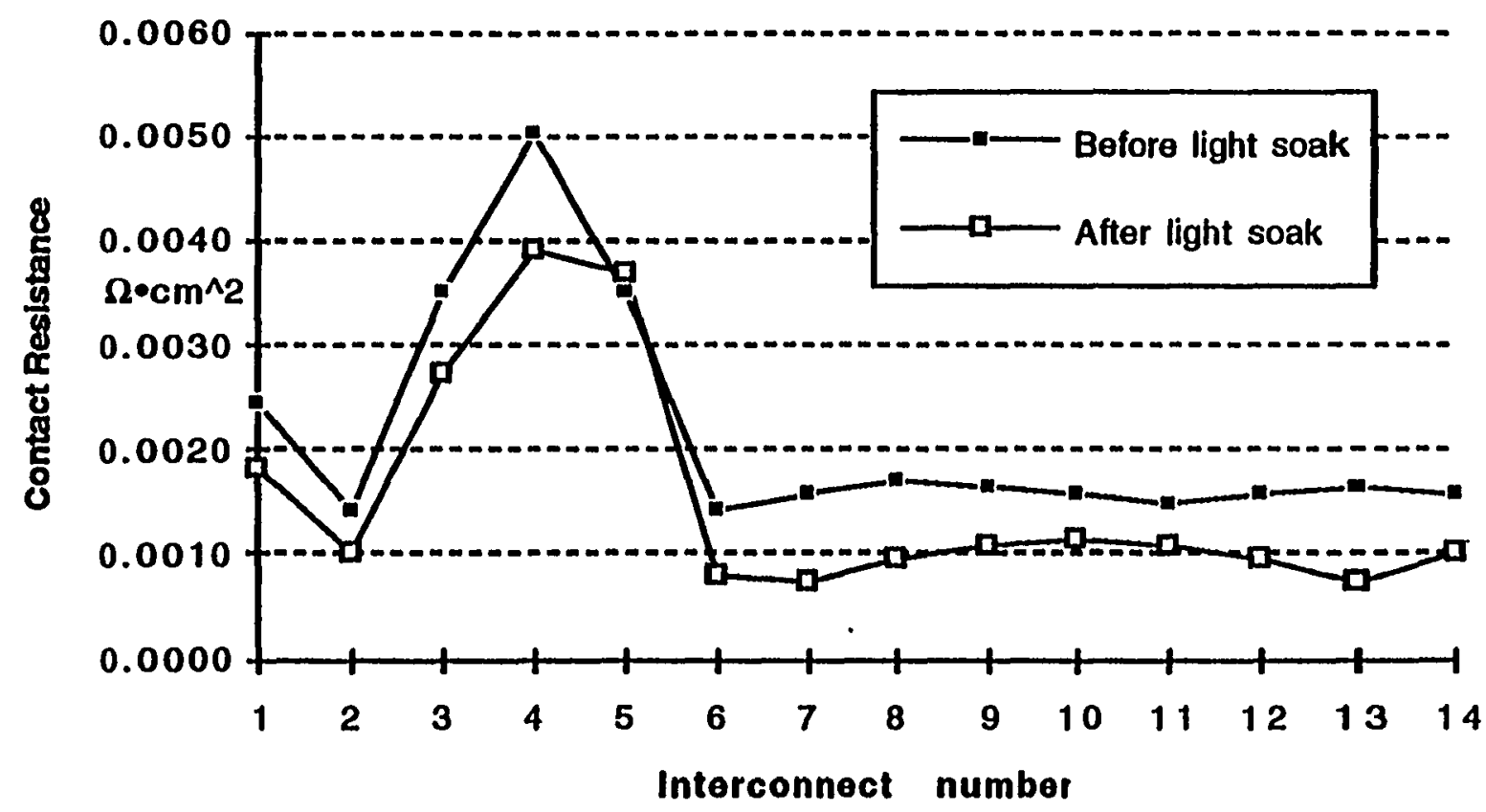




\section{The interconnect test structure has allowed us to optimize a mechanical scribe that gives consistantly low resistance and does not change during lamination.}

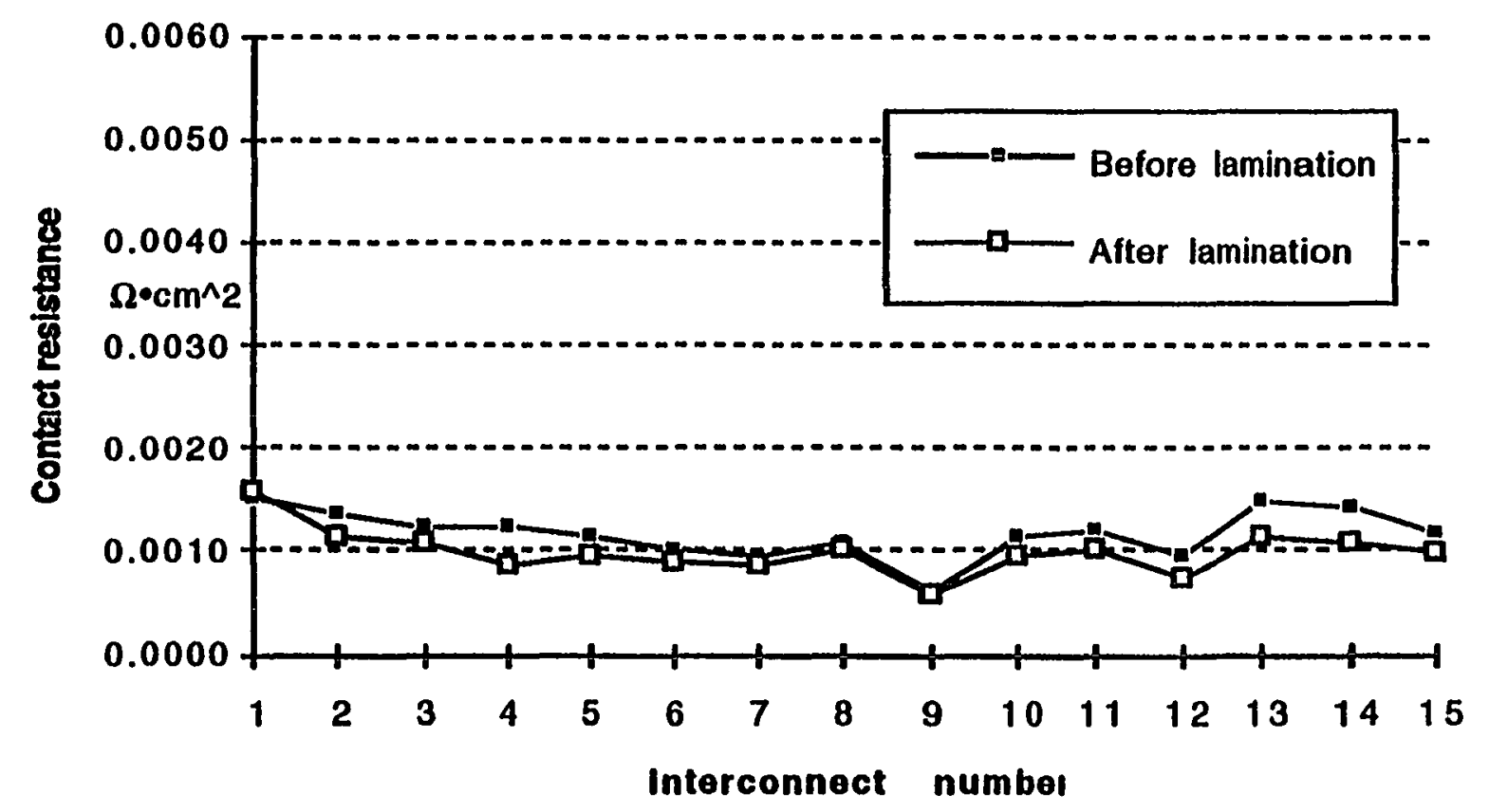




\section{Summary}

Many CIS-Based modules suffer a temporary loss in power when exposed to the lamination process.

This loss is due to an increase in the series resistance.

Part of this effect may be due to a thermal decay or depopulation of beneficial states which can be reversed with light soaking.

Interconnect test structures show that the contact resistance of the "via" may change in the lamination process. Changes may also occur with light soaking or thermal annealing.

Alternate patterning methods are being evaluated to provide a more robust module interconnect. 


\title{
TESTING FOR MODULE WARRANTIES
}

\author{
BY \\ JOHN H. WOHLGEMUTH \\ SOLAREX CORPORATION \\ FREDERICK, MARYLAND 21701
}

\section{Introduction}

The value of a Photovoltaic module depends upon the amount of electricity it can produce over time. The longer a module continues to produce electricity, the greater will be its value to the customer. Part of this value comes from the stated manufacturer's warranty that guarantees replacement for a specified period of time. Another part of this value comes from the history and testing of the product that went into establishing the warranty. Because PV modules are often the only source of electricity for the customer's application, the reliability as well as projected lifetime of the modules are important features.

On the other hand, a module manufacturer must have a great deal of confidence in the product and its projected lifetime before offering an extended warranty. Failure of a large number of modules while still under warranty, would impose a large financial burden on the manufacturer. Therefore, it is extremely important to perform long term testing on modules to assure that most of the modules will continue to meet the minimum specification for a much longer time than the term of the warranty requires. For the customer then, the value of the product is enhanced both by the longer warranty and by the assurance of reliability gained from the testing.

\section{History}

To understand the testing involved in establishing a PV module warranty, it is instructive to review the history of crystalline silicon module warranties at Solarex. Table 1 shows the dates when the warranty times were increased. It took Solarex 4 years to achieve a 1 year warranty, 6 years to offer a. 5 year warranty, 12 years to reach a 10 year warranty and finally, 20 years to extend the warranty to 20 years. These number point out quite clearly that it takes a long time to assemble the test data necessary to provide the assurance for increasing the warranty period. The question to be answered in this talk is where does this data come from?

\section{Testing Development}

The first step in module testing is outdoor exposure. Since this is where the modules have to work, this is where they should be tested. However, there are 2 problems with outdoor testing. The first problem is the variation in outdoor conditions from site to site. A module deployed in Arizona will experience different conditions than one deployed in Maryland or Alaska. The second problem is the length of time required for outdoor exposure testing. You have to wait 10 years to see if a module can last 10 years at that specific site. If a change in made in process or materials you have to wait another 10 years to see the effect. This is certainly unacceptable, so to overcome these problem, accelerated environmental tests are developed.

In designing accelerated environmental tests extreme care must be taken to insure that the test relates to both acceleration of the environment that the product is to be exposed to as well as to the mechanisms by wish the environmental stress causes failure in the product. In other words, the accelerated stress must 
cause the module to fail in the same way as it does in the field or the accelerated test is not a valid test. For example, if in trying to accelerate the influence of temperature, the module were heated above the $180^{\circ} \mathrm{C}$, the solder bonding the interconnects to the cells would likely melt, probably causing open circuit failures. However, melting of the solder is not the temperature induced failure mechanism seen in the field. Therefore, the stress, temperature in this case, has been accelerated too much, resulting in a different failure mechanism.

Much of the early work in this area was performed by JPL under the LSA Program ${ }^{1-4}$. JPL developed a series of module qualification test sequences for the Block purchases. A summary of the sequences are given in Table 2. Each of the tests in this sequence was developed to evaluate module performance against specific stresses that were related to failures observed in the field. In these early days of the PV industry, these tests were extremely helpful and at times very painful for the manufacturers.

Manufacturers used the accelerated qualification tests as quick feedback in the development of more reliable modules. By designing modules to pass the qualification tests, production modules no longer exhibited the early field failures caused by the failure mechanisms that the accelerated tests were designed to stress. The increased module reliability allowed PV companies like Solarex to offer module warranties for the first time.

The next step was field deployment of the modules that had successfully passed the early (Block I, II and III) qualification tests. Once again, field failures occurred, but this time the modules lasted for much longer periods before failures began. These new failures were analyzed, failure mechanisms identified and new (or modified) accelerated qualification tests were developed. For example, because a number of the early modules suffered from hail damage, a hail test was developed and added to the qualification sequence in Block IV. Module failures due to broken interconnects, especially in climates with large daily temperature extremes lead to increasing the number of thermal cycles from 50 to 200 in Block V.

It was during this time (late 70's and early 80's) that the reliability of crystalline silicon PV modules was established 5,6 . The field data showed that modules qualified to at least the Block II and III sequences had very low failure rates and projected lifetimes well in excess of 5 years. By 1980 most of the crystalline $\mathrm{Si}$ module manufacturers were offering warranties of up to 5 years on their products. In most cases the warranty was based more on passing the qualification tests than on actual field experience with the products being manufactured, since product designs changed frequently to lower cost and increase efficiency.

Block V was the last qualification sequence published by JPL. A Block VI procedure was being prepared with the addition of a long term humidity test and a bypass diode test ${ }^{4}$, but it was never published due to reduced DOE funding. Government sponsored qualification efforts them shifted to development of procedures for thin film modules?. Work on crystalline silicon modules continued as the manufacturers continued to monitor field results and to develop their own accelerated testing programs. Once again the emphasis was on identification of field failures, determination of failure mechanisms, development of accelerated tests to simulate those failure mechanisms, redesign of modules and materials to overcome the identified failure mechanisms and finally testing via the accelerated test sequence to verify that the problem has been solved. One example of this process was the reported field failures of $\mathrm{Ag}$ paste cells with PVB encapsulant ${ }^{8}$. While Solarex never used PVB encapsulant, the corrosion mechanism can occur to some degree in any encapsulation system unless the module is permanently hermetically sealed. Therefore, Solarex used this experience on other manufacturer's modules to design an accelerated temperature humidity test to verify that our metallization and encapsulation systems were not susceptible to this failure mechanism. Development and periodic use of these accelerated tests as well as the excellent record of field performance lead Solarex and many other PV manufacturers to extend their module warranties to the range of 10 years in the mid 1980's. It was assumed that crystalline silicon modules qualified to a Block $V$ sequence should last for at least 10 years in the field. 


\section{Lessons Learned from Carrisa Plains}

Carrisa Plains was a 6 megawatt grid connected PV system using flat plate modules with mirror enhancement and tracking. The system began to experience major power loss in the first 5 years due to degradation of the modules. Since these modules also exhibited severe discoloration of the EVA encapsulant. EVA degradation was blamed for the power loss9,10. Indeed it has now been conclusively shown that high temperature and high UV illumination will cause EVA to discolor ${ }^{11}$. However, the Carrisa system had other problems in addition to the EVA discoloration that contributed significantly to the power loss. Recent reports have shown that hot spot failures due to poor system design with inadequate diode protection caused a significant portion of the power loss at Carrisa ${ }^{12}$. Module hot spot testing is no substitute for good system design, especially in terms of diode protection via bypass and blocking diodes.

Reports of EVA discoloration at Carrisa lead to a survey of other EVA modules with reports of discoloration at a number of other sites in hot sunny environments. EVA discoloration depends on the site, the module mounting conditions, module construction and possibly even the properties and processing of the EVA used. The question of EVA discoloration is still under review (see the session scheduled for this conference). However, we do know that some EVA modules have been deployed for up to 12 years in the field without appreciable power loss ${ }^{12}$. The only reported power loss mechanism associated with EVA discoloration is the loss of optical absorption, which in most cases results in a slow loss in current, but not a catastrophic failure ${ }^{11}$. Development of an accelerated UV-thermal test is important for many crystalline silicon module manufacturers in terms of defining the "EVA lifetime" for their modules.

\section{Recent Qualification Tests}

Many of the lessons learned during the 80's were incorporated into an IEC (International Electrochemical Commission) crystalline silicon PV module qualification sequence that has now been approved by the international PV community and published as IEC-1215. This procedure was based on Block V and CEC-502 specifications. It includes all of the Block $V$ tests as well as a damp heat test at $85^{\circ} \mathrm{C} / 85 \% \mathrm{RH}$ for 1000 hours, an outdoor exposure test, a UV test and a robustness of termination test. We have already seen that adding the UV test before thermal cycling and humidity freeze is able to accelerate a failure mechanism previously observed in the field where certain tapes (that have been used in modules to hold the cells in position before and during lamination) delaminate. Clearly UV weakens the adhesive bond which then fails during thermal cycling and humidity freeze.

Work is now underway to develop both IEEE and IEC qualification documents that cover all terrestrial PV modules. The difficulty with this task is the need to identify all of the potential failure mechanisms for all of the different type of modules and then to develop accelerated tests that test for these specific failure mechanisms. This means that for each new PV technology, a new set of failure mechanisms may be identified from field experience and accelerated tests have to be designed to test for these mechanisms. A good example is the wet high-pot test developed to test for a corrosion problem observed on some amorphous silicon modules. This procedure is now routinely used to test crystalline silicon modules to identify possible problems with liquid water penetration into the active circuit elements, representing a possible high voltage danger. So qualification tests will continue to improve as PV matures.

\section{Testing Beyond Qualification}

When module technologies were being developed, qualification tests were sufficient for establishing the length of module warranties. Now, however, module warranties have been extended for times considerable longer than the accelerated stress tests in the qualification sequences were designed to simulate. Some of the tests, like the hail test, are not time dependent, but rather just increase the severity 
beyond that normally encountered in the field. However, most of the accelerated tests define a duration and/or number of cycles that were selected based on several years of field experience. These tests may have to have extended duration or increased cycles to evaluate product performance for long term operation.

Thermal cycling is an accelerated qualification test run for a specific number of cycles. The original thermal cycle test specified 50 cycles. However, module designs that had successfully passed 50 thermal cycles began failing in the field, especially desert environments, in 2 to 4 years due to interconnect failures. In response to these failures the number of thermal cycles in the qualification sequence was increased to 200. To better understand what field experience equates to 200 thermal cycles, we must estimate the acceleration factor associated with the specified cycles. Many thermally activated processes can be modeled by an activation rate that doubles for every $10^{\circ} \mathrm{C}$ increase in temperature ${ }^{13}$. The accelerated thermal cycle test cycles from $-40^{\circ} \mathrm{C}$ to $+90^{\circ} \mathrm{C}$, representing a $\Delta \mathrm{T}$ of $130^{\circ} \mathrm{C}$. In actual field experience the daily change in temperature varies from site to site as well as with the seasons. An estimate for daily module temperature change includes $15^{\circ} \mathrm{C}$ for the change in ambient and $25^{\circ} \mathrm{C}$ from the module increase in temperature above ambient, yielding an estimate of $\Delta \Delta \mathrm{T}$ of $40^{\circ} \mathrm{C}$. Therefore the accelerated thermal cycle test increases the daily cycle by $90^{\circ} \mathrm{C}$, representing an estimated acceleration factor of 18 . As a check on this value, 50 cycles would represent 2.5 to 3 years, approximately the time required for observation of field failures in the early modules. This acceleration rate indicates that 200 thermal cycles represents approximately 10 years in the field. So the 200 thermal cycle test is valid for a 10 year module lifetime, probably carrying a 5 year manufacturer's warranty. However, to test for a 30 year module lifetime and warranty the module for 20 years, the thermal cycle test should be run for 600 cycles.

The damp heat test $\left(85^{\circ} \mathrm{C}, 85 \% \mathrm{RH}\right)$ is another test where the duration is important. Otth and Ross ${ }^{14}$ estimated that 200 hours at $85^{\circ} \mathrm{C}$ and $85 \%$ RH represented 20 years of exposure in Miami, Florida, one of the US warmest dampest climates. Ricaud and Petersen ${ }^{15}$ calculated a range of probable acceleration factors and concluded that a 20 year field exposure could be simulated with up to 400 hours of exposure at $85^{\circ} \mathrm{C}$ and $85 \% \mathrm{RH}$. So this appears to be a case where the 1000 hour qualification test in IEC-1215 is more than adequate to test for a 30 year life or 20 year warranty.

The UV test is a recent addition to qualification test sequences. The UV test is important because of the interaction between UV exposure and other stresses including high temperature, thermal cycling and humidity. The identification of $\mathrm{UV}$ and high temperature as the cause for discoloration and degradation of the EVA at Carrisa Plains ${ }^{9,10}$ lead to a greater interest in accelerated $U V$ testing of modules. There is a UV test included in the IEC-1215 qualification test procedure, but the UV test procedure itself has not been approved for publication. In addition, the IEC test represents a UV exposure equivalent to only 325 hours of the UV component of the reference solar spectrum. This is clearly not enough UV and thermal stress to simulate the Carrisa problem. Solarex is using a mixture of long and short wavelength UV lamps to provide the appropriate spectrum with a UV acceleration factor of 5 as specified in the IEC UV draft document. Temperature can also be used as an acceleration factor during the $U V$ test. By running the test continuously at 80 to $90^{\circ} \mathrm{C}$ an acceleration ratio of 50 to $100 \mathrm{can}$ be achieved. However, at this acceleration rate it takes on the order of one-half a year to test for a 30 year module life. It is interesting to note that the Carrisa system, operating at $90^{\circ} \mathrm{C}$ with a UV acceleration rate of 2 , had an acceleration factor of approximately 10 over a normal flat plate system that runs at 60 to $65^{\circ} \mathrm{C}$. So we should be looking at the performance of the Carrisa system after 2 or 3 years to evaluate the effect of $U V$ and temperanure on flat plate modules after 20 or 30 years.

Most of the other tests in the qualification sequence (hot spot, mechanical load, twist, robustness of termination and cut susceptibility) are not time or duration dependent. They test for the modules ability to withstand a particular event. It is important that these tests be conducted after the long term stress tests to ensure that normal operation doesn't impair the modules ability to withstand these stresses. For example, 
the ability to pass the hot spot test depends among other things on the number and quality of solder bonds. Therefore, modules should be subjected to the hot spot test after thermal cycling and/or damp heat to determine if the module can still pass the hot spot test.

The humidity-freeze test is a special case. It does have a particular duration and number of cycles, but the mechanism of pumping moisture into the encapsulant and then freezing it, is more a measure of the strength of the adhesive bonds in the module rather than the measure of the modules ability to withstand a particular long term process occurring in the field. Like the hot spot test, the humidity freeze test does not have to be extended, but should be utilized after applying the other accelerated stresses to determine how well the adhesive bonds stand up to long term exposure to humidity, thermal cycling and UV.

\section{Summary}

The development of a valid qualification test sequence for a particular module technology takes a long time (many years) It requires an iterative process of field observations, identification of failure mechanisms, development of accelerated tests to simulate the failure mechanisms and finally more field testing to show that modules that pass the accelerated test also do not exhibit the failure mechanism during normal operation. Qualification tests are designed to test for failure over a moderately long time frame (5 to 10 years). Testing for longer term reliability (for 20 year warranties and 30 year lifetimes) requires longer term field testing, longer duration accelerated testing and the use of various combinations of accelerated tests to better understand how they interact. With 20 years of field and accelerated test experience for crystalline silicon modules, we now produce highly reliable and long lifetime products. However, we won't know what the average module lifetime or what the ultimate life limiting failure mechanism will be until we have 30 or 40 years of field experience with these modules.

\section{References}

1. A. R. Hoffman \& R. G. Ross, Jr. "Environmental Qualification Testing of Terrestrial Solar Cell Modules", 13th IEEE PVSC, p. 835, 1978.

2. A. R. Hoffman, J. S. Griffith \& R. G. Ross, Jr. "Qualification Testing of Flat-Plate Photovoltaic Modules", IEEE Transactions on Reliability, Vol. R.31, No. 3, p. 252, 1982.

3. JPL Publication 86-31 "Flat Plate Solar Array Project Final Report" Volume VI: Engineering Science and Reliability, 1986.

4. M. I. Smokler, D. H. Otth \& R. G. Ross, Jr. "The Block Program Approach to Photovoltaic Module Development", 18th IEEE PVSC, p. 1150, 1985.

5. S. E. Forma \& M. P. Themelis "Review of PV Performance at DOE/MIT Lincoln Laboratory Test Sites During the Period 1977-1982", 16th IEEE PVSC, p. 1198, 1982.

6. W. J. Bifano, R. DeLombard, A. F. Ratajcak \& L. Scudder "Status of DOE and AID Stand-alone Photovoltaic System Field Tests", 17th IEEE PVSC, p. 1159, 1984.

7. R. G. Ross, Jr. "Crystalline Reliability Lessons for Thin Film Modules", I8th IEEE PVSC, p. 1014, 1985.

8. G. R. Mon, J. Orehotsky, R. G. Ross, Jr. \& G. Whitla "Predicting Electrochemical Breakdown in Terrestrial Photovoltaic Modules", 17th IEEE PVSC, p. 1682, 1984.

9. D. D. Sumner, C. M. Whitaker and L. E. Schlueter "Carrisa Plains Photovoltaic Power Plant 1984 1987 Performance", 20 th IEEE PVSC, p. 1289, 1988.

10. H. J. Wenger, C. Jennings \& J. Iannucci "Carrisa Plains Power Plant performance", 21st IEEE PVSC, p. $844,1990$.

11. J. Pern "A Comparative Study of Solar Cell Performance Under Thermal and Photothermal Tests", Proceedings of Photovoltaic Pefformance and Reliability Workshop, SERI/CP-411-5184, p. 327, 1992.

12. J. H. Wohlgemuth \& R. C. Petersen "Reliability of EVA Modules", 23rd IEEE PVSC, 1993.

13. Franklin Research Center "Review of Equipment Aging Theory and Technology", Final Report, Sept. 1980, Prepared for EPRI. 
14. D. H. Otth \& R. G. Ross, Jr. "Assessing Photovoltaic Module Degradation and Lifetime from Long Term Environmental Testing", Proceedings of 30th Institute of Environmental Science Annual Meeting, May, 1984.

15. A. M. Ricaud \& R. C. Petersen "Environmental Stress Tests: Acceleration of Corrosion", 8th European Community-PSEC, p. 549, 1988.

TABLE 1

Solarex Module Warranty History

$\underline{\text { Year }}$

1973

1977

1979

1985

1993
Warranty

First Solarex Crystalline Modules

Manufactured - No Warranty

1 Year Warranty

5 Year Warranty

10 Year Warranty

20 Year Warranty

TABLE 2

JPL Block Qualification Tests

\begin{tabular}{|cccccc|}
\hline Test & I & II & III & IV & V \\
Year & 1975 & 1976 & 1977 & 1978 & 1981 \\
\hline Thermal & 100 cycles & 50 cycles & 50 cycles & 50 cycles & 200 cycles \\
Cycle & -40 to +90 & -40 to +90 & -40 to +90 & -40 to +90 & -40 to +90 \\
Humidity & $70 \mathrm{C}, 90 \%$ rh & 5 cycles & 5 cycles & 5 cycles & 10 cycles \\
& $68 \mathrm{hr}$. & $40 \mathrm{C}, 90 \%$ rh & 40 C, $90 \%$ rh & $54 \mathrm{C}, 90 \%$ rh & $85 \mathrm{C}, 85 \%$ rh \\
& & to $23 \mathrm{C}$ & to $23 \mathrm{C}$ & to $23 \mathrm{C}$ & to $-40 \mathrm{C}$ \\
Hot Spots & - & - & - & - & 3 cells \\
& & & & & $100 \mathrm{hrs}$ \\
Mechanical & - & 100 cycles & 100 cycles & 10000 cycle & 10000 cycle \\
Load & & $\pm 2400 \mathrm{~Pa}$ & $\pm 2400 \mathrm{~Pa}$ & $\pm 2400 \mathrm{~Pa}$ & $\pm 2400 \mathrm{~Pa}$ \\
Hail & - & - & - & 9 impacts & 10 impacts \\
& & & & $3 / 4^{\prime \prime}-45 \mathrm{mph}$ & $1^{\prime \prime}-52 \mathrm{mph}$ \\
NOCT & - & - & - & Yes & Yes \\
High Pot & - & $<15 \mu \mathrm{A}$ & $<50 \mu \mathrm{A}$ & $<50 \mu \mathrm{A}$ & $<50 \mu \mathrm{A}$ \\
& & $1500 \mathrm{~V}$ & $1500 \mathrm{~V}$ & $1500 \mathrm{~V}$ & $2 * \mathrm{Vs}+1000$ \\
\hline
\end{tabular}

Block I

JPL 5-342

Block II

JPL 5-342-1B

Block III

Block IV

Block V

JPL 5-342-1C

JPL 5101-16A and 5101-83

JPL 5101-161 and 5101-162 


\section{Field Wet Resistance Test Procedure and Results at PVUSA}

NREL PV Performance and Reliability Workshop

Denver, CO Sept. 1993

Charles M. Whitaker Benjamin E. Valega Endecon Engineering, San Ramon, CA 


\section{Description of PVUSA Systems}

\begin{tabular}{|c|c|c|c|c|}
\hline System & Description & Location & Rating & Installation Date \\
\hline $\begin{array}{l}\text { EMT } \\
\text { Siemens Solar Industries (SSI) }\end{array}$ & Flat-plate $\mathrm{Cz}$ & Davis, CA & $18.7 \mathrm{kWdc}$ & Jan-89 \\
\hline Sovonics & Flat-plate a-Si & Davis, CA & $17.3 \mathrm{kWdc}$ & Jun-89 \\
\hline Utility Power Group & Flat-plate a-Si & Davis, CA & $15.7 \mathrm{kWdc}$ & Dec-89 \\
\hline Solarex & Bifacial Cz & Davis, CA & $15.7 \mathrm{kWdc}$ & Oct-90 \\
\hline ENTECH & Concentrator $\mathrm{Cz}$ & Davis, CA & $16.5 \mathrm{kWdc}$ & Mar-91 \\
\hline$\frac{\text { US }}{\text { Advanced Photovoltaic Systems (APS) }}$ & Flat-plate a-Si & Davis, CA & $479 \mathrm{kWac}$ & Sep-92 \\
\hline Siemens Solar Industries (SSI) & Flat-plate $\mathrm{Cz}$ & Kerman, CA & $498 \mathrm{kWac} *$ & Aug-93 \\
\hline Integrated Power Corporation (IPC) & Flat-plate EFG & Davis, CA & $196 \mathrm{kWac} *$ & Aug-93 \\
\hline Siemens Solar Industries (SSI) & Flat-plate $\mathrm{Cz}$ & Davis, CA & $176 \mathrm{kWac} *$ & $? ? ?$ \\
\hline Host & Flat-plate a-Si & Maui, HI & $18.5 \mathrm{kWdc}$ & Oct-89 \\
\hline Integrated Power Corporation (IPC) & Flat-plate EFG & Austin, TX & $17.5 \mathrm{kWac}$ & Jul-92 \\
\hline
\end{tabular}

* Anticipated rating 


\section{Wet Resistance Test History}

$\square$ JPL-developed test to quantify module leakage current

$\square$ Pass/fail criteria need to address

- Safety (1-5 mA)

- Ground fault arcing $(\sim 50 \mu \mathrm{A})$

- Leakage current induced degradation: Corrosion (1-5 $\mu \mathrm{A})$

$\square$ Safety and G.F. based on single incidents. Corrosion based on cumulative leakage over time

$\square$ TCO wrap around on thin film modules: $10^{5} \mathrm{M} \Omega$ dry, $0.1 \mathrm{M} \Omega$ wet: Dry Hipot does not address adequately

$\square$ Incorporated in several module qualification tests:

- PVUSA Module qual. test

- NREL IQT

- IEEE Module Qualification Test (draft)

- IEC Thin-film Module Qualification Test (draft) 
Field Wet Resistance Test Setup

范

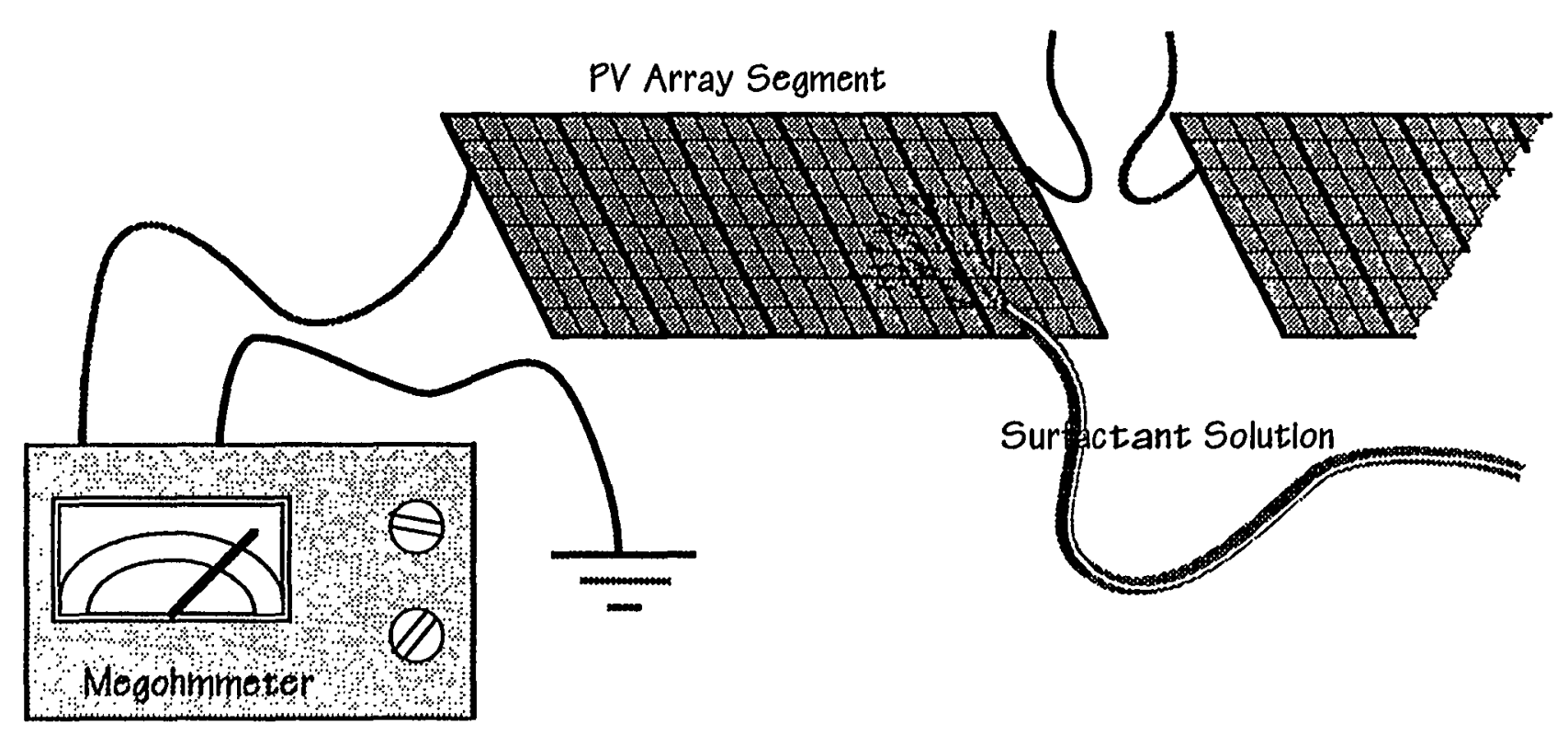




\section{Wet Resistance Test Criteria}

$\square$ Cumulative charge transfer to module failure

$\square$ Initial JPL testing based on 4" $x 4^{\prime \prime}$ coupons

$\square$ Scaling dependant on type of failure mechanism:

- Point defect ( 3 - 30 Coulombs for $30 \mathrm{yr}$ life)

- Perimeter dependant (0.1 - 1.0 Coulombs/cm)

- Area dependant (0.03 - 0.3 Coulombs $\left./ \mathrm{cm}^{2}\right)$

$\square$ For a 1'x4' module with perimeter-related leakage, $\mathrm{R}_{\mathrm{W}}{ }^{*}=129 \mathrm{M} \Omega$ to $1314 \mathrm{M} \Omega$

$\checkmark 100 \mathrm{M} \Omega$ suggested as indicative but not overly restrictive 


\section{Field Wet Resistance Test Issues}

$\square$ Surfactant (Liquinox 1:516)

$\square$ Module temperature

$\square$ Module size

- PVUSA: Resistance $\propto 12.5 \mu \mathrm{A} / \mathrm{ft}^{2} @ 2 \mathrm{~V}_{\max }+1000 \mathrm{~V}$

- IEEE Proposing $40 \mathrm{M} \Omega-\mathrm{m}^{2}$

$\square$ Array segment size $\left(R_{\mathrm{w}}{ }^{*} \geq 0.1 \mathrm{M} \Omega\right)$

$\square$ Array segment voltage

$\square$ Spray pressure

$\square$ Labor intensity $\left(\sim 0.1 \mathrm{mhr} / \mathrm{m}^{2}\right)$

$\square$ Safety

$\square$ Frequency 


\section{Effect of PV Voltage on Megger Reading}

N

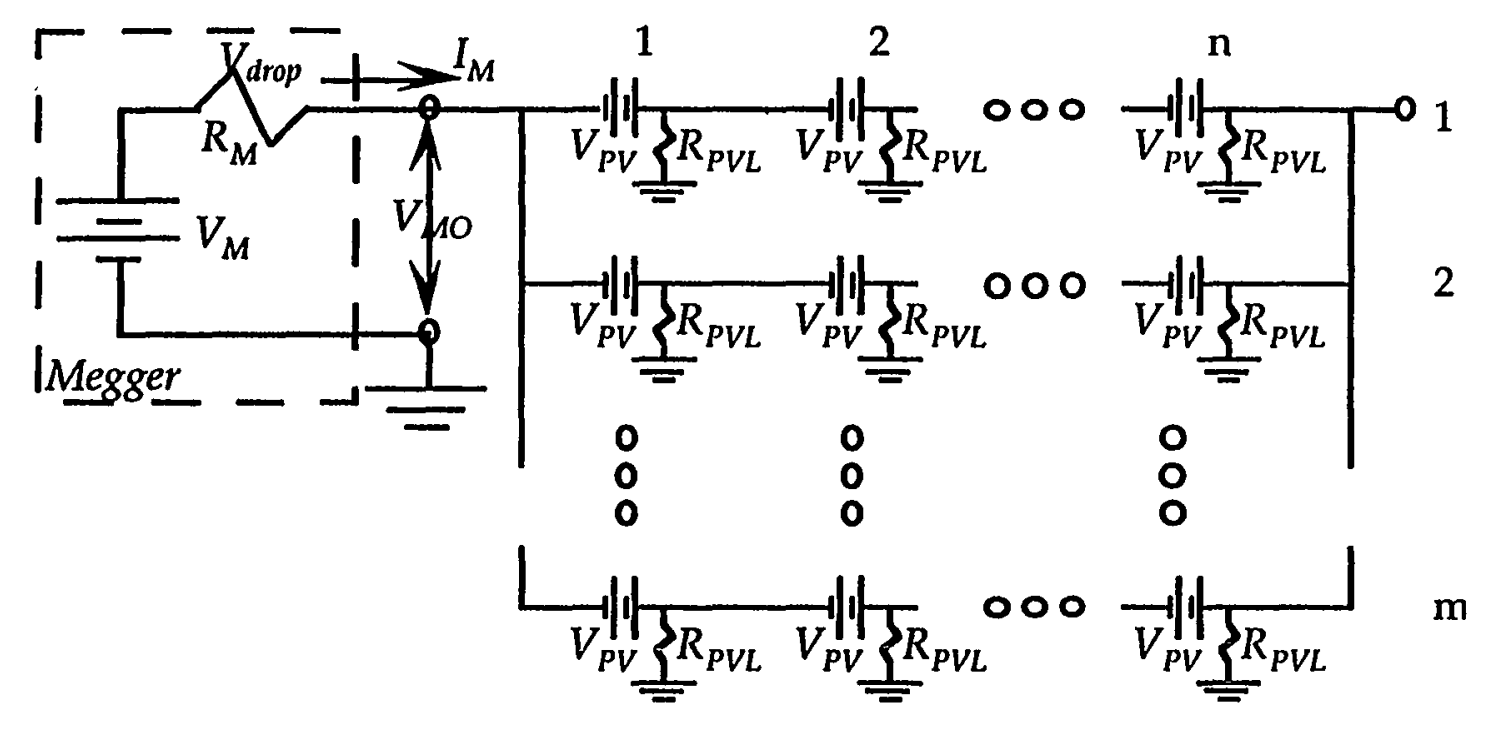

$$
R_{\text {MeggerReading }}=\frac{2 \times V_{M} \times \frac{R_{P V L}}{n \times m}-n \times V_{P V} \times R_{M}}{2 \times V_{M}+n \times V_{P V}}
$$




\section{PVUSA FWRT Results}

\begin{tabular}{|c|c|c|c|c|c|c|c|c|}
\hline & $\begin{array}{c}\text { \# of } \\
\text { Modules }\end{array}$ & $\begin{array}{c}\text { Array } \\
\text { Area } \\
\text { (m2) } \\
\end{array}$ & $\begin{array}{l}\text { Array } \\
\text { Power } \\
\text { (kW) }\end{array}$ & Harness & J-Box & Module & Unknown & Diode \\
\hline EMT1 Totals & 6988 & 1497 & 83.9 & 14 & 5 & 12 & 0 & 0 \\
\hline US-1 Totals & 14668 & 15629 & 849 & 229 & 139 & 60 & 52 & 23 \\
\hline US-2 Totals & 12240 & 5171 & 498 & 2 & 1 & 9 & 0 & 0 \\
\hline
\end{tabular}




\section{Conclusions}

$\square$ Provides detailed information regarding location and extent of

- Module and field wiring design, mfg., and QC flaws

- Shipping damage

- Installation damage

- Insulation system degradation

- Labor intensive: can do samples on "large" systems

$\square$ May result in "tight" J-boxes

$\square$ Untested systems are very likely to have multiple failures 


\title{
Performance of a $1.8 \mathrm{kWac}$ Dual-Junction Amorphous Silicon System
}

\author{
Presented by: \\ Troy Strand \\ National Renewable Energy Laboratory \\ Golden, Colorado (303) 231-1804
}

\begin{abstract}
:
On December 7, 1992 a $1.8 \mathrm{kWac}$ utility-interconnect photovoltaic (PV) system was brought online at NREL. The system was deployed in order to evaluate the performance of a dual-junction amorphous PV array in a utility-interconnect application. The system is unique in that the manufacturer installed construction grade insulation on the back of each module in an attempt to elevate the operating temperature of the array. This presentation details system performance versus name-plate rating, interim results covering the in-situ module/array performance and the predominate system experiences encountered thus far.
\end{abstract}

\section{Overview:}

The name-plate rating of the system is $1.8 \mathrm{kWac}$. Early on it was determined that the system was operating below this rating. In an attempt to raise the system output 6 modules were added to the array changing the number of modules per string from 16 to 17 in series. This change took place on 4/19/93. The system output as of $8 / 24 / 93$ meets the name-plate rating. Note: system monthly total AC and DC energy generated during the month of April was low due to the installation of the 6 new modules (system was down for approx. 51 hours).

The insulation was placed on the back of each module in the array to study the effect this might have on array degradation and performance. In-situ module performance characteristics were calculated based on temperature corrected/normalized data acquired using a portable IV curve tracer. This data showed as temperature dropped so did power and as temperature increased the power also increased. It was also seen that this trend deviated from that of the fill factor after $12 / 31 / 92$. Isc and Imax also rose as temperature increased after $12 / 31 / 92$. These changes are thought to be related to the increased module operating temperature, thus offsetting the effect of light induced degradation. However, seasonal changes in the solar spectrum may have played a prominent role here as well.

The degradation of the array was found to be about $20 \%$ based on the earliest measured array efficiency. This result is somewhat supported by the $21 \%$ module degradation determined from individual module IV data gathered $9 / 92$ and 8/93. 


\section{Performance of a $1.8 \mathrm{kWac}$ Dual-Junction Amorphous Silicon System}

Presented by:

Troy Strand (Staff Engineer)

September 8, 1993 
Acknowledgements:

This work was supported by the United States Department of Energy under contract \#DE-AC02-83CH10093

Robert Hansen (NREL)

(major contributions to the successful installation of the system)

Steve Rummel and Yehoshua Caiyem (NREL)

(module baseline measurements)

Dave Waddington (formerly of NREL)

(technical discussions)

Dr. Robert Ross (United Solar Systems Corp.) 


\section{OPNeI}

National Renewable Energy Laboratory

\section{Objective:}

$\simeq$ Evaluate the performance of a dual-junction amorphous

$\infty$ photovoltaic array in a utility-interconnect application. 
ARRAY SPECIFICATIONS:

\begin{tabular}{||l|l|}
\hline OPEN-CIRCUIT VOLTAGE (STC) & \pm 374 VOLTS \\
\hline SHORT-CIRCUIT CURRENT (STC) & \pm 5.4 AMPERES \\
\hline VOLTAGE @ MAX. POWER (STC) & \pm 265 VOLTS \\
\hline CURRENT @ MAX. POWER (STC) & \pm 4.2 AMPERES \\
\hline MAX. POWER (STC) & $2.2 \mathrm{~kW}$ \\
\hline SYSTEM VOLTAGE & 748 VOLTS \\
\hline
\end{tabular}

SYSTEM SPECIFICATIONS: 
ARRAY CONFIGURATION (4/20/93 to present):

POSITIVE SUBARRAY:

3 PARALLEL STRINGS OF 17 MODULES IN SERIES

NEGATIVE SUBARRAY:
3 PARALLEL STRINGS OF 17 MODULES IN SERIES

ARRAY CONFIGURATION (prior to 4/20/93):

POSITIVE SUBARRAY:

3 PARALLEL STRINGS OF 16 MODULES IN SERIES

NEGATIVE SUBARRAY:

3 PARALLEL STRINGS OF 16 MODULES IN SERIES 


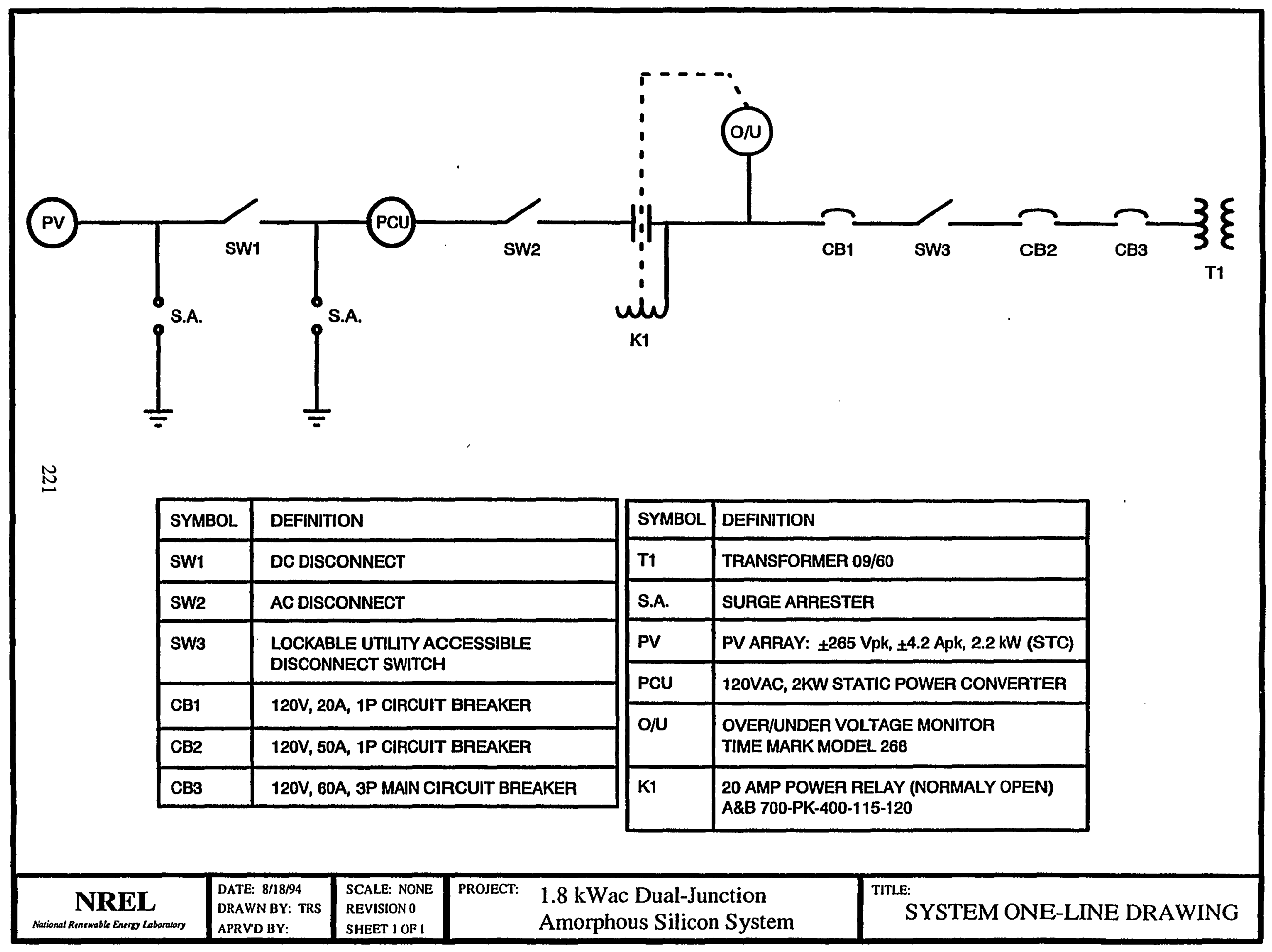




\section{POWER QUALITY:}

(as measured by PSCC on 2/5/93@11:52am using a BMI 3030A Power Profiler) IRRADIANCE AT TIME OF TEST WAS APPROX. $1017 \mathrm{~W} / \mathrm{m}^{2}$

\begin{tabular}{||l|l||}
\hline PARAMETER: & MEASURED VALUE: \\
\hline VOLTAGE THD & $7.1 \%$ \\
\hline CURRENT THD & $1.4 \%$ \\
\hline POWER & $1.732 \mathrm{kWac}$ \\
\hline CURRENT & $13.7 \mathrm{Amps}$ \\
\hline VOLTAGE & $127.7 \mathrm{Vrms}$ \\
\hline N-GND VOLTAGE & $3.3 \mathrm{Vmms}$ \\
\hline POWER FACTOR & $0.99 \mathrm{PF}$ \\
\hline
\end{tabular}


SYSTEM MONTHLY TOTALS FOR:

DC ENERGY, AC ENERGY AND POA IRRADIANCE

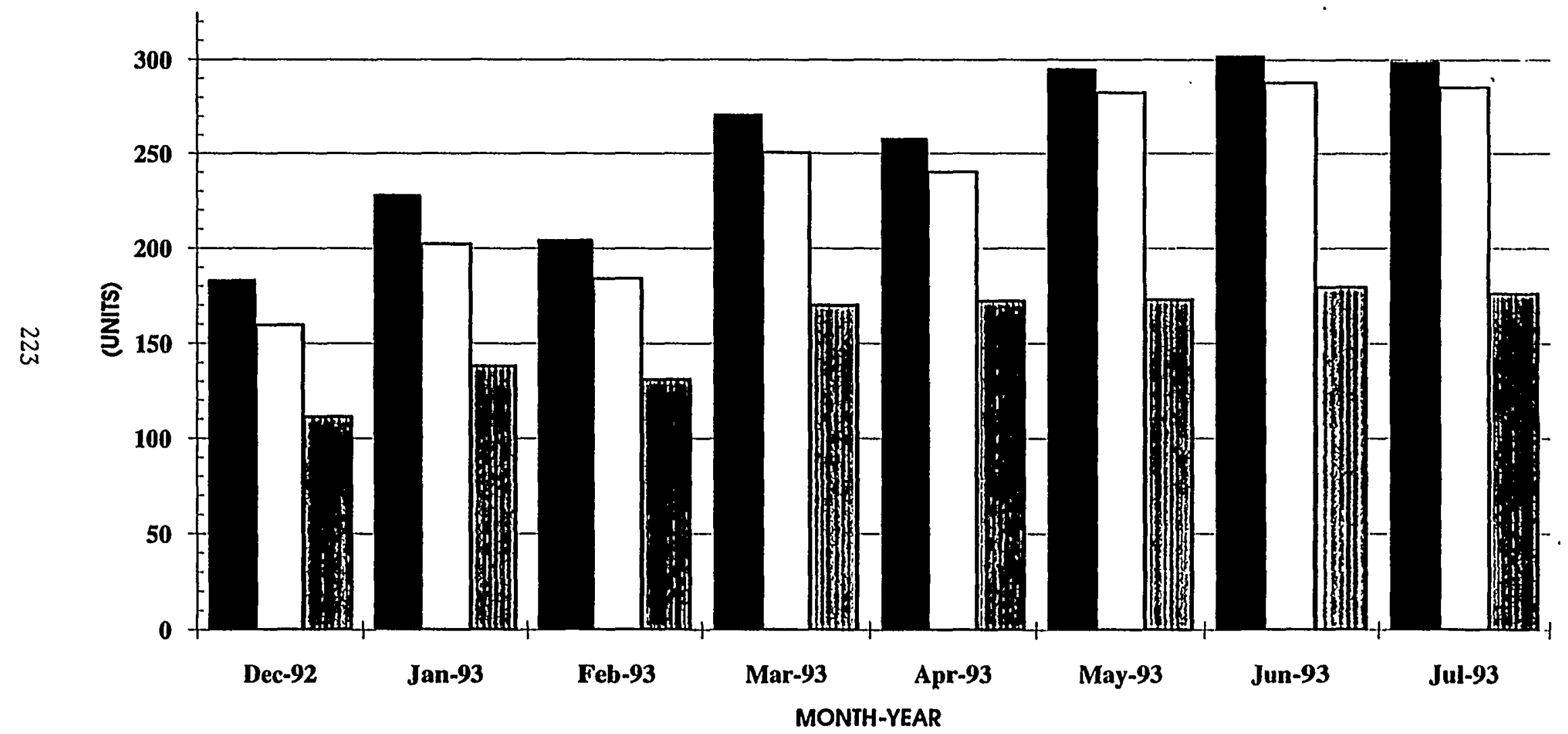

\begin{tabular}{|lll}
\hline DC ENERGY (kWh) & $\square$ AC ENERGY (kWh) $\quad$ O POA IRRADIANCE (kWh/sq. m) \\
\hline
\end{tabular}


$1.8 \mathrm{kWaC}$ UTILITY INTERCONNECT PHOTOVOLTAIC SYSTEM PERFORMANCE SYSTEM PERFORMANCE FOR APRIL 23, 1993 (BEST DAY)

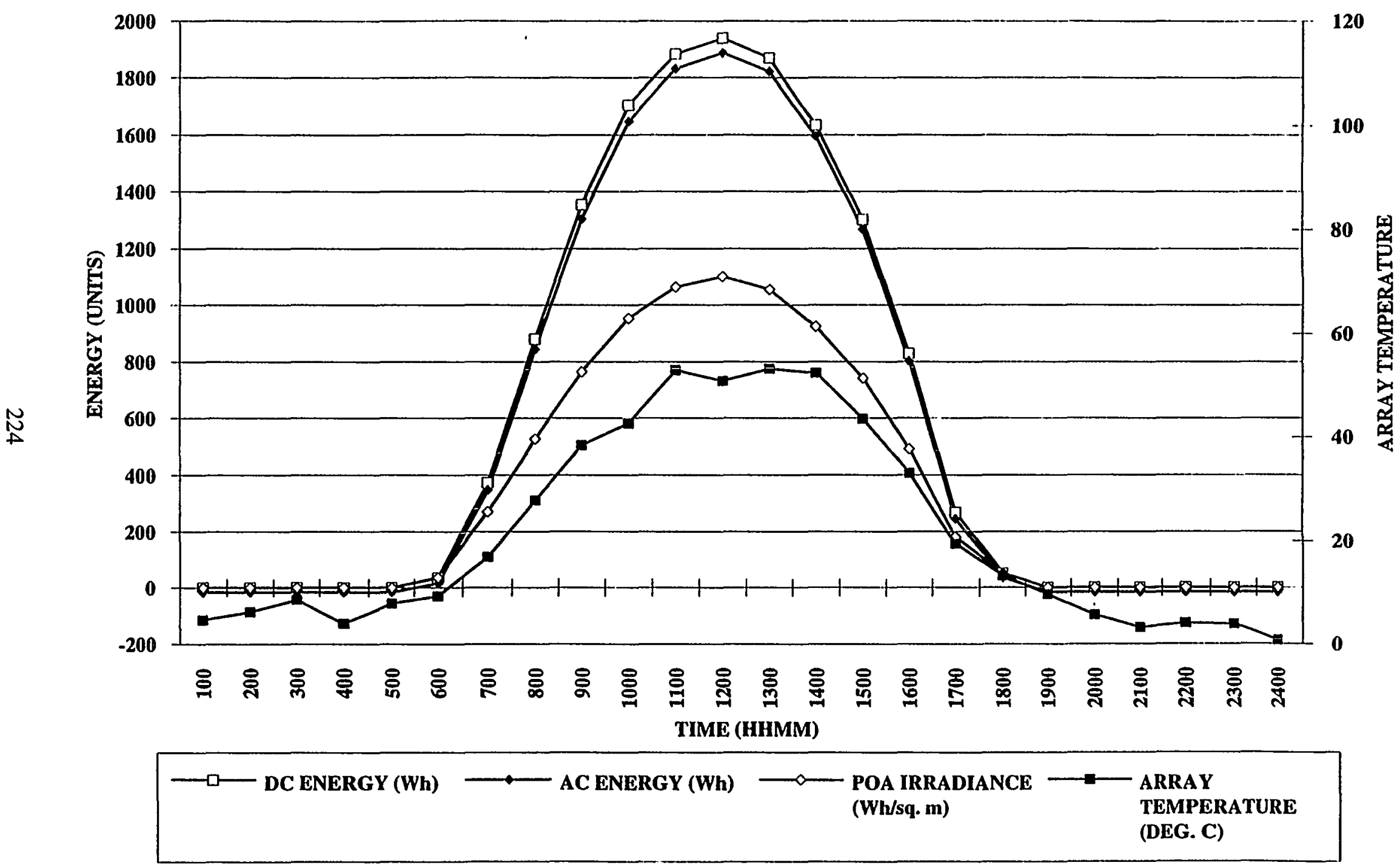


96 MODULE (3/24/93) AND 102 MODULE (8/24/93) AC RATINGS. BASED ON BEST DAY

PERFORMANCE (C.F. $=28.7,30.2 \%$ on $3 / 24$ and $8 / 23$ )

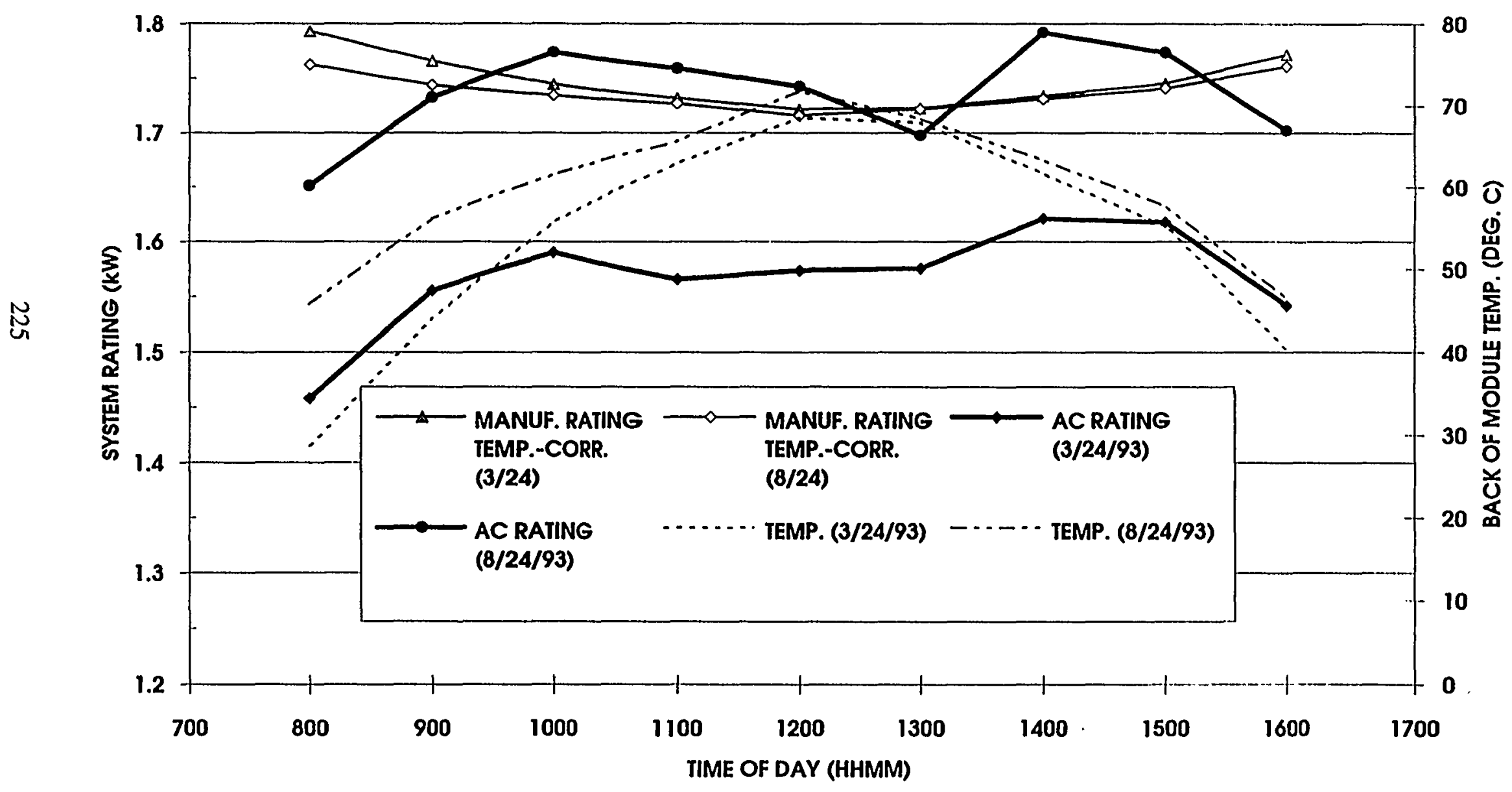




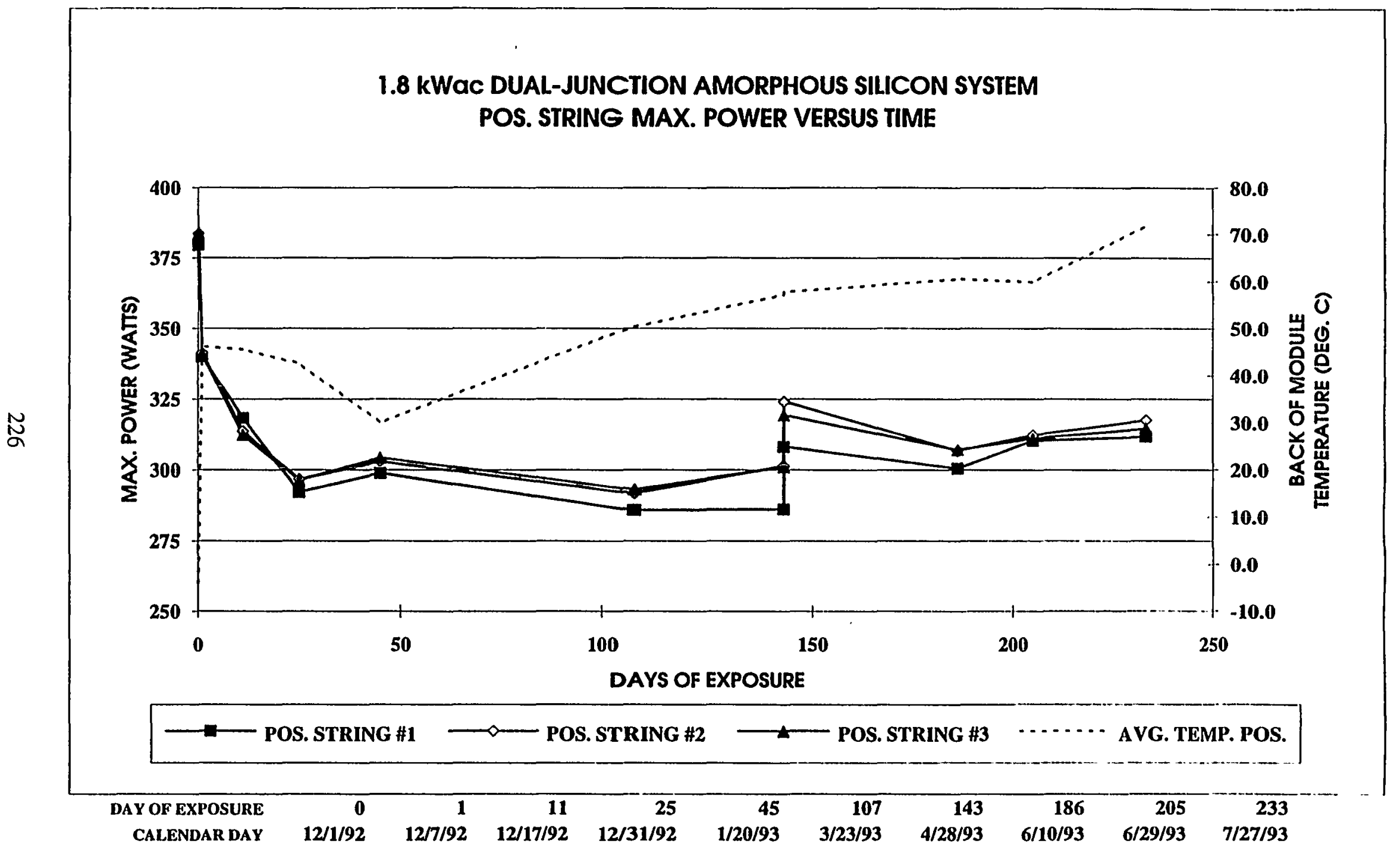


1.8 kWaC DUAL-JUNCTION AMORPHOUS SILICON SUBARRAY DEGRADATION TREND FOR APERTURE EFFICIENCY

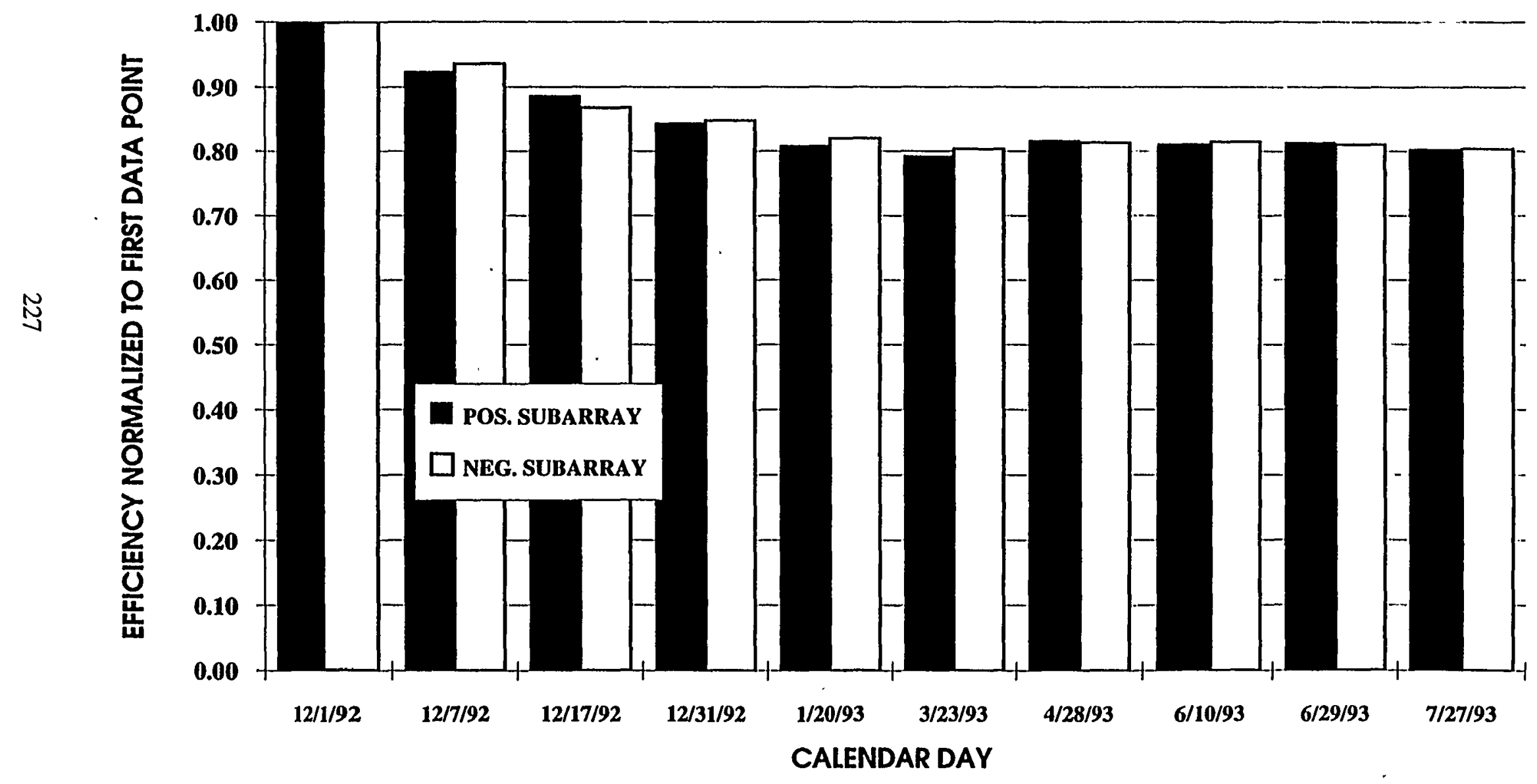


POS STRING \#1: IV CURVES NORMALIZED TO 1000W/sq. m (NO TEMP.-CORRECTION)

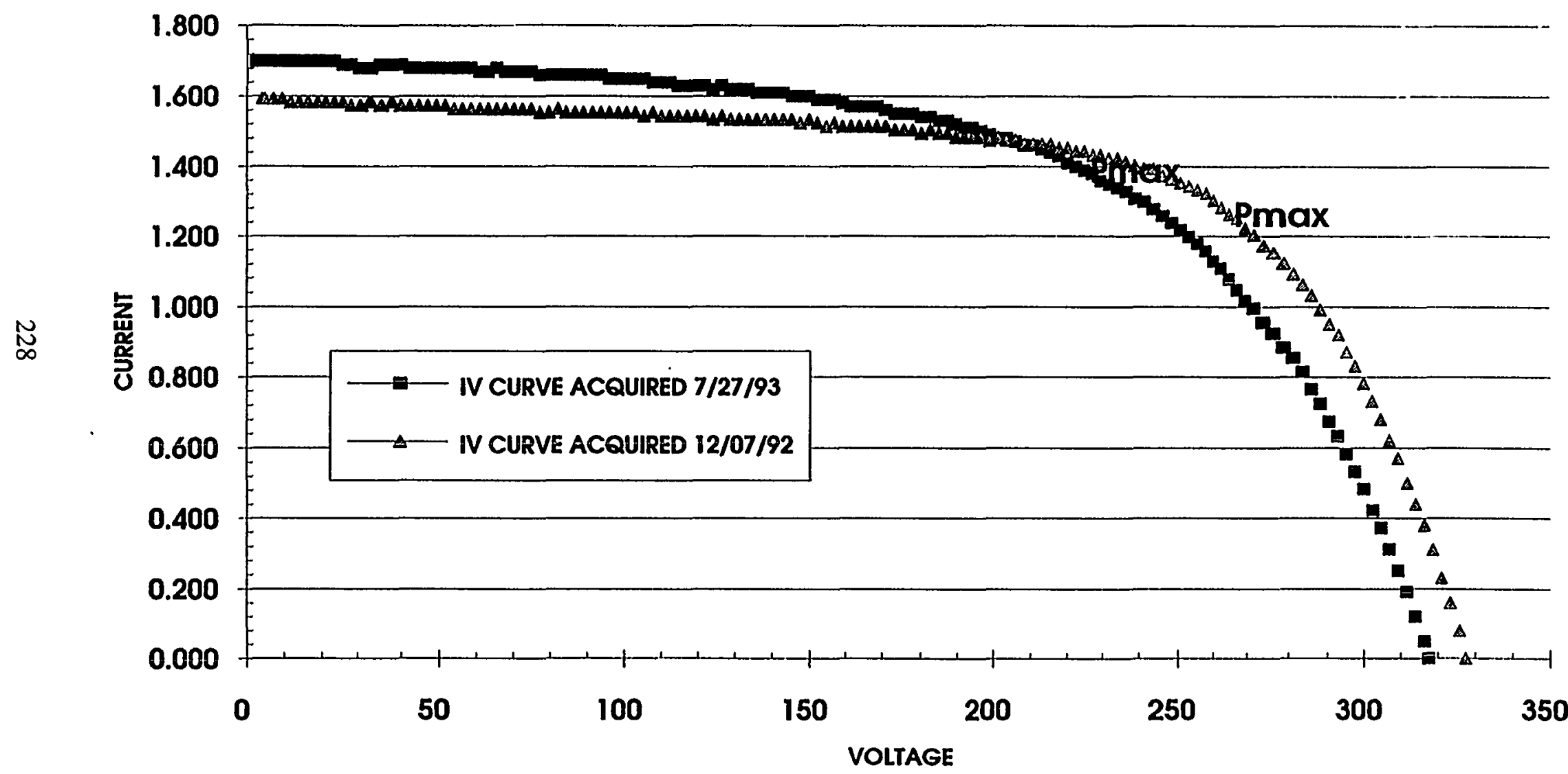

7/27/93: Isc=1.703, Voc=317.578, lpk=1.393, Vpk=225.147, Pmax=313.568, FF=58.005, TEMP.=71.6 12/7/92: Isc=1.594, Voc=327.393, lpk=1.346, Vpk=253.125, Pmax=340.702, FF=65.294, TEMP.=47.6 
IN-SITU MODULE MAX. POWER TREND: BASED ON POS. AND NEG. SUBARRAY IV DATA. (Vmax: TEMP.-CORRECTED USING MANUF.-SUPPLIED COEFF. OF -0.3\%/DEG. C ABOVE 25 DEG. C PER MODULE. ImaX: NORMALIZED TO $1000 \mathrm{~W} / \mathrm{sq} . \mathrm{m}$ )

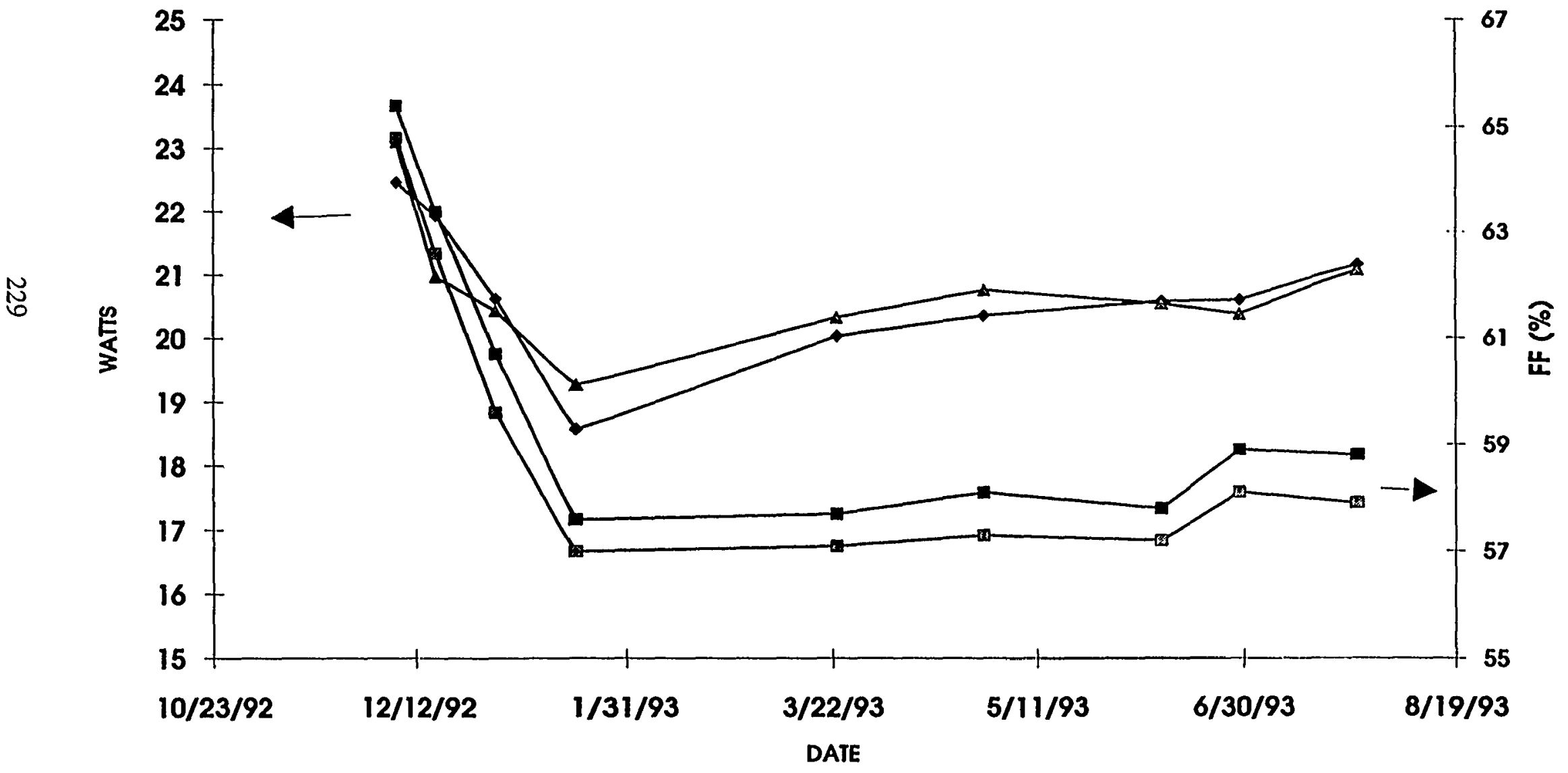


IN-SITU MODULE SHORT CIRCUIT CURRENT AND MAX. POWER CURRENT TRENDS: BASED ON POS. AND NEG. SUBARRAY IV DATA.

(DATA NORMALIZED TO $1000 \mathrm{~W} / \mathrm{sq} . \mathrm{m}$ )

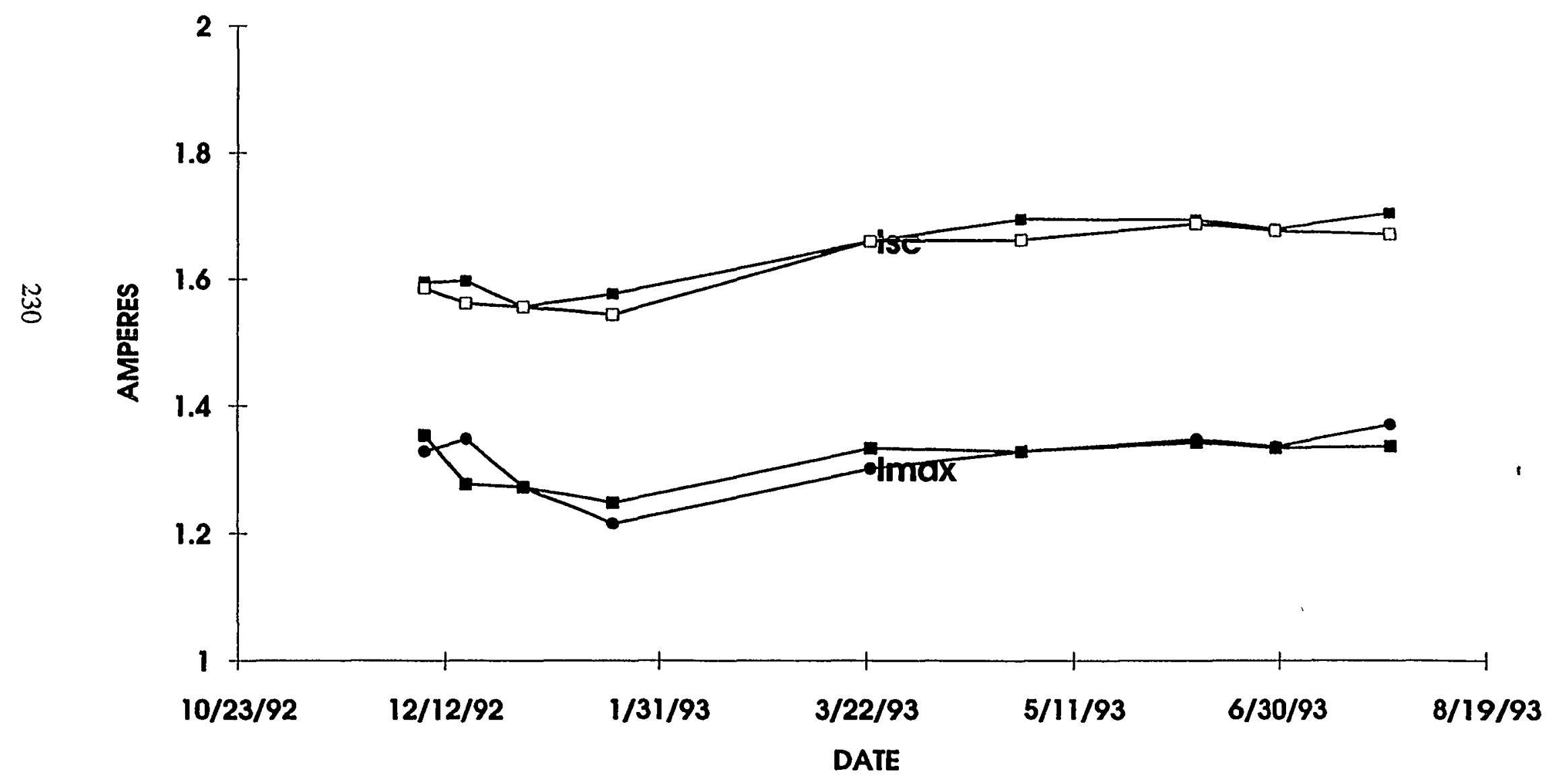


IN-SITU MODULE OPEN CIRCUIT VOLTAGE AND MAX POWER VOLTAGE TRENDS: BASED ON POS. AND NEG. SUBARRAY IV DATA

(DATA TEMP.-CORRECTED USING MANUF.-SUPPLIED COEFF. OF -0.3\% /DEG. C ABOVE 25 DEG. C PER MODULE)

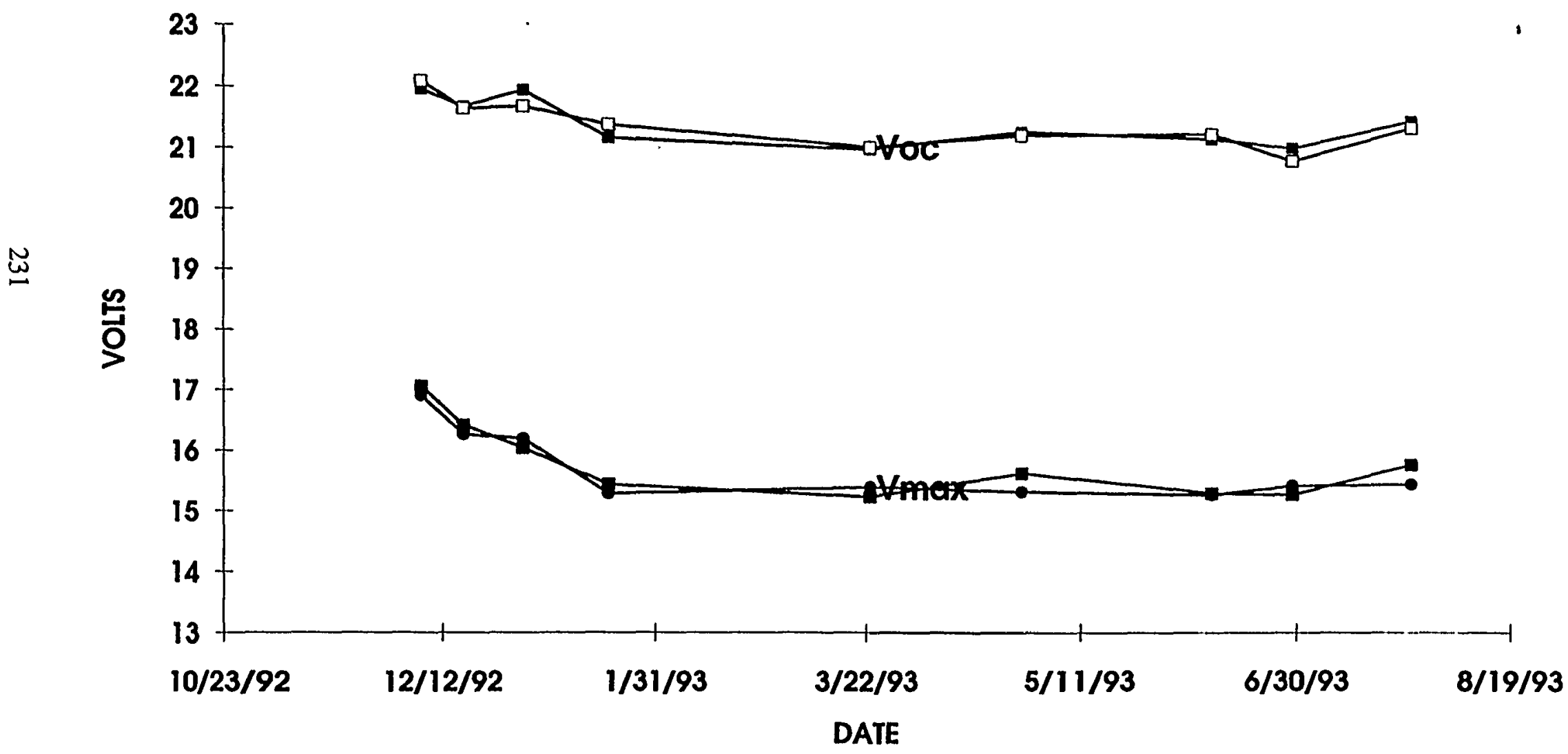


CHANGES IN MODULE PERFORMANCE CHARACTERISTICS

AFTER 246 DAYS OF EXPOSURE.

BASED ON 6 MODULES TESTED 8/23/93, NORMALIZED TO THE AVERAGE BASELINE DATA.

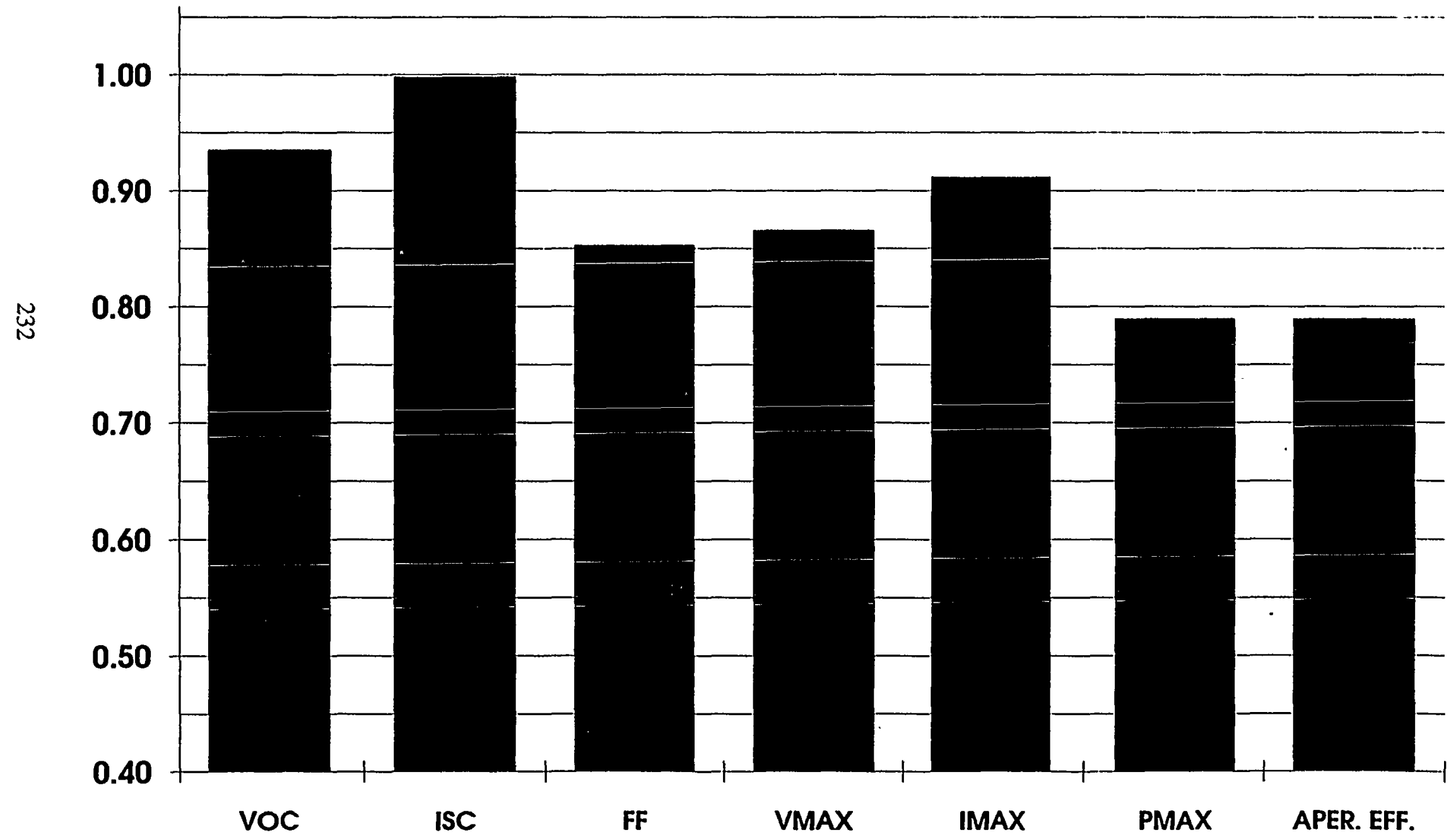




\section{Gin}

National Renewable Energy Laboratory

\section{SYSTEM EXPERIENCES:}

Problem:

- Inverter would not start in the early morning (subarray voltages were being driven down to $195 \mathrm{~V}$ by the Control Board while attempting to start)

- Positive and negative array voltages differed by as much as $110 \mathrm{~V}$ and as little as $3 \mathrm{~V}$

Fix:

- Replaced Control Board 1/4/93 
$1.8 \mathrm{kWaC}$ UTILITY INTERCONNECT PHOTOVOLTAIC SYSTEM PERFORMANCE FOR DEC. 14, 1992

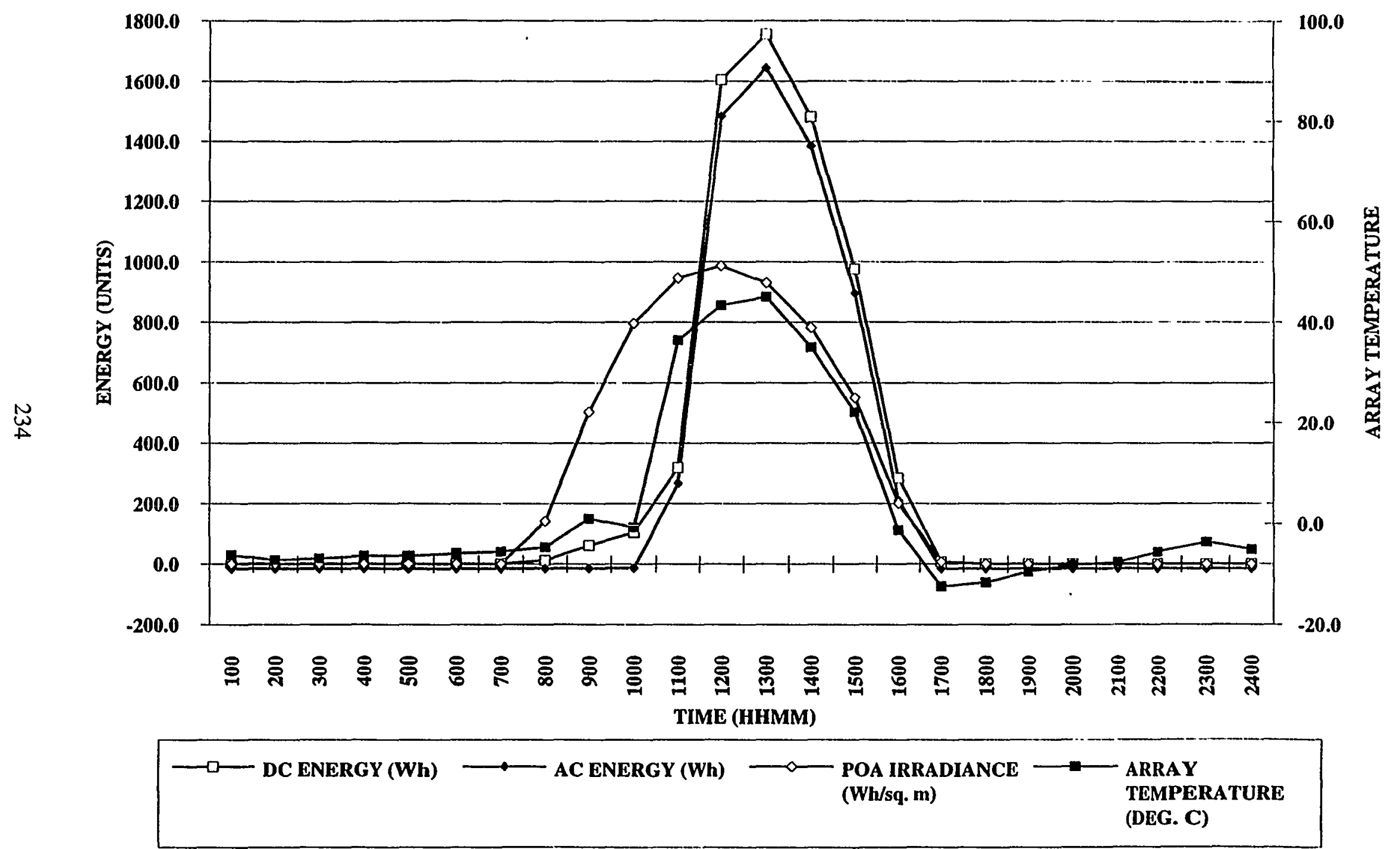




\section{SYSTEM EXPERIENCES:}

\section{Problem:}

- One module out of 108 exhibited a dip in its IV curve

$\widetilde{\widetilde{U}}$

Fix:

- Manufacturer supplied replacement module under warranty 


\section{OUTDOOR TEST 92A45 RUN No - 2}

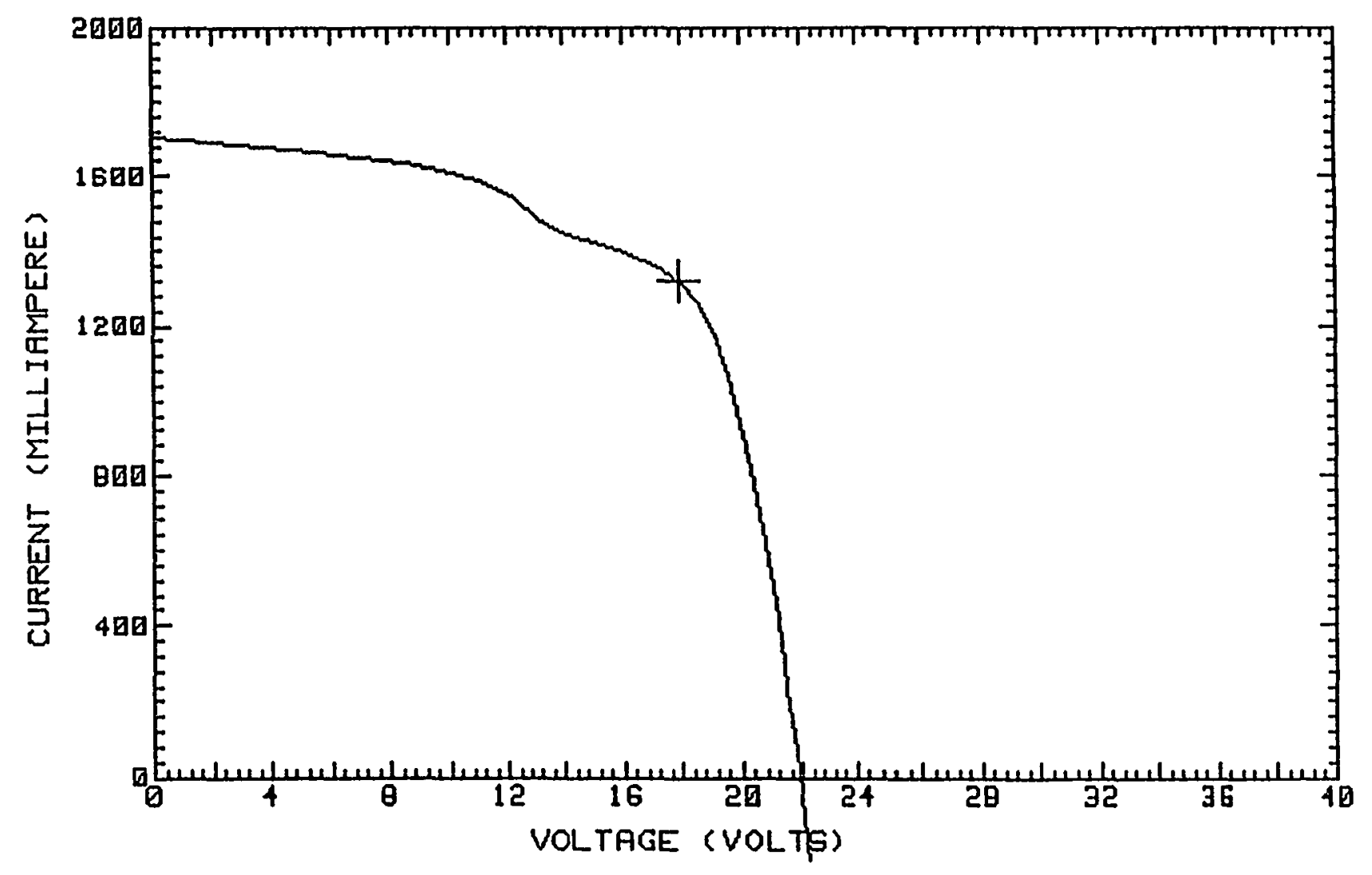




\section{CONCLUSIONS:}

System performance:

- System performance on $3 / 24 / 93$ was approx. $8.6 \%(-148 W)$ below system nameplate rating of $1.8 \mathrm{kWac}$. Addition of 6 modules (one per string) elevated system performance approx. $1.6 \%(+27 \mathrm{~W})$ above the nameplate rating as measured on $8 / 24 / 93$.

- Positive and negative subarrays have degraded approx. $20 \%$ with respect to earliest measured subarray efficiencies.

- Voltage THD of $7.1 \%$ is outside of PSCC's acceptable limits. Most probable cause is line impedance as indicated by a $4 \mathrm{~V}$ voltage drop between the inverter and $\mathrm{AC}$ utility disconnect switch. 


\section{CONCLUSIONS:}

Module performance:

- Module power, as measured on 7/27/93 in-situ, was determined to be within approx. $4.1 \%$ of manufacturer's un rated power.

- Modules have exhibited approx. a $21 \%$ degradation in efficiency as determined by IV traces acquired during baseline measurements and on $8 / 23 / 93$ (data gathered via a portable IV curve tracer).

- Average and maximum Capacity Factors for the period beginning $12 / 7 / 92$ and ending $8 / 31 / 93$ were $16.5 \%$ and $31.4 \%$ respectively. 


\title{
THE VIRGINIA
}

SOLAR PHOTOVOLTAIC MANUFACTURING INCENTIVE GRANT PROGRAM (SPMIGP)

\author{
Draft Guidelines
}

September 1, 1993

\section{DEFINITIONS}

\subsection{ASTM American Society for Testing and Materials}

1.2 Concentrating Collector A photovoltaic panel, environmentally protected, which consists of photovoltaic cells, a lens or device to focus light on the photovoltaic cells, an assembly to hold the lens or focusing device, and the photovoltaic cells in fixed positions relative to each other, a secondary concentrator to reflect off-center light rays onto the cells, and a means to dissipate excess heat produced by concentrated sunlight.

1.3 Environmentally Protected Covered and shielded from injury and destruction from outdoor climatic conditions including, but not limited to, rain, snow and wind.

1.4 Flat-Plate, Non-Concentrating Collector A photovoltaic panel which contains photovoltaic cells that are mounted on a rigid, flat surface beneath a transparent cover, and is environmentally protected.

1.5 Independent Testing Laboratory A testing laboratory not associated or affiliated with a photovoltaic panel manufacturer. A photovoltaic panel manufacturer, its parent companies or subsidiaries cannot have a financial interest in an independent testing laboratory, its parent companies or subsidiaries, employed to conduct tests for the SPMIGP.

1.6 Manufactured in Virginia A photovoltaic panel is considered as manufactured in Virginia when the following criteria are satisfied.

1.6.1 The substances, materials, films, crystals, or devices which produce electricity directly from incident solar radiation, and photovoltaic cells and photovoltaic modules using these substances, materials, films, crystals, or devices, are made, fabricated, constructed, or processed in Virginia from raw materials.

1.6.2 The photovoltaic cells and modules are assembled in Virginia with other components to form a complete photovoltaic panel which can produce electrical energy in a usable form, independent of any other 
device, suitable for connection to an electrical load.

1:7 Maximum Power Output The electrical output of a photovoltaic cell, module, or panel when operated at a point of its current-voltage characteristic curve in the power-producing quadrant where the product of current and voltage is a maximum.

1.8 Photovoltaic Module An assembly of two or more photovoltaic cells which are interconnected electrically.

1.9 Photovoltaic Panel A complete, environmentally protected assembly of one or more photovoltaic modules, mechanically fastened together and electrically wired together, which is capable of independent production of usable electrical energy, suitable for connection to an electrical load. The assembly consists of photovoltaic cells, electrical circuitry, optics, and housings. The assembly does not include tracking equipment or panel mounting systems.

1.10 Photovoltaic Cell The basic device which can produce electricity directly from incident solar radiant energy.

1.11 Randomly Selected Selecting out or choosing on a chance basis, in a manner to ensure that an object chosen has had an equal probability of being chosen as had the other objects capable of being chosen.

1.12 Rated Wattage The rated wattage of a photovoltaic panel to be used in determining the amount of the grant for which the panel manufacturer is eligible under the SPMIGP is the maximum power output as measured at the time the photovoltaic panel is constructed multiplied by the Solar Radiation Exposure Factor.

1.13 Solar Radiation Exposure Factor A weighting factor ranging in value from 0.0 to 1.0 which characterizes the decrease in generation of electricity by a photovoltaic panel due to the effects of incident sunlight over a specified period of time.

1.14 Usable Electrical Energy Electricity convenient and practicable for doing work.

\section{TEST PROTOCOLS}

\section{$2.1 \quad$ General Conditions}

2.1.1 Each model of photovoltaic panel for which a grant is requested from the SPMIGP is to be tested in compliance with the procedures and standards published in these guidelines. 
2.1.2 All costs associated with testing photovoltaic panels in accordance with these guidelines are the responsibility of the photovoltaic panel manufacturer.

2.1.3 The Commonwealth of Virginia reserves the right to require the retesting of photovoltaic panels in accordance with these guidelines at any time if the Commonwealth has reason to believe these guidelines are not being followed. All costs associated with the retests will be the responsibility of the photovoltaic panel manufacturer.

\subsection{Solar Radiation Exposure Factor}

2.2.1 The Solar Radiation Exposure Factor of a photovoltaic panel which uses crystalline silicon to produce electricity from incident solar radiation is 1.0 .

2.2.2 The Solar Radiation Exposure Factor of a photovoltaic panel which uses amorphous silicon to produce electricity from incident solar radiation will be 0.85 unless the panel manufacturer chooses to have the Solar Radiation Exposure Factor determined experimentally by an independent testing laboratory, in accordance with the procedures described in section 2.2.4.

2.2.3 The Solar Radiation Exposure Factor of a photovoltaic panel which uses a material other than crystalline silicon or amorphous silicon to produce electricity from incident solar radiation will be determined experimentally by an independent testing laboratory, in accordance with the procedures described in section 2.2.4.

\subsubsection{Experimental Testing Procedures}

\subsubsection{Selection of Test Samples}

a. A minimum of six (6) photovoltaic panels will be tested.

b. The photovoltaic panels are to be randomly chosen by a representative of the independent testing laboratory from among all of the panels manufactured during the twelve (12) month period prior to the beginning of the tests.

c. After a photovoltaic panel has been selected for testing, the panel is not to leave the control of a representative of the independent testing laboratory. 
d. A photovoltaic panel selected for testing is not to be pretested, modified, improved, or altered in any manner after its selection for testing.

e. Prototype panels cannot be used for testing.

f. Solar Radiation Exposure Testing must be performed after any major change in the design or construction of a photovoltaic panel or after a major change in the photovoltaic panel manufacturing process that will affect the rated wattage of the photovoltaic panel.

\subsubsection{Test Procedures}

a. Before a photovoltaic panel is exposed to direct solar radiation, the electrical performance of the panel is to be measured in accordance with the procedures presented in section 2.4 .2 of these guidelines.

b. Each photovoltaic panel will be exposed to direct solar energy for a sixty (60) day period.

1) Mount each photovoltaic panel so that it faces due south.

2) Mount each photovoltaic panel with a slope so that the panel surface is normal to direct solar radiation at solar noon on day thirty (30) of the sixty $(60)$ day test.

3) The photovoltaic panels will be operational and generate electricity throughout the duration of the sixty (60) day test period.

4) The average daily incident solar radiation throughout the duration of the test will be a minimum of 750 Watts per square meter.

c. Beginning on day thirty-one (31) of the test period, the electrical performance of the photovoltaic panel is to be measured daily in accordance with the procedures presented in section 2.4 .2 of these guidelines.

d. The Solar Radiation Exposure Factor for a photovoltaic panel is the maximum power output of the panel measured immediately after the day sixty (60) test period 
has been completed divided by the maximum power output of the panel measured before exposure to direct solar radiation.

e. The Solar Radiation Exposure Factor to be used in calculating the rated wattage of photovoltaic panels is the arithmetic average of the Solar Radiation Exposure Factors for the six (6) test panels.

\subsubsection{Reporting of Test Results}

a. Report test results in accordance with Section 3 of these guidelines.

\subsubsection{Certification of Test Results}

a. The test results are to include the name, address, and telephone number of the independent testing laboratory employee responsible for testing the photovoltaic panels.

b. The test results will have an original signature by the independent testing laboratory employee responsible for testing the photovoltaic panels.

\subsection{Electrical Performance Testing}

2.3.1 The electrical performance of each photovoltaic panel shall be measured by the manufacturer at the time the panel is constructed in accordance with the applicable methods which follow.

2.3.2 Electrical Performance Test Standards Photovoltaic panels are to be tested in accordance with one of the following test procedures and comply with each of the standards published in the procedure.

2.3.2.1 Non-Concentrating Collectors The electrical performance test is to be performed in accordance with ASTM Standard E1036, "Standard Methods of Testing, Electrical Performance of Nonconcentrator Terrestrial Photovoltaic Modules and Arrays Using Reference Cells", reference 1.

2.3.2.2 Concentrating Collectors The electrical performance test is to be performed in accordance with ASTM Standard E1036, "Standard Methods of Testing, Electrical Performance of Nonconcentrator Terrestrial Photovoltaic Modules and Arrays Using Reference Cells", reference 1, with the following changes in rated output conditions to those published in Table 1, 
paragraph 5.3 of reference 1.

a. Irradiance: 850 Watts per square meter

\subsubsection{Test Equipment Calibration}

2.3.3.1 Test equipment used by the photovoltaic panel manufacturer to determine the electrical performance of the panels is to be recalibrated on the schedule recommended by the test equipment manufacturers and by the standards referenced in 2.3.2.

\subsubsection{Reporting of Test Results}

2.3.4.1 Report test results in accordance with Section 3 of these guidelines.

\subsubsection{Certification of Test Results}

2.3.5.1 The test results are to include the name, address, and telephone number of the photovoltaic panel manufacturer's employee responsible for testing the photovoltaic panels.

a. The test results will have an original signature by the photovoltaic panel manufacturer's employee responsible for testing the photovoltaic panels.

\subsection{Electrical Performance Verification Testing}

2.4.1 The electrical performance of photovoltaic panels is to be measured periodically by an independent testing laboratory.

2.4.2 Electrical Performance Verification TestStandards Photovoltaicpanels are to be tested in accordance with one of the following test procedures and comply with each of the standards published in the procedure.

2.4.2.1 Non-Concentrating Collectors The electrical performance test is to be performed in accordance with ASTM Standard E1036, "Standard Methods of Testing, Electrical Performance of Nonconcentrator Terrestrial Photovoltaic Modules and Arrays Using Reference Cells", reference 1.

2.4.2.2 Concentrating Collectors The electrical performance test is to be performed in accordance with ASTM Standard E1036, "Standard Methods of Testing, Electrical Performance of Nonconcentrator Terrestrial Photovoltaic Modules and Arrays

Solar Photovoltaic Manufacturing Incentive Grant Program 
Using Reference Cells", reference 1, with the following changes in rated output conditions to those published in Table 1, paragraph 5.3 of reference 1 .

\section{a. Irradiance: 850 Watts per square meter}

\subsubsection{Selection of Test Samples}

2.4.3.1 A minimum of one (1) photovoltaic panel is to be tested for every 200,000 Watts of production or every six (6) months of production, whichever is more frequent.

2.4.3.2 Photovoltaic panels are to be selected for testing randomly from among all the photovoltaic panels manufactured since the preceding Electrical Performance Verification Test, or if there has been no preceding Electrical Performance Verification Test, from among all the photovoltaic panels manufactured since the start of production.

2.4.3.3 Photovoltaic panels are to be chosen by a representative of the independent testing laboratory conducting the Electrical Performance Verification Tests.

2.4.3.4 After a photovoltaic panel has been selected for Electrical Performance Verification Testing, the panel is not to leave the control of a representative of the independent testing laboratory.

2.4.3.5 A photovoltaic panel selected for Electrical Performance Verification Testing is not to be pretested, modified, improved, or altered in any manner after its selection for testing.

\subsubsection{Test Equipment Calibration}

2.4.4.1 Test equipment used by the photovoltaic panel manufacturer to determine the electrical performance of the panels is to be recalibrated on the schedule recommended by the test equipment manufacturers and by the standards referenced in 2.4.2.

\subsubsection{Certification of Test Results}

2.4.5.1 The test results are to include the name, address, and telephone number of the independent testing laboratory employee responsible for testing the photovoltaic panels.

2.4.5.2 The test results will have an original signature by the

Solar Photovoltaic Manufacturing Incentive Grant Program 
independent testing laboratory employee responsible for testing the photovoltaic panels.

\subsubsection{Reporting of Test Results}

2.4.6.1 Report the test results in accordance with Section 3 of these guidelines.

2.4.7 If the maximum power output value obtained during the Electrical Performance Verification Test is more than 10\% lower than the arithmetic average of the maximum power output values obtained by the photovoltaic panel manufacturer for all panels manufactured since the preceding Electrical Performance Verification Test, the maximum power output value obtained during the Electrical Performance Verification Test will be used to calculate the rated wattage of all panels manufactured since the preceding Electrical Performance Verification Test.

2.4.7.1 In the event that the maximum power output value obtained during the Electrical Performance Verification Test is more than $10 \%$ lower than the arithmetic average of the maximum power output values obtained by the photovoltaic panel manufacturer for all panels manufactured since the preceding Electrical Performance Verification Test, the photovoltaic panel manufacturer may choose to have additional panels undergo Electrical Performance Verification Testing. The arithmetic average of the maximum power output values obtained from the Electrical Performance Verification Testing of all panels, including the first test panel, will be used to calculate the rated wattage of all panels manufactured since the preceding Electrical Performance Verification Test.

2.4.8 If there has been no preceding Electrical Performance Verification Test, and if the maximum power output of the Electrical Performance Verification Test is more than $10 \%$ lower than the arithmetic average of the maximum power output values obtained by the photovoltaic manufacturer for all panels manufactured since the start of production, the maximum power output value obtained during the Electrical Performance Verification Test will be used to calculate the rated wattage of all panels manufactured since the start of production.

2.4.8.1 In the event that the maximum power output value obtained during the Electrical Performance Verification Test is more than $10 \%$ lower than the arithmetic average of the maximum power output values obtained by the photovoltaic panel manufacturer for all panels manufactured since the start of production, the 
photovoltaic panel manufacturer may choose to have additional panels undergo Electrical Performance Verification Testing. The arithmetic average of the maximum power output values obtained from the Electrical Performance Verification Testing of all panels, including the first test panel, will be used to calculate the rated wattage of all panels manufactured since the start of production.

\section{REPORTING OF TEST RESULTS}

3.1 A report summarizing all photovoltaic panel test results and test equipment calibrations for the preceding twelve month period will be submitted to the Director of the Virginia Department of Mines, Minerals, and Energy as part of the annual report of manufacturing and sales.

3.1.1 The summary report is to be divided into the following three sections.

\subsubsection{Solar Radiation Exposure Tests}

a. Solar Radiation Exposure Test results need to be submitted only in years during which testing takes place.

\subsubsection{Electrical Performance Testing}

\subsubsection{Electrical Performance Verification Testing}

3.2 The summary report will contain the following information.

\subsubsection{Manufacturer information}

3.2.1.1 name

\subsubsection{2 address}

3.2.1.3 telephone number

3.2.1.4 Virginia incorporation number or State Corporation Commission registration number (only if the manufacturer is a corporation)

3.2.1.5 Federal tax identification number

3.2.1.6 name of contact at manufacturer, with address and telephone number

\subsubsection{Photovoltaic panel information}

3.2.2.1 model name and number

3.2.2.2 panel serial number

3.2.2.3 nameplate ratings assigned by manufacturer

3.2.2.4 location of plant where photovoltaic panel was manufactured

Solar Photovoltaic Manufacturing Incentive Grant Program 
3.2.2.5 Report data for each photovoltaic panel tested

3.2.3 Independent testing laboratory information

3.2.3.1 name of laboratory

3.2.3.2 address

3.2.3.3 telephone number

3.2.3.4 name of individual responsible for testing, with address and telephone number

3.2.4 Test procedures

3.2.4.1 date(s) of tests

3.2.4.2 equipment used to perform tests

3.2.4.3 date of most recent calibration of test equipment, method of calibration, and results of calibration

3.2.4.4 statement of test procedures used

\subsubsection{Test results}

1 3.2.5.1 Information and data as required by the standards cited in sections 2.3 .2 and 2.4 .2 of these guidelines.

3.2.5.2 Test result certifications

\section{REFERENCES}

1. Electrical Performance of Non-concentrator Terrestrial Photovoltaic Modules and Arrays Using Reference Cells, ASTM Standard E1036, Philadelphia, PA, 1985. 


\section{DURABILITY AND RELIABILITY}




\section{Contact Corrosion on CdS/CdTe Solar Cells:}

a photoemission study of the formation of the $\mathrm{CdS} / \mathrm{SnO}_{2}$ interface

David Niles, Dennis Rioux, Rajesh Patel, and Hartmut Höchst

special thanks to

Kannan Ramanathan, Ramesh Dhere, Sally Asher, Amy Swartzlander, Art Nelson, Helio Moutinho and Al Czanderna 


\section{Application of Synchrotron Radiation UPS to CdS/CdTe contact formation}

- reason for studying the $\mathrm{SnO}_{2} / \mathrm{CdS}$ interface with synchrotron radiation UPS

- overview of synchrotron radiation UPS

- describe analysis of formation and electronic structure of the $\mathrm{SnO}_{2} / \mathrm{CdS}$ interface

- show band lineup at $\mathrm{SnO}_{2} / \mathrm{CdS}$ interface

- future work on problematic metal/CdTe interface 


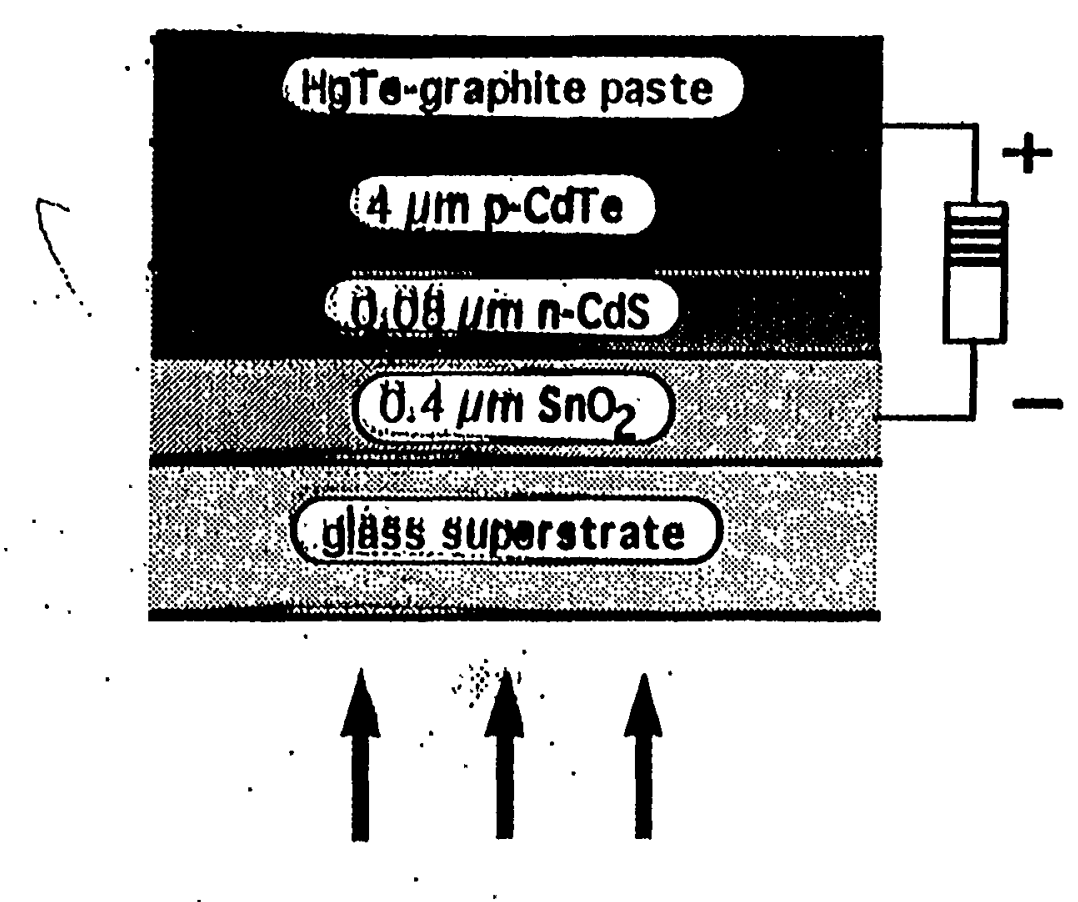

light

\section{Superstrat Geometry}

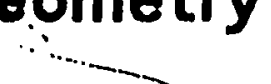

light

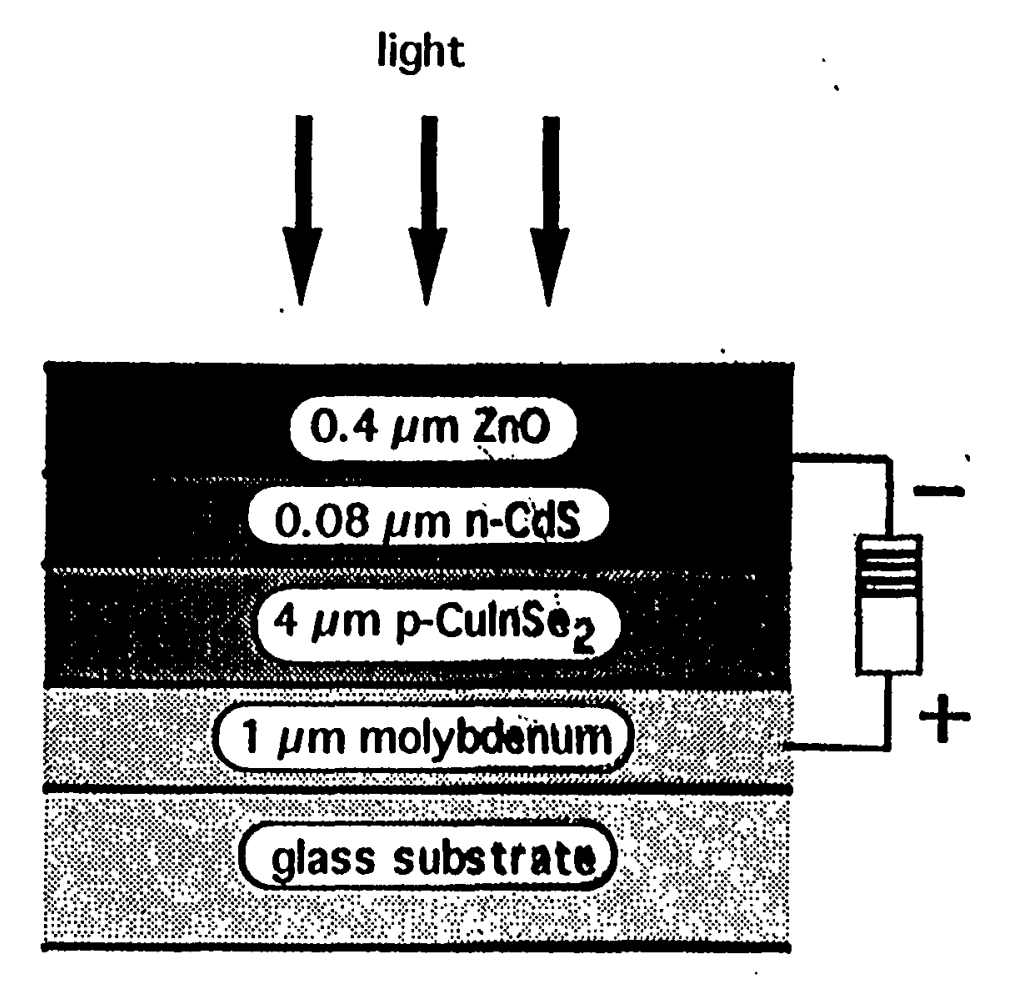

Substrate Geometry 


\section{Synchrotron Radiation Photoemission Spectroscopy}
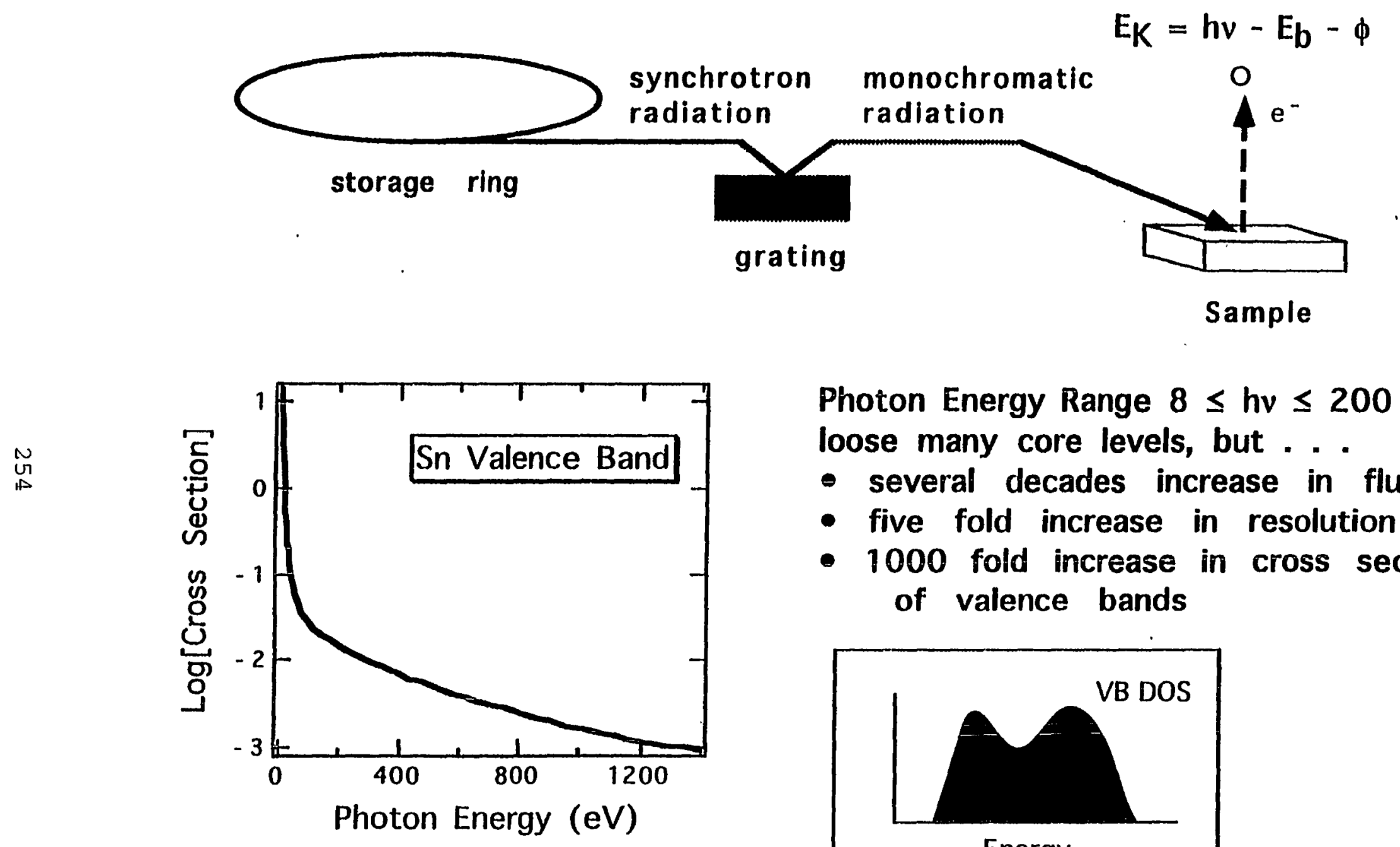

Photon Energy Range $8 \leq \mathrm{hv} \leq 200 \mathrm{eV}$ loose many core levels, but . . .

- several decades increase in flux

- five fold increase in resolution

- 1000 fold increase in cross section of valence bands

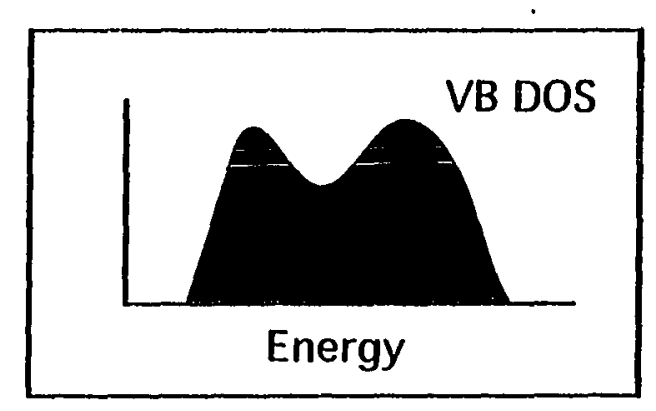




\section{Experimental Procedure:}

1. measure cleaned $\mathrm{SnO}_{2}$ surface

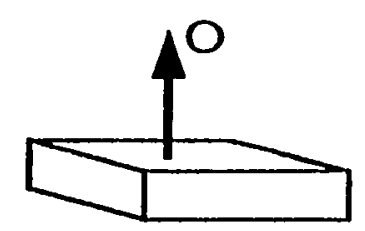

2. deposit thin (several A) CdS layer

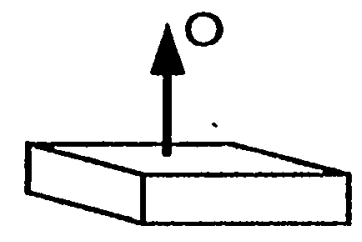

3. measure $\mathrm{CdS} / \mathrm{SnO}_{2}$ interface

4. deposit thick (100A) CdS layer

5. measure CdS surface

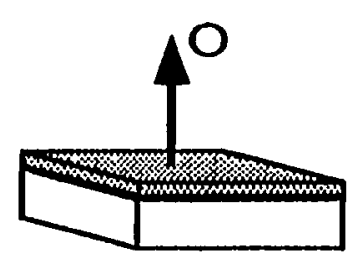




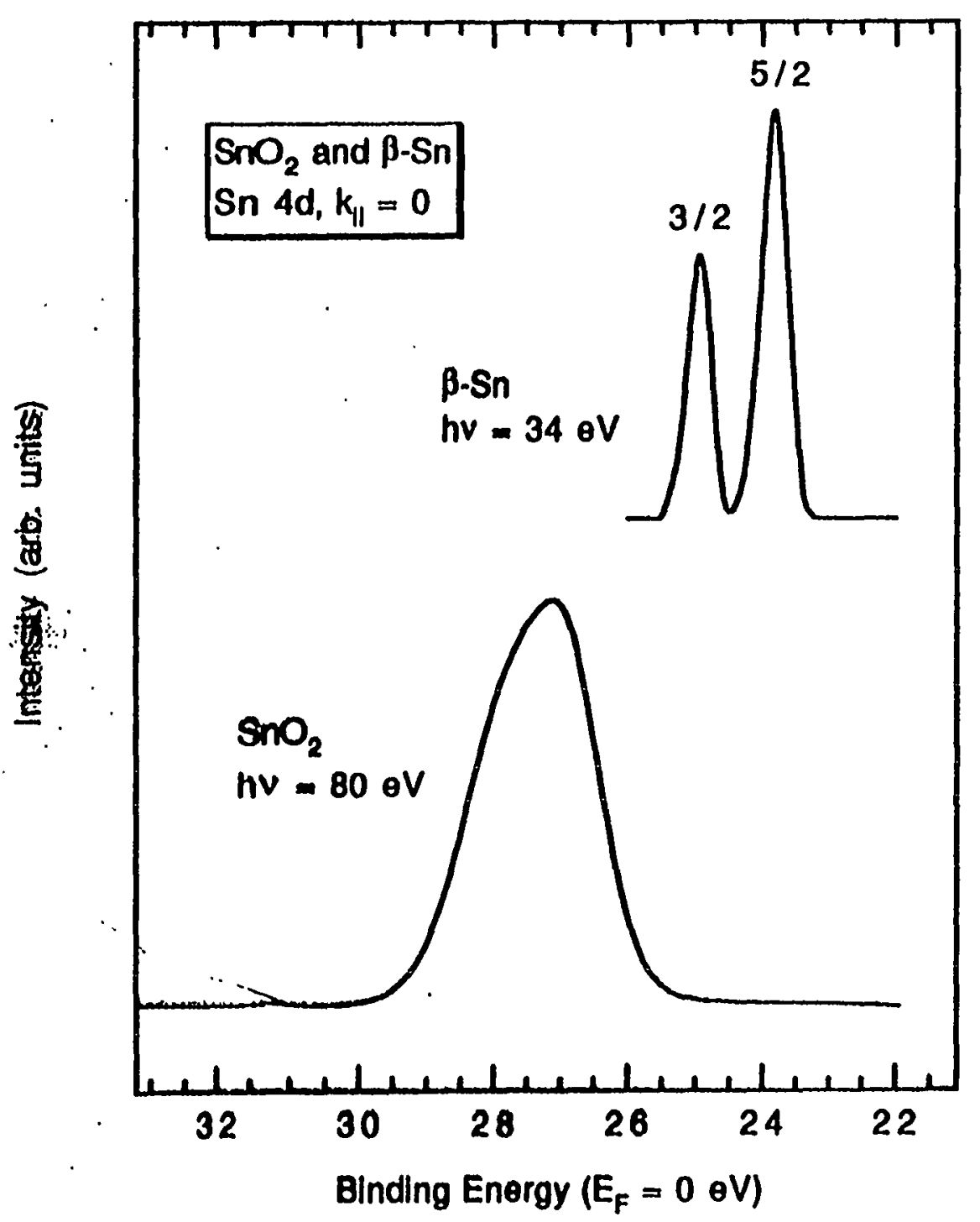

Dave Niles - NREL 


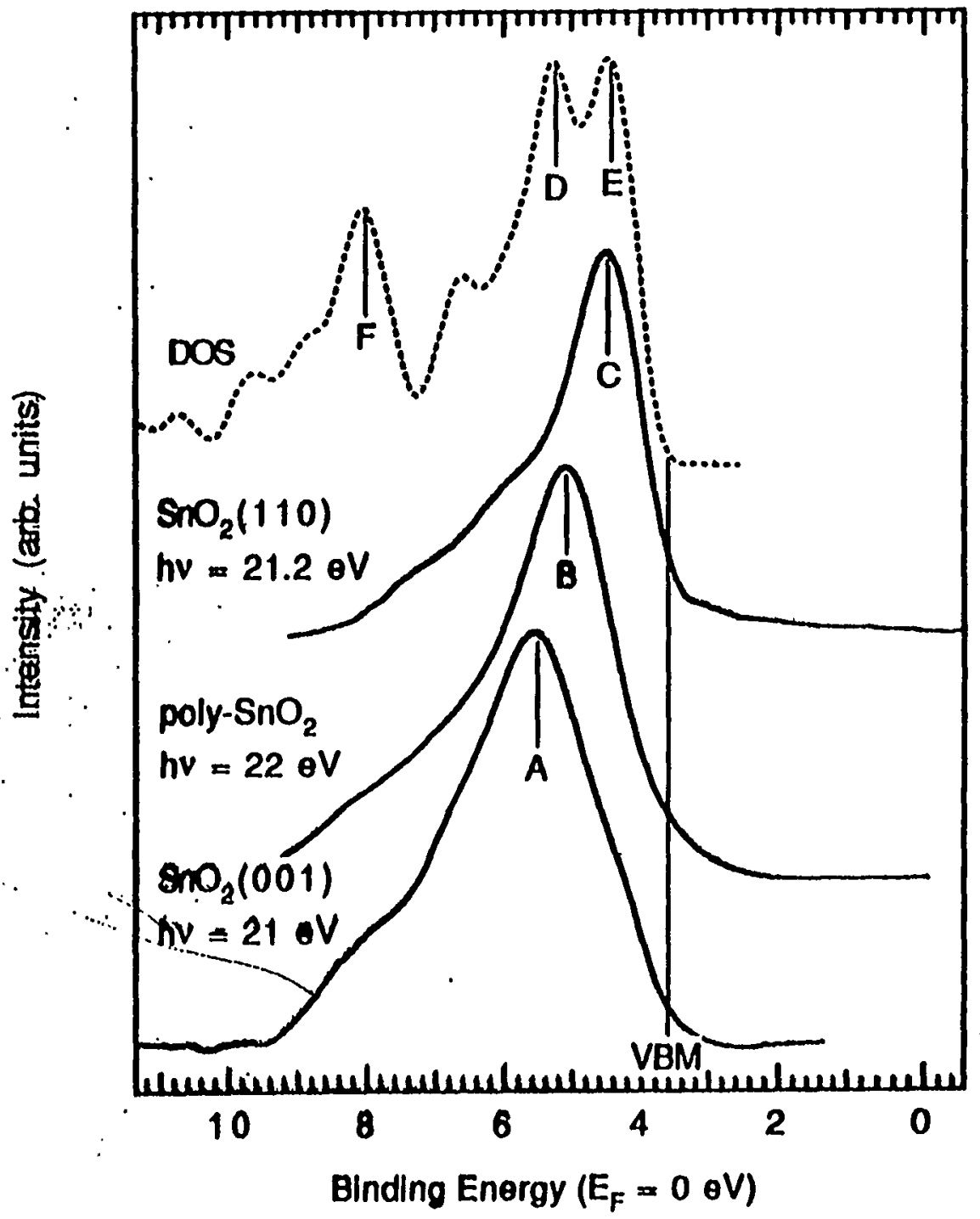

Dave NIIES - NREL 


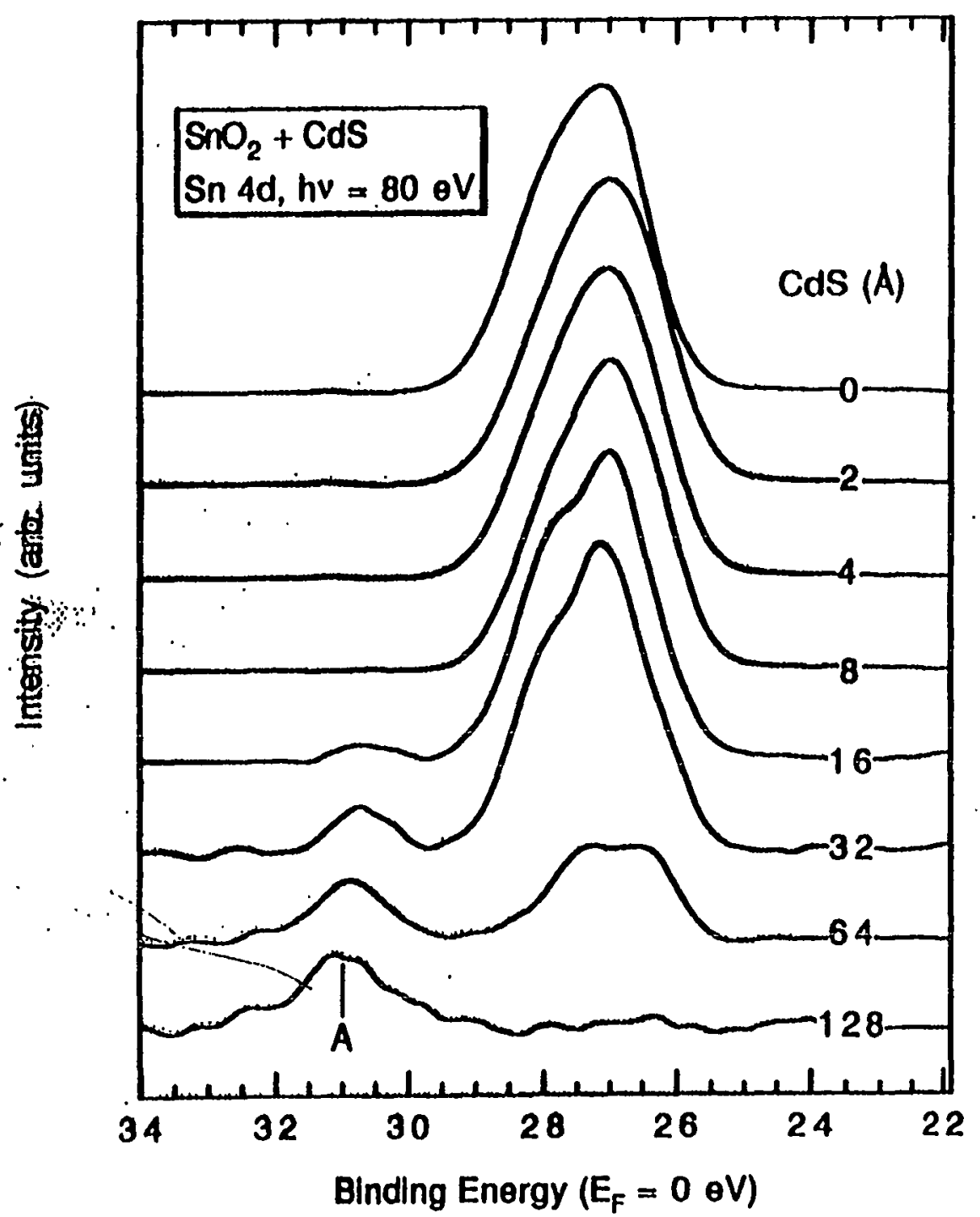

Dave Niles - NREL 


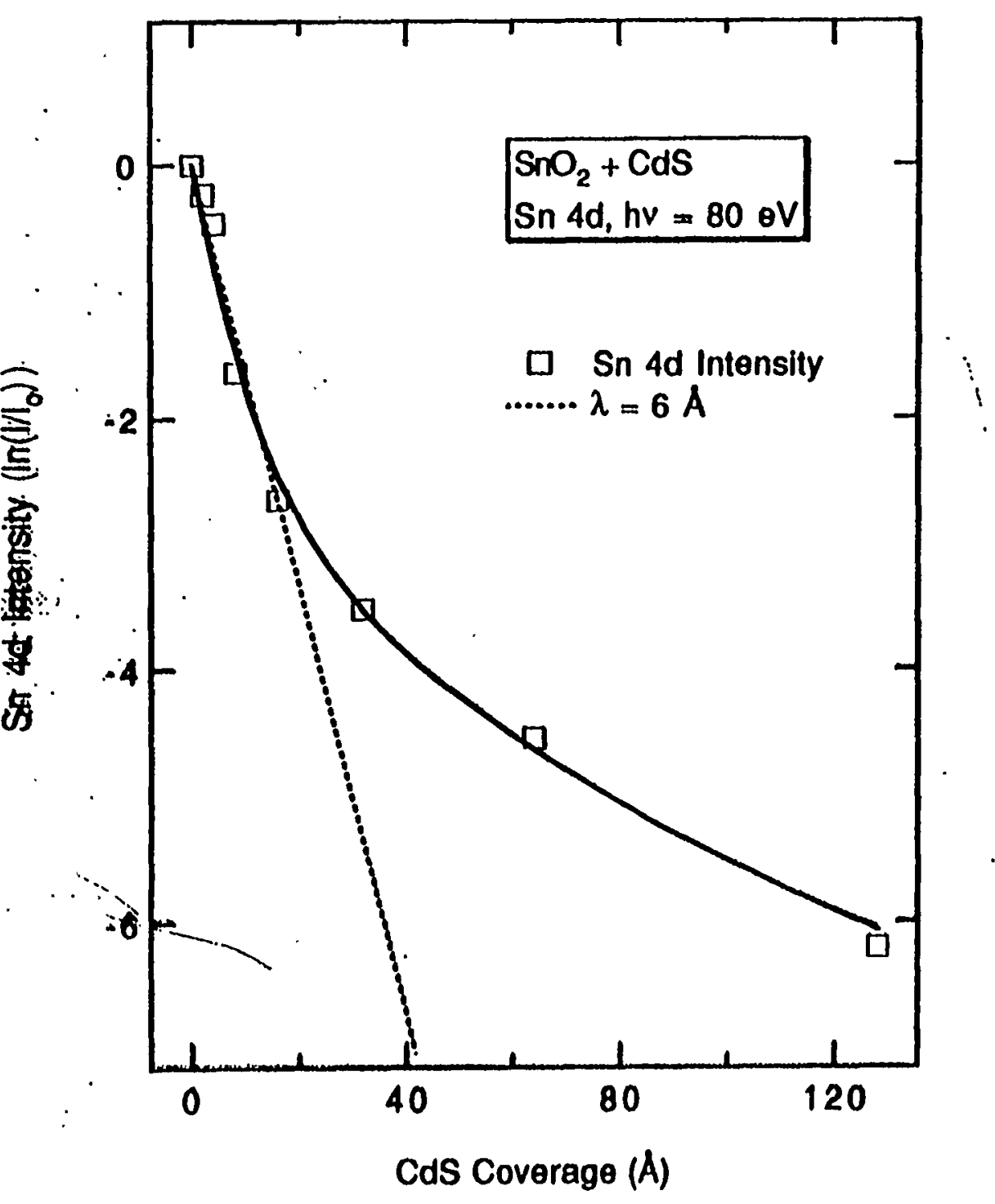

Dave NIles - NREL 


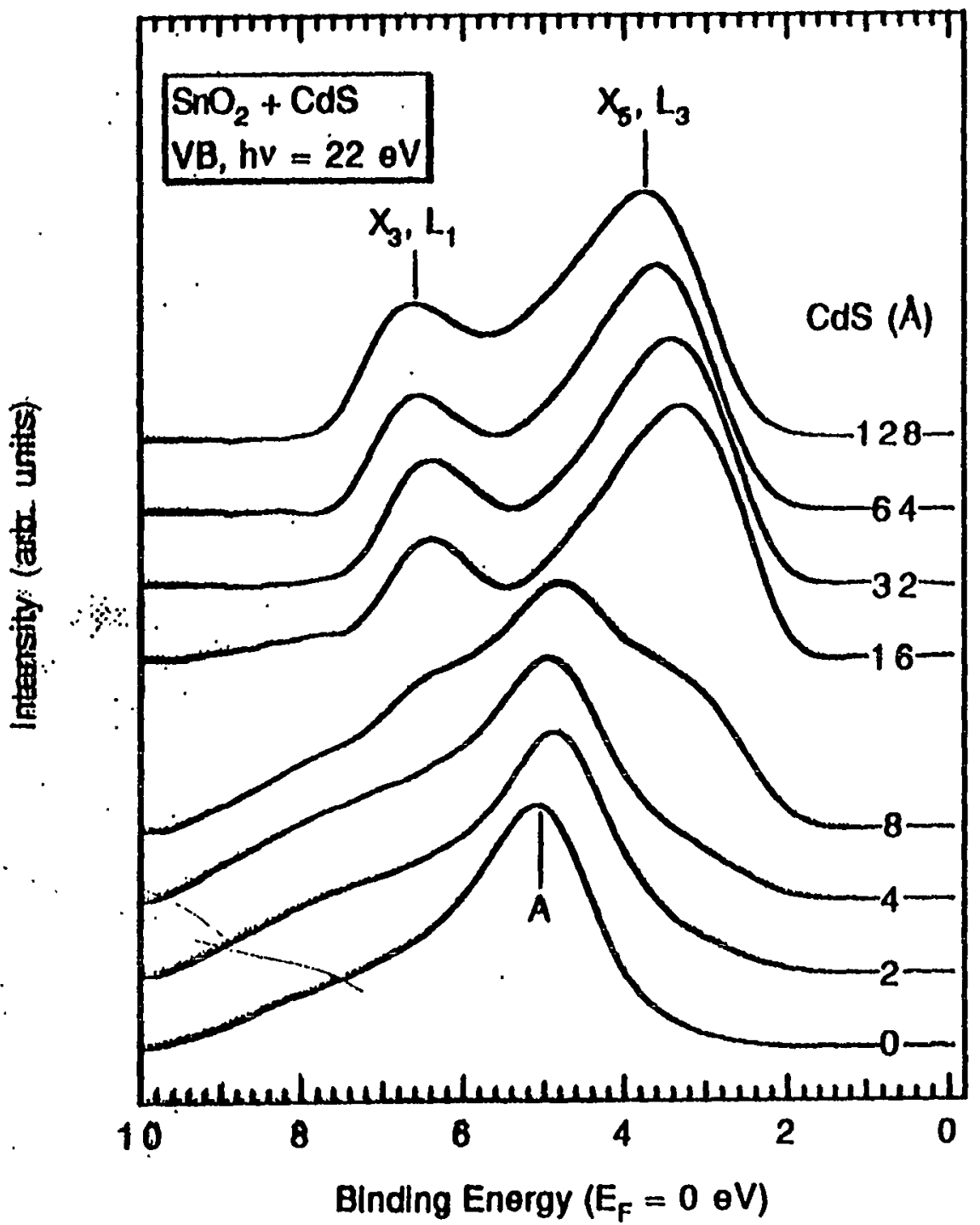

Davo NIIOS - NREL 


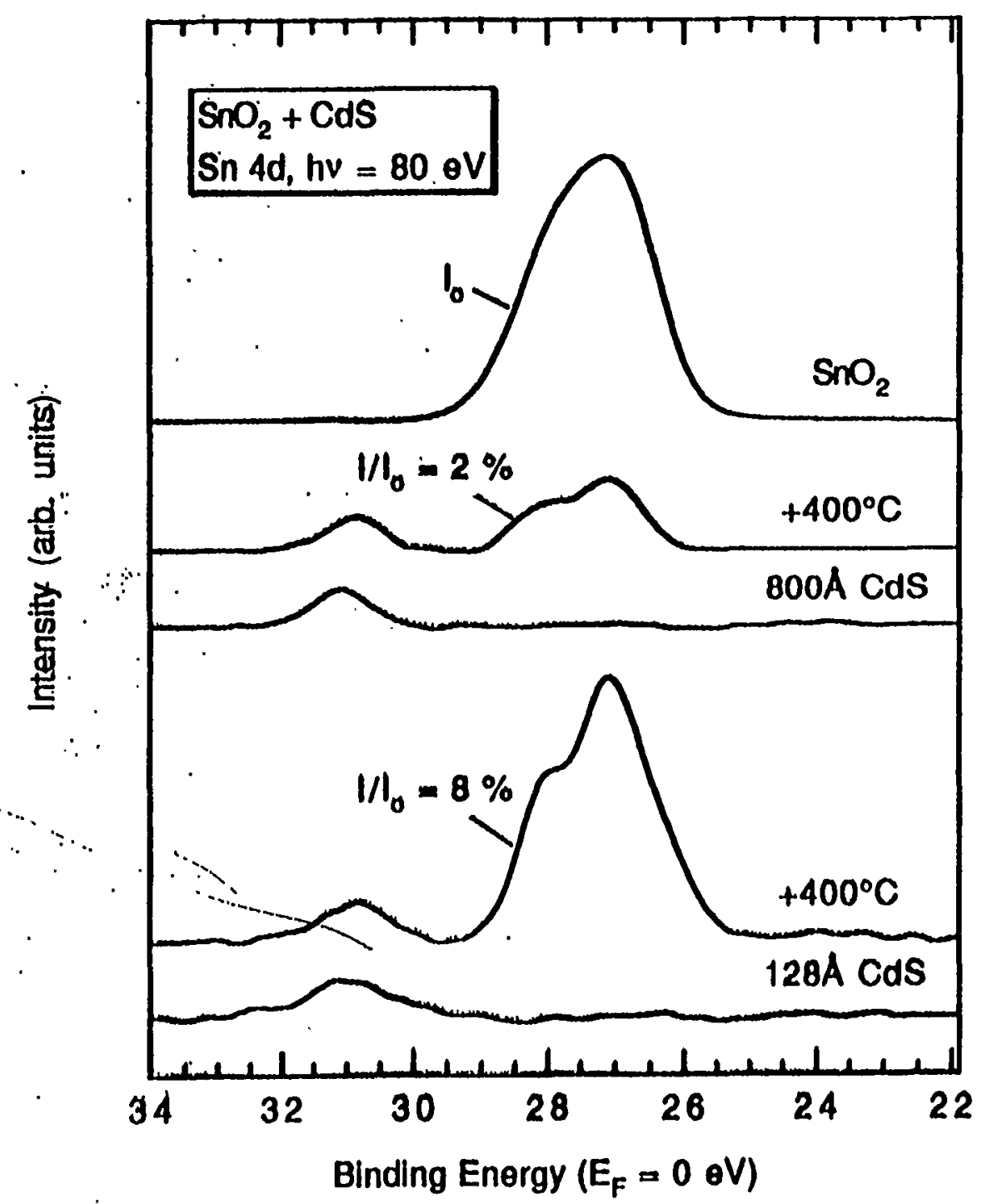




\section{Band Diagram for a \\ CdS/CdTe heterojunction solar cell}

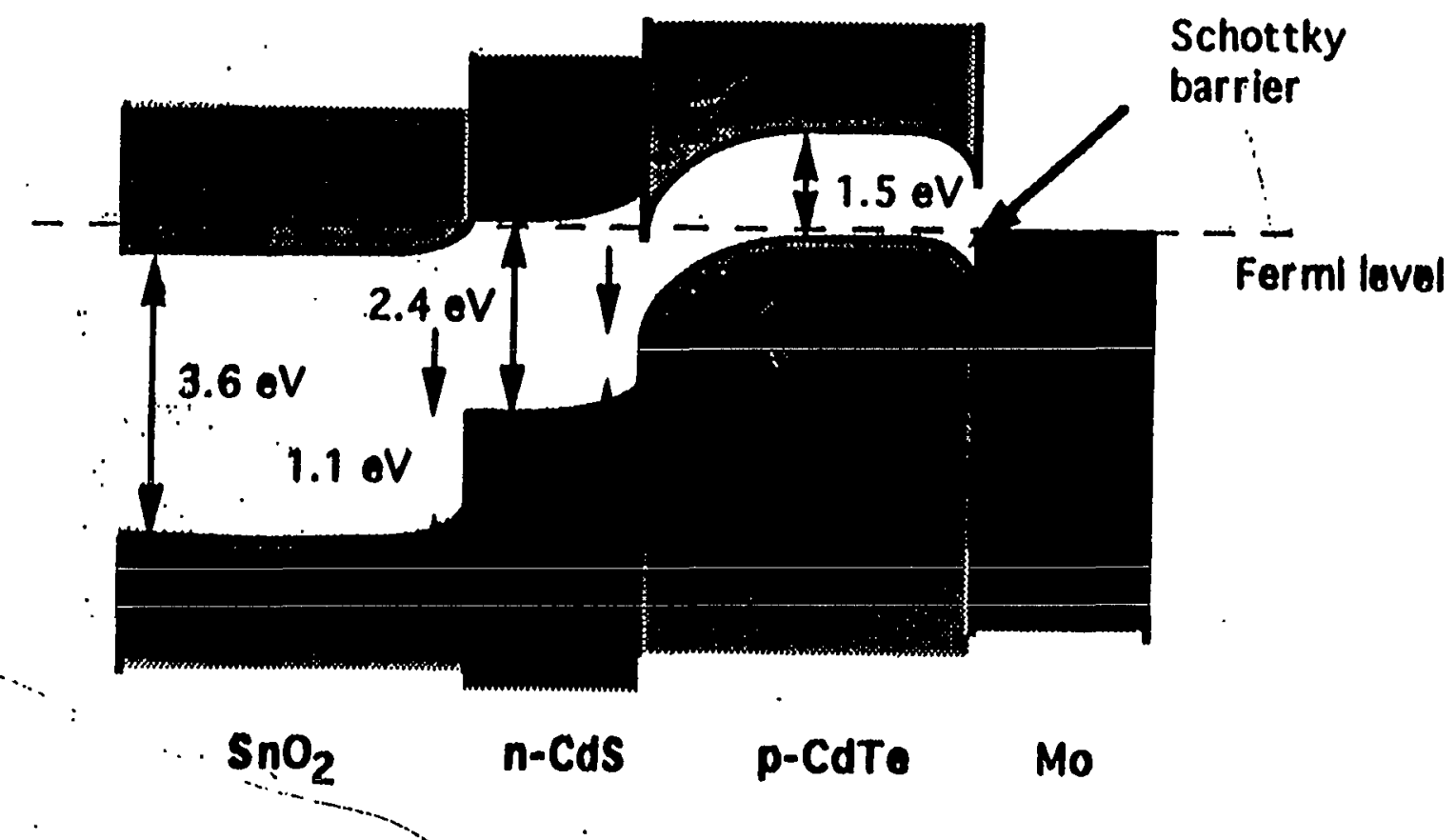




\section{Summary of $\mathrm{CdS} / \mathrm{SnO}_{2}$ interface}

- CdS agglomerates on $\mathrm{SnO}_{2}$ when deposited at $\mathrm{RT}$

- no heat-driven chemical interaction between $\mathrm{CdS}$ and $\mathrm{SnO}_{2}$

- moderate heat $\left(400^{\circ} \mathrm{C}\right)$ enhances agglomeration

- band lineup favorable for electron flow from CdS to $\mathrm{SnO}_{2}$ - perfect for photovoltaics

- future work focuses on the back contact more suseptible to corrosion than the $\mathrm{SnO}_{2}$ 
THERMAL BOND AGING OF THICK FIIM SILVER METALIIZED SOLAR CELLS

by

RONAID GONSIORAWSKI

MOBIL SOLAR ENERGY CORPORATION

BIILERICA, MA 01821

Presentation at the NATIONAL RENEWABLE ENERGY IABORATORY Photovoltaic Workshop

Sept 9,1993 
LIST OF TABLES AND FIGURES:

TABLE 1.0 FIRST INDICATOR OF THERMAL AGING IN SOLDERED CONTACTS TO THICK FILM SILVER SOIAR CELLS

FIG 1.0 THERMAL AGING OF ALTERNATE SOLDERS TO FERRO CONDUCTROX 3349, METALLIZED CELIS

FIG 2.0 POWER LOSS VS BOND YIEID

FIG. $3.0 \quad$ SN96 SOLDER TO FERRO 3349 BOND YIELD VS AGING TEMPERATURE

FIG 4.0 MEAN TIME TO FAILURE OF Sn 96/FERRO 3349 SYSTEM BOND SYSTEM

FIG. 5.0 BOND AGING PEEL STRENGTH OF Sn96: TO SPHERICAI VS FLAKE+SPHERICAL SILVER INK

FIG. 6.0 BOND AGING YIELD OF SN96 SOLDER TO SPHERICAI SILVER VS FLAKE+SPHERICAL SILVER INK

FIG. 7.0 MEAN TIME TO FAILURE OF Sn96 SOLDER TO SPHERICAL SIIVER VS SPHERICAL+FIAAKE SILVER INK 
THERMAL BOND AGING OF THICK FILM SILVER METALIIZED SOLAR CELIS

\author{
by \\ RONALD GONSIORAWSKI \\ MOBIL SOLAR ENERGY CORPORATION \\ BIILERICA, MA 01821
}

\title{
INTRODUCTION
}

Accelerated testing studies determined that thermal bond aging of soldered contacts to thick film silver metallization(TFSM) of silicon solar cells is an operative failure mechanism that can result in reduced photovoltaic product lifetime. The composition of the solder and the structure of the silver thick film material are primary factors that influence the rate of bond aging and the related extrapolated product lifetime. The MSEC patents entitled PHOTOVOLTAIC CELLS WITH IMPROVED THERMAL STABILITY (US 5,074,920) and METHOD FOR FORMING SOIAR CELL CONTACTS AND INTERCONNECTING SOIAR CELLS(US5,178,685) define improved embodiments of these key factors which we project to substantially improve potential product lifetime.

\section{FIRST INDICATOR OF OPERATIVE THERMAL BOND AGING:}

In the course of preparing single cell mini-coupons in a laminated construction of: Glass/EVA/Cell/EVA+3 layer backskin, for accelerated reliability testing we often observed cell fill factor degradation. The solar cells metallized with thick film silver were at that time dip coated with $62 \mathrm{Sn} / 36 \mathrm{~Pb} / 2 \mathrm{Ag}$ solder and reflow solder bonded with flattened copper wire tabbing that was coated with $\mathrm{Sn} / \mathrm{Pb}$.

Among the battery of subsequent tests to address the fill factor degradation was a simulation of the thermal process of lamination which produced a strong signal or indication of significant metallurgical alteration of the solder:silver system. The simulation of the thermal effects of the lamination process was conducted on electrically characterized discrete silver metallized solar cells that were overcoated with solder. The lamination simulation conducted at the EVA curing temperature of $150^{\circ} \mathrm{C}$ included extended exposure of 80 minutes. A summary of the results of that simulated lamination process is given in table 1.0 but without the results of control cells that were not overcoated with solder. The control cells without a solder were thoroughly stable to the lamination simulation which is important to the interpretation of the results.

Subsequent thermal aging of reflowed solder paste with a composition of $62 \mathrm{Sn} / 36 \mathrm{~Pb} / 2 \mathrm{Ag}$ to affect local bonds of tabbing to a number of sites along the silver busbar revealed rapid deterioration of the mechanical peel strength. The' early aging tests conducted at $150^{\circ} \mathrm{C}$ were of 20 to 120 minute duration. Cells thermally aged without solder and subsequently bonded to tabbing by the above process had consistently strong peel strength thereby strengthening the belief of a solder:silver thermal interaction as opposed to a silver:silicon 
interaction. Additionally, microanalytical analysis indicated the accumulation of tin at the failed interface of only the thermally aged solder:Ag bonds which heightened the belief that the $\mathrm{Ag}_{6} \mathrm{Sn}$ intermetalic compound was being formed.

A search of existing literature on this topic conducted by my colleague $\mathrm{J}$. Borenstein uncovered a wealth of information. The information was largely on silver thick film hybrid circuit technology of the 1970's that indicated brittle and swollen intermetallic compound formation on thermal aging at $150^{\circ} \mathrm{C}$ that was related to the solder composition. Thermal bond aging terminology was liberally used in describing this problem.

THERMAL BOND AGING DEGRADATION OF ALTERNATE SOLDER SYSTEMS:

The effects of solder composition to the resistance of thermal aging degradation in the solder:thick film silver solar cell system were systematically conducted. The solder composition was certified by the suppliers and provided in the form of solder paste/cream. This study used nickel coated copper tabbing to avoid confounding material interactions and a specific and reproduceable regiment of solder reflow to effect a tab/solder/silver bond. The response was measured by destructive peel strength measurements that represented the mean of 40 bond sites collected on 8 sites per cell for each data point plotted in the summarized results of figure 1.0. For the $\mathrm{sn} 96.5 / \mathrm{Ag}$ 3.5 eutectic system it was necessary to increase the sample size due to the apparently higher activation energy. 


\section{ARRHENIUS PLOTTING OF SOLDER BOND WEAKENING:}

To determine meaningful Arrhenius plotting of bond strength weakening it was necessary to first define the limiting lower limit that would constitute a representation of substantial product failure. For a representation of a severely weakened bond we modeled that at a strength of < 0.1 lbs the bond was not likely to survive temperature cycling without separation from the solar cell and therefore constituted a failed bond. From this position it was necessary to model the sensitivity of a module product's performance vs the yield or population of good bonds. Figure 2.0 summarizes the results of this modeling exercise for the stated specific boundary conditions. From this model, represented over a full range of bond yield (bonds $>0.1$ 1b), there is a threshold at the $25 \%$ to $30 \%$ bond yield region where the product essentially fails by excessive power loss.

From this information it was necessary to collect the experimental data that defined this $25 \%$ failed bond level for the solders of interest, as influenced by thermal bond aging at 3 or more temperatures, for this Arrhenius plotting objective. This exercise involved hundreds of cells to test the one(1) Sn 96 solder system, with 2 methods of solder reflow bonding of the tab: silver system. The tabbing for this portion of the study was Sn coated flattened copper. While the bond peel strength was a direct measured response the effective bond yield from this response over time at the temperatures of $150^{\circ} \mathrm{C}, 135^{\circ} \mathrm{C}$ and $120^{\circ} \mathrm{C}$ was the critical parameter of interest to this program. Figure 3.0 summarizes the experimental results for the B method of reflow solder bonding. The A method was similarly plotted but omitted in this presentation. Each data point represents the mean bond yield of 40 destructively tested bonds. The point of failure for the purpose of this study is the $75 \%$ bond yield point at the 3 tested aging temperature conditions.

The points of failure mentioned above were plotted as a log of time vs the inverse of absolute temperature (K) in figure 4.0 for bonding (reflow heating) methods $A$ and $B$. The solid lines represent the experimental data and the dotted line extensions represent their extrapolation to real product environmental thermal conditions. Figure 4.0 predicts a potential mean time to failure for Bond method $A$ that is 1.5 orders of magnitude lower than method B which in a location providing a temperature of $60 \circ \mathrm{C}$ for 6 hours a day will resist product performance degradation due to failed bonds for a minimum of 5 years. The area under the time-temperature solder reflow process curve for method $A$ is significantly higher in magnitude than method $B$ but the details of the specific bonding methods which are beyond the scope of this presentation, will not be discussed here. 
IMPROVED THERMAL STABIIITY OF SPHERICAI Ag vS SPHERICAL + FIAKE Ag IN THE Sn 96 SOLDER BOND SYSTEM:

Subsequent to the completion of the aforementioned studies and the related patent filing, pilot manufacturing adopted the Sn 96.5/Ag 3.5 solder composition. As expected due to the higher activation energy of the new solder:silver system compared to the former $\mathrm{Sn} 62 / \mathrm{Pb} 36 / \mathrm{Ag} 2$ system there was a positive overall impact to conventional ( $85 / 85$ ) accelerated endurance testing but numerous manufacturing improvements obscure quantification of a specific reason.

In the course of engineering manufacturing improvements, an investigation was conducted in an alternate structure of the silver particles composing the thick film Ferro 3349, Conductox silver ink material. The earliest experiments were an immediate success regarding further Iimitation of the thermal aging degradation of the solder:silver bond system. For manufacturability the alternate ink system was applied to only the busbar regions of the the solar cell electrode system. At a later date the alternate silver ink material was applied to the $\mathrm{p}^{+}$electrode regions to provide equivalent reliability to both electrode solder bond regions. The alternate silver material only effected a change that excluded flake shaped silver particles, thereby leaving a $100 \%$ spherical silver system.

The fully spherical system, we reasoned would pack more densely and thus limit surface diffusion of the solder system(solid or liquid phase). The preferred spherical silver particle size is in the range of 0.5 to 2.0 microns although a 0.5 to $10 \mathrm{micron}$ range is expected to be satisfactory. Additionally, there was no sensitivity seen of bond aging degradation to the fired film thickness over the tested range of 5 to 30 microns nor was there an operable sacrifice of cell efficiency seen in this study of the fully spherical silver applied to busses and $\mathrm{P}^{+}$ electrode regions.

Figure 5.0 summarizes the comparison of peel strength of the Sn 96 solder bond system to the silver systems of sphericaltflake vs fully spherical. Figure 6.0 summarizes the effective mean bond yield of these systems above the 0.1 Ib lower limit discussed previously. Lastly, figure 7.0 transposes the data in figure 6 to a log of time vs the inverse of absolute temperature for the purpose of extrapolating the effective mean time to failure at appropriate boundary conditions. The activation energy of the fully spherical system increased to the extent that the $75 \%$ bond yield or product failure point could not be experimentally defined; therefore the more conservative 95\% bond yield point (technically more difficult) was used for this case. The dotted lines in figure 7 are the extrapolations of the experimental data marked in solid lines.

The effect of the fully spherical silver system vs the sphericalt flake silver each using the $\mathrm{Sn} 96$ solder and bonding (reflow) method $A$ was to extend the mean time to failure in excess of 3 orders of magnitude. 
CONCLUSION:

A potential limitation of photovoltaic lifetime has been identified and an engineering/materials solution has been defined and implemented at MSEC. The goal of 25 year PV product life has been uplifted by this and other related achievements.

\section{ACKNOWLEDGEMENTS :}

For conducting the experimental processing and data collection I would like to thank Dick Billings. For their substantial contributions as co-inventors of the patents related to this program I thank $J$. Borenstein and $M$. Kardauskas. And to $J$. Amick, retired, I wish to express my appreciation for all his support and invaluable consultation. 


\title{
FIRST INDICATOR OF THERMAL BOND AGING
}

\author{
$\begin{array}{lllll}\text { TIME e150 C (Minutes) } & 0 & 20 & 40 & 80\end{array}$ \\ $\begin{array}{lllll}\text { Rbb (milliohms) } & 70 & 83 & 97 & 113\end{array}$ \\ $\begin{array}{llllll}\text { CELL FILL FACTOR } & .734 & .725 & .720 & .705\end{array}$
}

Rbb - Inter Busbar Resistance

Table 1.0 


\section{THERMAL AGING OF ALTERNATE SOLDERS FERRO CONDUCTROX 3349 METALLIZED CELLS}

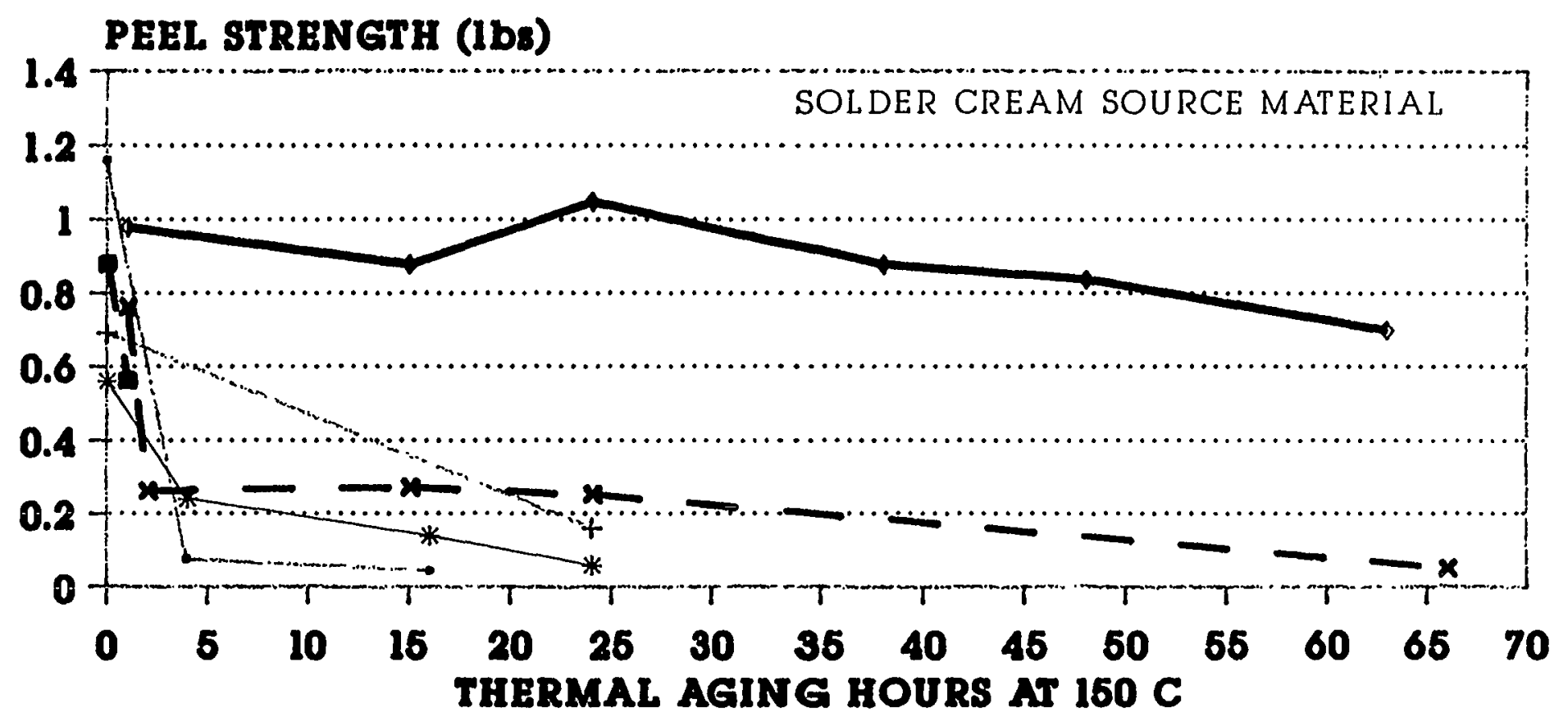

$$
\begin{array}{ccc}
\text { SOLDER } \\
\ldots-628 \mathrm{n} / 86 \mathrm{~Pb} / 2 \mathrm{Ag} & -+108 \mathrm{n} / 88 \mathrm{~Pb} / 2 \mathrm{Ag} & *-438 \mathrm{n} / 43 \mathrm{~Pb} / \mathrm{ABI} \\
\rightarrow-601 \mathrm{n} / 60 \mathrm{~Pb} & -* \cdot 261 \mathrm{n} / 76 \mathrm{~Pb} & -96.68 \mathrm{n} / 3.6 \mathrm{Ag}
\end{array}
$$

FIG 1.0 --MSEC/RCG--1990 
MODULE POWER LOSS VS BOND YIELD

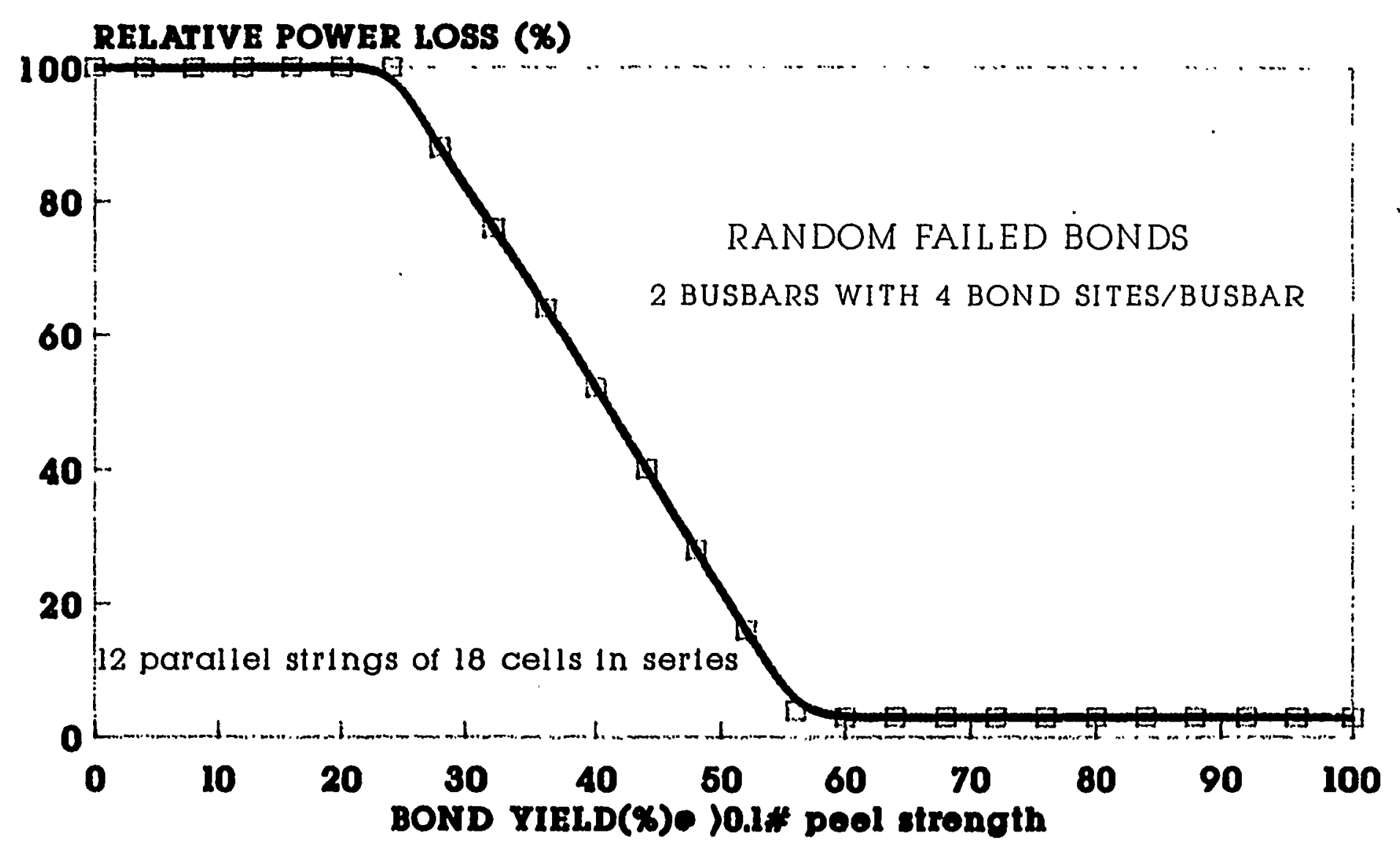

Sories 1

PIG10.M8EC.FEB.1990 


\section{Sn96 SOLDER BOND YIELD TO FERRO 3349 AG VS AGING TEMPERATURE}

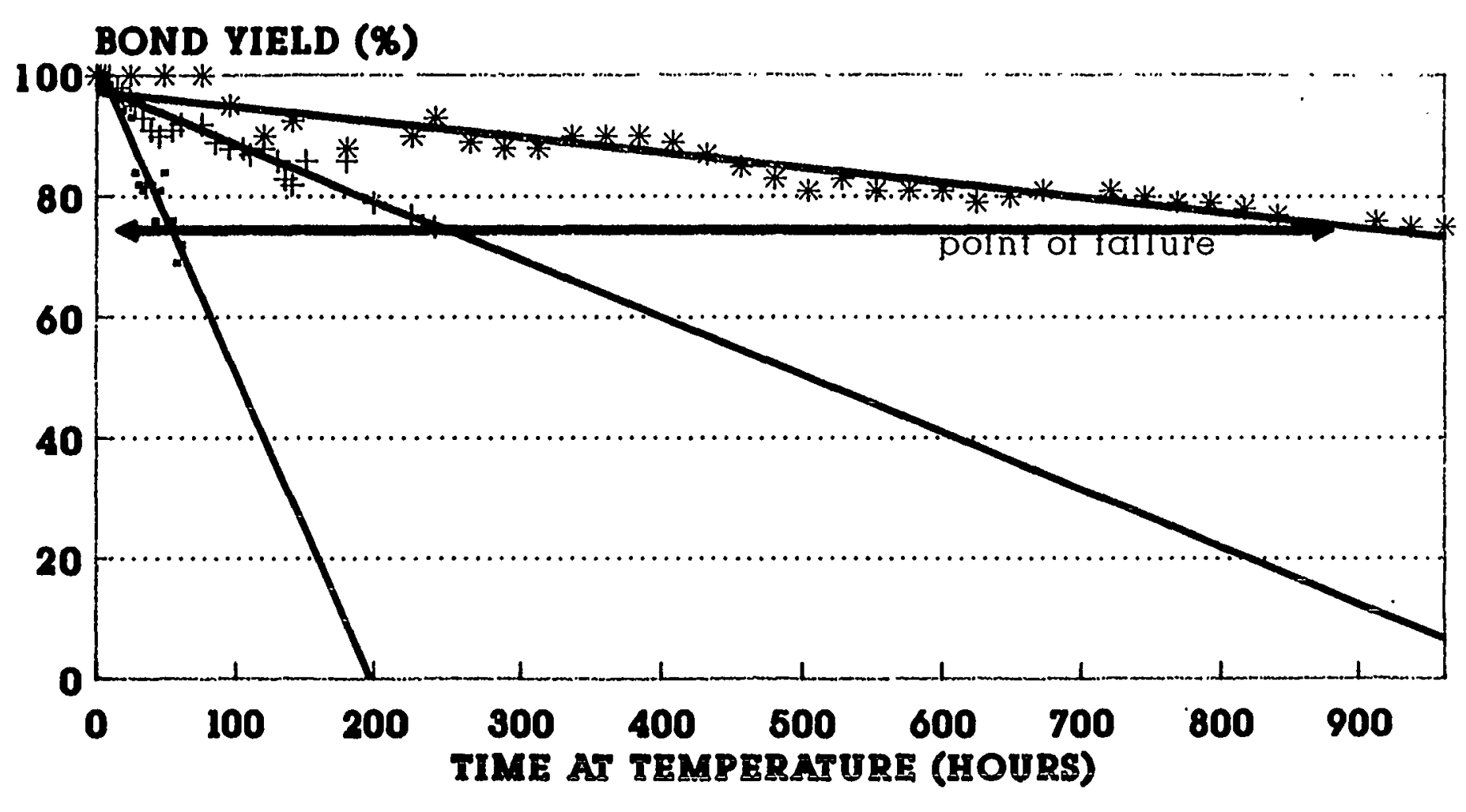

\section{AGING TEMP.( C)}

$-150 \mathrm{C}+135 \mathrm{C} * 120 \mathrm{C}$ 


\section{MEAN TIME TO FAILURE OF Sn96 SOLDER BONDS TO FERRO 3349 SILVER METALLIZATION}

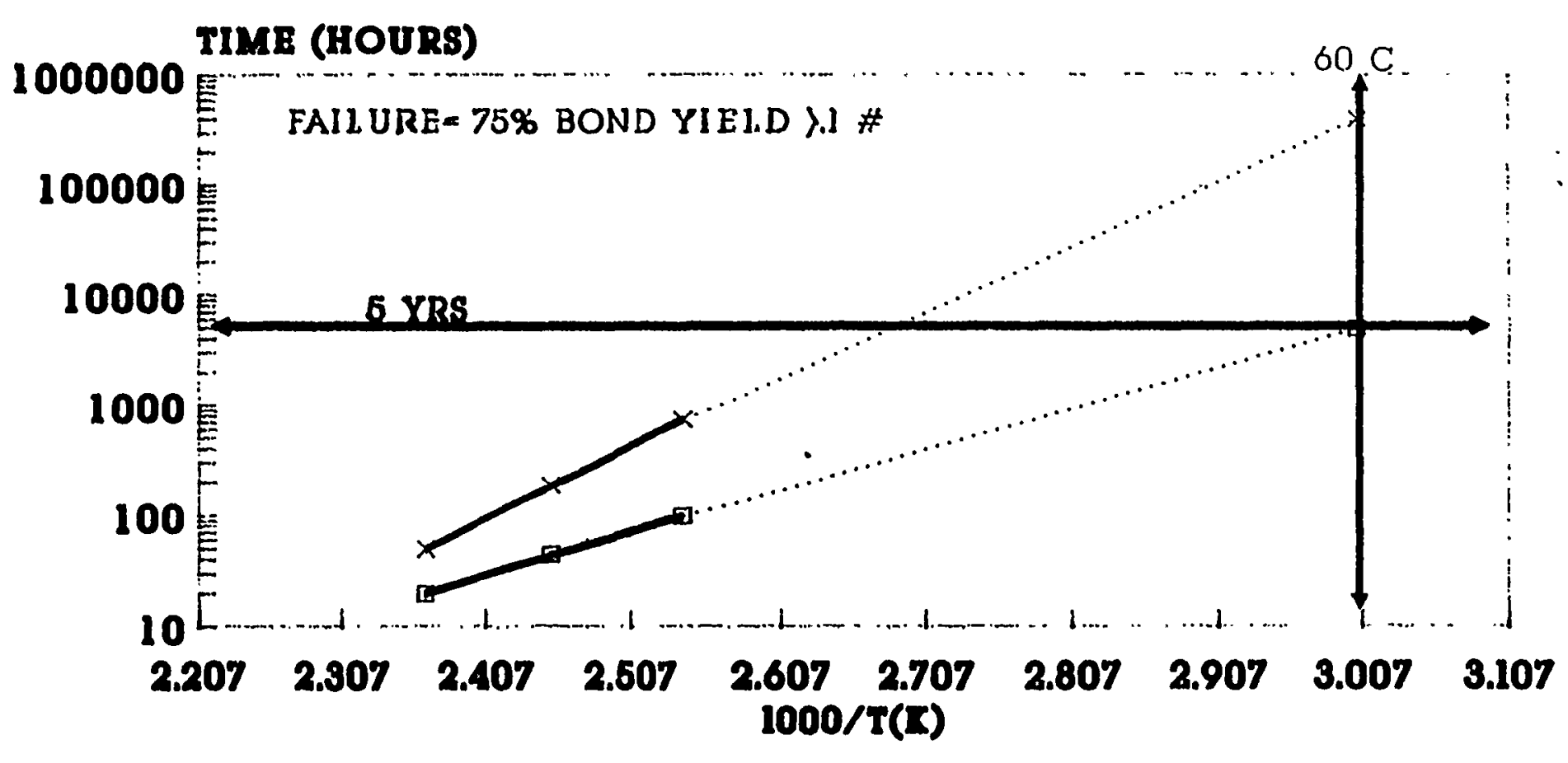

BONDING METHOD
- MBTHOd a ACtual
- Q. METHOD A EXTRAP
* METhOd b actual.
*X. METHOD B EXTRAP

FIG. 4.0, MSEC. $6 / 90$ 


\section{BOND AGING PEEL STRENGTH OF Sn96 SOLDER} TO SPHERICAL AG VS SPHERICAL+FLAKE Ag

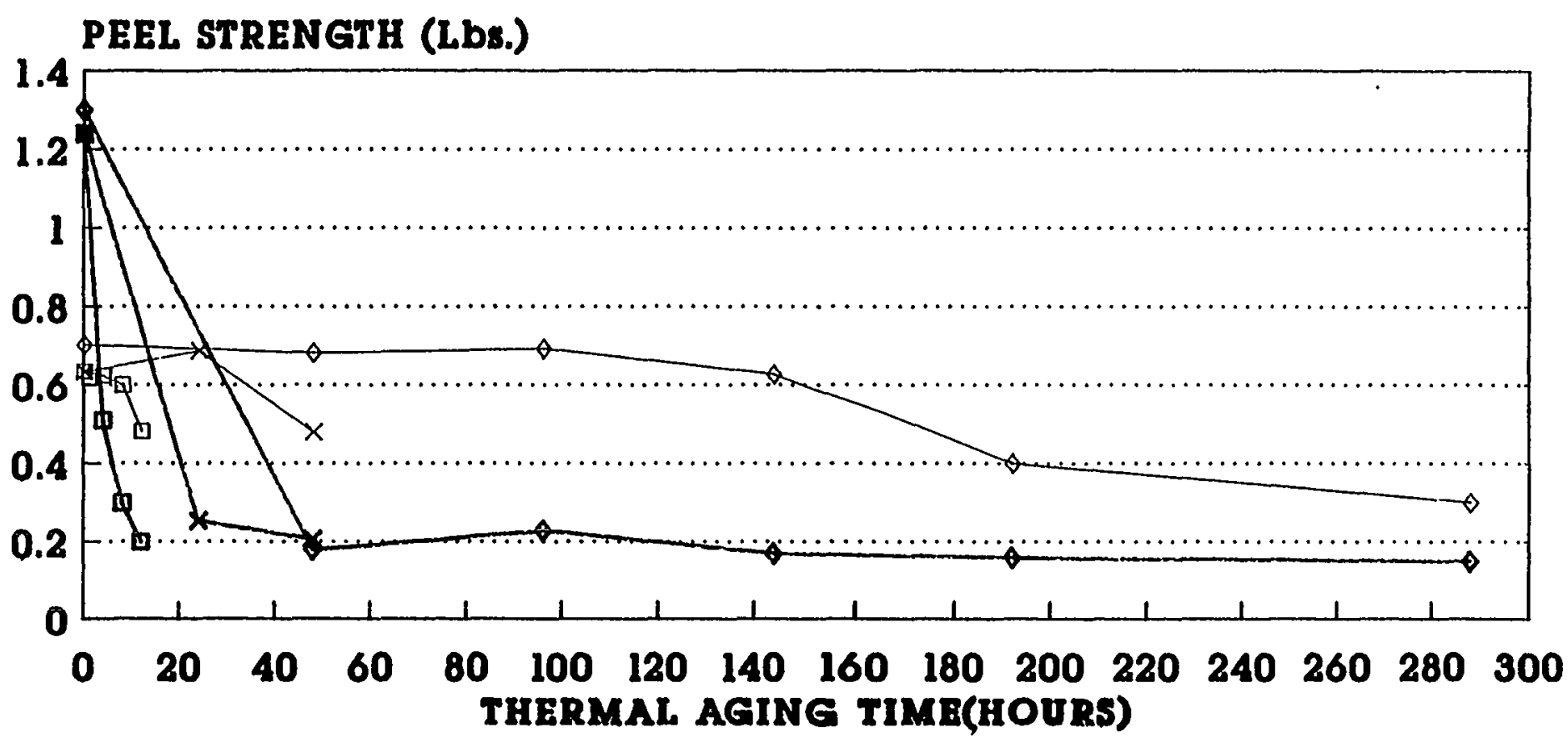

$$
\begin{aligned}
& \text { Ag TYPE/TEMP } \\
& \rightarrow \text { SPMERICAL/165 C } \rightarrow \text { SPHERICAL/160 C } \rightarrow \text { SPHERICAL/195 C } \\
& \text { - SPHER'L +FLAKE/166 SPHER'L +FLAKE/160- SPHER'L +FLAKE/135 C }
\end{aligned}
$$


BOND AGING YIELD OF SN96 SOLDER

TO SPHERICAL Ag vS SPHERICAL+FLAKE Ag

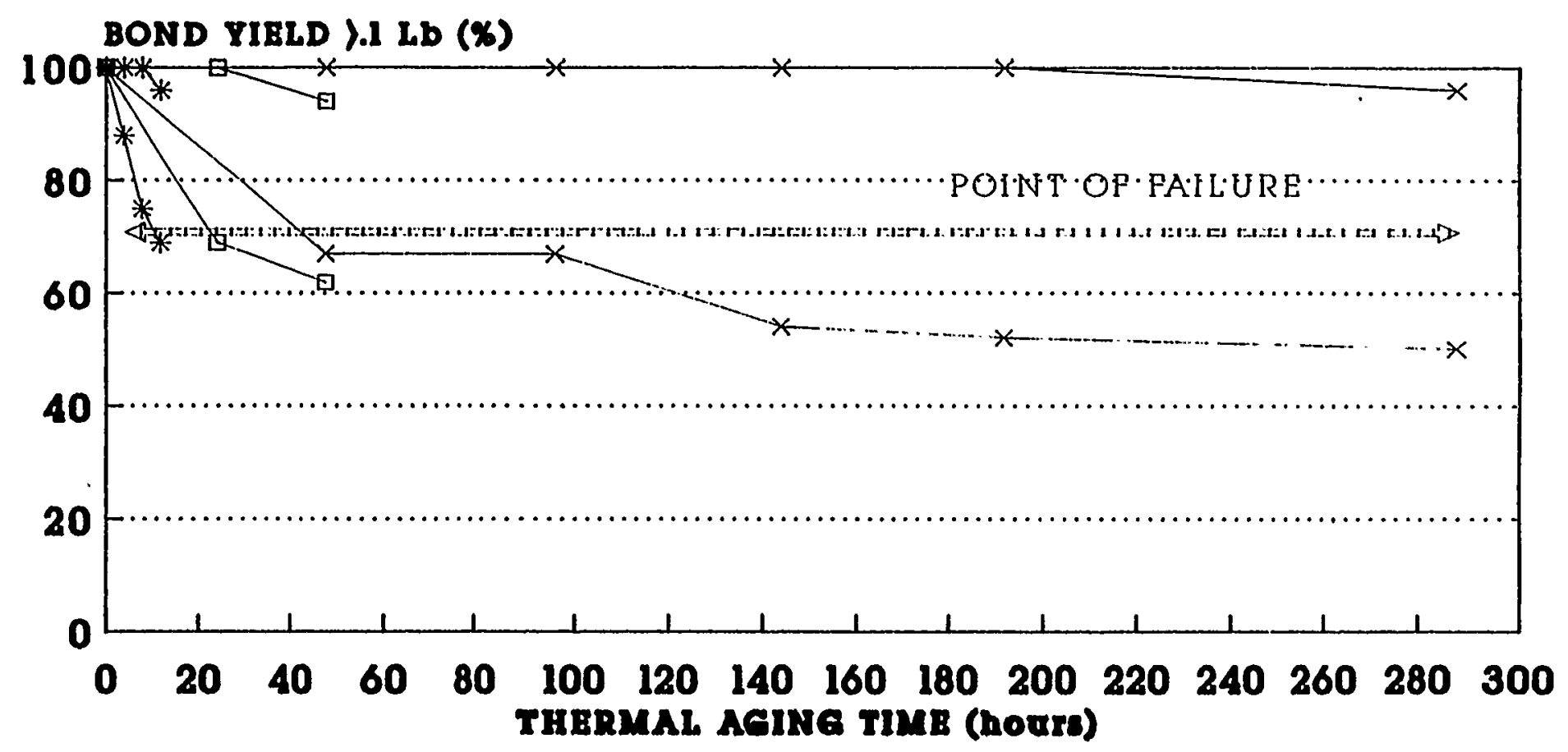

Ag TYPE/TEMPERATURE

* SPHERICAL/166 C - - SPHERICAL/160 C $*$ SPHERICAL/136 C

* SPHER'L+FLAKE/166 O७- SPHER'L+FLAKE/160 O SPHER'L+FLAKE/136 C 


\section{MEAN TIME TO FAILURE OF Sn 96 SOLDER BONDS TO SPHERICAL AG VE SPHERICAL+FLAKE AG IN STSTEMS}

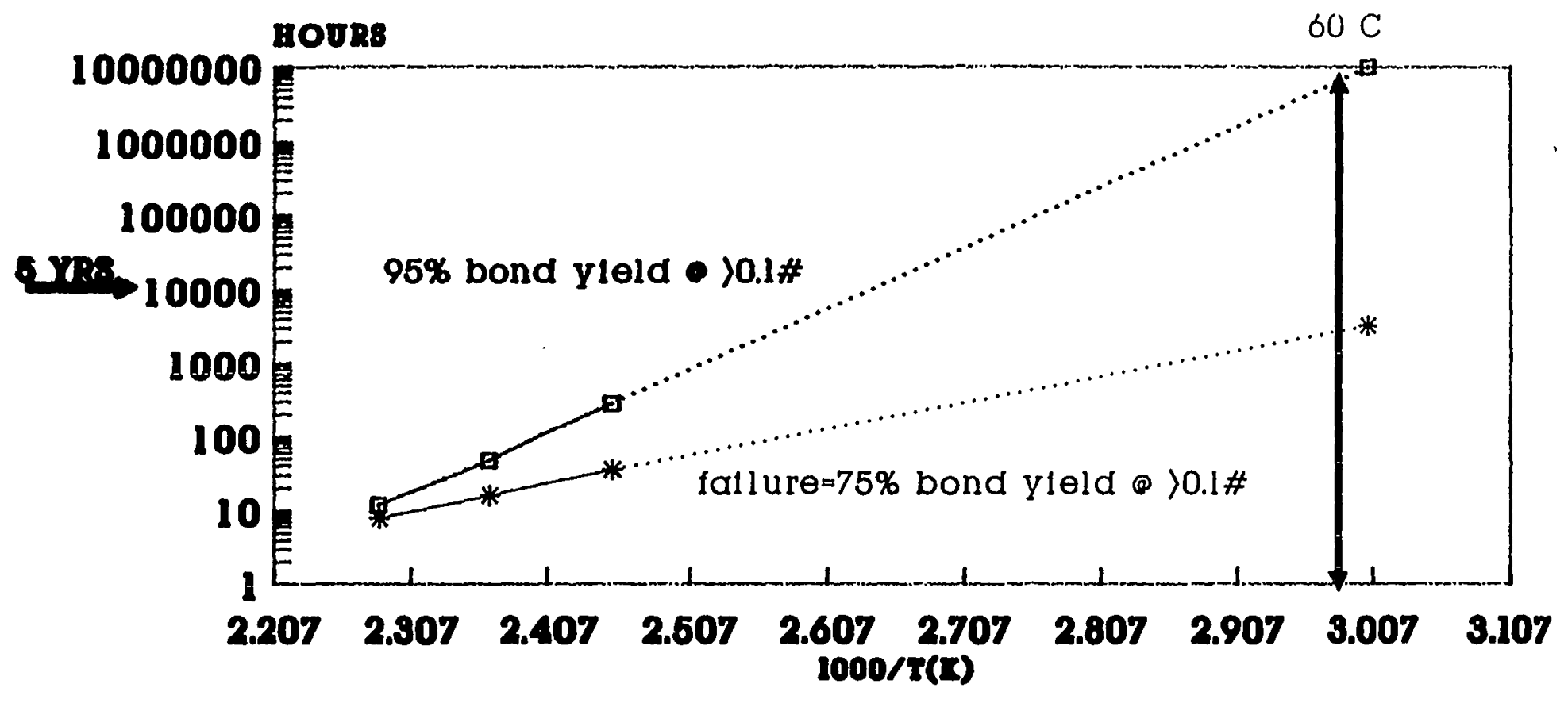

AO INT TYPE
* BPHER'L+FLAKE ACTUAL
*** SPHER'L+FLAIE EXTRP.
- BPHERICAL-ACTUAL
•Q.* SPHERICAL-EXTRAP. 


\title{
OUTDOOR AND INDOOR ACCELERATED UV EXPOSURE TESTING
}

\author{
WILLIAM J. PUTMAN \\ Heraeus DSET Laboratories, Inc. \\ 45601 N. 47th Avenue \\ Phoenix, Arizona 85027-7042
}


When designing accelerated tests the following elements must be considered:

○ Ultraviolet radiation

$O \quad$ Visible and near-IR radiation

- Application of moisture to specimens

- Enclosure boundary conditions

- Proper and accurate measurements of light, temperature and moisture 


\section{ULTRAVIOLET SPECTRAL ABSORPTION} . COEFFICIENT FOR OZONE

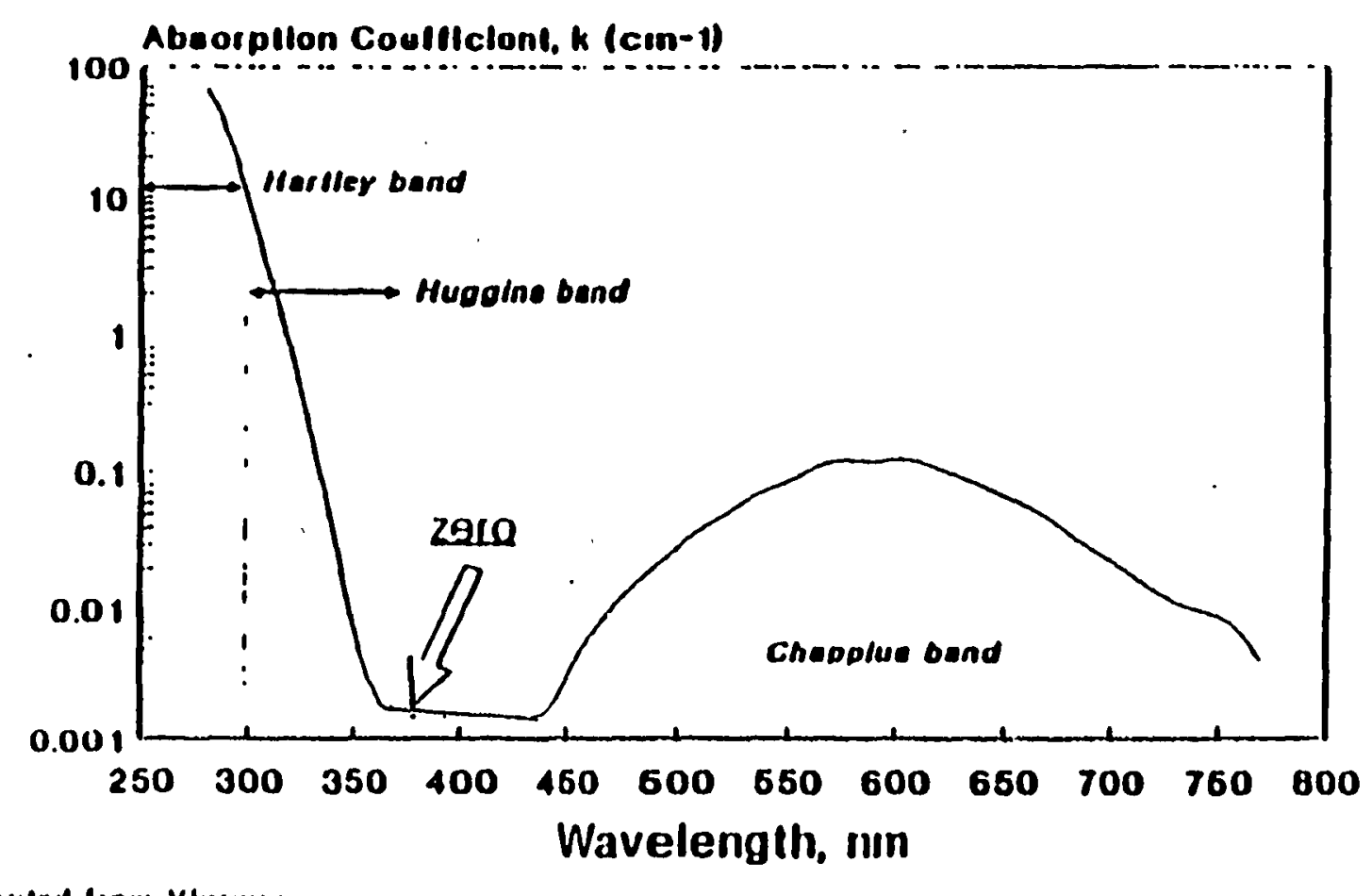

Allupled loom Vluroun 


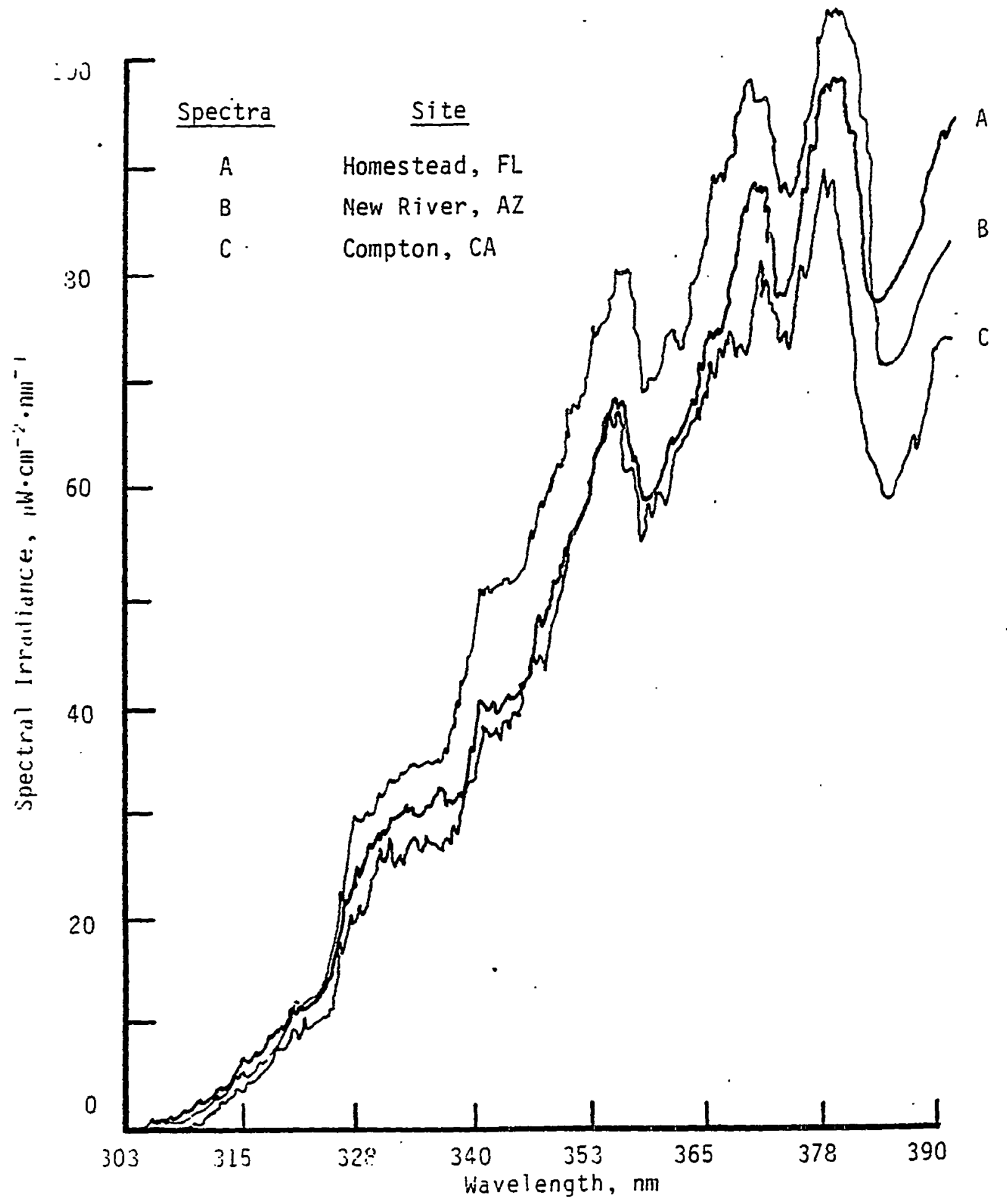




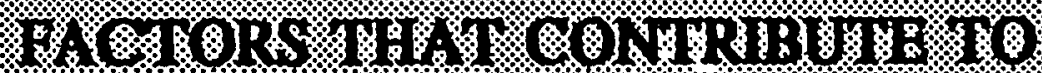

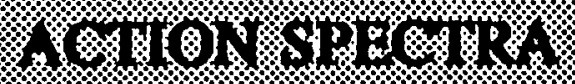

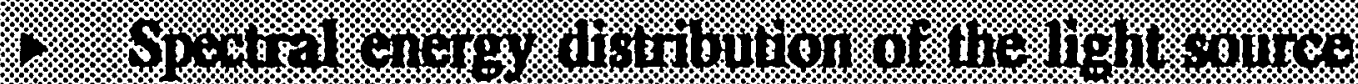
(i.). II. spectrum)

i. Spectiril Cnergy absompian by thic natetial or:

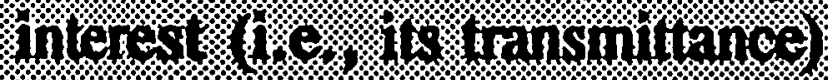

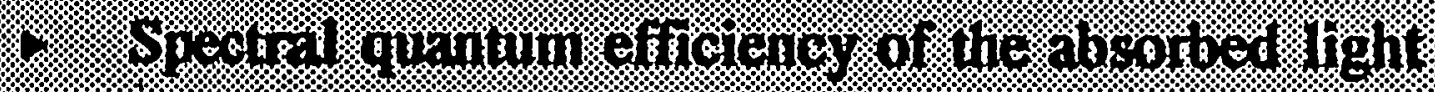

1. Degradiation nesponse measured 


\begin{tabular}{|l|c|}
\hline \multicolumn{2}{|c|}{$\begin{array}{c}\text { ACTIVATION SPECTRA OF SEVERAL POLYMERS WHOSE } \\
\text { PHOTO-OXIDATION CAN BE FOLLOWED BY } \\
\text { ULTRAVIOLET AND VISIBLE SPECTROSCOPY }\end{array}$} \\
\hline \hline \multicolumn{1}{|c|}{ Polymer } & Activation Spectra (nm) \\
\hline \hline Polyethylene & 300 \\
\hline Polystyrene & 318.5 \\
\hline Polypropylene & 390 \\
\hline Polyester & 325 \\
\hline PVC/Vinyl Acetate & $327 / 364$ \\
\hline Polyvinyl Acetate & 280 \\
\hline Cellulose Acetate Buryrate & $295 / 298$ \\
\hline Styrene Acrylonitrile (Film) & $290 / 325$ \\
\hline Polycarbonate & $285 / 305$ \\
\hline Polyvinyl Chloride & $330 / 360$ \\
\hline
\end{tabular}




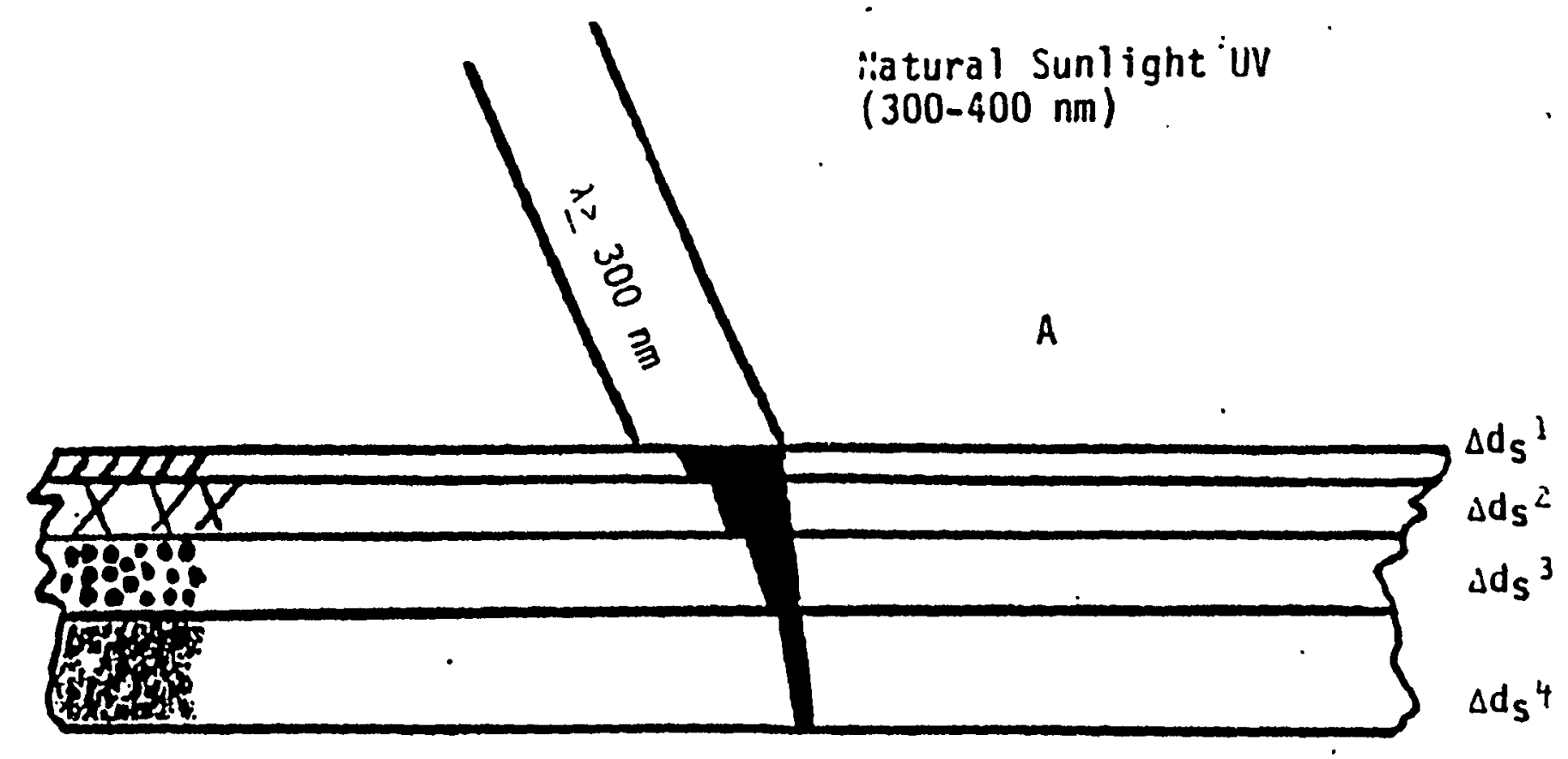




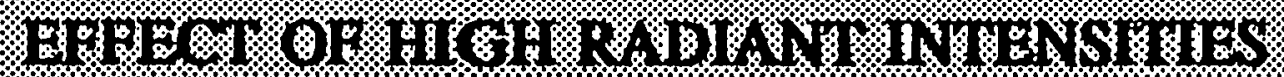

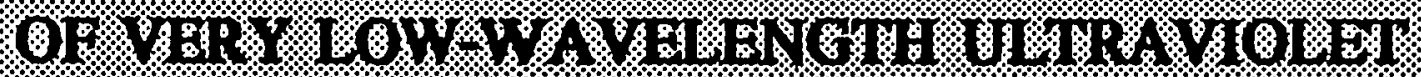

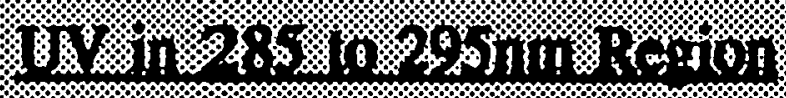

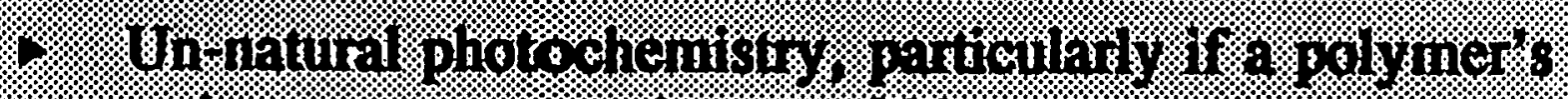

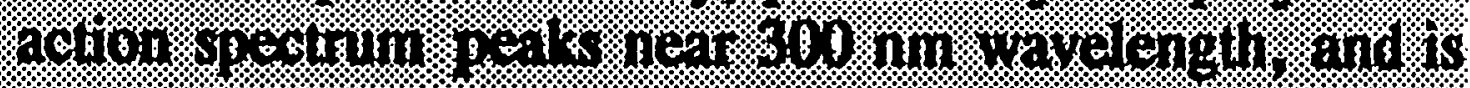

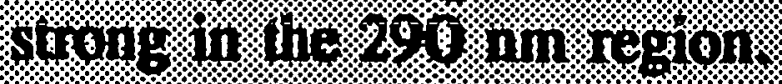

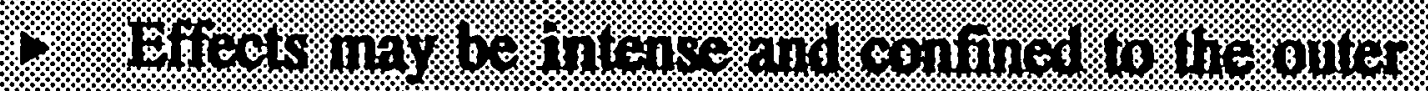

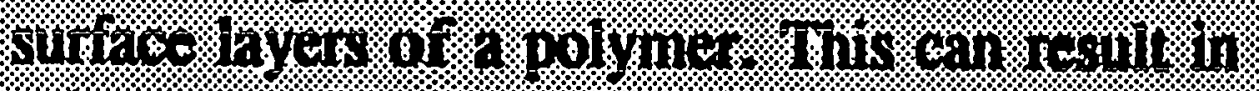

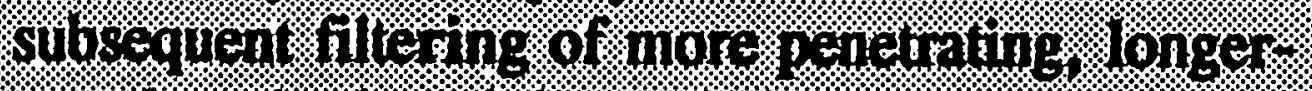

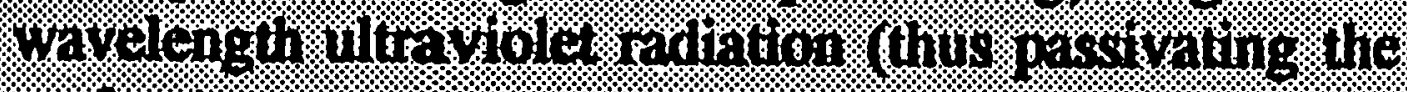
surtace) 


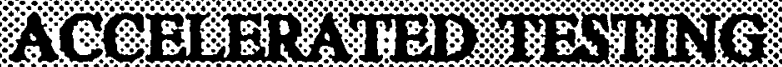

Test ahilo.sinht:

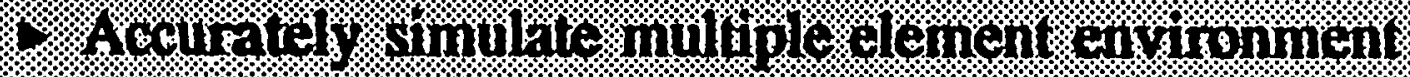

2. Highty ageressives worst case

Methodologe:

- Deterministic approacti.

Probabilistic approach 


\section{FACTORS NECESSARY FOR CORRELATION BETWEEN ACCEI BRATED AND NATURAI TESTS}

\section{Single Matenal}

4. Difference in property retention between two tests independent of stress level

4 1 groement in property retention at more than one stress level:

1. 1 greement with respect to more than one property 


\section{FAOTORS NECESSARY FOR CORRELATION} BETWEEN ACCELERATED AND NATURAL TESTS

Groups. or Set. of Materials

4. Resuits should exhibit few, if any, reversals between indoor accelerated and natural outdoor tests

2. 1 General agreement in property retention values at equal stress levels

- General agreement in more than one property of interest highly desirable 


\section{FAILURE TO CORRELATE ACCEIFRATED WITH}

NATURAL EXPOSURE TESTS

\section{Equipment/Design Considerations.}

$\checkmark$ Significant mismatch between UV source and sunlight below $300 \mathrm{~nm}$ wavelength.

$\checkmark$ - Mismatch between source spectra and a plastic s action spectra

Ultraviolet burner, or lamp deterioration

- Solarization of spectrum-modifying filters

- Inadequate control of specimen temperatures.

-1 Lack of uniformity of test conditions within the test chamber

- Reciprocity failures in devices exhibiting high intensity ultraviolet irradiance 


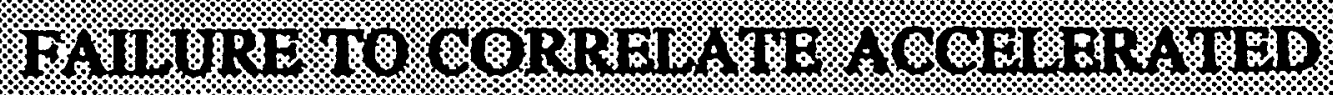

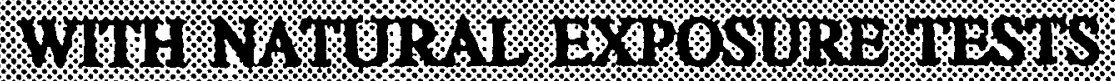

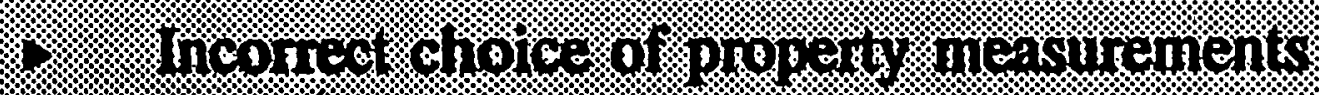

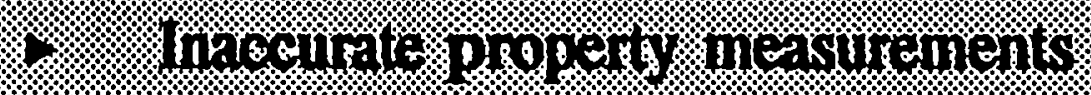

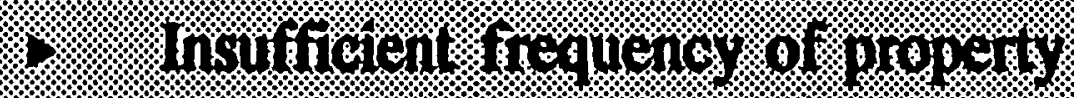
ineayinements:

1 - Intecurate neasurement, contirol or monitoring of Environmental varameters

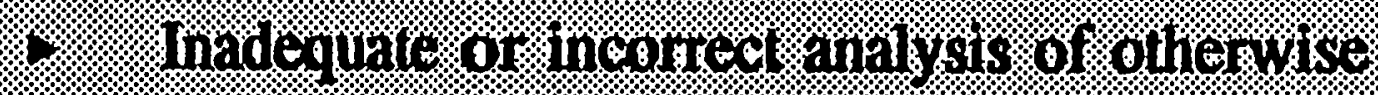
satisfactory. data. 


\begin{tabular}{|c|c|}
\hline \multicolumn{2}{|c|}{$\begin{array}{l}\text { Analysis and Measurement Techniques Used } \\
\text { to Evaluate Weathering Effects }\end{array}$} \\
\hline $\begin{array}{c}\text { Category I } \\
\text { Analytical, Diagnostic Techniques }\end{array}$ & $\begin{array}{c}\text { Category II } \\
\text { Engineering Property Tests }\end{array}$ \\
\hline $\begin{array}{l}\text { - Spectroscopic } \\
\text { - Infrared } \\
\text { - UV-VIS-NIR } \\
\text { - NMR } \\
\text { - ESR } \\
\text { - ESCA } \\
\text { - MS } \\
\text { - ATR } \\
\text { - Transmittance } \\
\text { - Reflectance }\end{array}$ & $\begin{array}{l}\text { - Colorimetric/Appearance } \\
\text { - Gloss } \\
\text { - Color Difference } \\
\text { - Spectrocolorimetry } \\
\text { - Yellowness } \\
\text { - Haze } \\
\text { - Chalk }\end{array}$ \\
\hline $\begin{array}{l}\text { - Chromatographic } \\
\text { - Gas } \\
\text { - Liquid }\end{array}$ & $\begin{array}{l}\text { - Mechanical } \\
\text { - Tensile } \\
\text { - Flexural } \\
\text { - Impact } \\
\text { - Abrasion } \\
\text { - Craze } \\
\text { - Tear }\end{array}$ \\
\hline $\begin{array}{l}\text { - Thermal Analysis } \\
\text { - TGA } \\
\text { - DSC } \\
\text { - DTA } \\
\text { - TMA } \\
\text { - DMA }\end{array}$ & $\begin{array}{l}\text { - Spectral Optical } \\
\text { - Absorbance } \\
\text { - Transmittance } \\
\text { - Reflectance }\end{array}$ \\
\hline $\begin{array}{l}\text { Microscopic } \\
\text { - TEM } \\
\text { - SEM/EDX } \\
\text { - Optical }\end{array}$ & \\
\hline
\end{tabular}




\begin{tabular}{|c|c|c|}
\hline \multicolumn{3}{|c|}{ Application of Analytical and Diagnostic Techniques } \\
\hline Technique/Instrument & Application & Sample Requirements \\
\hline \multicolumn{3}{|l|}{ Spectroscopic } \\
\hline Infrared & $\begin{array}{l}\text { Surface Chemical Structure } \\
\text { Bulk Chemical Structure }\end{array}$ & $\begin{array}{l}\text { Thin Film } \\
\text { Thin Film or Solution }\end{array}$ \\
\hline UV/VIS/NIR & $\begin{array}{l}\text { Surface Properties } \\
\text { Bulk Composition }\end{array}$ & $\begin{array}{l}\text { Thin Film or Sheet } \\
\text { Thin Film or Solution }\end{array}$ \\
\hline NMR & Molecular Structure & Solution \\
\hline$\overline{E S R}$ & Chemical Structure & Solution or Solid \\
\hline$\overline{E S C A}$ & Surface Chemical Composition & Thin Film \\
\hline$\overline{M S}$ & $\begin{array}{l}\text { Chemical Structure } \\
\text { Molecular Structure } \\
\text { Chemical Composition }\end{array}$ & Liquid, Gas, or Solid \\
\hline Chromatographic & Chemical Composition & Liquid or Gas \\
\hline \multicolumn{3}{|l|}{ Thermal Analysis } \\
\hline TGA & Chemical Composition & Powder or Granule \\
\hline$\overline{\mathrm{DSC}}$ & Molecular Structure & Powder or Granule \\
\hline$\overline{\mathrm{DTA}}$ & Molecular Structure & Powder or Granule \\
\hline TMA & Molecular Structure & Thin or Thick Film \\
\hline$\overline{\mathrm{DMA}}$ & Molecular Structure & Thin or Thick Film \\
\hline \multicolumn{3}{|l|}{ Microscopic } \\
\hline SEM/EDX & Surface Structure & Film or Powder \\
\hline TEM & Surface Composition & Film or Powder \\
\hline Optical & Surface Structure & Thick or Thin Film \\
\hline
\end{tabular}




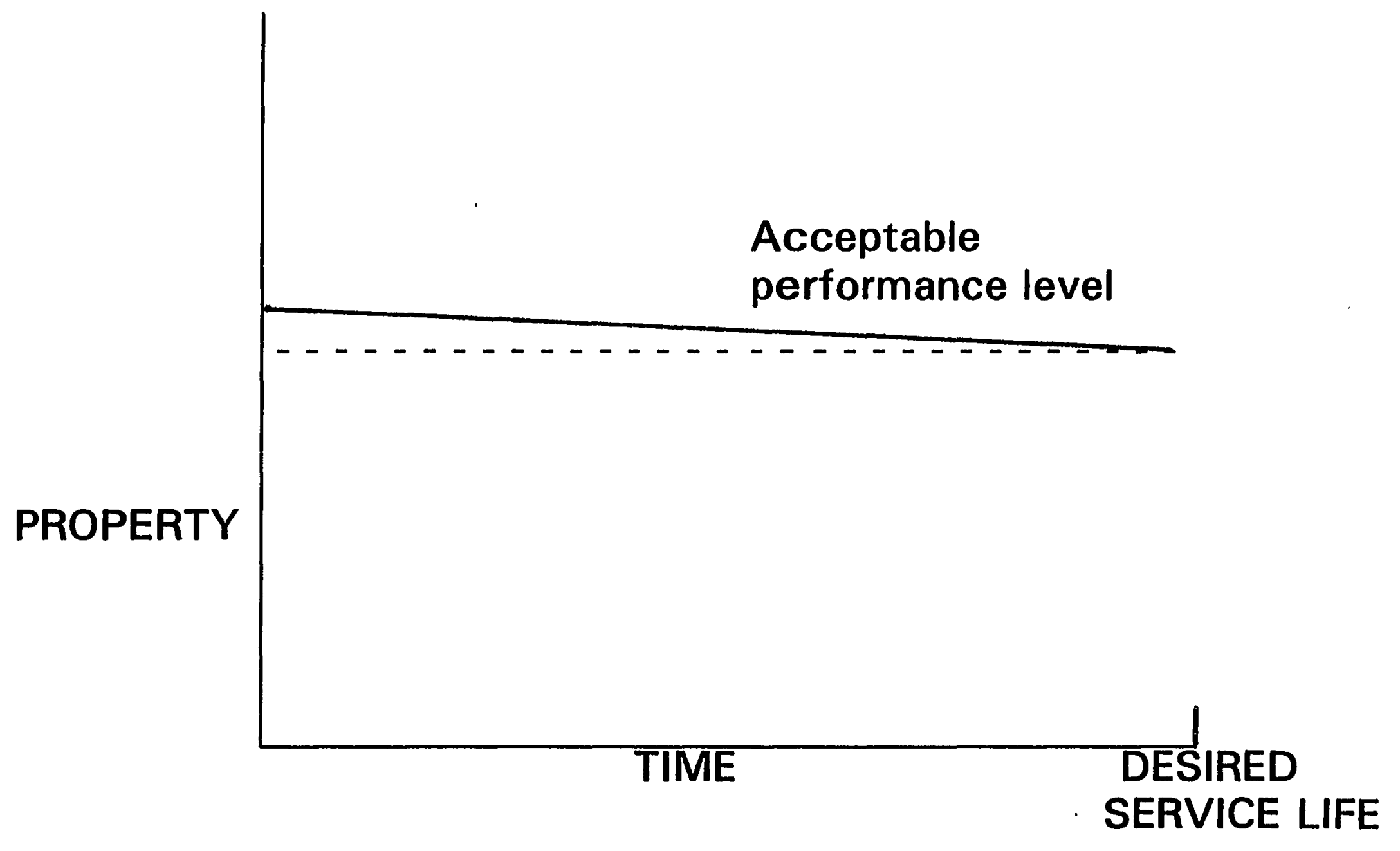

ACCEPTABLE DEGRADATION

DIFFICULT TO DISCERN BETWEEN THIS CONDITION AND THE LONG INDUCTION CATASTROPHIE FAILURE CONDITION 


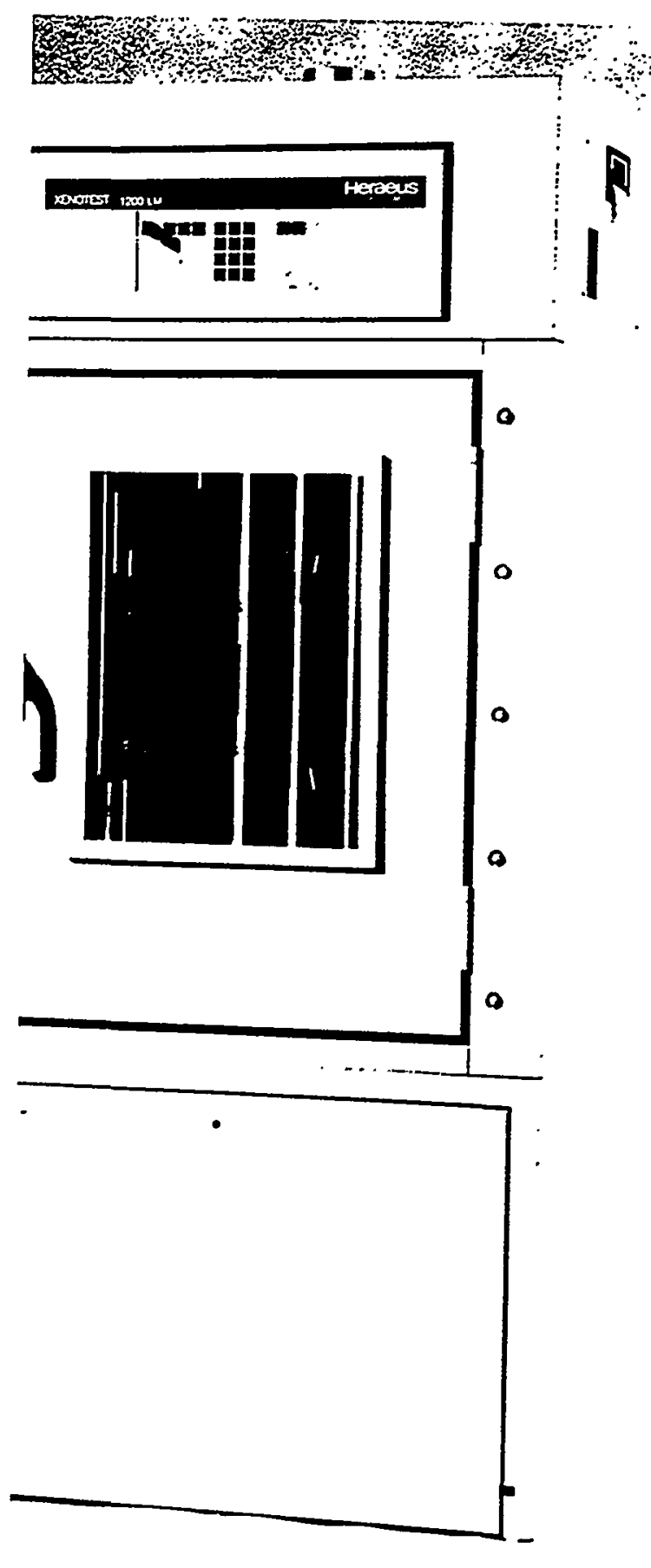

LM Xenon Weathering Device 


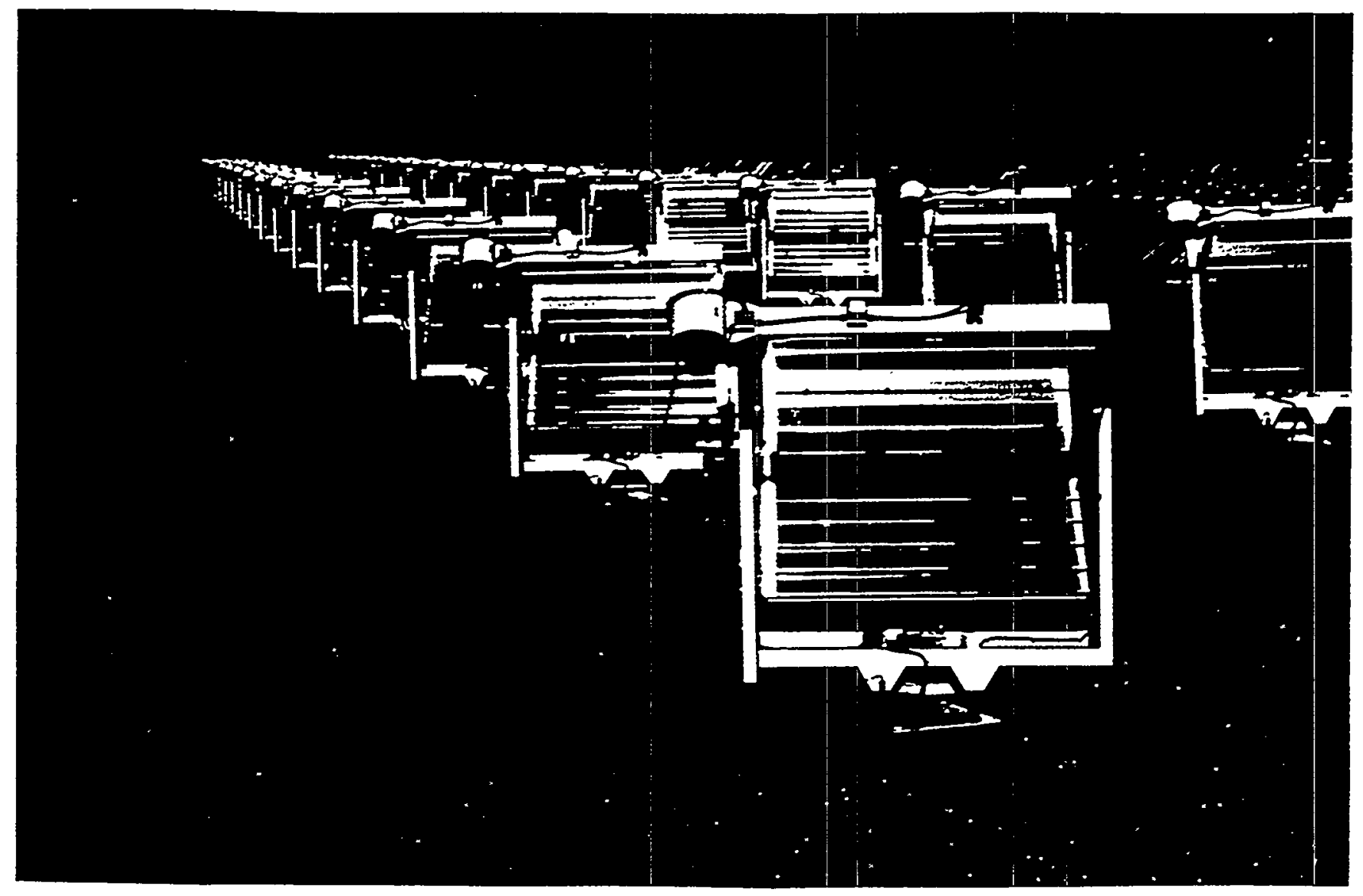

EMMAQUA $^{\circledR}+$ Test Field 


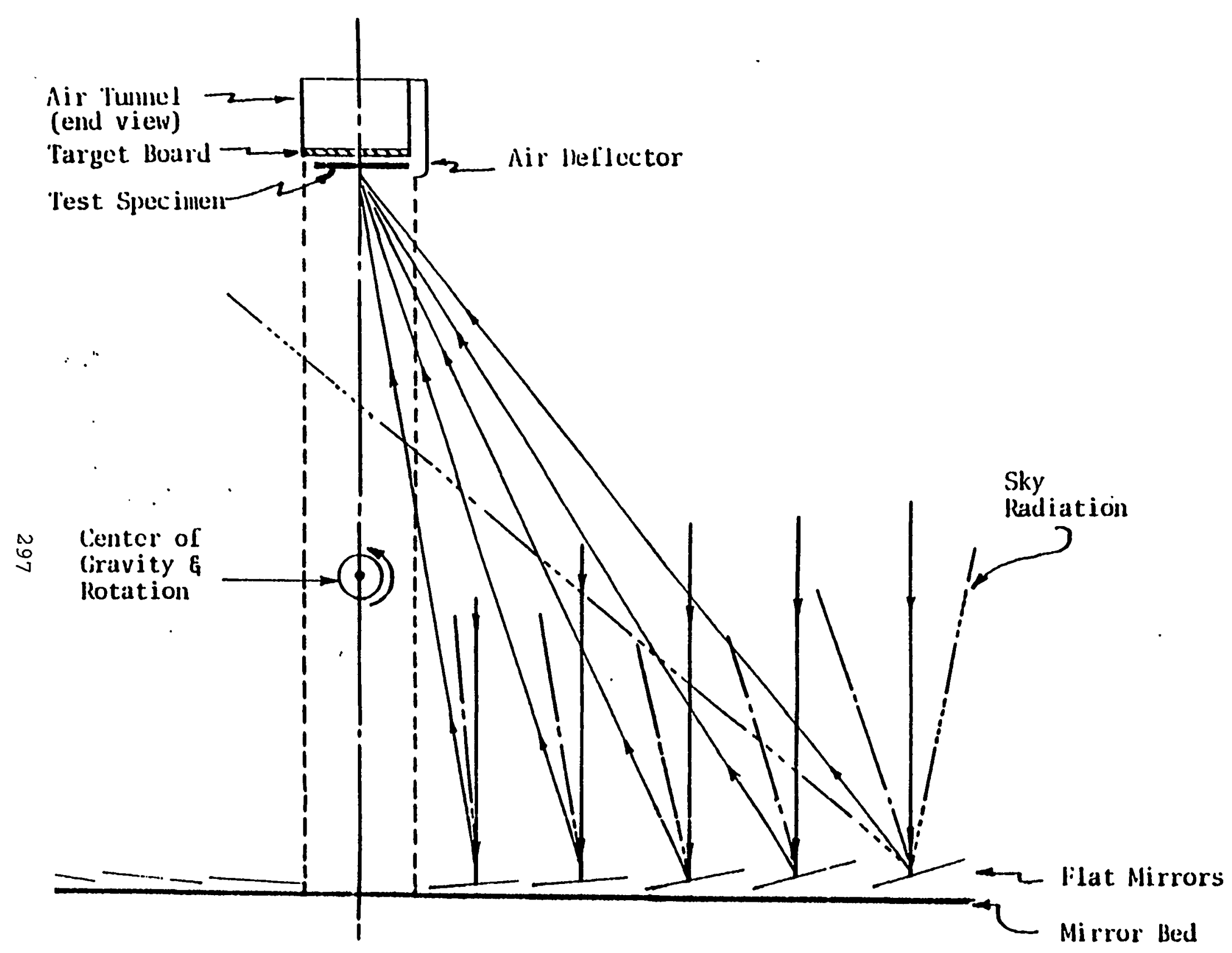

SCHEMATIC OF LMMAQUNOUIDOOR ACCELERATED WEATHERING DEVICL 


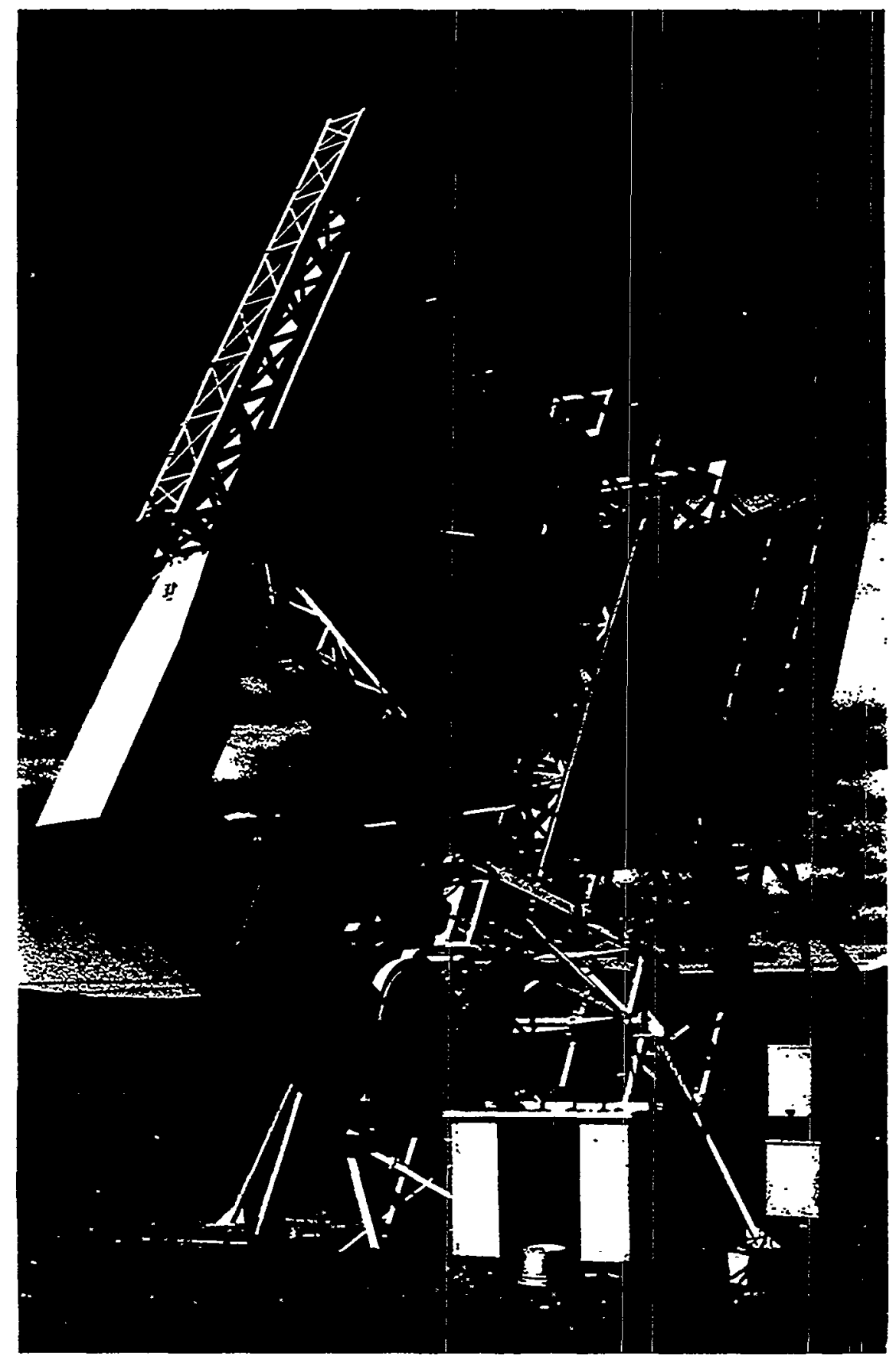

Super-Maq ${ }^{\circledR}$ Accelerated Outdoor Exposure Device 


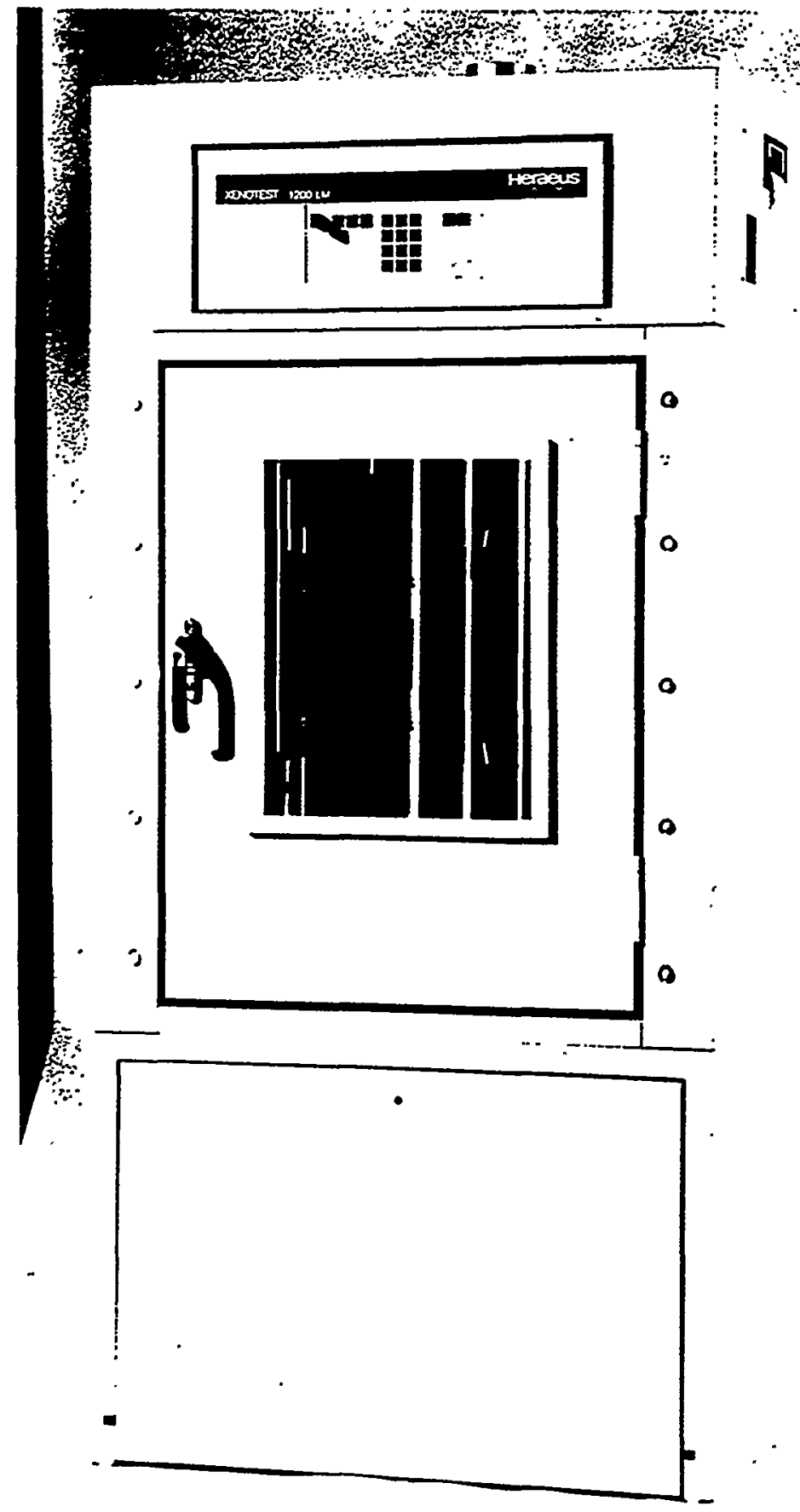

Xenotest $^{\circledast}$ LM Xenon Weathering Device 


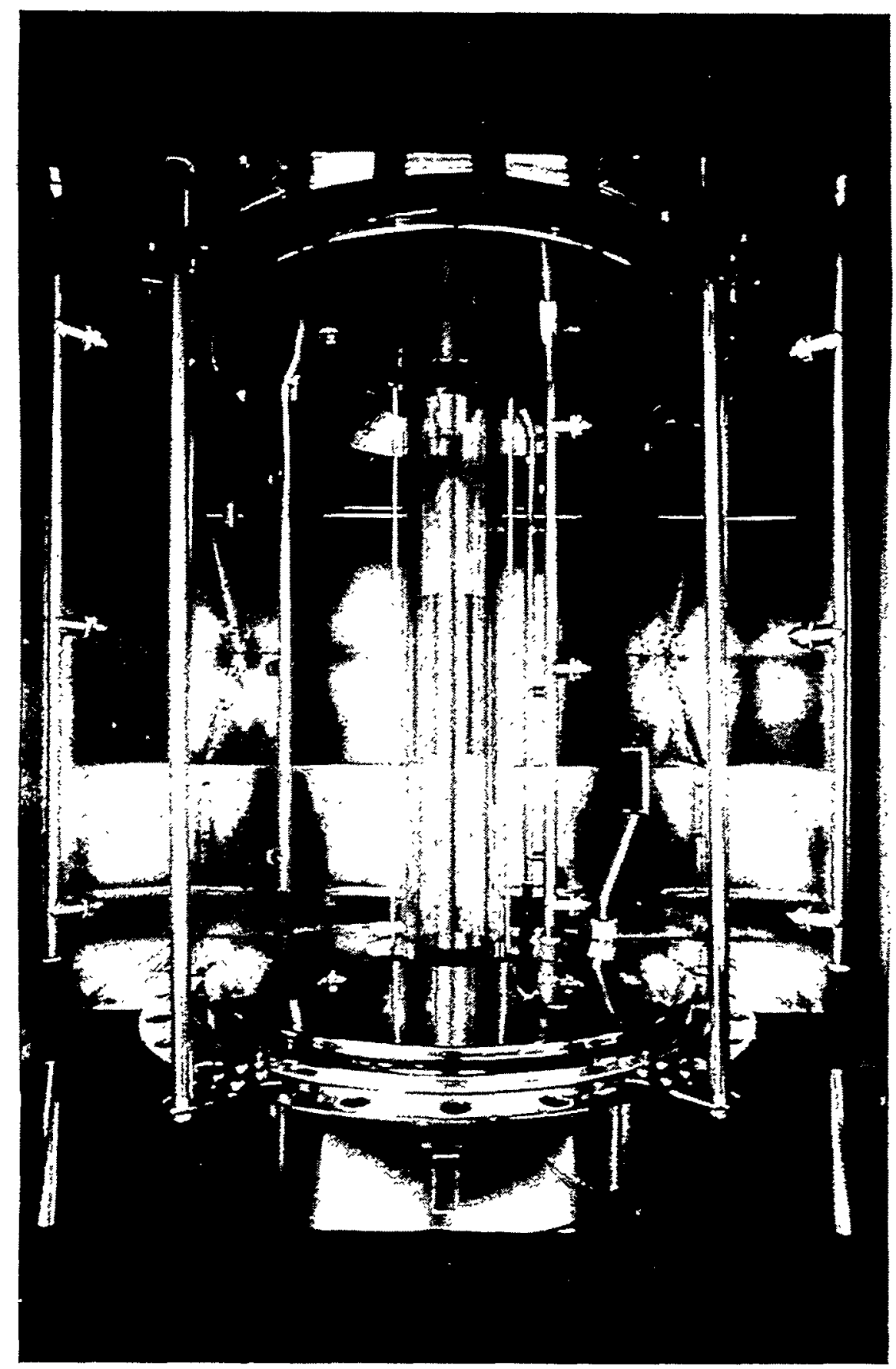

Xenotest $^{\circledR}$ LM Test Chamber 


\section{A Spectral Comparison of Natural Sunlight vs. EMMAQUA ${ }^{\circledR}$}

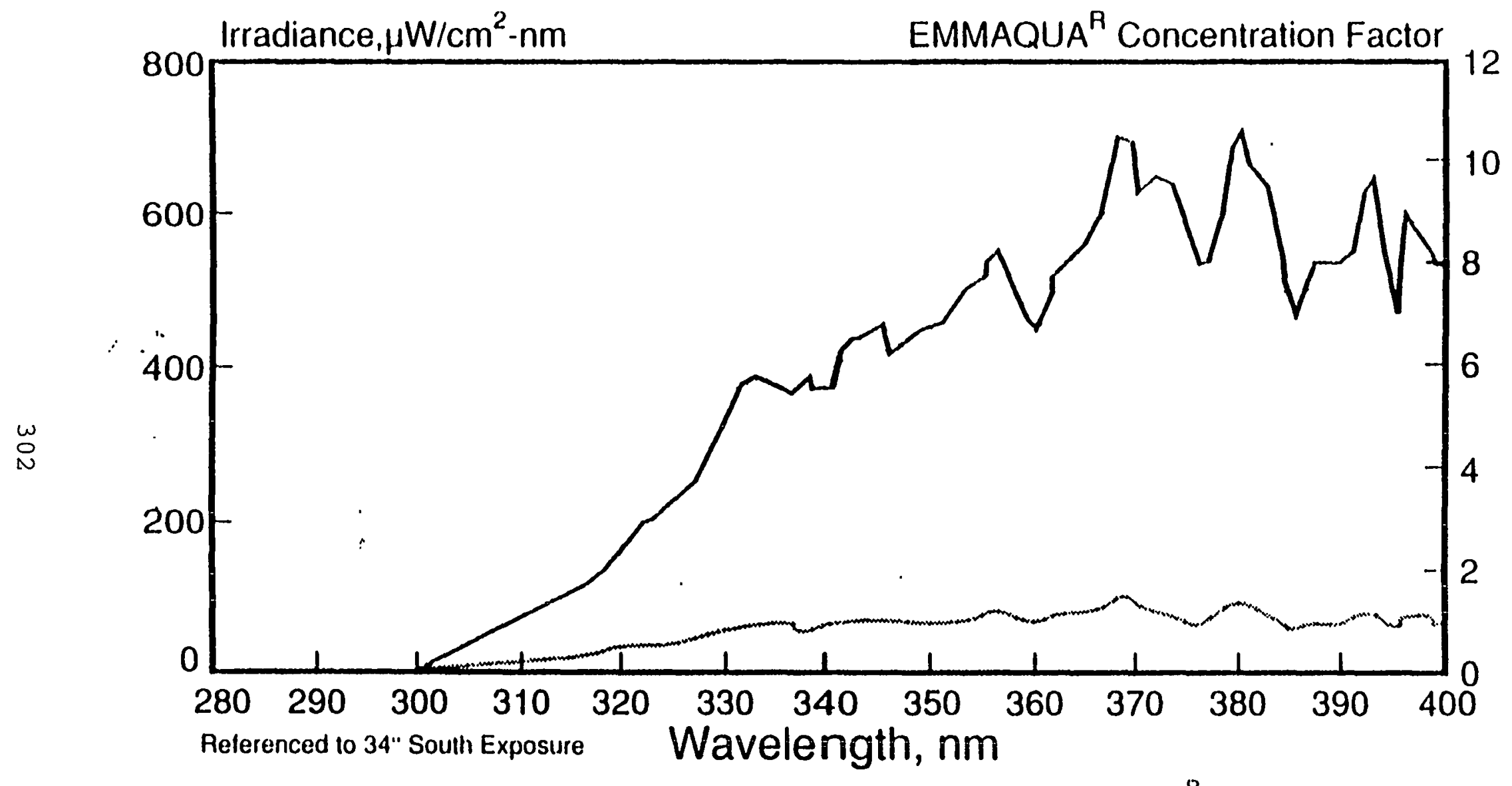

$$
\text { Global, 34"s Tilt _- EMMAQUA }{ }^{\mathrm{B}} \text { Target }
$$




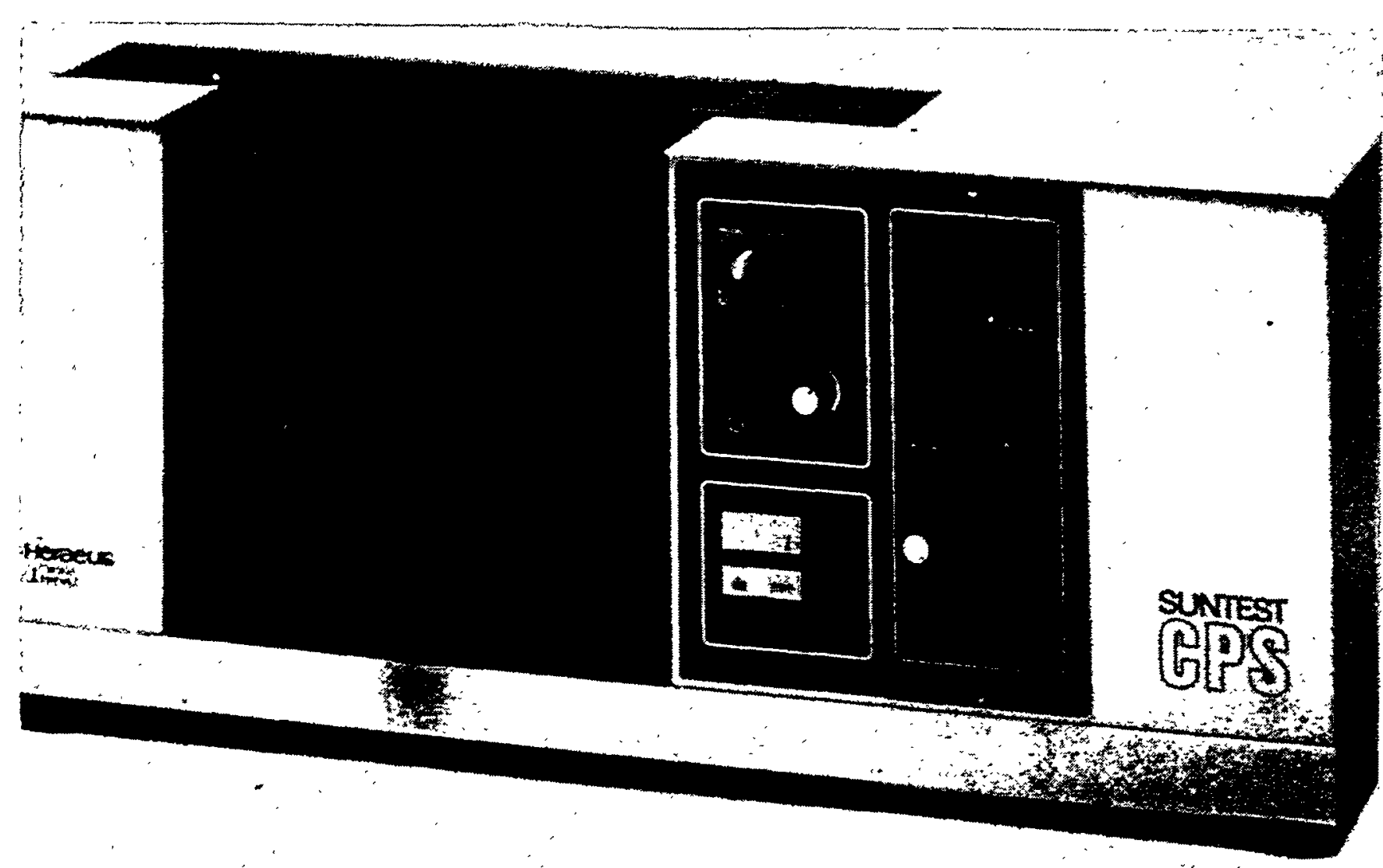

\section{Suntest ${ }^{\circledR}$ CPS Tabletop Xenon Weathering Device}

- XENCN Strahter

2 Uvi-Splege:

3 Licnt-Spleget

4 Juar2giasschale mit selektw. refiektierender Schicht

$\Xi$ Zusuzztiltor aus UV-Spezialglas ose: Speziai-Fensterclas

E Paratolretlektor

7 Erobenedene

1 YENON numzer

2 Ultrámolet mirror

3 Lignt muror

4 Ouarz glass dish with selective reflecting coatung

5 Sxpoptementary fíter made of special ultra-violet glass or sfecial wndow glass.

6 Perabohc reflecior

7 Specmen plane

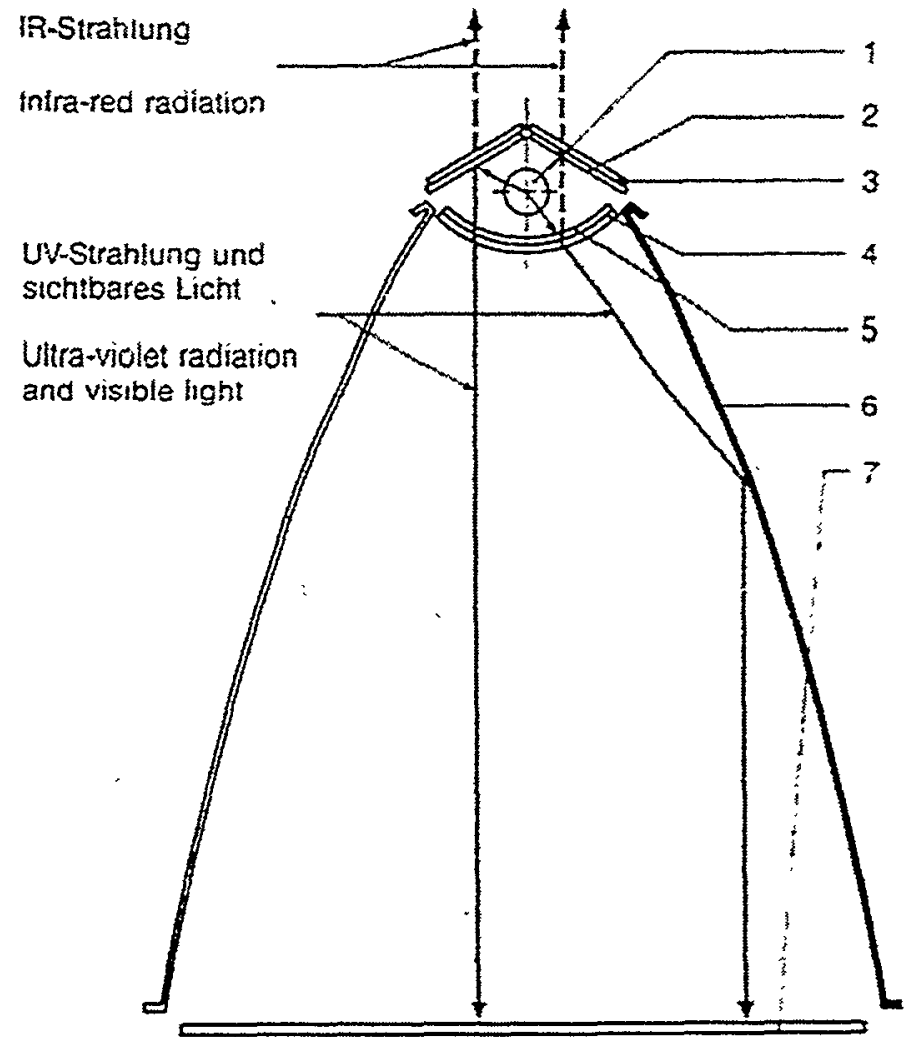

Cross Section of the Suntest ${ }^{\circledR}$ Optical System 


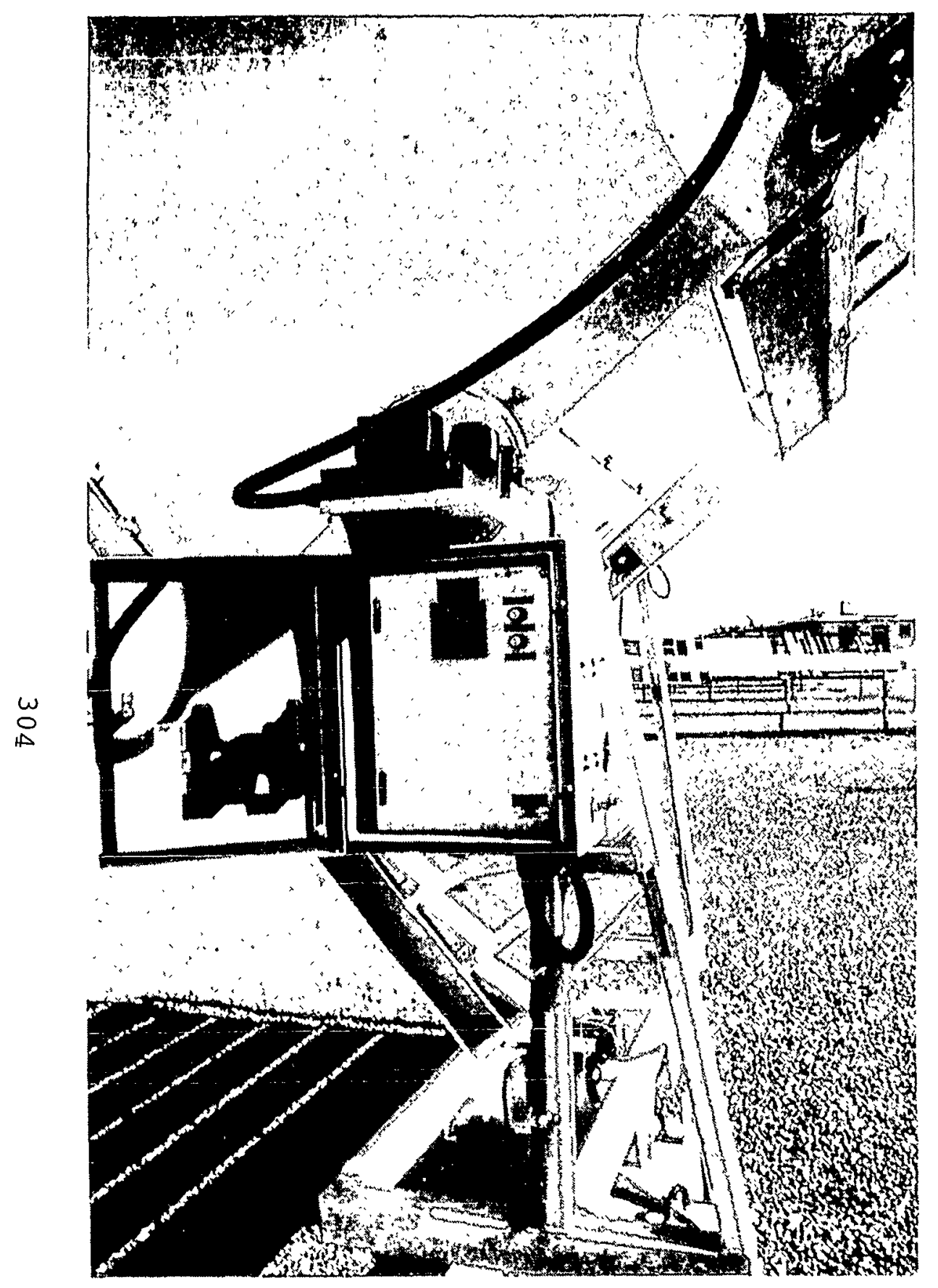

Control Panel for the EMMAQUA ${ }^{\circledR}+$

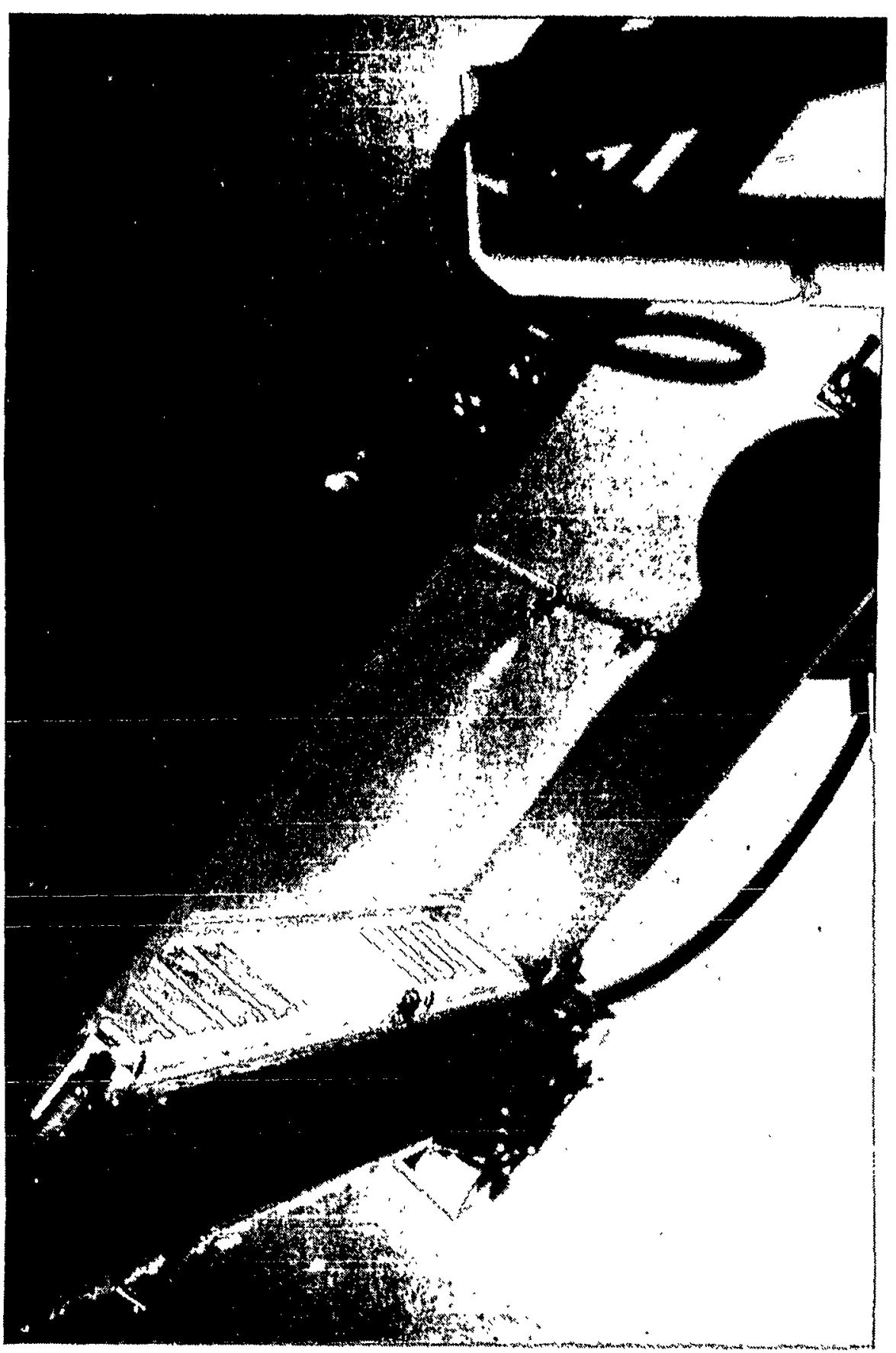

EMMAQUA $^{\circledR}+$ Spray Cycle 


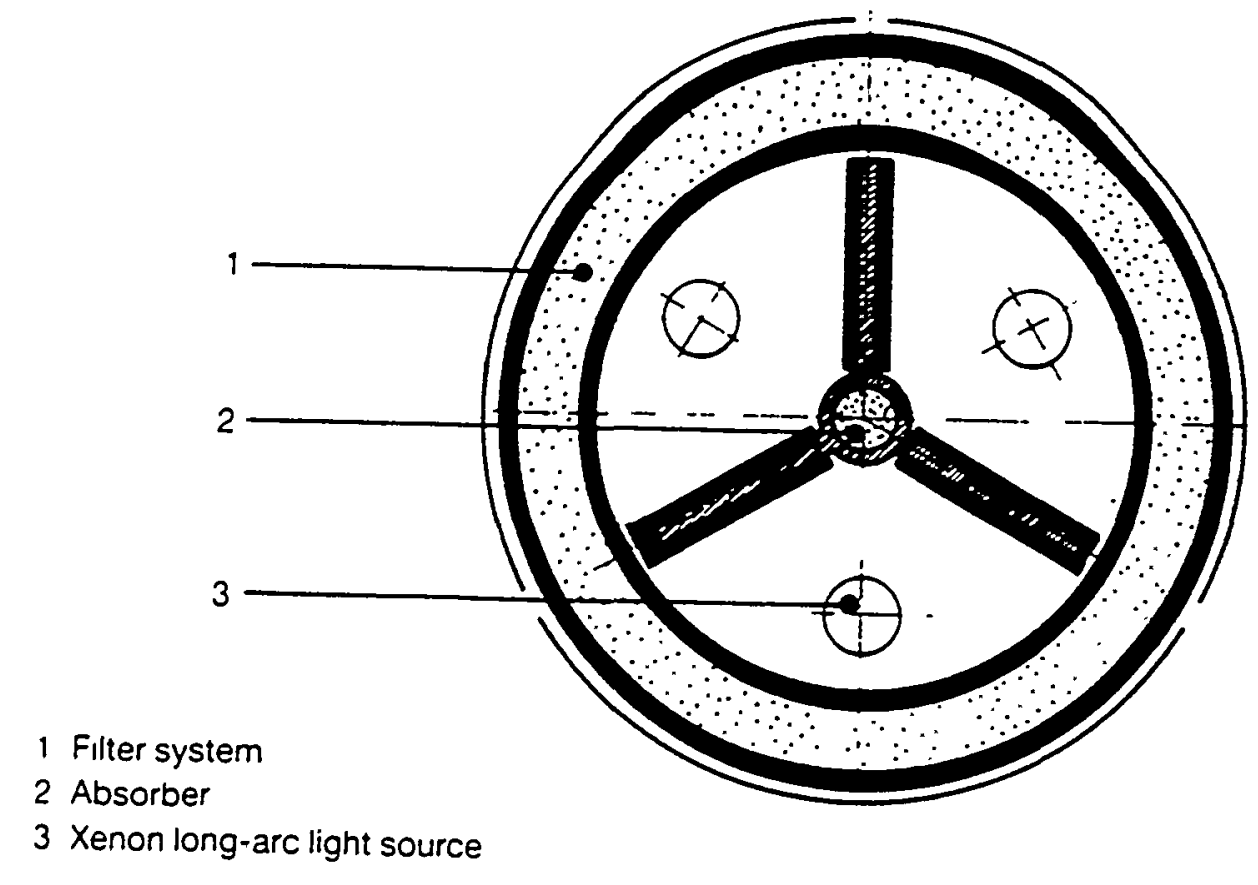

\section{Cross Section of the Xenotest $^{\oplus}$ LM Optical}

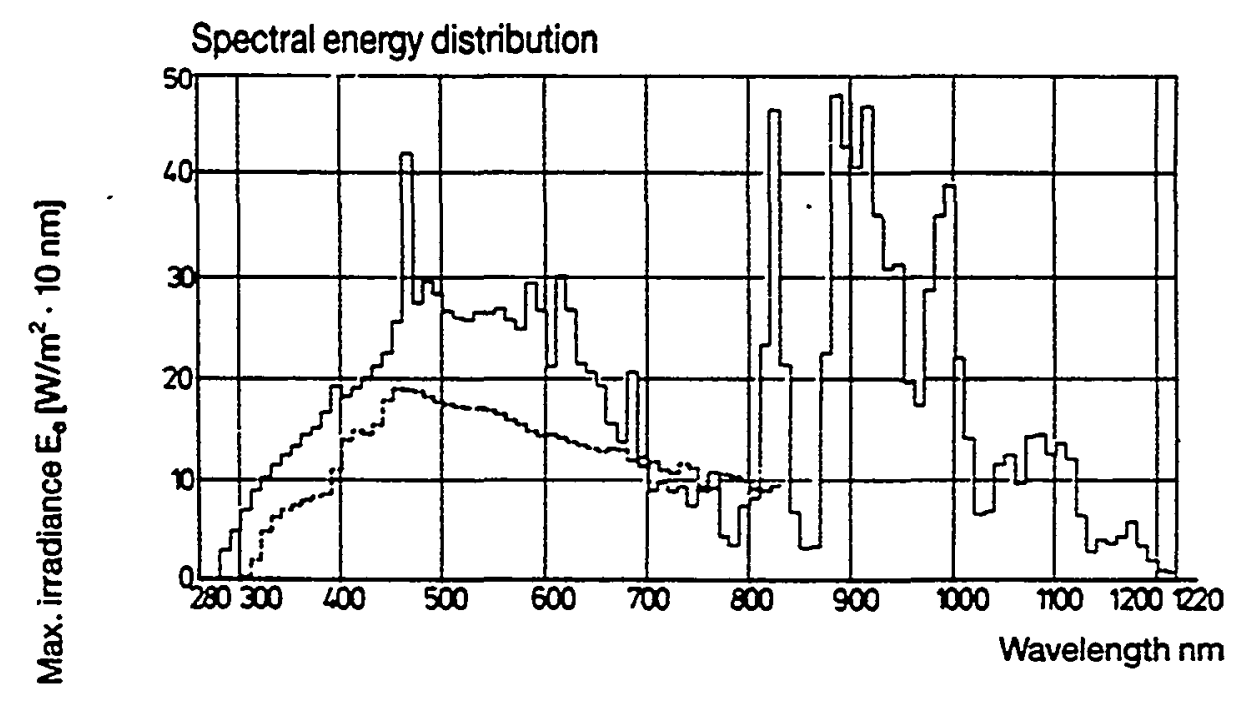

_ultra-violet mirror + coated quartz glass cylinder

. . . global radiation to daylight phase D65

\section{SystemXenotest ${ }^{\circledR}$ LM Spectral Energy Distribution}




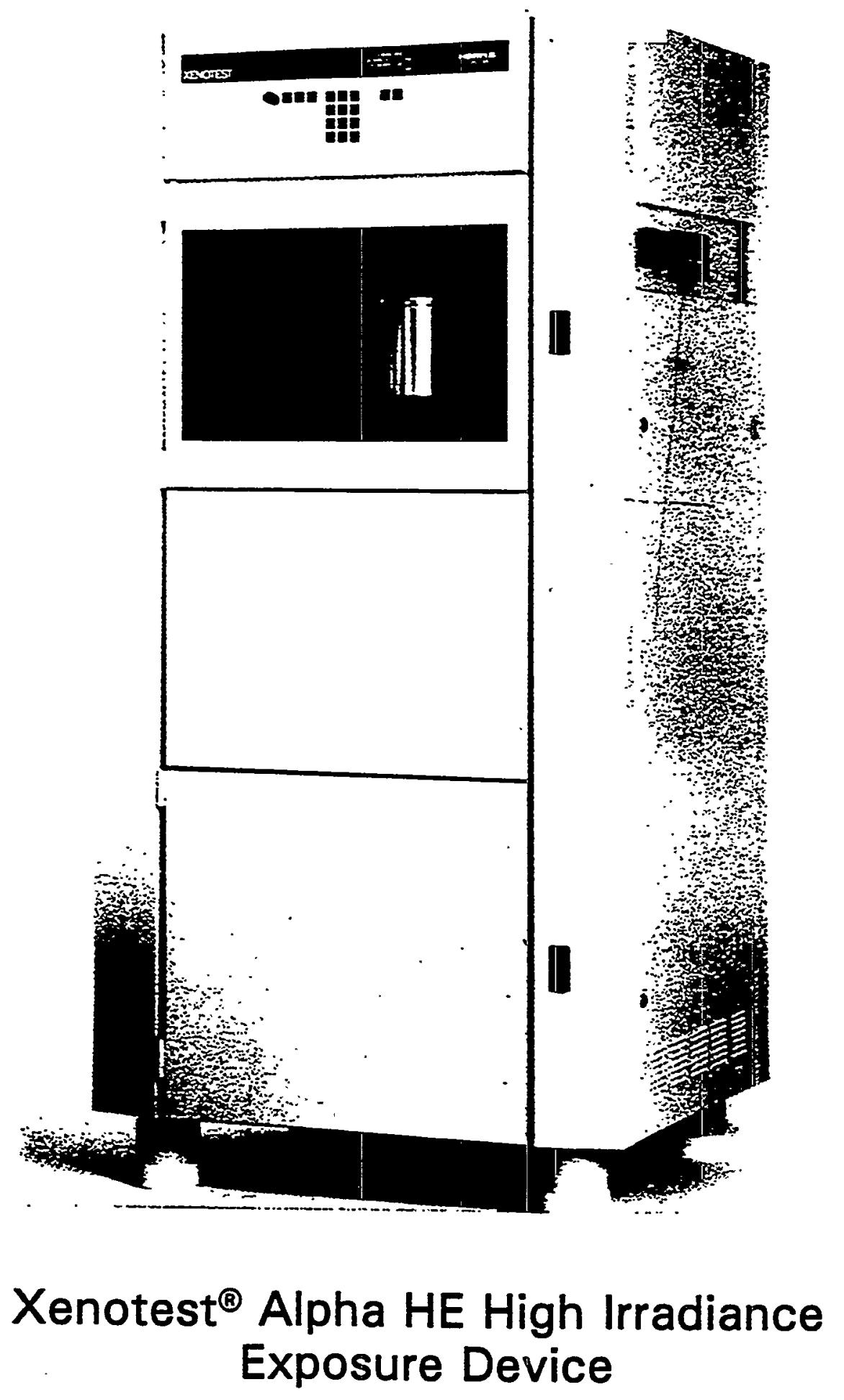




\section{Chamber of ALPHA HIGH ENERGY}

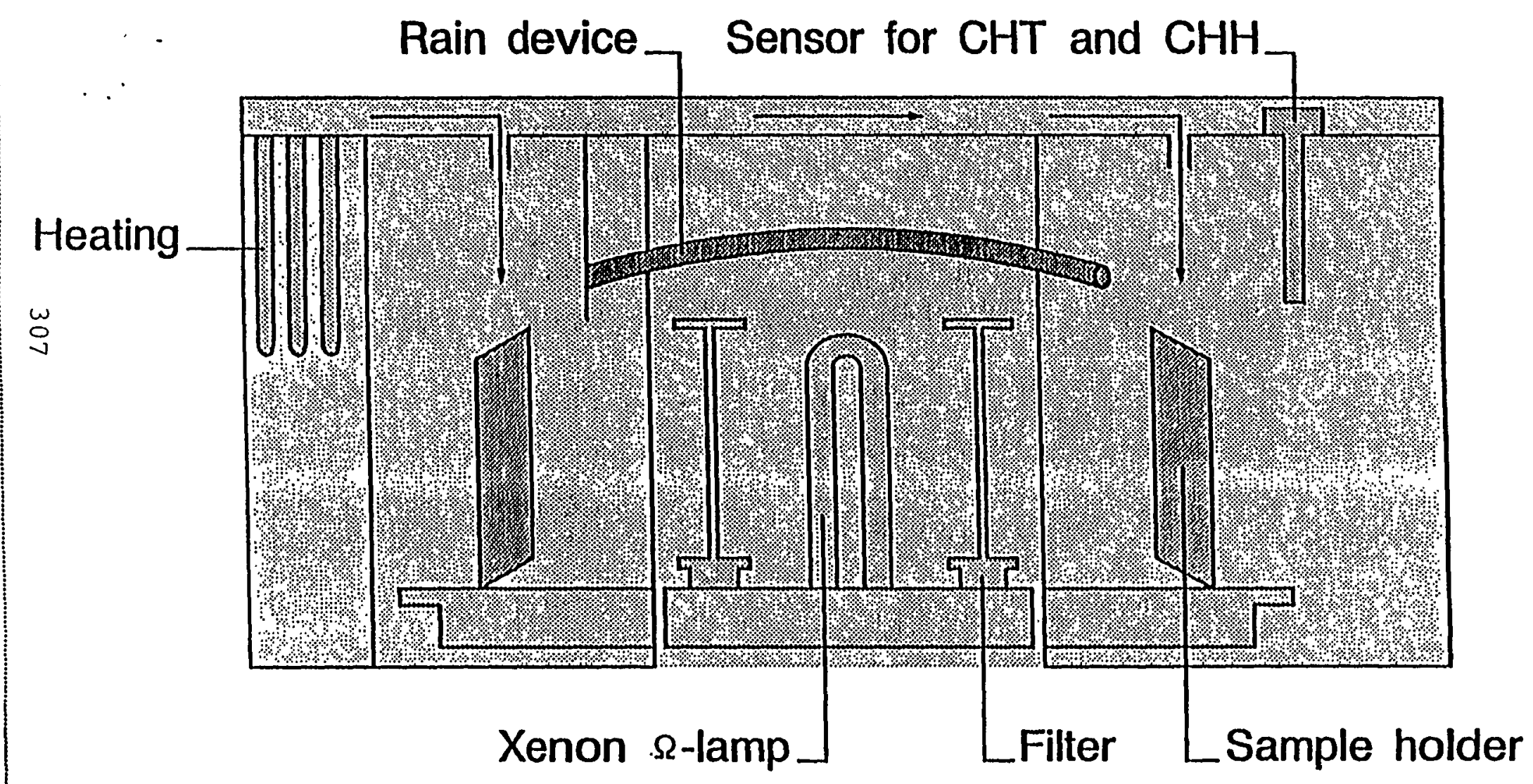




\section{Principle of the XENOCHROME filter system in ALPHA HIGH ENERGY}

Heraeus

INSTRUMENTS

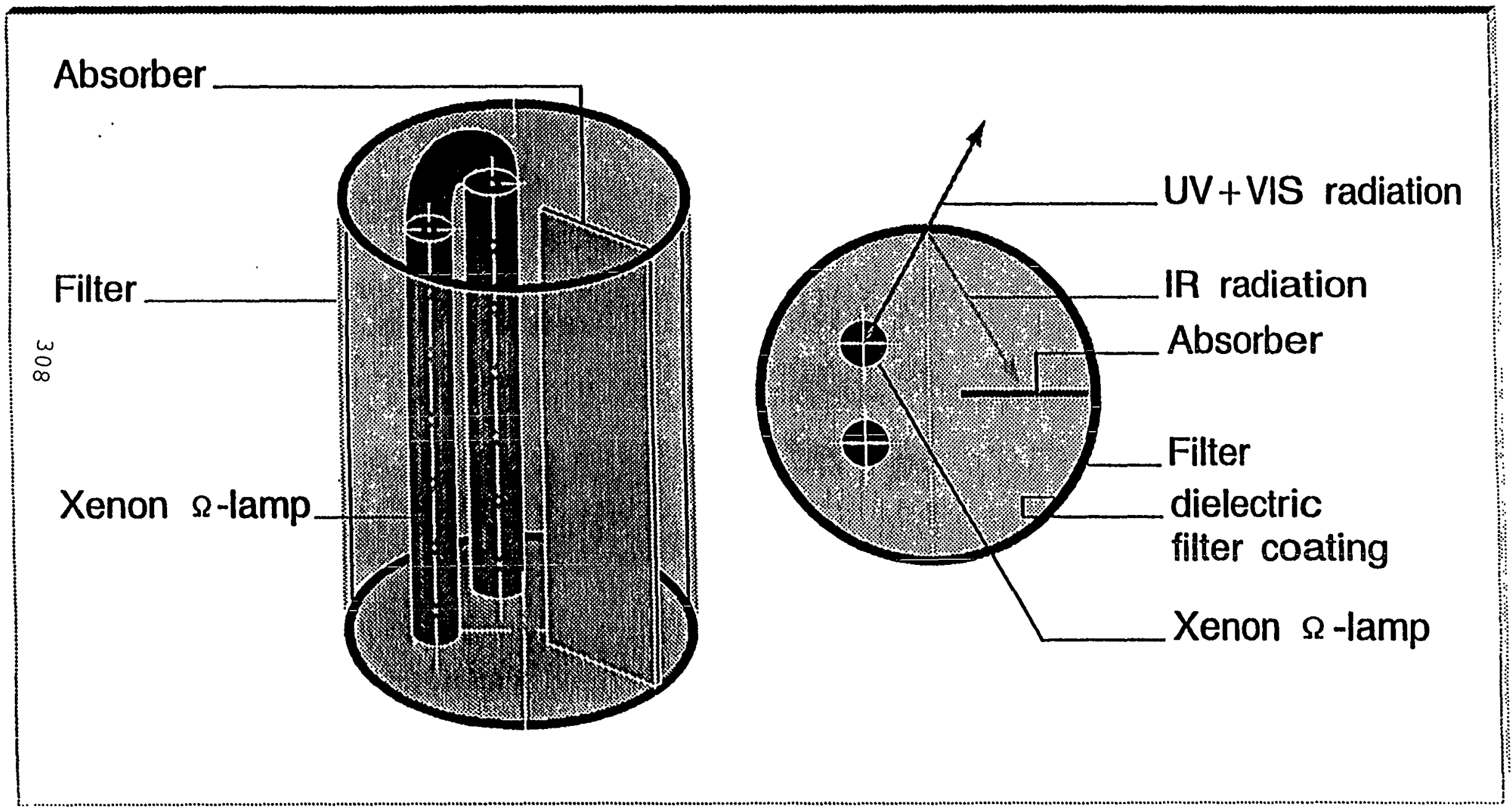


Filter System: XENOCHROME 300

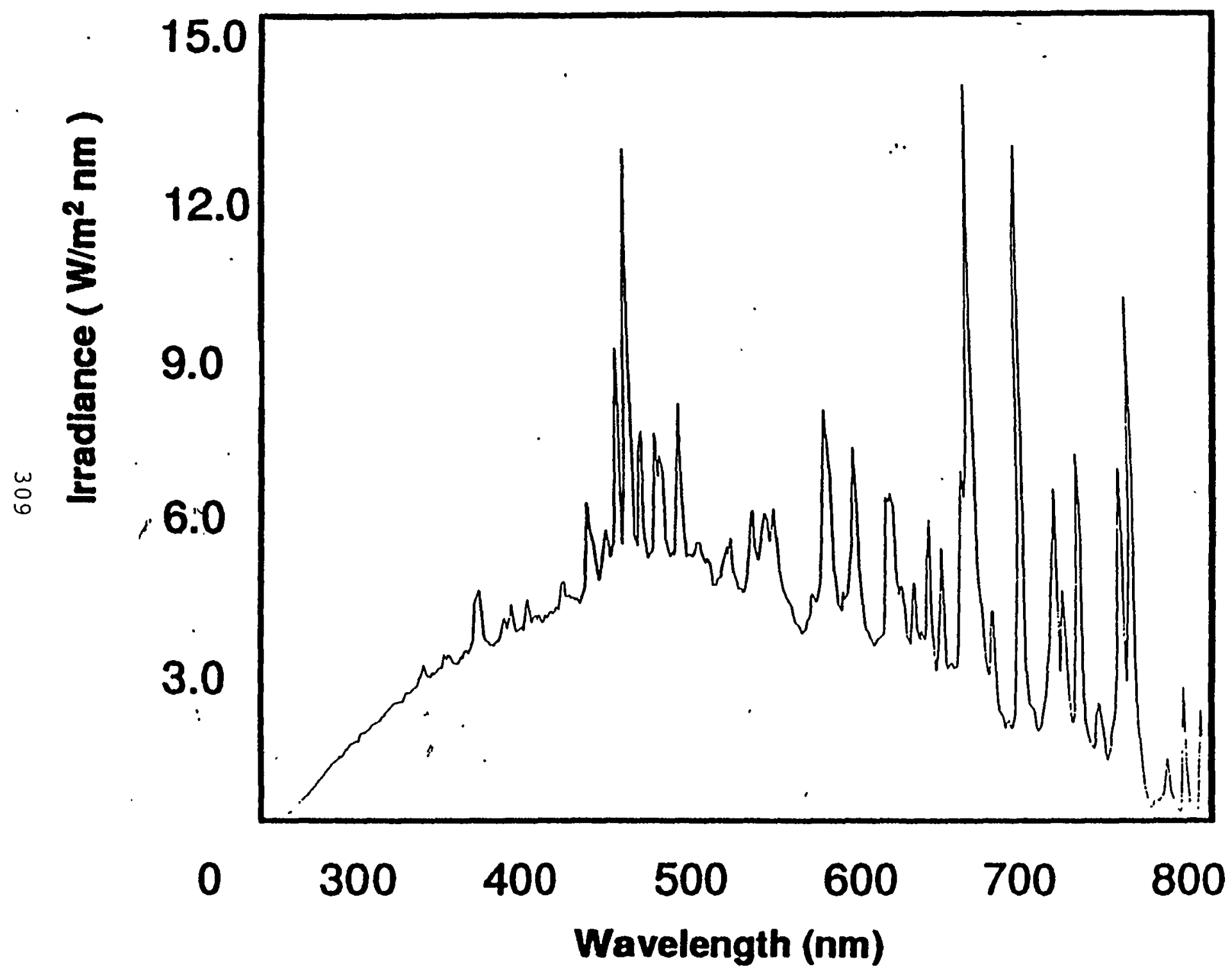




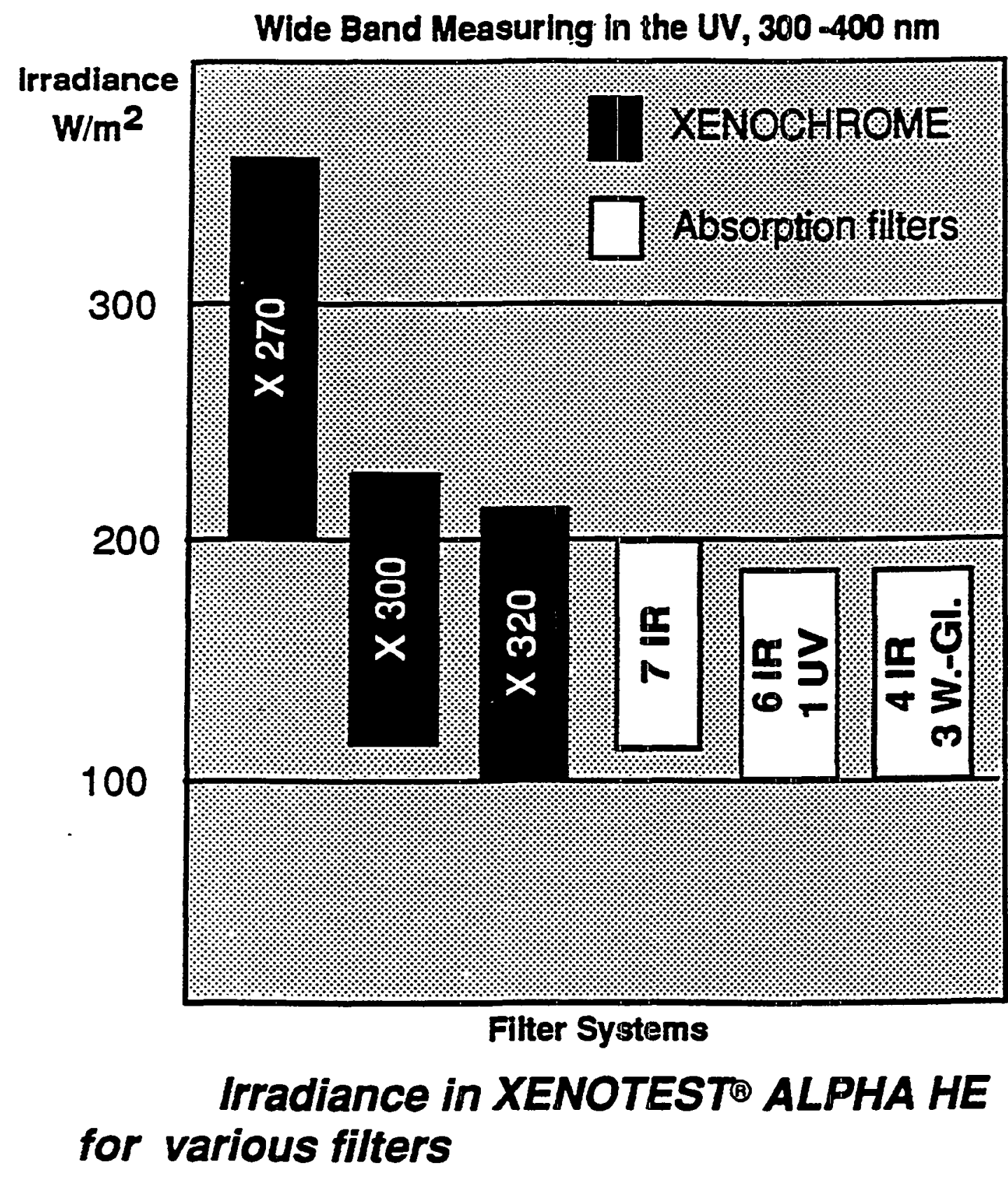




\section{EVA DEGRADATION MECHANISMS: REVIEW OF WHAT IS AND IS NOT KNOWN}

\section{A.W. CZANDERNA}

Measurements and Characterization Branch

National Renewable Energy Laboratory

Golden, Colorado

PV Performance and Reliability Workshop

Golden, Colorado

September 8-10, 1993 


\section{OUTLINE}

Introduction/Background

- What is EVA? (A9918 and 15295)

- What is the Problem?

$\stackrel{\sim}{\sim} \quad$ What is Known About EVA Degradation?

- Before 1987 and Now

What is Not Known About EVA Degradation 


\section{MAJOR POINTS}

- Module durability is more than an EVA problem

- EVA degradation is not new -- what is known

- What is not known about EVA degradation 


\section{PURPOSE -- MATERIALS SYSTEMS}

- Provide mechanical support for solar cells

- Facilitate maximum optical coupling -- sun/cells

- Isolate cells from degrading environmental factors (reactive elements/compounds, soiling, hail, etc.)

- Provide electrical isolation for solar cells

- Provide ancillary electrical circuitry for cells

- Emphasize low cost -- Maintain function for 30 YEARS

- i. e., All necessary functions except that of cell itself. 


\section{FAILURE MODES -- EARLY WORK}

$\mathrm{R}$ - Delamination at interfaces

$\mathrm{R}$ - Penetration of liquid water

$\mathrm{R}$ - Short circuit -- arcing

$\mathrm{R}$ - Cracking of solar cells -- TEXP

$\stackrel{⿱ 乛 灬}{\omega}$

R - Cell interconnect failures -- TCYCLING

$\mathrm{R}$ - Charring and melting of solder -- High T

D - Soiling

D - Weathering and physical degradation 


\section{REACTIONS/PROCESSES THAT LIMIT ENCAPSULANT DURABILITY}

(Not Includlng Edge Seals)

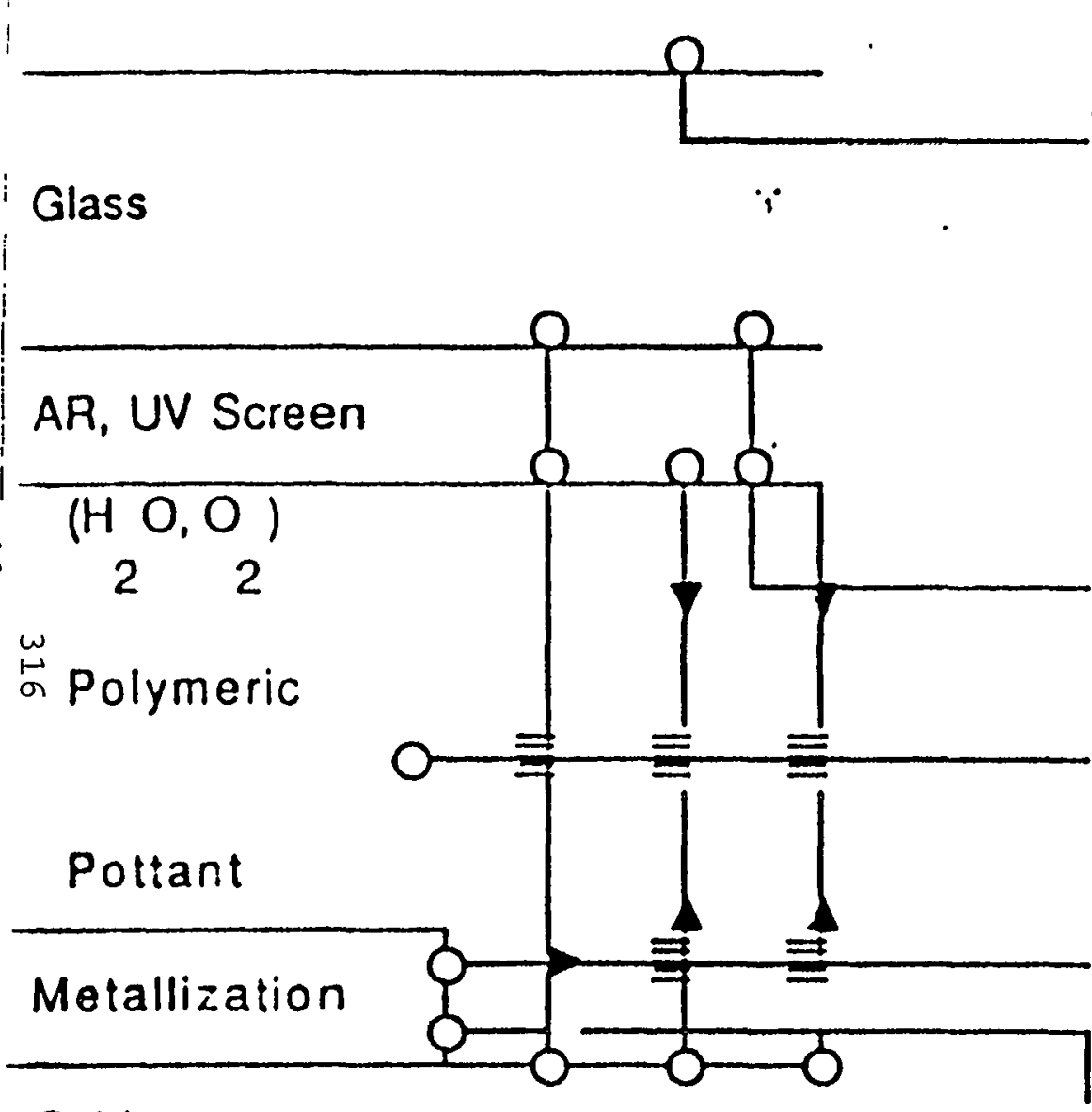

Oxide

Polymer/Metal (Oxide) Interfuces (Reactions, Delaminations)

Solar Cell Material

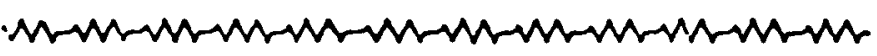

Interdiffusion (Especially, Cations/Arions into Polyme

Pholodegradation, Oxidation: CompositioniProperties Relationships

Corrosion, Oxidation, $\vec{E}$ induced Migration 


\section{POLYMERS AS A PV MODULE ENCAPSULANT}

- The Reality!

\section{ENCAPSULATION STABILITY}

- Multilayer stack on either side of active device material

- Extremely complex to predict -- large number of variables

- T effects including cyclic $\mathrm{T}$

- UV degradation -- Photothermal ,

- Concentration of $\mathrm{H}_{2} \mathrm{O}, \mathrm{O}_{2}$, and other gases

- Interface reactions/interdiffusion

- Compositional effects ... impurities

- Electric field influences

- Slow time-dependent effects (requires ALT) 


\section{SIMPLIFIED SCHEMATIC OF THE MECHANISM OF PHOTOTHERMAL DEGRADATION}

$\mathrm{R}=$ Polymer

$\mathrm{R} \underset{1}{\stackrel{\mathrm{UV}, \mathrm{T},[\mathrm{G}]}{\longrightarrow}} \mathrm{R}^{*} \underset{2}{\longrightarrow} \mathrm{R} \bullet \underset{3}{\longrightarrow}$ Degradation Products

- UV - wavelength? Intensity $\left(\mathrm{W} / \mathrm{m}^{2}\right)$

- Catalytic effect of degradation products.

- Exposure time for permanent damage?

- Synergistic influences from UV, $\mathrm{T}, \Delta \mathrm{T}, \mathrm{H}_{2} \mathrm{O}$, gases, impurities?

- Distribution of copolymer blocks. 


\section{PHOTOOXIDATION USUALLY RESULTS IN:}

- Deterioration of optical properties

- Deterioration of mechanical properties

- Reduction in tensile strength (TS)

- Reduction in elongation (e), i.e., more brittle

$\underset{\circlearrowleft}{\omega}$ - Reduction in transparency (Willis, 1986, VII-1). 


\section{POLYMER DEGRADATION CAN BE MEASURED BY CHANGES IN PROPERTIES}

- Mechanical: tensile strength, elongation, gel content, modules

- Optical: UV-vis (300 to $1100 \mathrm{~nm}$ ), fluorescence

- Chemical: [stabilizer]. [outgassing products]. interconnect corrosion

- Dielectric: E field stress, leakage current, electrical isolation 


\section{CONSEQUENCE OF PHOTODEGRADATION OF EVA}

- Scission: decrease polymer chain length/molecular weight

- Cross-linking: increase networking of polymer chains

=> change mechanical properties

- Formation of long polyconjugated $\mathrm{C}=\mathrm{C}$ bonds

$\Rightarrow>$ increased light absorption

$\Rightarrow$ reduced optical transmission

$=>$ luminescence

$\Rightarrow$ cross-linking 


\section{GENERAL FACTORS AFFECTING PERFORMANCE OF EVA STABILITY}

- Polymer/cover interface degradation

- Bulk polymer degradation

- Polymer/cell interfacial degradation 


\section{POTTANT/INTERFACES STABILITY}

- Thermodynamically unstable -- always in higher G state

- Always want a lower energy surface

- "Stability" depends on kinetic processes: composition

- At any $\mathrm{T}$ (or set of degradation parameters), ONE reaction usually predominates

- Typically, many reaction paths with different $E_{A}$. 


\section{EVA: WHAT IS THE PROBLEM?}

- Observed Degradation in the Field?

- Locations of Observed Degradation?

- Observed Degradation in the Laboratory? 


\section{EFFECTS OF EVA YELLOWING}

- Reduced optical transmission on EVA

- Reduced power output of PV modules

- Acidic corrosion of metallic circuits

- Acidic corrosion of solar cells

- Enhanced Mn+-catalyzed photodegradation

- Reduced service life of PV modules 


\section{DEGRADATION IN THE FIELD}

- Color changes - Yellow to Brown

- No color changes - Areas remain clear

- Evidence for Gas Bubbles

- Metalization Corrosion - Acetates

- Location Specific Degradation/Stability (Apparent)

- Massive Disaster - Rare 


\section{OVERALL STRATEGY -- SOLVING THE EVA PROBLEM}

- Understand why EVA is degrading

- Use/develop analytical capabilities

- Develop collaboration/cooperation with PV Manufacturers

- Expand effort for securing a better pottant and more stable encapsulated PV module systems 


\section{RECENT HISTORY - YELLOWING OF EVA COPOLYMER}

- 1984, SWRES, light yellow, 4 years after installation, one mfg.

- 1988, Carrisa Plains, 2.5 years after installation, mirrors; Schaefer

- 1990, (Feb.), Meeting at SERI to discuss EVA "crisis"; many

- 1990, (Oct.), EVA degradation at Carrisa; Rosenthal/Lane

- 1991, Less but increased browning of Segment 10, Carrisa; Schaefer

- 1992, SMUD, Phoenix, Albuquerque, Cape Canaveral, Morocco, Australia, Namibia, Saudi Arabia, Israel in addition to the above, Pern/Czanderna

- 1993, More examples continue to be reported 


\section{WHAT IS EVA?}

- Copolymer wilh 33\% Vinyl Acetate

- Added ingredients?

DU PONT ELVAX 150; SPRINGBORN A - 9918; EVA

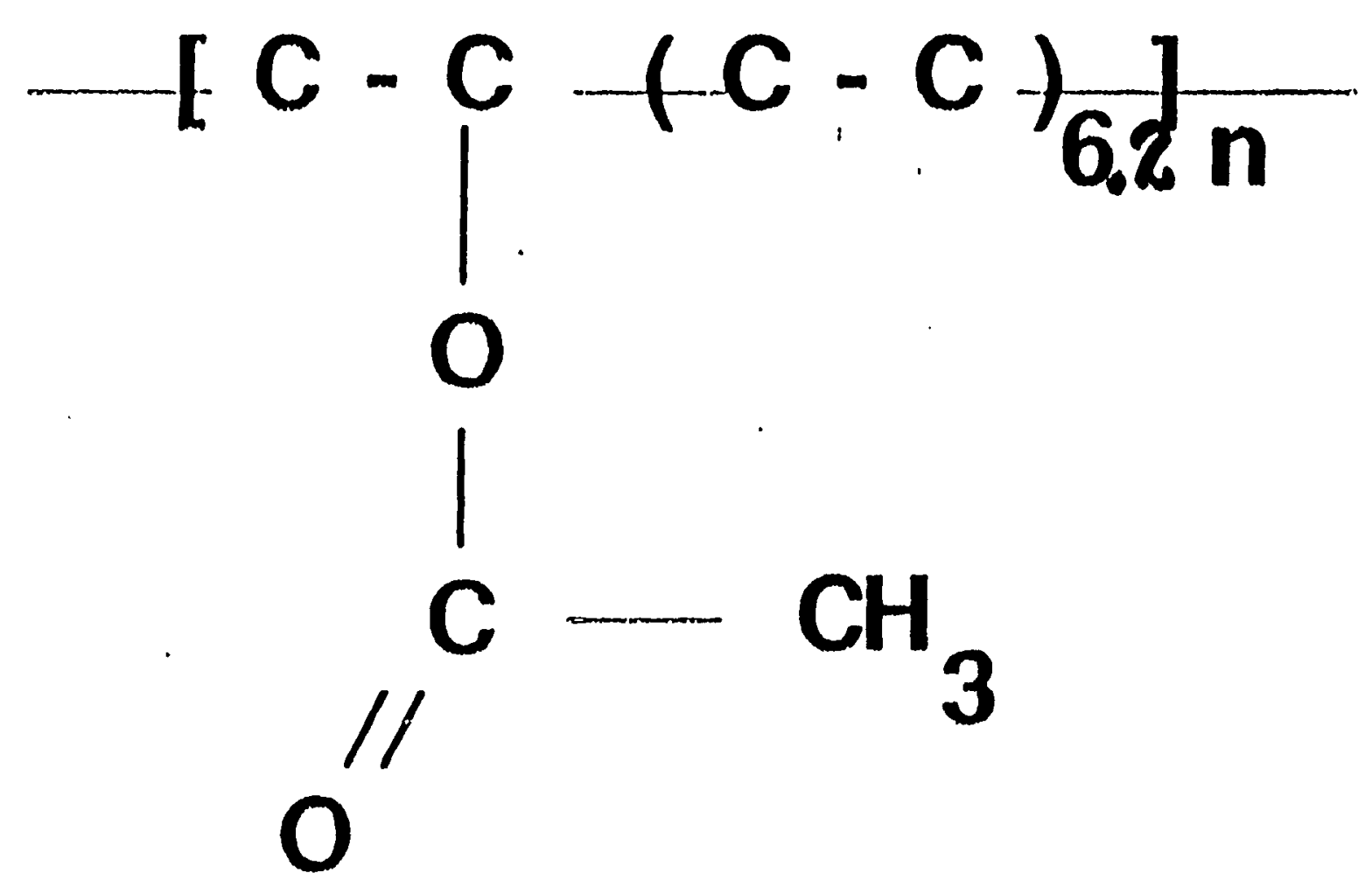


NORRISH MECHANISMS

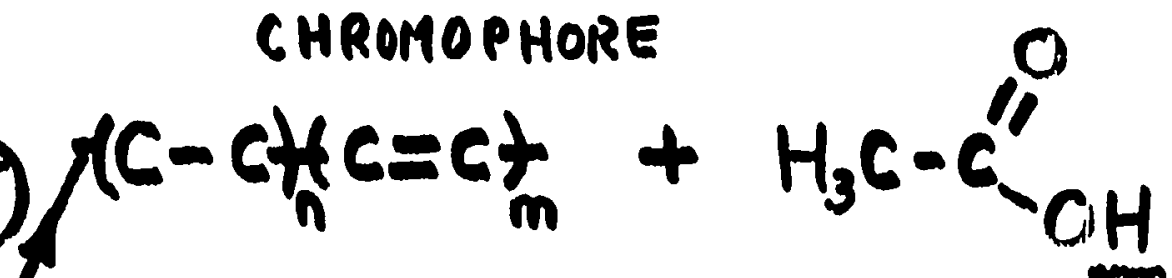

PREDomMar.II)

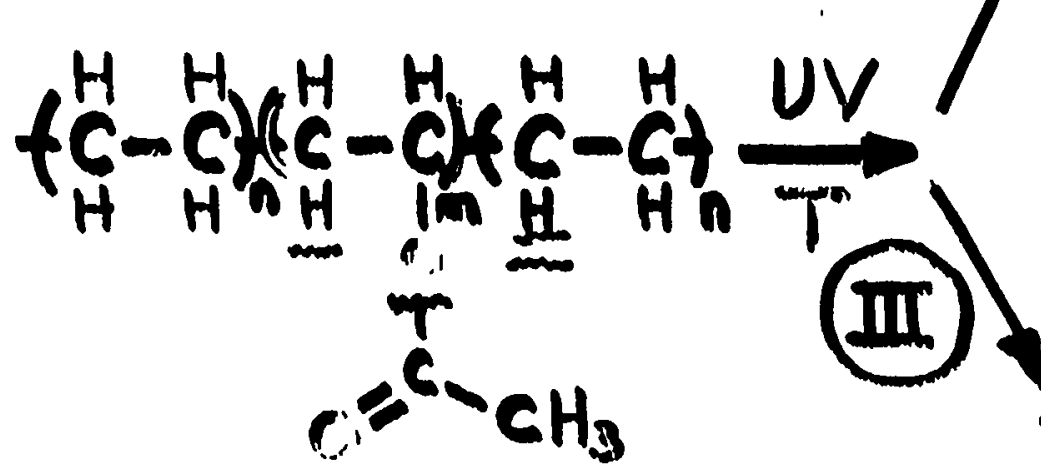

"ene conjugation Acetic Acid

DEACETYLATION REACTIONS

(I) $\mathrm{UV} \| \mathrm{T}$

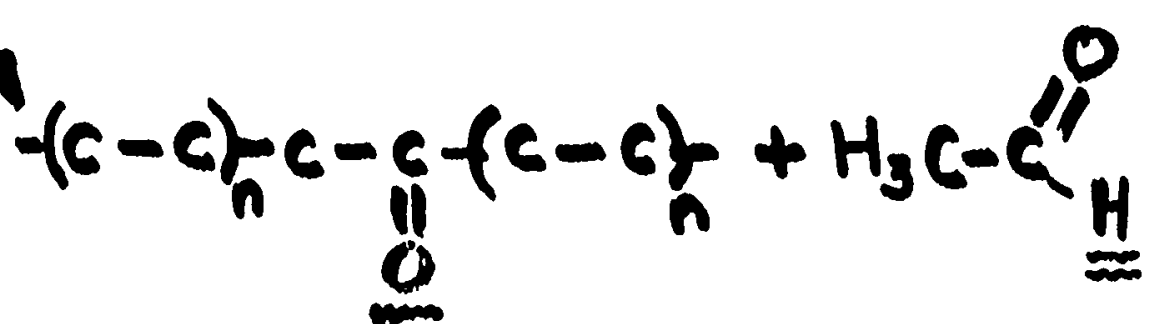

CHROMOPHORE ACETALDEHYDE<smiles>CCC(C)C=O</smiles>

Acetaldehyde<smiles>CC(=O)C=O</smiles>

RH

$\mathrm{H}_{3} \mathrm{C}-\stackrel{\mathrm{H}}{\mathrm{C}=\mathrm{O}}+\mathrm{R}$.

$\downarrow \mathrm{O}_{2}$

$Q \mathrm{CH}_{3}+\mathrm{CO}$

Methane

$\mathrm{CH}_{4}+\mathrm{RD}$ 
POLYENE, $m=3$, LIGHT YELLOW, 3 DEACETYLATIONS<smiles>C/C=C/C=C/C=C/C(C)=O</smiles>

OO POLYENE OXIO
OAH PEROXNDE<smiles>CC=CC(C)OO</smiles><smiles>CCCCCCC</smiles>

CHROMOPHORE ( UNSATUAATED<smiles>CC=CC(C)=O</smiles>
CARBONYL,

PHOTOOKIATN winh REDUCE MW OF Eactine R 


\section{FORMULATION/STABILIZATION OF ELVAX 150 (EVA COPOLYMER) AND COMMENTS}

- UV absorber [Cyasorb UV 531] - 90\% effective as UV absorber

- Anti-photo oxidant [Tinuvin 770] - Important to lifetime of UV 531

- Anti-thermal oxidant [Naugard P]

- Curing agent [A9918-Lupersol 101] — "slow cure," $50 \mathrm{~min}$. [15295 -Lupersol TBEC] - "fast cure," 7 min. (Cure time, of course, is $\mathrm{T}$ dependent)

- UV screen between cover/EVA - rarely used since early 1980s 


\section{WHAT IS KNOWN ABOUT EVA DEGRADATION AS}

OF DECEMBER 1992?

- Degradation in the Field-Yellowing

- Laboratory Studies/Mechanisms

- Thermal (EVA)

- Photothermal (EVA)

- Acetic Acid Catalyzed (EVA)

- Cyasorb Loss

- Photobleaching (Photo-Oxidation)

- Metal Ion Catalyzed 


\section{Glass}

yellow

clear

clear

yellow

yellow

clear yellow-brown $E$

yellow-brown $\mathbf{V}$

yellow-brown

\section{Grid}

And

Cell Material 


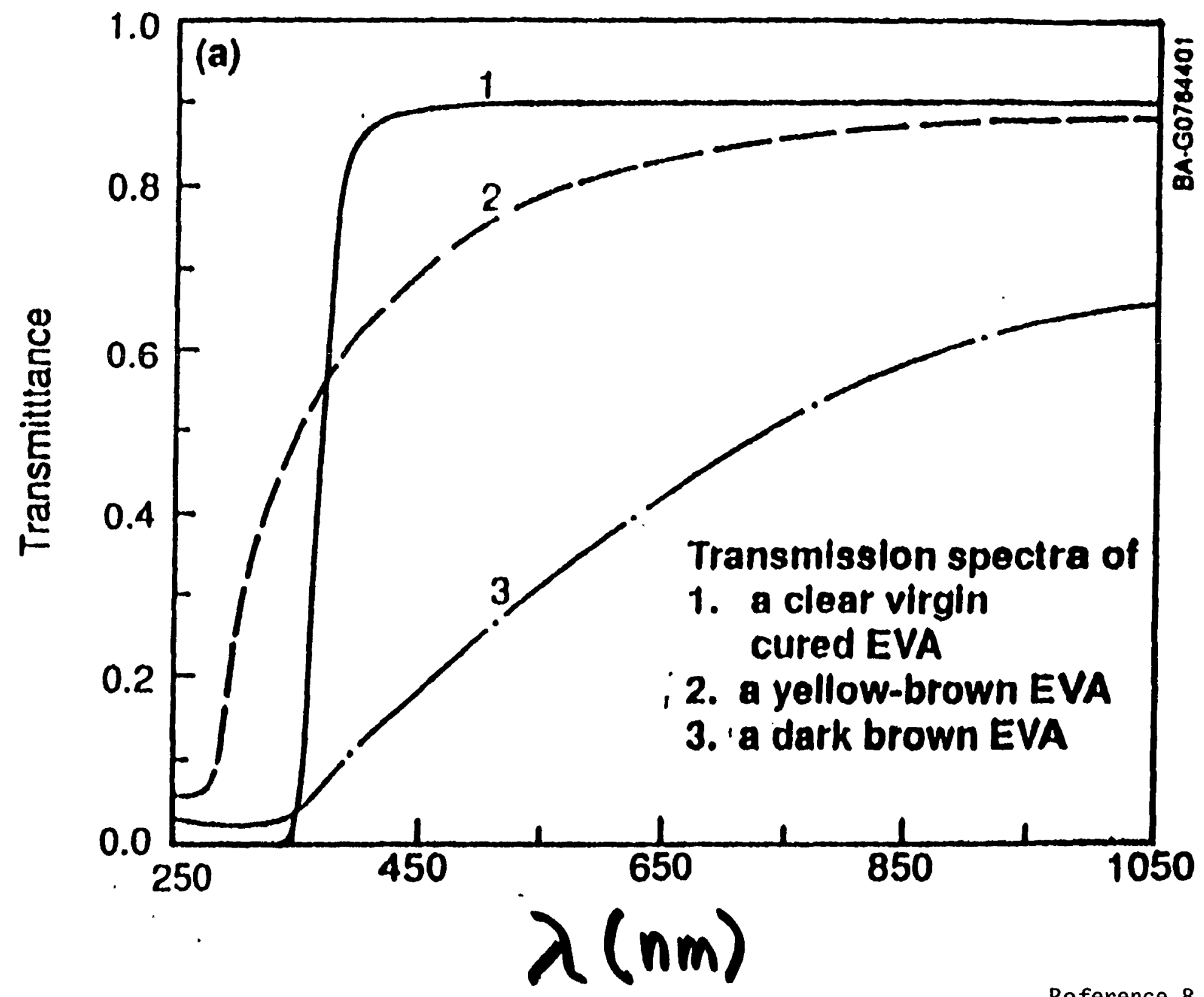

Reference 8 


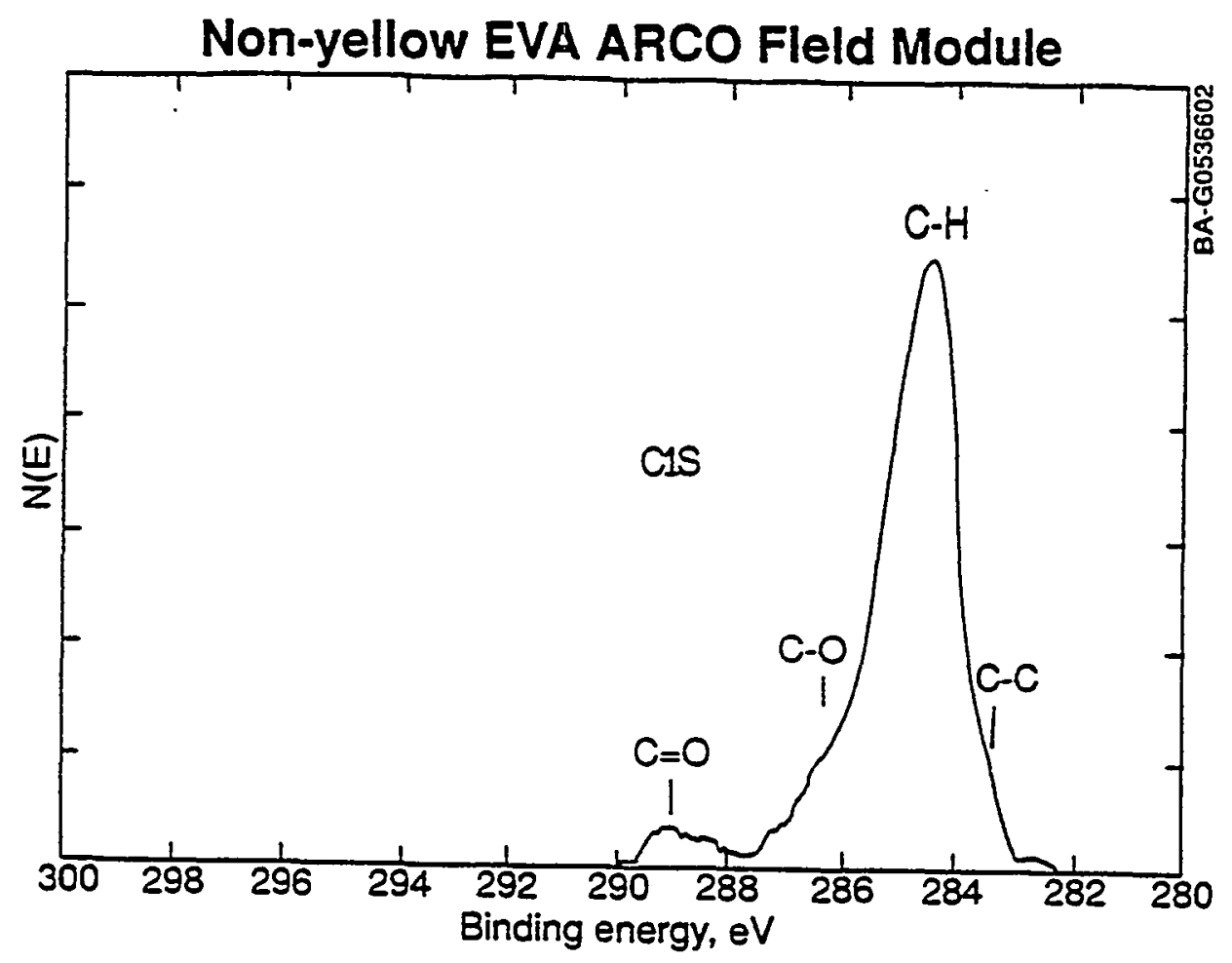

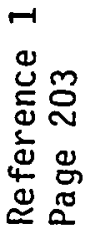

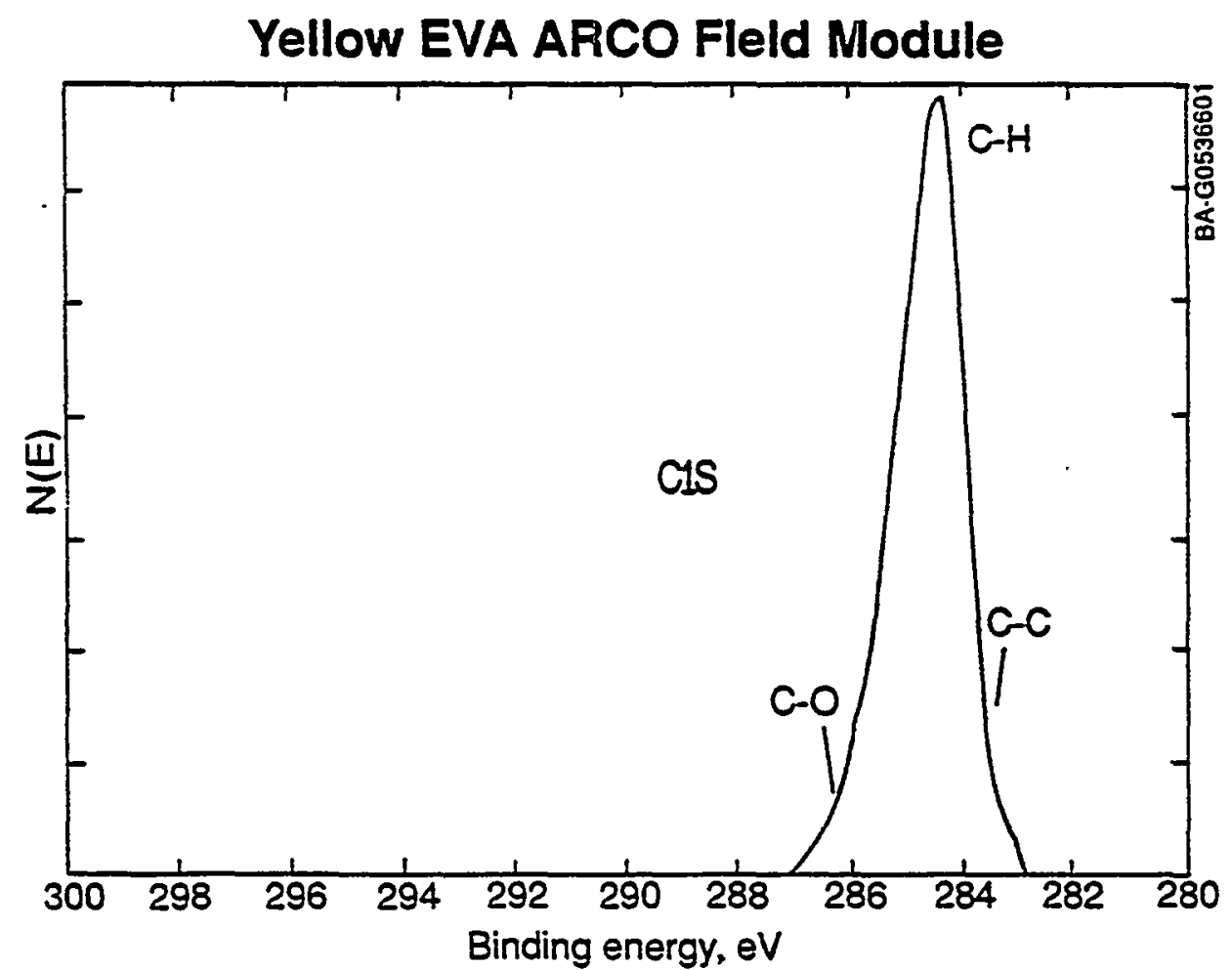




\section{EVA DEGRADATION: LABORATORY STUDIES}

- Fluorescence Analysis

- UV-vis

- Gel Content

- HPLC (Now in Process)

- Colorimeter Studies (Future)

- Electrical Performance (Minimodules)

- FT-IR

- Simulation 
(b)

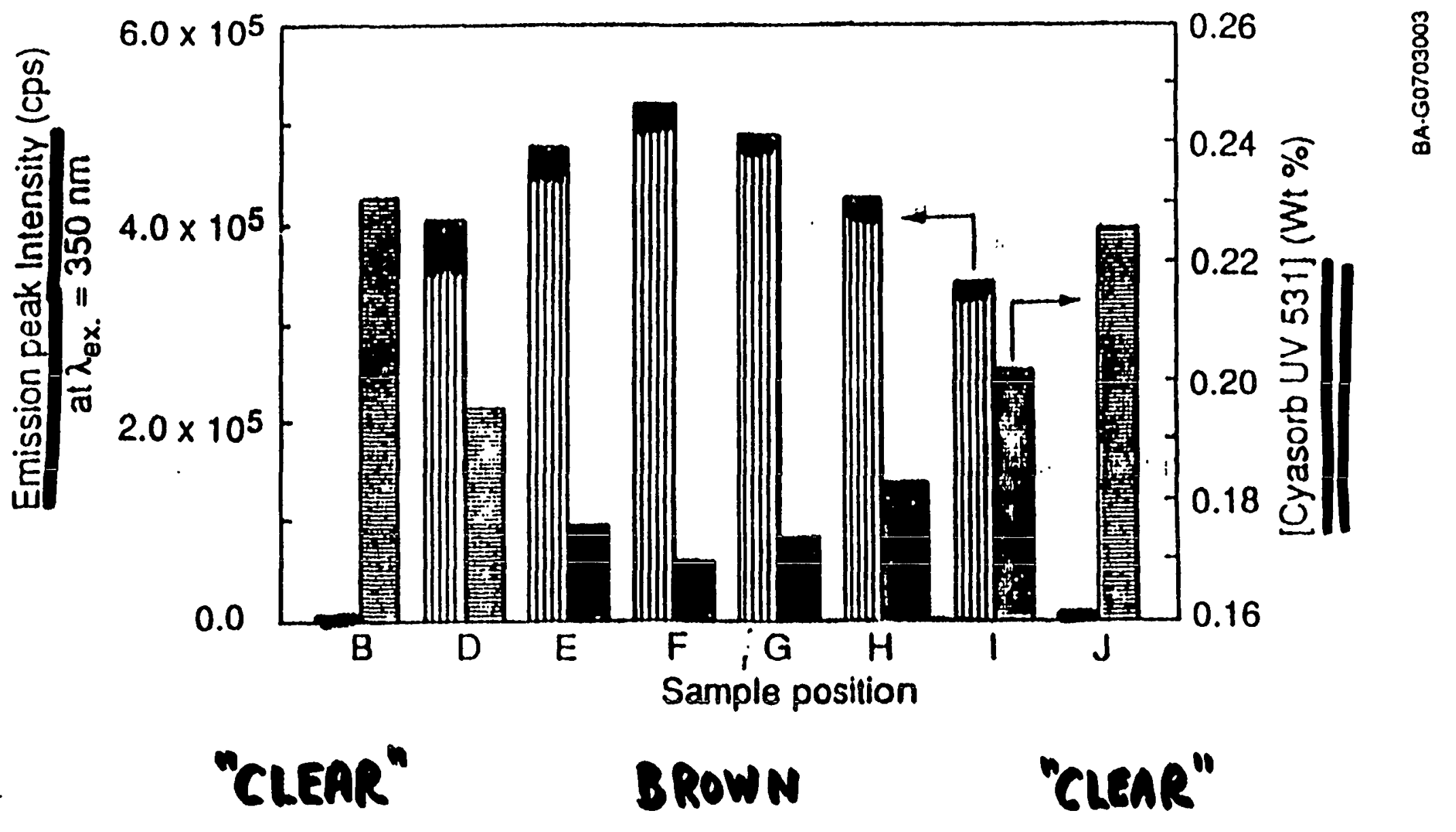

SINGLE CELL

Reference 8

$F A$ 
Flomerscence Amnlysis of li, VA mul olluer loulymers

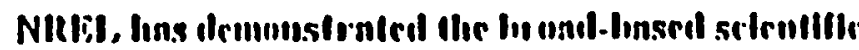

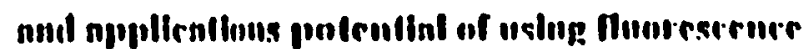

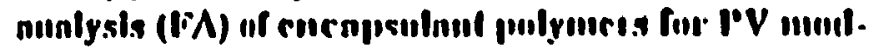

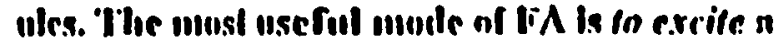

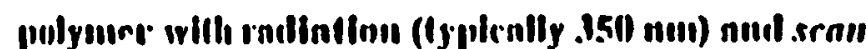

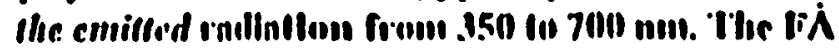

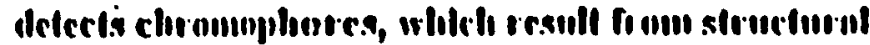

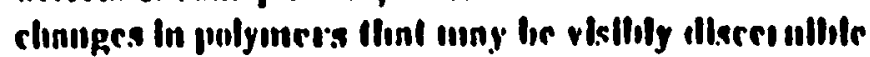

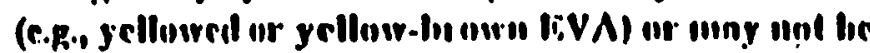

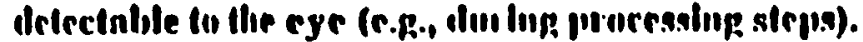

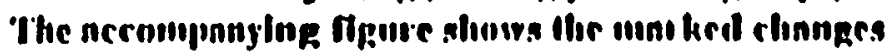

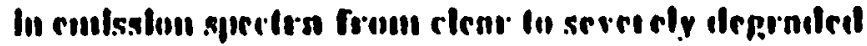

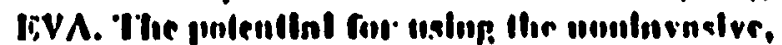

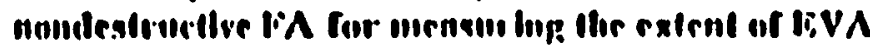

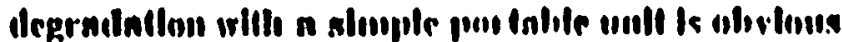

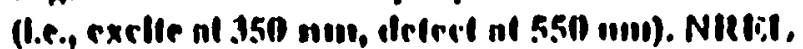

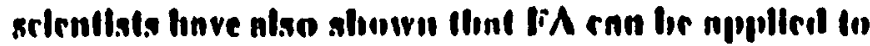

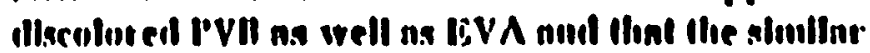

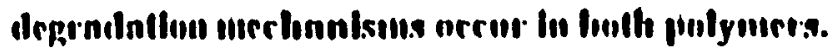

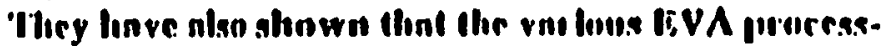

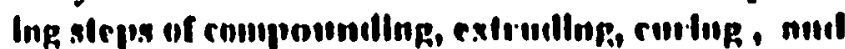

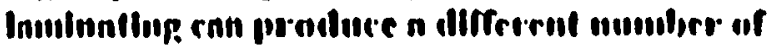

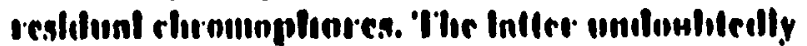

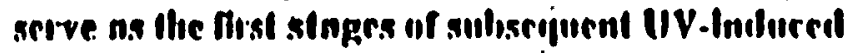

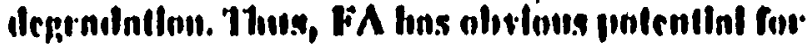

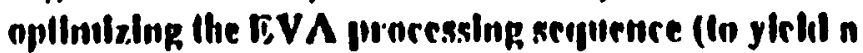

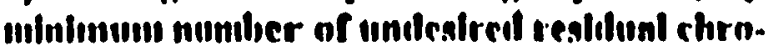
moplionres) as well na for helmp used for ono-llne. qunility control of the tinnt PV Iniminnted imodules.

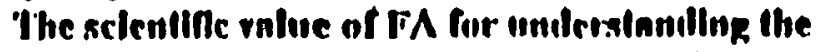

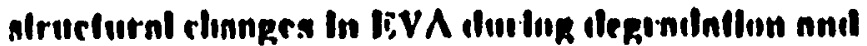

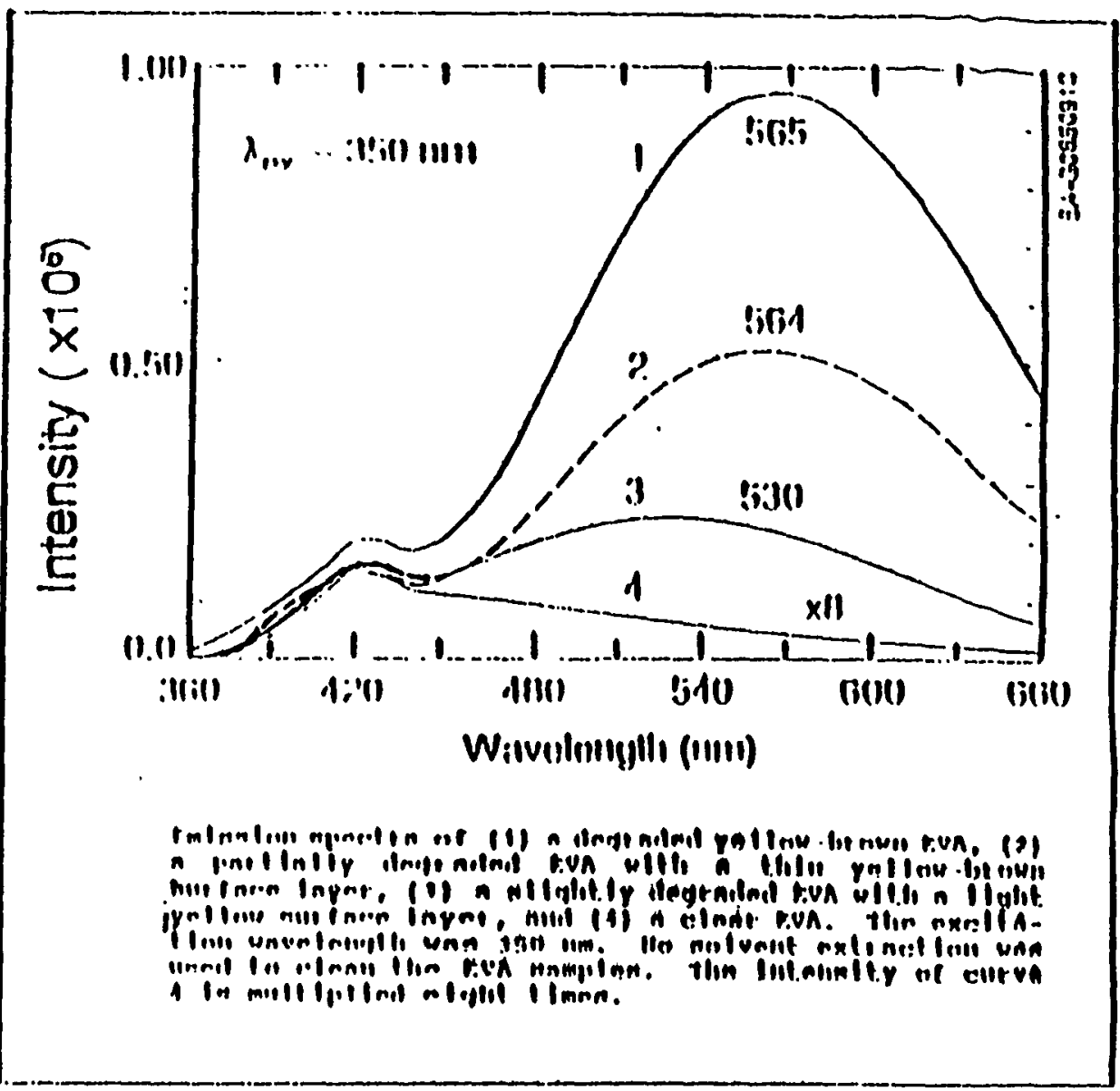

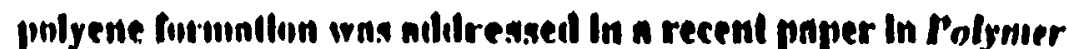
Degmidation and Sinhility by Fal. Pern (NAteLTT2-213-4605). A copy of

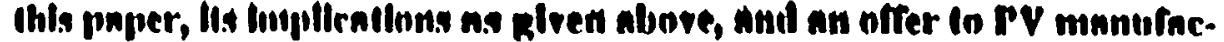

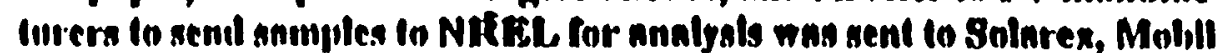
Sninr, Sicment, IISSC, Solar Cells, Inc., and UtC: In December, 1992, lis A.W. Cinnternn. 
Synchronous fuorescence spectra of EVA in solar cells simulation-degraded at 85C for 198 days

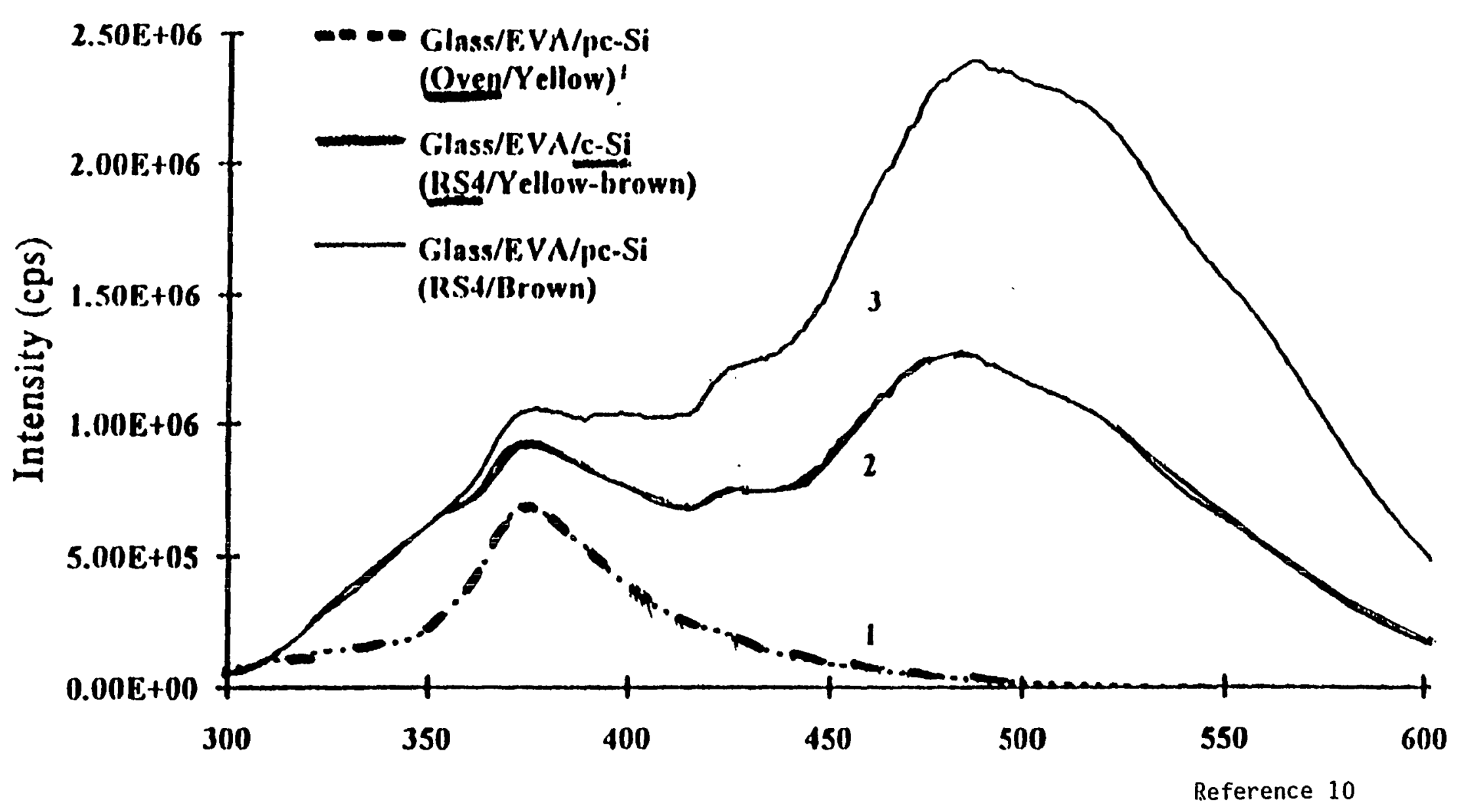




\section{Percent changes of solar cell performance parameters after treatments}

Treatment Cell Type Days Voc Isc FF Effi. EVA Color

at $85+-2 C$

(OVIN

$$
\begin{aligned}
& 1 " \times 4 " \mathrm{C}-\mathrm{Si} \\
& 4^{\prime \prime} \times 4^{\prime \prime} \mathrm{c}-\mathrm{Si} \\
& 2^{\prime \prime} \times 4^{\prime \prime} \mathrm{pc}-\mathrm{Si} \\
& 2^{\prime \prime} \times 2 " \mathrm{a}-\mathrm{Si} \\
& 2^{\prime \prime} \times 2^{\prime \prime} \mathrm{a}-\mathrm{Si}
\end{aligned}
$$

198

0.4

$-2.2$

$-\mathbf{- 0 . 7}$

$-2.5 \quad$ light-yellow

198

$-0.2$

$-3.5$

0.7

198

$-0.3$

$-0.5$

$-2.4$

-3.1 light-yellow

136

$-1.7$

1.2

1.0

$-3.1$

light-yellow

155

(cell breakdown)

0.4 light-yellow

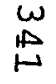

RS4-UV

$\begin{array}{ll}1 " \times 4 " \mathrm{c}-\mathrm{Si} / \mathrm{oc} & 198 \\ 2^{\prime \prime} \times 4 " \mathrm{pc}-\mathrm{Si} / \mathrm{sc} & 198 \\ 2^{\prime \prime} \times 4 " \mathrm{pc}-\mathrm{Si} / \mathrm{oc} & 198 \\ 2^{\prime \prime} \times 2 " \mathrm{n}-\mathrm{Si} / \mathrm{oc} & 136 \\ & 155\end{array}$

$-1.1$

$-1.7$

$-9.3$

\begin{tabular}{c}
0.2 \\
\hline-5.6 \\
-2.8 \\
-1.7 \\
\hline$n)$
\end{tabular}

$-10.1$

$-15.2$

light-yellow

IR I,amin) 4"x4" c-Si

208

$-1.5$

$-8.6$

$-19.3$

$-4.1 \quad-33.8$

$-37.6$

(cell breakdown)
brown
brown
brown
yellow-brown
yellow-brown

Measurement Error Range (+-)

7.6
2
ohn Pern

3.0

8.8

clear

oc: open circuit sc: shorted circuit

File: c:lExcellTestsiSet1-Sum.XIsS 9/13/92 John Pern 


\section{What happened to the EVA during degradation:}

Photothermal oxidation $==>$ Loss of UV absorber and Gel\% increase

$==>$ Deacetylation $==>$ Formation of long polyenes $==>$ Discoloration

\section{Luminescent chromophores in degraded EVA:}

$$
-(C=C)_{m}-C=O+-(C=C)_{n^{-}} \quad \text { Color }
$$

Extent of

Discoloration

(Degradation)

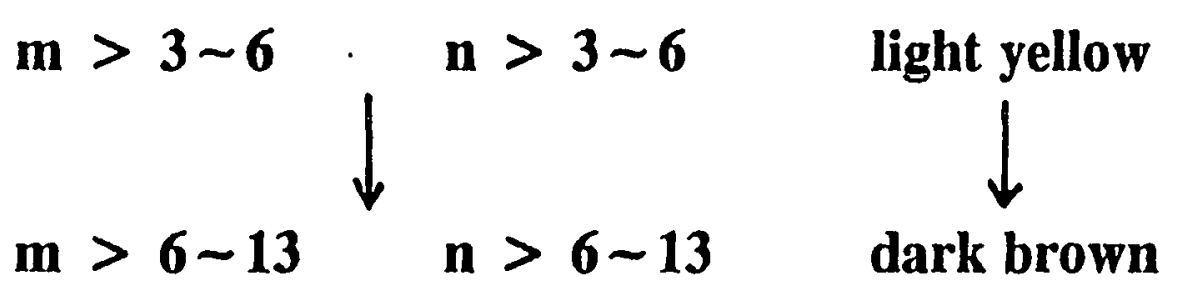

n $>6 \sim 13$

dark brown 


\section{DEGRADATION STRESSES}

- Thermal (T aging) both in air and inert atmospheres and hot spot Ts

- UV (the UV insolation should match the solar spectrum)

- Hydrolytic (water vapor)

- Catalytic (metal ion catalyzed)

- Reaction products (increased concentrations may catalyze)

- Combined, all of the above 


\section{SIGNIFICANT QUOTES FROM THE LITERATURE}

- "For Elvax 150, the onset of acetic acid loss is also affected by the presence of air oxidation and proceeds at lower temperatures than in an inert atmosphere." [Willis, 1986, VII-10]

- $\quad-[\mathrm{HOAc}]$ at $200^{\circ} \mathrm{C}$ in air but $340^{\circ} \mathrm{C}$ in nitrogen

- $\quad-[$ HOAc] for EVA A9918 is the same as for Elvax 150

- $\quad$ If the EVA was sustained continuously at $85-90^{\circ} \mathrm{C}$ for 20 years in the absence of oxygen and water vapor, this would correspond to a net conversion of only $0.006 \%$ of the acetate groups into acetic acid."

- $\quad$ A hermetic design would isolate the EVA from ...oxygen and water..."

- $\quad$ A problem associated with acetic acid generation over 30 years appears remote". [Willis, 1986, VII-14] 
Conclusions from all results obtained up to date:

A competition exists between the formation and bleacning of yellow EVA (i.e., polyenes) in field-dẹployed PV modules. Increase in the degree of cross-linking appears to be favored by exposure to the light at higher temperatures. Depletion or loss of Cyasorb UV 531 may be effected by photodecomposition and thermal diffusion via temperature gradient (over the solar cells) and is enhanced by the increased crosslinking. Acetic acid and other organic components are generated by exposure to the light and heating. Formation of polyenes will exceed bleaching when depletion of [Cyasorb] and accumulation of [acetic acid] are substantial. Yellowing of the EVA appears to be favored by higher operating temperatures of PV modules. 


\section{EVA DEGRADATION MECHANISMS THAT ARE KNOWN}

- Deacetylation of vinyl acetate pendant group results from $\mathrm{T}$ or UV

- Photothermal (T and UV) produces acetic acid and polyenes $-(-\mathrm{C}=\mathrm{C}-)_{\mathrm{m}}$ - (Higher T, UV flux and more energetic UV gives yellow to dark brown)

- Increased [acetic acid] catalyzes the photothermal degradation

- Oxidation of polyenes produces keto-chromophores (photobleaching)

- Cyasorb UV 531 photodecomposes (but details are not known)

- Degradation products are $\mathrm{HOAc}, \mathrm{CH}_{3} \mathrm{CHO}, \mathrm{CO}_{2}, \mathrm{CO}, \mathrm{CH}_{4}$, $\mathrm{H}_{2} \mathrm{O}$, etc. 


\section{EVA DEGRADATION - WHAT IS KNOWN FROM FIELD EXPOSURE AND/OR LAB TESTING}

- $\quad \mathrm{UV}>>$ Temperature alone

- Loss in performance results from discoloration (yellow to brown.

- Metallization and bus lines corrode; acetates and oxides identified (no mechanistic details)

- Some metal cations catalyze an increased rate of photothermal degradation near interfaces $(\mathrm{Cu}++>>$ anything else, Willis)

- Qualitative (and some quantitative) data support KNOWN mechanisms. 


\section{WHAT IS KNOWN ABOUT EVA STABILITY/ DEGRADATION}

- Molecular composition assures degradation will occur in the sun or in the dark at higher temperatures (UV/T synergism)

- Stability depends on location and climate although details are not known

- Degradation fastest @ high T, high UV flux, short wavelengths (e.g., hot, dry climates in the southwest USA and Africa)

- Degradation slowest @ lower T, lower UV flux, less short wavelengths (e.g., cool, wet or dry climates in the northeast and central USA)

- Thus, rate of degradation depends on season and time of day

- Thicker films take longer to yellow throughout

- Closed module design permits an increase [acetic acid], an accelerator

- Unfortunately, stability is poorest at locations where economics is best 
EVA DEGRADATION MECHANISMS

Variables

1. ' $\mathrm{I},\left[\mathrm{O}_{2}, \mathrm{H}_{2} \mathrm{O}\right]$

2. UV, T, [ ]

3. $\mathrm{M}^{+}, \mathrm{T},[]$

4. $M^{+}, U V, T,[]$

5. $\mathbf{M}_{8}^{+}, \mathrm{UV}, \mathrm{T},[]$

6. i flow in M plus 1-5

7. $\left[\mathrm{O}_{2}, \mathrm{H}_{2} \mathrm{O}\right]$ effects

8. [Original formulation]

9. Electrochemical processes plus 1-6

10. As 1. 2. but Hot T

11. Efrect of pin-holes or areas of high resistance

Mechnnism or Possible Mechanism

'I'hermal oxidative degradation

Phototherinul oxidntive degradation

Mctal-ion-catulyzed thermul oxidative degradation Melal-ion-cataljzed photothermal oxidative
degradution

Siurface-M+-catalyzed thermal of PT oxidative digrudation

i: induced nigration or $e^{-}$injection plus other Not studied mechanisms 1-5

1.-6 but [ ] dependence

1.-7 but [ ] additives

Reluted to 6. and $\left[\mathrm{H}_{2} \mathrm{O}\right]$

Any part of 1.-6. but initiated at hot spots
Well-studied

l'ew studies

Not studied*

Not studied*

Not studied

Minimal in 1. and 2

Minimal in 1. and 2.

Not studied

Isolated studies 


\section{WHAT IS NOT KNOWN - EVA DEGRADATION MECHANISMS RESULTING FROM:}

- Different magnitudes of UV (and energies) and temperature (any changes?)

- Different concentrations of $\mathrm{O}_{2}, \mathrm{H}_{2} \mathrm{O}$, other gases, plus the above (PA)

- Different additive, residual chromophores or initiators (Lupersol),

- Poor adhesion at interfaces (role of adhesion primer)

- Metal cations from (oxide) interfaces in the modules PA

- Contact with different metal (oxide) surfaces PA

- E field induced migration or e- injection PA

- Electrochemical processes at metallization interfaces PA

- Residual Damage from hot spots PA 


\section{INFLUENCES ON EVA STABILITY WHAT IS NOT KNOWN - RAW MATERIALS AND FABRICATION OF PV MODULES}

- Supplier of the raw materials (kind and composition - impurities)

- Variations in distribution of vinyl acetate blocks in Elvax 150

- Variations in formulations ([Cyasorb], Lupersol 101, (TBEC), primer)

$\underset{\mathrm{s}}{\mathrm{u}}$ - Processing variables used (Manufacturer Sensitive) during cure

- Cell design (grid pattern, metallization, bus line, and interconnects)

- Module design (glass/polymer superstrate, edge seal, hermetic?)

- Flaws during fabrication that cause long term problems (hot spots)

- Mounting (does it cause T increase?) 


\section{EVA STABILITY \\ WHAT IS NOT KNOWN - REAL TIME TESTING OF PV \\ MODULES (FIELD EXPOSURE)}

- UV insolation data, both $\mathrm{W} / \mathrm{m}^{2}$ and wavelength distribution

- Accurate module operating temperatures (Ts) and time at Ts

- Quantitative measures of degradation (degree of yellowing as well as degradation that occurs without yellowing)

- Time to yellow (see above), and proof the yellow is from polyenes

- Time to failure (how is "failure defined?"; i.e., what efficiency loss?

- Correlation between yellowing, degradation, and power loss?

- Effects of degradation products on module performance other than optical (e.g., bus lines, metalization, interconnects, balance of systems)

- Degradation on mechanical, electrical, and other physical properties

- Influence of property changes in EVA on the RATE of further degradation. 
TABLF, 1. Data Set: Photooxidallon Reactim Scheme and Actlvation Parametera

\begin{tabular}{|c|c|c|c|c|c|}
\hline \multicolumn{4}{|c|}{ Menetlon matris } & \multirow{2}{*}{$\frac{A}{0.10 \times 10^{-0}}$} & \multirow{2}{*}{$\frac{5}{b c a s / a n d}$} \\
\hline เ. & xanes & $\rightarrow$ & $\boldsymbol{K E T}$ & & \\
\hline 8. & $\operatorname{cst} t^{\circ}$ & $\rightarrow$ & $\operatorname{sino}_{2}+\operatorname{senco}$. & $0.00=10^{\circ}$ & $\bullet \bullet$ \\
\hline s. & sunco & $\rightarrow$ & $\operatorname{sino}_{2} \cdot \operatorname{co}$ & $0.00 \times 10^{11}$ & 18 \\
\hline •. & ket* & $\rightarrow$ & Alkene - saltiewaes & $0.14 \times 10^{\circ}$ & 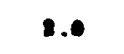 \\
\hline b. & selkowoses & $\longrightarrow$ & SMKET" & $0.10=10^{-10}$ & - \\
\hline$\bullet$ & SMKLT" & $\rightarrow$ & $\operatorname{AMIMO}_{2} \cdot \mathrm{CH}_{3} \mathrm{CO}$ & $0.32 \cdot 10^{18}$ & $\bullet$ \\
\hline 1. & sinkete & $\longrightarrow$ & Ilsieso - Acolosen & $0.10 \times 10^{\circ}$ & 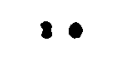 \\
\hline •. & noon & $\rightarrow$ & nO $\cdot \mathrm{OH}$ & $0.12 \cdot 10^{\circ}$ & $\bullet$ \\
\hline •. & $\mathrm{no}_{2} \cdot \mathrm{nH}$ & & $\mathrm{nOOH} \cdot \mathrm{nO}_{2}$ & $0.10 \cdot 10^{10}$ & $11 \bullet$ \\
\hline 10. & sAato $_{2} \cdot$ aH & & s:1:10nIt $\cdot \mathrm{MO}_{2}$ & - $10 \times 10^{10}$ & $11 . \bullet$ \\
\hline 11. & sathout & $\rightarrow$ & s.Miso $\cdot$ oll & $013 \times 10^{\circ}$ & - \\
\hline 18 & 5.1570 + 8.H & $\longrightarrow$ & $\mathrm{SLIROH} \cdot \mathrm{HO}_{2}$ & $0.16 \times 10^{10}$ & $\bullet$ \\
\hline 13. & no $P$ nн & $\rightarrow$ & noll - no, & $610 \cdot 14^{10}$ & 0.2 \\
\hline 11. & no & $\rightarrow$ & $\operatorname{sinsO_{2}} \cdot$ IIdasyat & $0.32 \cdot 10^{16}$ & 11. \\
\hline 16. & KIt* $t^{\circ}$ & $\longrightarrow$ & Kewte - MO - OH & $0.25 \times 10^{10}$ & $11 . \bullet$ \\
\hline 18. & SMKET" $\mathrm{SCOH}$ & $\longrightarrow$ & sil:islome - nO $\cdot \mathrm{CH}$ & $0.32 \times 10^{10}$ & 11.6 \\
\hline 11. & $\operatorname{sichco}-O_{2}$ & 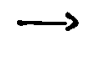 & S:LAtCO0O & $0.00 \times 10^{11}$ & $\bullet . \bullet$ \\
\hline 10. & sinco - aH & 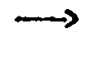 & $\mathrm{nO}_{1}$ - Aldobyen & $\cdot .10 \times 10^{10}$ & 1.8 \\
\hline 10. & $\operatorname{sinCOOO} \cdot \operatorname{AH}$ & $\longrightarrow$ & $\operatorname{sithCOOOH} \cdot \mathrm{NO}_{8}$ & $0.10 \times 10^{10}$ & $11 . \bullet$ \\
\hline 20. & $\sin C 000 \mathrm{H}$ & $\rightarrow$ & sacticco $+\mathrm{OH}$ & $0.12 \times 10^{\circ}$ & - \\
\hline 21. & $\sin c 00$ & $\longrightarrow$ & $\operatorname{SinHO}_{2} \cdot \mathrm{CO}_{2}$ & $0.10 \times 14^{10}$ & $\bullet . \bullet$ \\
\hline 22. & SiMHCON $\cdot$ HII & $\rightarrow$ & Acla $\cdot \mathrm{HCH}_{3}$ & $0.10 \cdot 10^{60}$ & $11 . \bullet$ \\
\hline 21. & $\mathrm{OH}+\mathrm{MH}$ & $\longrightarrow$ & $\mathrm{HO}_{2}$ - Want & $0.10 * 10^{19}$ &.$\bullet$ \\
\hline 21. & $\mathrm{CH}_{3} \mathrm{CO} \cdot \mathrm{MH}$ & $\rightarrow$ & $\mathrm{MO}_{2} \cdot \mathrm{CH}_{2} \mathrm{CHO}$ & $4.10 \times 10^{10}$ & 1.0 \\
\hline 28. & $\mathrm{CH}_{2} \mathrm{CO}+\mathrm{O}_{2}$ & $\rightarrow$ & $\mathrm{CH}_{2} \mathrm{COOO}$ & $0.00 \times 10^{11}$ & $\bullet . \bullet$ \\
\hline 16. & $\mathrm{CH}_{3} \mathrm{COOO}+\mathrm{AH}$ & $\longrightarrow$ & $\mathrm{CH}_{3} \mathrm{COOOH}+\mathrm{no}_{8}$ & $0.10 \times 10^{10}$ & $11 . \bullet$ \\
\hline
\end{tabular}

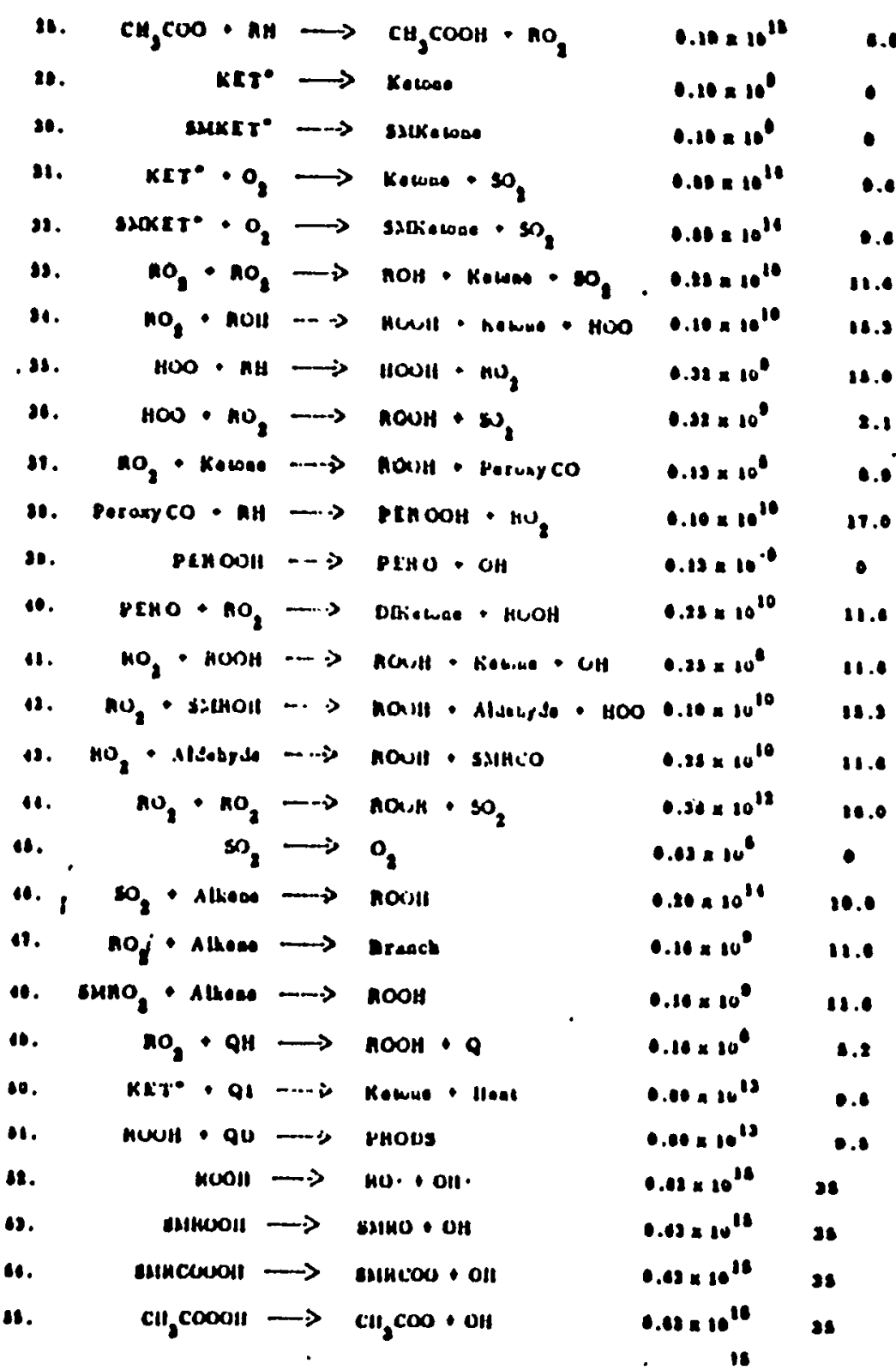




\section{ACKNOWLEDGMENTS}

E. Tormstrom, M, Kardauskas, M. Azzam, R. Micheels, J. Hanoka; Mobil Solar

J. Wohlgemuth and R. Petersen; Solarex

H. Chapman, J. Anderson, K. Mitchell; Siemens Solar

J. Galica, R. Yorgensen, R. White; Springborn Laboratories

L. Manring, J. Simms, J. Braemer, A. Beresnewicz, R. Reitz, K. Baker; DuPont

R. M. Fischer and W. D. Ketola; 3-M

J. Pern, R. DeBlasio, J. Webb, D. King, S. Glick, J. Folkvord, S. Asher, K. Emery, L. Mrig, P. Schissel, G. Jorgensen, P. Longrigg, A. Nelson, M. Himmel, and M. Seibert; NREL 


\section{HOW SHOULD "FAILURE" BE DEFINED FOR A PV MODULE}

- What loss in efficiency is tolerable?

- Over what period of time in years?

\section{IS THERE A FUTURE FOR EVA?}

- For what module lifetime?

- For what module performance efficiency after $\mathrm{x}$ years? 


\section{TO ASSURE SUCCESSFUL LIFETIME PREDITIONS, WHAT IS NEEDED FROM}

- Fundamental understanding?

- Mechanisms of degradative reactions?

- Testing of components, materials only, complete minimodules, complete modules, and complete systems?

- Characterization and analysis? Before, during, and after testing?

- Time-dependent power loss from degradative reactions 
REFERENCES:

[1] A. W. Czanderna, in L. Mrig, ed., Photovoltaic Module Reliability Workshop, SERI/CP-4079, October 25-26, 1990, pp. 159-216 (Available from NREL).

[2] P. B. Willis, Investigation of Materials and Processes for Solar Cell Encapsulation, Final Report, DOE/JPL-954527 - 86/29, August, 1986.

[3] J. Pern, unpublished.

[4] A. W. Czanderna, in course notes by R. V. D'Aiello and A. W. Czanderna, IEEE PVSC Tutorial, 22nd IEEE PVSC, Las Vegas, NV, 10/7/91.

[5] A. W. Czanderna, R. DeBlasio, and L. Mrig, Advanced PV Module Materials and Encapsulation Systems Initiative, SERI, 1/15/91.

[6] F. J. Pern and A. W. Czanderna, in R. Noufi, ed., AIP Conference Proceedings 268, PVARD Project, Am. Inst. Physics, NY 1992, pp. 445-451.

[7] F. J. Pern and A. W. Czanderna, Solar Energy Materials and Solar Cells, 25 (1992) pp. 3-23.

[8] F. J. Pern, Polymer Degradation and Stability, 41 (1993) pp. 125-139.

[9] F. J. Pern, based on ref. 8, Memorandum to DOE, 2/18/93.

[10] F. J. Pern, to be published, Proc. 23rd IEEE PVSC, Louisville, KY, 5/10/ 1993.

[11] A. C. Somersall and J. E. Guillet, Annual Report--1983, "Modelling of Photodegradation in Solar Cell Modules of Substrate and Superstrate Design Made with Ethylene-Vinyl Acetate as Pottant Material,"DOE/JPL955591-84/1, 


\title{
Modification of EVA Formulation For Improved Stability
}

\author{
John Pern \\ Measurements and Characterization Branch \\ National Renewable Energy Laboratory \\ Golden, Colorado
}

\section{Objectives}

1. To investigate the photothermal stbility of UV absorbers and determine the stabilization effectiveness of individual stabilizer

2. To identify the good candidates of stabilizers, polymer materials, and superstrates for modified EVA formulations, new formulations, and encapsulation.

3. To compare normal ( $\sim 1$ sun) exposure and accelerated exposure 


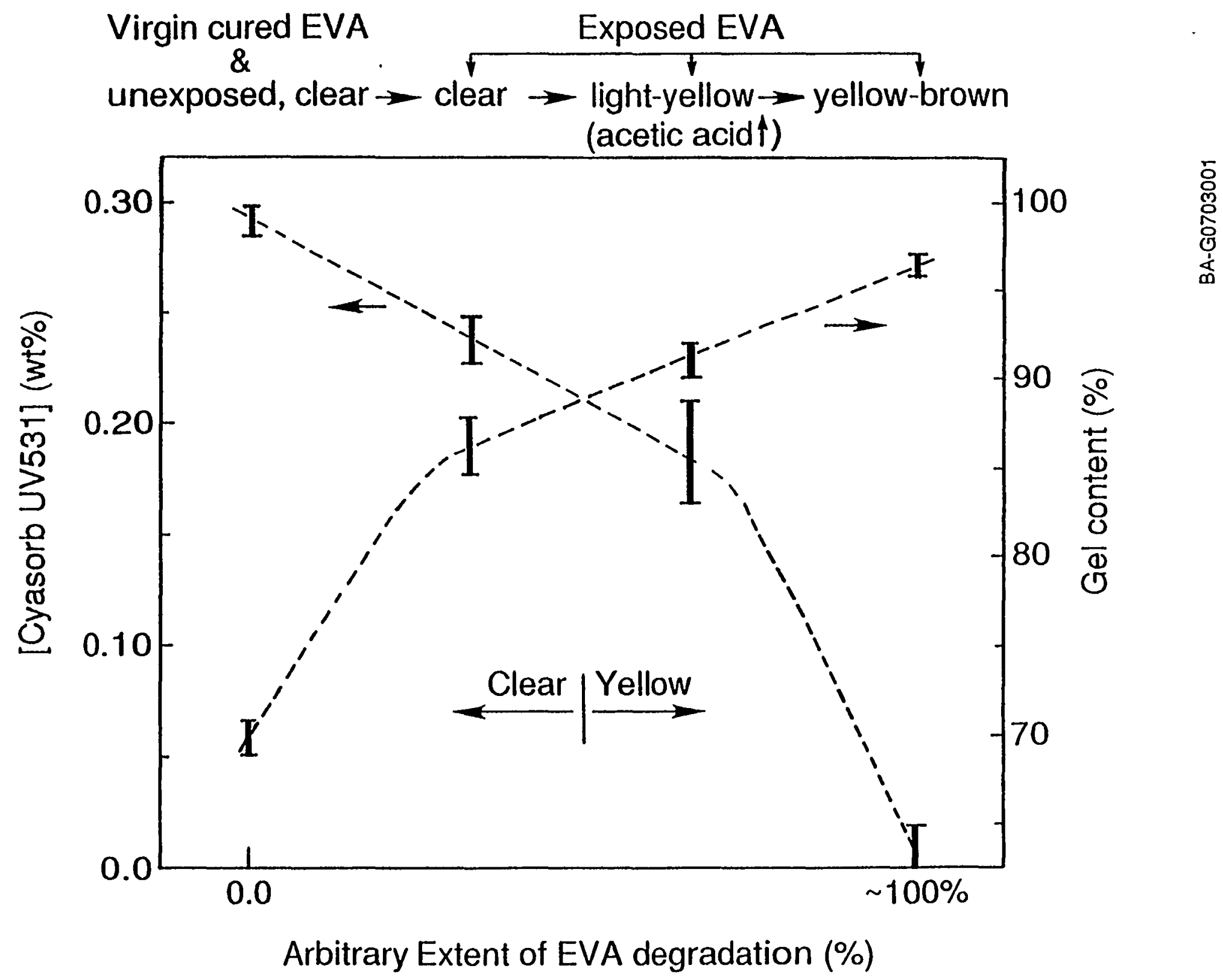


FPMA Composilion Analysis for the New and Exposed Buses

\begin{tabular}{|c|c|c|c|c|c|c|c|}
\hline Sample Source & Solar cell & Side of & EVA & \multicolumn{4}{|c|}{ Normalized Alom\% } \\
\hline PV module \# & Locution & Bus-line & Color & Pl|-M & Su-L & Cu-L & O.K \\
\hline New bus & & & & 39.52 & 60.48 & & \\
\hline Carrizo IlB & $1,9,1 R 2$ & IEVA & light ycllow & 10.96 & 68.57 & 5.35 & 15.12 \\
\hline Carrizo 309259 & $1,9, \mathrm{R} 2$ & IEVA & brown & 41.13 & 5.80 & 13.27 & 39.80 \\
\hline Carrizo 309262 & $1.9,182$ & EVA & datk brown & 15.91 & 30.60 & 20.41 & 33.08 \\
\hline Carrizo 309262 & L,7,R3 & EVA & dark brown & 46.56 & 4.62 & 8.08 & 40.74 \\
\hline
\end{tabular}
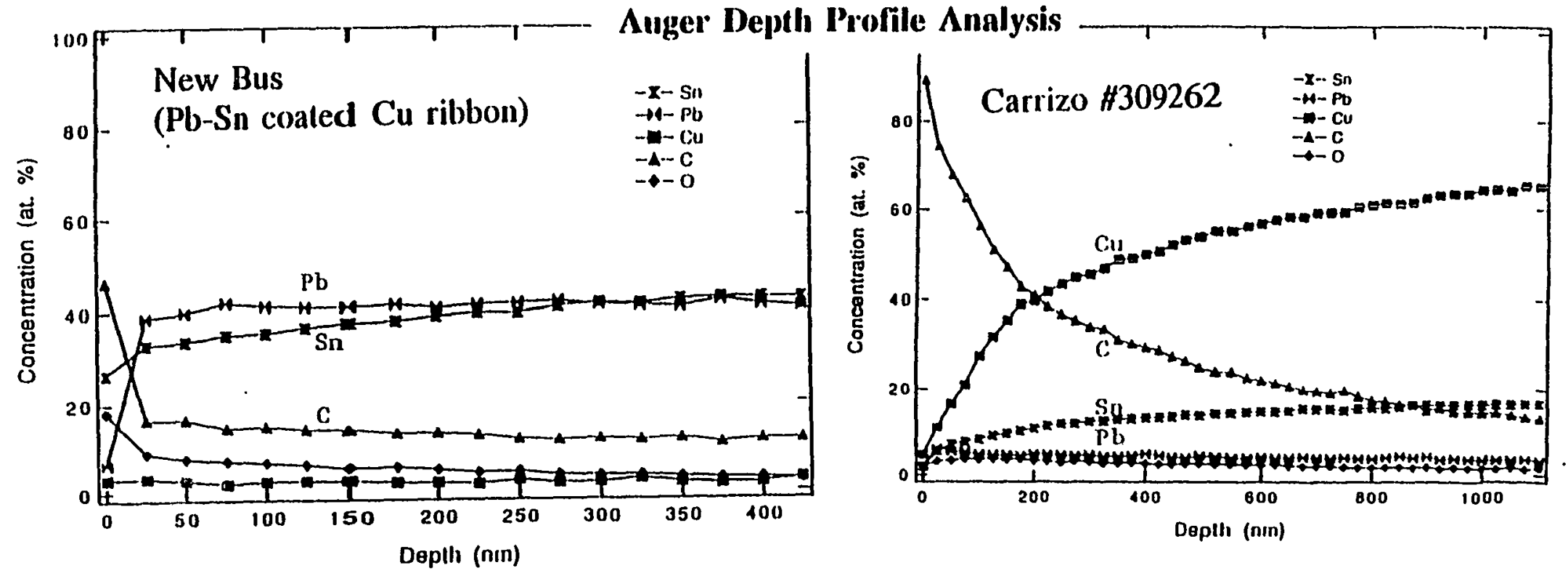


\section{General Views of Polymer Oxidation \& Photooxidation}

1. Oxidation, UV/heat $=>$ Hydroperoxides $=>$ Free Radicals Chain Initiation

$$
\left(\mathrm{PH}, \mathrm{O}_{2}\right) \quad \text { Peroxides, Carbonyls } \quad\left(\mathrm{P}^{\cdot}, \mathrm{PO} \cdot\right)
$$

2. Catalyst residues and Charge transfer $\quad \Rightarrow \quad$ Free Radicals

$$
\text { complexes (Chain carriers) }
$$

3. $\mathrm{P} \cdot+\mathrm{O}_{2} \quad-->\mathrm{PO}_{2} \cdot$

$\mathrm{PO}_{2}+\mathrm{PH}--->\mathrm{POOH}+\mathbf{P}$.

Chain Propagation

4. $\mathrm{POOH} \quad--->\mathrm{PO}+\cdot \mathrm{OH}$

$$
\begin{array}{lll}
\mathrm{POOH}+\mathrm{PH} & -\cdots> & \mathrm{PO}+\mathrm{P} \cdot+\mathrm{H}_{2} \mathrm{O} \\
2 \mathrm{POOH} & -->> & \mathrm{PO}+\mathrm{POO}+\mathrm{H}_{2} \mathrm{O} \\
\mathrm{PO}+\mathrm{PH} & -\cdots> & \mathrm{POH}+\mathrm{P} \cdot \\
\cdot \mathrm{OH}+\mathrm{PH} & -\cdots> & \mathrm{H}_{2} \mathrm{O}+\mathrm{P} \cdot
\end{array}
$$

5. $\mathrm{PO}_{2} \cdot+\mathrm{PO}_{2}:--->\mathrm{POOP}+\mathrm{O}_{2}$

Chain Termination

\section{Chain Branching}

$\rightarrow \mathrm{PO}^{+}+\mathrm{PO}^{\circ}+\mathrm{O}_{2}$

$>$ POOP 


\section{Principles of Stabilization}

1. To reduce/block the Rate of Chain Initiation

$\Rightarrow>$ reduce UV excitation of chromophores

$=>$ deactivate excitation states

2. To reduce/block the Rate of Chain Propagation

$=>$ intercept/neutralize free radicals

3. To reduce/block the Rate of Chain Branching

$=>$ reduce the formation of free radicals

\section{Chemical Methods}

use UV screens or absorbers use quenchers

(Primary/Chain-breaking antioxidants)

use free radical scavengers

(Secondary/Preventive antioxidants)

use hydroperoxide decomposers

Stabilizers used in EVA Formulations (A9918 \& 15295):

Cyasorb UV 531

$(0.3 w(\%)$

Naugard $P$

Timuvin 770

Lupersol 101 or TBEC

$(1.5 \mathrm{wt} \%)$

Typical thickness of laminated/cured EVA films:
UV absorber \& Quencher

IIydroperoxide decomposer (Processing anti-oxidant)

Free radical scavenger (UV light stabilizer)

Peroxide, thermal cross-linking agent

$\sim 0.46 \mathrm{~mm}$ 


\section{Design of Experiments}

Investigate the photostability of UV absorbers (UVA) as an indication of free radical-induced degradation mechanism and the stabilization effectiveness of individual stabilizer.

\section{Samples:}

$\begin{array}{ll}\text { 1. Solution phase (cyclohexane) } & \text { 2. Thin film phase (in Elvax 150) }\end{array}$

\section{Compositions:}

UVA (e.g., Cyasorb UV 531)

UVA + anti-oxidant (e.g., Naugard P)

UVA + free radical scavenger (e.g., Tinuvin 770)

UVA + anti-oxidant + free radical scanvenger

\section{Compounds studied:}
UV absorbers:
Cyasorb UV 531, Ciba-Geigy's Tinuvin family
Free radical scavengers:
Anti-oxidants:
Ciba-Geigy's Tinuvin, Irganox, and Chimassorb families
Naugard P, Ethanox 398, Irganfos 168 


\section{Sample Preparation}

1. Cyclohexane solutions of Elvax 150 mixed with various stabilizers of pre-determined concentrations

2. Thin films in cuvettes made from cyclohexane solutions in (1)

3. Oven-treated at $\sim 75^{\circ} \mathrm{C}$ for $\sim 30 \mathrm{~min}$ to settle the films before exposure

\section{Exposure Conditions (UV $\geq 290 \mathrm{~nm}$ ):}

a). DSET Suntest CPS tabletop system: (for many thin film samples per run)

- 1-Sun Exposure

UV-filtered 1.8-KW Xe arc lamp light, $\sim 770 \mathrm{~W} / \mathrm{M}^{2}(300 \mathrm{~nm}-800 \mathrm{~nm})$,

$55-60^{\circ} \mathrm{C}$ BPT (black panel temperature)

b). Oriel 1-KW Xe light source:

Accelerated Exposure

(for one solution sample per run)

UV-filtered with aq. $\mathrm{CuSO}_{4}$ and a $\mathrm{LP} 305 \mathrm{~nm}$, light beam was condensed to $\sim 1$ " diameter,

Very intense light, $55-60^{\circ} \mathrm{C}$ BPT

\section{Analysis:}

UV-vis absorption to monitor [UVA] as a function of exposure Methanol and/or THF solvent extraction after exposure

Spectral data analysis 


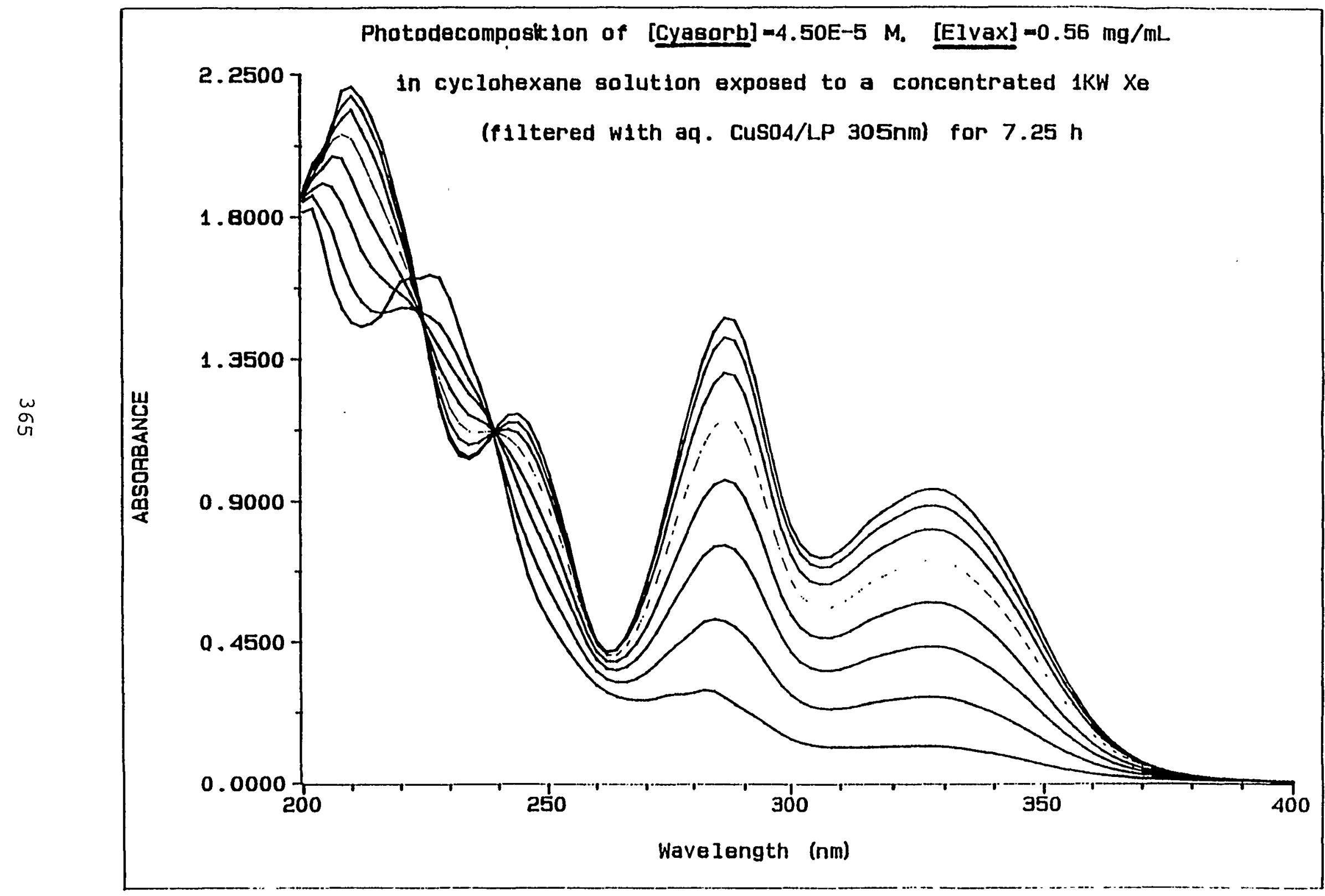




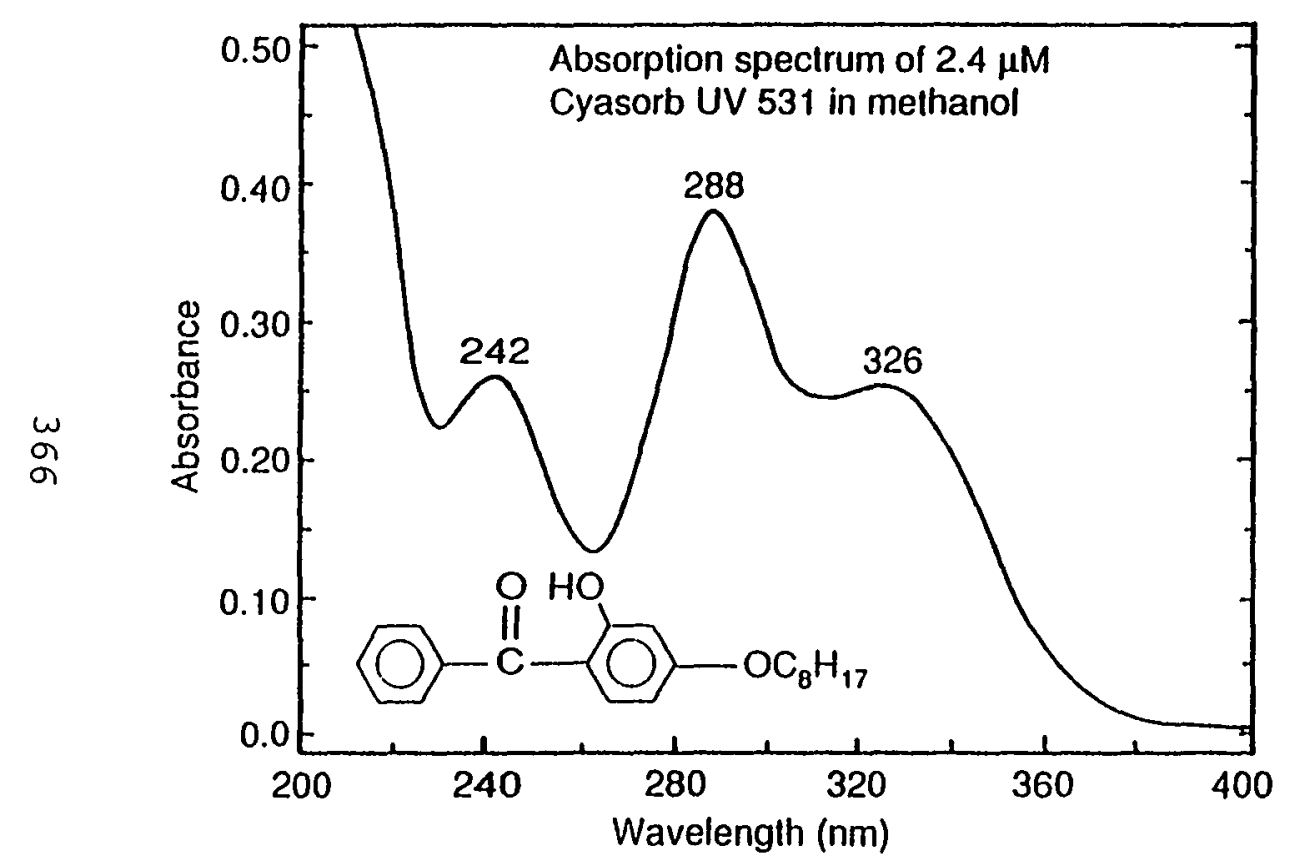

Stabilization Mechanism of Cyasorb UV 531

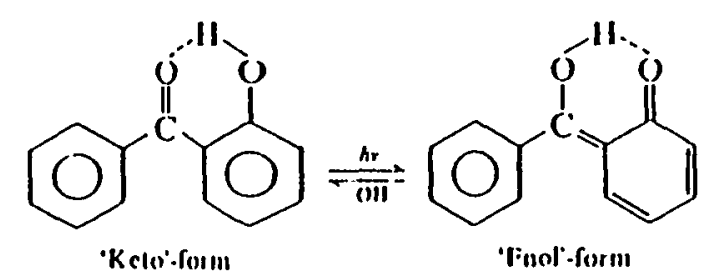

Photodecomposition of Cyasorb UV 531

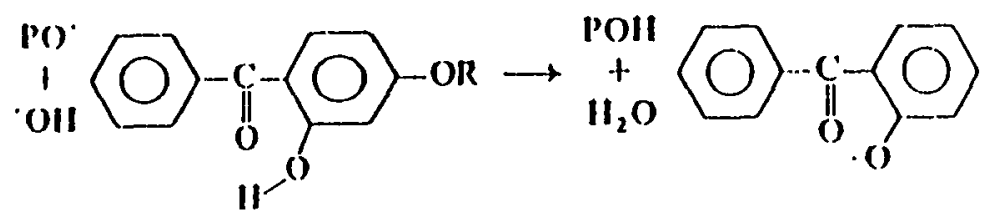

(attacked by free radicals)

$$
\mathrm{UV}, \mathrm{O}_{2}
$$

Substituted benzene compounds (structure unidentified) 
Photodecomposition of Cyasorb in cyclohexane solutions by a condensed, (CuSO4 + LP305nm) filtered $1 \mathrm{KW}$ Xe light at 55-60C

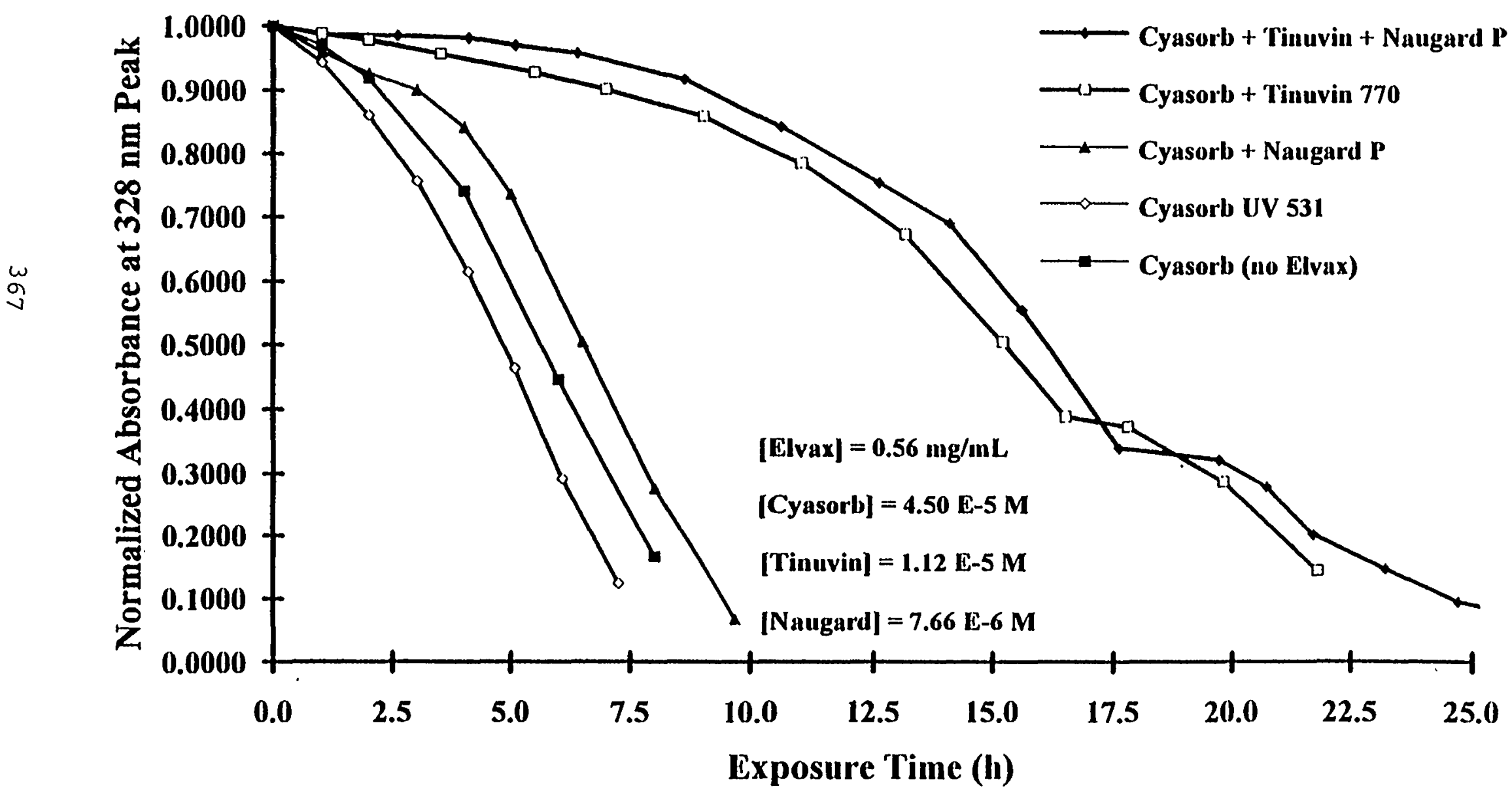


Photodecomposition of Cyasorb in Elvax film by a concentrated 1-KW Xe light at 55-60C

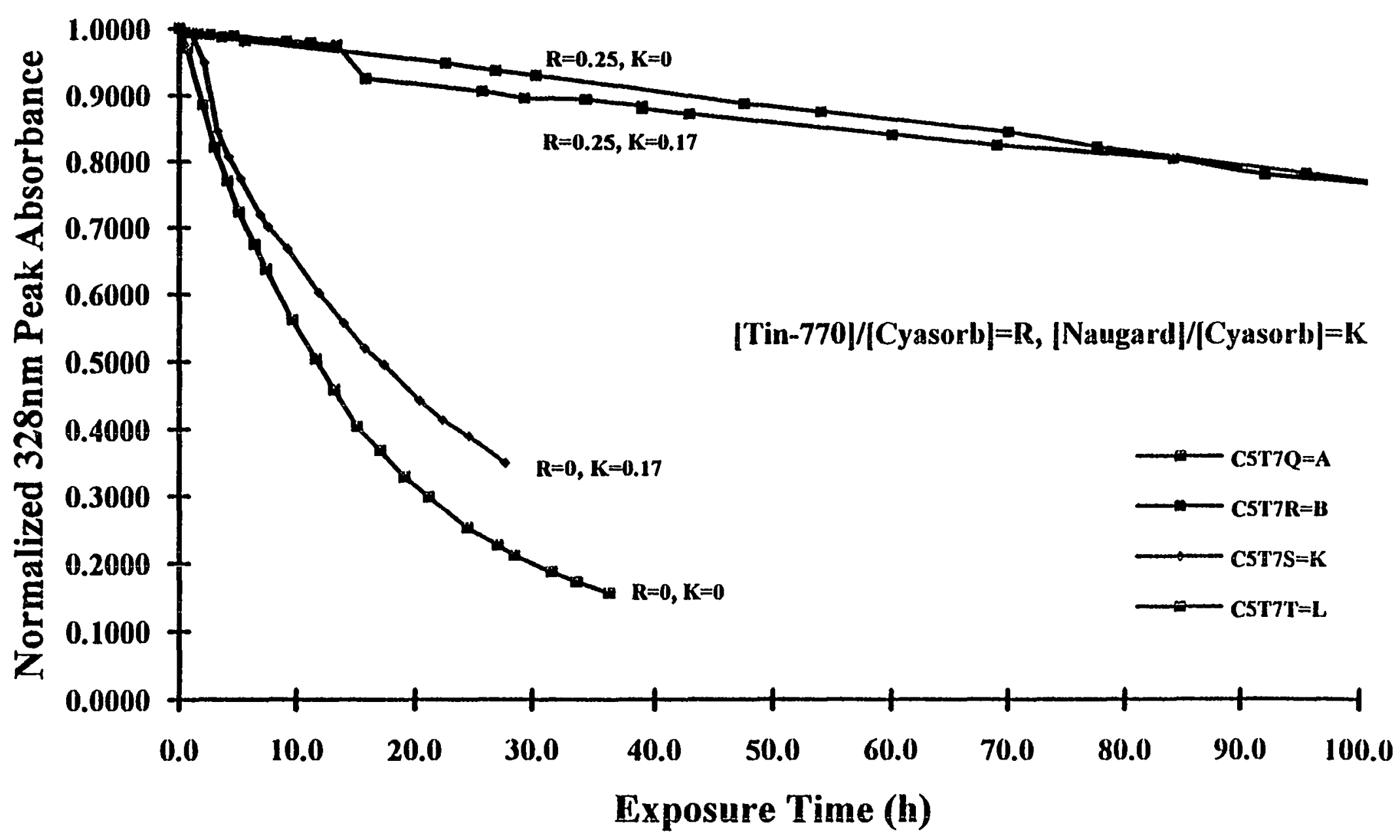


Photodecomposition of Cyasorb in Elvax 150 Film by DSET's 1.8-KW Xe light at 55-60 C

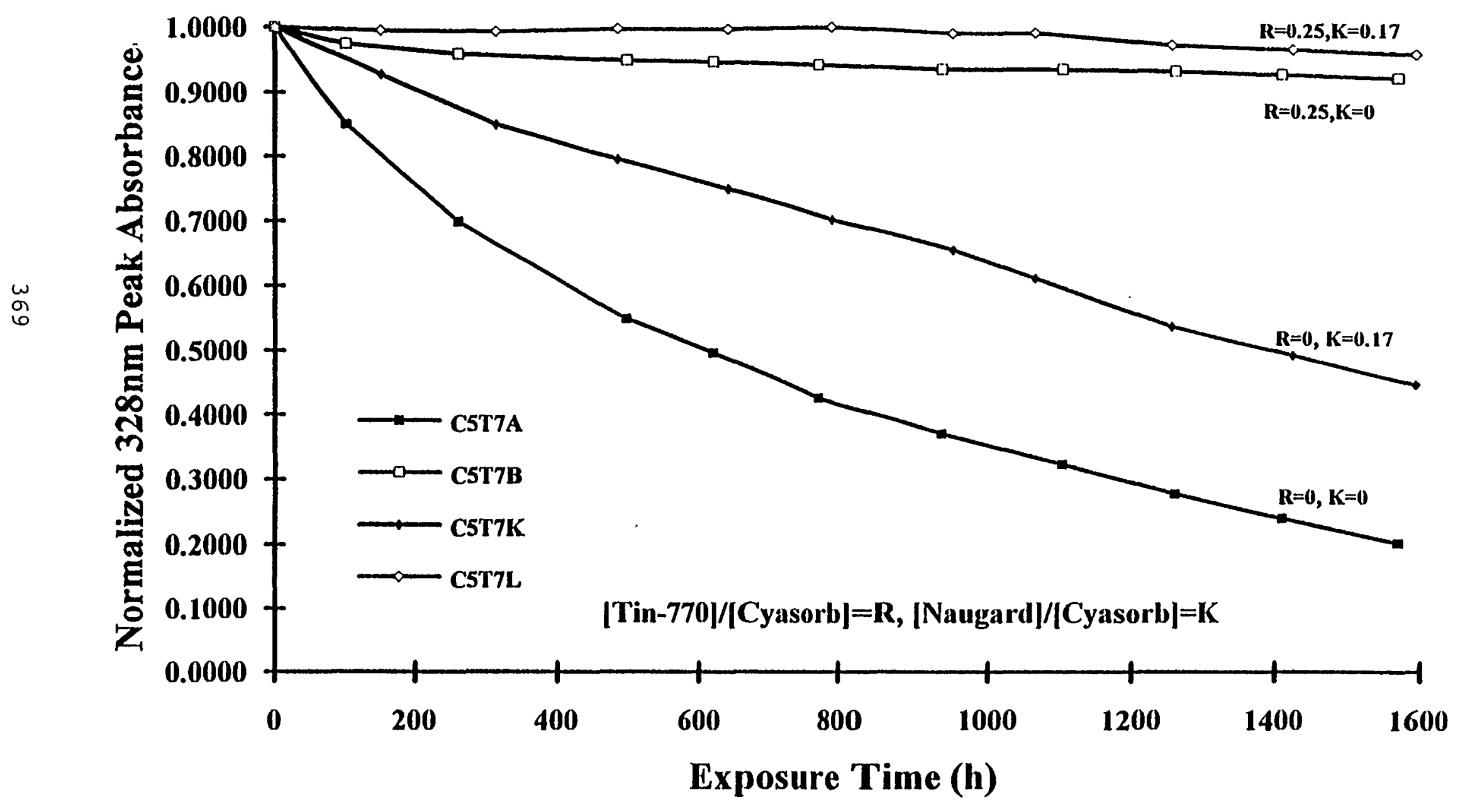


Photodecomposition of Cyasorb in Elvax film by DSET's 1.8-KW Xe light at 55-60C [Tin-770]/[Cyasorb] $=\mathbf{R}$, [Naugard] $/[$ Cyasorb] $=K$

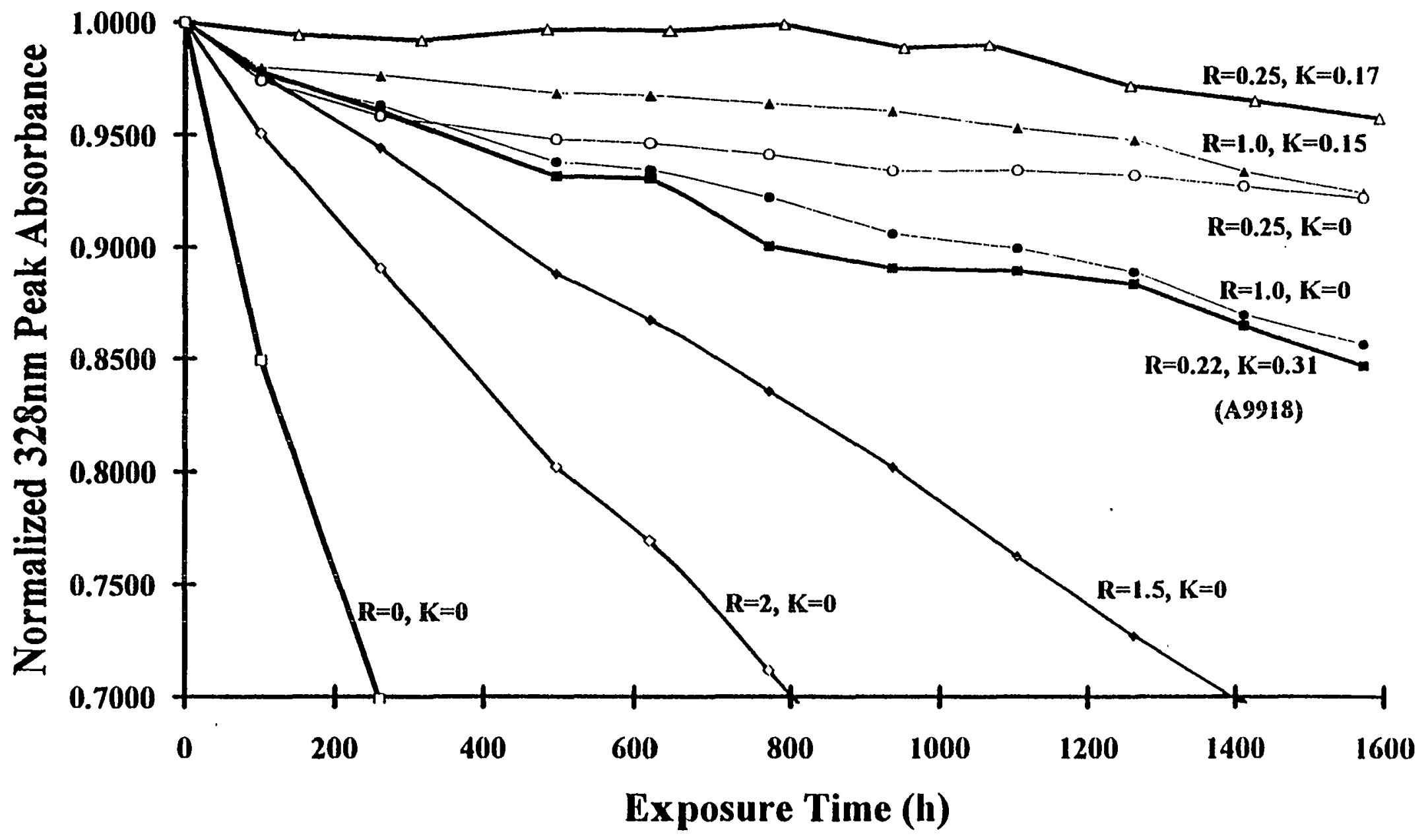


Photostabilization of Benzophenone-type UV absorber in Elvax Thin Films Exposure: DSET $1.8-\mathrm{KW} \mathrm{Xe}, 55-60^{\circ} \mathrm{C}, 1200 \mathrm{~h}$
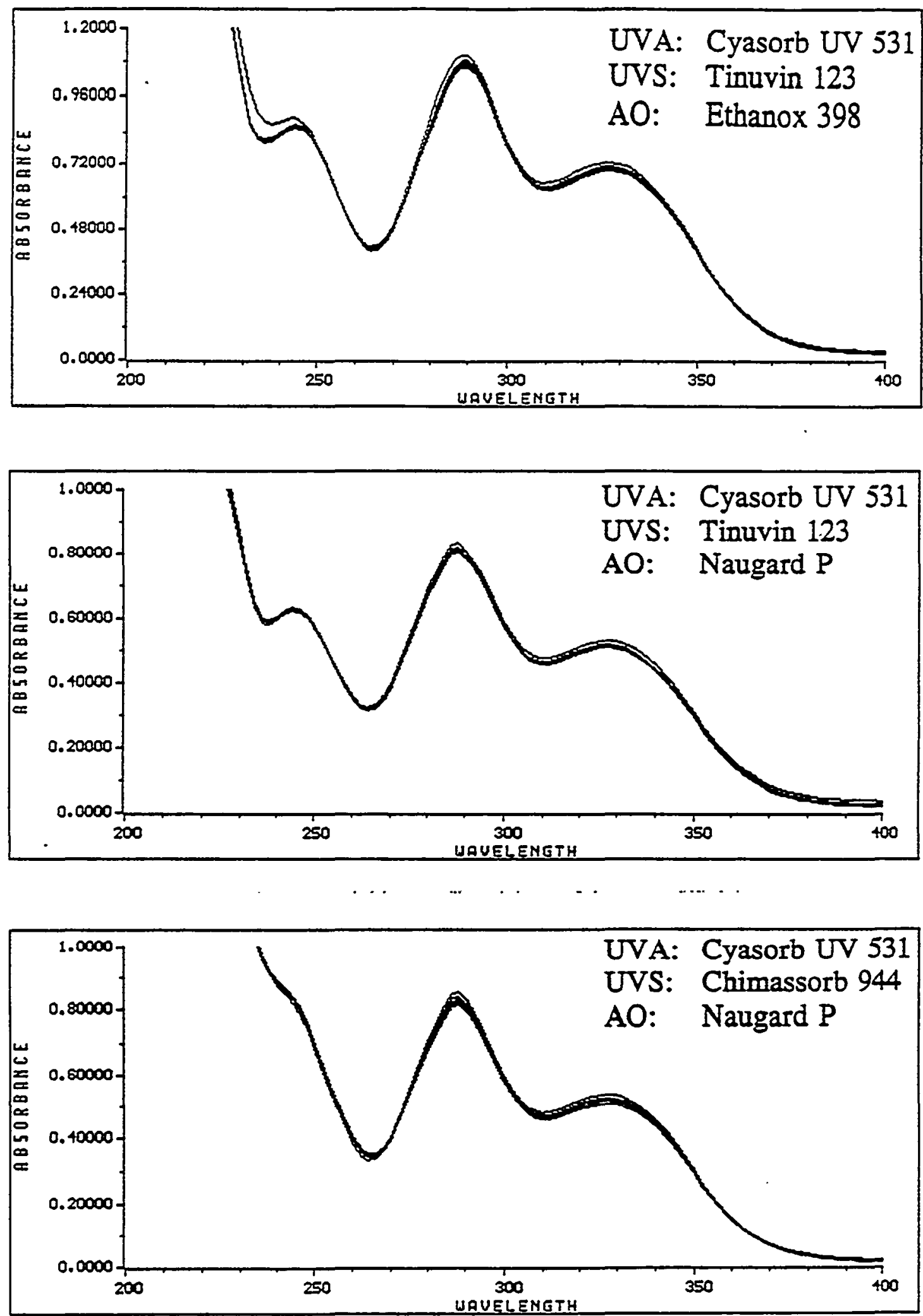
Photodecomposition of Benzotriazole-type UV Absorbers in Elvax Thin Films Exposure: DSET 1.8-KW Xe, 55-60 $\mathrm{C}, 1200 \mathrm{~h}$
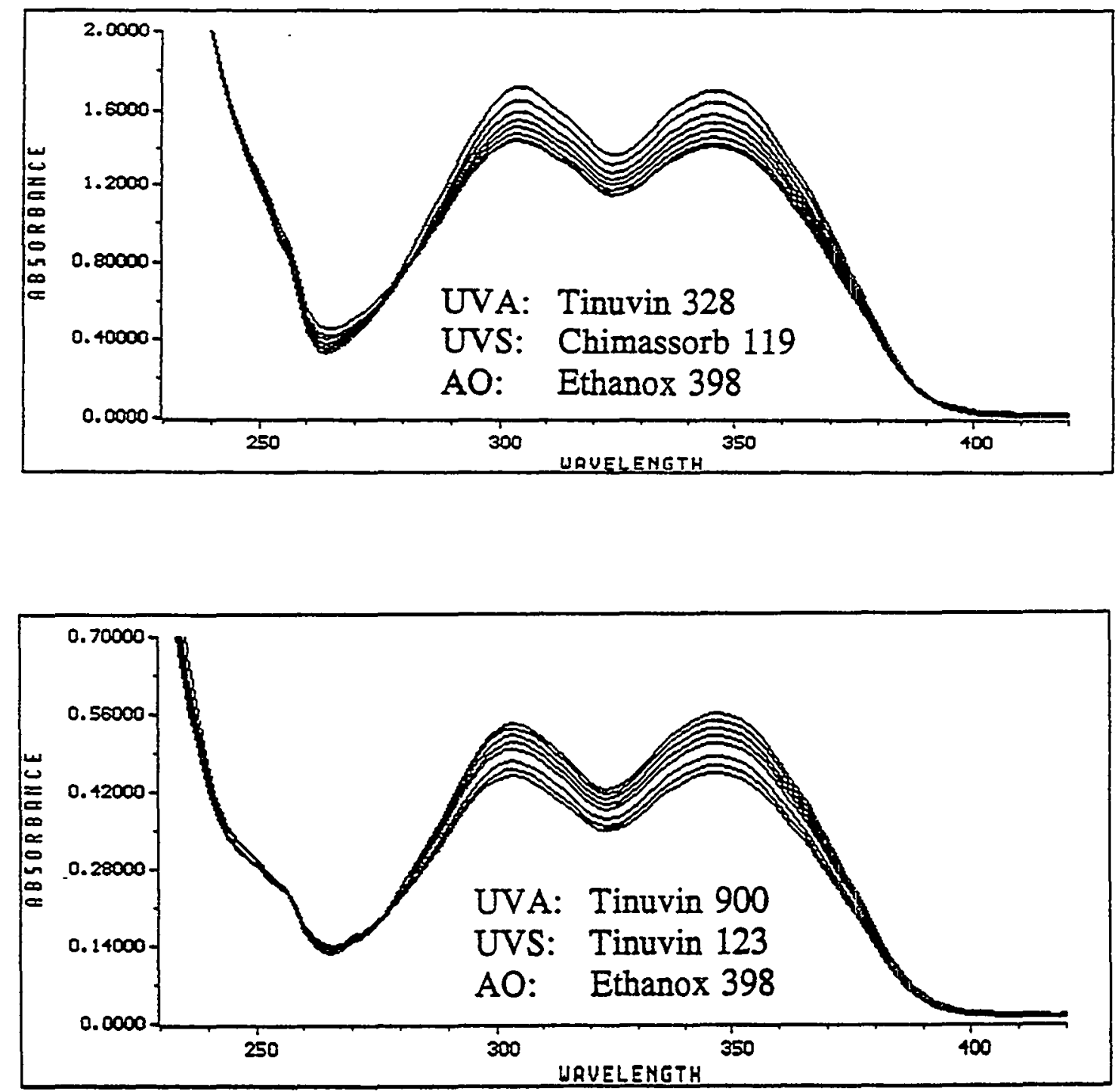


\section{Conclusions:}

A. Photodecomposition of Cyasorb UV 531 (UV absorber) in cyclohexane solutions and Elvax 150 films is significant, resulting in substituted-benzene compounds.

All UV absorbers including Cyasorb promotes large gel formation (cross-linking) of Elvax 150 when used alone.

Tinuvin 770 (free radical scavenger) stabilizes Cyasorb effectively and prevent gel formation. But Tinuvin 770 at high concentration will not stabilize Cyasorb.

Naugard P delays but does not stabilize Cyasorb from photodecomposition.

Stabilization effect of Tinuvin 770 and Naugard $P$ on Cyasorb is synergistic.

B. Improved photothermal stability of current EVA formulations can be achieved by using the three key stabilizers with their concentrations properly balanced.

Similar improvement can be obtained by using other stabilizers with Cyasorb UV 531.

Benzophenone-type (e.g., Cyasorb) UVA is better than benzotriazole-type UVA for EVA.

C. Accelerated exposure is useful to determine the photostability of a trial formulation in a relatively short period of time.

Whether a well-correlated acceleration factor can be established remaines to be determined, although for thin film samples studied here, somehow similar photodegradation profiles of Cyasorb are obtained under normal and accelerated exposure conditions.

D. Future work: (1) Test the photostability of thick films made with modified formulations, (2) Determine by HPLC analysis if Tinuvin 770 and Naugard $P$ are also photodegraded. 


\section{Acknowledgment}

S. Glick (Associate)

A. Czanderna (Task leader)

R. DeBlasio (Project manager)

DOE contract no.: DE-AC02-83CH1009 


\title{
Durability of Photovoltaic Modules at the Southwest Region Experiment Station Las Cruces, New Mexico
}

\author{
Andrew L. Rosenthal
}

September 1993 


\section{Southwest Region Experiment Station}

- Established by DOE funding in $\mathbf{1 9 8 0}$

- 3-acre test and evaluation facility located on the campus of New Mexico State University

- 11 Prototype PV structures $30 \mathrm{~kW}$ of PV installed

- Operated by the Southwest Technology Development Institute (TDI) 


\section{NREL/TDI Long-Term Module Evaluation Program}

- Part of NREL's Module Reliability Research Task

- Test program begun in May 1992

- Test program to run for $21 / 2$ years

- Field work to be performed by TDI engineers

- Laboratory analyses to be performed by NREL scientists

- Goal: Help define the mechanisms and rates of module performance decline 


\section{Long-Term Module Evaluation Program}

\section{Selection Criteria}

- EVA encapsulated, Block V modules

- Diversity of PV materials: crystalline, polycrystalline, amorphous silicon

- Preference for modules with the longest cumulative solar exposure

- Preference for modules having documented history

- Modules Selected: 1 crystalline

1 polycrystalline

2 amorphous silicon 


\section{Long-Term Module Evaluation Program}

\section{Test Plan}

- Select 12 modules from each array under test

- Develop dedicated hardware, establish test procedures

- Collect baseline performance data during May/June 1992

- Remove 2 modules from each array: 1 module returned to NREL for destructive analysis 1 module placed in storage 


\section{Long-Term Module Evaluation Program}

\section{Test Plan (continued)}

- Collect IV curves of all modules every 2 weeks: Archive the data

- Prepare quarterly reports of module IV data

- Remove modules for postmortem testing at NREL (as required) 


\section{Curve Data Limits of Error and Accuracy}

\begin{tabular}{llc} 
& Accuracy & Repeatability \\
LiCor Pyranometer & $\pm 3 \%$ (typ) & $\pm 1 \%$ \\
Current Shunt & $\pm .1 \%$ & $\pm .1 \%$ \\
Voltage Transducer & $\pm .1 \%$ & $\pm .1 \%$ \\
Thermocouple (type T) & $\pm 1^{\circ} \mathrm{C}$ & $\pm .2 \%$ \\
A/D Converter (14 bit) & $\pm 1 \mathrm{LSB}(1 / 16 \mathrm{k})$ & $\pm 1 \mathrm{LSB}(1 / 16 \mathrm{k})$ \\
\cline { 2 - 2 } & $< \pm 5 \%$ & $< \pm 2 \%$ \\
\hline ASTM 1036 & $\pm 3 \%-5 \%$ & \\
\hline \\
\hline
\end{tabular}




\section{Module 42 -- Historical Data}

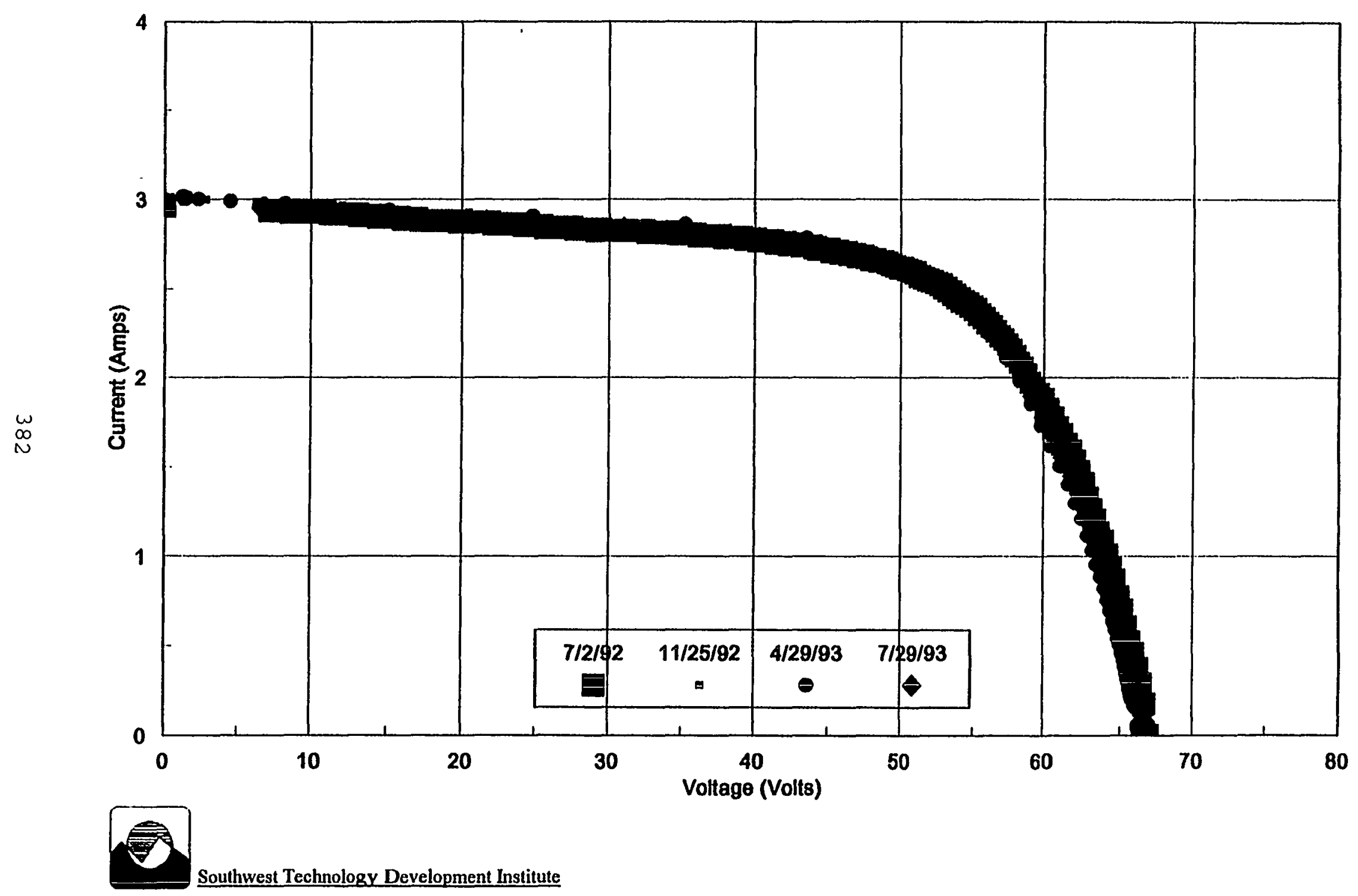




\section{Module 33 -- Historical Data}

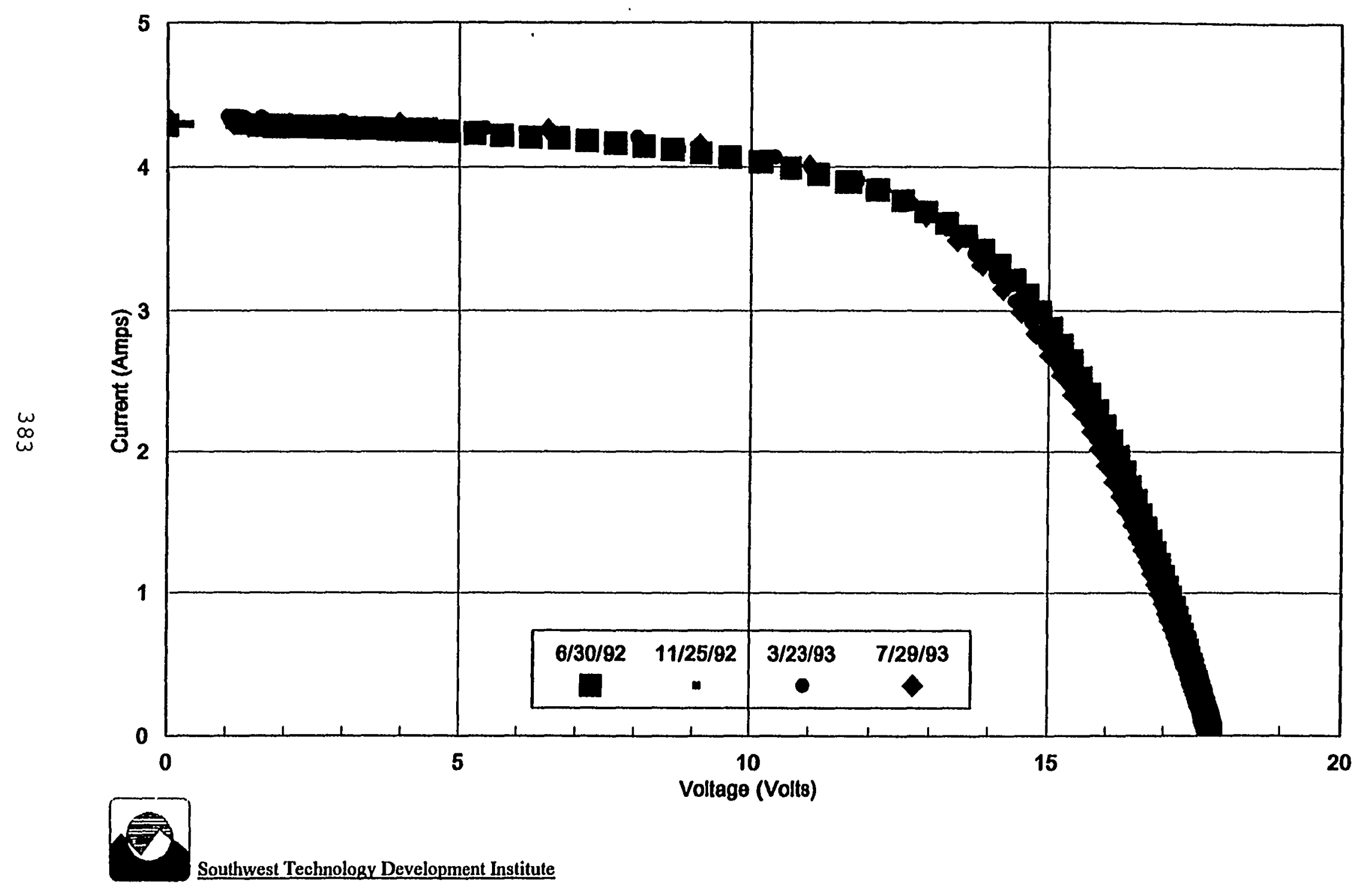




\section{Module 6 -- Seasonal Comparisons}

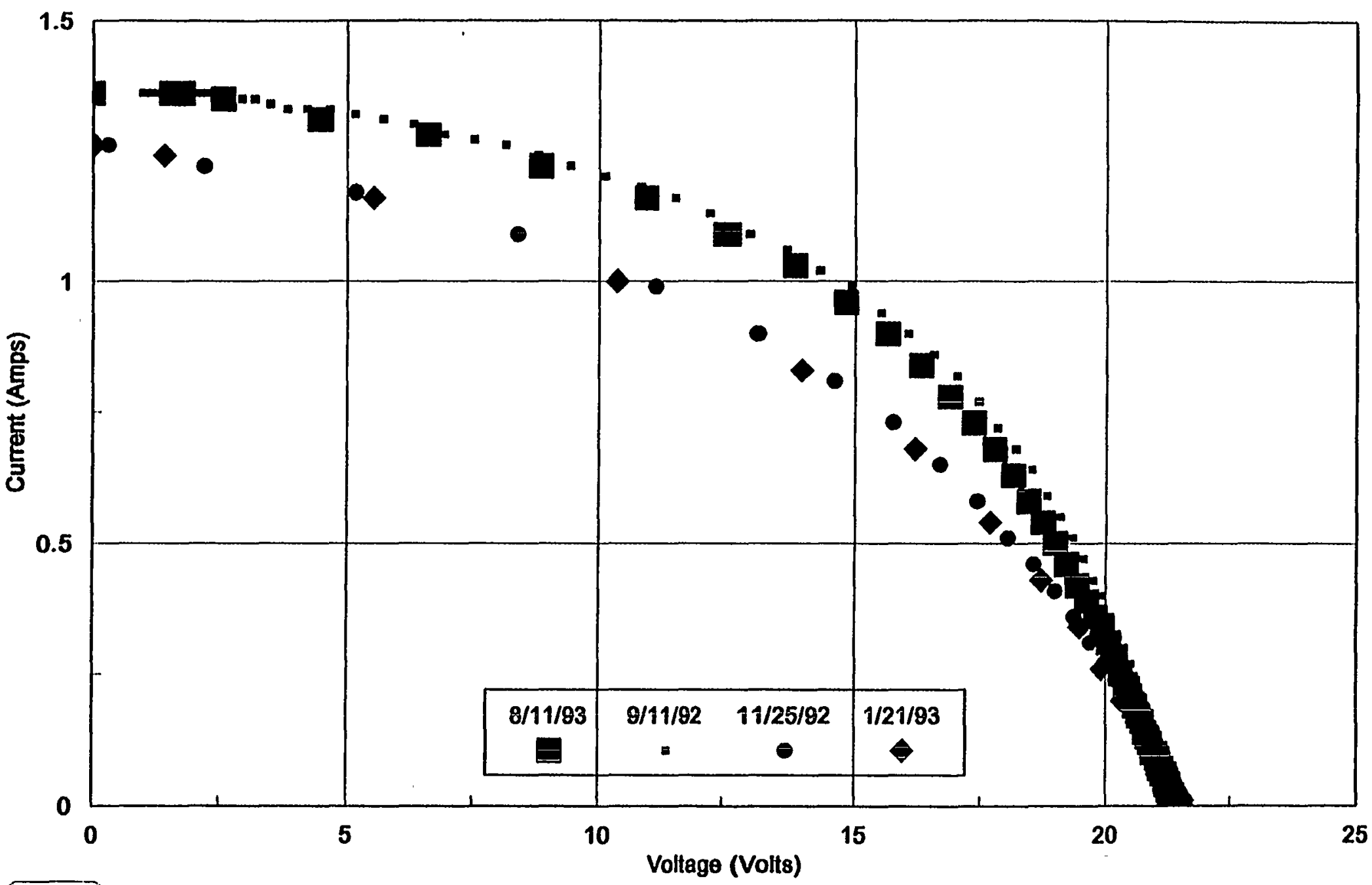




\section{Module 6 -- Historical Data}

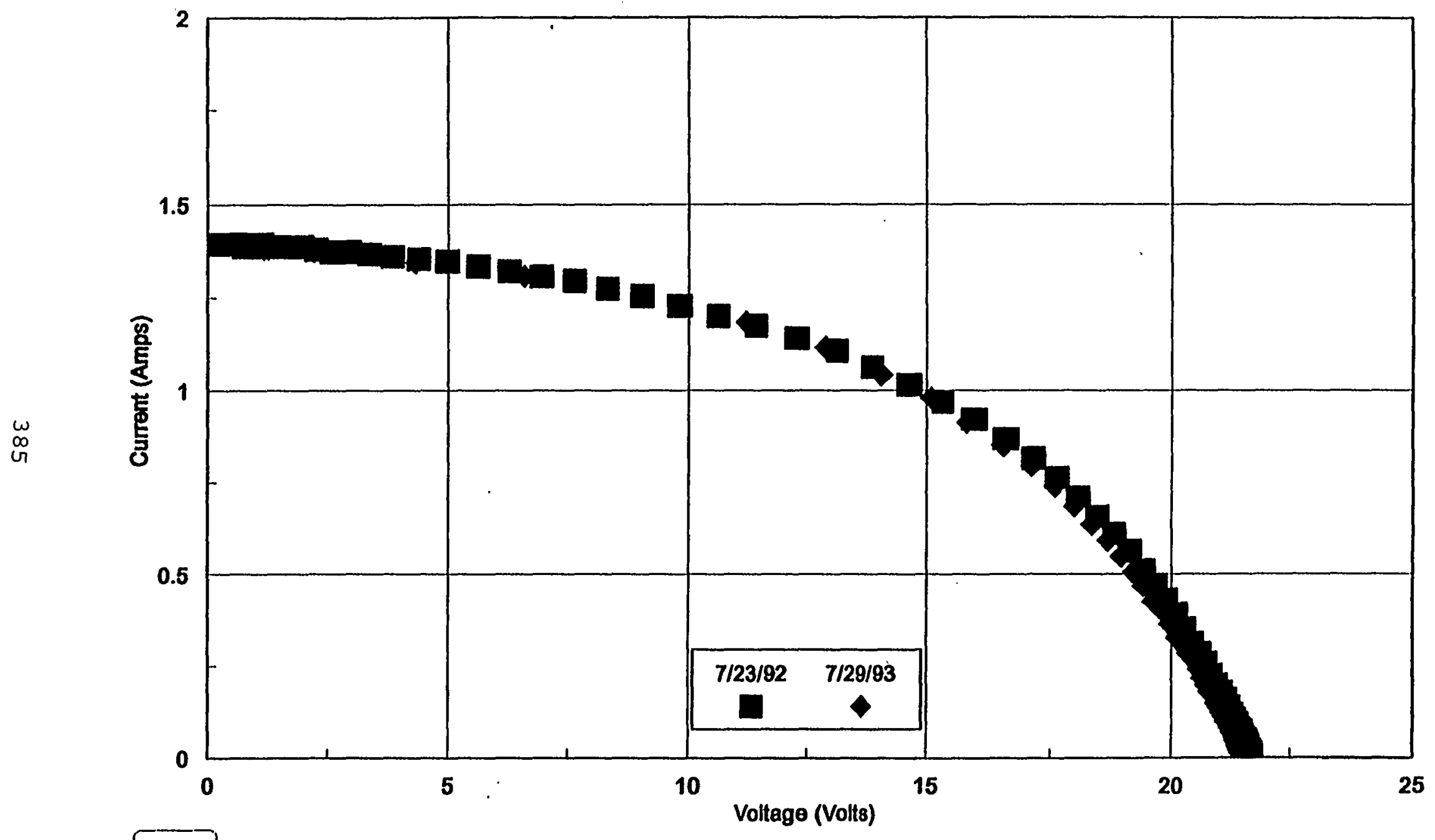

Southwest Technology Development Institute 


\section{Module Performance/Reliability Discussion}

Who needs module performance and reliability information?

- Industry

- characterize their product

- assess effects of design changes

- warranty considerations

- Research

- further the state of the technology

- assist industry to provide better products

- System Designers

- meet the needs of prudent system design

- provide for worst case operating conditions

- General Public 
TEAMED RESEARCH AND DEVELOPYENT ON

PVLAT, PHASE 3A - SBARED PROCESS ISSUES

Improved Non-discoloring Encapsulant for Flat Plate PV

JANUARY 1993 - DECEMBER 1995

For

RATIONAI RENETABLE ENERGY LABORATORY

Under Subcontract 2AG-3-112:9-02-105661

By

SPRIMGBORN LABORATORIES, INC.

Enfield, Connecticut 


\section{SPECIFIC OBJECTIVES}

* betTer define causes of eVA discoloration thru stUdy OF LITERATURE AND CASE HISTORIES IN THE FIELD

* USING LAB STUDIES, DETERMINE PROBABLE MECHANISM(S) AND ROLE OF HEAT, U.V., EVA GRADE, MODULE CONSTRUCTION, ETC.

* DEVELOP "STABILIZATION STRATEGIES" FOR PROTECTING PV ENCAPSULANT FROM DISCOLORATION

* CONDUCT LAB. AND FIELd TESTING OF SMALL IAMINATES AND FULL MODULES TO DEMONSTRATE "FUNCTIONAL ADEQUACY" OF IMPROVED ENCAPSULANTS

* IMPLEMENT SUCCESSFUL STABILIZATION STRATEGIES BY INFORMATION EXCHANGE AND MAKING IMPROVED ENCAPSULANT AVAILABLE TO INDUSTRY 
PROGRAY SCOPE

YEAR ONE

TASK 1 - SURVEY CASE HISTORIES OF EVA DISCOLORATION

TASK 2 - FURTHER DEFINE PROBLFMI THRU CONTROLLED LAB STUDIES

TASK 3 - DEFINE DISCOLORATION MECHANISHS THRU ANALYSIS

TEAR TWO

TASR 4 - DEVELOP STABILIZATION STRATEGIES TO REDUCE DISCOLORATION

TASR 5 - CONDUCT ACCELERATED TESTING OF LAB-SIZE LAMINATES

TASK 6 - EXIRUDE PILOT QUANTITIES OF PROMISING ENCAPSULANT SHEET

\section{YEAR TEREE}

TASR 7 - TEST MODULE-MFG. -PREPARED IAB-SIZE MIINI-MODULES

TASR 8 - INTERIY QUALIFICATION TESTING OF FULL-SIZE MODULES

TASK 9 - MODULES FIEID TESTING WITH DATA ACQUISITION 
History of Flelded, EVA- Encapsulated PV Modules

\begin{tabular}{|c|c|c|c|c|c|c|}
\hline Location & $\begin{array}{l}\text { Hodule } \\
\text { Hfg }\end{array}$ & Eormulation & Color & $\begin{array}{l}\text { Approx. Max. } \\
\text { Iemperature }\end{array}$ & $\begin{array}{l}\text { Time of Observed } \\
\text { Color (Years) }\end{array}$ & Construction (2) \\
\hline Davis, CA & D & 19918 & clear & - & 3 & $z$ \\
\hline SHRES Las Cruces, HH & $\boldsymbol{A}$ & 19918 & brotn & _ & $3-4$ & - \\
\hline Hoнаil & B & A9918P & clear & - & 4 & $x$ \\
\hline Detroit & B & A9918P & clear & - & 4 & $x$ \\
\hline Callfornia & B & A9918P & clear & - & 4 & $x$ \\
\hline San Ramon, CA & $A$ & - & light anber & $64 \cdot c^{(3)}$ & - & w \\
\hline San Ramon, $\mathrm{CA}$ & B & A9918P & faint yellor & $64 \cdot c^{(3)}$ & 4.5 & $x$ \\
\hline San Remon, CA & C & other & light anber & $64 \cdot c^{(3)}$ & $4-5$ & $x$ \\
\hline Sen Remon, CA & D & 19918 & light anber & $64 \cdot c^{(3)}$ & - & $x$ \\
\hline Davls, CA & c & other & clear & - & 4.5 & $x$ \\
\hline China Lake, Ca & $A$ & 19918 & discolored & - & 5 & in \\
\hline China Lake, CA & E & A9918 & brosn & - & 5 & - \\
\hline Sells, Az & c & other & $80 x$ brown & - & $6-8$ & $x$ \\
\hline city of Austin, ix & c & other & slight brown & $60-71 \cdot c^{(3)},(4)$ & 7 & $x$ \\
\hline SMEO, CA & D & $A 9918$ & light anber & $65^{\circ} c^{(5)}$ & 7 & $x$ \\
\hline Caples Lake, CA & C & other & clear & $52^{\circ} c^{(6)}$ & $>7$ & $x$ \\
\hline Carisen Plains, CA & c & other & slight brown & $\cdot$ & 8 & $x, 2$ \\
\hline John Long, Phoenix, Az & c & other & moderate & $\pi \cdot c^{(3)}$ & 8 & $x$ \\
\hline Sandia, Albuquerque, HH & D & A9918 & lloht anber & - & 8 & $x$ \\
\hline SHOD, CA & c & other & sllght brown & $\pi \cdot c^{(3)}$ & 9 & $x$ \\
\hline San Remon, CA & $\mathbf{F}$ & A9918P & clear & - & $9 \cdot 10$ & $x$ \\
\hline Carrisa Plains, $\mathrm{cA}^{(7)}$ & C & other & dark brom & $80-90 \cdot c^{(7)}$ & 10 & $\overline{x, z}$ \\
\hline Costa Rica & G & A9918 & clear & - & 10 & $x, y$ \\
\hline Mohavl Desert & E & 19918 & cleer & - & 10 & $x$ \\
\hline "Around the Morld" & E & 19918 & cleer & - & 10 & $x$ \\
\hline Cape Canaveral, FL & $\mathbf{A}$ & 99918 & discolored & $\cdot$ & 10 & $n$ \\
\hline SWRES LaE Cruces, NH & D. & 19918 & light anber & $75 \cdot c^{(6)}$ & 10 & $x$ \\
\hline
\end{tabular}

(1) Estimated, no "hard" data avallable, (summer) measurements taken mostly from back-side of module

(2) H- Glass/EVA/Cell/EVA/FOIl, X-Glass/EVA/Coll/EVA/FIlm leminate, Y-Tefzel/EVA/Cell/EVA/FIlm laminate, Z- Bifacial

(3) Average amblent temperature plus $30^{\circ} \mathrm{C}$

(4) High and low mounted racks

(5) Hanufacturer's date

(6) Estimated based on high wind veloclty (ambient temperature plus $20^{\circ} \mathrm{C}$ )

(7) Hodules operated at opproximately 2 suns (mirror enhanced) 
AVERAGE DAILY DIRECT NORMAL SOLAR RADIATION $\left(\mathrm{MJ} / \mathrm{m}^{2}\right)$

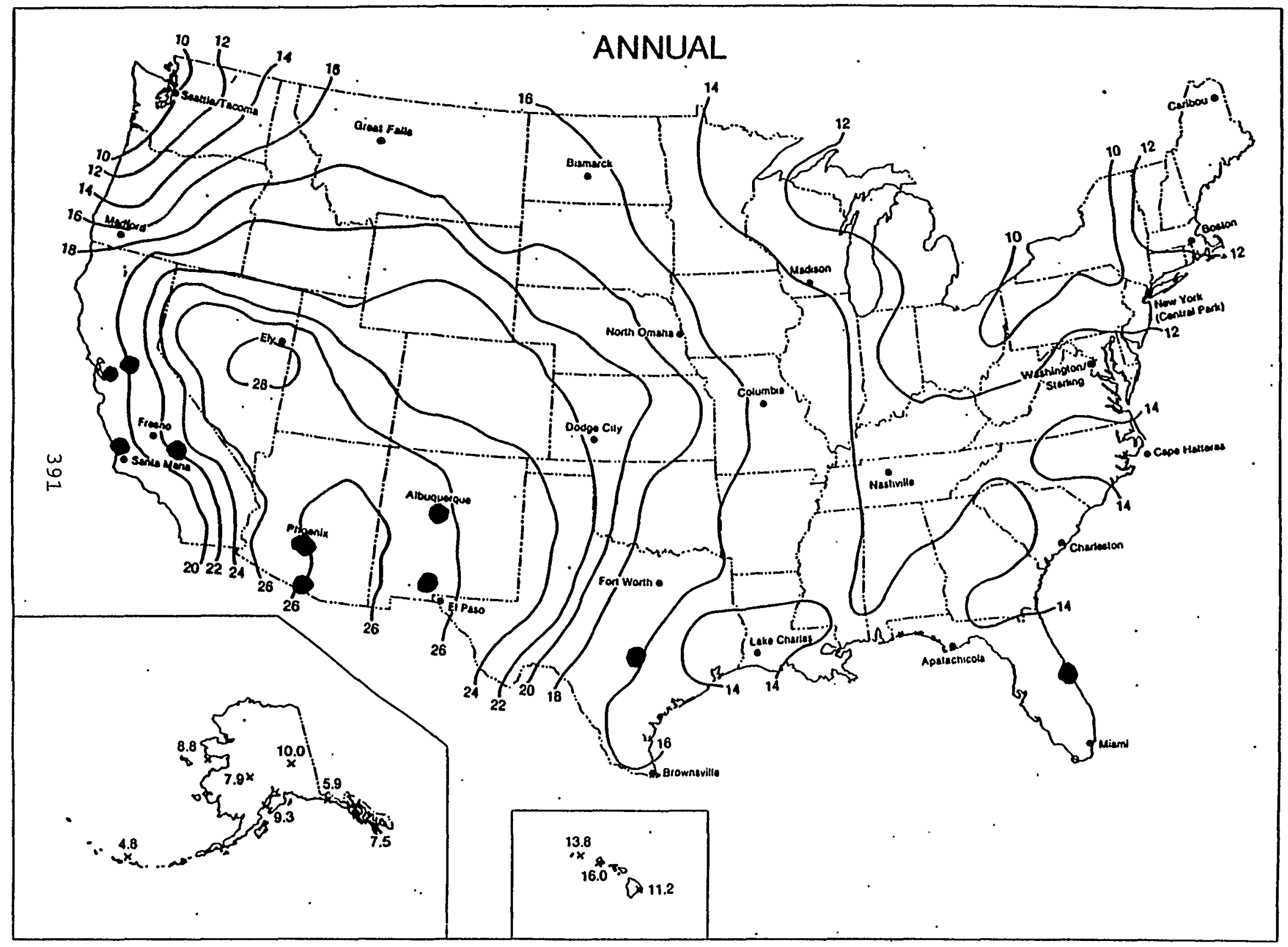




\section{OVERVIEW OF SURVEY ON GASE HISTORIES OF EVA DISCOLORATION}

* No CASES OF EVA DISCOLORATION HAVE BEEN UNCOVERED FROM EASTERN AND CENTRAL U.S. OR WESTERN EUROPE.

* GENERAILY, THE TIME FOR ONSET OF EVA DISCOLORATION IS NOT WELL KNOWN. DISCOLORATION OFTEN WAS NOT DOCUMENTED UNTIL FAIRIY ADVANCED.

* GENERALIY, EVA DISCOLORATION WAS NOT A FOCUS OF MODULE FIELD TESTING PROGRAMS.

* CONSEQUENTLY, INFORMATION ON DISCOLORATION IS QUAIITATIVE RATHER THAN QUAN.

* IN GENERAI, HARD DATA ON OPERATING TEMP. AND SOLAR INSOLATION WAS UNAVAILABLE.

* MOST CASES OF EVA DISCOLORATION APPEAR MILD IN COMPARISON TO THAT AT CARISSA.

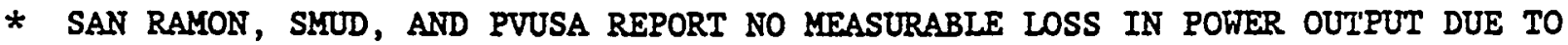
DISCOLORATION OF THE EVA ENCAPSULANT.

* WHILE THERE HAVE BEEN REPORTS OF MODULES FROM ONE MANUFACTURER DISCOLORING MORE QUICKLY THAN OTHERS, WE SAW LITTLE EVIDENCE AT SMUD, SAN RAMON, AND PVUSA TO SUPPORT THIS, OR TO INDICATE A GREATER DEGREE OF DISCOLORATION FROM ONE MANUFACTURER'S MODULES TO ANOTHER. 
GENERAI CONCIUSIONS FROH CASE HTSTORIES

* EVA DISCOLORATION IS NOT LIMITED TO THE MODULES OF ANY ONE MANUFACTURER. KODULES OF ALI MAJOR MFG. USING CRYSTALIINE OR SEMI-CRYSTALIINE CELI TECENOLOGY HAVE BEEN REPORTED TO DISCOLOR.

* DISCOLORATION IS NOT LIMITED TO THE EVA ENCAPSULANT OF ANY ONE SUPPLIER.

* IN GENERAL, DATa WAS INSUFFICIENT TO DRAW HaRd CORREIATIONS

* HOWEVER, SOLAR INSOLATION IN COMBINATION WITH MODULE OPERATING TEMPERATURE APPEAR TO BE PRIMARY FACTORS IN EVA ENCAPSULANT DISCOLORATION, WITH ALI REPORTED CASES APPEARING IN THE WEST AND SOUTH WHERE BOTH ARE HIGH 


\title{
STABILITY OF EVA IN PV MODUILES
}

\author{
BY \\ JOHN H. WOHLGEMUTH \\ SOLAREX CORPORATION \\ FREDERICK, MARYLAND 21701
}

\section{Introduction}

Yellowing and darkening of the EVA encapsulant in PV modules was first reported for the modules deployed at Carrisa Plains ${ }^{1-3}$. The energy production efficiency of the array declined linearly at a rate of 8 to $12 \%$ per year from 1986 to $1989^{2}$. The two facts were then equated and EVA degradation was blamed for the major power loss at Carrisa. However, subsequent analysis has shown that a significant portion of the power degradation of the Carrisa modules was a result of other loss mechanisms not related to EVA discoloration ${ }^{4}$. Nevertheless, after the Carrisa observations, EVA yellowing and discoloration on modules deployed at other sites in hot sunny climates was reported 5 .

The National Renewable Energy Laboratory (NREL) has been sudying the behavior of EVA modules6-8. They have reported on EVA degradation of modules with field exposure as well as modules that underwent accelerated UV/temperature exposure in the laboratory ${ }^{8}$. UV/temperature induced degradation of EVA was reported, producing byproducts, including acetic acid, that lead to EVA discoloration.

While the NREI and Carrisa Plains data show that EVA will discolor under accelerated stress conditions, neither study provides guidance on the expected performance under normal one sun application. In this paper a summary of field results for Solarex modules will be presented. The field and accelerated test results will be utilized to evaluated the expected contining performance of these modules. Finally, recommendation will be made for the direction of future work on the EVA encapsulation system.

\section{Field Tests}

Solarex has now been manufacturing EVA modules for more than 13 years. Modules from a number of sites are being monitored on a continuing basis. Module data is now available from a number of sites as detailed in Table 1. The Solarex modules at Sede Boqer, Israel have been exposed to a similar environment as the Arco modules were at Carrisa ${ }^{9}$. These Solarex modules have experienced much less discoloration and power loss than the Arco modules did in their first 6 years of deployment at Carrisa Plains. Field data on Solarex EVA modules indicates that high temperature, high irradiance conditions do cause measurable degradation and observable discoloration, but the degradation and discoloration rates are low in comparison to some other field reports.

At sites with low to moderate insolation levels and moderate temperatures like the mid-Atlantic or Northeastern US there is no evidence of EVA discoloration. At sites with high insolation levels, but moderate temperatures (i.e. high altitudes) like at NREL there is still little observed discoloration of the EVA. The sites with appreciable degradation are those with high insolation levels and hot temperatures for most of the year, like the US Southwest. These conditions are exaggerated by mounting schemes that result in higher module temperatures and of course by concentrating more sun light onto the modules. 


\section{Degradation Mechanisms}

Reviewing the data and observations on the performance of EVA under UV and thermal stress can tell a great deal about the degradation mechanism. The worst case discoloration occurs in regions that are enclosed. Around the edges of cells and near cracks in cells or glass, the EVA remains clear. Modules with hermetically sealed backs (double glass or Al foil backsheets) experience more severe discoloration than those modules with a plastic (Tedlar) backsheet. Something either must diffuse into or out of the EVA to keep it from discoloring. A likely candidate for diffusing out of the EVA is acetic acid produced by the photothermal breakdown of EVA. The EVA would then be clearer in the regions where the acetic acid is gone and will be darker where the acetic acid builds up accelerating further degradation ${ }^{8}$. Another possible mechanism is the diffusion of oxygen into the EVA leading to a photobleaching process in the EVA $^{8}$.

The fact that both clear and discolored EVA occur on the front of the same module, results from a balance of 2 competing mechanisms. In the clear areas the diffusion in (or out) of the crucial species is sufficient to minimize the photothermal degradation with the EVA remaining clear. In the areas over cells the rate of generation of the light absorbing species or creation of light absorbing bonds is greater than the diffusion out of the light absorbing or reaction catalyzing species (or photobleaching from diffusion in). Therefore, the EVA over the cells discolors. A slow rate of degradation or discoloration means the reactions are close to equilibrium and therefore, the degradation reaction will continue to be slow unless the reaction rates are changed by changing the external environment or until the Cyasorb, UV stabilizer, is lost. However, it has been found that the extent of discoloration is closely related to the decrease in Cyasorb concentration ${ }^{10}$. There is very little Cyasorb lost from the clear areas of modules even when the areas over the center of the cell has discolored appreciably with a major loss of Cyasorb. So in modules with no discoloration or a minor degree of discoloration the Cyasorb concentration is expected to remain high and the degradation rate will remain low. This is an extremely encouraging result, leading to the conclusion that, since Solarex modules have already proven that they only experience minor discoloration in more than 10 years of exposure in some of the worst one sun conditions, the degradation rate of the EVA is low and is expected to remain low. Therefore, Solarex EVA modules should have service lives much longer than the 10 to 13 years of already demonstrated life.

\section{EVA Cure}

Discoloration and degradation of EVA has been linked to increased gel content in the material ${ }^{6}$. While the initial gel content in new modules is approximately 70\%, Pern and Czanderna measured a gel content of 82 io $88 \%$ in the clear areas and 90 to $92 \%$ in the discolored areas from degraded EVA modules ${ }^{10}$. This fact was used to indicate that even the clear EVA in these modules is degraded. It should not be surprising that the gel content of EVA has increased in modules that have experienced high operating temperatures. While curing of EVA is usually performed at temperatures above $120^{\circ} \mathrm{C}$ for short times, curing will occur at 80 to $90^{\circ} \mathrm{C}$ over long periods of time. There is nothing wrong or potentially degrading about this increase in gel content.

The gel content measurement does not measure the degree of cross-linking of the EVA. It measures the percentage of EVA that is cross-linked. EVA that has $100 \%$ gel content may still have many additional bond site available for continued cross-linking. Such EVA still has adequate physical and chemical properties to continue serving as a encapsulant. Eventually the EVA could become so cross-linked that it would embrittle and stop serving as a good encapsulant. However, we have never observed brittle EVA either from modules that have been exposed in the field, from modules that have undergone long term accelerated thermal tests (for example 1000 thermal cycles), nor from modules that have been inadvertently over cured during production. Specially prepared test samples of EVA with $100 \%$ gel content are still flexible and pliable. 


\section{Future Work}

It is very important that the careful field monitoring of EVA modules continues. Solarex will continue to monitor the performance of modules from a variety of sites. We are also cooperating with NREL and the Ben-Gurion University to monitor the mirror enhanced system at Sede Boqer. This site is especially interesting because of the similarity with the operating conditions at Carrisa Plains, but with very different degrees of module degradation.

It is also important to establish accelerated testing procedures for the EVA degradation mechanism ${ }^{11}$. Because of the presence of competing mechanisms, it may not be possible to accelerate this process by a great deal without changing the nature of the failure mechanism. Even accelerated tests may take the better part of a year to test for a 20 or 30 year module lifetime.

Work on understanding the chemical reactions that are occurring in the EVA due to photothermal stress and the competing reaction(s) that keep some of the EVA clear is also important. This effort must precede the development of an improved EVA formulation that maintains the many desirable properties of EVA, while eliminating the photothermal degradation from occurring under normal flat plate terrestrial operating conditions.

\section{References}

[1] D. D. Sumner, C. M. Whitaker and L. E. Schlueter, "Carrisa Plains Photovoltaic Power Plant 19841987 Performance", Twentieth IEEE PVSC, 1988, pp. 1289.

[2] H. J. Wenger, C. Jennings and J. J. Iannucci, "Carrisa Plains PV Power Plant Performance", Twentyfirst IEEE PVSC, 1990, pp. 844.

[3] A. L. Rosenthal and C. G. Lane, "Field Test Results for the 6 MW Carrizo Solar Photovoltaic Power Plant", Solar Cells, 30, 1991, pp. 563.

[4] J. H. Wohlgemuth and R. C. Petersen, "Reliability of EVA Modules", Twenty-third IEEE PVSC, 1993.

[5] J. Pern, "Recent Generic Studies of Ethylene Vinyl Acetate (EVA) Degradation", Proceedings of Photovoltaic Module Reliability Workshop, SERI/CP-4079, 1990, , pp. 279.

[6] F. J. Pern and A. W. Czanderna, "Characterization of ethylene vinyl acetate (EVA) encapsulant: Effects of thermal processing and weathering degradation on its discoloration", Solar Energy Materials and Solar Cells, 25, 1992, pp. 3.

[7] F. J. Pern, A. W. Czanderna, K. A. Emery and R. G. Dhere, "Weathering Degradation of EVA Encapsulant and the Effect of its Yellowing on Solar Cell Efficiency", Twenty-second IEEE PVSC, 1991, pp. 557.

[8] J. Pern, "A Comparative Study of Solar Cell Performance Under Thermal and Photothermal Tests", Proceedings of Photovoltaic Performance and Reliability Workshop, SERU/CP-411-5184, 1992, pp. 327.

[9] D. Faiman and M. Slonim, "Efficiency Measurements on the 189 Solarex SX-146 modules of the Paz photovoltaic system at Sede Boqer", Israel Ministry of Energy Report EN-12-92 (October, 1992). 
[10]F. J. Pern, "Luminescence and absorption characterization of ethylene-vinyl acetate encapsulant for PV modules before and after weathering degradation", Polymer Degradation and Stability, 41, 1993, p. 125.

[11]J. H. Wohlgemuth, "Testing for Module Warranties", Proceedings of Photovoltaic Performance and Reliability Workshop, Sept. 1993.

TABLE 1

SUMMARY OF FIELD TEST RESULTS

FOR

SOLAREX EVA MODULES

\begin{tabular}{|ccccc|}
\hline Location & Type of Array & $\begin{array}{c}\text { Years of } \\
\text { Exposure }\end{array}$ & $\begin{array}{c}\text { Evidence of } \\
\text { EVA } \\
\text { discoloration }\end{array}$ & $\begin{array}{c}\text { Power } \\
\text { Loss } \\
\text { (\%) }\end{array}$ \\
\hline $\begin{array}{c}\text { Solarex } \\
\text { Frederick, MD } \\
\text { Southwest Res } \\
\text { Las Cruces, NM } \\
\text { Sandia }\end{array}$ & rack mounted & 10 & no & 0 \\
$\begin{array}{c}\text { Albuquerque, } \\
\text { NM }\end{array}$ & rack mounted & 8 & yes & 0 \\
$\begin{array}{c}\text { SMUD } \\
\text { Sacramento, CA } \\
\text { Sede Boqer }\end{array}$ & rack mounted & 6 & no & 0 \\
Israel & $\begin{array}{c}\text { mirror } \\
\text { enhanced }\end{array}$ & 6 & slight & $2-3$ \\
\hline
\end{tabular}


Highlights from the Panel Discussion at the Durability and Reliability Session, Photovoltaics Performance and Reliability Workshop September 9, 1993, Golden, Colorado

A. W. Czanderna, Session Chairman and Panel Members: Niles, Gonsiorawski, Putman, Pern, Rosenthal, Holley, and Wohlgemuth)

Widely varying opinions that were expressed by the panel members and workshop participants about EVA discoloration in which the opinion expressed by utilities (U), PV manufacturers (I), and NREL (N) are identified are as follows:

- Why be concerned if loss is only $1 \% /$ year-- it is only economics (U)

- Lifetime prediction is not possible at this time because many potential degradation mechanisms are not known and too little information about the intial starting materials, processes, etc., results in too much uncertainty about the value of presently field deployed modules $(\mathrm{N}, \mathrm{I})$

- Slow long term loss may become catastrophic by a mechanism not identified as yet (DSET)

- It is only a problem in some hot sunny areas of high UV intensity and in which mirror enhancement has been an "overuse" (I)

- Why accept any loss in performance when the problem can probably be solved by using a polymer with a different pendant group at a cost of 20 to $30 \mathrm{M} \$$ over 5 to 7 years? (I,N)

- If up-front economics can justify accepting a $20 \%$ decrease in efficiency over 20 years, then losses are OK and aesthetics is not an issue (U)

- Aesthetics do matter and discoloration is repulsive (U)

- Degradation in performance is a problem, aesthetics are important, and both should be corrected $(\mathrm{I}, \mathrm{N})$

- $\quad$ EVA needs to be improved because it is a problem and industry will probably accept a better or "super-EVA" more readily than a new copolymer formulation (I)

- $\quad$ EVA, even optimally stabilized, will always be subject to producing acetic acid, acetaldehyde, and other degradation products. Who wants acetic acid. a known catalyst for further degradation, present in PV modules? A super-EVA might be an appropriate transition material for the near term. However, a copolymer that will not discolor or produce aggressive degradation products needs to be identified, tested, and established as a 30-year PV module material $(\mathrm{N})$ 


\section{SYSTEM FIELD EXPERIENCES}




\section{PSCO \\ RENEWABLE ENERGY INVOLVEMENT \\ TO DATE:}

by Chris Thompson, Engineer

Public Service Company of Colorado

Presentation to NREL

PV Performance and Reliability Workshop

September 9, 1993

Although we are here today to talk about PSCo's field experience with photovoltaics, we must acknowledge that PSCo's history of involvement has also included other renewable energy technologies.

In 1984, 1985, and part of 1986, PSCo Generation Engineering Division monitored three wind sites in Colorado and wyoming that looked promising according to existing national wind data. These were: Harriman, wyoming (located approximately 30 miles $N$ w of Cheyenne, along the Colorado/Wyoming border); Burlington, Colorado (located in East-Central, Colorado along I-70 approximately 13 miles west of the Colorado/Kansas border); and Petes, colorado (located in Northeastern Colorado, approximately 30 miles north of sterling, along the Colorado/Nebraska border). The most promising site of the three was was Harriman, Hyoming, which showed a rating of a wind Power class 7 site.

In 1988, a Waste-to-Energy Feasibility Study was conducted as a joint effort between PSCo and the City and County of Denver. The purpose of the study was to determine the feasibility of constructing a waste-to-energy facility in the city and county of Denver. The basic finding of the study was that the economic realities currently surrounding solid waste disposal in the Denver area did not support the construction and operation of a waste-toenergy facility at that time. Environmental issues were also addressed during the study. Since Denver is a non-attainment area for a number of air pollutants, the introduction of a new emission source into the city would not be easily accomplished or accepted.

Over the last ten years, there have been more than 60 costeffective Photovoltaic (PV) (Solar) powered systems installed for remote monitoring and cathodic protection of PSCo's WestGas's transmission system. All of these units were smaller than 200 watts. It is not uncommon for solar units to be installed because in many cases Gas transmission lines are located in remote locations. The cost of installing an electric distribution line may be more expensive and/or it may be impractical to install the electric distribution line. 
Last year it was found to be more economical to cathodically protect an underground PSCo Boulder Division electric transmission Iine that crosses the median strip of Hwy 119 between Gunbarrel and Niwot substations with a PV-powered system than to extend a distribution line to the site. The cost of this PV system was approximately $\$ 1500$.

In effect since March 3, 1991, Rule 31 (Section X) required utilities to provide new customers, in certain circumstances, with a comparison of the cost of an electric line extension with the cost of installing a photovoltaic system. Application of section $X$ required that the utility receive an estimate of an applicant's monthly kilowatt-hour usage and distance from the nearest feeder line. If the ratio of monthly kilowatt-hour usage to line extension mileage is 1000 or less, the utility will supply a cost comparison between a line extension and photovoltaics. on May 11, 1992, the Commission held a hearing the evaluate the rule's effectiveness and to determine if any modifications should be made. The outcome of that hearing was a change in the rule as requested by PSCo that eliminated a great deal of PSCo paperwork and helped to maintain PSCo's credibility with its customers.

Only about $1.5 \%$ of the over 5,000 requests received in the last 29 months have fallen in to the category where a cost comparison was required. This may mean there there really aren't many costeffective applications for photovoltaics or it may mean that the correct audience may not be targeted as yet.

potential:

Three sites have been targeted for investigation of solar

1) Ft. St. Vrain: As part of the repowering of Ft. St.Vrain, a proposal was initially suggested that $14 \mathrm{MW}$ of PV power (roughly the equivalent house power of the plant) would be installed incrementally at the repowered Ft. St. Vrain. Further investigation of this technology revealed that more benefits could be experienced if this generating capacity was moved closer to the loads-a distributed generation scheme. Since that time, PSCo and NREL have been negotiating to have a $50 \mathrm{~kW}$ Amorphorous silicon photovoltaics system belonging to NREL installed and to provide the interconnection to the Ft. St. Vrain 480 volt house power bus.

2) Initial indications show that the valmont plant in Boulder might be a much better place to install photovoltaics, and rather than install the APS system at the repowered Ft. St. Vrain, Valmont might be a better site. Boulder's solar insolation has been well monitored over the years because of the many different laboratories that reside there. NREL is now helping PSco determine whether further monitoring at valmont will be necessary.

3) The small mountain community of White Pine in the Mtn. Division is served by a single-phase distribution line that goes over the continental divide. obviously, by this slide, this line can be a challenge to maintain. There are approximately 25 
PSCo customers out of approximately 35 residents, the majority of which live there only during the summer months. The cost to rebuild PSCo's line to this town has been estimated at approximately $\$ 132 \mathrm{~K}$. The cost to serve this town from a hybrid PVpropane generator system (approximately $35 \mathrm{~kW}$ of $\mathrm{PV}$ ) has been estimated at between $\$ 500 \mathrm{~K}-\$ 700 \mathrm{~K}$. PSCo would pay the avoided cost of this line and is continuing to search for cost-sharing partners in this endeavor. The information gathered from such an installation would be useful to the PV community, other utilities, as well as PSCo.

PSCo has completed a preliminary investigation of its feeders and substations in conjunction with the Utilities Renewable Energy Forum group's inquiry. The purpose of this investigation was to determine if there were any situations in which installation of a distributed generation $500 \mathrm{~kW}$ PV system could be a cost-effective delay of a substation bank or feeder upgrade. Analysis of a similarly-sized PV system by PG\&E (for their Kerman substation) indicated that this was the case. PSCo's present worth analysis showed that this was not the case (by a factor of 10) for its most promising site. In addition, most of PSCo's feeders had a peaking period which was after sundown--thus requiring storage and additional costs.

\section{PSCo is involved in the following renewable energy organizations:}

a) Photovoltaics for Utility Scale Applications (PVUSA) is a national public-private partnership that is assessing and demonstrating the viability of utility-scale photovoltaic (PV) electric generating systems. PVUSA participants include Pacific Gas \& Electric (PG\&E), the U.S. Department of Energy (DOE), the Electric Power Research Institute (EPRI), the California Energy Commission (CEC), and eight+ utilities and other agencies. PVUSA offers utilities hands-on experience needed to. evaluate and utilize maturing PV technology. The project also provides manufacturers a test bed for their products, encourages technology improvement and cost reductions in PV modules and other system components, and establishes communication channels between utilities and the PV industry. The project consists of two types of demonstrations: Emerging Module Technology (EMT) arrays, which are unproven but promising state-of-the art PV technologies in $20 \mathrm{~kW}$ arrays; and Utility scale (US) systems, which represent more mature PV technologies in $200-$ to $500 \mathrm{~kW}$ turnkey systems. One additional advantage of PVUSA is the ability to use EPRI tailored collaboration funds.

b) The Utility Renewable Energy Forum (UREF) is a Colorado coalition of utilities, regulatory agencies, suppliers and manufacturers, and other groups interested in renewable energy technology. The major purpose of UREF is to exchange technical information and experience in order to encourage the use of these renewable technologies in colorado. Since its first meeting at 
NREI in Jan 1992, information on PV, Wind, and Thermal Solar technologies have been shared.

c) The Utiltity PV Group (UPVG) is a chartered organization with $28+$ utility members representing investor-owned utility companies, publically owned, and rural electric cooperatives. This utility-driven effort has a two-fold thrust:

1) to accelerate the use of PV in cost-effective applications and 2) to accelerate the commercialization of PV.

PSCo has not been required to own, operate, or maintain renewable technologies. However, in order to learn firsthand about the O\&M requirements of photovoltaics, PSCo become involved in four PV projects:

a. PSCo was a host utility for an EPRI/Sandia National Laboratories-sponsored photovoltaic-powered stockwatering project. This small PV pumping system (100W) is located in a PSCo customer's well in Brush, Colorado and is used in the summer to water cattle. PSCo has coordinated the design, contract, installation and maintenance of this system and has provided reports to sandia National Laboratories, EPRI, and NEOS corporation. We completed final testing of the system this summer. We encountered a few problems with this installation and we've learned a great deal from our experience. (although the PV panels gave us no problem, we did have a pump failure and our contracted vendor went through a complete reorganization during this time period.) And for all of our systems, we've learned that one of the more frustrating facts is that a great majority of the time, the sun does not always shine when you have the people and time to test the systems. We learned that there is a great need for an adequate maintenance infrastructure that does not exist today. We will continue to follow-up with the customer in order to determine if there is a market for this type of system. We've learned that customer satisfaction is extremely important. The cost of the system including installation was $\$ 3400$.

b. PSCo, in conjunction with NREL, DOE, and the south Suburban Parks and Recreation District installed a photovoltaicpowered pumping system and a photovoltaic power supply for an irrigation system in the South Platte Park northwest of Santa Fe and Mineral Avenue in April of 1992. This total system is designed to pump approximately 9500 gallons of water a day in the summer from Cooley Lake to irrigate approximately 1400 trees, part of the 10,000 Trees urban reforestation project along the platte River. PSCo has been a part of the design, procurement, and installation process and had plans to monitor the operation and maintenance experience of this total system for only two years after installation (April 1992), but have been requested by the Parks Depart to come back next year for further testing. Psco owns this $2.5 \mathrm{~kW}$ system and the Parks and Recreation District is contracted to maintain it. The total cost of this system was approximately $\$ 43,000$. 
The system has performed very well during the last two years, and overali the Parks Department is pleased with the system. I was surprised and yet not surprised that the Parks Department is still wary of this system and asked that PSCo and the PV contractor both be present when the system was turned on this Spring. This is a good example that customer satisfaction is imperative. I foresee that a little "hand-holding" with our customers will be necessary until their confidence is built up--not unlike our relationship with NREL. Unfortunately, the Parks Department has had irrigation subcontractor problems and delays and we've had to do without a main flowmeter this summer and without a main pressure meter once the flowmeter was finally replaced. In addition, about 3 weeks ago 2 of the 42 panels were stolen from the site. The locknuts that were using proved worthless and we've since secured the panels to the frames by spotwelding. We will be replacing the panels and plan a meeting of the project participants in september to open up the discussion of security for not only this installation but future projects that PSCo is involved with. This is a serious subject that really hasn't been dealt with to date.

c. PSCo is working with NREL and the University of Colorado at Denver on a project to gather data and test commercially-available stand-alone PV lighting systems. PSCo provided one of the area lighting systems and has also had recent field experience with three PV-powered area lights placed at the World Youth Organization headquarters at the Cherry Creek Reservoir during the Papal visit.

d. PSCo has begun to assist NREL in testing their $5 \mathrm{~kW}$ PV grid tie in Golden. We are assisting with harmonics testing on the existing $2 \mathrm{~kW}$ system and will be doing the same for the new NREL SERF building when it comes on line.

Where do we go from here?

I'm proud to answer that question. On August 19, 1993, PSCo began our Voluntary Renewable Energy Program (VREP). our Market Research has shown that our customers want to play a major part in our involvement with renewable energy. This VREP is a customerdriven program designed to accelerate the development of renewable energy sources in PSCo's territory. We are in the beginning stages of forming a Citizen's Advisory Panel (CAP) that will help PSCo encourage funding participation among our customers and will help us to direct those funds to the renewable technologies and projects that our customers desire. Members of PSCo's Renewable Energy strategy Team (REST) have been working on some of the initial projects that we will be presenting to the CAP. PV technology projects will be among these initial and future proposals. 


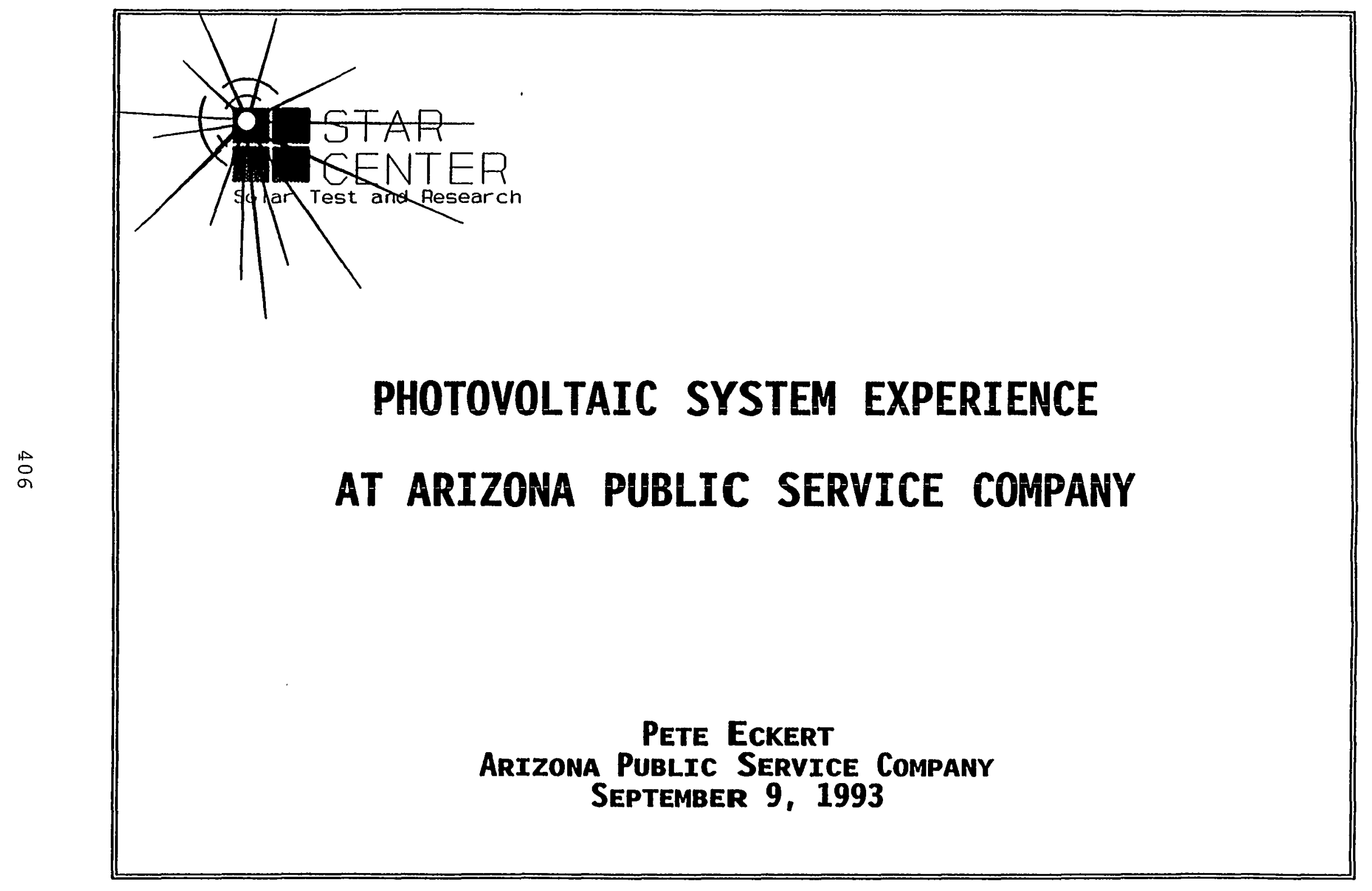




\section{INTRODUCTION}

APS has used cost-effective applications of PV since the mid-70's

APS has been involved in PV system testing and demos for many years

- Sky Harbor concentrator PV project (1982)

- Yuma residential system (1982)

- STAR Center (1988)

$\checkmark$ EPA/DSM projects (1993)

Valuable experience will help to design and implement future PV 


\section{HISTORICAL PROJECTS}

COST-EFFECTIVE PV APPLICATIONS

- Gas telemetering

- Telecommunications applications

- Sectionalizer switches

- Communications trailer

- Flume control

Water pumping

$\checkmark \quad$ Warning sirens

SKY HARBOR CONCENTRATOR PV SYSTEM

- 1980 Martin Marietta design

- $200 \mathrm{~kW}_{\mathrm{ac}}(802$ 2-Axis tracking arrays)

- Experimental design - Largest in US at that time

- First 300 kW inverter failed - Replacement very reliable

- Expensive system improvements

- O\&M costs decreased and reliability increased over time 


\section{hISTORICAL PROJECTS (CONTINUED)}

\section{YUMA RESIDENTIAL PV SYSTEM}

- Installed in 1982

- $4 \mathrm{~kW}_{\mathrm{ac}}, 132$ Photowatt modules

- PCU 95\% Efficiency, THD: $1.8 \%$

- Produces $6000 \mathrm{kWh}$ per year

- $\$ 61,000$ or $\$ 15 /$ Watt

Customer savings over 10 years: $\$ 4,473$ or $\$ .079$ per $\mathbf{k W h}$

O\&M cost over 10 years: $\$ 519$ or $\$ .009$ per $\mathrm{kWh}$

- $99.5 \%$ availability

$\checkmark$ Required maintenance:

Replace 2 muffin fans

Replace DC disconnect (original not DC rated)

Replace 1 Blocking Diode. 


\section{STAR CENTER ACTIVITIES}

MODULE TESTING

- Capacity to test 60 modules, dynamically loaded

- 32 under test

- 9 Crystalline

- 13 Thin Film

- 10 Concentrators

$\checkmark$ Results

- Thin Film less reliable then crystalline

- Solarex - Internal junction failure (no longer used)

- 2 Chronar - Efficiency decreased to $2 \%-1$ finally died

- Advanced Photovoltaic Systems - DOA

- 2 Wattsun - Concentrator modules literally fell apart

- Some manufacturers are better than others at rating their modules 


\section{STAR CENTER ACTIVITIES (Continued)}

\section{GRID-CONNECTED SYSTEM TESTING}

- 28 Sky Harbor modules configured as a $2 \mathrm{~kW}$ array

- 24 Intersol modules configured as a $2 \mathrm{~kW}$ array

- Three $2 \mathrm{~kW}$ Mobil/Omnion systems

- 12 kW Siemens/Dickerson system (State-owned)

Results

- Acrylic concentrator lenses have held up since 1982

- Drive mechanisms have been reliable at STAR

- ECU signal cables have failed several times

- One array blew past limit switch

- Array tracking comparison:

Fixed position

One-axis tracking

Two-axis tracking

$\begin{array}{ll}2245 \mathrm{kWh} / \mathrm{m}^{2}-\mathrm{yr} & \text { Reference } \\ 2720 & +21.2 \% \\ 3090 & +37.6 \%\end{array}$

- One-axis only 3\% lower than 2-axis during summer months 


\section{STAR CENTER ACTIVITIES (ContInUed)}

\section{POWER CONDITIONING UNIT TESTING}

Installed 3 Omnion and 2 Pacific Inverters in 1988

- Interaction between PCU's

- Both manufacturers worked to solve problem

- Both manufacturers made revisions to ALL of their units

- Upgraded units were compatible

- Omnion unit had software glitch - hung at 400 watts

- All 5 units have been very reliable over past 3 years

Installed Dickerson inverter in 1992

- Unit susceptible to VSD noise in adjacent power plant

- Still evaluating unit performance 


\section{STAR CENTER ACTIVITIES (ContINUEd)}

\section{ARRAY TRACKING METHODS}

SPATS - Solar Panel Array Tracking System - Stone \& Webster

- Very reliable - Economical

- Accuracy / versatility compatible with Flat Plate systems

- Open loop control

Martin Marietta Electronic Control Unit (ECU)

- Reliability improved with time

- Tendency to track clouds on partly cloudy days

- Signal cabling failed due to repeated flexing 


\section{STAR CENTER ACTIVITIES (CONTINUED)}

\section{ARRAY TRACKING METHODS}

Prime Industries - Stand alone intelligent array controller (1986-87)

- Extremely complex design

- Closed loop design

- Reliability decreased over 3 years

- Expensive

Solar Technologies International (Sandia design)

- 1st generation design

- Relatively economical

- Rough start due to hardware problems

- Initial software setup was difficult

- Still evaluating unit performance 


\section{STAR CENTER ACTIVITIES (Continued)}

\section{PORTABLE PV GENSET}

- Owned by State of Arizona

- 48 ARCO M55 at 55 deg tilt - $2.54 \mathrm{~kW}$

- 1375 AH battery bank

- 6 kW LP Generator w/250 Gal tank

- Generator powers battery charger (not AC loads)

- 24 Vdc to 240 Vac

- Heliotrope "Quasi" Sinewave inverter

Comments

- Needed 240/120 transformer

- Mismatched Hardware

- Battery capacity reduced by $15 \%$

$\checkmark \quad$ PCU not suited for some loads

- e.g. some inductive \& electronic loads

- Generator ran more often then anticipated

- PCU THD 45-49\% 


\section{EPA DSM PROJECTS}

$4 \mathrm{~kW}$ residential system in Peoria

$8 \mathrm{~kW}$ commercial system in Scottsdale (hospital outpatient clinic)

$4 \mathrm{~kW}$ commercial system in Flagstaff (high school)

Areas of Concern

- PCU operating in hot garage

$\forall \quad 1$ String is grounded

$\checkmark \quad$ High cell temperatures

$\rightarrow \quad$ Potential PCU problems at low temperatures

Low system output 


\section{OVERALL CONCLUSIONS}

- PV system costs have decreased by $50 \%$ since 1982

- Well designed / installed systems are reliable

- Balance of System has been the cause of most difficulty with PV systems

- EVA browning starting to appear on several modules 


\section{Performance of Maspeth a-Si PV System}

presented by Byron Stafford

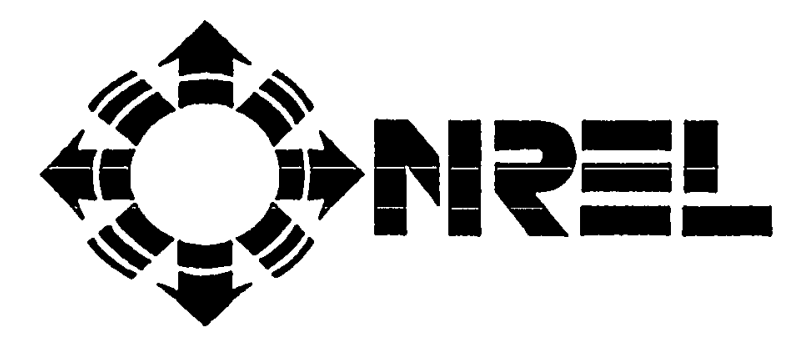

PV Performance and Reliability Workshop

September 8-10, 1993

Golden, Colorado 
Subcontract with Integrated Power Corporation using United Solar System Corporation's UPM-880 modules

\section{Phase 1 Goals}

- Demonstrate $22 \mathrm{~W}$ modules after 600 hours illumination at $1000 \mathrm{~W} / \mathrm{m} 2,50 \mathrm{C}$, and under load

- Demonstrate passage of Interim Qualification Tests (IQT)

- Design and approval of PV system 


\section{Results From Phase 1}

- NREL measured 21.5 W average stabilized power after 600 hours of illumination at $1000 \mathrm{~W} / \mathrm{m} 2,50 \mathrm{C}$, and under load

- NREL accepted USSC's IQT Certification

- System design accepted by Review Team (NREL, Sandia, PVUSA) 


\section{Phase 2 Goals}

- Deploy the modules in a utility interconnected PV system

- Performance greater than $15 \mathrm{~kW}(\mathrm{ac})$

- System rating determined after 60 days of operation 


\section{Maspeth a-Si PV System Facts}

- PV system is installed on the roof of a New York City Transit Authority warehouse in Maspeth, NY (Queens).

- System is utility interconnected in cooperation with New York Power Authority connected to Consolidated Edison.

- System contains 1008 USSC UPM-880 a-Si modules.

- 24 modules are connected in series, 3 parallel groups per row, 7 rows per monopole, 2 monopoles.

- Modules are tilted at 10 degrees and face south.

- System uses a $20 \mathrm{~kW}$ Omnion Series 3200 inverter for 3-phase, $480 \mathrm{~V}$ (ac).

- System has been operating since June 18, 1993.

- After 60 days, system operates around $17 \mathrm{~kW}(\mathrm{ac})$.

- IPC's innovative BOS uses ballast weights for roof mounting with no penetrations. 
- DC performance of individual rows. - Each row contains 72 modules.

\begin{tabular}{|r|r|r|}
\hline & 18-Jun-93 & 26-Aug-93 \\
\hline ROW & Power (W) & Power (W) \\
\hline Row 1 & 1497 & 1437 \\
\hline Row 2 & 1504 & 1414 \\
\hline Row 3 & 1533 & 1429 \\
\hline Row 4 & 1532 & 1471 \\
\hline Row 5 & 1522 & 1462 \\
\hline Row 6 & 1527 & 1460 \\
\hline Row 7 & 1518 & 1444 \\
\hline Row 8 & 1522 & 1453 \\
\hline Row 9 & 1511 & 1433 \\
\hline Row 10 & 1546 & 1472 \\
\hline Row 11 & 1528 & 1446 \\
\hline Row 12 & 1531 & 1441 \\
\hline Row 13 & 1532 & 1442 \\
\hline Row 14 & 1533 & 1444 \\
\hline Prow & 1524 & 1446 \\
\hline Average de Power per Row & 21.2 & 20.1 \\
\hline (includes diode \& wiring losses) & & \\
\hline
\end{tabular}




\section{System Performance}

- Selected data from 8/21-26/93

- POA irradiance $>750 \mathrm{~W} / \mathrm{m} 2$ and wind speed $<4 \mathrm{~m} / \mathrm{s}$

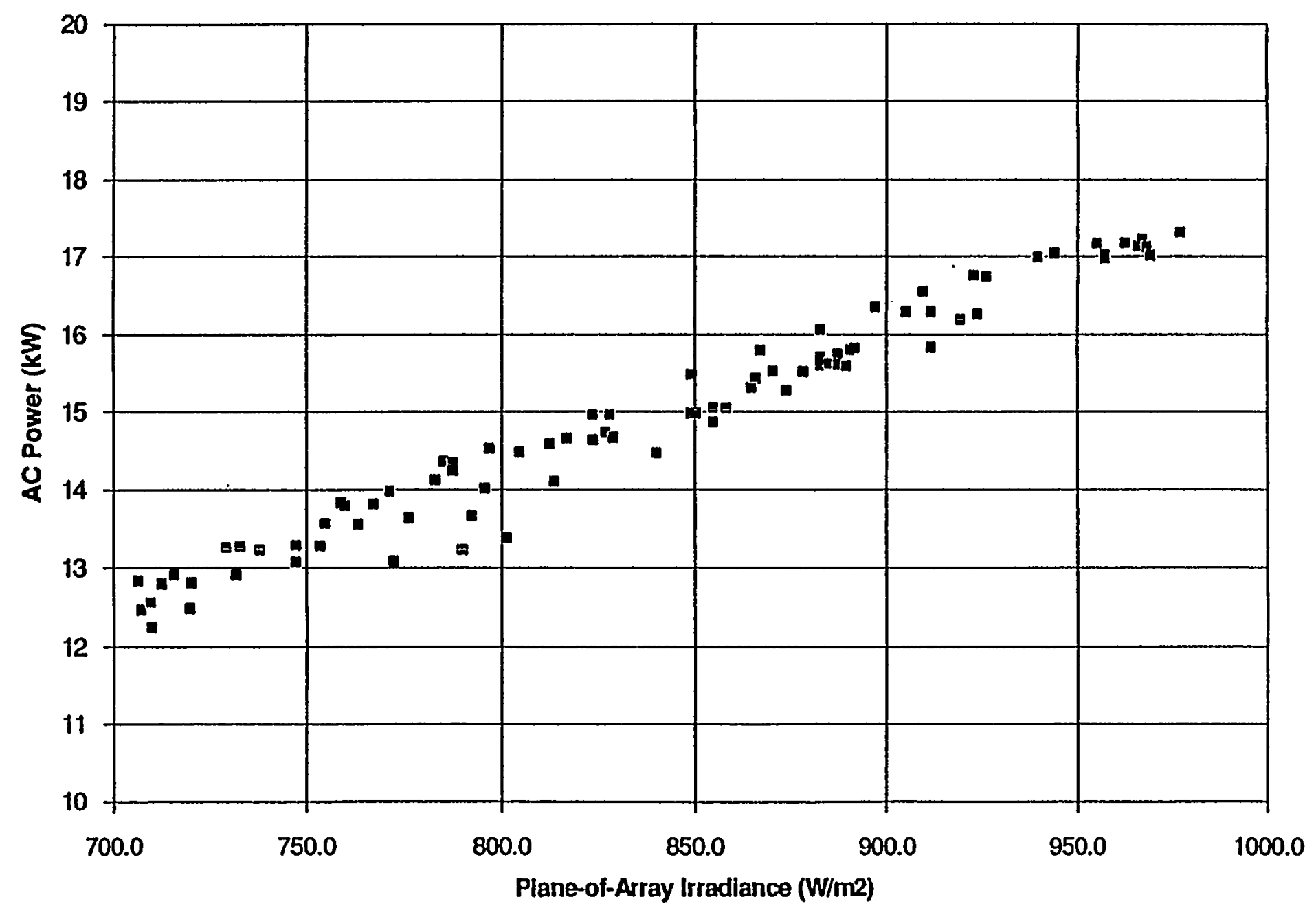




\begin{tabular}{|c|c|c|c|}
\hline & & PV1 & PV2 \\
\hline PLANT RAT & IG (AC) & 1 Megawatt & 1 Megawatt \\
\hline DATE OF O & ERATION & August 1984 & February 1986 \\
\hline $\operatorname{cost}$ & SMUD & $\$ 3.2$ Million & $\$ 3.2$ Million \\
\hline & DOE & $\$ 6.8$ Million & $\$ 6.8$ Million \\
\hline & CEC & $\$ 2.0$ Million & $\$ 0.0$ \\
\hline & TOTAL & $\$ 12.0$ Million & $\$ 10.0$ Million \\
\hline & PV Cost/Watt & $\$ 5.60 /$ Watt & $\$ 4.80 /$ Watt \\
\hline INVERTER, & Rating & 1 Megawatt & 1 Megawatt \\
\hline & Manufacturer & Omnion & Toshiba \\
\hline & Type & Line Commutation & Self Commutation \\
\hline & Efficiency & $96.5 \%$ & $96 \%$ \\
\hline $\begin{array}{l}\text { PV CELL M/ } \\
\text { TECHNOLO } \\
\text { CAPACITY } \\
\text { PV CELL EF }\end{array}$ & $\begin{array}{l}\text { NUFACTURER } \\
\text { Y } \\
\text { T S.T.C) } \\
\text { CIENCY }\end{array}$ & $\begin{array}{l}\text { ARCo } \\
\text { Single Crystal } \\
1.17 \text { Megawatt } \\
10 \%\end{array}$ & $\begin{array}{l}\text { ARCO } \\
\text { Single Crystal } \\
900 \text { Kilowatts } \\
12 \%\end{array}$ \\
\hline & & & $\begin{array}{l}\text { SOLAREX } \\
\text { Poly Crystalline } \\
200 \text { Kilowatts } \\
10 \%\end{array}$ \\
\hline & & & $\begin{array}{l}\text { MOBIL } \\
\text { Ribbon } \\
35 \text { Kilowatts } \\
8 \%\end{array}$ \\
\hline TRACKING & Type & Single Axis & Single Axis \\
\hline & Motor Rating & $1 / 20 h p$ & $1 / 50 h p$ \\
\hline & Panel Rotation & Clock Driven & Clock Driven \\
\hline CONTROL C & OMPUTER & Analog Device & Analog Device \\
\hline DESIGN A\& & & Acurex & Acurex \\
\hline
\end{tabular}




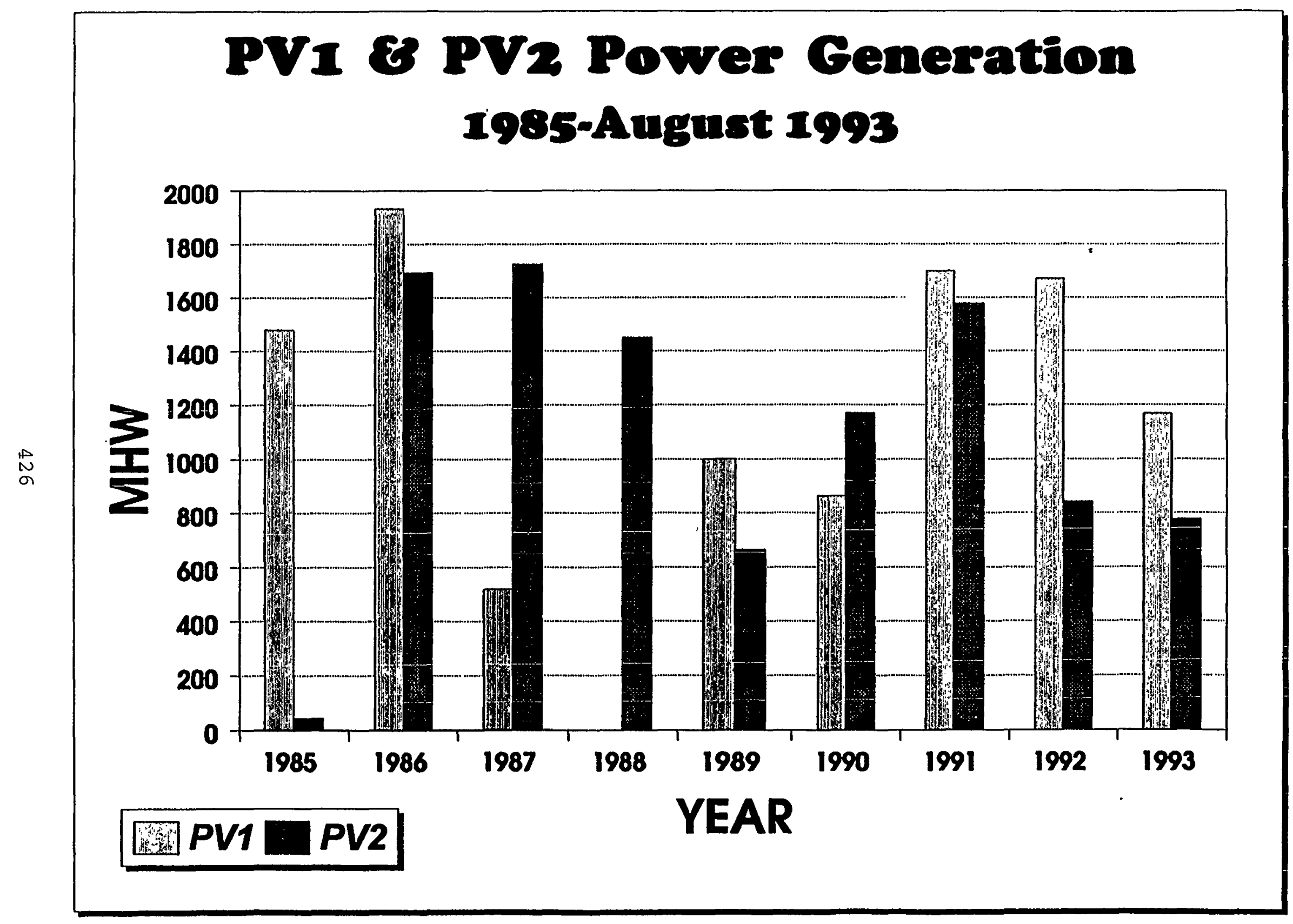




\section{PV1 \& PV2 1991 GENERATION}

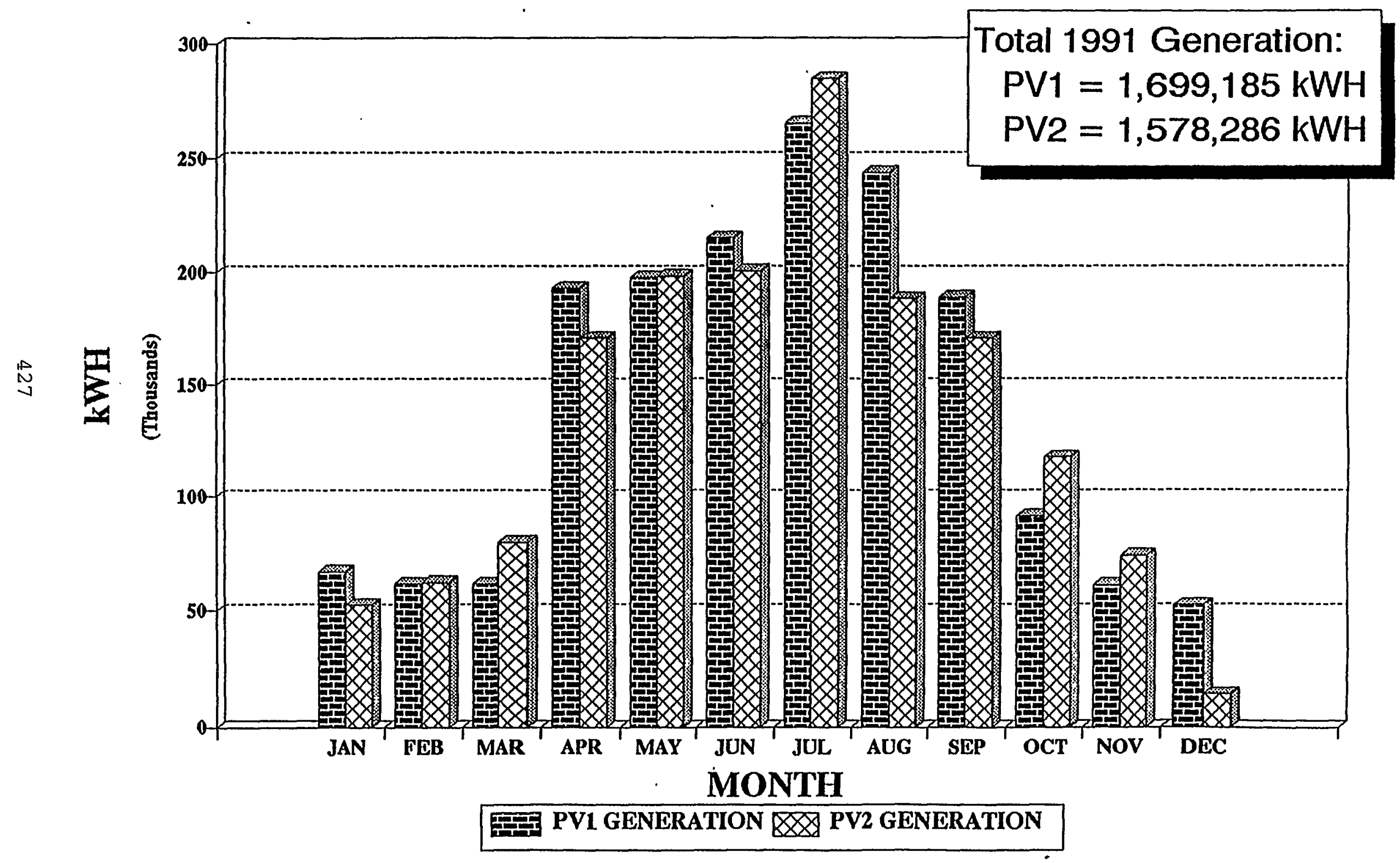




\section{SMUD'S ELECTRIC VEHICLE SOLAR CHARGING STATION}

On August 5, 1992, the Sacramento Municipal Utility District (SMUD) unveiled the first Solar Powered Electric Vehicle Charging Station in the western United States. By utilizing advanced photovoltaic (PV) panels, energy from the sun will now be used to provide power for up to sixteen non-polluting electric vehicles. This bold step further underscores SMUD's commitment to cleaner air and renewable sources of energy production.

\section{General Information}

- The free standing structure, measuring 8 feet by 130 feet, provides 16 shaded parking spots specifically reserved for Electric Vehicles.

- Automated rotation of the array optimizes the sun angle, providing maximum power at all times - even on cloudy days.

- Peak output from the array is $12 \mathrm{~kW}$. Average daily energy production is $68.4 \mathrm{kWh}$ AC.

- The 1,000 square foot array provides enough energy to drive:

1 Compact Pickup 30 miles, AND

4 Compact Sedans 30 miles each, AND

10 Neighborhood EVs 25 miles each.

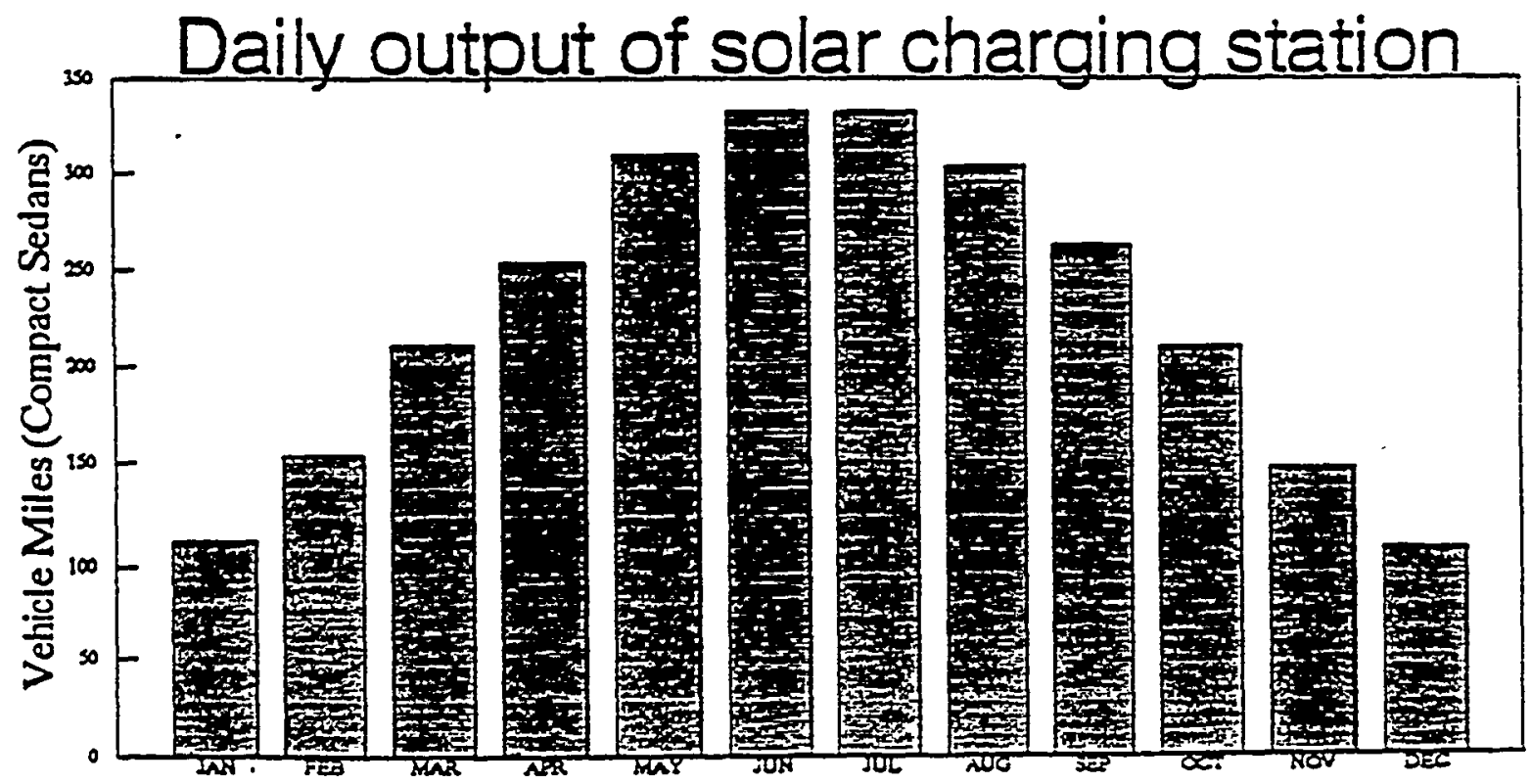

August 1992 


\section{SYNOPSIS OF SMUD'S 1993 PV PROGRAM}

SMUD is a leader in utility grid-connected applications of PVs with the world's largest operating PV power plant (SMUD PV1/PV2, 2 MW), the first PV electric vehicle recharge station in the West, residential grid-connected PV installations, and numerous remote power and sensor applications. In 1993, SMUD is installing $640 \mathrm{~kW}$ of grid-connected PV systems. These systems will include 1003 to $4 \mathrm{~kW}$ residential, roof-mounted PV systems; a $40 \mathrm{~kW}$ commercial building sited, concentrating PV system and a $200 \mathrm{~kW}$ substation sited, distribution support PV system.

\section{The 1993 Residential PV Pioneers Project}

\section{Siemens Solar Industries}

Partnership with our customers - PV Pioneers

$1004 \mathrm{~kW}$ residential PV systems

Demonstration project- grid-connected, residential-sited

distribution generation using photovoltaics

$\$ 7.07 /$ watt (1992 residential PV systems were over $\$ 12 \mathrm{~W}$ )

Fixed array mounted on residential sloped rooftops

400 square feet of roof area

installed by the contractor in 1993.

PV PIONEERS - "green pricing" - 15\% premium on existing rate for PV generated energy, held constant until the general rate reaches the same level at which point the PV rate will be kept the same as the general rate. Over 300 customers have volunteered to participate in this program.

\section{Commercial Sited Photovoltaic Project}

Solar Energy Applications Corp. (SEA)

One 40 kW Commercial Building Sited PV system

Innovative, concentrating PV system

Uniquely adaptable to roof-top applications

Substantial potential for significant cost reduction

On a SMUD owned building (Headquarters Building)

Demonstration project - grid-connected, commercial building sited, distributed generation using photovoltaics

$\$ 9.11$ /watt

Roof mounted, single axis tracking, concentrating PV system

4000 square feet of roof area

Installed by the contractor in 1993.

\section{Substation Photovoltaic Generation Project}

Utility Power Group (UPG)

One 200kW ground mount PV system at a SMUD substation site

Demonstrate the ability and versatility of placing medium size PV systems for District distributed generation benefits

$\$ 7.70 /$ watt compared to $\$ 8.90 /$ watt for the PG\&E 500kW Kermin PV plant completed in Spring 1993 Ground mount, single axis tracking system utilizing Siemens solar modules

Installed in 1993. 


\section{THE SMUD PV PIONEER PROGRAM}

At dawn this morning, the sun went to work for SMUD customers. A solar power plant near Rancho Seco generated enough electricity for hundreds of customers... rooftop solar water heaters lowered many residential electric bills... and scores of photovoltaic panels turned some Sacramento homes into mini power plants.

These are just some of the ways SMUD is putting the sun to work. In so doing. Sacramento's customer-owned electric utility is drawing on diverse energy sources that include hydroelectric and geothermal power. In the near future SMUD will add cogeneration, wind power and other renewable sources of energy. This clean and reliable energy mix will work in concert with SMUD's conservation programs to power Sacramento well into the 21 st century.

SMUD Solar Power Brochure, 1993

The Sacramento Municipal Utility District (SMUD) is the fifth largest public utility in the nation and serves a 900 square mile area in and near Sacramento County, California. Under the leadership of SiMUD General Manager S. David Freeman and its publicly elected Board of Directors, SMUD is committed to a 800 Megawatt (MW) "Conservation Power Plant" and 400 MW of renewable and advanced energy projects by the year 2000 . Solar energy will provide an important part of both the "Conservation Power Plant" and renewable resource technologies. Investments made in solar power today will provide the customer-owners of SMUD with enormous long-term energy and community benefits.

The 1993 SMUD PV Pioneer Project establishes a partnership with customers willing to assist in the early adoption of photovoltaic (PV) technology. This year SMUD will purchase, own, install and operate about 1003 to 4 kilowart (kW) residential rooftop PV systems. Customers participating in this project (the PV Pioneers) are volunteering to share in this effort through a form of "green pricing" and by providing the roof area to place the environmentally friendly, solar electric generation PV systems. In doing so, the PV Pioneers will have the satisfaction of generating clean, renewable energy on their own roottops! SMUD will gain experience in the installation, operation, maintenance, pricing strategies and other aspects of residential PV systems. This joint effort will help advance the development of the solar technology and accelerate the commercialization of PV through a process of sustained, orderly development. SMUD is also installing a $200 \mathrm{~kW}$ single-axis tracking PV system at the Hedge Substation for grid suppor and a $40 \mathrm{~kW}$ concentrating PV system on one of the SMUD buildings.

The use of solar energy has many benetirs to SMUD, the Sacramento community and the United States in general. Solar technology reduces the use of non-renewable resources. It is a renewable and sustainable energy source and helps improve air quality. Solar technology is environmentally benign.

It is up to local communities, states, the utilities and the public at-large to take the lead in demanding and providing the extensive use or solar energy. The following recent survey shows that the people of Sacramento are interested in helping to lead the way to a cleaner, sustainable future. The survey, taken this Spring, showed that $26 \%$ of the general population and $57 \%$ of the "green" population in Sacramento would be willing to pay a premium price $(15 \%)$ for PV generated electricity from their own rooftops. Further, $49 \%$ of the general population and $77 \%$ of the "green" population would be willing to pay the premium (15\%) for "rooftop PV" with rate stabilization of the PV portion. Finally, the support for general investment in a clean, renewable energy future was overwheiming with $70 \%$ of the general population and $88 \%$ of the "green" population willing to participate in a general "green pricing" utility effort to establish a "Clean Energy" program to add renewables, such as PVs, to the District's 
system (not necessarily on their own roof).

Due to SMUD's commitment to advancing the use of this clean, renewable energy source-for oniy a $15 \%$ premium, mere dollars a month, PV Pioneers can enjoy the satisfaction of generating their own clean, renewable PV power on their own rooftop. In addition, this premium will protect them from future rate increases until the general rate exceeds the special "PV Pioneer" rate.

Among the added benefits PV Pioneers will receive are:

Membership in the SMUD PV Pioneer
Club
The Solar Pioneer News
Updates on new SMUD Energy
Efficiency and Solar Programs
Priority processing and participation in
new SMUD Energy Efficiency programs

There are only a limited number of systems that will be installed each year and there are particular rooftop requirements. They include:

- Roof orientation: sloped, south to south west exposure

- Roofing material: Composition shingle in good condition

- Roof size: Approx 400 square feet of shade free area where the PV paneis will be installed

Solar energy is here today. Working together, SMUD and its customer-owners can put the sun to work for a better and cleaner Sacramento. The PV Pioneers are on the cutting edge of bringing environmentally benign, sustainable energy to Sacramento by demonstrating their commitment to a clean and safe environment. If you are interested in becoming a PV Pioneer call SMUD at 4552020.

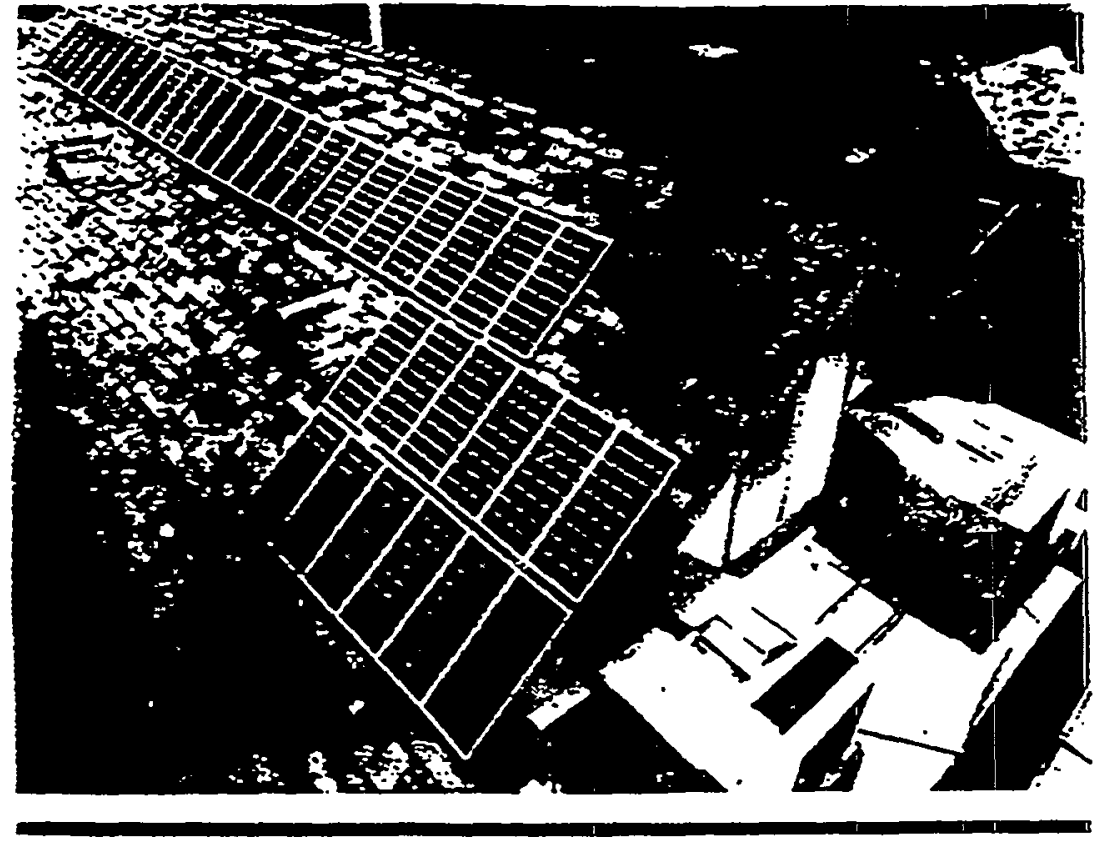

When the sea risas in Sacramento. alectriety begins flowten on the root of Joha hamry Canter's 80-yeat-old comvened finhouse. PV tarats colloct coough power to mast the arurge annual eseror deets of Caner's oftles.
THE SACRAMENTO UNION / MONDAY, JUNE 7, ;993.

\section{SHUD hamesses sn porier}

The Sacramento Municipal Utility District installed its first "roottop oower plant" on an 80-year-old converred firenouse at 41720 th SL. The installation, for building owner John Harvey Carter, is the first in a $\$ 4.9$ million SMUD pilot project designed to provide information on the cost and effecitveness of a SMUD investment in solar energy. SMUD is seeking another

i00 volunteers to test the roottop system. which is installed and

maintained by the utility, although volunteers pay a 15 percent premium for the clean. reniewable energy. The roottod power plant uses photovoltalc panels io absorb the sun's rays and create direct-current electricity, wnich is then converted to alternating current by means of an invertor. For more information on becoming a volunteer. call $455-2020$. 


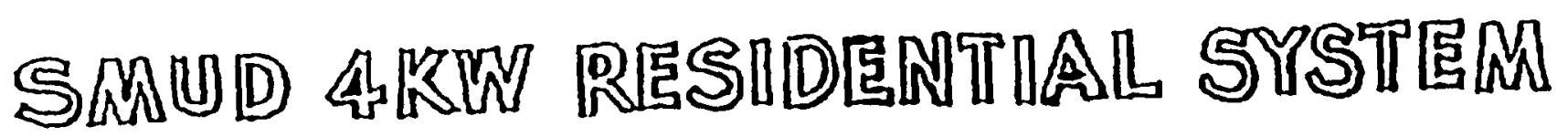

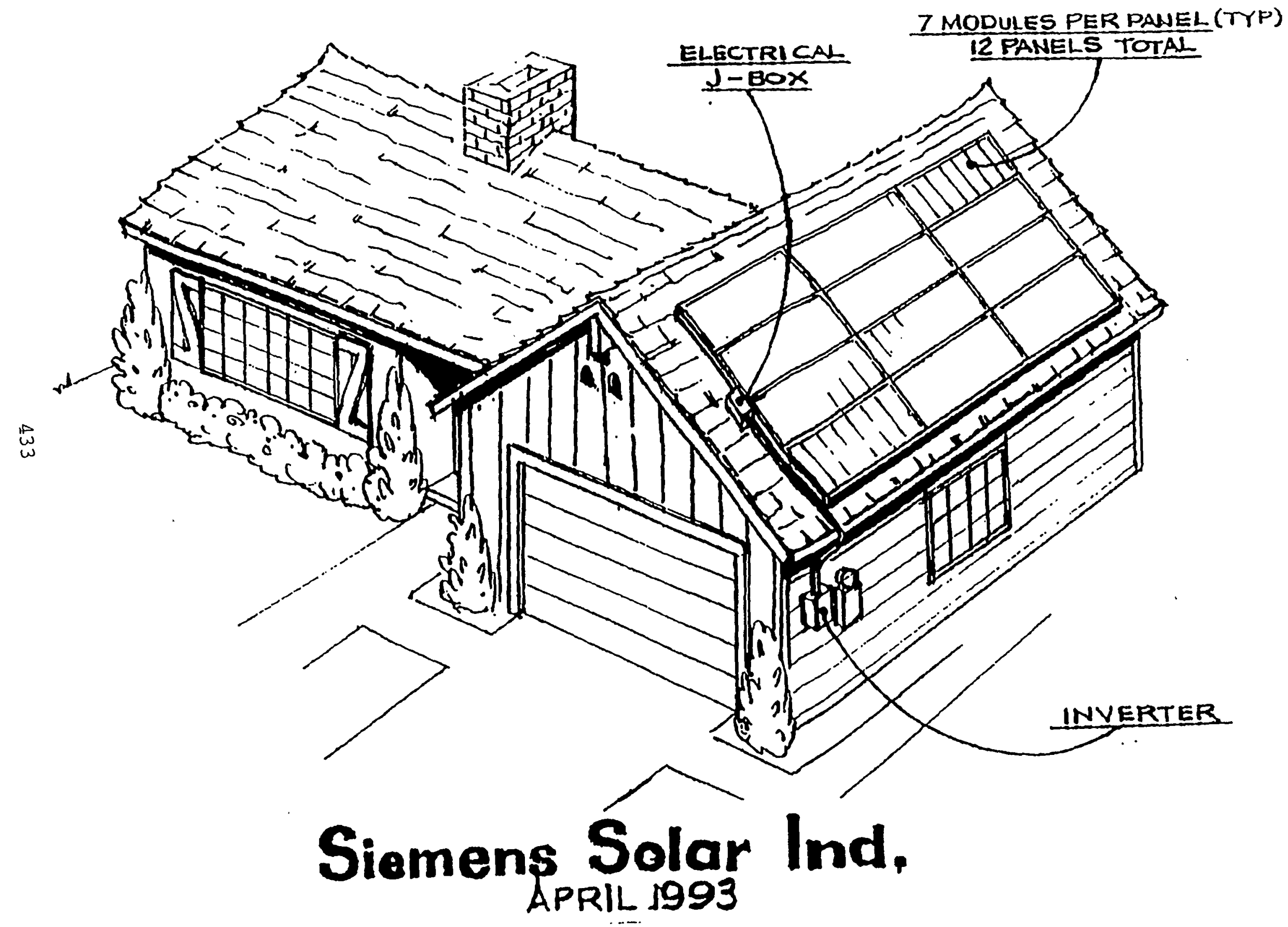




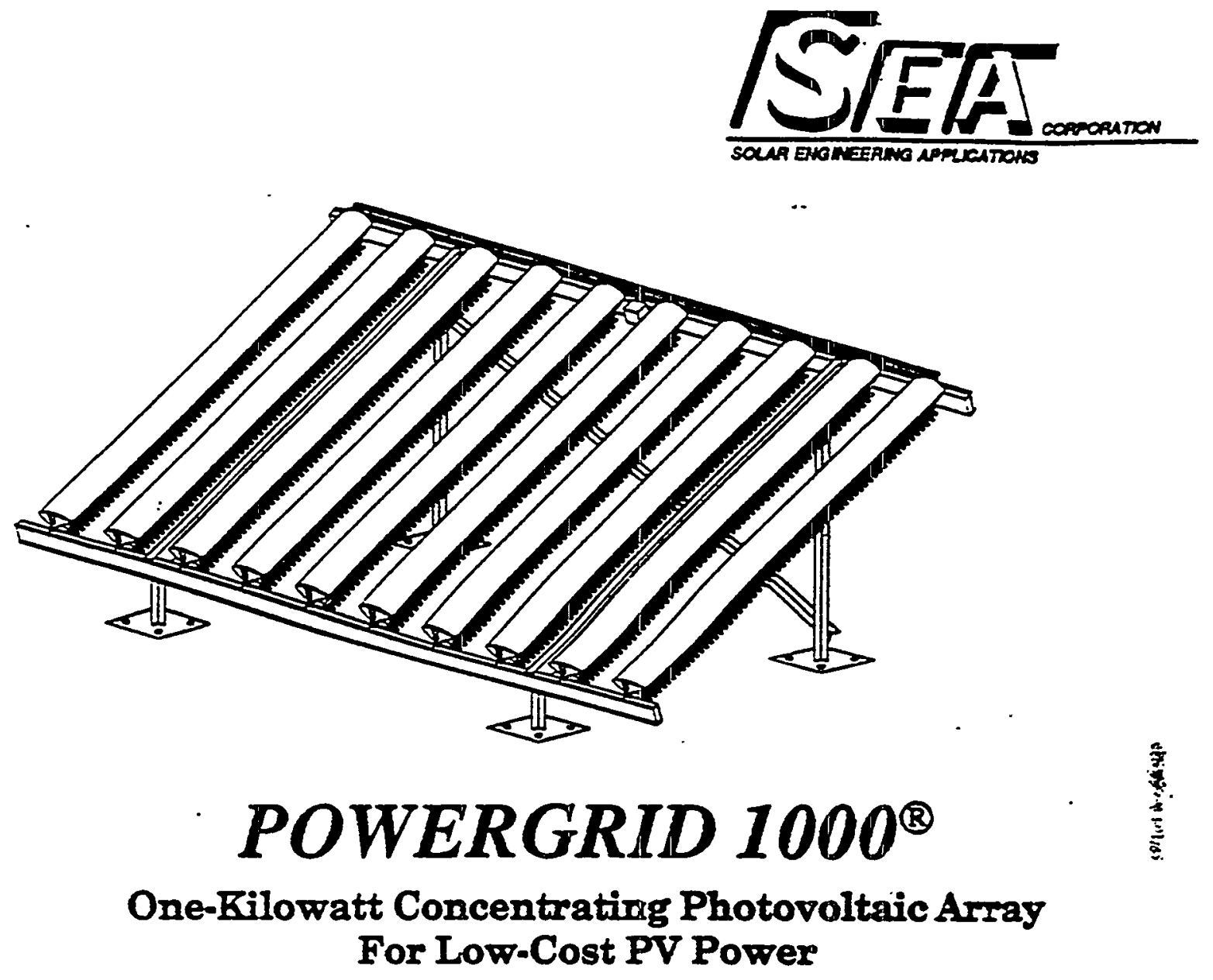

Until now, the widespread use of photovoltaic power (PV) bas been hampered by hith cost. Now SEA Corporation, working under DOE funding, has designed a mique PV concentrating system which, when manufactured at a production rate of $100 \mathrm{MW} / \mathrm{sr}$, cen supplo D.C. power for under \$1.00/Watt. At this price, the system will produce AC busbar power at less than 6e/BW-br.

The POWERGRID 10000 is a one-kilowatt array utilizing 10 concentrating modules supported on a fixed frame. The 100 Watt modules are linked to a single-axis tracking system which operates automatically and unattended, requiring no batteries or external power source. Single axis tracking allows the POWERGRID $1000^{\circ}$ to produce $30 \%$ more power than equivalent fixed flat-plate systems.

The light weight construction miakes the array suit. able for roof top or field installations. It can be mounted independently or linked in groups for any electrical application; from charging battery banks to addressing utility loads.
- Lowest cast per wott installed

- Wide acceptance cangle

- 30 year design life

- Roof or Earth mount installation

- Independent or linked applica. tions

- Simple, Reliable, Single-axis tracking

- $30 \%$ more power than equivalent non-tracking flat plate systems

- No additional support structure required

\footnotetext{
* This effort is supported in part by United States Deparment of BnergJ contracts 05-4299C and 40-8941C
} 


\section{THE POWHRGRID $1000^{\circ}$ IS DESTGNED FOR MANUFACTURABILITY AND LOW COST}

From its inception, the POWBRGRD $1000{ }^{\circ}$ was designed as a commercisl product using cost-effective, curren tly available components and high volume manufacturing processes.

The POWERGRD $10000^{\circ}$ modules use a minimum number of simple parts resulting in an inexpensive and reliable system. It was designed for high speed automated manufacturing. Cells are adhesive bonded to an anodized aluminum heat sink, formed from inexpensive sheet material. Integrated lens and module sides are formed by extrasion and then bonded to molded plastic endcaps with integral bearings. When the assembly is joined, it becomes a rigid, seifsupporting structural element (module). This is far simpler, and less expensive than any other photovoltaic system available today.

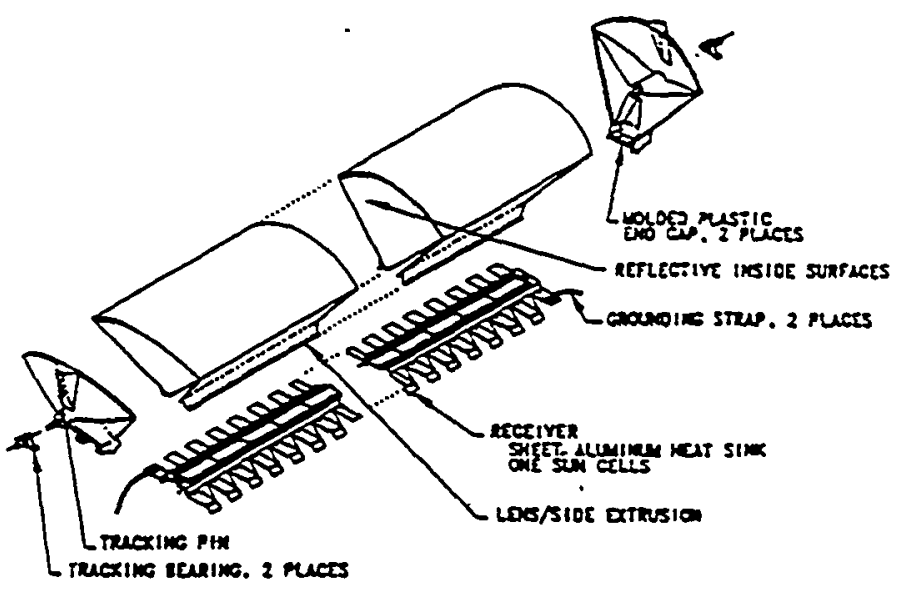

The combination of the 10-inch wide extruded acrylic Freanel lens and reflecting module sides creates primary and secondary elements of a unique optical system which has a wide acceptance angle. The wide acceptance angie allows more efficient operation in diffuse sunlight and larger tracking wis.dow. The SEA: lens can be produced for one-sourth the cost of competing technologies.

SEA's 10-gun photovoltaic cells were designed to be manufactured using one-sun technology. This allows the cost benefit of concentration (less cell area per Watt output) without the uvual high cost of concentrator cells.

\section{A WIDE VARIETY OF APPLICATIONS}

The POWERGRID $10000^{\circ}$ can be configured for many power requirements. Single arrays can delive output from 18 volts (ideal for charging 12 volt batteries) to 180 volts. Multiple arrays can be linized in series to working voltages as high as 650 voits.

SEA's engineering team has a reputation of technical excellence and many years of experience in the photovoltaic industry. We have the capability to configure a POWERGRID system for a wide variety of applications.

\begin{tabular}{|ll|}
\hline Current (Typical Q Load) & $53 \mathrm{Amps}$ \\
\hline Voltage (Typical O Load) & $18.9 \mathrm{VDC}$ \\
\hline Short Circuit Current & $59 \mathrm{Amps}$ \\
\hline Open Circuit Voltage & $24 \mathrm{VDC}$ \\
\hline Marimum Working Voltage & $650 \mathrm{VDC}$ \\
\hline
\end{tabular}

Measured at $1000 \mathrm{~W} / \mathrm{m}^{2}$ direct normalinsolation, $20^{\circ} \mathrm{C}$ ambient temperature, and $1 \mathrm{~m} / \mathrm{s}$ winc speed.
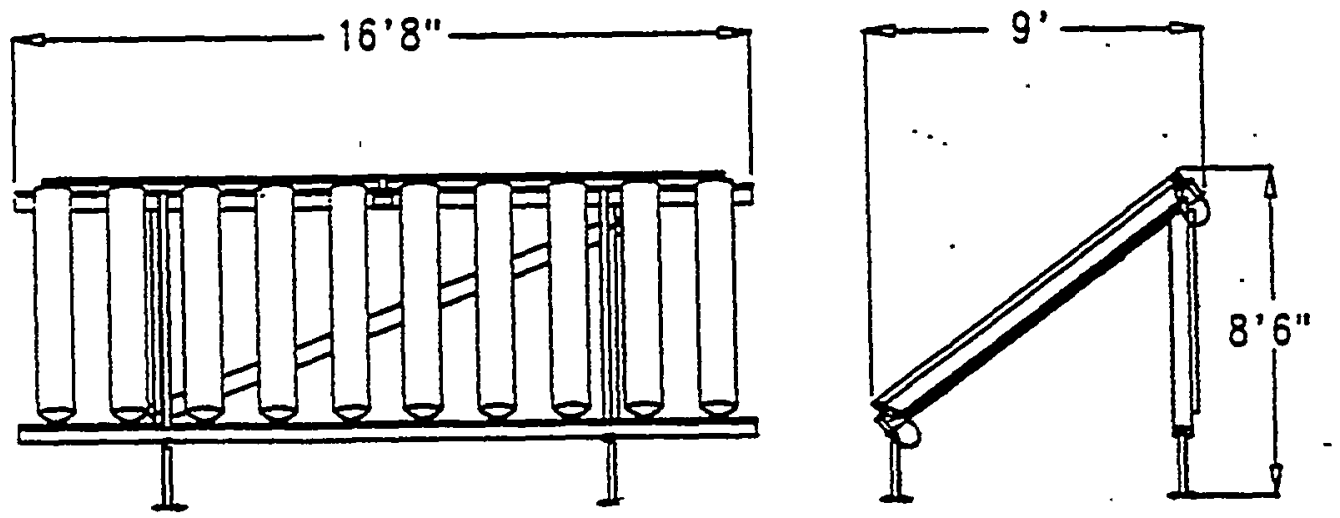


\title{
Building Integrated Photovoltaic Systems NEES's Gardner \& EPA's PV-DSM Projects
}

\author{
Edward C. Kern, Jr. \\ Ascension Technology, Inc.
}

NREL Photovoltaic Performance and Reliability Workshop

Golden, Colorado

September 8-10, 1993 


\section{Building Integrated PV Systems Experience from 1979 through 1993}

- John F. Long Properties - ARCO Solar "batten-seam"

- Hawaii Natural Energy Institute - ARCO Solar stand-off

- NE, SW \& SE Regional Experiment Stations

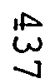

- Carlisle, "Impact 2000", "Solar One" homes

- New England Electric / Mobil Solar Gardner homes

- San Diego Gas \& Electric / ARCO Solar Laguna del Mar condos

- Massachusetts Energy Office Nantucket School Project

- Environmental Protection Agency PV DSM Demonstrations

- Sacramento Utility / Siemens Solar 100 home project 


\section{Performance and Reliability Gradual and catastrophic effects}

- Most PV modules have exceptional reliability

- Roof-mounting methods have proven durable

- Most static power converters have problems

- DC wiring and switchgear have minor problems

- Simple performance models yield reasonable agreement with measured system performance 
SEVEN YEARS OF EXPERIENCE WITH AUSTIN'S 300 KILOWATT SINGLE-CRYSTAL PHOTOVOLTAIC ARRAY

City of Austin Electric Utility Department 


\section{OVERVIEW}

- Plant Design

- Seven-Year Performance (1987-1993)

- Plant Power Rating

- Tracking Actuators

- Laminates (Modules)

- Conclusions 


\section{FACT SHEET}

- Start-up date: July 29, 1987

- Plant cost:

\$3 Million

- Operation:

Utility line tied

- Cells:

Siemens, single crystal silicon

- Tracking:

1-axis, passive

- Inverter:

Toshiba, self-commutated

- Rating in 1987: $283 \mathrm{~kW}$ at STC

- Array Field: 6160 Laminates

- Aperture area: $2620 \mathrm{~m}^{2}$ 


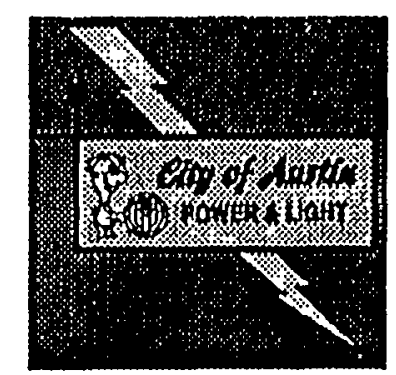

DC POWER vs. CELL TEMPERATURE

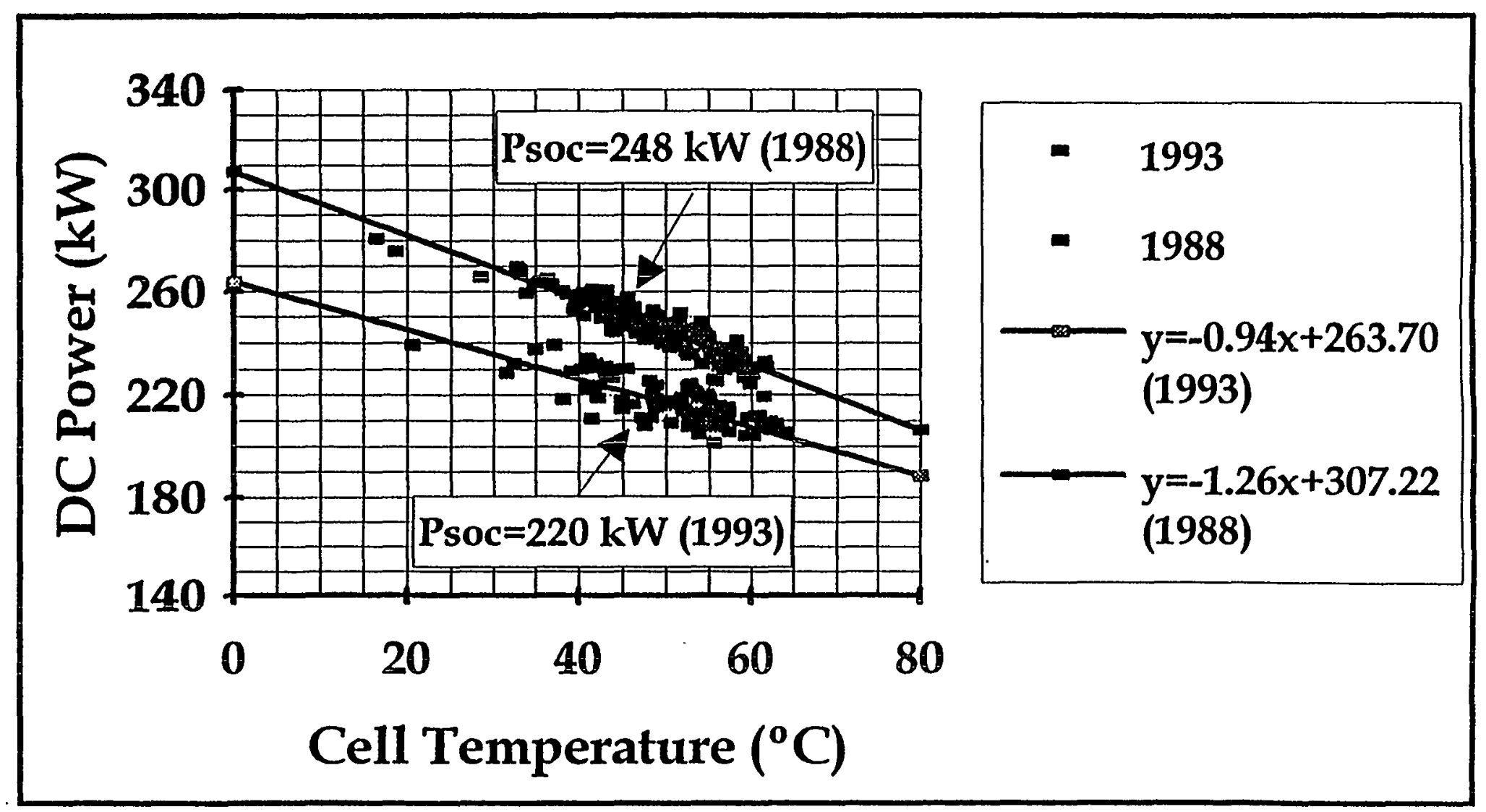


DC POWER RATING ON AN ANNUAL BASIS

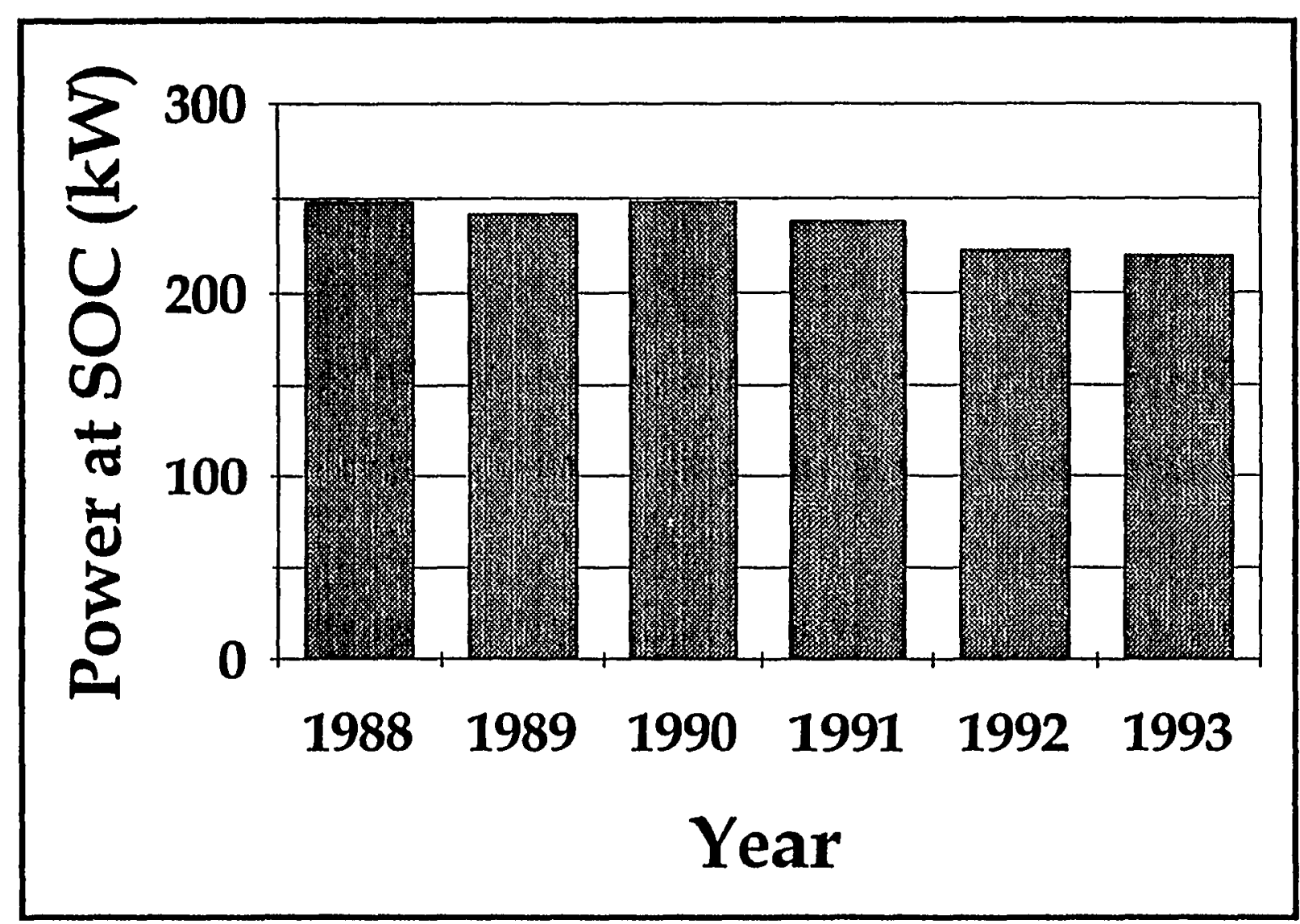




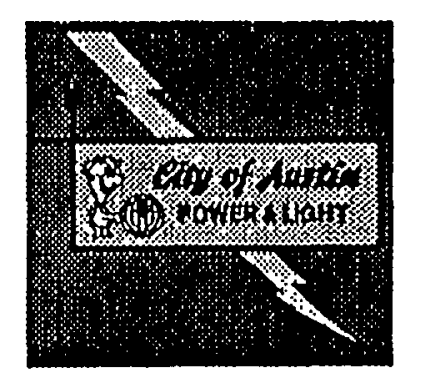

\section{VARIATION IN SOLAR RADIATION}

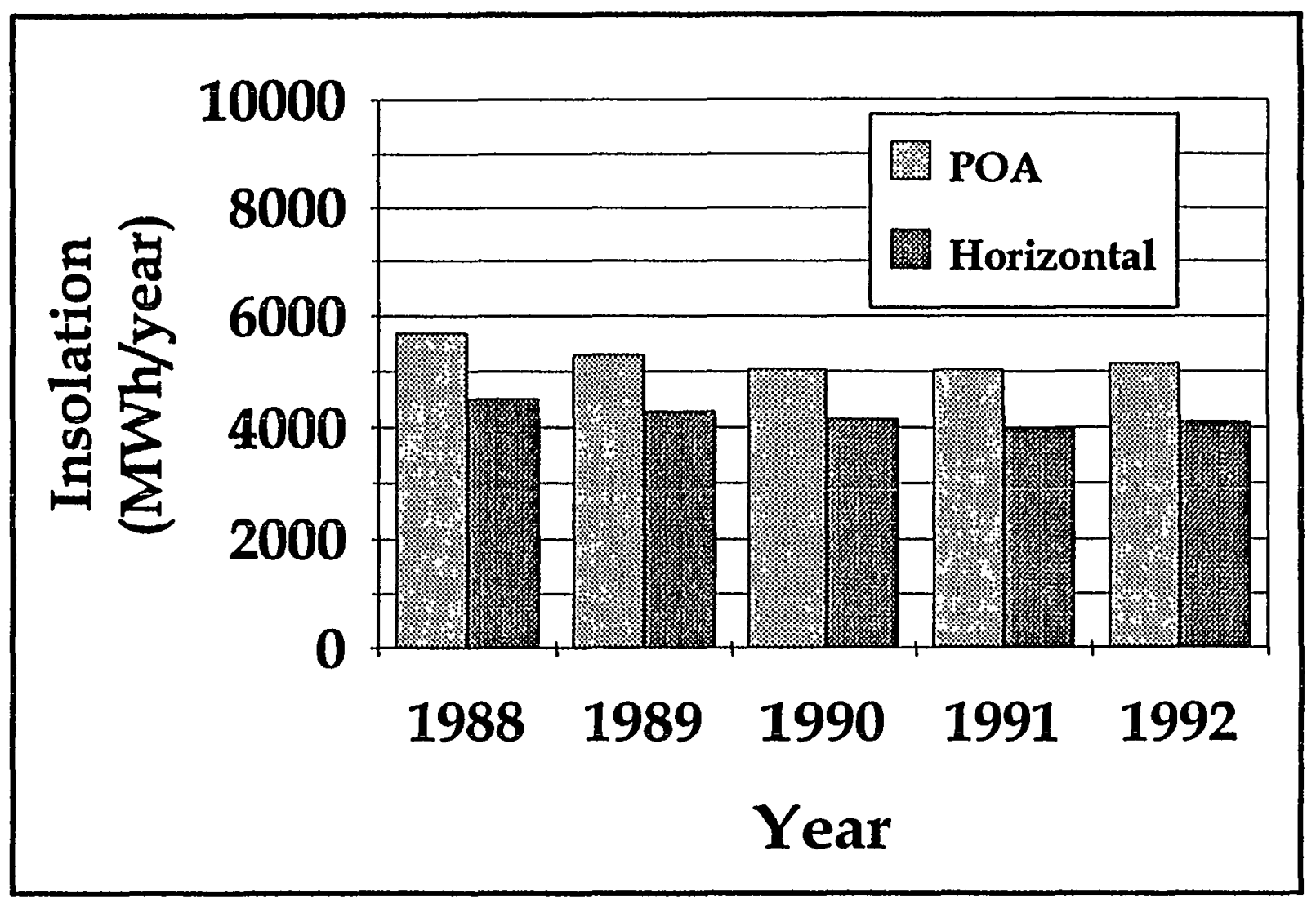




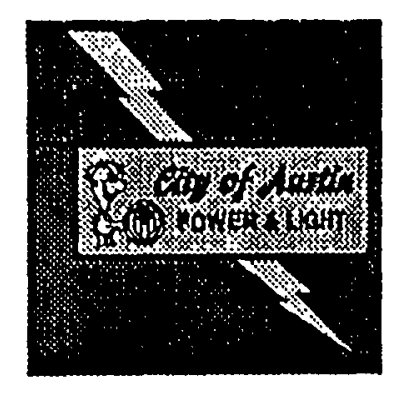

\section{VARIATION IN ANNUAL ENERGY PRODUCTION}

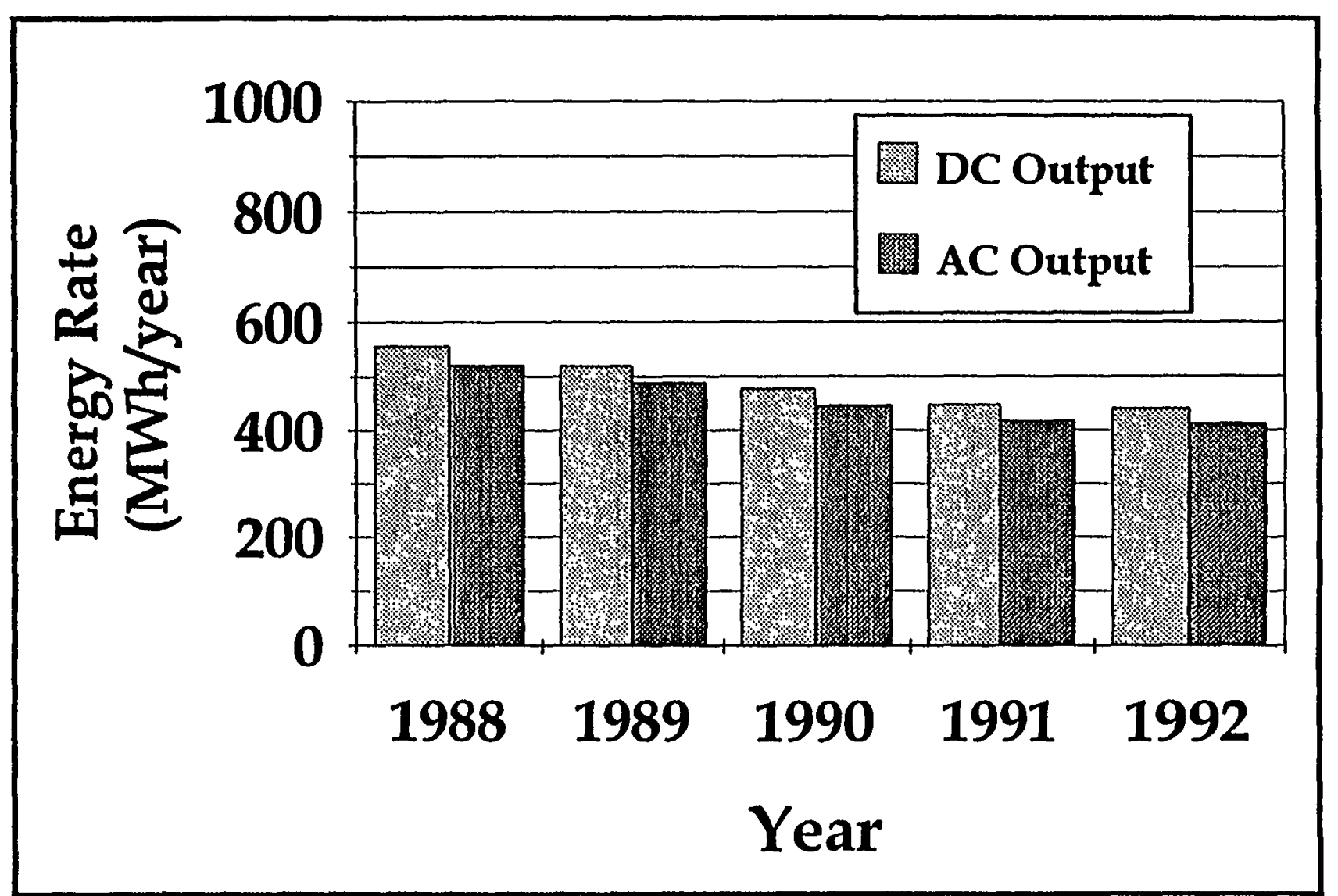




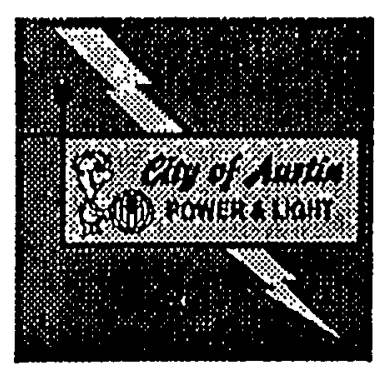

ANNUAL CAPACITY FACTORS

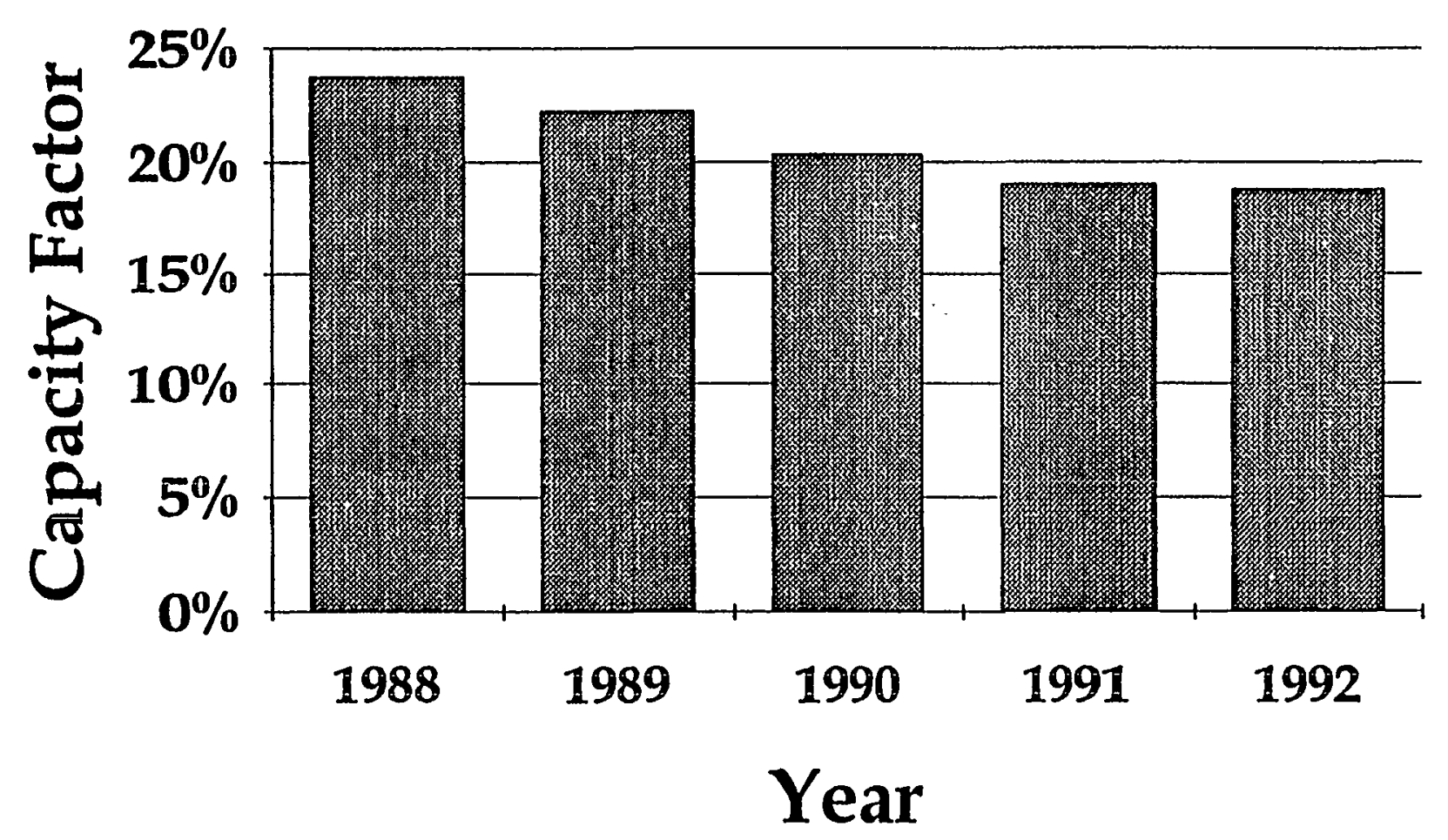




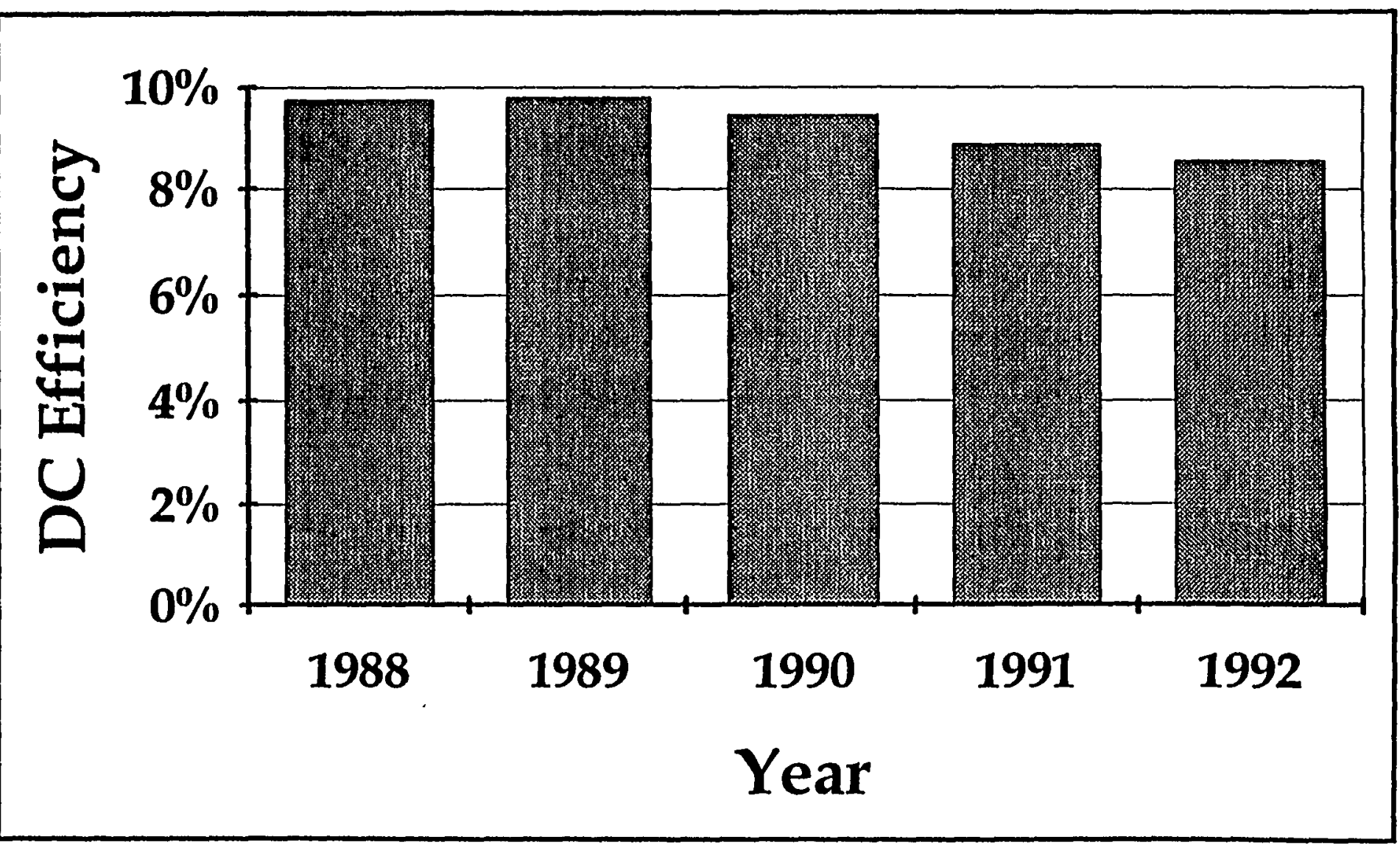


ACTUATOR FAILURES (Total field includes 42 tracking actuators)

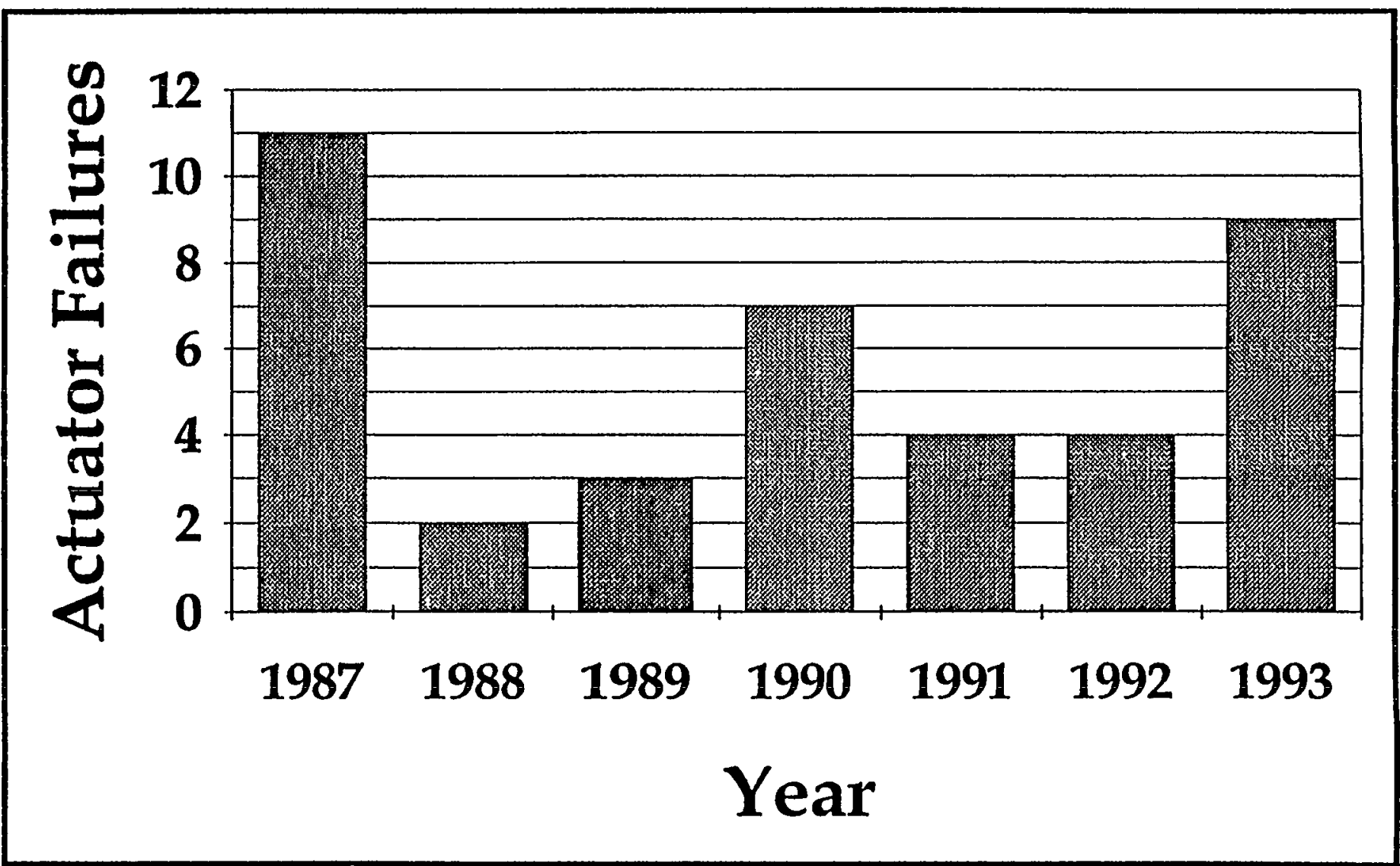




\section{LAMINATE FAILURES (Total array field $=6160$ laminates)}

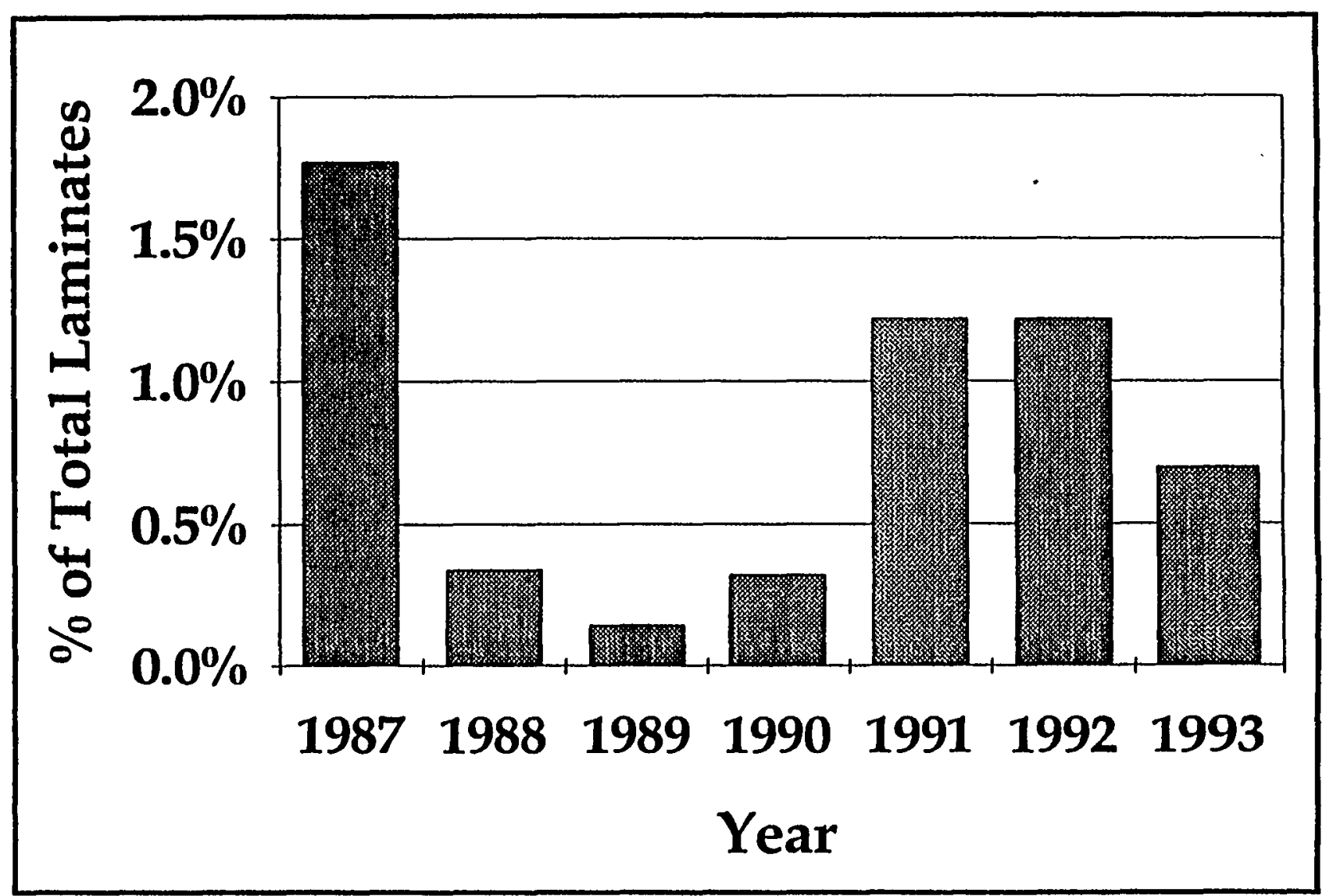



AVAILABILITY

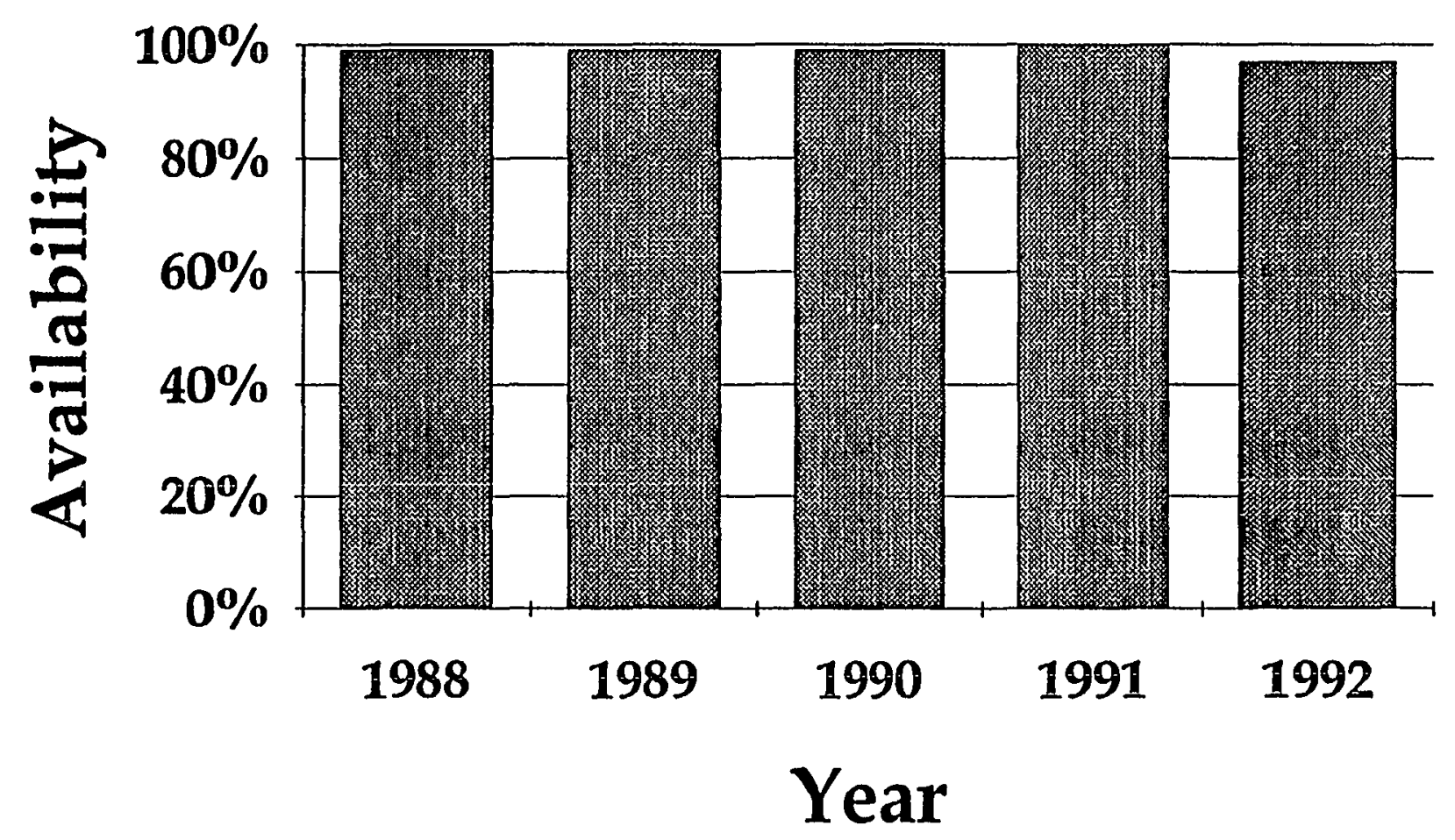




\section{CONCLUSIONS}

- Plant reliability has been high.

- Average annual availability was $99 \%$.

- Average annual capacity factor was $\mathbf{2 1 \%}$.

- Inverter reliability has been high with only two component failures in seven years.

- Leaks in tracking actuator seals tend to occur at a rate of 6 per year. 


\section{CONCLUSIONS cont'd}

- Data indicate that the full power rating has declined since start-up.

- Factors that are believed to contribute to the power loss are:

- corrosion and shearing of laminate ribbons;

- tracking actuator failures;

- delamination;

- reduction in EVA transmissivity. 


\title{
The Performance of PV Systems
}

\author{
Marjorie L. Whipple
}

PV Reliability Workshop

Sept.840, 1993

Sandia National Laboratories

For the Department of Energy

\section{Will Present Several Pieces Of the Reliability Puzzle}

Background

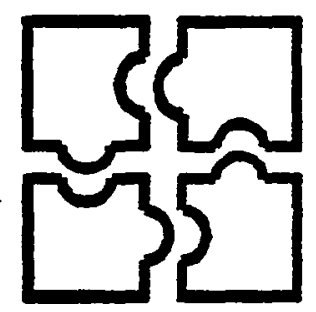

- Changes in Systems Performance Over Time

- Charge Controller and Battery Issues

What Needs to be Done Next?

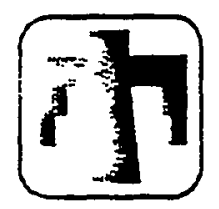




\section{Pre Block V \\ Non-producing Modules 10,143}

Failed (88.6\%)

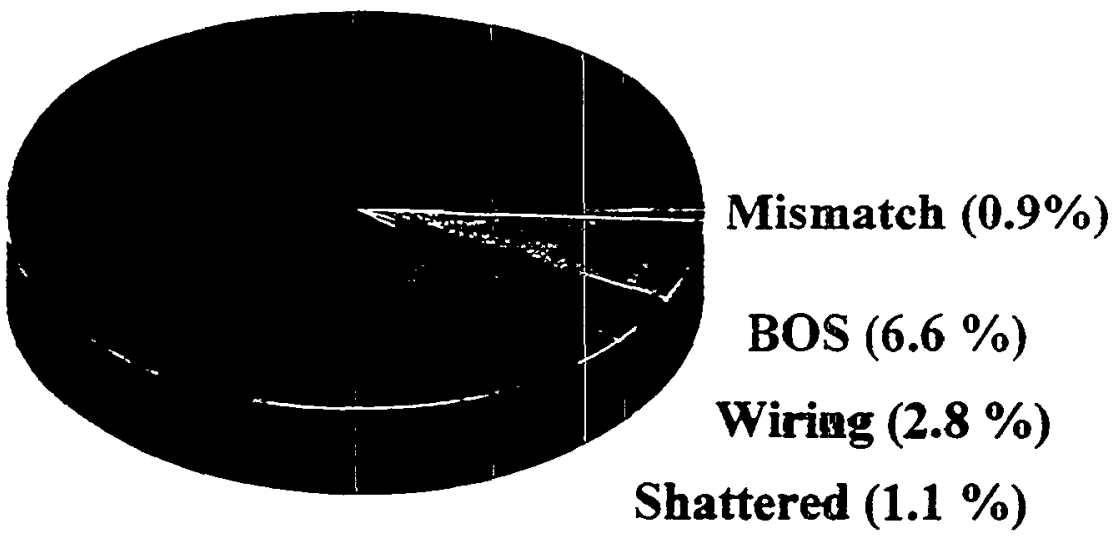

\section{Total number of modules tested: $\mathbf{1 9 , 9 5 6}$}

Southwes Technotogy Devedopen instive

\section{Block V \\ Non-producing Modules 4,463}

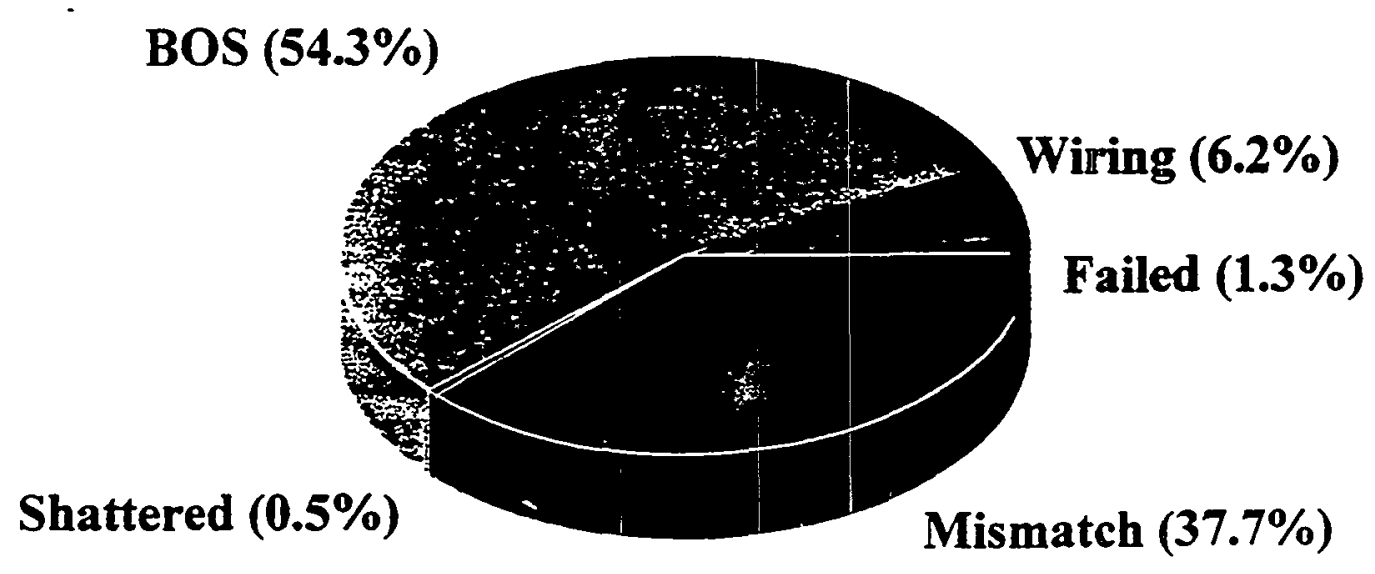

Total number of modules tested: $\mathbf{6 8 , 7 3 9}$ 

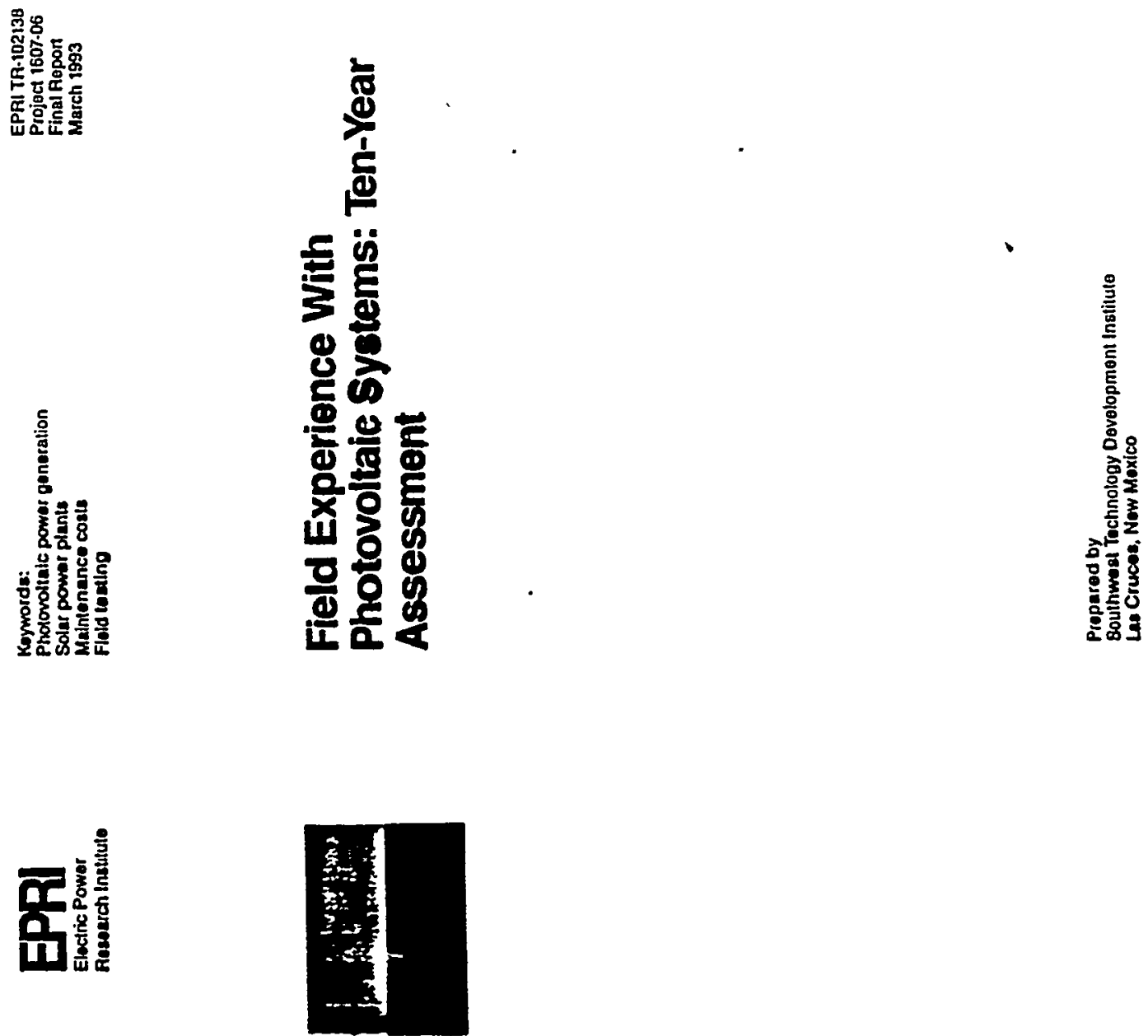

\section{Module Performance Has Been Documented \\ (by Rosenthal, Thomas and Durand)}

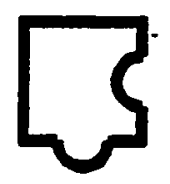

Modules

Systems
Pre-Block V

45\% Failure Rate

$5 \%$ of Modules Not Producing Due To BOS, Wiring,

\& Mismatch
Post-Block V

$<0.1 \%$ Failure Rate

$6 \%$ of Modules Not Producing Due To BOS, Wiring,

\& Mismatch

Module Failures Are Less Significant Than Other Systems Reliability Issues

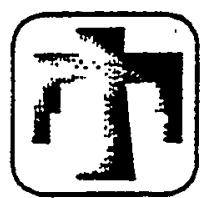




\section{Ten-Year Systems Performance Data}

Are Also Documented

- More Than 10 Different Systems Studied

Mostly Crystalline Silicon Modules

Geographic Locations Across the U.S. \& Puerto Rico

$\rightarrow \quad 1-3 \%$ Per Year DC Power Performance Degradation is the Trend

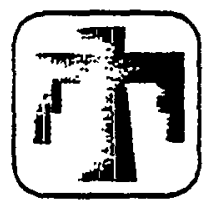

\section{We Formulated a Hypothesis About This} Change in Systems Performance ¿

\section{HYPOTHESIS}

\section{Performance degradation is due to}

optical absorption and reflection by the encapsulant, solder bond failures, and

changing Balance of Systems components. 


\section{Lab \& Industry Staff Examined Over}

Ln

\section{Modules From 8 Sites}

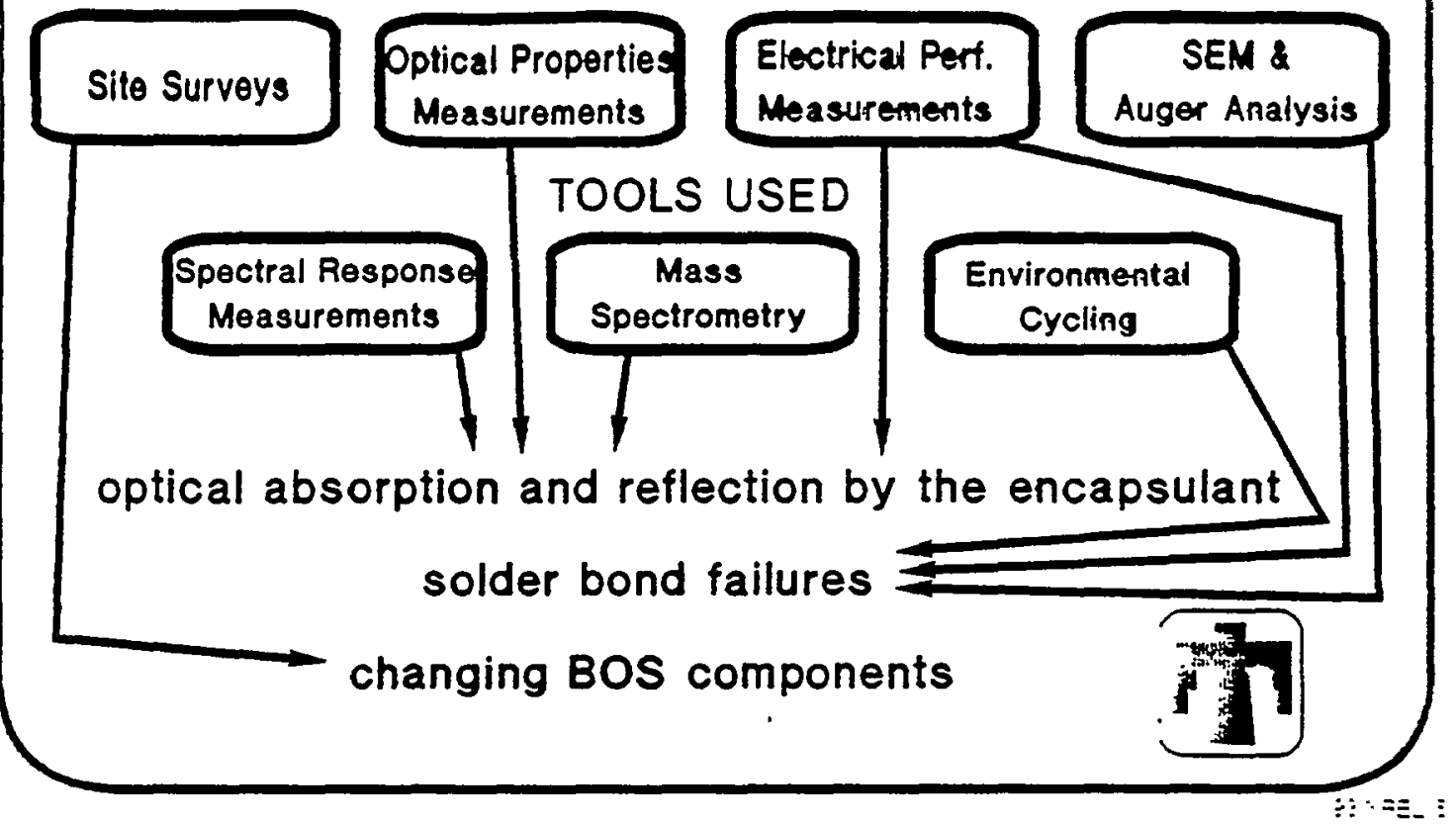

\section{We Have Drawn 3 Conclusions}

From These Data

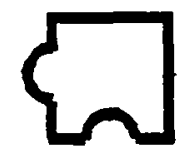

- Approximately $1 / 2$ of the Degradation is Due to "EVA Browning"

- Mismatch \& BOS Issues are Equally Significant

- "Delamination" \& Module Solder Bond Failures are Secondary Factors

Improved BOS Reliability Is Needed

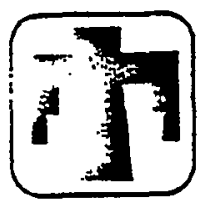




\section{BOS Component Reliabillity Issues Are Numerous}

Power Conditioner Problems

Failures of Contactors, Wiring Connectors, Switches, Bypass Diodes, and Fuses

Charge Controller and Battery Design, Selection, and Operation

\section{Battery \& Charge Controller Reliability}

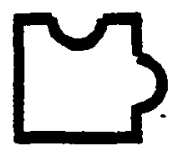

\section{Is One Critical Issue}

\section{BATTERIES}

Based on a Survey of PV Systems \& integrators ...

- Approximately $50 \%$ of New Batteries are not Conditioned Properly, Allowing Degradation to Begin

Less than $50 \%$ of Batteries are Operating at the Recommended Temperature $\left(77^{\circ} \mathrm{F}\right)$

$\rightarrow$ Lack of Information About Batteries in PV Application Results in Reliability Problems

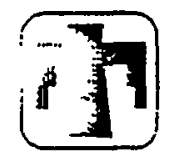




\section{CHARGE CONTROLLERS}

$80 \%$ of Systems Employ ON/OFF Regulation (Not Generally Understood, No Standardized Set Points)

Many Systems Operate With Excessive ( $>C / 25)$ Charge Rates $(\mathrm{C} / 20-\mathrm{C} / 15$ is recommended).

- Information Exchange Between Manufacturers \& Systems Designers Reduces These Problems

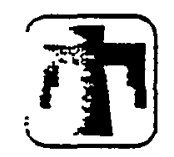

\section{What Needs to be Done Next?}

DOE's PV Program is Supporting...

Solutions to Module Degradation Through NREL Staff \& PVMaT Contractors

Reduced Costs and Increased Reliability of BOS Components Through Sandia Systems Activities

Other Suggestions...

- New "Tests" to Help Identify BOS Reliability Issues Prior to Fielding Hardware

- Your Ideas Welcome!

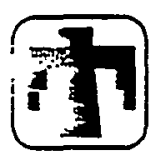




\section{PV Systems Performance and Reliability Issues are Connected}

- Module Failure Rates are Low ( $<0.1 \%$ Per Year)

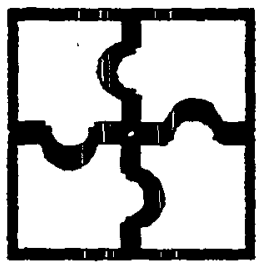

- Systems Degradation is a Serious Issue ( $1-3 \%$ Per Year)

- BOS Component Reliability Needs More Work (BOS Issues are of Greater Magnitude than Module Issues)

- Please Provide Your Input on "Next Steps" 


\section{STANDARDS AND CODES}




\section{Report on 1993 PV \\ Standards \& Codes Forum}

Carl R. Osterwald

National Renewable Energy Laboratory A NPE 


\section{Purpose:}

- To provide information and status of current photovoltaic standards and codes development activities in the U.S.

- To provide a forum where all U.S. PV standards organizations meet together for discussions and work 


\section{Outline}

- Standards \& Codes Forum

- ASTM E44.09 subcommittee meeting

- IEEE SCC21 meeting

- IEC TC82 US TAG meeting

- Working groups

- Major topics 


\section{Standards \& Codes Forum (1/2 day)}

- Introductory, organizational, and status of committees presented by representatives of:

- IEEE SCC21

- ASTM E44.09

- Proposed changes to National Electric Code for non-utility PV systems

- IEC TC82 US TAG

- Open panel discussion 


\section{ASTM E44.09 meeting (1/2 day)}

- Ballot results:

- New draft standard for module solar weathering passed subcommittee ballot

- New draft standard for module salt water endurance passed subcommittee ballot

- Revision of module insulation integrity and ground-path continuity testing amended and sent for reballot 


\section{ASTM E44.09 (cont.)}

- Status of interlaboratory comparison discussed

- Module wet insulation integrity draft standard discussed and revised

- Working group formed to develop draft standard for multijunction device performance testing 


\section{IEEE SCC21 meeting (1/2 day)}

- Approved two new Project Authorization Requests

- Infield Test Methods and Procedures for Grid-Connected Photovoltaic Systems

- Guidelines for Terrestrial PV Power System Safety 


\section{IEC TC82 US TAG meeting (1/2 day)}

- Results of May 1993 meeting of TC82 in Ischia, Italy presented and discussed 


\section{Working groups of SCC21 (1 day)}

- PAR 1262 Recommended Practice for Qualification of Photovoltaic (PV) Modules

- Battery and charge controller group

- New PAR - Guidelines for Terrestrial PV Power System Safety 


\section{Major topics}

- How can the National Electric Code be changed to be more accommodating to non-utility PV systems?

- Is wet insulation breakdown (hi-pot) testing needed for module qualification?

- Should wet insulation resistance and hi-pot testing be performed with full immersion of the module?

- Concensus-yes 


\title{
INTERNATIONAL PV PERFORMANCE STANDARDS
}

\author{
INTERNATIONAL ELECTROTECHNICAL COMMISSION \\ TECHNICAL COMMITTEE 82 \\ SOLAR PHOTOVOLTAIC ENERGY SYSTEMS
}

\author{
BY \\ Robert Klein \\ SEIA, NREL and DOE
}

\begin{abstract}
Whether we address PV performance standards or standards of any other technology, society is impelled to acknowledge the global impact that international standards have upon the world marketplace today. International standards are the key that helps create a thriving world economy. Today the world stands on the threshold of a major breakthrough. Once closed doors are now opening and can become a lucrative market to United States industry. However, it is important that we build a well-managed standards program that can strengthen the United States position in this new global economy. To achieve our goal we must financially support the process, build an industry government working relationship and make certain that any produced standards meet the users needs.
\end{abstract}

\section{CLOSED DOORS NOW OPEN}

- Build a well managed international standards program.

- Financially support the program.

- Build and promote an industry government working relationship.

- Produce standards that meet user needs worldwide.

- Financially assist and permit United States experts to participate in the international standards writing process.

Within the European Community (EC) efforts are underway to link the computer systems of a number of the EC governments into an overall program, termed the European Nervous System (ENS). This system is one part of the EC move toward an open market.

A world standards day has been announced for October 14 each year. The 1993 theme will be Information Management - Faster and Better with Global Standards. The International Electrotechnical Commission (IEC) and the International Organization for Standards (ISO) are encouraging their member organizations such as the American National Standards Institute (ANSI) to celebrate World Standards Day. The event will recognize thousands of volunteers, world wide, who help to advance international standardization.

In view of the EC movement towards a more open world market, IEC Technical Committee 82, Photovoltaic Energy Systems, is striving to produce PV standards that meet the user needs world wide. In the United States we have built an international PV standards program. However, we are yet lacking 
adequate financial support and are yet in need of a stronger total PV industry-government working relationship. A strong internal bond is necessary for any nation in this new global economy.

\section{Working Group 1, Glossary}

In 1993, IEC/TC82 reactivated working group 1, Glossary, Terms and Symbols that pertain to PV technology. At present the group is compiling previously approved TC82 terms and symbols so that they can be printed as a TC82 Glossary Publication.

\section{Joint Battery Working Group (JWG)}

Experts from Working Group 4, Storage Systems, have been participating in a Joint Working Group of TC21, Accumulators and TC82. This group is presently in the process of writing a standard that will address a Test Procedure to Determine Suitability for a Battery to be Cycled in a Photovoltaic System. This standard will describe a test method to determine the number of discharge/recharge cycles that a secondary battery can provide in a simulated PV regime.

\section{Working Group 3, Systems}

Working Group 3, Systems, should commence work on drafts that address a "Reference Solar Day", "Efficiency of Power Conditioners", " PV Array I-V Characteristics - Transiation Procedures", and " OnSite I-V Characteristics Measurement Procedures for PV Arrays". A draft document entitled "Characteristics of Utility Interface" has been circulated for voting as a Draft International Standard (DIS). The bulk of the input to this standard was supplied by the United States. This standard addresses the interface requirements between the PV system and the utility. These requirements include power quality, flicker, harmonics and power factor. Working Group 3 continues to work towards producing a draft on "Safety Guidelines for Grid-connected PV Systems Mounted on Buildings".

\section{Working Group 2, Modules}

Subsequent to the 1992 Tokyo meeting of TC82, Working Group 2, Modules, prepared a draft on "Requirements for Reference Solar Modules" that has been circulated for voting as a DIS. This standard gives requirements for the selection, packaging, calibration, marking and care of reference solar modules. It is intended to be a supplement to the printed IEC Publication 904-2, "Requirements for Reference Solar Cells":

Working Group 2 is preparing a "Design Qualification and Type Approval of Terrestrial Thin-film Photovoltaic Modules" draft. This standard is a parallel standard to the recently published IEC Publication 1215, "Design Qualification and Type Approval of Crystalline Silicon Terrestrial Photovoltaic (PV) Modules". The thin-film document will give the IEC requirements for the design qualification and type approval of terrestrial thin-film PV modules suitable for long term operation in moderate open-air climates, as defined in IEC Publication 721-2-1. The thin-film document will present a qualification test sequence that contains such tests as visual inspection, wet leakage, light soaking, UV, annealing, thermal cycling, humidity freeze, twist, etc. 


\section{WORKING GROUP 1 \\ GLOSSARY}

- Reactivated in 1993.

- In process of compiling previously approved TC82 terms and symbols for printing as a separate publication.

- Will assist all other TC82 working groups in defining terms applicable to all future TC82 publications.

\section{JOINT (BATTERY) WORKING GROUP}

(JWG)

IEC/TC21, Accumulators

IEC/TC82, Solar Photovoltaic Energy Systems

- Comprised of experts from both technical committees.

- Preparing a test procedure to determine suitability for a battery to be cycled in a photovoltaic system.

\section{WORKING GROUP 3 \\ SYSTEMS}

- "Characteristics of Utility Interface" Draft International Standard (DIS) Out for vote.

- In the process of preparing a draft document on:

"Safety guidelines for grid-connected PV systems mounted on buildings"

\section{WORKING GROUP 2 MODULES}

- "Requirements for reference solar modules" Ready for circulation as a Draft International Standard (DIS) for voting.

- In the process of preparing a draft document on:

"Design Qualification and type approval of terrestrial thin-film photovoltaic modules" 


\section{IEC/TC82 DOCUMENTS PRINTED}

\section{SINCE MAY, 1992}

- IEC Publication 1215,

Design qualification and type approval of crystalline silicon terrestrial photovoltaic (PV) modules.

- IEC Publication 1194, Characteristic parameters of stand-alone photovoltaic (PV) systems.

- IEC Publication 1173, Guide -overvoltage protection for photovoltaic (PV) power generating systems.

- IEC Publication 891 - An amendment to take into account thin-film devices. Document 891 gives procedures that should be followed for temperature and irradiance corrections to measured I-V characteristics of crystalline silicon photovoltaic devices.

All published IEC standards are available from:

American National Standards Institute

11 West 42nd Street

13th Floor

New York, NY 10036

Telephone \#

$212+642-4900$

Fax \#:

$212+398-0023$

\section{ACKNOWLEDGMENTS}

On behalf of the Solar Energy Industries Assaciation (SEIA), I thank DOE and NREL for their support in the international photovoltaic standards program.

Further, I wish to thank each company and each individual expert for their invested time and participation at various TC82 and its working group meetings. 


\section{CLOSED DOORS NOW OPEN}

- Build a well managed international standards program.

- Financially support the program.

- Build and promote an industry government working relationship.

- Produce standards that meet user needs worldwide.

- Financially assist and permit United States experts to participate in the international. standards writing process. 


\section{WORKING GROUP 1 GLOSSARY}

- Reactivated in 1993.

- In process of compiling previously approved TC82 terms and symbols for printing as a separate publication.

- Will assist all other TC82 working groups in defining terms applicable to all future TC82 publications. 


\section{JOINT (BATTERY) WORKING GROUP(JWG)}

IEC/TC21, Accumulators

IEC/TC82, Solar Photovoltaic Energy Systems

- Comprised of experts from both technical committees.

- Preparing a test procedure to determine suitability for a battery to be cycled in a photovoltaic system. 


\section{WORKING GROUP 3 SYSTEMS}

- "Characteristics of Utility Interface" Draft International Standard (DIS) Out for vote.

- In the process of preparing a draft document on:

"Safety guidelines for grid-connected PV systems mounted on buildings" 


\section{WORKING GROUP 2 MODULES}

- "Requirements for reference solar modules"

Ready for circulation as a Draft

International Standard (DIS) for voting.

- In the process of preparing a draft document on: "Design Qualification and type approval of terrestrial thin-film photovoltaic modules" 


\section{IEC/TC82 DOCUMENTS PRINTED SINCE MAY, 1992}

- IEC Publication 1215,

Design qualification and type approval of crystalline silicon terrestrial photovoltaic (PV) modules.

- IEC Publication 1194,

Characteristic parameters of stand-alone photovoltaic (PV) systems.

- IEC Publication 1173,

Guide -overvoltage protection for photovoltaic (PV) power generating systems.

- IEC Publication 891 - An amendment to : take into account thin-film devices. Document 891 gives procedures that should be followed for temperature and irradiance corrections to measured I-V characteristics of crystalline silicon photovoltaic devices. 


\title{
PUBLICATION AVAILABILITY
}

\section{All published IEC standards are available from:}

\author{
American National Standards Institute \\ 11 West 42nd Street \\ 13th Floor \\ New York, NY 10036
}

Telephone \#: $\quad 212+642-4900$

Fax \#: $\quad$ 212+398-0023

Photovoltaic Performance and Reliability Workshop 


\section{ACKNOWLEDGMENTS}

On behalf of the Solar Energy Industries Association (SEIA), I thank DOE and NREL for their support in the international photovoltaic standards program.

Further, I wish to thank each company and each individual expert for their invested time and participation at various $\mathrm{TC} 82$ and its working group meetings. 


\title{
Photovoltaic arid the \\ National Electric Code
}

Presented by:
David Meakin
Solar Energy Industries Association

\author{
At the \\ National Renewable Energy Laboratory \\ Photovoltaic \\ Performance and Reliability \\ Workshop \\ September 8-10, 1993 \\ Golden, Colorado
}


Introduction:

The Solar Energy Industries Association (SEIA) has been working closely with the Nationa 1 Renewable Energy Laboratory (NREL) to address a variety of standards and codes issues. I would like to talk today about these efforts with respect to the National Electric Code (NEC).

Under a contract form NREL, SEIA has been to exploring ways to increase the Photovoltaic Industries participation in the code making process, in specific the NEC. I will explain in detail what SEIA is doing to realize this goal in a moment. First I would like to give a brief history of the NEC to put our efforts into context.

\section{Historical Overview}

The first edition of the National Electric Code (NEC) was published in 1897 as a result of the efforts of various electrical, architectura 7 , insurance, and allied interests. Under the banner of the National Conference on Standard Electrical Rules, delegates from a variety of national associations drafted and published the first edition of the code. In 1911 the National Fire Protection Association (NFPA) took over the sponsorship of the NEC when the National Conference on Standard Electrical Rules was disbanded. Then in 1920 the NEC came under the auspices of the American National Standards Institute (ANSI), which at the time was known as the United States of America Standards Institute and subsequently became the American Standards Institute. While ANSI took over responsibility for the NEC, the NFPA continued in the role of Administrative Sponsor and has been publishing the Code in pamphlet form since 1951 as we 11 as including it in the National Fire Codes.

The process of amending and publishing the NEC takes three years and is the responsibility of the National Electric Code Committee. This committee consists of 20 individual Code Making Panels (CMP's) coordinated under a central Correlating Committee. The membership of the Code Making Panels cone from many different disciplines such as electrical manufacturing, safety testing, electrical inspection and engineering design. The broad base representation is necessary to since it is the responsibility of each CMP to review, comment on, and accept or reject proposed amendments. It is also necessary since each pane? may be responsible for as few as three or as many as 15 code articles. For example, CMP-3 is responsible for Article 690 which addresses Photovoltaic systems as well as Articles 300 and 305 which are consider wiring methods and temporary wiring.

The actions of the individual panels are coordinated by the correlating Committee. This committee is a 7 so responsible for publishing the comments and actions taken by each CMP for public comment. It is from this committee that the final version of the amended code is issued for final acceptance and publication.

\section{The NEC}

The NEC its self is intended to address issues concerning the safe installation and operation of nearly a 11 electrical power systems. However, there are exceptions. Excluded form coverage by the NEC are, for instance, Utilityowned and operated power generating and distributing installations, automobiles, railway cars, and maritime vehicles i.e. ships, boats, etc. Ignoring for the moment the exception, it can be readily assumed that almost all devices that require connection to an external power supply are covered under one or more 
articles of the NEC including Photovoltaic systems.

Until recently photovoltaic systems had not been explicitly mentioned in the NEC. Never the less, it was generally assumed by Electrical Inspectors, who are responsible for enforcing the code, Electrical contractors, and Electricians that the NEC had jurisdiction over photovoltaic power systems. It was not until 1984 with help from the Department of Energy that Article 690, which explicitly covers PV power systems, was incorporated into the NEC. Since then the article has been revised twice, once in 1987 and again in 1990.

However, due to rapid advancements in PV technology, it has become necessary to revise Article 690 again. Unlike previous changes which have been relatively minor it has become obvious that a comprehensive review of the code must be conducted in order to bring. the code up to date with current PV technology and applications.

SELA's involvement with the NEC.

The realization of the need for a compressive review of the code was made apparent during the 1993 code cycle which began in November of 1990. In January of 1991 CMP-3 considered a proposal to amend Article 690 that would have allowed for exception to requirements stated in Articles 220 and $230-42^{1}$. This amendment wou $7 d$ have added a new section to Article 690 that would have exempted stand-alone PV systems in residential dwellings from the service entrance requirements imposed on $A C$ power distribution systems. This proposal, identified by the NFPA as proposal 33$137(\mathrm{log} \# 1408)^{2}$ was not rejected because of unsound engineering practices or because it was considered unsafe. It was rejected because it was considered outside the scope of Article 690.

As a result SEIA's representative to $C M P-3^{3}$ drafted a letter to the Chairman of the NEC Correlating Committee explaining his dissenting opinion. He also asked that the Correlating Committee consider convening a Technical SubCommittee to review the scope of Article 690 .

In response to this request, based on recommendations from the Correlating Committee, the Chairmen CMP-3 offered the PV Industry the opportunity to convene a panel of experts that would constitute the core of a Technical Review Committee (TRC) with the intent of reviewing Article 690 .

As mentioned before, the process of amending the code is a cycle that begins once every three years. Therefor, to take full advantage of the opportunity SEIA began soliciting the PV Industry to nominate participants for the TRC. As a result we have approximately 20 representatives from the PV industry that have committed to the project. Including representatives form PV panel manufactures, Inverter manufacturers, Design houses, and the National Laboratories. He also hope to involve the Safety Testing and Electrical Inspector community. It is SEIA's opinion, as well as that of others, that the most diversified possible representation on the TRC will be beneficial to the entire review process.

The TRC is will meet for the first time on October 22, 1993 to begin the three years process at the end of which the committee will submitted its final recommendations to the NFPA for the 1999 code cycle. Keeping in mind that the 1999 code cycle begins in November of 1996, at best the results of the review will not become effective for another six years.

During the three review several objectives will be addressed. To begin, a cover to cover assessment of the current code with respect to Article 690 wijl need to be conducted. The committee will seek to identify Articles of the code 
that need improvement in guidance with respect to PV, Articles that give conflicting directions to those stated in Article 690, and those that need to reference or be referenced by Article 690. Based on this review the committee will be able to recommend some of the necessary changes needed.

The committee must also decide, at the outset, what other issues it will address. This is necessary since these issues will have an effect on the entire review process. Some of the more prominent issues are rewriting the scope of Article 690, Categorization of PV systems, Ground methods, and the 600 volt Timit.

Without a doubt the most prominent issue that will be addressed by the TRC is the scope of Article 690. It is obvious from the events that brought this review about that the current scope of Article 690 must be addressed. What remains to be seen is how.

Another possible candidate for consideration is the concept, put forward by several members of the PV Industry, of categorizing PV systems with respect to size. Unlike conventional AC systems, PV systems can be configured for a wide range of operating voltages and power ratings. In order to avoid undue technical and economic burdens on sma 11 systems, it has been proposed that different categories or classes of PV system be defined. There could then be specific requirements within the NEC that would be applicable to each class of system.

For example, it would make economic as well as design sense to differentiate between a 200 watt stand-alone water pumping system, a 2,000 watt residential power system, and a 6 Magawatt grid-connected power system.

Another argument for such a classification comes into play when large power generating systems are considered. A large grid tied power systems owned by electric utilities are subject to regulation by the National Electric Safety Code (NESC), an IEEE ma inta ined document, not the NEC. However, as it currently stands an identical system operated by a non-utility cooperation or private company is subject to the NEC requirements which can differ from the NESC. It does not make economic or technical sense to have identical systems regulated by different codes. By creating a classification with in the NEC for such systems it would be possible to either resolve the differences between the codes or exempt such systems form the doma in of the NEC.

The issue of grounding has been an ongoing debate for some time. The impetus for using non grounded systems comes form the Europeans where ungrounded systems are common. However there are safety issues that are also driving the debate. To resolve the safety and technical issues the committee will need to work closely with other standards bodies such as IEEE SCC-21 to develop a technical bas is for any recommendations made.

As a final example, the 600 volt limit. Currently the NEC treats systems over 600 volts, in some cases, very differently from systems under this limit. The question then arises, is this necessary for a 17 PV systens over 600 volts and if not under what circumstances should exceptions be made?

These examples do not conctitute a comprehensive list rather they are a starting point from which the $\mathrm{TC}$ can proceed. The issues eventually addressed by the TRC can only be determined by the committee its self. And the ir decisions will, in large part, be based on input form the PV Industry. This is why it is incumbent to the PV Industry to involve its self in the process as much as possible.

Conclusion: 
Because of the length of time required to effect changes in the code it is imperative that the PV Industry actively participate in the codes process so as not to miss opportunities to effect codes to its benefit.

It is through opportunities such as the offer from CMP-3 to review the NEC that SEIA will continue to assist the PV Industry in becoming more involved in the standards and codes process.

It is important that PV manufacturers and System Designers be aware of the requirements of the NEC. Without this awareness products wi11 be developed that will not be acceptable for application in many of the markets that are now developing for the PV Industry.

\section{Acknow ledgrents:}

I would like to thank everyone who has made the realization of this Technical Review possible. Though I can not mention everyone I would like to give special thanks to Laxmi Mrig at NREL for his advice and guidance and to John Wiles at Southwest Technology Development Institute for his unselfish willingness to share his technical knowledge and expertise of the National Electric Code.

1. Article 220 defines branch circuit feeder calculations and Article 230-42 considers services in particular residential service requirements.

2. Proposal was submitted by John Wiles, Southwest Technology Development Institute, Las Cruces, NM 88003.

3. Robert Nicholson, Solar Cells, Inc., 2650 Raymond Road, Toledo, Ohio 43615 
PV Performance \& Reliability Workshop

September 8 - 10, 1993

Attendee List

FINAL LISTING

1. A.M. (Al) Al-Ibrahim

Graduate Student

Solar Lab; Eng. Res. Bldg.

1500 Johnson Drive

Madison, WI 53706-1687

(608) 263-4027

2. Robert S. Allan

Florida Power \& Light Company

P.O. Box 14000 - PDL

Juno Beach, FL 33408-0420

3. James Amick

Mobil Solar Energy Corporation

76 Ledbrook Lane

Princeton, NJ 08540

(609) 924-5207

4. Gobind Atmaram

Florida Solar Energy Center

300 State Road 401

Cape Canaveral, FL 32920

(407) $783-0300$

5. Moneer Azzam

Mobil Solar

4 Suburban Park Drive

Billerica, MA 01821

(508) 667-5900

6. Thomas Basso

National Renewable Energy Lab

1617 Cole Blvd.

Golden, CO 80401

(303) 231-7035

7. Elvira Beck

National Renewable Energy Lab

1617 Cole Blvd.

Golden, CO 80401

(303) 231-1774
8. William Brooks

North Carolina Solar Center

Box 7401, NCSU

Raleigh, NC 27695-7401

(919) $515-3480$

9. Joe Burdick

NREL

1617 Cole Blyd.

Golden, CO 80401

(303) 231-1765

10. Yehoshua Caiyem

NREL

1617 Cole Blyd.

Golden, CO 80401

11. Theodore Cannon

NREL

1617 Cole Blvd.

Golden, CO 80401

(303) 231-7247

12. Anthony Catalano

NREL

1617 Cole Blvd.

Golden, CO 80401

(303) 231-7846

13. Michael Cholod

ATO Haas

P.O. Box 219

Bristol, PA 19007

(215) $785-8070$

14. David Collier

SMUD

P.O. Box 5830

Sacramento, CA 95852 
PV Performance \& Reliability Workshop

15. George Coonley

Atlas Electric Devises Co.

4114 N. Ravenswood Ave.

Chicago, II 60613

(312) $327-5420$

16. Ced Currin

Currin Corporation

P.O. Box 1191

Midland, MI 48641-1191

(517) 835-7387

17. Al W. Czandema

NREL

1617 Cole Blvd.

Golden, CO 80401

(303) 231-1240

18. Doug Dahle

National Renewable Energy Laboratory 1617 Cole Blyd.

Golden, CO 80401

(303) 231-6016

19. Richard DeBlasio

National Renewable Energy Laboratory 1617 Cole Blyd. Golden, CO 80401

(303) 231-1286

20. Pat Dippo

National Renewable Energy Laboratory

1617 Cole Blvd.

Golden, CO 80401

(303) 231-1310

21. Steve Durand

Southwest Technology Development

P.O. Box 30001

Department 3SOLAR

Las Cruces, NM 88003

(505) 646-1049
22. Pete Eckert

Arizona Public Service

P.O. Box 53999

Phoenix, AZ 85072-3999

(601) $360-3170$

23. Glenn Eiden

Suntracker

302 U.S. Highway 30, East

New Haven, IN 46774

(219) $749-4297$

24. Keith Emery

NREI

1617 Cole Blvd.

Golden, CO 80401

(303) 231-1032

25. Bethanne Felder

Texas Instruments

P.O. Box 655012 MS35

Dallas, TX 75265

(214) $995-7032$

26. Halden Field

NREL

1617 Cole Blvd.

Golden, CO 80401

(303) 231-1485

27. Kim Francis

Southern California Edison

P.O. Box 800

2244 Walnut Grove Avenue

Rosemead, CA 91770

(818) 302-2488

28. Troy Glatfelter

United Solar Systems Corp.

1100 W. Maple Road

Troy, MI 48084

(313) $362-4170$ 
PV Performance \& Reliability Workshop

September 8 - 10, 1993

Attendee List

29. Stephen H. Glick

NREL

1617 Cole Blyd.

Golden, CO 80401

(303) $231-3350$

30. Ronald Gonsiorawski

Mobil Solar Energy Corporation

4 Suburban Park Drive

Billerica, MA 01821

(508) $667-5900$

31. Jerry Gruninger

TRW

One Space Park, R4/2166

Redondo Beach, CA 90278

(310) $813-2443$

32. Jeff Hahn

DOE

1617 Cole Blvd.

Golden, CO 80401

33. Milfred Hammerbacher

Texas Instruments, Inc.

6947 Sperry

Dallas, TX 75214

(214) 995-6956

34. Robert Hammond

Arizona State University

Box 875806

College of Engineering/Science

Tempe, AZ 85287-5806

(602) $965-0377$

35. Robert J. Hassett

U.S. Department of Energy

Office of Solar Heat Technologies

1000 Independence Ave. SW

Washington, DC 20585

Phone: $202 / 586-8163$
36. Sheila Hayter

NREL

1617 Cole Blvd.

Golden, CO 80401

(303) $275-6036$

37. Ed Henderson

Mobil Solar Energy Corp.

4 Suburban Park Drive

Billerica, MA 01821

(508) $667-5900$

38. Steve Hester

2497 Morello Heights Cr.

Martinez, CA 94553

(510) $372-5716$

39. John Hoffner

City of Austin Electric Dept.

721 Barton Springs Road

Austin, TX 78704

40. Stephen T. Hogan

Spire Corp.

1 Patriots Park

Bedford, MA 01730

(617) $275-6000$

41. William Holley

Springborn Laboratories, Inc.

One Springbom Center

Enfield, CT 06082

(203) $749-8371$

42. Roland Hulstrom

NREL

1617 Cole Blvd.

Golden, CO 80401

(303) $231-1220$ 
PV Performance \& Reliability Workshop

September 8 - 10, 1993

Attendee List

43. Thomas Hund

Sandia National Laboratories

P.O. Box 5800, Dept. 6213

Albuquerque, NM 87185

(505) 844-8627

44. Christina Jennings

Pacific Gas and Electric

3400 Crow Canyon Road

San Ramon, CA 94583

(510) $866-5305$

45. Terry Jester

Siemens Solar

4650 Adohr Lane

P.O. Box 6032

Camarillo, CA

(805) 445-6500

46. Steve Jones

San Diego Gas \& Electric

P.O. Box 1831

San Diego, CA 92112

(619) $696-4247$

47. Edward Kern

Ascension Technology

P.O. Box 314

Lincoln Center, MA 01773

48. Robert Klein

SEIA

1242 Dartmouth Street

SEIA STDS Office

Scranton, PA 18504

(717) 346-1364

49. Ben Kroposki

NREL

1617 Cole Blvd.

Golden, CO 80401

(303) 231-1210
50. David Kulik

SunWize Energy Systems

P.O. Box 191

Ellenville, NY 12428

(914) 647-6718

51. Cary Lane

Neos Corporation

165 S. Union Blvd., Suite 260

Lakewood, CO 80228

(303) 980-1969

52. Patrick Lasswell

AstroPower

Solar Park

Newark, DE 19716-2000

(302) $366-0400$

53. Cecile Leboeuf

NREL

1617 Cole Blvd.

Golden, CO 80401

(303) 231-1066

54. James Lovelady

Spectrolab

12500 Gladstone Ave.

Sylmar, CA 91342

55. Gregg Mackell

Western Area Power Administration

P.O. Box 3402

Golden, CO 80401

(303) 231-7045

56. Trish Maxson

Ato Haas

P.O. Box 219

Bristol, PA 19007

(215) 785-8851 
PV Performance \& Reliability Workshop

September 8 - 10, 1993

Attendee List

57. Warren McNaughton

Comice Engineering, Inc.

P.O. Box 2542

Durango, CO 81302

(303) 247-9548

58. Peter McNutt

NREL

1617 Cole Blvd.

Golden, CO 80401

(303) 231-1847

59. David Meakin

SEIA

1242 Dartmouth Street

Scranton, PA 18504

60. Ronald Micheels

Mobil Solar Energy Corp.

4 Suburban Park Dr.

Billerica, MA 01821

(508) 667-5900

61. Alex Mikonowicz

Siemens Solar

4650 Adohr Lane

P.O. Box 6032

Camarillo, CA

Phone: (805) 445-2815

62. Mohan Misra

Martin Marietta

P.O. Box 599, B3085

Denver, CO 80123

(303) $971-9390$

63. Richard L. Mitchell

NREL

1617 Cole Blvd.

Golden, CO 80401

(303) 231-1379
64. Laxmi Mrig

NREL

1617 Cole Blvd.

Golden, CO 80401

(303) 231-7178

65. Daryl R. Myers

NREL

1617 Cole Blvd.

Golden, CO 80401

(303) 231-1490

66. James Negley

Davis, Joseph \& Negley

3905 Laguana Vista Cove

Austin, TX 78746

(512) $328-6790$

67. Art Nelson

NREL

1617 Cole Blvd.

Golden, CO 80401

(303) 231-7128

68. Cynthia Nickerson

Mobil Solar Energy Corp.

4 Suburban Park Drive

Billerica, MA 01821

(518) 667-5900

69. David Niles

NREL

1617 Cole Blvd.

Golden, CO 80401

(303) 231-1424

70. Carl Osterwald

NREL

1617 Cole Blvd.

Golden, CO 80401

(303) 231-7130 
PV Performance \& Reliability Workshop

September $8-10,1993$

Attendee List

71. Robert Oswald

Solarex Corporation

Thin Film Division

826 Newton-Yardley Road

Newton, PA 18940

(215) 860-0902

72. Lawrence J. Pace

Southem California Edison

P.O. Box 800

2244 Walmut Grove Ave.

Rosemead, CA 91770

(818) $300-2955$

73. John Pem

NREL

1617 Cole Blvd.

Golden, CO 80401

(303) 231-7635

74. Jim Pruett

NREL

1617 Cole Blvd.

Golden, CO 80401

(303) 231-1064

75. William Putman

Heraeus DSET Laboratories, Inc.

45601 N. 47th Ave.

Phoenix, AZ 85027

(602) 465-7356

76. James Rannels

U.S. Department of Energy

Forrestal Bldg., CE-131

1000 Independence Ave., S.W.

Washington, DC 20585

77. Vem Risser

Daystar, Inc.

3240 Majestic Ridge

Las Cruces, NM 88011

(505) 522-4943
78. Richard Roberts

Naval Air Weapons Station

Code 8303

China Lake, CA 93555

(619) 639-6561

79. Marc Roper

Renewable Energy Coordinator

Colorado OEC

1675 Broadway, Suite 1300

Denver, CO $80202-4613$

(303) $620-4292$

80. Andrew Rosenthal

Southwest Technology Development

P.O. Box 30001

Department 3SOLAR

Las Cruces, NM 88003

(505) 646-1049

81. Steve Rummel

NREL

1617 Cole Blvd.

Golden, CO 80401

(303) 231-1917

82. Y.B. (Saf) Safdari

Bradley University

Dept. of Mch. Engr.-Jobst 110

Peoria, II 61625

(309) 677-2708

83. Dan Sandwisch

Solar Cells, Inc.

1702 N. Westwood Ave.

Toledo, OH 43551

(419)534-3377

84. Stephen Sargent

Western Area Power Administration

P.O. Box 3402, A7100

Golden, CO 80401

(303) 231-1694 
PV Performance \& Reliability Workshop

September 8 - 10, 1993

Attendee List

85. Russell Schmit

Solar Program

Texas Instruments

13532 N. Central Expressway

Dallas, TX 75265

(214) 995-7961

86. Howard Shanks

Iowa State University

ASCI, 1925 Seholl Road

Ames, IA 50011

(515) 294-7732

87. Lawrence Slominski

United Solar Systems Corp.

5278 Eastgate Mall

San Diego, CA 92121-2814

(619) 625-2080

(800) $397-2083$

88. Robert Somers,II

2rw Consulting Engineers

800 E. Jefferson St.

Charlottesville, VA 22902

(804) 296-2116

89. James Spillson

Solar Cells, Inc.

1702 N. Westwood Ave.

Toledo, OH 43607

(419) 534-3377

90. Byron Stafford

NREL

1617 Cole Blvd.

Golden, CO 80401

(303) 231-1726

91. Michael Stem

Utility Power Group

9410-G DeSoto Ave.

Chatsworth, CA 91311

(818) $700-1995$
92. Troy Strand

NREL

1617 Cole Blvd.

Golden, CO 80401

(303) 231-1804

93. Thomas Surek

NREL

1617 Cole Blvd.

Golden, Co 80401

(303) 231-1371

94. Amy Swartzlander-Franz

National Renewable Energy Lab

1617 Cole Boulevard

Golden, CO 80401

95. John Synhorst

Metro State College of Denver

P.O. Box 173362

Campus Box 29

Denver, CO $80217=3362$

(303) $556-2504$

96. Pat Weis Taylor

Consultant

2890 S. Interlocken Drive

Evergreen, CO 80439

(303) $670-9426$

97. Roger Taylor

NREL

1617 Cole Blyd.

Golden, CO 80401

(303) 231-1332

98. Chris Thompson

Public Service Company of CO

2701 W. 7th Ave.

Denver, CO 80204

(303) 5471-3541 
PV Performance \& Reliability Workshop

September 8 - 10, 1993

Attendee List

99. John Thornton

NREL

1617 Cole Blvd.

Golden, CO 80401

(303) $231-1269$

100. David Trudell

NREL

1617 Cole Blvd.

Golden, CO 80401

(303) 231-1000

101. Edward Twesme

Solarex Corporation

Thin Film Division

826 Newtown-Yardley Road

Newton, PA 18940

(215) $860-0902$

102. Harin S. Ullal

NREL

1617 Cole Blvd.

Golden, CO 80401

(303) 231-1486

103. Jerry Ventre

Florida Solar Energy Center

300 State Road 401

Cape Canaveral, FL 32920

(407) 783-0300

104. Hermann Volltrauer

Advanced Photovoltaic Systems, Inc.

195 Clarksville Road

Lawrenceville, PA 08648

(609) 275-5000

105. Ali Wali

Public Service Com. of WI

P.O. Box 7854

Madison, WI 53707-7854

(608) 267-3592
106. Margie Whipple

Sandia National Laboratories

PV Technology Evaluation

P.O. Box 5800, Dept. 6219

Albuquerque, NM 87185

(505) 844-3154

107. Charles Whitaker

Endecon

3401 Crow Canyon Rd., Suite 253

San Ramon, CA 94583

(510) $867-3360$

108. Joe Wiehagen

NAHB Research Center, Inc.

400 Prince George's Boulevard

Upper Marlboro, MD 20772-8731

(301) $249-4000$

109. Dennis Willett

Siemens Solar

4650 Adohr Lance

Camarillo, CA 93010

110. Douglas Willowby

NASA MSFC

EB74/Douglas Willowby .

MSFC, Alabama 35812

(205) 544-3334

111. Ed Witt

NREL

1617 Cole Blvd.

Golden, CO 80401

(303) 231-1402

112. Larry Wittrup

Sacramento Municipal

Utility District

P.O. Box 15830 - MS 99

Sacramento, CA 95852-1830

(916) $732-5844$ 
PV Performance \& Reliability Workshop

September 8 - 10, 1993

Attendee List

113. John Wohlgemuth

Solarex Corporation

630 Solarex $\mathrm{Ct}$.

Frederick, MD 21701

(301) $698-4375$

114. Joseph R. Woodworth

Sandia National Laboratories

P.O. Box 5800

Albuquerque, NM 87185

(505) 844-7247

115. Sewang Yoon

Amonix, Inc.

3425 Fujita Street

Torrence, CA 90505

Phone: 310/325-8091

FAX: $\quad 310 / 325-0771$

116. Robert Yorgensen

Springborn Laboratories, Inc.

One Springbom Center

Enfield, CT 06082

(203) 749-8371

117. Behrouz Zandi

Mobil Solar Energy

4 Suburban Park Drive

Billerica, MA 01821

(508) 667-5900

118. Gerhard Zinke

Siemens Solar Gmbh

Frankfurter Ring

Munich, Germany 80807

(89) $3500-2533$

119. Ken Zweibel

NREL

1617 Cole Blvd.

Golden, CO 80401

(303) 231-7141 